
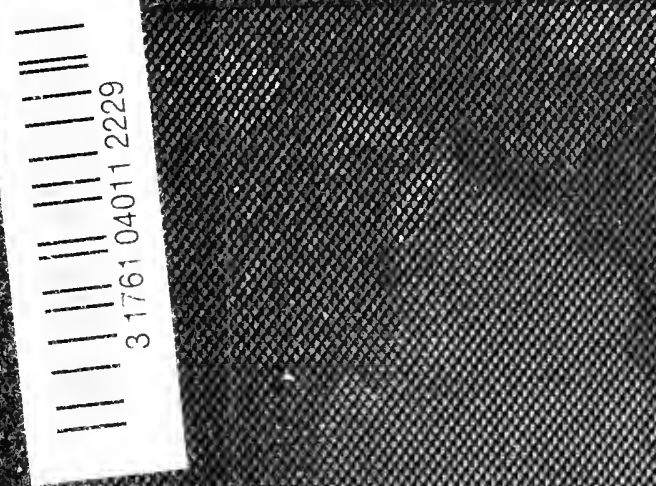


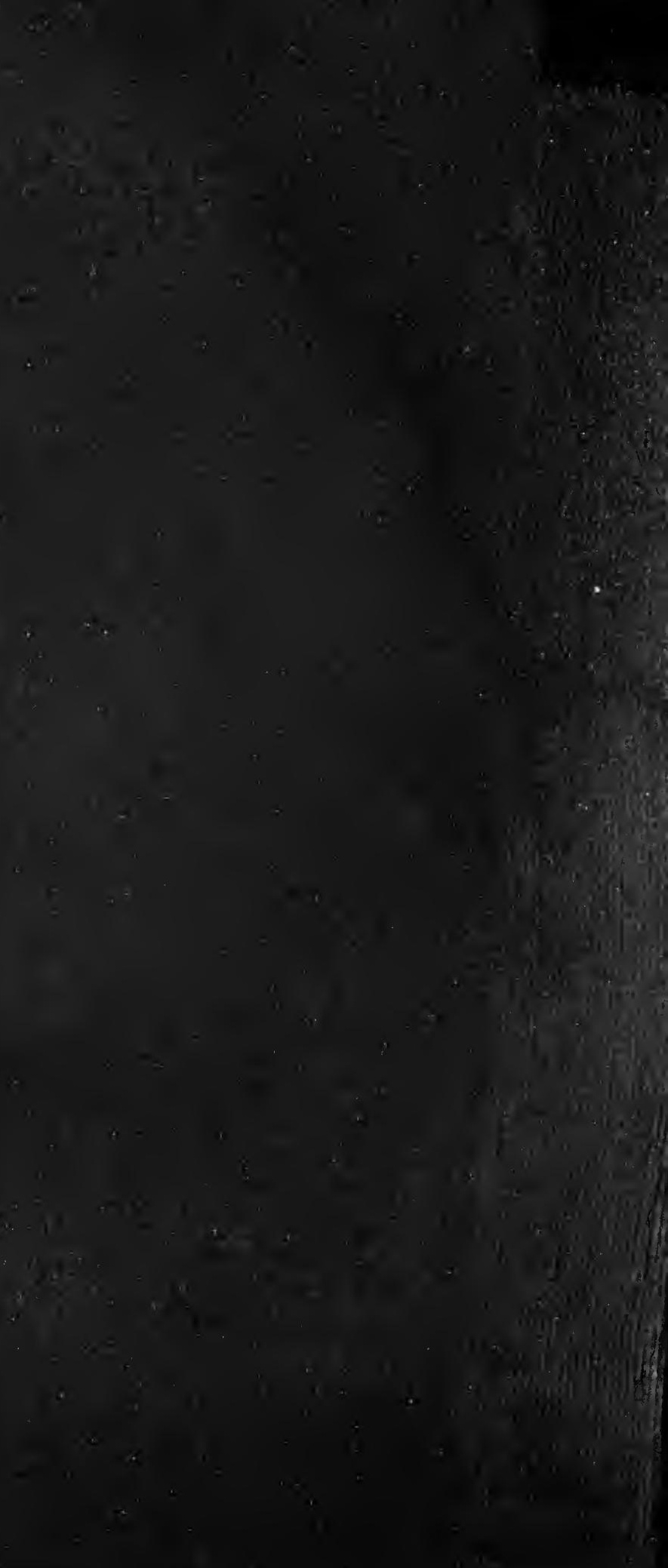











\section{PHILOSOPHY OF CONDUC'}





\title{
PHILOSOPHY OF CONDUC'T
}

\author{
A TREATISE
}

OF THE

\section{FACTS, PRINCIPLES, AND IDEALS \\ OF ETHICS}

BY

GEORGE TRUMBULL LADD

PLOFESSOR OF PHLOSOPIY IN YALE UNIVERSITY

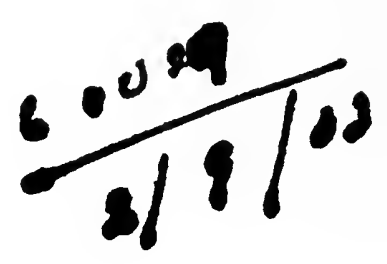

NEW YORK

CIIARLES SCRIBNER'S SONS

1902 
Copyright, 1902,

BY Charies Scringer's Soxs

Published, Februnry, 1:102

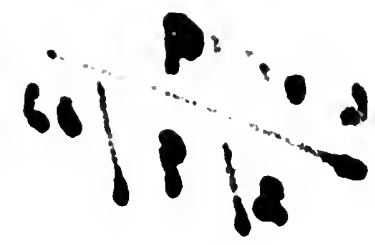

EThibersitg 抽ess

Juhi Whoson axin Son, Cambitinge, C.S.A. 
!

En Grateful ftlemory

(IF

A GOOD MLAN - MY FATHER

.7 
"Ile who loes not unconditionally believe in the Might of Goodness in the world and in its final victory, he ean no longer lead in human affairs - I do not say rightly, but even with any lasting suecess."

Rothe. 


\section{PREFACE}

Tне number of voluminous works dealing with man's moral life and moral development which have recently appeared has been by no means inconsiderable. Among these some have been especially noteworthy, both for the array of phenomena which they have marshalled, and also for the scientific spirit and method which have characterized their treatment of thesc phenomena. It is difficult to say how much this fact discloses as to the revical of a more profound and rital interest in the study of morality - properly so-called. Doubtless the history of the evolution of the race on the side of manners and morals arouses in many minds only the same kind of curiosity as that to which the sciences of biology and anthropology are so vigorously ministering, all over the scientific world, at the present time. But such interest is by no means necessarily the equiralent of that which is demanded by the kind of inquiry upon which I have entered in this volume. For this inquiry proposes at least to raise, even if it cannot completely answer, the more ultimate problems of conduct as our experience forces them upon the reflectire thinking of mankind. I have, therefore, called this treatise of human moral life and moral development a "Philosophy of Conduct."

The title must not, however, be understood as though my proposal were to write a book on Ethics with only scanty regard for the actual facts of conduct, or for the current opinions of mankind respecting the significance and the value of these facts. As the introductory chapters expressly explain, and as the procedure and conclusions of the entire treatise make clear, I consider the "high-and-dry" a priori method 
wholly unsuitable to ethics. Indeed, I may confidently appeal to all my previous work to slow that such a method is unsuitable for adequate treatment of any of the various branches of philosophy, even the most purely metaphysical. For philosophy itself is the investigation and interpretation of the sum total of human experience - with all its implicates by the method of eritical, harmonizing, and synthetic reflective thinking. Ethics especially, however metaphysical it may become, must always remain practical. For ethics has its roots in facts of experience; and its fruitage must be an improvement of experience. The experience with which it deals is of conduct; that is to say, the whole circle of morality lies within the practical life. And yet, the experience of man's moral being and moral crolution is also of such a nature as to demand a philosophical treatment throughout; for until fact is transcended the ethical is not reached. As I have clearly shown in this book, a merely empirical ethics, which is without metaphysics, leaves the mind in a region where all that has regard to the highest principles and more ultimate sanctions of conduct is darkened, if not wholly obscured, by doubt, confusion, and bewilderment.

I have therefore aimed to gire this treatise some special claim upon those who wish for a more fundamental discussion of ethical problems than has been customary of late; and yet to conduct the discussion in the modern method and with due regard for all the interests involved. This aim has been realized in the following particular ways. In Part First, the nature of the Moral Self, or of man as equipped for the life of conduct, has been described as this nature appears in the light of psychological science, both individual and ethnic. Here the attempt has been made to adjust according to the actual known facts the conflicting claims of those who regard man's moral life throughout as a sort of divine, and once for all ready-made endowment and of those who, on the other hand, assume to explain morality as the result of a psycho- 
physical, or an economic, or even a purely physiological evolution. This attempt has resulted in an analysis of man's ethical consciousness which is, so far as I am aware, at the same time more thorough and more modern than that attempted in any other similar treatise.

In Part Second, which treats of the Virtuous Life, it has been my aim to show how, in spite of the bewildering variety of opinions and practices which has always existed, there is still, and, so far as can be discovered, always has been, a rery substantial agreement touching the characteristic traits and habitual practices of the "good man." This agreement does not, however, favor any of the more current theories of the moralists regarding the true nature and unity of the virtues; or regarding the nature and obligations of the so-called "Moral Law." But the argument, as based upon these facts of agreement, does lead to another conception, at once more subtly and delicately ideal and yet more truly and unchangeably real, of both the nature of virtuous living, and of the laws and principles whose dominion and rational rights such living acknowledges, and to which it yields obedience and offers allegiance.

And, finally, in Part Third I have discussed the Nature of the Right. It is, of course, this Part in which the method of philosophy is most prominently and unmistakably employed. For metaphysies is invoked to undertake the speculative solution of those ultimate problems of ethics which an investigation of the phenomena of man's moral life and moral evolution from the empirical points of view leares wholly unsolved. Yet the more distinctively philosophical third of this treatise should not be considered as in any respect independent of, not to say separated from, the treatment of man's moral selfhood and of the conditions and principles of his virtuous living. Only, whereas philosophy has subordinated itself to psychology and anthropology in the collection and interpretation, by primary intention as it were, of the phenomena, it finally 
answers the imperative demand of these sciences to construct a theory which shall offer a more ultimate explanation of the same phenomena.

I make no apology for the frequent references to other works of mine which are found in this book. Properly and of necessity, the psychological views and theories which liave been elsewhere discussed are here made use of in treating of the Moral Self and of the Virtuous Life. More especially important has it been that certain truths regarding the nature of knowledge, of reality, and of the mind's life, should be assumed and earried up into the realm of ethical discussion, wherever this discussion shows the imperative need of receiring illumination from these truths. For, in fact, psychology, epistemology, and metaphysics are all in some sort subordinate and contributory to ethies. The most important ministrations to human welfare which they can perform are directed toward the elucidation and improvement-the rational and practical betterment - of the life of conduct. As for myself, in all my investigations hitherto, I lave had this end in view. And it was, in no small degree, the conviction that human morality cannot be made safely and permanently to repose upon a false psychological basis, or upon an agnostic view of knowledge, or upon an inadequate metaphysics, which stimulated and guided me throughout all these earlier works. For man is a unity - although having indeed a wonderful complexity of activities with their various ends and interests. And he cannot safely build the structure of a rirtuous life upon false opinions of his own Being or of the Ultimate Realities; neither ean he easily find true riews on these subjects when he departs widely from the path of virtuous living. He must rise, or fall, or stand still, as that unique unity which he really is.

If, then, any reader of this book should occasionally be offended by an appearance of dogmatism at points where discussion, or eren concession to contending riews would seem 
more appropriate, I must ask him either to pardon the manner of treatment or else to resort, for this discussion, to those other writings where it may be found.

Such a philosophy of conduct as I have attempted to establish will probably meet with opposition chiefly from three sources of influence. The first of these is the current theory of biological evolution. So long as this theory remains on its own grounds the philosophy of human morality need raise no objection to its speculations, however well or ill founded they may be. There " the struggle for existence" may perhaps be best treated as a bare, unmodified, and brute fact. But when biological science proposes to employ the same method, and to regard the phenomena from an unchanged point of view, the moral life and moral development of man being the subject for investigation, its proposal deserves the most prolonged and searching criticism. There can be little doubt, I think, that the practical effect of the intrusion of biology into the sphere of ethics is, for the present, exceedingly mischierous to the moral life of the people, and to the current opinions regarding the right and wrong of conduct. It is in part under its influence that we are witnessing a return to the brutish point of view, to the doctrine of the right of might, to the coneealed or expressed opinion that it is justifiable for the strong to go as far as they can by way of pushing the weak and the unfortunate over the wall. This view of ethical phenomena I have controverted throughout by showing that ethics does not properly begin until the biological point of view, and the conclusions from this point of view, are transcended.

The second source of theoretical and practical antagonism to a sound philosophy of conduet is the reigning spirit of commercialism. This cannot be met by ethics on scientific grounds. For it is not itself scientifie. Its show of theoretical justification, even when it rises no higher than the lower ranges customarily occupied by a so-called "ethics of economics," is not intended as a serious discussion of the prin- 
ciples or problems of conduct. It is, as a rule, simply an impotent attempt at self-justification for practices which it is proposed to continue whether those practices be justifiable on genuinely ethical grounds or not. All, therefore, which ethics can properly do to remove this obstacle is to point out the essential immorality of this spirit, and the bad morals of the conduct it either fosters or condones; and, in connection with this work of criticism, point out also "the more excellent ray."

The third reason why the student of the philosophy of conduct may expect indifference, if not secret or more open antagonism, toward any serious effort to deepen rational reflection and elevate the tone of the prevalent moral consciousness is found in the relatively low and nerreless ethical condition of the current Christianity. I say " relatively" - as compared with the output of energy in other directions. Of course, the fact that such is the condition will be made a matter of dispute. Of comrse, too, a treatise of ethical principles - especially in its Preface - does not furnish the proper place for establishing, or eren for arguing this fact. A word of explanation, however, as to the interpretation of the charge I have just made is certainly in place here. Whether the morals of the Christian nations of the world, considered as a matter of conduct in their more domestic social and commercial relations, or in their intercourse with one another - have improved or deteriorated does not concern us at the present time. The only too patent facts seem to me to be these: The ethically didactic or prophetic tone, when assumed by the public teachers, is just now especially unpopular and obriously ineffective. The great political, commercial, and social problems, the consideration of which is most imperative, are not customarily discussed or settled from the predominatingly moral point of riew. Moral principles, whether presented in the form of abstract deductions or of concrete maxims, command a relatively small amonnt of thoughtful interest or at- 
tention. The tone of the preralent moral sentiment is neither strenuous nor lofty. The presence of baleful "double morality" is quite generally either openly proclaimed or secretly tolerated. The high ideals of the best ethical teachings of the past - even, and especially, of the New Testament - are not taken to heart, or made the models of actual living. And in all this the multitude who compose the existing Christian organizations - with a considerable number of notable and noble exceptions - take the part of silent acquiescence, if not of unquestioning or bewildered conformity, rather than of remonstrance and opposition. I repeat that the ethical spirit is low and nerreless just now in the body of that community which bears the name of the world's greatest teacher of a spiritual and divinely inspired morality.

But not science, nor trade, nor society, nor religion itself, can permanently alter, or for a long period in the world's listory neglect, the fundamental principles and ultimate ideals of the moral life. If amid the evolution of things, the flux of interests and opinions, the ehanging constitution of human society, and the rise and fall of empires, there is anything to remain substantially inviolable, it is these principles and these ideals. "There is no human function," said Aristotle, "so constant as the actirities in accordance with rirtue; they seem to be more permanent than the sciences themselves." And said that great moralist, Sophocles : -

" They ne'er shall sink to slumber in oblivion;

A power of God is there, untouched by Time."

As sharing in this same confidence I therefore put forth this essay in times which I am compelled to regard as by no means farorable to its most unprejudiced and practically effective reception.

GEORGE TRUMBLLL LADD.

Yale Livensity, New Haren, 1902. 



\title{
TABLE OF CONTENTS
}

\section{INTRODUCTORY}

\author{
CHAPTER I \\ THE SPIERE AND PROBLEM OF ETHICS
}

PAgE

The Problem of Conduet important-Character of this Problem Nature of Ethical Discussion - Distinctions recognized by Ethics - Ethics as involving the Icleal-And the Conception of "the Ought" - Definition of Ethics - Ethies as Practical . . . . . 3

\section{CHAPTER II \\ METHODS AND DIVISIONS OF ETHICS}

Different Ways of approaching the Problem of Conduct - The Three Methods of Ethics-The Psychological Method - "Data of Ethics" so ealled - Necessity of Interpretation - Need of Psychology The Historical Method - Combination of Methods necessary - 'The

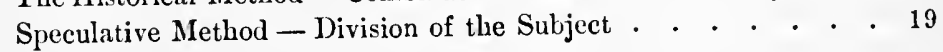

\section{CHAPTER III}

TIE CONCEPTION OF TIE GOOD

Ancient and modern Conception of Etlics - Titles like "good" and "bad" as applied to Conduct - Consciousness and the Good Degrees of the Good, and their Measurement-The Hedonistic Conception - Value of Discipline - Instrumental and final Good - Conception of "the Good-in-Itself" - Classification of Goods The eommon Element-Development of the Conception of the Morally Good - The Ideal Good . . . . . . . . . 34 


\section{PART FIRST}

\section{TIE MORAL SELF}

\section{CIIAPTER IV \\ ANALYSIS OF MORAL CONSCIOUSNESS}

Man as Ethical - The two Clases of Mage

Ethical Feelin

ical Intellection - Ethical Volition

\section{CIIAPTER V}

\section{THE FEELING OF OBLIGATION}

Primary Nature of the "Ought-Consciousness" - Its Relation to Thought and Volition - Conditions of its Origin - Influence of Imitation - And of Tribal Sympatly - Its Connection with PleasurePains - Feeling of Obligation uniquely human - Development of the Feeling - Effect of Repetition - Formation of Judgments of Obligation - Fusion with particular Passions and Affections Primacy of Feeling - Relation of, to Stages of Development Nature of Conscience.

\section{CHAPTER VI}

\section{OTHER ETHICAL FEELINGS}

Nature of Moral Approbation - Relation of, to the Virtues and Vices - And to the Pleasure-Pains - Resemblance to Asthetical Feeling - Development of Moral Approbation - Feelings of Ethical Merit and Demerit - Social Nature of these Feelings - Implications as to the Moral Order

\section{CHAPTER VII}

\section{ETHICAL JUDGMENT}

The so-called Intellectual Virtues-Development of Time-consciousness necessary - And of Self-conseiousness - And of the Causal Principle - Grounds of Ethical Judgment - Psychological Charaeteristics of this Judgment - Predicate of all ethical Judgments Category of "the Right" - Historical Sourees of ethical Juigments - Domestic, tribal, and religious Customs - Intellectual 
Development and the Growth of Moral Judgment - Natural and acquired Power of Judging - Cliaracteristic Experience - Ideas of Ends and Values - Stages in the Evolution of Ethieal Opinion . 106

\section{CHAP'TER VIII}

\section{MORAL FREEDOM}

Conception of "Moral Freedom"-Interest of Ethics in the Problem - Difficulties in the Way of Discussion - Present Position of Determinism - Method of Procedure - Data of Experience - Freedom the Function of no one Faculty - Danger of Hypostasizing -The Fact of Self-Activity - Its Physiological Basis - Nature of deliberate Cloiee - Counter Arguments - Consciousness of Imputability - Testimony from Custom and Language - Imperfect Conceptions of Personal Responsilility - Objections to Freedom classified - Empirical Determinism - The "Old-Fashioned "-And the "New-Fashioned" - Relation of Motives to Volitions - Incomparability of Impulses and Ideals - The Conception of Character - And of Habit - Relation of Brain-States to Psyclioses The Materialistic Outcome - The Argument from StatisticsThe Conception of Causation applied - The Self not a Mechanism - The Residuum of Mystery . . . . . . . . . . . . . 133

\section{CHAPTER IX}

THE MORAL SELF

The Conception of Conscience - Inclusive Nature of Moral Selfhood - The Moral Self and the Social Self - The Scientific and the Ethical - The Pursuit of Ideals - Personality and Development

- Evolution of the Moral Ideal . . . . . . . . . . . 189

\section{PART SECOND}

\section{THE VIRTUOUS LIFE}

\section{CHAP'TER $\mathrm{X}$}

\section{CLASSIFICATION OF TIIE VIRTUES}

'Twofold Distinction of Concluct - Conception of Virtue - The Search for Unification - Different Principles of Classification - Self-regarding and Social Virtues - The Distinction criticised Classification according to Objects - The psychological Classification adopted - Unity of the Moral Self . . . . . . . . 211 


\section{CIIAPTER XI}

virTtES OF TIIE WILL: COURAGE, TEMPERANCE, ETC.

Elements of Strength in Charaeter - Nature of the good Will-- The eardinal Virtues of Will-Natural Fears - Natural Effects of Fear - Courage as Self-control of Fear-Rational Fears - Apparent Prudential Virtues - Moral Value of Courage - The Vice of Cowardice - Temperanee as a Virtue - The Control of Anger - And of Sexual Appetite - And of the Desire of Possession Inunility - Constancy as a Cardinal Virtue - Subordinate Phases of the Virtues of WVil

\section{CILAPTER XII}

VIRTUES OF TIIE JUDGMENT: Wisdoi, JUSTNESS, ETC.

Judgment itself is Conduct - Cardinal Virtues of Judgment - Wisdom defined - Wisdom as Evaluation of Ends - And Estimate of Means - Genuine Prudential Virtues - Iesignation as a Cardinal Virtue - The Virtue of Justness - Moral Value of this Virtue - Conception of Justness - Resulting Doetrine of Rights - Relations of Custom and Law to Justice - The Virtue of Trueness - General Estimate of this Virtue-The Evaluation of Truth - Vices of Thoughtlessness - And of Dogmatism - Anıl of Partisanship Truth-telling - Is Deceit or Lying Justifiable? . . • . . . . 269

\section{CIIAPTER XIII}

VIRTUES OF FEELING: KINDNESS, SYMPATHY, ETC.

Social Origin of these Virtues - Natural Impulses to Kindness - And Social Relations which define its Objeets - Nature of Friendship, - The Virtue of Hospitality - The Virtue of Pity - Origin and Nature of Sympathy - The Feeling of the Species - Development of Benevolence - Influence of Philosophy - And of Art - And of Religion - The opposite Vices - Ingratitude - Pleasure-giving Quality of these Virtues

\section{CHAPTER XIV}

TIE LXITY OF VIRTUE

The Search for Unity - Analogies from I'sychology - The two Forms of Unifieation - Tests of External Behavior - And of Motive And of Intention - Virtue not mere "good Intention" - Nor irlentieal with Benevolence-Nor with Love-The highest Self- 
Welfare involved - Justness and Trueness not reducible to Benevolence - Unity of Personality implied - And Devotion to the Moral Ideal

\section{CHAPTER XV \\ DUTY AND MORAL LAW}

Importance of these Conceptions - Implications of the Conception of Duty - Duties to Self - Feeling of Obligation involved - Origin of the Conception of Duty - Are Duties and Virtues Co-extensive? - Duty and Merit-Duties and Rights - The Conception of Moral Law - Origin of moral Laws - Their Character of an " external Imponent" - Conception of a personal Source - Moral Law never Impersonal

\section{CHAPTER XVI}

\section{UNIVERSALITY OF MORAL PRINCIPLES}

Prineiples and Laws contrasted - Nature of Moral Principles - And of their Universality - Development of Moral Principles - Dependence upon Moral Institutions - And upon the Abolition of Distinctions - Simplifying of Moral Principles - Rational Deduction of Moral Principles - Influence of Individual Examples - And of Ethical Philosophy - Restrieting Power of Custom . • . . 389

\section{CHAPTER XVII}

\section{CASUISTRY : MORAL TACT AND CONFLICT OF DCTIES}

Difficulties of the Subject-Casuistry as Ethical Discipline - Sources of Casuistry - Nature of Moral Tact - Necessary Elements of its Cultivation-Sphere of Casuistry - Conflict of Duties - Reality of such Conflict-Different Classes of Conflicts - The Principle of Individuality - The Case of 'Truth-telling examined . . . .415

\section{CHAPTER XVIII TIIE GOOD MAN}

General Description of the Virtuous Life - Influence of the particular Ideal of Self - Conformity of the Actual to the Ideal - Danger of excessive Idealism - Discovery of ethical "Antinomies"The sentient Self and the moral Self - The Self-regarding and the Altruistic "Good Man" - Development through Discipline . . . 436 


\title{
PART THIRD
}

\section{THE NATURE OF THE RIGHT}

\author{
CHAPTER XIX \\ THE CLTINATE PROHLEI
}

The Statement - The Method of Treatment - Different "Schools of Ethics" - The Need of Metaphysics . . . . . . . 457

\section{CHAP'TER XX \\ UTILITARIANISM IN ETHICS}

The Ancient Hedonism - The Modern Utilitarianism - Nature of

"I'leasure-Pains" - Sourees of IIuman Happiness - The Evaluation of Happiness - The Standird of Measurement - Problems of a Iledonistic Ethics - Egoistic and Quantitative IIedonism - The Question of Sanctions - Altruistic and Quantitative Hedonism Qualitative Hedonism - The Goal of Ethics - The Utilitarian Modifications - And their Failure - The Problem of Rational Worth . . . . . . . . . . . . . . . . . . . .467

\section{CIIAPTER XXI \\ LEGALISII IN ETHICS}

Anteeedent Improbability of this Theory - Ethics always Personal - Inapplicable Conceptions of Law and Order - Moral Law as Rational - Views of Kant eriticised - Law and Reality . . . 497

\section{CHAPTER XXII \\ IDEALISM IN ETIIICS}

Conduct and the idealizing Activity - The Ideal of Rationalism And of Utilitarianism - Problems of Idealism - Claims of "Intuitionism"-And the Faets in its Support - Contradictory Facts - The Right, subjective and objective-The Social Ideal - Application of the Conception of Evolution - Individuality of 
the Ideal - The Time of Realization - Personal Character of Ethical Ideals - Influence of the two Conceptions, Personality and Development . . . . . . . . . . . . . 507

\section{CHAPTER XXIII}

TIIE ETHICAL SCIENCES

The eomprehensive Sphere of Conduct - The Uncthical View Economics as an Ethical Science - Common Basis of Ethics and Economics - Politics as an Ethical Science - And so-called Social Seience .

\section{CHAPTER XXIV}

\section{MORALITY AND RELIGION}

Untenable Character of the "Positivist View" - Two Extremes of Opinion - Universality of Religion - Influence of Religion upon the Conception of the Virtues - And upon their Praetice - The common Psychological Origin - Twofold Nature of Picty - Specifically Religious Duties so called - Ethical Influence of Religious Faiths and Practices - Religious " Purifieation" - The Moral Support from Religion - Religious Fears and Moral Obligation Effect of Religion on Moral Ideals - "Double Morality" - Religious Vicw of the Moral Antinomies - Influence on Morality of the religious Postulates - Especially in their Supcrior Form . . 552

\section{CHAPTER XXV}

THE GROUND OF MORALITY AND TIE WORLD-GROUND

Nature of the Problem - Its Ultimate Character - Need of Help from Philosophy - The Kantian Vicw - The Theory of Reality implied - And of the Philosophy of Knowledge - Comprehensive Character of the Metaplyysics of Ethics - Philosophical Conception of the World-Ground - The Absolute as Moral Self - Naturalism in Ethics - Positivism in Ethics - A Rational Anthropomorphism - God as the Source of Moral Standards - And of Moral Sanctions - Morality of Natural Law - And of Social Enactments The Appeal from Social Standards - Doing the Divine Will Ground of the Community of Interests - The World-Ground and Moral Ideals - Solution of Ethical Antinomies - Conflict between the Real and the Ideal 


\section{CIIAPTER XXVI}

THE LLTIMATE MORAL IDEAL.

The Ideal of Conduct "in-itself" Good - The Morally Ideal Self Social Character of the Ultimate Ideal - Possibility of its Realization - The Permanence of Conflict - Idealism and Realism in Ethies - Reconciliation by Development-- Conclusion . . . . 636

INDEX . . . . . . . . . . . . . . 659 


\section{PHILOSOPHY OF CONDUCT}





\section{PIIILOSOPIIY OF CONDUCT}

INTRODUCTORY 

"IIowever men approach Me, even so do I accept them; for the path men
take from every side is Mine."

Bhagavad Gítí. 


\section{CHAPTER I}

\section{THE SPHERE AND PROBLEM OF ETHICS}

IF one consults the wisdom of the ages it will be found nearly unanimous in the opinion that, of all inquiries the most important are those which coneern the right and wrong forms of human conduct. As a matter of fact, however, multitudes of men, through considerable periods of their lives, seldom deliberate, or even consciously propose these inquiries. Necessities of a physical kind seem to compel them to a daily walk along well defined paths of action; and where these necessities are less powerful, the established social customs that environ them leave comparatively little room for the more independent exercise of any individual's judgment. But perhaps more than all else, the habits they have themselves formed through years of an activity which, in accordance with a well-known psychological law, has now become a passive submission, ward off attacks from any stimulus that would make imperative or attractive the question: How shall $\mathrm{I}$ act at the present moment? In a word, physical necessity, social convention, and indiridual habit combine to answer for most men, as though they were matters of course, all ordinary questions of ethical import. And so the multitude not only eat, drink, and sleep, and go the daily round of tasks or pleasures, but they also discharge many of the higher social and politieal functions without much intelligent and serious debate as to the quality or the consequences of their conduct. 
As a matter of fact, however, nearly or quite all of this saine multitude do at certain times somewhat carefully weigh important problems of more definite ethical import. And the questions which the wisdom of the ages considers so important are themselves the questions of the ages. It is not the wise alone that have raised and answered these moral problems with more or less of sclf-conscious fecling and judgment. The common people have opinions, with show of reasons attached, upon matters of conduct. Even fools are not always lacking in a sort of cunning dialectic, or in a somewhat systematic rationalism, upon such matters. It is, to be sure, chiefly when the problems of conduct are brought to mind as objectified in the concrete bchavior of some fellow actor in life's drama toward themselves that their ethical emotions are most stirred and their ethical judgments are most clear-sighted and emphatic. It is when some other bow than the one held in their own hands has speeded the arrow that men question and hotly resent the deed which has caused them the painful sting, the dangerous wound. Above all other occasions do they experience a lively arousement of moral consciousness when the misdeed has not only hurt them as indiriduals, but has also been a notable breach of the established customs of society. The multitude are made more refectively moral by feeling themselves to be in some way injured or inconvenienced through the action of individuals who disregard the customary morality. But beyond all this, and deeper down, lie the questions concerning right conduct to which the wise have reference, and to which most men at some time in their lives give at least a passing consideration.

Now it is plain that any scrious inquiry after right and wrong forms of conduct may lead the mind of the inquirer in either one, or in all, of several different directions. In its most frequent form the ethical problem concerns the proper or most feasible means of sccuring a certain end. 
For although the opening dictum of the Nicomachean Ethics - namely, that "every art and every research, and likewise every act and purpose" has some end of a good in view - is not strictly true, since many ends of every man's life are pretty clearly defined by circumstances over which he has little immediate control, the thing which most concerns his success in the attainment of ends is the selection of means. The artizan, the merchant, the professional man, even the most stupid laborer, knows fairly well what he is aiming at, and does not ordinarily question the rightness or wrongfulness of his aims. For the most part also the means available for pursuing these ends are provided, as defined by law, or custom or convention. But ordinarily the means are much more variable than are the ends; and the circumstances requiring an adaptation of means to any particular end are always subject to change. It is evident, however, that when men deliberate questions of conduct concerning the use of means, their problem is still somewhat complicated. By this I do not mean simply that it is often difficult for them to know which of several deeds or courses of conduct furnishes the most likely means to attain the desired end. 'The rather are we interested here again to discover indications of those further and deeper problems which concern the right and wrong in human conduct.

For let it be supposed that, of two or more ways of attaining one's end, there is one way against which the laws or the customs of society have definitively pronounced. Then the ethical problem is tolerably sure to take upon itself a somewhat different character. Then the problem becomes not merely a questioning of experience for the instrument most likely to be successful in attaining a given purpose. Even the bare consideration of the more immediate, as well as the more remote consequences of conduct is modified in such a case as this. The law or the custom, has already said No, in answer to other similar inquiries. It has 
apparently solved the general problem in a negative way. The individual, therefore, must go on to inquire: What will the government, or society, do to me, if my answer differs from theirs? And this inquiry, although not the same thing, is very intimately associated with another question: What do my fellowmen consider to be right and wrong forms of conduct?

But such a change in the character of the problem of conduct, and its increased need of deliberation and far-secing choice, prepares the way for raising a yet more fundamental and difficult inquiry. For here the feeling and judgment of the individual, whether he take the point of riew from which to regard the consequences of his act, or the point of view from which moral consciousness strives to discern the inherent quality of the act, may begin to ask the reason, Why? True, society seems to have clearly indicated its judgment as to what is right, what wrong, in such a case as this. But - just now, at any rate - perhaps the feeling and judgment of the individual do not precisely accord with the social custom. How did society arrive at this, its secmingly corporate conclusion? By what reasons, whether in the way of appeal to facts, or dialectic from assumed principles, or probable inference as to consequences, can others justify the right to control my decisions on matters of conduct? And, furthermore, what shall I think of myself in case I renture to choose another deed, another course of conduct, than that which society has ordained? Rarely, it may be, yet sometimes and, if at all, always most significantly, do men, eren the aduits of the common herd, raise with themselves, or with one another, problems which have this deeper and vaster significance.

It is the attempt to answer, by processes of reflective thinking upon a basis of facts of experience, such practical questions as the foregoing, which gives rise to an inquiry into the principles of human conduct. If, then, we did not 
desire to avoid at the beginning of our inquiry insignificant objections and fruitless debating, we might adopt this preliminary definition: Ethics is the Science of human conduct. For conduct is a fact; or rather, it is an infinitcly raried and ever-changing network of facts. It affords a tangled skein of inquiries which require a methodical consideration. And although one may easily enough dissent from Wundt's conception, - "Ethics is the original science of norms," one cannot so easily disregard the significance of his further declaration: 1 "The estimate of the value of facts is also itself a fact, and a fact which must not be overlooked when it is there to see." Now if we may treat facts of human feeling, imagination, and judgment (whether they are established by a direct appeal to consciousness or in some other more objective and historical manner) by scientific method, may sift them, classify them, concatenate and explain them, interpret their import and reason speculatively about their implicates, it is difficult to see why we may not properly speak of a possible "science of ethics." But why spend time in discussing so futile an inquiry?

We will be contented then, at present, simply to say that ethics results from the scientific (the systematic and properly regulated) study of human conduct - its sources, its development, its sanctions, and its most general principles. The fuller justification of this rude, fourfold classification of ethical problems may be left to appear during the progress of the attempt at completing our task. But the suggestion, if not the authentication of it, follows from a reflective treatment of the import of such questions as have already been proposed. All these questions concern human conduct - the subject matter of our philosophizing or reflective thinking. But the manifold forms in which the questions recur suggests the need of investigating not only the present

1 Ethics: The Facts of the Moral Life ; I, pp. 5 and 9. [English translation by Julia Gulliver and Edward Bradford Titchener.] 
exterual facts, but also the beginnings, the historical ongoing, the rational grounds - the sanctions and the principles - of human conduct.

Even this brief preliminary definition implies the further need of certain very profound distinctions. Taken altogether, these distinctions require the addition of an exceedingly signiiicant clause to our conception of the sphere of ethics. Let us then enumerate and briefly discuss these distinctions.

And, first, the sphere of ethies can be defined, and its problem understood, only by making a distinction between the real and the ideal, between what is, as matter of actuality or fact, and what is conceived as better than the fact, an idea of what might be, or should be. There are sciences of actuality so-called. They begin with the individual facts; they derive their principles by generalization from the modes of the actual behavior of things or of minds; their metaphysics treats speculatively the assumptions, or the most fundamental principles, which concern what has actual being. Ethics, too, begins with facts; it makes generalizations that are based upon the habitual, actual forms of the behavior of men. But so long as human conduct is considered merely as fact, and the forms into which it has crystallized are regarded merely as actual historical developments, the way is only prepared, but not entered upon, for the discussion of the more distinctively etlical problems.

Superficially regarded, the words used to describe a study of human conduct-especially in the three languages, Greek, Latin, and German - scem to favor the conception of ethics as a purely historical or anthropological science. According to these languages, ethics appears to be a science of actually existing customs. But this fact is itself relatively unimportant and due to the influence of the terminology employed by Aristotle and by succeeding writcrs. ${ }^{1}$

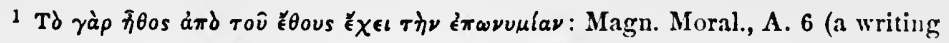
of the later $\Lambda$ ristotelian school). So the Latin Moralis in Cicero, De fato, 1. 
Neither Aristotle nor Cicero, however, for a moment thought of making the philosophy of conduct deal with facts alone, to the exclusion of men's ideas as to the evaluation of what is fact by comparison with some sort of a conceptual standard. And no modern writer of treatises called "Data of Ethics" succeeds in discussing its problems without eonstant reference to conceptions of the individual and of society concerning an obligation and concerning sanctions that transcend any actually existing example.

It would, indeed, be altogether too vague, as well as somewhat misleading, to define ethics as the science of the Ideal. Such a definition would not difference it from æsthetics, or specify its most characteristic qualities. It must also be borne in mind that all the positive sciences are largely based upon, and interpenetrated with conceptions which are not wholly of the actual, but which consist largely of ideas as to what might be or should be. Otherwise, their derotees could not talk intelligibly of norms and types, etc., or describe and explain the individual examples in terms of a theory of evolution. It is the character of its ideal, and the way in which the individual examples are brought into relations to the ideal, which chiefly distinguishes ethics from all the other sciences. Nevertheless, in Profossor Sidgwick's contention with Mr. Spencer we must take our stand with the former rather than the latter, in his conception of the proper sphere of ethics. ${ }^{1}$ Ethics does not primarily lead us to deal with the "doubly ideal." It does not, in the first instance aim at determining the ideal forms of eonduet under ideal conditions. As Aristotle long ago said: "Our inquiry is obviously about an excellence that is human" (Nic. Eth., I, xiii, 5). Ethics, then, however it may finally carry our thought and imagination into Utopia, or into the sphere of that far-away, ideally perfect social eommunity which the Biblical writers eall the "Kingdom of God,"

1 See p. 17 f. and the note, p. 20, The Methods of Ethics (4th ed.). 
primarily treats of actual facts of man's conduct under the actually existing conditions of man's historical development. It views the actual, however, in the lights and shadows of the ideal.

By an Ideal I understand: a conception, dereloped by the combined activity of thought and imagination, to which there is not necessarily attributed any real existence as its correlate, but which appears in consciousness as an object of contemplation or of aspiration. But this conception of the ideal leads our thoughts at once to another distinction which is also necessary to a correct conception of the sphere of ethics, -namely, the distinction between other ideals and the specifically ethical ideal. In the ethical discussions of the Greeks that loosely organized but comprehensive and fascinating idea which was designated "the Good" was central and controlling. There can, of course, be no philosophizing of an ethical sort without making use of one or more elements and aspects of this idea. Moreover, there is great significance in the fact that the human mind persists in its effort to free these elements and aspects from that lack of unity which they exhibit in all human experience, and thus to form the fair and alluring picture of a state or socicty in which they shall all be harmoniously united. The bare faith in the possibility of such harmony is a problem for ethies. The firm confidence of many that this possibility will become realized is another problem. But these and all kindred problems belong fitly to the later theoretical conclusions rather than to the preliminary considerations of the student of ethics. He must, howerer, soon be brought to recognize the fact that the human mind invariably constructs several different ideals, or at any rate sereral aspects of the one highest ideal; and that the concern of ethics is primarily and chiefly with the ideal of conduct.

Subordinate to the distinction just discussed are the two following: - the first of which is the distinction between 
action and conduct. It is not mere doing, whether of this or of that sort, which gives to the student of ethies his peculiar problems. Conduct implies something more than action. Conduct implies the consciousness of an end that may be striven for; it implies the knowledge of means that are adapted to the attainment of the end; it implies the power of choice with reference to both end and means. In a word, conduct is action rationally shaped; it is the doing of a Molal Self. Moral action is not, indeed, a specific kind of action, set apart, as it were, for some definite species of external performances, to the exclusion of other species. ${ }^{1}$ In fact, the presence of ethical ideals is to be discerned in everything which man consciously and voluntarily does. Higher or lower degrees of these characteristics of all conduct are actually found as far back in history, as low down in ethical or intellectual degradation as we can follow the development of humanity. In his eating the adult human being does not merely feed. In his drinking he does not simply swill his drink. He raises the social cup, ho pours out a libation to the gods; and the gods at any rate must be treated politely by the most shameless and gluttonous of cannibals. And where, as amongst the various Hindu castes in India, custom and morality and religion are so confused as to constitute a nearly complete enslavement of all the activities and interests of human life, the necessity and validity of this distinction are all the more to be emphasized.

The second of the distinctions which follows from the attempt to confine the sphere of ethies within its more

1 I sympathize heartily with the import of Prof. Dewey's declaration (Ontlines of Fthics, p. 16i): "The habit of conceiving moral action, as a certain kind of action, instead of all action so far as it really is action, leads us to conceive of morality as a highly desirable something which ought to be brought into our lives, but which upon the whole is not." But at the fourth use of the word "action" we must change it to conduct, in the above sentence. Prof. Dewey has himself previously distinguished action from conduct, Ibid, p. $3 \mathrm{f}$. 
appropriate ideal is the distinetion between mere characteristies of being and the moral character, in the ethical significance of the latter word. The character of men is never estimated by themselves or by their fellows as though it were simply a matter of fact. In that interesting symbolism of language which shows the mysterious feeling of kinship with nature on man's part, we find the really significant truth to be, not that man regards himself as a being devoid of moral character, but rather that he regards the lower animals and even inanimate objects as sharing with himself in the potentialitics of eharacter. The superstitious savage does not so much excuse his offending fellowman for his bad character, because he could no more help being bad than could the dog, or the tree, or the stone. On the contrary, he is more apt to consider dog, or tree, or stone, as bad with the quasi-ethical judgment and feeling, that they, too, ought to have known and done better! In man's ease especially, character not only implies disposition, as an ethical potentiality; but also the moulding effect of conduct on the actual characteristies of disposition. We might, then, say that the sphere of ethics is regulated by man's ideals of conduct and of character.

There is one other distinction which is very powerful in determining the proper conception of moral philusophy. This "Inight-be," this "should-be," of ethics has its own peculiarity; and this peculiarity is better expressed by the significant phrase, "ought (or ought not) to be." The sphere of ethics, then, covers that which is actual in human conduct and character as related to that which ought to be. Indeed, this last distinction is so essential, so fundamental, in all genuine philosophy of eonduct that one almost might affirm: The business of ethics is the inrestigation of the ought and the ought not in conduct.

It will be found that, in its developed form the feeling of the ought stands in a peculiar relation to human volitions, 
and so to human action as dependent upon volitions - i. e., to that human conduct which has already been defined as the proper subject for ethics. For the feeling of obligation constitutes a sort of mandate for the will. The recognition of this relation, and of its importance for all the more strictly ethical forms of discussion, is essential at the rery beginning of every ethical treatise. On the contrary, says Schopenhauer:1 "In this ethical book no precepts, no doctrine of duty must be looked for. . . . In general, we shall not talk at all of 'ought,' for this is how one speaks to children and to nations still in their childhood, but not to those who have approp:iated all the culture of a full-grown age. It is a palpable contradiction to call tlie will free, and yct to prescribe laws for it according to which it ought to will. 'Ought to will' - wooden iron!"

Now it is doubtless true that the "must" which attaches itsclf to the "ought" recognized by ethics often arises on other than distinetively ethical grounds; not infrequently it begins as some form of external compulsion. Thus, for example, the unconquerable feeling of the orthodox Jew that he ought not to eat pork may have arisen in a sanitary regulation. Hinduism, on its ethical side, is so full of examples of this sort that its practical ethics may almost be said to consist wholly of them. It is also true that in multitudes of cases, in all times and among peoples of every degree of moral advancement, many seemingly strong ethical repulsions are elosely akin to that residuum of nausea, in memory and in imagination, which makes some persons fecl that it is morally wrong to indulge at all in tobacco or in alcohol. But just now our inquiry does not concern the origin of this feeling answering to the words "I ought;" nor do we question as to how it becomes attached to any particular piece of eonduct. Our claim is that its essential and unique character must be recognized as lying at the very

1 The World as Will and Idea (translation of Haldane and Kemp), I, p. $350 \mathrm{f}$ 
threshold of the study of ethical problems. And this because as a matter of fact we find it there at the entrance; and not only at the entrance, but also as a constant and inseparable companion in all ethical investigations. Nor is the experience of the individual student of ethics at all individual in this regard. Every student of ethics meets everywhere with this feeling, this conception of the ought; and every writer on ethies does actually take account of it. Schopenhauer himself is by no means an exception to the universal rule. In proof of this statement, were proof just now necessary or desirable, appeal might be made to human moral consciousness, to human language, to literature, and to the actions of men in society and in all human history.

The sphere of ethics, then, is not a domain of fact to the exclusion of ideals, nor a domain of ideals that has no basis in, or application to, the world of fact. The reflective thinking which a moral philosophy proposes does not consider the conduct of men simply as an actual event, or simply as a series of related events under the laws of habit, or under the general laws of physics, biology, and psychology. Ethics demands to know something more about its subject than the bare datum of its existence, its origin in past history, its probable or known consequences in the future. It inquires into all these matters diligently, but it does not regard them wholly in themselves or in their relations to one another. It reaches its more ultimate aim only when it judges all human conduct in its relations to a standard. And that standard is an ideal one, a construct of a developed activity of thought and imagination - upon a basis, to be sure, of facts of feeling, judgment, and action. We may then complete our preliminary conception of the sphere of ethics by adding a further clause: "Ethics results from the scientific study of human conduct - its sources, its derelopment, its sanctions, and its most general principles" - - $a_{8}$ related to a rational ideal. 
The word rational is doubtless one of the worst abused terms in the English language; it is almost necessarily vaguely comprehensive in its meaning when employed by the student of any form of philosophy in whatever language. Witness its many uses by Kant in his three immortal Critiques having "reason" as their subject of investigation. Recall also how Aristotle in his attempt to define ethics as a kind of politics affirms of the total function of man that it is "an actirity of soul in accordance with reason, or not independently of reason" (Nic. Eth., I, vii, 14). ${ }^{1}$ All that ethics is entitled to mean by this term "a rational ideal" cannot, of course, be described or justified at the beginning of an ethical treatise. On the contrary the detailed description and completer justification of this conception is one of the most difficult and complex problems of philosophy. Nor should we make any large advances in the task before us if we dwelt farther upon the patent truth that the rational ideal to which ethics relates conduct and character is itself an ethical ideal, an ideal, that is to say, of conduct and of character. Like the phrases of those who define ethics as the "science of moral habits," and then by destructive criticism leave the mind in doubt as to what the word "moral" signifies, we should thus tarry too long in what Plato sarcastically calls the "puppy-dog" stage of science.

It will be helpful, howerer, to anticipate at the very beginning of the inquiry the large conclusion to which the inquiry itself will bring back the mind again and again. The rational ideal to which ethics relates all the particulars of conduct as to a standard, this conception of that which ought to be, and which therefore gives the law to which the actual in conduct fecls the obligation of conforming, is the Ideal of a Self, or "Person." But, of course, such a Self


to," or "at least implying," a rational standard, as nearly as we can reproduce them. 
cannot exist in reality, cannot even be conceived of, as an individual separated from all social relations. In saying this, the problem of ethics is anticipated; it is brought before us, indeed, in all its most comprehensive and glorious significance. This problem is the realization of the Self, in social relations with other selves, and in accordance with a consciously accepted ideal.

At once the conclusion follows as to the relation in which the theory of ethics stands to life. Ethics cannot be merely theoretical and speculative; it must, from its very nature, also be applied and practical. A "pure" science of ethics, modelled after the pattern of logic or of mathenuatics, is an impossibility; it is more than that: it is an absurdity equivalent to a contradiction in terms. And this, for two reasons. Ethics has no body of principles that can be established apart from their closest contact with, their embodiment in, the concrete examples of human history and of present experience with its changes of conditions and of requirements from age to age. The philosophy of conduct caunot possibly be made "pure," in this meaning of the word. Neither can its principles be held as mere theory; they are themselves of such a nature as to demand and to guide their own application to concrete and individual instances of conduct. They cannot be kept "pure," in this other meaning of the word. The general statement with regard to stealing, for example, - whether it take the form, "The good man does not steal," or "The good man will not steal," or "The good man ought not to steal," - cannot be established a priori or derived by any process of reasoning that does not take into account all the complicated actual relations of the changing life of man. But neither form of this general statement can be restrained from becoming at once the practical mandate: "Thou shalt not steal." And it is vain, as will appear subsequently, to attempt to estab. lish such a priori moral principles by confining the word 
"moral" exclusively to the deed, or to the consequences of the deed, or to the inward intention or mental disposition or habit out of which the deed proceeds.

The sphere of ethics is, then, peculiar to itself, its veritaule own and no other. This is because there is nothing else which is so similar to human conduct, when conduct is viewed in its relations to its own ideal, as that a safe comparison may be made between its proper method and its conclusions and the method and conclusions of ethics. On this account we should not classify ethics and logic together, as Wundt 1 does, and call them the only "purely normative sciences." But more misleading is the view of Paulsen ${ }^{2}$ who - to be sure, in a rather vacillating way - ranks ethics among the natural sciences. The intimate relations of ethics to psychology and to anthropology are obvious enough from its very conception as defined in the most preliminary and tentative manner. Since ethics deals with the conduct of man, it must know man. Since the whole of man is involved in his conduct, since all his faculties of body and mind are employed and all his being is expressed in conduct, ethics must know man in the most comprehensive way possible. While the sphere of ethics includes much from both psychology and anthropology, it does not wholly coincide with either of the two. To attempt to substitute either for ethics is to miss the peculiar province of ethics altogether; but even to speak of "a practical ethics without psychology" is to be guilty both of a tautology and of a contradiction. For there is no ethics that is not practical, and there is no ethies at all without psychology.

If, then, we expand somewhat and slightly modify his meaning, it will be found that the first great writer upon this subject in a systematic way had a not unworthy conception of the work he lad undertaken to accomplish. Aristotle believed himself to be investigating, not simply for

1 Ethics, I, p. 7.

${ }^{2} \Lambda$ System of Ethics, p. 13 f. 
purposes of pure science but also in order the better to guide himself and mankind generally, a eertain kind of life. ${ }^{1}$ 'This was the total life of man, so far as it may be brought under the control of the will and consciously directed to a rational and worthy end. The standard, as I shall attempt to show in detail, which sets this worthy end, and which becomes a mandate to its own progressive realization, as well as a law for the evaluation of ourselves and of others, is the Ideal of a perfect Self existing in social relations with other selves.

1 Nic. Eth., I, vii, 12. Z 


\section{CHAPTER II}

\section{METHODS AND DIVISIONS OF ETHICS}

The question of the sphere of ethics is complicated with the question of the methods of ethics; and this latter question determines, in large measure, the question of the virtual, if not the explicit, divisions under which to discuss the various ethical problems. How, indeed, shall one approach, in the effort to answer such inquiries as the following: What is right and what wrong in conduct? Whence come the sanctions which men attach to that conduct which they call right; and, What is the ultimate end at which all right conduct seems to aim?

The problems of ethics may be approached, first, as a study of the subject of conduct, of the moral agent, the being under moral law, the sensitive and appreciative consciousness which is, in its activity, seeking some form of the good. Or second, the same problems may be approached as a study of the kinds of conduct actually existing and objectively regarded; together with the consequences which attach themselves to the different kinds, whether such consequences arise from the action of other men or from the working of natural laws. Or, finally, a speedy if not immediate resort may be taken to speculation; the effort may be made by processes of reasoning as nearly as possible a priori and independent of facts (subjective or objective) to arrive at the most universal and unchanging principles of conduct, and to determine the nature of its ultimate idcal. 
Of these three methods the first is the more distinctively psychological; its body of conclusions, when systematically arranged, might seem to merit the title of "psychological ethics." The second, however, is mainly historical, and its pursuit results in the collection and classification of "data of ethies," a sort of science of morals, - rather than a philosophy of morality. The third method, of course, gives rise to metaphysics of ethics, a system of principles which is often supposed by its adrocates to have what Kant would call an "apodeictic certainty." As a matter of fact, all three methods have becn employed to some extent by every school of writers and thinkers on ethics. But each school has shown its preference for one of these methods, - and usually to the relative depreciation of the other two. The school of Intuitionism so-called, naturally enough, has relied chiefly upon the psychological method. It has claimed to find its principles directly revealed to the self-conscious mind or the fecling heart; and the sufficient authority and guaranty of the principles resides in the fact that so they are given (data) in human self-consciousness. All forms of Hedonism, including modern Utilitarianism, on the other hand have been more inclined to busy themselves with the collection of objective "data" and with tracing out the practical consequences of conduct as affecting the exterual interests of mankind. The rigorist in morals, howerer, since from the very nature of his claim (and here Kant is, of course, the most distinguished and typical example) he cannot possibly prove it by an appeal to experience, has the more readily resorted to the "high and dry" a priori method.

An instructive historical guide to the right method in ethics is found in the fact - to repeat - that all the schools of ethics which attempt to give any complete treatment to its principal problems feel themselves obliged, in a measure, to make use of all three of the methods just described. It is necessary, then, to examine each of these methods and, if 
possible, to determine what may be accomplished by their use and how best to combine them for purposes of successful research.

The psychological method investigates the being of man as capable of conduct. In some sort, then, it is the primary and the most promising and actually rewarding manner of approaching the study of ethical problems. The very nature of these problems is such as to force the conviction that ethics must begin by a study of human nature with a view to discover what its ideal of eonduct, in fact, is, and in what respects man is equipped to roalize this ideal. Where, indeed, otherwise than as it is datum of the individual's consciousness, can one possibly look for the answer to any inquiry after the sources, the development, the sanctions, the laws of the moral life? Plato was, indeed, "the first to propose for ethics a psychological foundation." Buthe is entitled to be called "the first," because that which all previous thinkers and disputers had been doing in only a halfconscious, fitful, and fragmentary fashion, Plato proposed to render more thorough, immediate, and systematic. If others went to the human soul, as to an oracle, only through the heterogeneous and conflieting means of the prevailing customs, opinions, and laws, - the products of souls in their complicated intercourse with one another, - this great searcher for the truth aimed to reach the priestess herself, the soul in its immediateness, and to hear directly from her what she had to tcach. Of his psychological division of the soul as a foundation for a theory of virtues, it has been well said: "Rudimentary as it may now appear, it was an important contribution towards the scientific theory of morals." And all the discussions and conclusions of Plato's great pupil, the founder of ethics in a more objective and scientific way, are distinctly psychological. This remark is true of Aristotle's doctrine of the end of the moral life, of his discussion of the nature of virtue in the large, as 
it were, and of each particnlar kind of virtue; it is true also of his doctrine of the mean, and of that division of the virtues which a modern writer has said "may well be called one of the greatest philosophical discoreries of any age."

Undoubtedly in modern times there has been a strong and perhaps there is a still increasing revolt against the more purely psyehological method in ethics. To this there is the less objection if the revolt be directed toward the unintellirent and too exclusive use of the distinetively psychologieal method. But suppose that, for the moment, we displace this method entirely by the more objective and historical method, and then try to think ourselres through to the conclusions which can be reached in the latter way. There is now before us a vast, a practically unmanageable amount of "data of ethies," consisting of the customs, conventions, laws written and mwritten, of men of different ages and of every degree and kind of intellectual and ethical development. The student is sternly forbidden to copy the too proud and self-confident attitude toward this heterogeneous mass of the doings and sayings of his fellowmen which Aristotle assumed when he declared (Nic. Eth., I, ir, 6): "Nothing but a good moral training can qualify a man to study what is noble and just." But the purely objective and historical method in ethies is inevitably doomed to failure. In other words, in the study of ethical problems, one must find much both of the facts and of the standard in his own cousciousness; the "good judge" in such a case is the man who carries within him, in his own sonl, the highest natural and acquired qualifications for good judgment. These qualifications are, of course, theriselves moral; they are nothing else but the character of the individual soul that passes the judgment.

Indeed, in the last analysis, how can one escape some such conclusion as this, to which the assumption of the psychological standpoint seems to compel the mind? But 
how does the case of ethics differ in this regard essentially from the standpoint necessary to be taken, from which to view the alleged facts and principles of every form of human science? What the knower knows, or can know, depends upon his own intellectual and more distinctively moral character. If, for the time being, we extend the conception of conduct over the "dianoëtic" as well as over the more strictly "moral" virtues, or exccllencies, this dependence of the investigator for truth on his own moral character is as essentially true (though not in precisely the same way, nor to the same extent) of the natural and physical sciences as of the philosophy of conduct. Truth and knowledge, as well as ideas of duty and feelings of obligation, are determined, in the last resort, for every individual by what takes place in his own consciousness.

In the case of ethics especially, how shall its problems be understood, or how shall any conclusions concerning them which have even the aspect, not to say the essence, of morality be reached, unless the soul interpret the data of facts into terms of its own experience? For the external actions, or the custom in which the actions of many individuals lave become crystallized, is an affair of interest to the student of ethics only as it issues from, and terminates in, some state or more permanent condition of the soul. Each fact must be interpreted in order to become a datum of ethics. There is only one interpreter for every man, who must constitute the last link in every chain of communication which binds him to nature and to his fellows; and that one interpreter is his own soul.

In gencral the results which words and things significant of "right" or "rights," of "duty" and "obligation," of consequences of "pain" or "pleasure," of "interest" and "utility" - and whatever other words and things the study of ethics may acquaint us with - shall have to contribute toward an ethical science or a philosophy of morals, can 
only be determined by a process of interpretation. Data of ethics are no more data of ethics than are the movements of the stars in their courses or the formation of erystals, or the growth of trees, unless they are rendered into facts and laws of consciousness by the mind trained in psychology. And inasmuch as ethics lays stress upon one particular import or aspect of the consciousness of man, its data require for their fullest and most satisfactory interpretation the mind that has made itself acquainted with the Self as a being fitted for conduct.

Nor must this defence of the psychological method in: ethics be too narrowly apprehended. For, as will appear. more in detail subsequently, all of man's being, so far as it can become connected with his conscious states and, in any way or to any degree, brought under the control of the will, is concemed in his conduct and in the development of character. This statement is true of his bodily organs, - of his eye and hand, of his sexual and digestive mechanism. Of course, his entire outfit of psychical characteristics contributes toward the determination of questions of right and wrong in conduct, and of the good and the bad in cliaracter. Generalize as broadly as the student of ethics may, and rise as loftily on the wings of a priori speculation as he can, it still remains true that, not only the practical solution of every detailed question of morals, but also the rational solution of the problems regarding the fundamental principles of morality, implies the actual complex structure of the human being in its relations to other beings known to be similarly constitutcd, on a basis of experience. For man's moral nature is not an affair of moral fecling, or of moral judgment alone; and there is no single one among the many conceptions which have attached themselves to the word "conscience" that affords a complete description of his fitness for the moral life. Without recognitive memory, without a play of imagination which enables him to rise in his mental picturing quite above the levels to which the highest of the 
lower animals are confined, without a corresponding development of his powers of observation and of reasoning, so as to anticipate the future consequences of his own conduct and of that of other men as an important part of his anticipation of the future operation of natural laws, man could not possi. bly be the "moral agent" which he most certainly is.

In the further detailed discussion of the problems of ethics by use of the psychological method, the investigation may therefore appropriately pay deference to the tripartite division of the current psychology. But, inasmuch as the moral life, when studied in its characteristic development, and especially in connection with the search after the origins and sources of that development, seems to justify a change in the customary order of discussion, I shall treat first of the affectional side of human nature in its total equipment for conduct. This distinction will lead to the unfolding of the subject in the following order: (1) certain forms of feeling in which man's fitness for the moral life consists, so far as that fitness is distinctively a matter of the affections and emotions; (2) the judgments and conceptions which mark the derelopment, on the side of intellection, of his moral life; and (3) the character of the volition which man has, or attains, and which makes it possible for him to adopt as his own his actions, and courses of action (so as to constitute a veritable piece of conduct), and to choose amidst the conflict of ends and the varied means such ends and such means as agree or disagree with the moral ideal.

In all the discussions of psychological ethics most of the principles employed, and many of the conclusions attained, must be borrowed from psychology. For although all of the so-called faculties which psychology inrestigates are conccrned in conduct, and so become also matters of ethical appreciation and concernment, not all of the facts and laws relating to these faculties demand renewed inrestigation at the hands of the student of ethics. The general facts and 
laws of consciousness, and of the different classified processes or states of consciousness, may - nay, must - be assumed as though they were already sufficiently determined by previous studies in another but kindred discipline. No doubt any author's views upon certain problems of ethics will be largely, although perhaps unwittingly influenced by his psychological positions. This will be especially true of such psychological problems as the unity and reality of the human soul, or mind, the question in debate between the adrocates of determinism and so-called "freedom of the will," the existence and nature of the higher sentiments and emotions, the nature of pleasure and pain, and the relations of mind and body. For myself, I can neither, on the one hand, claim to approach certain ethical problems with a complete freedom from all prejudice due to opinions already formed and advocated on related psychological problems; nor, on the other hand, can I repeat in detail, or discuss anew, the conclusions to which I have elsewhere come respecting truths, half-truths, and errors in psychology. ${ }^{1}$ It is enough for my purpose to claim the right to make use of these conclusions and discussions to the best advantage of the following ethical treatise.

Let it be assumed, then, that the use of the psychological method in its strictest form is appropriate to the subject matter of ethics; and that all historical and objective study only prepares the mind for the act of conscious interpretation and evaluation of the data of ethics collected by such study, - an act which itself makes the highest possible demands upon the analysis of the trained student of human nature. But here, as everywhere in the use of the psychological method, the dictum of Goethe remains in full force:

"The gauge that from himself he takes

Measures him now too small and now too great."

1 The works to which reference is here implied are especially, Psychology, Descriptive and Explanatory (1894), and Philosophy of Mind (1895), both by Charles Scribner's Sons, N. Y. 
Especially is this true of ethies, within whose sphere the habitual and the customary is with the multitude of men almost inseparably related to the ideal standard which is set up by the individual soul. The intimacy of this relation between the better custom and the ideal standard is witnessed to by all the language which men employ when treating of matters of conduct, and by the impossibility, in many particular cases, of drawing legible and fixed lines so as to determine where custom ends and morality, in the stricter and higher meaning of the word, begins.

Suppose, for example, that the definition of Wundt be adopted: "Custom, in the sense in which it is ordinarily used to-day, means a norm of voluntary action that is valid for a national or tribal society without enforcement by ex: press command or by punishment for non-conformity." At once it must be admitted that every essential element in this definition admits of degrees of variation which serve to shade the conception of custom off toward morality on the one side and toward law on the other side. As the author himself admits: "It is true that custom finds its own means of compulsion." But it is not so obviously true, or it is not true at all, that "these, like custom itself, are nerer of the obligatory kind. They consist neither in subjective commandrnents like the moral laws, nor in objective menaces like the laws of the state." For in multitudes of cases, and indecl as a general rule, the eustom is, in the consciousness of the individual (and often rightfully) a "subjective commandment like" a moral law; and the menaces which threaten him who breaks the "cake of social custom" are quite as objective and as terrifying as any enacted by the laws of the state. Moreover, there is constant interchange of status amongst all these three - namely, custom, law, and morality. This interchange is essential to man's ethical development. Under the influence of the law of the

1 Ethics, I, p. 151 f. 
state, or of the subjective commandment, either of which may easily enough at its beginning only express the opinions and the will of a few individuals regarding some particular matter of conduct, the custom forms and grows and widens its sphere of influence. Under the same legal or moral influence the custom may be broken down. Or, on the contrary, the development of the custom may render the law nugatory, a dead letter; or the same derelopment may quite transform the character of the subjective mandate, the voice of conscience, the so-called "roice of God." Instances of all these interrelated transformations are not so rare that they need to be cited in the present connection. They are, indeed, so numerous as to eonstitute almost the entire valuable data of historical and evolutionary ethics. The evolution of that marvellous and formidable compound of social customs, religious ideas, and ethical conceptions and opinions, which constitutes the life atmosphere of the modern IIindu is made up of examples. Not less so the more recent history of how this compound is slowly disintegrating. But the same thing is true of those reactions of the popular moral consciousness on its environment which belong to the daily experience of us all.

The student of ethics who would take account only of the dictates of his own soul - however cultured and fair - can never find therein the sufficient data for a science or a philosophy of human conduct. He may, indeed, justly say: "I, too, am a man." He may even fit himself by bestowing analysis and reflection upon his own moral consciousness, for the righteous claim to know more than ordinarily well what belongs to human moral consciousness. But others, too, are men. They, too, furnish worthy ata of ethics. And inasmuch as they cannot appear in propria persona before the inrestigator and testify out of a full mind and heart what they think and feel about the right and wrong of conduct, the good and bad of character, their testimony 
must be taken in a more indirect and external way. In all this there are some obvious advantages. For although the real meaning of the testimony as thus obtained is more doubtful, and the voice of the witnesses is at first appallingly conflicting, the generalizations possible are placed upon a broader basis, and the insights into eternal and universal moral principles are more capable of being defended and of being transmitted to other minds.

The historical and objective method must, therefore, be combined with the psychological and more purely subjective method in all successful study of ethics. Indeed, there is much to commend the attempt of a modern writer ${ }^{1}$ to combine the two in the claim that the straight road to ethics lies through ethnic psychology; and this is defined "as the history of custom and of ethical ideas from the psychological standpoint." But after all, whether the path followed be deseribed as belonging to one method, or to two allied methods, is not a matter upon which great stress need be laid. The history, the objective facts, must be regarded; otherwise our attempt at a science of ethics is, at best, only the "confessions of a fair soul." But this history, these objective facts, must be interpreted, must be rendered into terms intelligible to the individual's moral consciousness. Otherwise so-called "data of ethics" are not more ethical than are the facts with which the merely narrative historian deals. They are mere chronicles of deeds, not genuine data of ethics. Especially is it true that the comprehensiveness and loftiness of the moral Ideal which each investigator holds aloft in his own conscious soul will chiefly determine his attitude toward the sanctions and ultimate principles of human conduct.

When the data hare been sufficiently collected, whether by the psycloological or by the historical method-or still better, by a skilful combination of both - the problems which are implicated in the data require further treatment 1 Wundt, Ethics, I, p. vi. 
by reflective thinking. Every appeal to human moral consciousness reveals, in its dawn, rise, and fuller effulgenee, a certain ideal which solicits and, in some sort, compels the allegiance of the human mind. Conceptions have to be recognized, which, although admitting of an almost indefinite variety of detailed application, have a universal and unchanging import; they come before the student of ethics for analysis, and for adjustment in that system of ultimate principles and most inclusive ideas which philosophy aims to establish. Just as every sphere of facts, when subjected to scientific treatment shows a residuum of problems of a more ultimate kind, which must be handed on to philosophy for speculative discussion, - so especially, ethics.

Man is a speaking, social, and religious being. All these attributes are true of hin, so far as the most penetrating research ean discover, whererer we find him in time and space, and in whatever stage of his evolution in history. But speech, social intercourse, and religious faith and worship are all species of conduct. And the man who uses language, who transacts business and enters into relations of friendship or enmity and strife with his fellows, who prays and saerifiees and contracts the obligations of membership in the religious community, is one and the same man. He it is also, who develops the arts and sciences; and who makes practical applieation of them to the amelioration or degradation of the conditions of human living. This being is born, at one and the same time, into the world of nature, into the socicty of his fellows, and into what he comes to believe are more or less real and vital relations to the gods. IIis conduct is a matter that has to do with right and wrong adjustments in all these activities and relations. What Muirhead ${ }^{1}$ seems to think has already come true, - namely, "the dissolution of the ancient partnership between philosophy and its various branches" and the reduction of ethics to a purely

1 The Elements of Ethics, p. I I f. 
empirical science, - can never become true. Such a rending of human nature as is implied in this dissolution is impossible; just as is also the implied result of restricting the sphere of philosophy with its method of reflective thinking.

And, indeed, no thorough attempts at a so-called "science of conduct" have ever been made (less even than formerly, in these later days when "empirical science" is so boastful in its claim to cover the entire field to the exclusion of metaphysics) which did not largely resort to the method of speculative philosophy. What Professor Watson says ${ }^{1}$ was true of the Sophists is true of those who, to-day, arrocate a practical ethics "without metaphysics." "The main idea common to them all was that customary morality was not absolute, but was a fair subject of discussion and criticism." No: customary morality is not absolute. The thinker over the problems of human conduct, whatever his method or school, has never found himself able to identify the customary with the absolutely right. But whence comes this persistent, this provoking idea of "the Absolute" into all our discussions of ethics? Why cannot the investigator stick to the proper sphere of a truly empirical science and refuse to discuss or even consider the conceptions that are tainted with this metaphysical idea of an absolute?

It will appear that the distinctively ethical problems of a more ultimate character with which the metaphysics of ethics finds itself compelled to deal, concern chiefly the relations of human conceptions of the Right and the Wrong in Conduct to that which has Reality. What is it to be really right? What Ground in reality has the Right? Is the World-Ground an ethical Being; and is the really existent System of beings an ethical system? Problems which have the virtual significance, if not the exact form of such questions as the foregoing, inevitably emerge when we try to think ourselves straight through the most profound and

1 Hedonistic Theories, p. 11. 
interesting experiences of man regarding the sources, the development, the sanctions, and the final principles of human conduct. And so the metaphysics of ethics must try to bring the ethical conceptions of mankind into harmony with the best philosophical cognitions and opinions respecting the nature and final purposes of the really existent World and its Ground.

Making use to the best of my ability of all three of the proper methods of ethics, I shall, therefore, attempt the following task: - to inrestigate the nature of man as moral (capalle of conduct), to classify and discuss the different forms of his conduct as coming under moral law and constituting the so-called "duties" and "virtues," and to treat speculatively the ultimate ethical conceptions regarded as having their ground in the existing system of the Universe. Such a treatment naturally results in the three following divisions of the one treatise of the Philosophy of Conduct: (1) The Moral Self; (2) The Virtuous Life; and (3) The Nature of the Right. Of these three the first part is mainly psychological, the second mainly historical and objective, the third mainly critical and speculative. But in each of the three parts the three branches of the one method must be employed in combination.

Upon the study of ethics thus pursued the following remarks now seem appropriate. First: Ethics, so far as it can be rendered scientific, is one of the sciences of man. Henee its dependence upon psychology and anthropology is to a certain extent absolute. Hence also, second: Ethics, like any other similar discipline, should begin inductively. It should strive to plant itself upon a basis of undoubted facts, and from this basis, with a constant attention to the demands for a frequent return to this basis, proceed to the discussion of speculative problems. In this way, third, ethics becomes an important and eren necessary pedagogic for the other sciences or disciplines, which deal with the 
conduct of man, - especially for law, economics, politics, and theology.

What definite and defensible results may reasonably be expected from this combination of the methods appropriate to the systematic study of human conduct? To this inquiry only the actual achierements gained by each student's efforts can give the satisfactory reply. But Aristotle's caution applies to all alike. It is not fitting, in accordance with the very nature of the subject to expect, or eren to seek for, that more perfect accuracy which is demanded of the physical and natural sciences. The haunting consciousness that ethics did not admit of a strictly scientific construction seems to have accompanied Aristotle ${ }^{1}$ in all his work of investigation. Neither in respect of minuteness of detail, nor of mathematical exactness, nor of definiteness, nor of finish, nor of justifiable subtlety of argument shall we expect, or strive, to rival the work of the physicist, the chemist, or even the physiologist or biologist.

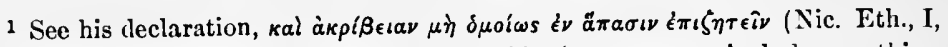
vii, 18). Here and elsewhere the conception of ákpí $\beta \in \iota$ seems to include something of all these five characteristies of a typical scientific investigation : (1) minuteness of detail, (2) mathematical exactness, (3) definiteness of form, (4) finish of form, and (5) subtlety, - especially, perhaps (1), (2), and (5). How the consciousness of this necessary lack of scientific perfection did haunt Aristotle we learn from his repeated references to the subject. (See also II, ii, iii, and iv). Compare the note to the passage in Sir A. Graut's The Fthics of Aristotle, I p. $449 \mathrm{f}$. 


\section{CHAPTER III}

\section{THE CONCEPTION OF THE GOOD}

There is a certain universal way of human thinking and acting, if not a certain determinate form of conception, which connects the subject of ethics with a number of closely allied forms of inquiry. Indeed, so close is the connection that the investigation of the actions of men from the point of view held by this conception has often been made the most important part of entire ethical systems. Undoubtedly all adult human beings give much consideration to what is "good" or "bad" for them to experience; and, accordingly, they habitually act with the intention to secure as much as possible of what they consider good and to aroid as much as possible those experiences which they consider bad. Writers on the history of ethical opinion are fond of reminding us that, whereas the modern Occidental man dwells more upon conceptions of rights, duties, and the moral law, the ethics of ancient Greece laid stress upon the conception of the Good. Certainly this Idea was, in the Platonic system of thinking, not only the supreme ruler over all the other ethical ideas but the chief and lord over all those ideas with which the philosopher found himself concerned in his efforts to understand the problems of the physical world and of human life. The predominance of this conception in the Greek ethics as compared with the ethical studies of modern times is, however, scarcely more than apparent. The feelings, thoughts, and actions of men, which cluster about and follow along with this conception, are always an inseparable, an integral 
part of moral philosophy. It is only as discerning and desiring, as estimating and striving for, whatever is good that man is capable of dutiful and virtuous conduct, or is a subject of moral law. Some study of this conception is, then, almost a necessary prelude to the fuller analysis of the nature of a Moral Self.

Only slight examination, however, is necessary to conrince one how vague and yet comprehensive are the mental processes which answer to such a phrase as that under consideration. The criticism of this conception is one of the most important and difficult tasks in the philosophy of conduct. Every one knows what particular smells, tastes, sounds, and sights he considers good, what bad; and perhaps, what he should more readily characterize as neutral or indifferent. It is more difficult for men generally to say which of these two contradictory epithets they should wish to apply to those more elaborate combinations of sensuous impressions that are discoverable in eren the most meagre "works of art," so-called. Is this picture, or piece of sculptured stone, or moulded metal, good or bad? Do you approve or disapprove of this tune? Such questions as these are answered with more hesitation and obrious doubtfulness than questions which concern the simpler sensuous impressions.

But now, again, if inquiry be raised as to any piece of conduct, whether it be good or bad, it is interesting to notice how the mental attitude of the majority of men stands toward such an inquiry. In case the particular conduct admits of easy classification under any one of several already accepted titles, the judgment as to its character may be promptly rendered, more or less suffused with the appropriate fecling. Is this particular act of stealing, lying, murder, or impurity, good or bad? Every adult member of society has a judgment in store and ready to be applied to such a question, as a part of his stable equipment for the moral life in society. Eren the thief, the liar, the murderer, 
the rake, need not hesitate long orer his choice of epithets: this particular theft, or lie, or murder, or seduction, may in the vicious man's judgment be at least partly good (because of the manner of its performance or the end secured by it); but another deed, quite similar in its external characteristies may for some reason be deemed either wholly or largely bad.

But if the particular piece of conduct to be judged is not easily classified, or if it is complicated with intricate considerations of motive and of consequences, or if it is taken for its answer before different individuals whose social conditions vary greatly or whose moral consciousness has been quite differently trained, then the greatest variety of judgments and emotions will be elicited. Some will pronounce it "good;" but others, with equal confidence, will say, "bad." And not a few, perhaps, will be puzzled to know what answer they shall give.

Judgments about the good and the bad appear, then, to indicate a somewhat important difference in the way in which men use these words, depending upon whether the object is a matter of sensuous, of more nearly asthetical, or of inore definitely ethical appreciation.

"What is most just is noblest, health is best,

Pleasantest is to get your heart's desire."

When quoting this Delian inseription, Aristotle (Nic. Eth., I, viii, 14) announces the conclusion that "happiness is at once the best and noblest and pleasantest thing in the world, and these are not separated." But the conclusion is hasty and ill-taken, and based upon insufficient grounds. The important thing now to notice, however, is that, plainly, this same Delian inscription means to emphasize the undoubted fact of a popular classification of the goods. The noble, the practically useful and desirable, the sweet, - these are, indeed, all good; but they are not precisely the same kind of good. How, then, do they differ as kinds of the Good; and 
What is that common characteristic which they all possess, so that they can all be called good?

The most primary court of appeal in answer to such inquiries as those raised above is, of course, psychological analysis. But such analysis, in order to be trustworthy, must be based upon a wide acquaintance with the workings of the human mind. It will subsequently be found that the fundamental differences between the important schools of ethics are deeply concerned with the discussion of the nature of the Good; and, accordingly, no thorough treatment of the subject ean properly anticipate the critical examination of the claims of these schools. But a preliminary psychological inquiry will prove helpful.

The most important thing to notice respecting this conception may be stated as follows: Every form and degree of what men call either good or bad has reference to a state of sentient and conscious life. And all the higher and more significant forms have reference to the experiences of a selfconscious life. There is no good that is not a good which is serviceable for or actually realized in some condition of a Self. We try, indeed, to picture to ourselves some remnant of good truth and beauty belonging to the system of things, if all conscious selves were removed from existence. The extinction of self-conscious life is, to be sure, in the philosophy of Schopenhauer and of some of the Vedantic writings, the alone true good, the end which, for the good man, is devoutly to be wished. The object which Kant coupled with the moral law within, as exciting his highest admiration for its noble goodness, was the starry hearens abore. If the good of the extinction of conscious life could be attained, there would, indeed, be no remaining badness in the universe, of any degree or kind. But, then, there would also be no good. For the only xsthetieal and admirable good which the science of astronomy could elicit was in Kant's own appreciative soul, or in the conscious state of some other 
soul, - not excluding the imagined happiness of the WorldSoul in contemplating its own cosmogonic achievements. To talk of good, or of bad, of any kind or degree, without reference to good or bad states and activities of a Self is to talk the unimaginable and the absurd. Only as we mentally endow things with some of the qualifications of selfhood or consider them with reference to selves, can we bring things under this conception. Only as we make quasi- or partial selves out of the animals can we apply the same terms to them. It is the projection into the Other than Self, of our own conscious happiness or unhappiness, beauty or ugliness, moral goodness or badness, which induces and justifies the use of the conception. What is good? What is bad? States of selves, and what has reference to states of selves. Beyond such states, or without reference to such states, there is no good, no bad, either instrumental or final.

Taking our start from this subjective and yct unalterable and universal point of view, we ean easily see how it is that every thing, and every event or deed, may both merit and receive the title of good, or its opposite, as it is considered from an indefinite number of subordinate and more special points of view. This tool, for example, is good for one kind of service, but bad for another. This article of diet is good, if the end be the production of pleasure, but bad if the end of health be kept in view. Or it is good for both pleasure and health in the case of one digestive apparatus and bad for both purposes in the case of another person's digestion. This instrument is good for the good deed of the executioner, and equally good for the bad deed of the murderer. The pure pleasure of the peasant in the contemplation of his bad picture of the Madonna is good; and good or bad may be the act of worship according to what it means for the worshipper or according to its effect upon others. And does not erery one know that it is indeed "an ill wind (however destructive) which blows no good"? So shifty and variable in its par- 
ticular applications is this conception of the Good. But the reasons for these characteristics are all to be found in the statement just made as to the essential nature of all that to which the various kinds and degrees of the conception are applied. As varying and shifty as are the conscious states of the soul of man as well as the relations of these states to things and to other men, so many and changeful are the uses of the terms good and bad when applied to things, to events, and to the deeds of men.

Now, however, another most important consideration comes before us respecting the essential characteristics of this comprehensive conception. Plainly, as all human language shows, whatever is good admits of some kind of relatire estimate or measurement. We have already spoken of degrees, as well as of kinds, of what men call good or bad. And when one remembers that characteristic of nearly, if not quite all of the conscious states of the Self, upon which psycho-physics relies, whether popular or scientific, and whether more or less symbolic and uncertain in its methods and in its conclusions, then we understand the source of this popular doctrine of the measurement of goods. For all such conscious states do, in some sort, vary in the degrees of their intensity and comprehensivencss. As respects their seizure upon the entire circuit of consciousness, the emotional warmth which goes with them, and the depth of the present impression which they possess, they are not the same. Our language is, indeed, figurative; its real meaning is often painfully vague; it may be doubted whether any comprehensive science of psycho-physics can be based upon such experiences. Nevertheless, the experiences are genuine and universal; and in them we find the explanation for the more or less, both of goodness and of badness, which things and events and deeds are held to possess.

It is not in degrees alone, however, that the goodness and badness of different experiences need to be compared. An 
estimate of values, that is not merely quantitative, is undoubtedly placed by men upon those experienees to which the conception of the Good is applied. This fact, and the enormous significance of this fact for our entire understanding of human nature, as well as especially for all attempts at a philosophy of conduct, will be frequently discussed in other connections. Just now our intention is much more limited in its range. The psychological principle which applies to the conception is this: All measurement of "the good," which is not merely intensive or extensive (an estimate of quantity), implies some standard which must be assumed as differing in kind from the particular form of good which is measured. Estimates of magnitude apply within one and the same kind of good. Estimates of value cannot be applied in the same way. If $I$ am asked to judge between two conscious states and tell which is the most pleasurable, I may be able, at least in some rough and imperfect manner, to weigh them one against another. I like honey, for example, better than sugar. This means that I get more pleasure from the former than from the latter. I prefer reading a passage from a poem or a chapter from a novel to eating either sweet; this may mean the same thing. For, if I am asked, Why? I may answer once more, beeause I get more pleasure from the former than from the latter. Here again the reference is to two pleasurable states of consciousness which may be somehow compared quantitatively. But if, on being asked Why? I answer, because I think that the happiness of reading a good piece of literature is better, more noble, or worthy, is higher and more refined, than the pleasures of gratified taste for sweets, then I am referring to another standard than the merely quantitative one. Some other kind of good is regarded as mixing with the good of pleasure which gives it a peculiar excellence. An estimate of goods according to their values, and not merely according to their intensity or extension is implied. 
The explanation of all such experiences is not difficult for the candid student of psychology who is willing neither to deny nor to sophisticate the facts. It is a fundamental and indisputable fact that men estimate the different conscious states of the Self as differing in value according to a standard which is not merely quantitative. In other words, goods differ, as estimated in human consciousness, not only in degrees, but also in excellence or worth. That there are kinds of goods which have different - higher and lower - values is thus an opinion common alike to the multitude and to all the reflective thinkers of mankind. This opinion is but the expression of that preference for certain states of consciousness over other states, irrespective of their relations as regards quantity of the same kind, which belongs to all the artistic and ethical development of man. It is in the effort to account for this preference, to give it validity, to defend it against attacks, and to judge ourselves and others in the light of its radiance, that the problems of ethics divide men into different opinions and different schools. For a science of ethics begins only when it is seen that men's actions are consciously dirceted toward, or unconsciously terminate in, some one of the several forms of "the Good" (or its opposite); and then the effort is made to give a rational unity to all these forms, and to regard the accepted rules of conduct as the different ways in which, as mon believe, these forms may be obtained.

Plainly, however, other distinctions are necessary in order to understand, eren in a preliminary way, the influence of the conception of the Good upon a science of conduct, or a philosophy of morality. That classification which is based upon the distinction between good as a means (instrumental good) and good as an end is now introduced. It is, however, in fact of comparatively little assistance in determining the essential nature of the conception. This is often due to the implied theory that the application of the distinction, at 
least in eertain instances, can be made absolute. Especially is such a theory held by those who take the Hedonistic, eren when modified into the so-called Eudxmonistic point of view. These writers are quite too ready to assume that when we come to the good of happiness we have reached a necessary limit to our inquiry: Good for what? For, surely, they say, happiness is good-in-itself; although all things and all events were treated as instrumental goods, and were summoned before the conscious soul to tell what good they contribute to it, the happy condition of that soul itself cannot be questioned in the same way. The rational man might, indeed, be challenged as to why he does this or that, and his answer would be accepted as rational if he could declare: In order that I may be happy, or may make some other one happy. The deed is good because it is means to happiness; if it is means to others' happiness, it is a good deed. But to ask, What good is there in being happy? - this is to be absurd; for happiness is good as an end in itself. Happiness is an initself-good. To prove that it is so may, indeed, be impossible. But this is because the matter is self-evident and so admits of no proof, as it needs none. Has not Bain declared: "Now there can be no proof offered that happiness is the proper end of all human pursuits, the criterion of all right conduct" ?

I am not at present discussing either Hedonism or Eudxmonism in any of their sereral forms; I am not even raising the question whether happiness is the "proper" end and criterion of human conduct. I am simply in search of the - psychological facts as to men's conceptions of the differing kinds and degrees of that which they call good. Is it true, in fact, that men never regard happy conscious states, quoad happy, as means to another form of good, but always as good in themselves, - as being, of course, good? It is not true in fact. For many men do frequently regard pleasurable states of consciousness as instrumental and not final 
goods. Indeed, it might almost be said that the stage of morality, in distinction from custom considered as mere fact, is not reached until pleasure-pain states of consciousness cease to be regarded solely as ends in themselves, and come to be regarded also as means related to the attainment of another kind of good. This truth seems to be especially illustrated by an appeal to the two extremes of the moral life, as they are manifest in the evolution of the race. Sarage and uncivilized peoples join with the loftiest specimens of moral culture in all times, in a relative depreciation of, if not a positive scorn for, happiness as the only or chief in-itself-good; while, on the other hand, it is the average well-to-do man under favorable conditions of a somewhat advanced civilization, the well-fed and successful Englishman or American, ${ }^{1}$ who is most likely to prize so highly the ideas and arguments of a skilfully devised Eudæmonism.

It is simple matter of fact of ethnic psychology that, in the ease of the lower races the conduct and character of men is not considered good or bad with reference to the relation which it sustains to the production and increase, or to the decrease and destruction of the happiness whether of the individual or of the community. Sterner rules of behavior than this view could produce are necessary to existence itself. More primitive and yet mysterious and vague ideas than those which the "greatest happiness" theory can account for are already in control of the nascent social life. The whole theory and practice of discipline as it is found actually operative amongst these races compels a different point of view. Here pleasure-pains, of every kind and de-

1 It would be a most interesting and suggestive ethical inquiry to trace the connection between physical well-being, especially such as is bronght about by commercial suceess or successful empire, and the prevalent tenets as to the nature of morally right conduct and as to the basis upon which repose the sanctions of morality. Well-to-do merchants, or the official classes, or the men who have attained a measure of academic prestige, are perhaps naturally inclined to some form of Iledonism or Eudæmonism. 
gree, are largely treated as instrumental; the end is the fitness of the individual for his place in the community, in accordance with the prevalent idea of those characteristics of Selfhood in which such fitness consists. Thus the Melanesians and many other tribes are wont to kill a large proportion of their infants, especially of the females, immediately after birth, because the food-supply is limited and they are "not fit for war." Yet some of these tribes are exceedingly gentle toward helpless living children. In the training of those left alive, pains are freely taken by the parents, and freely inflicted upon the children, to the end that they may the better do their duty, as such duty is defined by the customs, laws, and circumstances of the tribe. The young human cub is licked into shape with only an occasional sidelong glance at the Hedonistic motive. As a boy he is mercilessly subjected to the discipline held to be necessary to conform him to the existing crude ideal of nanhood. With this end in view his early years are rendered full of misery. When he reaches puberty and is ready to be invested with the rights of manhood, the ceremonial ordinarily takes little account of his happiness, while striving to enhance his feeling of the worth of his new possession by emphasizing the suffering with which he pays the cost of it. For example, among some of the Polynesians, the candidate must endure to have his skin cut through with sharp mussel-shells, or his teeth dragged out by the rough dentistry of the priest-doctor.

In all cases similar to the foregoing, religious superstitions are apt to play an important part; but the part which they do play is such as to reinforce the conclusion that nan naturally and necessarily seeks a variety of goods; and that in this search he by no means hesitates to regard the good and bad of happiness as subordinate and instrumental to other forms of good. This view of the relations of the pleasure-pains to the end of existence is illustrated by the 
doctrine and practice of "tabu" among savage and halfcivilized tribes. Here the individual finds himself forbidden, in the interest of certain ends, and for certain reasons of which he has only a vague and shifting conception, to realize the various desires whose satisfaction brings happiness. To be sure, fear of some disaster which is regarded as certain to follow contact with, or enjoyment of the tabued object is one of the most powerful motives in enforeing the regulations belonging to tabu. But he has a shallow view of human nature who cannot recognize more than this as concerned in the matter. The germs of a reverential awe toward the mysterious Unknown and of aspiration to stand well in His sight, to be thought worthy by Him, are also patent here. And this is an end which, although closcly allied to, and often confused with, the end of happiness, is not precisely the same. The doctrine of Nemesis, the way in which the gods furnish men with their moral ideals, the mystic and ascetic elements of the religious cult, furnish arguments for the same conelusion. But these subjects belong more especially to the philosophy of religion.

Of course, the answer to the foregoing arguments made by those who hold that happiness is invariably and necessarily a good in-itself is not difficult to anticipate. It may be said that all the pains voluntarily endured or inflicted are regarded as only temporarily and relatively instrumental. They are regarded as unavoidable means to the end of a greater measure or a higher kind of happiness in the future. Thus, after all, it is happiness which is constantly kept in mind and, however ignorantly, pursued as the true and final end that is good in-itself. Here, however, we have one of those sophistries of argument which are based upon misinterpretation of psychological facts. The very distinction which is emphasized by all the ethical judgments and by all the words for conduct is entirely orerlooked by such an argument. The man who makes his own happiness the "in-itself- 
good," and who follows this end in ways that run contrary to the moral judgment of the community, however crude and loosely organized, is the bad man. But whoever exhibits most of those qualities which conform to the moral judgment, with most of enduring and courageous sacrifice of lis own happiness, he is the good man.

As the conditions of social welfare become more complex, and the society interested in it becomes enlarged by the conquest, amalgamation, or fusion otherwise of different tribes, the same general rule applies to the conduct with reference to one another of its different elements. The bad king, or chief, is he who seeks the happiness of himself or of his family in ways that run counter to the established judgments as to what a good ruler ought to do. The same thing is true of any of the larger factors in the social organism. The family, or the clan, or the faction, which always makes happiness the end-in-itself of its conduct is regarded by the other families, clans, or factions, as bad morally, whether it be successful or unsuccessful in its endeavor. And now that the principles of morals have become expanded so as to cover, at least in some vague and inperfect way, the entire human race, essentially the same standards of ethical judgment continue to be applied. We are, indeed, forced to witness the spectacle of the most civilized and Christian nations, arming themselves to their utmost capacity in order to enforce their own notions, each one, as to what will render them most prosperous and most happy. And prominent diplomats are not wanting who openly arow that the only standards of moral excellence in the conduct of uations toward each other, are furnished by the intelligent pursuit, by each, of its own happiness as an in-itself-good. No wonder that race hatred scems just now to be on the increase. But when the theoretical moralist attempts to justify this conduct, as far as it can be shown to be instrumental to the future greater happiness of the greatest 
number, he, on the one hand, admits our contention that men habitually regard conduct from other points of view than its pleasure-pain accompaniments or consequences, and habitually practise as though happiness were instrumental to certain ends that lic beyond itself; and, on the other hand, the theorist has now run his doctrine of happiness, as always an in-itself-good, out into so misty and limitless a domain that, for the average sight of humanity its precise form can no longer be discerned. At any rate, the theory of happiness as the alone good-in-itself has now passed beyond the point where psychology or ethnology can test it. Its further discussion must be reserved for a more purely speculative treatment.

In that complex system of means and ends which human thought and imagination frames, and to the existence of which human practice bears tostimony, it seems difficult to carry out any fixed and absolute distinction. The consciousness and the conduct of men show beyond doubt that they do recognize the existence of various degrees and kinds of what they consider to be good. And since in this recognition of kinds of good the preference is not always for the greater quantity of the same kind, their notions and their behavior confirm the suspicion that different ideal standards are made use of by different men, and by the same men on different occasions and under different circumstances. It still further appears that all these different kinds of good may possibly stand, at one time or another, in relations of instrumental good to that which is good-in-itself. For man is a very complex being; his interests are many; his appreciations are varied; his sensibilities are capable of an acute and refined development. The concrete problems of conduct are increasingly complicated. Different individuals, and different large collections of individuals, require and actually receive different forms of treatment, - whether to their well-being or ill-being, and whether the well-being be con- 
sidered as more strictly eudæmonistic, or æsthetical, or ethical. Thus, by some persons, under some circumstances, conduct regarded as a moral affair may be made instrumental to the end of happiness, or to the realization of some æsthetical ideal. By others, under other circumstances, the beautiful object may be constructed and used as the instrument of happiness or of a certain moral invigoration and improvement. Still others, under still different circumstances, show themselves ready to sacrifice all considerations of morality and, as far as possible, all considerations of happiness, to the realization of their æsthetical ideal. Nor are these differences found only in application to brief courses or single pieces of conduct. They distinguish different persons with reference to those ends which they chiefly pursue in life, and whose influence pervades and characterizes all that they think and do respecting the solution of life's most important problems. Some men lire for pleasure, and care little for the morally good or the good of beauty otherwise than as the minister of pleasure. Some men lire for art; and some men live for righteousness' sake and to make themselves and others more perfect in righteousness.

Is life worth living? This problem, in spite of its antiquity and the monotony belonging to its reappearances for discussion, retains much of its pristine fascination. Perhaps, indeed, it is growing more engaging as it becomes more complex. But what thinker cannot readily see that no answer is possible unless one has already an answer to these preliminary inquiries: What is the end of life? and, What is the proper standard of worth, or value? Is the end $\mathrm{my}$ own happiness; and is the standard of value quantity and duration of happiness? Then many, perhaps the majority, must say, No; and there are few that at some time must not render this negative answer. Accordingly, were it not for that mysterious dread of the hereafter, which most men feel, whether the dread be rational or not, suicide would be the 
logical answer. Yet how many are there whom we find setting their teeth together, and stiffening their limbs, that they may walk on regardless of suffering toward the finishing of some work of science, of art, or of benerolence?

In spite of the truth that the distinction between instrumental goods and the in-itself-good is not absolute, I will here repeat what has already(p. 36 f.) been indicated with regard to the classification of kinds of "the Good" considered as the end of human conscious and voluntary action. In this relative way one may distinguish three kinds of that which has worth for its own sake, of the goods to which all things and events are regarded as means to the end of their attainment. These are the more strictly eudæmonistic good, or good of happiness, the æsthetical good or good of beauty, and the ethical good or good of conduct and character. There are, then, three forms of the Good, whether regarded as means or end; - namely, the eudæmonistic, the æsthetical, the ethical.

Three remarks upon this classification will serve both to explain and to justify its future uses in the treatment of the problems of ethics. And, first, these subordinate catcgories of the Good may be regarded as sustaining a number of eurious and interesting relations to each other. This truth has already been illustrated by calling attention to those instrumental uses of pleasure-pain states and conditions which are so numerous and important in the development of the life of the race. Much of our popular language is justified only in view of the reality of these relations. "The whole ethical vocabulary," says Wundt, " "falls into two great divisions: words that denote ethical characteristies like 'good' and 'bad,' and words that indicate the emphasis put upon ethical characteristics, like 'esteem' and 'contempt." Almost the same thing, however, might be said of the distinctively eudæmonistic or distinctively æsthetical vocabulary. Hence

1 Ethics, I, p. 41 f. 
arises much crossing and confusion in the use of similar terms in every language. But any more precise and restricted use of the same terms only serves to bring out more clearly these curious and interesting relations amongst the categorics of the Good. Is it not a man's duty to seek his own happiness; or at any rate the happiness of his friends and his fellowmen? Ought this bad artist to paint such bad pictures; or is it right for the man who might produce so much better art to stoop to the inferior? Was that not a beautiful (æsthetically good) deed of kindness, - and all the more meritorious (ethically good) because undescrved? Was not that form of punishment bad (asthetically or ethically), because it caused needless or useless suffering (was, eudæmonistically considered, an evil)? But why multiply instances, when the daily life of man is so full of similar questionings?

But, second, all these relations amongst the different kinds of good - whether regarded as instrumental and final, or regarded as appertaining to the eudæmonistic, the rsthetical, or the ethical good - are suggestive of some sort of

- a unity which shall bind them together both in their conceptual form and in their objective realization. Thus far I have considered the facts, as such, of human thinking and feeling, and of the actual beharior of men as influenced by their conceptions of the "goods" of existence. These facts, however, have served the student of ethics both as his incitement and as his guide to that supreme attempt at generalization which tries to embody itself in a conception of "The Good," - of a good that is entitled to be called the Ultimate, or the Supreme and all-inclusice Good. It is, of course, only in an extremely crude and inchoate form if indeed at all, that any such conception belongs to the lower stages of ethical development, whether of the indiridual or of the race. Primitive man has other ends and interests too closefitting and imperative to encourage such a generalization. 
If we really knew anything about primitive man we might perhaps be compelled to admit that he had not enough of thought and imagination even to frame such a conception. Yet in the "happy hunting-ground" of the North American Indian there is plenty of fish and game; the customary morals of the tribe are not rudely disturbed; and it is probable that some truly artistic glamour must be spread over the scene. In the blessed rule of King Yima the ancient Parsi beliered that men and cattle were immortal; there was no drought, no cold nor heat, no enry nor old age. And according to the Buddhistic way of thinking, there was long ago an age of glorious soaring beings who had no sin, no sex, no want of food. In the mind of the more highly cultivated reflective man there rises the alluring image of a conscious life which shall combine in perfect harmony all those states and conditions that are in-themselves good. Objectifying this image and multiplying it by the various members of the community of such lives, it becomes the conception of a realized social ideal. Of this the poet sings :-

"Nothing is here for tears, nothing to wail

Or knock the breast; no weakness, no contempt,

Dispraise, or blame ; nothing but well and fair."

But if this conception be rendered definite in terms only of Eudæmonism, then we shall have the enthusiastic æsthete declaring against "that miserable word enjoyment, which falls infinitely short of the high æsthetic experience and may be a thousand lcagues aside from it, having nothing to do with it whatever;" while the enthusiast for a perfect moral condition will affirm of Eudxmonism that "the very intensity and unremittingness of its appeal to the senses and understanding end by fatiguing and revolting us," and by breeding in us "a desire for cloud, storm, effusion, and relief."

What now is that common element which belongs to all 
those states of conseious life which men esteem in-themselves good? How shall thought and imagination frame a conception of that which is the Good, ultimate, supreme, and yet subjective? To express this vague and comprehensive conception we hare no one word that is not ambignous and therefore liable to misappropriation by way of too exelusive appropriation to some one of the higher goods of man's conscious life. Let us call it the complete Satisfaction of the ideal Self; only in the use of this word "satisfaction" we must continually and strenuously call back the thought to the psychological and ethnological facts pertinent to the subject. These show that man, as man and everywhere, has longings and aptitudes for different allied and causally related forms of conscious good. He has appreciations of three cognate and yet not identical ralues. He has sensibility; he is capable of happiness and of suffering. He is an artist and a lover of the beantiful. He is a truly moral being; and the different kinds of conduct and of character scem to him to have a value that is peculiarly precious and peculiarly their own. When any manifestation of that which he values as good - the happy, the beantiful, the morally right - is presented to his conscions appreciation he is satisfied. But neither of these goods, apart from the others, gives him a full satisfaction. ${ }^{1}$ The picture of a selfeonscious life in which they shonld all be raised to the highest potency and perfectly united is the picture of the complete subjective satisfaction, - the nltimate and supreme Good for the rational and sentient soul.

To this subjective satisfaction corresponds the objective condition, for which we may perhaps most properly employ the word Welfare. . . . If, now, the thinker, by the highest

1 The $\pi \rho \hat{\omega} \tau o \nu \psi \epsilon \epsilon \bar{\delta}$ os of every methorl of Eudxmonism - whether it result in the earlier and grosser forms of IIedonism or be the direet method of Mill's Ltil. itarianism or the indirect method of Sidgwick's Utilitarianism - is the identifi cation of happiness with the whole of the in-itself-good. 
exercise of his powers of reflection and imagination, objectifies that which brings complete subjective good and gives it the form of a community of selves, so favorably placed as respects their external circumstances, and so well and intelligently disposed toward one another that they all realize their highest satisfactions (happiness, beauty, and the morally right), then he is prepared to captivate the mind with a picture of the supreme Social Good. Let it be the "Republic" of Plato, the ideal State of Aristotle, the "Kingdom of Heaven," as opened to all believers. Here every longing is to be satisfied, - the longing for perfect happiness, the longing for unblemished beauty, the longing for complete purity of character. This is the Ideal that satisfies the different sides of human nature as it rises to its highest heights of aspiration and endearor. But it is the Ideal as yet forever unrealized; and, it would appear, forever unrealizable under the actual conditions of human existence.

One more important consideration follows from this preliminary discussion of the conception of "the Good." The conception is itself, in every aspect, phase, and kind, a subject of development. The actual, available means by which any form of good is to be realized are constantly changing. This is true of the means of happiness, as well as of the means of xsthetical and ethical excellence. Nor does any of the three ideals which stand in human imagination for the highest stage of their respective kinds remain unchanged from age to age. Plato's ideally good man is not precisely the same as Aristotle's; and the ideal Self of the later Greek or Roman Stoic differs from that of either of those masterly teachers of ethics. The perfect Englishman does not satisfy fully either the asthetical or the ethical consciousness of other nations; nor is the type of the thoronghly good man which they exalt by any means wholly satisfactory to him. Each feels it necessary to condescend 
from his own superior height even to admire mildly some of the other's more cherished characteristics. Much wider is the difference between the typically good man of the Orient and the man who seems to merit that title in the Western World. From age to age, whether we consider the ideally good individual or the supremely good social organization, the grand and all-inclusive moral Ideal seems always changing; - now rising and now falling, now growing dim and now shining forth with a renewal of its own white, selfillumining radiance. Who is the wholly satisfactory good man? Where shall we find and how describe lim? And how in detail shall we construct that perfect welfare of social conditions in which all men, in all respects, correspond with this type? The answer to these questions is itself, to a large extent, undoubtedly a subject of development.

Yet one may not hastily conclude that in ethics all is in a condition of perpetual flux. For ethical development does not extinguish or alter, but, rather, unfolds the unchanging characteristics of human nature. As capable of happiness, of esthetical aspiration and endearor, and of the appreciation of conduct and the development of character, the lowest savage entitled to be called a man is more essentially like than unlike his most exalted fellow. There is common "stuff" in all human conceptions of the Good, whether we consider it as means or end, and especially if it be what is deemed good in conduct and in character. The particular differences are indeed great; but, after all, they are chicfly differences of proportion, arrangement, and place of emphasis. All this will appear more clearly and abundantly in subsequent discussions. Even, howerer, in the preceding definition of ethies and in the preliminary analysis of this important ethical conception traces of relicf from the temptation to confusion and scepticism have appeared. Here I will only call attention to the fact that, wherever either the 
goods of happiness or the xsthetical goods are regarded as dependent in any manner or degree upon man's own volun. tary and rational life, there men begin to employ such phrases as "ought" and "ought not" with reference to these goods also. But this usage suggests the truth that the sphere of ethics spreads over the eudæmonistic and æsthetical life of man and tends to render all the interests and conditions of his life matters, largely or chiefly, of human conduct and human character. That is to say, every attempt to subordinate the moral ideal to economical, eudæmonistic, or æsthetical goods, only results in introducing a new form of emphasizing "the ought." Thus a sort of supremacy of the Ethical Good orer the other forms of the so-called "initself Good" seems to be indicated in a naire and unreflecting but impressive way.

To these considerations might be added such others as are, in Professor Green's splendid argument, ${ }^{1}$ made to show how the development of ethies has itself enlarged the application and elevated the content of the ideal Good. Conduct, as we have seen, is the sphere of ethies. In so far, then, as the ideals of happiness and of art are dependent upon conduct, they somehow fall under the sphere of ethics. Still further, if the developing ideal of man, even or especially in its moral aspect, rises so fast above the horizon that the slow climbing upward of his thought, imagination, and endeavor, seems constantly to be further and further, not only from its complete realization, but eren from the complete agreement as to precisely what that Ideal is, this inereasing distance between the conception and its realization, and this expanding of the conception, are not necessarily a good ground for scepticism, or for the refusal on any man's part to aspire and to strive. That is not always best or most influential which is most clearly discerned and scientifically defined.

1 See his Prolegomena to Ethics, book III, chapters ii-iv. 
And it may be not only the surest destiny but the highest privilege of man to have his thinking baffled and his imagination outstripped whenerer he attempts to give the full account of what it means to him to use such a phrase as this - the Highest Good, or that which is perfectly and inclusively good. 


\section{PART FIRST}

\section{THE MORAL SELF}


"So in man's self arise August anticipations, symbols, types of a dim splendor ever on before In that eternal circle life pursues."

Brownisg. 


\section{CHAPTER IV}

\section{ANALYSIS OF MORAL CONSCIOUSNESS}

The more detailed study of the moral self, or of man as capable of and responsible for conduct, may fitly begin with a survey of human nature from the point of view held by psychological ethics. What that point of view is has already (p. $21 \mathrm{f}$.) been sufficiently indicated. In other words, the first problem of ethics may be expressed as follows: What equipment for the moral life belongs to the subject of that life? In considering this problem it is not necessary to appeal to facts in order to sustain the conviction that, in all essential respects, man has always had the same kind of a moral equipment. By the student of ethics, this equipment must therefore be considered as an endowment. Indeed if one were to press the ethnological or anthropological discussion to its last ground of standing, one might feel fully justified in saying: If at any time there existed a being half or three-quarters ape and half or one-quarter man, who differed essentially in this respect from man as we now know him, such being would not properly be called a "man." Man, as we now know him, is essentially ethical. His ethical development is not one with which he can dispense and yet continue the claim to be what, psychologically and ethnologically considered, is properly called human.

Moreover, in the broadest extent of the inquiry all the socalled faculties and distinctive characteristics of human nature are involved and employed in the life of conduct and in the development of character. Yet a very important dis- 
tinction should be made at this point. Some of these functions and activities are not distinctively ethical, as others certainly are. Man, as cognitive merely, as acting in the interests solely of the growth of knowledge and the attainment of science, - if we may for the present purpose and by a somewhat difficult measure of abstraction conceive of him as merely cognitive, - uses precisely the same powers in the same way as when he is acting in the interests of the moral life. On the other hand, there are certain forms of mental functioning which the student of ethics is not at liberty to consider in precisely the same manner. A distinction may then be drawn between such part of man's endowment for the life of conduct as is more general and involves all his so-called faculties, and such other part as may be more specific and distinguished by uniquely ethical activities. Perhaps, indeed, the picture of a being with a superb intellectual outfit and an exquisitely cultirated xsthetical judgment and sensibility, but quite without "conscience" in the popular meaning of this word, is not impossible to construct. Actual examples of men long dead or now living may be pointed out, who have not failed to suggest the abstract possibility of such a being. This possibility suggests a classification the fuller justification of which will follow in connection with all the subsequent discussion of allied topies.

The ordinary division of the psychical actirities or functions may conveniently be adopted. Ethics, studied psychologically, will then have to consider the possibility, and the actual nature of (1) ethical feelings, (2) ethical cognition, and (3) ethical volition or choice as a moral affair. In the consideration of each class of the subjects suggested by this tripartite division, it will be found that the previous twofold distinction must also be borne in mind. For certain - forms of feeling, of judgment, and of willing, will be found to be ethical, in a more specific and unique way. The psychological (whether, or not, it be also rational) primacy - 
the first position in the order of actual development - must be given to the feelings, where our problem is that of tracing the sourees and the unfolding of the moral life of man, whether of the individual or of the race.

The affective (or affectional) equipment of man for the moral life consists in two classes of feelings. The first of these includes such affections, emotions, passions, or other forms of feeling (and here for the moment we may mention certain impulses and appetites) as do not of themselves have any special ethical significance, but by their intensity or extensity, adjustment, and predominance or control, influence conduct and determine character. Much of this affective equipment man shares with the lower animals, - as, for example, anger, fear, shame, pride, jealousy, sympathy, etc. Their sum-total, so to speak, constitutes the greater part of what is popularly called each man's "disposition." In the same eategory, with reference to the purposes of a philosophy of conduct, may perhaps best be placed such impulses as curiosity, acquisitiveness, the so-called instinet of selfpreservation, etc. It is these affective and impulsive qualities of human nature which it is particularly diffieult for psychology to classify or even to discriminate and enumerate with any degree of scientific completeness. It is they which, when they are considered as habits or trained facultics under the principle of moderation ("the mean "), Aristotle ${ }^{1}$ denominated the "moral excellences" or virtues. Under what circumstances these affective and impulsive forms of functioning take to themselves a more distinctively ethical quality, and become entitled to such terms as "good" or "bad," in the distinctively ethical meaning of the words, the discussion of such problems as the nature of virtue and vice, the classification of the virtues and the unity of virtue must be permitted to show.

But besides such portion of man's moral endowment of 1 Nic. Eth., II, vf. 
feeling as is constituted by his natural impulses, emotions, and passions, in the relation which all these necessarily come to sustain toward the life of conduct and the development of character, there are certain unique forms of distinctively ethical feeling. Of these the most primary and distinctive - indeed, the distinctive and unique affective element in moral consciousness - is a certain feeling which I will renture to call "the feeling of the ouglit" (or its opposite, "the ought-not"). In its more developed form this affective movement becomes the feeling of moral obligation. Closely allied to, and yet by no means the same with, this feeling is the fecling of ethical approbation (and its opposite). Of these two, when they are compared, it is noticeable that the former stands much nearer to the ultimate and unanalyzable sources of the moral life of man. For ethics, or the science of conduct, has already been distinguished as having to treat of that which ought and ought-not to be done in conduct, and with that which ought and ought-not to be in character. The morally good is equivalent to that which "ought," and the morally bad is that which, on the contrary, answers to the title "ought-not." Unless man were endowed with, or capable of developing the feeling of obligation, - that peculiar and unique attitude toward certain kinds of conduct, - he could not possibly lead the moral life. To himself, and so far as his own self-consciousness is concerned, he could neither be good nor bad morally. But the feeling of approbation (or its opposite) is frequently, if not generally, almost as much a hedonistic or æsthetical as a strictly ethical affair. That is to say, the fecling of pleasant satisfaction which is experienced on contemplating a morally good deed or an upright character is ordinarily a mixture of sympathetic happiness, xsthetical admiration, and gratified moral consciousness. In case there is something naturally painful or asthetically ugly about the deed which, howerer, as ricwed from the moral point of riew, one is still compelled to 
approve, a partial or complete separation of the elements composing this mixture is effected. Even then, however, if the person performing the deed is regarded as triumphing over his own foclings of pain and of æesthetical repulsion in the interests of a high moral ideal, the more strictly hedonistic and æsthetical elements of one's approbation return with redoubled force. The father suffering keenly while he punishes his well-beloved son, or the righteous judge with sympathetic cmotion condemning his dear friend, are the subjects of a hedonistic and asthetical, as well as of a more strictly ethical approbation.

The fceling of merit (or its opposite, the feeling of demerit) should perhaps be added to the other two as belonging to the more distinctly ethical endowment of man on the side of affection or sentiment. But here the psychologist scems to be dealing with states of consciousness yet more complex. The workman in any line of art may well enough feel that he descrves recognition for the good work that he has done, whether or not he has wrought with a moral motice or in accordance with rules laid down by the current conceptions of virtue and of vice. The joy of work finished, or of inven-tion and discorery, especially when difficulties hare been overcome, is not altogether alien from the ethical feeling of merit. Thus we read of Gay-Lussac dancing about his laboratory when a piece of chemical research was successfully accomplished; and Nicbuhr tells of a feeling which must be akin to the Divine joy in creation, over his own well completed task. Still, of the feelings of merit and demerit, as well as of the feelings of approbation and disapprobation, when they attach thomselves to the kind of conduct as viewed from the moral standpoint, it seems true: there is to be recognized in all thesc affectional movements of human consciousness a specific fitness for the moral life.

Ethical cognition, or the knowledge, half-knowledge, and opinion, which characterizes man's entire moral derel- 
opment, is also a complex affair. Indeed, the completed moral judgment has its roots in all the cognitive processes and faculties. All human intellection is concerned in, and determinative of, the life of conduct and the development of character. But such cognition culminates, as do all the processes which lead up to and are inrolved in a completed act of knowledge, in a certain form of judgment. It is the character of this judgment which furnishes the only distinctire characteristic of the moral life in respect of its intellectual or cognitive aspect.

The fuller exposition of the part which intellection plays in man's moral life belongs to the doctrine of ethical judgment and to the discussion of the virtues and of the various theories as to the nature of the right. But the barest preliminary analysis of human moral conscionsness must detect the following important facts. Any judgment upon questions of the right or wrong in conduct implies a certain cultivation of those intellectual activities which result in the forming of ideals. Any considerable development of moral character implies a relatively high degree of such culture. It is man as capable of idealization who is also capable of conduct in the profoundest and truest meaning of this word. But the formation of ideals - the more emphatically, the higher and nobler the ideals are - requires the reflective and productive activity of thought, and the reproductive and spontaneous activity of imagination. $\mathbf{A}$ growth of that knowledge which is gained by experience as to the appropriate and ordinarily successful means for realizing (however imperfectly) his ideals, and growing capacity to predict the consequences of conduct, are also an indispensable portion of the intellectual equipment of man for the moral life. All this, however, implies an elaborate derelopment of time-consciousness, and the formation of a more or less distinct and elaborate consciousness of self. It also implies the unfolding of the faculty of recognitive memory, and of reas- 
oning from cause to effect, and from effect to cause. Without this forward-and-backward running of reason man could not impute the consequences of good and bad conduct to the personalities whose conduct has entered into the chain of causal influences. We hare thus far been considering those processes terminating in ethical cognition which, although an indispensable part of man's moral equipment, are not themselves distinctively ethical.

A distinctively and uniquely ethical conception appears, however, to be somehow involved in every act of judgment whose subject is either a piece of conduct judged as such, or some type or exhibition of character. This conception forms the predicate of every genuinely ethical judgment. For in every such judgment the eonception "rightness" or "wrongness" (in the peculiar meaning of these words which ethies is foreed to recognize) belongs to the predicate. Ethical judgment is an adjudging of the "right," or the "wrong," to conduct and to eharacter. Such are the words which earry in them the subtile essence that is distinctive of the result in which all the powers and processes of human intelligence express themselres, when they combine to form an ethical pronouncement. What is it that human intelligence can do, with all its wonderful development in comparison with the lower animals, of the distinctively and uniquely moral sort? It can form and apply the category of the Right to conduct and to character. In all his ethical judgments - and all his intellectual equipment for the moral life culminates in acts of judgment - man can use the predicate of rightness (or its opposite) to characterize to himself and to others the peculiar marks whose significance the science of ethics investigates. Judging what is right and what is wrong, man is uniquely a moral intelligence.

That some special development of the faculty of volition is necessary to conduct and to the development of character is admitted with a practical unanimity both by the unthinking 
multitude and by the writers of the various schools of ethics. From Aristotle to Leslie Stephen, from first to last eren among the more clearly pronounced of the Determinists, this admission is the prevalent opinion. In order to actions which deserve the name of moral virtues, Aristotle ${ }^{1}$ holds that the doer must choose to do them; that only the roluntary is the praiseworthy he thinks to be the sclf-evident opinion of all men. "Voluntary action, or action determined by the motives of the agent," says Leslie Stephen, 2 "is the definition of what is strictly conduct." We shall see later on that this alleged universal testimony is by no means so clcar as is customarily supposed; and especially, that the attribution of conduct to the Self, as somchow its own (no matter how rague, inchoate, and inaccurate the conception may be of what constitutes a Self), is far more universal, primary, and self-evident than is the testimony to the voluntary nature of all conduct. Howerer, that man, on the side of his volitions, is capable of a development which puts him into control of himself in a manner quite superior to the control exercised over their actions by any of the lower animals is a universal assumption of all human social relations; it is at once a presupposition and a conclusion of all psychological and ethmological inrestigation.

The proposition that num is possessed of a truly moral freedom is not to be defended merely by taking the popular voice or by accepting ready-made, as it were, the conclusions of the libertarian philosopher. The popular roice does not sound from depths that have no need of exploration; the conclusions of philosophy are quite too often imported from fields of systematic metaphysies that bear little resemblance to the actual, living, moral consciousness of man. Only as our reflection arises fresh from the skilful interpretation of all the facts of this conscionsness and kecps itself tolerably

1 Nich. Eth., II, iii, and III, if. ; and passim.

2 The Science of Ethics, p. 239. 
clear of entanglements with the assumptions of physical science and with the uncertain calculations of economics, politics, and sociology, can it lead to that doctrine of moral freedom which most fully satisfies the demands of the profoundest ethical principles and the loftiest ethical ideals. Meantime, the fact of analysis remains certain that a relatively high degree of volitional faculty constitutes an indispensable part of man's equipment for the moral life. Whether man, considered as a Moral Self, has actually achieved a distinctly new kind of freedom cannot be determined by a preliminary analysis.

Two supplementary observations may fitly finish the task of this chapter. It is customary to say ${ }^{1}$ that the feelings, the emotions and sentiments - as, for example, anger, fear, or eren bencrolence - are not "in themselves" moral, are indifferent, and neither good nor bad. But this saying is also true of the cognitive and volitional factors of conduct; "in themselves" they have no moral value or significance, because in themsolves they have no existence whatever. I * cannot too much insist that the qualifieations of moral goodness or badness, like all the other qualifications of human nature, attach themsclves to the entire psychical, complex activity or attitude, - thought, feeling, will; or rather they are the Self as in this attitude, as thus conducting itself. Without ideas of value, and feeling appreciative of differing values, and without experience as to the consequenees of conduet and as to the means of realizing the ends of conduct, man's willing and choosing would have no moral significance. The same moral worthlessness attaches to the having of ideas that stir no moral feeling, are not capable of issuing in conduct, and eannot possibly be regarded as either accepted and embraced or rejected and banished, by a deed of will.

And, further, in the moral crolution of the indiridual 1 So, for example, Dewey (quoting Bentham), Outlines of Ethics, p. 6. 
and of the race the entire Self must move forward as a unity, and in a manner accordant with that close interdependence of all the so-called faculties which the very nature of its mintary being both requires and secures. As the customary figures of spech permit us to say: A darkened mind or a callous leart does not favor a good will; nor can the good will remain good which does not aim at and secure mental illumination, the refining and elevating of the ideals, the increase of wisdom, the quickening and the harmonizing of the higher and nobler forms of sentiment. 


\section{CHAPTER V \\ THE FEELING OF OBLIGATION}

INTo every genuinely human consciousness, into every subject of the truly human life there enters at some time a form of emotional disturbance which is ehronologically primary and essential to the very idea of ethics, as well as the unique possession of man. It is only when this feeling becomes attached to the idea of a certain action, that the action becomes conduct and the truly moral life begins. This statement must be reccived as applying in the strictest way to the development of moral consciousness in the individual; but it may be taken on grounds which, although largely speculative, are quite tenable, to apply also to the development of morality in the race. It follows from the very nature of this feeling, as wcll as from the circumstances of its first origin in human consciousness, that all analysis ends with its recognition; neither the memory of the individual, nor any sort of records kept by mankind, can recall and represent the occasions or the conditions of its origin in the race. As in similar cases, however, it is possible in this case to place on a firm basis of observed facts our views as to what takes place in the development of the individual, and to make out an acceptable argument as to what must have taken place in the history of the race.

By their language and their customs, considered both in the keeping and in the revolt against them, and by all their judgments, whethor more or less reflective, men quite universally show the focling of obligation. It is only by the 
infusion of this feeling into those excellences of conduct and of character which are called the virtues, that these excellences bccome regarded as duties and accepted as affording some sort of a mandate to the will. "I ought" (or "I ought not"), "he ought" (or its opposite), this deed or class of actions "ought to be done," but the other deed or class of actions "ought not to be done" - such expressions of judgment as these are the commonplaces of the talk of mankind in all times and communities, and under every variety of intellectual and social development. But the universal presence and the perpetual recurrence of those feelings and judgments to which such expressions bear indisputable testimony, are not more impressive than is the marrellous variety of opinions and practices which emerge to answer the question: What, then, do men generally feel and judge that they ought to do? In illustration of this variety it is only necessary in the present connection to refer to such shocking extremes as are exhibited by those who, like certain Kamchatkans and Mongolians tolerate or approve of murder, adultery, and theft, but verily think that he who scrapes snow from his shoes with a knife, or lays iron in the fire, or strikes his horse with the rein, ought to be punished with death. It is plainly necessary, then, for the student who approaches the problems of ethics from the psychological and ethnological point of view to admit a very important distinction at this place in his survey of the field of ethics. "The feeling of the ought" is primary, essential, unique; the judgments as to what one ought are the result of environment, education, and reflection.

$I$ liave just said that the feeling of obligation in its most original form defies further analysis. By this statement it is not meant that this fecling does not ordinarily, or even universally, arise blended or mixed with other forms of feeling and associated with a certain content of perception or of ideas. All states of consciousness in which the affectire 
aspect is most emphasized are a blend, or a confusion, of various elements which psychological analysis may be able to detect, but which are rarely or never found existing separate in the actual life of the soul. Simple feelings, like simple sensations, are only theoretical factors of the conscious states. Nature's chemistry is synthetic here; and the concentration of the mind's point of self-regard upon any one aspect of the psychical complex only serres to recognize its existence within the complex, but not to impart to it existence apart from the complex; or even to justify the opinion that simple psychoses can have any such separate existence. 'Thus with the "feeling of the ought." This feeling may be - although as to this it is difficult and perhaps impossible to say with perfect confidenee - always connected with feelings of the pleasure-pain sort. Or, if the expression be preferred, it may be claimed that the feeling of obligation, like all other feelings, always has some tone of either pleasure or pain. That men do recognize duties which are pleasant and other duties which are painful, as well as both pleasant and painful vices, is an indubitable fact. And no amount of theoretical manipulation or practical quibbling can destroy the significance of this fact. It may also be true that the feeling of obligation, especially and of necessity in all its historical development, always has some content of thought to which it is attached. About this, howerer, some doubt may properly be expressed when we have regard to the many hidden and mysterious ways in which the feeling arises. But, whatever position may be taken upon these and all similar questions of psychological analysis, it still remains true, to admit the fact that habitually, or even universally and necessarily, conscious pleasure or pain, and a content of idea, blends with and modifies and defines the feeling of obligation, is not the same thing as to hold that this feeling can be resolred into, or classified with the pleasure-pains.

When adult men say, "I ought," or other words equivalent 
to these, they are customarily expressing a complex attitude of mind toward a particular piece of conduct. Like every other attitude of mind that which is thus expressed involves feeling, thought, and will. And, indeed, one may emphasize either of these three aspects of the total situation by modifying one's expression. Thus one may emphasize the emotional factor by declaring: "I feel (more or less intensely" and nuswervingly) that I ought," or may lay stress upon the intellectual factor, the presence of judgment, by saying; "I think (more or less elearly, and with consciousness of reasons or grounds) that I ought;" or even; "I must indeed, and I shall, because I ought" - in this way bringing into evidenee the volitional impulse or rational mandate given to the will. Separating in thought, what cannot be found wholly apart in the actual life of the Self, the conclusion is justified that this feeling of the ought is not to be identified with any other content of human conscionsness.

But although we cannot, strictly speaking, explain the fecling of obligation by resolving it into any other form of fecling, we may observe and describe the occasions on which it probably arises in the life of the individual man. And here the patent and the most important fact is this; no moral life originates with the individual as an experience isolated from his social environment. From the first the human offspring is a member of the family, of the tribe, of the larger or smaller social community, and perhaps of the state or nation. It is idle in this connection to conjecture whether the human child, if born and reared without any environment or education which in any way embodied and enforced some system of concrete judgments as to the right and wrong of conduct, conld experience - not to say develop - the feeling of obligation. 'The very conditions of the continuance and the nurture of the physical life of the infant render it impossible to obtain any trustworthy evidence in support of such a conjecture. We have no satisfactory evi- 
dence to determine whether the "wolf-children" of India, or the wild men of the woods, show any traces of a feeling of obligation, the occasion of whose origin is not connected with some quasi-social enviromment.

'This ought-consciousness, even in its most primitive form, may be said to have both its positive and its negative poles; it is, by nature and essentially, a binding to and a binding not-to, - a fecling which gocs with the judgment, I ought to do this or I ought not to do that. It is probable, however, that as a rule this emotional disturbance first arises in conseiousness in some conerete but negative form: It begins as a fecling of repulsion when some natural impulse receives its check by coming into collision with the system of customs or laws which constitute a part of every individual's social enviromment.

It would seem also that, in order to convert the fecling of repulsion awakened by any painful experience into a negative feeling of obligation, the enforcement of the prohibitory custom or law must be recognized as arising from a personal source. The memory-image of the pain of burning teaches the child that it should not again take in hand the hot coal or drink from the steaming cup of milk. The lingering reminiscence of how the dog reacted after its tail had becn carelessly or sportively trodden upon by the child stirs up and enforces a conseionsness more nearly rescmbling the first crude beginnings of the feeling of obligation. And, indeed, in its earlier experienees, things, animals, and its fellow human beings are not clearly distinguished, either as respects the feelings entertained toward them or as respects the feelings with which the childish imagination has endowed them. From this point of view the child who punishes with a kick the stone that has stumbled him, and the savage who threatens or destroys the fetish which has failed to bring him the fitting good luck, are very much in the same attitude of mind. In the casc of the 
animal no long time is needed to discorer that, whaterer may be the feelings of the stone or of the fetish, it has within a well-spring of appetites and passions similar to the child's own, and a store of like painful and pleasurable expericnees.

It is not unlikely, however, that the cause of the abused animal may be espoused by some human being who has either the rights of ownership in it, or is mored to protect the animal's interest by either anger or fear, or sympathy. In any such case as this other more intelligible signs of a social and at least quasi-moral disapprobation are brought to the attention of the offending child. The "should-not," or "better-not," unless you want to get hurt, becomes an "ought-not" because it is not right, because the act causes pain to some other sentient life. It is probable, howerer, that those influences tending to stir the more primitive morings of the consciousness of the ought, which come from his earlier relations with things and animals, are relatively insignificant when compared with those that are due to the same child's more direct transactions with human beings. And here the principles of imitation and of what may be called tribal sympathy are very important. The former of these influences is a powerful factor in the education of certain selected classes of actions, - those, namely, which constitute the forms of conduct preferred by the life of the community. The physical conditions, or the economic and religious considerations, in which the customs originated may have been long ago forgotten. They may, indeed, never hare been brought to a clear, conscious recognition by the popular mind. But such ignorance as this has no influence whatever to deter the unreflecting child or adult from falling in with the custom; - and this all the more heartily if he has earlier been made the subject of painful impressions on account of either an impulsive or a more deliberate breach of any of the prevalent forms of conduct. All expressions of social disapprobation serve to stir the morements of the conscious 
feeling of the "ought-not;" the less frequent and pronounced expressions of social approbation arouse the feeling which answers to the words "I ought;" and the principle of imitation, so universal, so powerful, so little dependent upon thought, re-enforces and repeats unceasingly the occasions for both these allied forms of the feeling of obligation. Thus this distinctively ethical emotion separates itself in consciousness from the accompanying feclings of pleasure and pain; and thus, although always attended by them, it becomes more and more discernible as just that peculiar and distinctively social and moral feeling which it is - having a character to fit it for its most primeval and essential position in man's endowment for the moral life.

Man, like all the other higher animals, and more powerfully and intelligently than any of them, is under the influence of tribal sympathy. He feels a strong and almost irresistible tendency, the origin and significance of which he by no means wholly comprehends, to share in the emotions and sentiments of the community of his fellows. For sympathy appears, when understood in the most fundamental way, to be no one particular form of affective excitement. It is the rather that tendency of which all human beings partake to run together in common channels of feeling, - be this feeling of whatsoever kind. Thus the title "sympathetic" applies to all the natural forms of human emotion and sentiment; and our investigation of man's equipment for the moral life must take account of sympathetic anger, sympathetic fear, sympathetic pride, etc., - on to the end of the chapter which enumerates the different forms of fecling common to mankind. To classify the various passions and affections, then, as "egoistic" and "altruistic," is to prepare the way for a confusion of qualifications that are distinctly different by making at the outset a distinction which is false. Anger, fear, pride, jealousy, etc., and love and hate, may all be either egoistic or altruistic; and as a rule 
they all are both, because they are rarely free from the influence of a sympathetic tendency to share in the feelings of the tribe.

It is plain, however, that the words "tribe" and "tribal" must be, in this connection, somewhat liberally interpreted. In the dawn of the moral life, when the feeling of obligation is just emerging into consciousness, one's "tribe" is represented by the few individuals of the same - namely, the human kind, who constitute the more definite social environment. These are the objects which the child early comes to recognize as, more than other things including the lower animals, like itself. It is, indeed, the reactions that take place in its relations with such like objects, which enable the child to constitute itself as a moral Self in social intercourse with other moral selves. Naturally, instinctirely, and at first quite irresistibly, the human infant feels the impulse to the same emotions and sentiments which those of its ou'n peculiar kind show that they feel. Thus, not only does it come to imitate them in all their fixed forms of action, but also to accompany thesc actions with the same forms of fecling which they display. In this manner does the feeling of the ought become intensified, made more distinetly social; thus does the feeling get itself fixed in connection with those definite, concrete actions which the community preseribes to the individual as the right form of conduct for him. For there is something painful and unnatural in an individual's not feeling with the other individuals of his own kind. In some such way, I believe, is the origin of the feeling of oughtness to be described, and its earlier developments explained.

So far as the earlier exhibitions of the feeling of obligation on the part of the race are concerned, they appear to resemble those of the individual member of the race. But here observation, as well as memory, soon fails to furnish trustworthy facts. But the truth, as supported by ethnological and anthropological researches, is as follows: The 
individual members of the more childish and undeveloped tribes and races show signs of a strong but blind and unintelligent feeling of obligation binding them, under the influence of the psychological forces of imitation and sympathy, to those forms of conduct which are the fixed customs of the same tribes and races. Here, as in the case of the indiridual in early life, even among the most upright and intelligent communities, eustom and morality are nearly identical. For the feeling of oughtness is first aroused and trained to service in the behalf of the prevalent customs. At the moment when the custom is either obeycd or disobeyed, with an aceompanying excitement of this peculiar emotion, the moral life on the side of feeling has already begun. For there has arisen in the human consciousness a disturlance which is significant of something having another value than that of mere pleasure, and which is pregnant with the promise of another than the merely sensuous or intellectual life.

It should be noticed in this connection that the early movements of the feeling of obligation are very frequently strongest in the direction of that which is sensuously painful or repulsive. Indeed, this is probably the rule. In the family or tribe where the code of conduct is most simple and void of compliance with the principles of a high-toned morality, the sufferings which excite and enforce the feeling, "I ought not," ordinarily much exceed the pleasures which are experienced through satisfaction of the feeling, "I ought." The boy trained to picking and stealing commonly has small share in the proceeds of success in his art. But if he fails, or if he turns his aequired skill against those who have trained him and have habitually profited by his success, his sufferings become the more abundant. And if we try to apply any theory which identifies even the crudest beginnings of the feeling of obligation with any member of the pleasure-pain series, in the case of multitudes of the race, 
and especially where the mysterious but almost omnipotent motives of religion are felt; what anomalies arise! Here one might appeal to instances like the following: - to the ignorant devotee of popular Hinduism, who feels that he ought to make his disgusting bererage of the secretions of the sacred cow; or to the learned and honored chief justice of one of the provinces of India who considered it his duty daily to drink the water in which his mother had washed her feet!

To take other instances; the strictest of the Jains will not drink water which has not been boiled by some one else, or breathe in air which has not been filtered through some screen, lest perchance, they may violate the feeling of oblimation not to destroy animal life. But the English milord takes pride in publishing the scores of thousands of living things, to kill which he has with good conscience devoted limself as to his life sport. The former looks upon the latter as guilty of the most heinous crimes; the latter regards the former as being, on account of his silly superstition, somewhat beneath contempt. But after all, if the two are coming upon any common ground of meeting within the domain of ethical feeling, the one must acknowledge the obligation to suffer one's self rather than destroy another's good; and the other must smother the obligation not to destroy another's good by strictly attending rather to the satisfaction of his own desire for pleasure. Which is the more moral of the two does not concern us at this point.

Undoubtedly, feelings of selfish interest, and the desire to earn for one's self the greater reward mingle in all these and similar instances. But whoever, with lawyer-like subtlety, argues that these elements solve the problem of the entire conscious state, and that we hare not here to deal with something quite distinctive and unique, simply does not know his case.

It appears, then, that the student of ethics must assume, 
as the necessary presupposition of the origin and development of the moral life, the existence in man's consciousness of the germinal feeling of obligation. In its earliest manifestations this feeling is vague and obscure, as is the case with all emotional excitements; and, like all other forms of feeling, it is mixed with emotional excitements of a different order and kind. But there it is - defying further analysis, yet demanding recognition as something quite peculiar in the complex content of the individual soul. Like the other earlier manifestations of psychical life, we can rarely or never put our finger precisely upon the time of its origin; but, as a rule, it appears whenever by rod, or gesture, or language coming from one of his own kind, the natural impulses of the child are checked and corrected through a conflict with the custom of his social enrironment. Much less can its origin be traced with the whole race of men, by any possible extension of anthropological rescarches. Man, as man, is from the first equipped with this peculiar form of feeling in reaction upon his existing social environment.

And moreover, although one can never speak with a perfoct confidence respecting one's analysis of the consciousness of the lower animals, there is sufficient reason to hold that the feeling of obligation is uniquely human. We have no evidence that an emotional excitement, much less a rational judgment, corresponding to the phrase, "I ought," ever arises in the mind of any of the lower animals. Anger, fear, pride, jealousy, sympathy, love and hate, they share with man. In these forms of feeling they are, if you please, our younger and weaker brethren. Under the influence of such emotions they perform deeds which have the semblance of human virtues, and which we cannot help (and need not try to help) admiring with a truly ethical approbation. We admire these actions, with a truly ethical and not merely an $æ s t h e t i c a l$ admiration; because we fecl that they are the 
actions which, under the circumstances, ought to be done. Were we so situated, as is the cat whose kittens are in danger of burning or the dog whose master is attacked, and tempted to sacrifice our feeling of duty to the instinct of selfpreservation, we feel that our highest satisfaction would come in resistance to the temptation. 'That the animal is tempted, as we are tempted, that a feeling of obligation is aroused in favor of that which is threatening to the interests of the pleasure-pain sort, that resistance to the temptation will be followed by the feeling of a satisfied moral consciousness, - all this, and all that is strictly of the same order as this, there is apparently no sufficient reason for attributing to the animal consciousness. But whaterer psychology and biology may enable us to decide about all this (and it is entirely unlikely that they will ever enable us to decide in view of any newly discovered reasons), the truth of ethics remains unchanged. Man has this feeling of obligation. In its most primitive form, it is peculiar, distinctively moral, and to be recognized and classed apart. Its first appearance in any series of conscious states marks the dawning, the first distinctive fact of the moral life.

It is the more necessary to insist upon this result of the analysis of the content of moral consciousness, because confusion or lack of clearness here is apt to vitiate all one's subsequent theoretical conclusions. This is especially true of those writers on ethics who adrocate unreservedly the purely Eudæmonistic and evolutionary points of view. Their psychological basis is in general not well taken. What, for example, but such lack of clear analysis could lead Mr. Leslie Stephen, ${ }^{1}$ with that splendid but scarcely justifiable confidence which characterizes those who expect to find all the sources of a ralid view of ethical problems in the still muddy and rapidly shifting currents of biological evolution, to deny the unique character of the feeling func-

1 The Science of Ethics, p. $311 \mathrm{f}$. 
tion of so-called conseience by contrasting it with the operations of the sense of hearing?" "The ear," says he, "decides authoritatively that certain sounds are discordant and others harmonious." But conscience does not so decide. Now the illustration is most apt in contradiction of the view it is designed to illustrate. As mere feeling, the ear "decides" nothing; as mere fecling, conscience decides nothing. Decision in matters of sense or of conduct is an affair of the judgment. The psychological facts are these: In the one case a form of pleasurable or painful feeling arises which is capable of becoming modified and cultivated, while not essentially altered; and so of being the emotional basis, as it were, for a certain class of judgments, for a certain kind of æsthetical satisfaction and æsthetical development. By making the necessary changes a similar declaration may be confidently ventured with respect to the relations in which the fecling of obligation stands to the origin and development of the moral life. It is, probably, about as correct to say that the lower animals have no true feelings of harmony or discord as to say that they have no true feeling of obligation. Both these classes of feelings have to be assumed before one can advance a single step in comprehending either the æsthetical or the moral development of man. How, too, does Professor Sidgwick completely miss the mark at this point by identifying the question as to the primary character of this kind of affective consciousness with the question as to the "rationality" of conduct!"

After accepting the general correspondence to the facts of this account of the most primitive fecling which characterizes the beginnings of man's moral life, it is not difficult to trace its unfolding in a series of judgments and habits of action. For the emotional excitement out of which emerges the consciousness of obligation is not wont to occur without some definite occasion and content of an intellective and

1 The Methods of Ethics, book I, chap. iii. 
volitional sort. As everywhere else in the psychical life, so in the more distinctly ethical forms of that life, it is concrete, individual experiences and not abstract conceptions or any slightest grasp upon general principles, in which the origins of morality must be sought. The simple initial fact in the evolution of the moral consciousness of the individual is this: the feeling of oughtness gets itself connected with the idea of a certain action and, of course also, with the inner experience in which this action has its impulse or its motire. For example, under the spur of anger the young human animal strikes a blow; or moved by impulsive desire it snatches and craftily conceals another's toy. Or, yet again, the influence of imitation and of impulsive sympathy leads the child to surrender to some fellow a portion of its own good. The expressions of social approval or disapproval thus called forth, may easily constitute a first lesson in morals. Pain reinforees the negative pole of the feeling of obligation; pleasure, its positire pole. For although pleasure-pains never form the essential whole of the feeling of being morally bound; they do serre to bind this feeling to certain definite, concrete actions and to their originating or accompanying states of consciousness.

Next in the evolution of the moral life must be noted the effect of repetition and the operation of the law of habit. This is true both of the individual and of the race. For the study of ethies never discovers the individual in any situation where he is not compelled by his social environment to the repetition of certain experienees and to the formation of the corresponding habits. Nor is it possible to conceire of the whole of mankind, or of any isolated portion of the race, as beginning their ethical development in a vacum from which all the residuary habits of their ancestors hare been removed. Always and everywhere, the experienees which tend to connect the feeling of obligation with eertain concrete kinds of conduct are sure to be repeated. Thus habits 
of association are formed between definite actions and the ethical feeling of obligation.

It is certain that in the earlicr stages of moral evolution only a minimum of judgment, and little or no attempt to form abstract conceptions of right and wrong, accompanies the advanees of the moral life. Neither in ethical nor in other concernments, do men first generalize and then experience the feelings appropriate to their generalizations. The child of an advanced civilization and the childish savage both proceed from feeling to judgment rather than in the reverse direction. Therefore that is first judged to be right which has actually, through the powcrful influence of the social environment, aroused the feeling of oughtuess; and that is judged to be wrong which has, through the same influences working in the opposite direction been welded to the feeling, I ought not. In the first instance of argument with one's self, if argument at all there be, the reasoning of the unfolding moral Self runs as follows: I judge this wrong, because the idea of it excites the feeling of ought-not; but I judge that right, because the idea of it exeites the feeling, I ought. In a word, the earlier inchoate forms of moral judgment are made upon a basis of the feeling of obligation, after this feeling of obligation has been aroused, directed, and associated according to forms pre-existing in the individual's social environment.

But the relation which judgments of this class sustain to the fecling of obligation does not remain unchanged. The second stage in the cultiration of the "ought-consciousness" is quickly reached. In this stage judgment begins to take the lead; a growing intelligence assumes the guidance of feeling. Certain attitudes of the moral Self toward particular forms of conduct which express these attitudes are now to be made the basis of generalizations which bring them under the predicates "wrong" and "right." The conditions of reaching this second stage of moral development 
require attention to the following three considerations. Langruage is the first, if not the indispensable condition of such development. Human society informs its new members by speech as to what they must judge about different kinds of conduct under the category belonging to all conduct. This category is, of course, that of the morally right (and its opposite). Early judgments that are not merely expressive of impulsive or habitual forms of feeling, but are the result and the expression of a process of generalization are themselres, for the most part, taught in words. In matters of conduct these words signify the approbation or disapprobation, the collective "ought-consciousness," of the social environment. They convey to the child the resultants of the forces which have worked through generations of experience to produce a certain average moral status, in those forms of conception and judgment which human language permits. It is not right to lie, to steal, to strike in anger; or, at least, it is wrong to lic to some persons, if permissible in other cases; it is wrong to steal from onc's parents or one's "pals," although encouraged by them to steal, when others are the victims, ete. The acceptance, out of deference to pre-existent and all-encompassing social authority, of a certain set of rules, precepts, maxims, or other forms of generalized judgments, reverses in a measure the relation hitherto maintained between the intellect and the fecling of obligation. The order of relation in the quasi-moral argument now becomes somewhat as follows: I feel that I ought not to do this, because - as I have been taught and, therefore, myself judge - it is wrong; or I feel that I ought to do that, because I know that it is right. In this second stage of the cultivation of the feeling of obligation, feeling tends rather to follow judgment than, as in the earlier stage, wholly to determine it.

In this connection, however, another set of considerations becomes most important. These concern the effects of a 
fusion of the "ought-consciousness" with particular passions and affections so as to make the latter themselves the objects of the feeling of oughtness. It is in the fact of such a fusion that the view of the so-called "Emotional Intuitionists" finds its support. The fact is significant and undoubted. But the view taken by these theorists misinterprets the significance of the fact through misunderstanding its psychological nature and origin. "In a Creature capable of forming general Notions of Things," says Lord Shaftesbury, " not only the outward Beings which offer themselves to the Sense, are the Objects of Affection; but the very Actions themselves, and the Affections of Pity, Kindness, Gratitude, and their Contrarys, being brought into the Mind by Reflection, become Objects. So that, by means of this reflected Sense, there arises another kind of Affection toward those very Affections themselves, which have been already felt, and are now become the Subject of a new Liking or Dislike." Now that the feeling of obligation becomes attached to, or fused with, the different forms of affective excitement, so that men come to regard these forms as partaking of that quality to which the ought-consciousness responds, is an obvious experience. But the experience is not a proof, it is not even an indication of the truthfulness of that view which regards some of these passions and affections as having inherently a superior moral quality (or, indeed, any moral quality at all); or which represents conseience as the innate tact or faculty of judgment capable of discriminating this inherent superior quality. All the natural passions and affections of man anger, fear, pride, jealousy, sympathy, love, and hate - are in themselves equally moral, or rather non-moral. But by their mixture with each other, their attachment to the feeling of obligation, their indulgence or control by the intellect in the pursuit of various ends, they become either

1 Inquiry, Book I, Part ii, Section 3 ; See L. A. Selby-Bigge, British Moralists, I, p. 11 . 
good or bad. All these passions and affections alike may be called the "stuff" or raw material of certain virtues and vices. 'Their virtuousness or viciousness does not arise from the insight of any inborn or quasi-divine faculty of feeling or of judgment, but is created by the connections brought about between them and the "ought-consciousness" as the result of carly education and of social influences.

In communities where ethical development is still in a low and relatively primitive stage (and this is true in not a few respects of the most highly civilized [sic] and so-called Christian communities), certain kinds of anger, fear, pride, jealousy, and hate, which a refined and rational morality condemns, are not only tolerated but are approbated as though they were the most fundamental, if not the most exalted of the virtues. In communities which have reached a higher stage of ethical development, the force of the feeling of obligation may give to the natural and equally non-moral feclings of pity, kindness, gratitude (though to this last, most rarely of all), a character which a still higher point of view must regard with doubt when the claim is set up that these feelings are the chiefest and most distinctively right forms of affection. The truth is obvious enough; it is simply this. The frequent arousing of the conscionsness of obligation in connection with any form of the passions and affections seems, in the first instance, to make men blindly feel that some of them ought, and others ought not, to exist in consciousness or to be indulged. Judgments affirming the obligation are immediately framed in riew of this fusion of fecling; these judgments are also taught in terms which express to the individual the formulated moral law of his social superiors. So that, if at first the child simply fecls the obligation to indulge or to control anger, pride, etc., and bases its more primitive judgments on this feeling, it soon accepts the judgment, It is right (or wrong) to indulge anger, pride, etc.; and feels that, because it is right (or wrong), 
anger, pride, etc., ought (or ought not) to be indulged (or to be controlled).

A certain primacy of feeling in the actual order of the moral life may, then, properly be maintained. But to maintain (as does, for example, Hermann Schwarz) that we immediately feel the worth of sympathy to be higher than that of selfishness is to mistake the psychology of moral feeling, and the history of the evolution of customs and of morality. For psychology knows no such simple form of feeling or mental principle of any sort as selfishness; and, as we have already seen (p. $75 \mathrm{f}$.), sympathy is a word which must stand for that universal tendency to feel with the feeling of the other members of the same speeies which belongs to man everywhere, and, indeed, to many species of the lower animals.

Certain forms of man's varied emotional equipment are, indeed, much more likely than others to lead to attacks upon the person and property of others, and so to wrong-doing whether in the form of a breach of custom or a violation of the precepts of the higher morality. Certain other forms are much more frequently on the side, as it were, of cstablished custom and of the purer moral precept. Thus anger, jealousy, and hate are in the main, and rightly, esteemed wrong by the cultivated moral consciousness; pity, generosity, and love are deemed to have a higher worth when they appear for judgment at the bar where refined feeling renders its verdict. On the other hand, however, anger, jealousy, and even hatred, safeguard not only the rights of the individual but also the marital and other rights of the family, the tribe, and the nation; - yes, in the last resort, the sacred and eternal rights of the weak and defenceless members of the human race against the violent or the insidious endeavors of the unserupulous rich and the strong. And the individual, or the race, that had not just these forms of emotional excitement committed - however fitfully and imperfectly - 
to the interests of moral development would have small chance indeed of realizing the moral ideal. How far off the most eivilized communities are at present from this ideal may be judged by this among many other indications: they ean scarcely conceive of these emotions being other than selfish; while unthinking pity, generous use of the fruits of injustice, and injudicious and injurious love are without further critical examination commended as giring satisfaction to the consciousness of obligation.

When then, as Lord Shaftesbury said, "the affections of pity, kindness, gratitude, and their contraries," become themselves "the objects of affection," "the subjects of a new liking or dislike," a new phase in the culture of the conseiousness of obligation results. The human being begins to feel: I ought (or ought-not) to be angry, jealous, fearful, pitiful, generous, kind, etc. From the very nature of human socicty, the so-called altruistic feelings come, on the whole, to have upon their side the feeling of obligation - at least, within the limits of the community which is regarded as constituting the individual's peculiar social environment. Such a stage of ethical development is, as a rule, embodied in the social prineiple: Every man ought to love his neighbor and hate his enemy.

A third set of considerations serves to make clearer the place which the feeling of obligation holds in the original equipment and continuous development of the moral life. $\boldsymbol{A s}$ in the case of all other judgments, so in respeet of judgments concerning the right and wrong of conduct, men grow in knowledge by asking and answering the question, Why? In this case also, as in the case of all kinds of judgments, the answer may be either specious or genuine. It may serre to satisfy the demand for explanation either by distracting the attention or by disclosing a real reason. When I say: I judge this to be right, because I feel it ought to be done; or that wrong, because I feel it ought not to be done, the import 
of my judgment is still simply this: I have the feeling of obligation to do or not to do. That is to say, the judgment is declarative of a subjective and mainly affective attitude of the Self. The word "because" adds no real reason to the judgment. When, however, I say: I both judge and feel this class of actions to be right, and the other to be wrong, because they are accordant with, or contrary to, the precept, maxim, law, or custom, which has become a part of my intellectual equipment for the moral life, then I do ground both judgment and fecling in reasons that lie in part beyond themselves.

But a still further stage in moral development is inevitable. Some time and somehow - perhaps frequently and in many ways - the child growing to adult life and influenced by varied experiences, asks of the very judgments it has unthinkingly accepted from socicty still a reason, Why? $\Lambda \mathrm{s}$ in other matters, so in ethical concernments, the prevalent maxims, precepts, laws, and customs must account to the intellect of the individual for their own right to cxistence as the guides and lords of his moral life. And with the raising of this question there goes inevitably a new agitation of the feeling of obligation; - an inquiry whether, after all, this fecling itself "ought to" maintain its own time-honored attachments and associations! The problem: "Ought I really to feel as I actually feel I ought?" is surely one of the strangest and yet most significant and interesting of all problems. Its meaning and its bearings upon the nature and the development of man's moral life can be understood only when we have considered in detail the significance of the phrase which was added to the definition of the sphere of ethics - a study of human conduct as related to a rational ideal.

The further exposition of the part which the feeling of obligation plays in the moral development of man requires that the working of other faculties in his equipment for the 
life of conduct should be taken into the account. In part the origin, nature, and cultivation of ethical judgments must he discussed before we can understand the later forms of this consciousness of oughtness. But two or three classes of familiar phenomena deserve at least a reference in this connection. First, it may readily be seen that vacillations and uncertaintics of this form of ethical fecling are inevitable. These are not simply due to its obscuration and blunting by the so-called selfish emotions. Doubt about the rightfulness of the control of the fecling of obligation by the current rules of conduct is essential to a higher derclopment of the individual and of the race. But such doubt inevitably leads to the disturbance of the feeling and to its possible detachment from its old associations. While this fecling trembles in the balance, as it were, between the old and the new point of attachment an important influence is being exercised upon the entire attitude of the individual toward the conception of duty and toward the dutiful life. In large communities, and over continents occupied by different races and different constitutions of existing socicty, periods of "illumination" are always connected with unusual disturbances in morals and in the moral consciousness. This was true of the cpoch when the Sophists became prominent in Greece, of the Renaissance in the Middle Ages, of the Aufklärung in Europe in the eighteenth century; it is true of to-day in connection with the modern discoveries of ethnology and with the application of some of the cruder views of biological evolution to the development of morality in the human race.

And, sccond, the place of the feeling of obligation in the moral life explains, in part, how divergent views as to the nature and authority of so-called "conscience" may arise. To speak of a conscience, or the conscience is likely to induce misunderstanding of the most primary data of psychological ethics. Moral consciousness man has; or, rather, he is esscutially a moral consciousness. But in this moral 
nature of his consciousness are found involved all of his socalled faculties, or powers, in so far as they have reference to the production and the criticism of conduct. No wonder, then, that those theorists who appeal solely to the feeling of obligation fail to convince others who take their appeal to the bar of an enlightened judgment. And just as little wonder that the latter, when they offend the feeling of obligation by their coolly intellectual judgments, run the risk of being described as essentially immoral in their standards of judgment. Thus fine feeling and sound judgment in matters of conduct may seem to be involved in a perpetual conflict.

But, third, these same considerations show how this kind of eonflict in morals, with all the tragedy to which these words indubitably bear witness is the fate of the indiridual and of the race, - the price that must be paid for all essential progress under existing social conditions toward the realization of the moral ideal. If moral judgment, based on grounds that lie outside itself and beyond the reach of mere feeling, is ever to be framed, then feeling and judgment must betimes come into conflict. But since the rational man fecls the obligation to be rational, - and, sometimes, as his supremest obligation, - therefore the fecling of obligation is liable to be divided against itself. He who has not judged that he ought not to do that which he, nevertheless, still feels that he ought to do has probably not yet passed beyond the earliest stages of moral development.

And, finally, we are now prepared in a general way to give an opinion upon one of the contentions of the extreme evolutionary school in ethics. This school would make out that all which concerns the feeling of obligation is relative, is subject to erolution. In the case of the individual man such a conclusion plainly is not true to the facts in the case. With the individual the most primary movings of an "oughtconsciousness" are not modifications of the pleasure-pain feeling, or of any of those forms of emotional excitement 
which are so often improperly divided into egoistic and altruistic. On the other hand, the most primary forms of the quasi-ethical judgments are only propositions stating the fact of the arousement of this feeling, and the particular actions to which this feeling makes its earliest and firmest attachments are explicable by reference to influences of education and environment. In the later development of the Moral Self, the feeling of obligation becomes modified and changed in its associations by the changed character of the same influences, as these influences work upon all the passions and affections, and upon a system of increasingly intelligent judgments.

Thus do man's moral convictions form themselves; and they always have the twofold aspect in which the feeling of obligation stands to his voluntary nature. They have a passive aspect; they are a consciousness of being under law. They have also an active aspect; they are an emotional excitement which constitutes a call to rolition. The feeling of obligation is a feeling of being bound; for "the ought" partakes, in a measure, of the nature of a "must;" it is also an impulsive feeling, and in its more intense forms comes very near to passing over from emotional impulse into an "I will."

What is true in the small sphere is probably true in the large. What is true of the ought-consciousness of the individual is, so far as we can discover, true of the place which the feeling of obligation has always taken in the development of the moral life of the race. 


\section{CHAPTER VI}

\section{OTHER ETHICAL FEELINGS}

THE preceding discussion of the feeling of obligation has been so detailed as to make unnecessary a lengthy treatment of the other ethical feelings. Certain changes being made, most of what has been already said with reference to it is also applicable to them. In general they may be spoken of as the feelings of approbation and disapprobation, and the feclings of merit and demerit - all to be regarded from the distinctively ethical point of view. But these affective attitudes of human consciousness toward conduct and toward character, when analyzed, appear more complex than the more primitive and distinctively ethical feeling of oughtness.

The feeling of moral approbation may be described as that pleasant satisfaction which the morally awakened consciousness has when contemplating a piecc of conduct that is in accordance with the fecling of obligation. The feeling of disapprobation, on the other hand, is the unpleasant dissatisfaction with which conduct is contemplated that violates the feeling of obligation. The very language which we are obliged to use in every attempt at describing these feelings suggests some of the more important differences from, as well as certain likenesses to, the early emotional stirrings of the "ought-consciousness." Of such differences I shall now bricfly call attention to the following four.

It is not unimportant to notice a difference in the ethical feclings as respects their temporal relation toward the deed. In imagination, at least, the feeling of obligation is fitly 
excited in view of a deed that is about to be done. This feeling looks forward to the future conduct; it arises on contemplation of conduct that is still to be. What shall I do, or refrain from doing? is the inquiry which stirs the feeling of "I ought" or "I ought-not." The question what ought he to have done is speculative; a problem which, for its very consideration requires an act of imagination setting the Self into time relations before the deed in regard to which the question is raised. But with the feelings of moral approbation and disapprobation just the reverse is true. These feelings are always and necessarily aroused in view of conduct regarded as already done. The deed may, in fact, only be imagined as done, may be contemplated and passed upon with approbation or disapprobation when its transaction is a purely subjective affair. But even in all such cases the temporal relation of the different members in the conscious series remains unaltered. The fecling of obligation looks forward; the feelings of moral approbation and disapprobation look backward. Of course, it must be remembered that all one's own passions and affections are, in so far as they are conceived of as controlled by the self, regarded as actions or deeds. And thus one may come to look upon their continued, even momentary indulgence or prompt repression, with the feeling of obligation; while men contemplate the just past indulgence or repression of these same passions and affections with the feeling of approbation (or its opposite).

The characteristic difference just mentioned is almost identical with another, when the whole subject is considered from a slightly changed point of riew. To employ language, the fuller import of which requires further analysis, it may be said that the feeling of obligation constitutes a "motice" for the will. The emotion partakes of the nature of those states of conscionsness which are regarded as impelling and attracting toward, or repelling and deterring from, certain actions, and the choices on which the actions depend; it is essentially 
a demand to do something - a summons issued to the voluntary nature. But the feelings of approbation and of disapprobation are of a more contemplative character; they more nearly resemble the æsthetical stirrings with which an artistically good or bad piece of work is regarded. In either case, of course, one may wish to punish or to reward the docr of the work. But this wish is an impulse to another pieee of conduet which in its turn will have to be contemplated, when it is finished, with feelings of approval or of disapproval.

$\Lambda$ third difference between the two kinds of ethical feeling will be found important when we come to consider the nature, the formation, and the derelopment of the various virtues and vices. The whole complex mental condition, especially as determined by the predominance, or even by the presence, of these feelings is different. Above all is this true of the relations which they both sustain to our pleasures and our pains. The feeling of obligation to do, when strongest and worthiest of a high place in the scale of ethical values, may be most painful; and the same thing is true of the feeling of obligation when it corresponds to the judgment, "I ought not." Whereas, although one may fitly speak of pleasant duties, the increment of pleasure which comes from the feeling of obligation to indulge the inclinations or to perform the actions which constitute these so-called "pleasant duties," is ordinarily very small. But a certain amount of pleasure is an essential element - or, rather, it is the characteristic and universal tone - of the feeling of approbation; and a certain amount of pain naturally and necessarily tinges the feeling of moral disapprobation. Both the pleasure and the pain are however, ordinarily of a predominatingly mild and rather ineffective character. And if either of them becomes intense, it is almost certain to be the pain.

It is eustomary on the part of all the more persuasive of the hedonistic theories to emphasize the value of those pleasures and pains which go with the approving or the disapprov- 
ing of conscience, by calling them "higher," "nobler," "worthier" of a rational being, etc. The hedging which such a course to the argument involves will be tracked out later. But this fact of human experience may as well be noted and emphasized at once. 'I'he feeling of obligation is for the most part, both in its positive and in its negative form (both as the feeling, "I ought," and the feeling, "I ought not"), far more productive of pain than of pleasure. And most of the positive pleasures which the individuai sccures come from actions that either violate this feeling or give scanty recognition to it. On the contrary, the pleasures which eome from the feeling of strictly moral approbation are, as pleasures, comparatively weak and ineffective as motives to right conduct, while the pains that are an essential part of the emotional excitement which wrong-doing occasions are relatively strong; and, in the case of a morally awakened conscionsness, they may become very intense. Now if all the pleasures of the approving consciences of all mankind were, quoad pleasures, to be placed in the scale with the pains which all mankind hare suffered both in doing the right and in disapproving the wrong, there can be little doubt which way that scale would turn. In a word, the sufferings of humanity far exceed its pleasures as immediate results or accompaniments of obedience to the moral law.

The fourth class of differenees which characterize the feeling of obligation and the fecling of moral approbation (or its opposite) is still more distinctive. Or - better said, perhaps - there are no feelings of approbation and disapprobation which, either as respects their origin or their character, are quite distinctively and uniquely ethical. This fundamental fact was indicated when ethies was called, even in an only partially satisfactory way, the scientific study of that which "ought to be" in conduct and in character. Probably no one would think of defining the subject-matter of ethics as though it were wholly, or chiefly, concerned with 
that pleasant satisfaction and unpleasant dissatisfaction which men feel in contcmplating different kinds of conduct. At any rate, the feelings of approbation and disapprobation with which men do actually regard conduct and character are, considered barely as modes of affective consciousness, very closely allied to certain non-moral forms of feeling. Indeed, they are so closely allied to corresponding æsthetical feelings as to make difficult or impossible any distinction which has a sufficient permanent basis in psychological 2 analysis. Here the difference between the xsthetical and the ethical is much more a difference in the character of the objects, and in the results which flow from this difference in objects, than a difference in the essential character of the feelings themselves.

The distinction just drawn requires further illustration. There are certain qualities of all beings, whether of things and animals in the system of so-called nature or of men in the existing social system, which are naturally regarded with feelings of approval; certain other qualities, with feelings of disapproval. Exhibitions of power on a large scale, or of skill in the adaptation of means to ends, or of judgment and good taste in arranging colors and forms, when these exhibitions are not regarded as in any way inimicable to their interests, are met by men everywhere with feelings of pleasant satisfaction. This is but the natural attitude of human consciousness toward the various kinds of goods. It is not necessary at present to inquire whether the approval is the source of the plcasure, or is only its effect or its accompaniment. It may, in fact, on various occasions stand in either one of these three relations to the happiness of the conscious soul. In all cases, approbation is the characteristic human way of greeting with appropriate feeling that which the mind apprehends as an instrumental or a final good. For example, the savage approves of the bow or the war-club or the spear that has done him good service, 
or that is beautifully decorated. The worshipper of the stars or of the sacred firc regards the object of his adoration with a similar feeling. The traveller stands "like-minded" before the Taj Mahal or the Pyramid of Cheops; or he looks off from Observation Hill at Darjeeling upon Kinchinjanga and its attendant members of the Himalayas with emotions of wonder and admiration that strive to become an adequate expression of what is due to those qualities of grandeur in beauty which such objects seem to possess. But now let the same savage contemplate his chicf, or himself, using bow, or club, or spear, in deeds of prowess; and his feeling toward the author of such worthy conduct remains, as feeling, essentially unchanged. The same thing is true when the traveller remembers the builder of the colossal structure of the pyramid, or the arehitect of this gem of beauty, the Taj Mahal; or even when he regards the Infinite One as the creator of the loftiest mountains of the world. In each case the approbation is an emotion of pleasant satisfaction accompanying the contemplation of that which is regarded as a species of good.

When, however, any object is definitively contemplated as the product of some conscious agent, as a piece of his conduct, so to say, then a change in the attitude of the contemplating mind occurs; but it is rather a change in the point of attachment for the fecling of approbation than a change in the character of the feeling itself. That is to say, the conduct is met with the feeling of a pleasant satisfaction on account of its qualities as good conduct; and the responsible agent is approbated - at least so far as this particular action is concerned - as a good man.

Something further is needed in order to connect as strictly as possible the feeling of approbation with the most distinctively ethical elements of consciousness. Suppose now that the motives which led to the observed conduct become fully known; and, as well, the kind of real character which the 
conduct evinced. Suppose that this deed which seemed so noble was really done from base motives. It was a seeming good which originated in hypocrisy, cowardice, avarice, or malicious hatred. $\mathrm{Or}$ it was a piece of splendid inprudence, rash generosity, mistaken kindness. Then we shall see the emotional stirrings of the contemplative soul become yet more complex. A curious struggle between feelings of approbation and fcclings of disapprobation now emerges in consciousness. The deed is approved, the motive disapprored. Or deed and motive are both approved, but only in a qualified or faint-hearted way. The man did well and meant well, and yet - he should have been less hasty, more deliberate and wise about probable consequences. Suppose, however, that this is one of those rare and splendid cases where, in obedience to the feeling of obligation but at cost of immense self-sacrifice, with deliberate judgment and with a noble scorn of one's own suffering, with a wise use of means in the interests of a worthy end, and with the worthiest exhibition of economically directed strength, the deed was both chosen and executed; then, however our sensitire natures shrink with sympathetic pain, our whole æsthetical and ethical being approves. How truly splendid, how perfectly excellent a piece of conduct it was! Why? Beeause it presents to the moral consciousness a picture of the highest kind of activity belonging to an ideal Self. And this realization of the moral ideal in the object gives its most distinctively moral character to the approving feelings with which our consciousness greets the object.

Kceping these differences in mind, what was said in treating of the nature, origin, and development of the moral life as dependent upon the feeling of obligation may be briefly recalled, but need not be repeated in detail. These feclings of approbation and of disapprobation with which men everywhere, and in all stages of development, regard their own and others' conduet, must be assumed as natural for every indi- 
vidual. The origin of these feelings for the race is lost in obscurity; but it may be said that men began to approve and to disapprove morally, whenever they began to be moral, i. e., whenever they began to regard actions and states of consciousness leading to action from the point of view held by the feclings and judgments of obligation. All that is deemed good is approved, - the happifying, the beautifying, the morally good. But the man who is morally approbated is the man who does what ought to be done.

The same distinctive and unique character which belongs to the fecling of obligation can, therefore, scarcely be claimed for that feeling of pleasant satisfaction with which all men greet what is considered as morally worthy in conduct or in character. For - as I have alrcady said - ethical approbation is so closely akin to the admiration with which our æsthetical susceptibilities regard whatever is sublime and beautiful that it is difficult or impossible always to distinguish between the two. Full and mhesitating admiration is rendered to the hero who does the good deed in a strong and beautiful way. And eren he who, like Milton's Satan, does the morally wrong deed, in a manner that scems strong and beautiful, is the object of admiration. Nor can this admira- tion be said to be cntirely non-moral in its character. For strength and beauty in the exceution of one's purpose are, of necessity, considered as significant of that strenuous will and fine discerning judgment which are distinctive and highly important qualifications of the ideal Self. And this ideal Self is the Ideal of ethies, - the standard by which moral consciousness measures the worth of conduct and the right to approval which good conduct possesses. The uncultured consciousness is not wholly wrong when it looks with approbation upon the behavior exploited in melodrama, or narrated in the biography of dashing rogues, like Dick Turpin or Sixteen-string Jack.

The development of the feelings of ethical approbation or 
disapprobation is dependent upon the relations which are established between these feelings and the ideas and judgments that concern conduct and character. Thus the answer to the question, Why are particular forms of conduct and types of character approved, and others disapprosed? like the similar question in art, can be understood only as the result.of a detailed historical investigation. Such an investigation, when carried on in a comprehensive way, reveals the enormous complexity of influences which surround and shape the unfolding of the moral consciousness of the individual and of the race. Like all other feelings these ethical emotions may vary in intensity and in that quality called "refinement" which is, after all, rather a change in the intellectual and ideal aspect of moral consciousness regarded as guiding the restraining control of will. Here, as everywhere, the principle of habit becomes exceedingly important.

Those feelings which I have ventured to call ethical merit and demerit are yet more complex, - less distinclively and uniquely primitive and original. This will appear if we consider all that is involved in Professor Bowne's ${ }^{1}$ excellent definition of merit as "the descrt of moral approval and the right to be rewarded accordingly." This definition must be interpreted as involving at least the following factors: (1) A feeling of obligation to approve (I ought to be morally approbated); (2) a feeling of right to assert a claim (I ain entitled to some form of the good, which ought to come to $\mathrm{me})$; (3) a vague feeling of another's duty, as it were (for another than I ought to treat me "accordingly" - by bringing me some reward).

It is plain that such fenlings as those just analyzed imply much more than is revealed at once even to the most penetrating and thorough analysis. Indeed, it may be claimed not inaptly that they imply a somewhat firm grasp of conviction - however vague and incoherent the accompany-

1 The Principles of Ethics, p. 171. 
ing ideas and judgments may be - upon the existence of an extended social system which is at least partially conducted in accordance with moral principles. It is, indecd, true that the higher one's culture in essential morality grows, the less does one care for, or work for, the reward of merit. And the typically good man is he who is good, "not for the sake of gaining hearen or of escaping hell." Still further, he who encourages within himself the feeling of a right to assert the claim of nerit may easily dull the fine edge of his own feeling of moral approbation, and dim the lustre of the moral quality of his deed. There is another side to all this, however - most true, most significant. The good man feels that he ought to approve the virtues of others and to assist, so far as in him lies, in seeing to it that virtue is rewarded and rice disapproved and punished. He is also filled with the conviction that no society is as yet properly constructed so long as the goods of life are distributed by it with seanty regard for the merit or demerit of its own individual members. The more one insists upon the importance of righteousness in social development, the more important becomes the practical effectiveness of the feclings designated by the words merit and demerit.

If we study the historical erolution of customs, laws, and the opinions and codes that embody the eurrent feelings and judgments of an ethical kind, the strength and tenacity of the same conviction among mankind are still more plainly evinced. The man who has done another "a good turn," or has labored, suffered, and achieved, in the interests of the tribe or of the nation, instinctively feels that some reward is of his right and is bounden duty on the part of his fellows. Eren

"Thanks to men

Of noble minds is honorable meed."

On the other hand, total and cold indifference, or an attitude of haughty scorn, toward the moral approval of others is 
in itself discordant with the moral Ideal; while all the strongest forces that bind and move men together - such as imitation, tribal sympathy, community of interests, yearning for social connections and desire for this very thing, the moral esteem of one's fellows - are pledged to operate against the total suppression of the feelings of merit and demerit. It is, indeed, doubtful whether indifference to all reward for right conduct is not uniformly more or less feigned, and the scorn for the approbation of other moral beings, as a rule, only another and more subtle way of asserting the same sense, when we have done right, of our "right to be treated accordingly." Under the influence of this feeling men turn from the jury at hand to the jury more remote, from the court at present sitting to the court of the future, from the human judgment to the judgment of the invisible powers, from the verdict of the race even to the infallible verdict of God. One of the most curious instances of the conviction that he who has done what he ought has acquired "the desert of moral approval and the right to be rewarded accordingly," coupled with a yet more curious contradiction of involved beliefs, was given years ago by Mr. Spencer in his "First Principles," 1 when, reflecting upon the certainty that he would be misunderstood in his effort to reconcile science and religion, he comforted and justified himself as follows: "Whoever hesitates to utter that which he thinks the highest truth, lest he should be too much in advance of the time, may reassure himself by looking at his acts from an impersonal point of view. . . He, like every other man may properly consider himself as one of the myriad agencies through whom works the Unknown Cause; and when the Unknown Cause produces in him a certain belief, he is thereby authorized to profess and act ont that belief."

How this natural and well-nigh universal readiness to

1 Second edition, p. 123. 
extend so far our confidence in the implications of the feelings of merit and demerit points toward a moral system of the universe, and toward the continuanee beyond the visible into the invisible, and beyond the present life into the future life, of a system of rewards and punishments, it belongs to the later extensions of ethical theory, or to the philosophy of religion, to diselose. It is perfectly erident at this point, howerer, that a considerable development of ideas and judgments of the social order is indispensable in giring an account to ourselves of even the eruder and lower forms of such ethical feelings as these.

'The pleasant satisfaction which the feeling of merit affords, when its right is satisfied, is closely related to the mild pleasure of a gratified pride; the dissatisfaction following the failure to be approbated by others, and "to be treated accordingly," is much more than an equivalent in its productivity of pain. Here again the path along which duty leads, as marked out by the ethical feelings, is much less strewn with roses than with thorns. He who thinks to pay himself for doing what he ought in eoin of merit will almost surely fail in the business. Indeed, one of those curious anomalies with which ethical study is full, is encountered here. It is as a rule, the meanest and least moral men who have the most lively satisfactions from the sense of their own merit, and who most intensely feel their right to a reward, for the oceasional small, meritorious services they render their fellowmen.

The feeling of demerit is doubtless to a certain extent a natural means of punishing past misdeeds and a motive to refrain from misdoing in the future. Oceasionally this feeling acquires that sharp and pungent character which the word "remorse" is meant to signalize. In this form it may - but only rarely - give an adequate reason for the saying that the evil-doing, the sin, brings in the form of self-reprobation its own self-punishment. But I am persuaded that 
the intensity of this feeling, and the aetual poteney of its influence, are usually greatly exaggerated by the orthodox systems of ethics. The arenging furies, the demon of the remorseful conseience, the Erinnys, do indeed, appear in real life. It is only when they are the emissaries of those dread, mysterious powers to which religious belief eommits men, that they are potent for good through their appeal to the feeling of demerit. For the most part, otherwise, they are the relatively impotent constructs of the imagination of the poet or of the priest.

These ethical feelings, in the course of attachments to certain judgments, detachments, and reattachments, which they follow are subject to the same eonditions which have already been suffieiently described. Indeed, the entire development of the moral life requires us to understand how it is that ethical judgments arise, and beeome changed and modified so as to give rise in the mind of the individual and in the social structure to a system of moral principles; and thus to awaken the conception of a moral law and of an inalienable and unalterable nature for the Right. But I cannot proceed further in the effort to describe and explain the working of the emotional elements in moral consciousness, before taking into account the more distinctively intellectual and voluntary endowment of the moral life. 


\section{CHAPTER VII}

\section{ETHICAL JUDGMENT}

Since the time of Aristotle the relation in which man's intellectual equipment stands to his moral life has been quite customarily misunderstood by writers upon the philosophy of conduct. This great analyst of psychical states closes the first Book of the Nicomachean Ethics with a division of human "excellenees" into the "intellectual" and the "moral;" "when we are speaking of a man's moral character

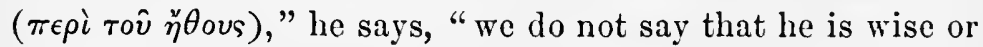
intelligent, but that he is gentle or temperatc." In this, as one of his most recent commentators " declares, "A ristotle is founding the distinction between the Intellectual and the Moral which has lasted erer since." The same division is justified at the beginning of the second Book by several arguments which may, however, all be summarized as follows: (1) the intellectual excellences are implanted in us by nature, the moral result from training and habit; (2) and, therefore, the latter alone stand in such a relation to the roluntary Self as that they are attributable to it and can properly be praised or blamed and rewarded or punished.

No such distinction as that advanced by A ristotle, although it " has lasted ever since," can justify itself before the analysis of a thorough and consistent psychological ethics. The "intellectual excellences" - to continue the use of this phrase - are no more and no less natural than are those feelings and passions which constitute the "raw material"

1 Sir A. Grant, The Ethics of Aristotle, I, note to p. $476 \mathrm{f}$. 
of the "moral virtues;" and the former are as much in need of training under the labit of right choice as are the latter, in order that the proper rules of conduct may be observed and the ideal of Selfhood progressively realized. This is implied by Aristotle's entire doctrine of moderation, or the observance of the "mean," as entering into the very essence of erery moral virtue. But it is especially important at the point now reached in our study of the philosophy of conduct to insist that only rational beings can be moral, and that the degree of rationality attained or attainable depends upon both the inherited intellectual endowment and the voluntary training of the intellectual powers. So obvious is this truth with reference to that task which morality sets before the human imagination whenever it is necessary to construct any kind of an Ideal, that nothing need be added to what has already been said upon this subject (see p. 64 f.). And the larger part of what will subsequently appear true in the discussion of the Nature of the Right and of the Ultimate Moral Ideal will further illustrate and enforce this claim. In order to understand the nature of ethical judgment, however, there are three respects in which man's rationality far surpasses the intellectual possibilitics of the lower animals, that demand a more particular consideration at this point. These are his development of (1) Time-consciousness, of (2) Self-consciousness, and (3) his application of the Causal Principle to the synthetic construction of experience.

A development of the consciousness of Time is a necessary part of man's equipment for the moral life. If the same sort of a continual flux of unorganized sensations, or the same shifting mechanism of fused and associated memoryimages, which marks the limits of the animal's consciousness of time, were also all that man could attain, then the life of conduct and morality would be impossible for him. Indeed, such a succession of states cannot be said in themselves to form eren the basis for an inchoate and undereloped time- 
consciousness. But man's recognitive memory is something different from this. As a developed faculty it brings into consciousness, in a way to influence the conduct of the present moment, a more remote and a more orderly past than is possible for the animal, - a past that is regarded as a real past in its relations to the conseious present. Undoubtedly, such a rational cognition of the past is a matter of varying degrees even among men of the same period; probably, if not undoubtedly also, it is a form of consciousness which has been rising in elearness and moral value in the development of the race. It is, at least in part, for this reason that reward or punishment, praise or blame, should follow quickly upon the good or bad deed in the case of children and savages; while they are more fitly and effectively deliberate and deferred in the case of civilized adults. So also, where the passions are hot and uncontrolled, and where memories are short-lived and speedily grow faint, the distinctively ethical feelings will not bear to wait long for their satisfaction. In the case of the developed man the long stretches of time over which extend the feclings of merit or remorse, and the determination to reward or punish, are proof of his superior intellectual equipment for the moral life. By imagination, acting under the category of time, man predicts and anticipates the consequences of conduct, and its due rewards. It is a most astonishing mark of his intellectual excellence that he consciously directs his behavior with reference to that which is remotely situated in time. Thus he fears punishment from the descendants of the one he has injured, and he understands in some dim way the truth of Schiller's couplet:

"This is the very curse of evil deed,

That of new evil it becomes the seed."

It is not the cultivated German poet alone who can reason thus. "One event is the son of another and we must never 
forget the parentage," said the Bechuana chief to Casalis, the African missionary $;^{1}$ and in saying this he showed how far beyond all merely animal development is the moral endowment of human savages. Human imagination creates a future T'artarus and Elysium; it peoples them with gods whose attitude toward human conduct will endure relatively unchanged after men have forgotten their own past. It ministers to the belicf in an eternity of consequences as flowing from what is done in the conscious present-a doctrine of Karma, an everlasting heaven and hell. But to punish or to reward, even five and ten years after the deed, the faulty or the good work of the draught-horse or of the hunting-dog, would be neither wise policy nor commendable morals; for the animal could neither perform the act of imagination necessary to anticipate the postponed punishment or reward, nor, when the pain or pleasure came, connect it by an act of memory with somcthing done in the remote past as its occasion or cause. It is man's relatircly high development of time-consciousness which imparts the needed continuity to morality and which makes possible a truly moral development - the life of conduct progressively approaching to, or withdrawing from, the Ideal.

In what has just been said the development of Selfconsciousness as a necessary postulate of ethical development is also implied. ${ }^{2}$ It is to the moral Self that the fecling of obligation attaches; it is from the inmost selfhood that the feelings of approbation and disapprobation seem to spring. Whose is the merit or the demerit of conduct, and whose "the right to be treated accordingly?" Undoubtedly, our answer to every such question must always involve some conception of the meaning properly belonging to the word "Self." But this very conception is itself a subject of development,

1 See Tylor, Primitive Culture, I, p. 4.

2 On the development of Time-consciousness and Self-consciousness, see the following works of the author: "Psychology, Descriptive and Explanatory," p. 495 f. and "Philosophy of Knowledge," p. $193 \mathrm{f}$. 
having a markedly different content and a largely rariable wealth of meaning, as it is formed by different individual intellects and by the reciprocal intellectual efforts of different communities of individuals in different periods and under different circumstances, in the life of the race. Thus the offending member of the child's bodily self is made to suffer for the vice or fault of the soul; "an eye for an eye, and a tooth for a tooth" is the proper rule for regulating the measure and place of application for the demerit of him who has violated the rights of some other Self. The hand of the matricide must be cut off before he is executed; castration is the fitting reward for the adulterer; eyes that have looked too curiously on forbidden objects must be put out; and tongues that have been guilty of slander or betrayal deserve to be rooted out. Gross and vicious bodily selres will get roasted and tortured in the hereafter; but equally gross yet virtuous selves (because "faithful" to their religion) will be feasted and indulged in the hereafter.

As, however, the conception of the Self becomes more refined and spiritual, the entire nature of virtuous or vicious conduct, of righteousness and sin, together with the nature of the inducements to right conduct and of the rewards and punishments of conduct, undergo important modifications. Pure, spiritual selres do not crave to be feasted and indulged; and intellectually developed but wicked selres do not fear being roasted and otherwise tortured. But in all stages of the development of self-consciousness, it is the actual Self, set by thought and imagination into relations with other selves, and measured by the standard of an ideal Self, which determines the character of ethical theory and of the practical moral life. This is necessarily and unchangeably so; for virtues and vices are qualifications, not of things or of actions as such, but of selves; and the distinctively ethical feelings are self-binding and self-appropriating. Inasmuch, therefore, as conduct is, essentially considered, 
a voluntary adjustment of one moral self to other moral selves through the media of things, the character of the prevalent sclf-knowledge influcnces essentially the wrong and right of conduct. In a word, only a being that is consciously a Moral Self can be at once the author and the subject of moral law, the appropriate, because rational object of approbation and disapprobation, and of reward and punishment, in the distinctively ethical meaning of these terms.

That any being must be intellectually equipped with the power to pass from causes to effects and from effects to causes, in order to be eapable of the moral life, scarcely needs argument. Indecd, without somehow raising and answering the questions, Whenee? and Why? it is quite impossible to set forth in imagination the conccivability of a moral life. In saying this I do not intend to emphasize the fact that all the virtues connected with, and dependent upon, our human conceptions of truth are unintelligible apart from the domain ruled over by the so-called "principle of sufficient reason." Nor do I mean simply to assert that without rational knowledge of the consequences of conduct as affecting the interests of ourselves and others, no popular or scientific knowledge of ethical principles could possibly be attained. But still further, as will be shown in another connection, the relation between motive and deed of will is itself the most typical and immediately present example of the causal relation; and the experience of men with this relation is the precursor and the postulate of all their reasoning about external causes and effects, and about means and ends in the world of physical phenomena. Without that extended development of reasoning faculty under the control of this principle which belongs to man alone among the animals, no conception of a moral law, or of a social unity which shall admit of the practice of virtuous and vicious forms of conduct, - much less of a universal moral order extending itself over gods and men and over all spaces and all 
times - could possibly dawn, rise, and grow clearer within the consciousness of humanity.

In this, as in all the other intellectual endowments for the life of conduct and the acquirement of character, both the individual and the race come under the principle of development. That is to say, the clearness and effectireness with which the causal principle is intellectually recognized and voluntarily applied admits of a great varicty of degrees; and, in fact, a great variety of such degrees marks the place in the scale of ethical evolution occupied by different persons and different portions of mankind. In the more elementary stages of culture little or no thought of rational and ineritable connections manifests itself in moral consciousness; the Whence and the Why of conduct, of custom, and of the current ethical precepts are scarcely inquired after and not at all understood. In a later and somewhat higher stage the caprice of the gods, the command of some person superior in intelligence and authority, or the bare Will of the Omnipotent, is esteemed a sufficient answer to most of such inquiries. Still later those conceptions of Necessity and Law which convert the totality of human experience with the interaction of persons and things, and of persons with persons, into a colossal System of physical and psychical mechanics, may for a time rule the thinking and satisfy the questionings of men. Such is perhaps the level of the thought and imagination reached by the majority of those who claim to be cultured at the present time. But I am confident that a yet more strenuous and comprehensive thinking and a loftier imagination inevitably produce and justify another picture of the connections of the moral World-Order. Such thinking and imagining enter inevitably, and in an integrating way, into the moral life of the race by enlarging and improving the conceptions of the Moral Self as Will and as Reason, and by the growth of the conception of the Ground of all causal relations as an Absolute Self. 
The special application of all man's cognitive faculties to the interests of ethics always takes the form of an Ethical Judgment. In this respect ethical consciousness resembles all other conscious mental processes; for judgment is the distinctive and culminating thing in all human intellection. And general notions whether about conduct and principles of conduct or about other content of experience, are the results of, rather than the material for, the really effective acts of judgment. But judgment itself is a piece of conduct; and, especially where it concerns the qualities of conduct, judgment itself is either good or bad conduct. In its developed form it implies a certain affective and voluntary attitude of the Moral Self toward the conduct which is judged.

No fact of experience is more instructive to the student of ethics than the pronouncing of judgment by his fellowmen upon matters of right and wrong in conduct. He notes as important a remarkable difference in the character of their different ethical judgments, in the manner in which, in any considerable community, different matters of conduct are pronounced upon by the different members of the community. But the most elementary analysis of the content of human consciousness has already made it apparent that one conception is strictly universal for all ethical judgments; it is this which makes them ethical; it is the character of the predicate. This is expressed by the significant words, Right and Wrong, in the more definitively ethical use of these words.

Let now an inquiry be made as to the grounds on which these different kinds of ethical judgments repose, and another series of somewhat confusing answers will be elicited. Some men will refer to unreasoned feeling; some to the prevalent custom; some to self-interest or to the relation sustained by their judgment to the pursuit of their own wellbeing; some to the sanctions of religion, - the will of the 
gods or the Holy Divine Will; and some to reasons which lie either in the consequences of the actions judged, or in a certain conception of the nature of moral law, or even of the so-called abstract "Nature of the Right."

What appears true of any particular community, when examined with respect to its present conditions of ethical judgment, seems also to be enforced and illustrated by the history of the evolution of ethical judgment in the whole race. The same difference of judgments about matters of conduct and of the reasons more or less intelligently rendered in answer to the questions, How? and Why? belongs to the great diversity of human institutions under all the changing conditions of man's development. Custom sets the general standard for such judgments; the rather is custom, subjectively considered, itself identical with the standard judgments. But a possible distinction is always to be noticed between the custom considered as embodying the mere fact of judgment and that judgment to which the reason and feeling of the individual find themselves bound to respond. And, in fact, actual divergences, at first on the part of a few individuals, are constantly arising and then gaining strength and numbers until both external custom and the system of moral judgments corresponding to the custom become largely modified or quite completely reversed. But all the while, as far back as man is man, and everywhere that man is found, the predicate of all judgments about matters of conduct remains unchanged. The custom itself is subject to this predicate; customs are liable to be judged as either right or wrong. Hence the outcries of reformers of custom, like that of Laotsu, are heard down the centuries to the remotest past: "Nowadays we despise love of humanity and are insolent; we despise economy and are wasteful; we despise modesty and strive to surpass erery one else. These ways lead to death."

Such phenomena as those just described demand investi- 
gation in the effort to obtain, if possible, some satisfactory answer to a series of questions. Of these questions the first which I shall raise may be stated as follows: What is the distinctive psychological nature of the judgments of men respecting matters of conduct? The following three characteristics seem to afford, for the present, a sufficient answer to this question. Of these, the first has already been noticed; it is the character of theil predicate. Persons and things, considered from every other point of view, have an indefinite number of qualities, which may be either affirmed or denied of every particular person or thing; but conduct has only one quality, when regarded from the ethical point of view. We may, indeed, be in doubt in any particular case which of the forms of this universal predicate, the positive or the negative, to apply; we may even be inclined to divide our judgment between the two poles, and to say "partly right and partly wrong;" and we certainly recognize an endless variety of degrees in our qualification of conduct. But if we judge on moral grounds alone, we can only affirm either right or not right for this matter of judgment. Thinking is either logical or illogical; speech is either correct or incorrect; judgment itself is either false or true; but all conduct is either right or wrong.

Another psychological characteristic of all ethical judgment is its somewhat pronounced emotional character. Men do not ordinarily affirm, this is right or that is wrong, with the coolness with which they pronounce a familiar proposition in geometry or in some matter of physical science. Judgments about matters of conduct are apt to have color, to be warmed or even to glow with fecling; and not infrequently they excite the most intense passions or the most effective enthusiasms. The principal reasons for this characteristic of ethical judgment appear to be the two following: first, such acts of judgment usually have some connection with the more visible and palpable interests of men; and, 
second, they are, from their very nature, inseparably concerned with those moral feelings in which they either have their origin or to which they make a more or less immediate and forceful appeal. Hence, all the natural passions and emotions, - such as anger, fear, jealousy, pity, sympathy, love, and hate, - and all the ligher ethical sentiments of moral obligation, approbation, and merit (or their opposites), flow into the consciousness of the judge and prevent his judgment from being "cool" and strictly "scientific." Moreover, the common feeling and judgment of mankind, as well as the deductions of psychological ethics, support the opinion that it is fitly so. Ethical judgment ought to be formed under an influence from moral feeling; it is reasonably of a somewhat pronounced emotional character.

It is doubtless true that men do, with no little intensity of emotion, debate questions of truth and falsehood, even of the abstract sort, when no human conduct can be supposed to have any possible influence upon the decision of the questions, and when no decision of the questions can excrcise any discernible influence upon their physical welfare. Indeed the fiercest quarrels and most pronounced enmities sometimes arise over such debate. No mathematies or physics is so pure, no metaphysics so remote from all practical concernment, no scholastic hair-splitting so obriously unprofitable, as that its judgments may not be hotly contested. It may not be difficult to see why monophysites and orthodox should wish to kill each other, or why ecclesiasticism should find it necessary to persecute Copernicus or Galileo. But why should scholars fall out with one another over some philological punctilio, or over the nature of the infinitesimal in calculus, or over the possibility of an $n^{\text {th }}$ dimension of space? The only credible answer to such questions recognizes the characteristic quality of the ethical judgment. Men quarrel over their differing judgments, because they regard all truth as discoverable and statable 
only by an activity of mind which somehow itself partakes of the qualities of a piece of conduct. All human judgment is regarded as, at least potentially, a moral affair; it may be that voluntary deficiencies or vices in the Self account for the very manner of the mental seizure and pronouncement of the truth. And where this is suspected, "cool judgment" is not the appropriate attitude of the critical mind. Coolness of judgment is an intellectual exccllence, a virtue, in the investigation of truth, - as well truth of conduct as other truth; but where the false, or imperfect, or dilatory judgment is itsclf a matter of bad conduct, there coolness of judgment with reference to it is not the normal and appropriate condition for the human mind.

The third psychological characteristic of ethical judgment is the peculiar relation which it sustains to the voluntary states. This relation follows, with a surt of nccessity, from its emotional character. To judge about a matter of conduct is to establish a claim upon the will. For ethical judgment is not simply of something that is, or is not so in fact, or is, or is not true in principle; it is a practical affair. Reasoning about matters of ethics may, indeed, be logical or illogical, - a pure theory, a play with the weapon of the syllogism, an exercise in polemics. But this is not the manner in which men usually discuss important problems of conduct; and when judgment is reached, even if its statcment be in the most impersonal and abstract form possible, it is after all a judgment of something that some person ought to do, or to have done. If you believe in the truth of the ethical judgment, you are bound to carry your belief out into the voluntary life. Given opportunity, judgments respecting the right and wrong of conduct become convictions of duty.

The idea of the Right has been shown to be the one ethical category. Our next question is, then, the following:What is the psychological origin of this category? How does this conception of rightness arise in human conscious- 
ness and come to take its place of supremacy among all the moral conceptions? The answer to such an inquiry as this is not difficult if the investigation is confined to the development of the conscious processes as this development takes place with every newly born individual in a community already organized upon a social and ethical basis. But the application of the principles of biological evolution to the problem of the origin of ethical judgment in the race only results in the same confusions which mark our inquiry into the rise and development of all the most universal and necessary notions of mankind.

If the so-called "category," or general notion of rightness be compared with the categories usually recognized as giving the forms according to which all human judgments must be shaped, certain differences, as well as certain resemblances will be discerned. It is desirable to examine these differences and resemblances, at least in a preliminary way, because of the connection which this category has with the theoretical discussion of the Nature of the Rirght.

What, then, that accords with facts of experience, is meant by calling the conception of "the Right" the one ethical category? In answer to this question - first - one may refer to the already established fact of its unirersal and necessary character. However men may answer the question Why? and whatever reasons they may allege as the ground of their answer, there is always this same moral qualification assigned to the conduct by the act of judgment: the eategory of Rightness (or its opposite) gives the universal form of ethical judgment. This same conception fixes also the necessary form of all ethical judgment; it is the rubric which must be employed by man in accordance with his moral nature, as now constituted in the evolution of the race. And as far back as we can trace the history of the evolution of morals among mankind, the same formal characteristic of all ethical judgment is to be traced. 
Nor can it be denied, in the second place, that an immense number of ethical judgments are passed by all men where the act of judging seems to amount to a sort of envisagement of the moral quality of the conduct judged. And when we include, as we must, the indulgence or the restraint of all the impulsive and emotional conscious states under the conception, we may perhaps claim that most of human conduct has its moral quality discerned in a quasi-intuitive way.

Finally, however, this intuitive character of the ethical conception of Rightness is easily understood when we refer again to its psychological origin. It is the experience of ethical feeling (as already described, chapters $v$ and vi) in its reaction upon the stimulus of the environment, which forms for the individual the earliest basis of the generalized notion of rightness. Certain forms of conduct, that is to say, are habitually accompanied or followed by the feelings of ethical obligation, approbation, and merit (or their opposites), and these determine the so-called right (or wrong) forms of conduct. The judgments which declare these experiences are, in their earlier form, like all judgments of the undeveloped intellectual life, concrete and individual. They are judgments of the individual's experience; and they appear in this intuitive form, because, in their origin, they are not the results of conscious processes of ratiocination, but of the prompt response of feeling and of its fusion with certain ideo-motor experiences.

In multitudes of other cases, howerer, judgment is not, and cannot be, so intuitively pronounced. Elaborate processes of reasoning fail to make perfectly clear whether the particular piece of conduct ought to be called right or wrong; and this is even as true of inward states, of motives, and impulses, as it is of actions. But further discussion of this subject must be left for the more theoretical portion of our task.

It becomes obvious, therefore, that in order to understand 
the origin and character of ethical judgment we have yet other questions to raise and to answer. The individual man, who is the subject and the critic of conduct, the agent and - the judge, is never merely an individual; he is always and pre-eminently a member of the race, at a particular time and under especial circumstances in the evolution of the life of the race. None of the so-called "categories" - not even those of Space, Time, and Causation - escape important modifications under the influence of these all-embracing facts. Much less than the others can such a so-called category as that denominated "Rightness," which is in its origin and essential nature so pre-eminently social, fail to undergo important changes in the particular characteristics of its manifestation and its application.

We are compelled, then, to ask: What is the historical origin of many of the ethical judgments of men? To this inquiry I answer: They, too, are judgments of experience that have acquired the immediacy, certainty, and necessity, which they possess for the individual as a result of the prevalent historical conditions shaping the life of the race.

- Such judgments embody the conclusions reached upon a basis of interaction between the varions members of the community, and between the community as a whole and its physical, social, and political environment.

Of the principal sources for men's ethical judgments I now distinguish the following four. The established life and government of the family furnish many such judgments. In respect of no other equally important matter do we find the morals of men - the relations they enter into and sustain with good conscience and with the approbation of their fellows - so changeable as in respect of the customs and forms of the family life. Always and everywhere there are right and wrong relations recognized as possible, existing between husband and wife. But eren where some sort of fidelity is rigidly exacted of the woman and some sort of pro- 
tective kindness is required of the man, in the most important matters affecting their relations the rules of good conduct toward each other are exceedingly variable. Thus the law of the family may enforce the husband's right to his wife by punishing adultery with death, but think it a duty for men to lend their wives to their guests, or to exchange them with their friends. Among some of the Arabian tribes the wife is required to remain true to her husband three days out of four; but every fourth day it is right for her to do as she will. The Samoan father may properly resent the seduction of his daughter by one of the same tribe, but must esteem it right for him, as a host, to make a temporary loan of her. The most righteous of the Patriarchs, with good conscience and without divine rebuke, practised polygamy; and the sentiment of to-day, which approves of the penitentiary for the bigamist, regards it as a mark of its higher civilization that divorce is constantly made easier. As to the right limits of consanguinity between husband and wife the same diversity is found. The royal priests of ancient Egypt consecrated the marriage of brothers and sisters; while the Church of England still refuses to consecrate a remarriage which is in not a few cases, the most rational possible, viz., with the sister of one's deceased wife. As respects children and parents, in aneient Rome and in Old Japan the patria potestas was so construed as to make it right for the father to put to death his disobedient child; and the same thing was cxpressly commanded to the Hebrews by the Mosaic Law. But now in large portions of the most refined communities, the use of physical force or physical pain to secure obedience in the family is deemed not only the height of unwisdom, but a kind of crime which discredits the moral character of the parent. Thus the most sincere and enlightened judgments which the individual approves have, many of them, their historical origin in the development of this institution on which the very existence and 
continuance of the race depends. And the intuitive character which such judgments appear to possess must be explained historically as arising in the experience of the race.

The codes of the different social classes, professions, businesses, and organizations of every kind, furnish the individual with many unquestioned and unreasoned judgments upon matters of right and wrong conduct. In such spheres the æsthetically proper or fitting thing, and the morally right thing, are nearly if not quite identical. For example, some amount and sort of clothing is almost universally deemed necessary for adult human beings, and the wrong-doing of non-conformity to the enstom here is generally, though not universally, regarded as a breach of the virtue of modesty. But quite as universal is the judgment that different sorts of persons ought to wear different sorts of elothing. 'The Fiji Chief submits to the painful process of tattooing; and the Englishman of the upper elasses endures in August weather the torture of black coat and starched shirt and collar - both that they may appear as gentlemen of distinction ought to appear. The priest or clergyman who dresses like the jockey or the flashy "tough" is, with warmth of conviction, blamed not only for his lack of good taste but also for an immoral orerstepping of the customs of his class. If one set of critics considers it to argue a wicked disrespect for the dead not to give them an expensive funeral and also wear mourning garments for them; does not the other set consider it an equally wicked, because useless extravaganec to conform to the custom in these regards? And what ean the good man do to aroid both these forms of wrong-doing better than quietly to conform to the ruling eustom, while availing himself of Aristotle's principle of "moderation"?

But judgments as to the right and wrong in matters of clothing for different classes and different occasions are, from the higher and more strictly moral point of view, trivial compared with many other kinds of what I shall call 
the "classified" ethical judgment. "Honor among thieves" is no less honor, no less a virtue so far as it goes, because it is so limited in its application. To love one's neighbor and hate one's cnemy, undoubtedly expresses the moral sentiment of one side of the Old-Testament morality. And to deccive or even to lie in war is not to-day regarded as a breach of essential morals by the great majority of Christian people, - while the same majority, hot as it is to resent cruelty and savagism when turned against itself, looks with tolerance, if not with approbation, upon its own cruel and savage treatment of so-called "inferior races." Among the mercantile classes, how few are they whose moral consciousness is at all sensitive to the customary false weights, false labels, and deceitful advertisements? What would be the purifying effect upon our courts of justice, and upon our halls of legislation, if lawyers and politicians no longer made special exceptions for their class from the strictest demands of veracity and sincerity? And as to social purity, only the grossest ignorance of facts ean fail to appreciate the enormous difference which the highly civilized, as well as the grossly barbarous communities, make between what is right or wrong in the conduct of the "privileged classes" and the right and the wrong for "ordinary people."

In the wider circle of the laws, written or unwritten, and the general customs of the tribe, the state, the nation, lie the sources of many of the individual's spontaneous judgments. The very foundations of the political structure in all its forms would be shaken and quite undermined, if all keeping of the laws as obligatory upon the conscience of the citizen were left to discussion and to inference. The day has indeed gone by when the theory held by Hobbes as to the origin and nature of the Right can be successfully resuscitated. But there was a certain large measure of truth in this theory. No theory can define a priori just where the duty to accept the judgment of the ruling power, 
when embodied in law or national custom, comes to an end; and where the higher right of appeal to one's own moral consciousness begins. No amount of tact can always infallibly detect this dividing line. But undoubtedly it is in general the duty of every individual unquestioningly to obey the law, and to conform to the custom of the land. This is true quite irrespective of the amount of self-government which belongs to the average citizen. Indeed, the anomalous thing about this land of America to-day, where the maximum of self-government is supposed to have been reached, is the fact that the right and duty to make the laws have bred a feeling of right to break them; and that in no small number of cases, the law-makers are the chief law-breakers in every state and in the nation at large. Yet even this anomalous condition cannot contravene the yet more general fact that, on the average and in the long run, the individual does actually get his judgments as to matters of right and wrong, without much reasoning of his own - as it were, intuitively - from the laws in force and the customs current in the organized society of which he is a member.

In the fourth place, the customs, precepts, and statutes of religion furnish a source of the spontaneous judgments of the individual in matters of conduct. Until morality and religion have become separated in a somewhat formal and crystallized way, no other source of those ethical judgments which seem most self-evident and obligatory is so powerful as religion. Judgments originating in this source penetrate all the other sourees; ethical judgments pertaining to the life of the family, judgments of so-called "class morality," and the laws and most general customs of the whole people, are everywhere largely of religious origin. Nor is this coincidence in the sources of judgment on matters of morals and religion at all surprising when we consider how closely allied are the moral and religious natures in the one human nature. To treat the gods with disrespect, to attempt to 
deceive them, or to defraud them of their property or of their dues, is a particularly heinous and dangerous kind of wrongdoing among those communities that are lowest in the ethical scale. In the relations of the sexes also, the priesthood or clergy are almost universally regarded as coming under special provisions respecting the right and wrong of conduct; although opinion may differ as to what is right, what wrong, all the way from the rule which makes it a sin for a priest even to look upon the face of a woman to the code in force among some of the Hindu castes, which considers it right for the Brahman to enjoy an almost unlimited license. Such license was conceded by the opinion of ancient Greece as right for the gods in their intercourse with men. In similar way elaborate coremonial purifications become of the most obligatory moral character; and not to abstain from many desirable gratifications, because religion has rendered these tabu, is to outrage the moral law. In India almost the only moral restraint upon the conduct of the multitudes, a restraint as powerful as it is spontaneously and unquestioningly accepted, consists of the code of religious ceremonial, belief, and superstition. The ten commandments which are an undisputed part of the creed of millions of twentiethcentury men and women were originally due to a "thus saith the Lord," understood to have been uttered to the founder of an ancient religion. For the great majority of men, all over the earth's surface and far back in the world's history, the one class of judgments respecting the right and wrong of conduct to which heart and reason alike has seemed most unhesitatingly and intuitively to respond comprises the customs, precepts, and statutes, that have had their origin in the religious experience of humanity.

But with unreasoned ethical judgment the moral consciousness of men has not reached its highest intellectual development. Whaterer of immediate self-evidence can be made out for certain instances in the application of the so- 
called category of Rightness no more prevents the use of reflection and inference in forming judginents upon matters of conduct, or the growth of the moral code, than the intuitive character of the category of space prevents the progress of geometry or of surveying. Without intellectual development on the part of the individual, neither ethical theory, nor systems of morals, nor essential morality, could exist or develop. It is to the men who doubt the essential morality of the prevalent custom, who question the rationality of the current ethical judgments, who insist on knowing the Why? of conduct and character, that the race owes most for such ethical adrances as it has already made. He who does not

$\checkmark$ transcend the stage of intuitive feeling, or of unquestioning acceptance of the cominon judgment, remains a morally undeveloped man.

As an historical fact all adult individuals, no matter how rigidly fixed the moral code may have become previous to their existence, and in spite of the most intolerant and oppressive reign of conventionality and custom, do take some part in the framing of the current and ruling judgments on questions of the right and wrong of conduct. He who, as a member of the commonwealth of ethical judgment, only aims to think and feel precisely as the others do, nevertheless becomes himself a moulder of the community's thought and feeling. His influence may seem quite inappreciable, but it is none the less real. In the case of those more independent minds who - as the popular saying runs - "think for themselves," the ethical judgments made by the indiridual on a basis of conscious inference may not only determine the dominant maxims of his own moral life but in time eren effect an important moral revolution in the judgments of the society of which he is only a single member.

Undoubtedly, the clearness with which different men think out their conclusions on matters of conduct differs very greatly; and as well, the character of the grounds on which 
they place their ethical judgments, the reasons they are ready to assign for the conclusions at which they have arrived. Hence the possibility of unlimited debate about what is right and wrong; hence also, in part, the doubtful character belonging to all elaborate systems of casuistry. But this is only to call attention to the general psychological fact that, in matters of conduct as in all other matters, different persons have different degrees and combinations of the judging faculty, and different stores of experience on which to draw for the material of reasoning and its concluding judgment.

Moreover, there is in ethics, both practical and theoretical, another most potent cause of difference; men differ as respects their entire conception of the aims and values of life, and as respects the character already acquired in the more or less intelligent pursuit of those aims, under the estimates of value assigned to each of them. In a word, the ethical judgments of different individuals, so far as they are based upon conscious inference, will depend in the main upon these three considerations: namely (1) natural or acquired power of forming judgment; (2) characteristic experience (the experience which belongs to the individual); and (3) ideas of ends and of values, - while over all, and through all, the principle of habit will assert its power.

Of these three considerations only the last two admit of a brief treatment. The accumulation of experience is a growth of knowledge as to the relations of means and ends, and of causes and effects. But every man's conduct is his way of setting himself into the great system of means and ends, of causes and effects, - into the World-System. Every man's conduct is also, in some peculiar meaning of the words, his very own contribution to the total working and final outcome of this World-System. As the individual man acquires experience of what he can conseiously and voluntarily effect he becomes increasingly capable of relatively independent and well-reasoned ethical judgment. His conduct is thus 
an intelligent means to certain ends; and the consequences of his conduct are effects which are attributable to his Self as to their cause. He becomes conscious, that is to say, of his Self as both effect and cause, both means and ends; and, in some degree, he learns precisely how the manifold desired relations are, in fact, to be secured. Thus the - rightness or wrongness of the particular forms of conduct is made to depend upon a judgment whose grounds are to be found in the conscious experience of the judging mind.

In all this, however, the supreme consideration is often if not always - found in the estimate which is placed upon the value of the ends to be attained and, in a subsidiary way, of the means to be employed in their attainment. There is, indeed, a certain side of all human experience which goes a considerable way toward the seeming justification of Schopenhauer's contention for a blind and purposeless forthputting of Will, in the World at large and in the individual man. On the other hand, it is a most indubitable fact of experience that man, and especially developed man, does consciously

- pursue ends that have in his eyes higher or lower degrees of different kinds of value. And in the case of each individual, the character of these ideas of ends and of ralues idetermines his judgments upon matters of conduct and of 'character.

It should not be necessary again at this point to remind ourselves that we are not now considering how to determine which of two contending ethical judgments is most trustworthy; or which of the different aims or methods of evaluation is most justifiable in the light of the supreme moral Law or of the highest moral Ideal. Our present purpose is much more modest. It is simply to show how, in the development of ethical judgment, a higher or lower stage of quasi-independent reasoning is reached by every adult individual; and what is the effect of this fact upon that use of human rational faculty which all morality and moral development implies. 
There are two important general assumptions to which one is brought by the psychological study of ethical judgment. First, man's intelligence is rightfully regarded as obligating . him to its own use in planning and guiding his own conduct. Noblesse oblige, - and not less the nobility of rationality than the nobility of rank or birth. Thus the thought is led around again to a position which is in neighborly contiguity with the position from which the discussion of the nature of ethical judgment took its departure: So-called "Conscience," as a matter of intellectual equipment for such judgment, is no whit different from so-called ordinary intelligence. But this "ordinary" intelligence is human intelligence; it is man's intellect, in its full use, culminating in judgment as to the right and wrong of conduct. Moreover, this use of intelligence is itself either right or wrong - in the ethical meaning of these words; for this use is a species of conduct. And the moral feelings of obligation, of approbation and dis. approbation, and of merit and demerit, have as much place, and as binding an authority, in respect of this, as of any other species of conduct. If we generalize this fact which, like a silent postulate, permeates all our estimates of the nature and value of ethical judgment, and bring our generalization into correspondence with that conclusion to which a!l our study of psychologieal ethies is pointing the way, we may anticipate the following conclusions. The intellectual processes are, of course, essential to the existence of moral Selfhood; the noblest and best use of them is characteristic of the Ideal Self; and such a use is morally obligatory, necessarily to be approbated by moral consciousness, and to be considered meritorious; for it is an essential part of the realization of the Ideal of a perfect Self existing in social relations with other selves.

The second assumption involved in the doctrine of ethical judgment is this: Only through the exereise of intelligence does the so-called "motive" pass over, as it were, into the 
choice and into the deed. It is not motive alone, or judgment alone, or deliberate choice alone, whether followed or not by a suceessful executive action, to which the qualification of moral goodness or badness should be attached. It is $\checkmark$ rather to the total Self in action - Feeling, Intellect, and Will, in a living unity. Motives must, indeed, be judged morally; but they must also be more or less willed, in order to be really motives. Judgments, too, are motired and more or less subjected to volition. The highest expressions of will, the deliberate choices, are themselves the subject of both moral feeling and moral judgment. Good intentions alone are not the only moral good; as Professor Dewey has well said: "The conceived results constitute the content of the act to be performed. They are not merely relevant to its morality, but are its moral quality." Therefore, I affirm without hesitation: A virtuous intellect is essential to a virtuous man.

We are now in a position to understand the main features of the evolution of ethical judrment, both in the individual and in the race. This evolution follows the same laws which control man's total development of intelligence. In a certain somewhat loose way, three stages may be distinguished. In

- the earliest stage, it is feeling largely, if not almost wholly, which determines the judgment; in this stage, the judgment is searcely more than a declaration of the fact of feeling. Children and childish men think little as to the reasons why they feel and therefore judge as they do; they know almost nothing of the influenees which are operative upon their own minds, whether these causes belong to the original constitution of human nature or are themselres the result of the previous experiences of the race. In a word, amongst savages as amongst the children of eivilized communities, judgments about the right and wrong of conduct arise in blind, instinctive feelings. If we could get very near to the so-called primitive man, we should undoubtedly find him yet more a 
creature and a subject of feeling. We should find him - if as yet man, however primitive - moved by passions and emotions to do certain things which the sentiments of obligation and of ethical and esthetical admiration and approbation were moving him not to do. We should find him in this strange conflict of feeling, this schism between the lower and the higher Self; but the schism would not be comprehended; nor would the grounds be recognized on which the authority of the higher moral consciousness was reposed.

The second stage in the evolution of ethical judgment is reached whenever experience of the effects of conduct has embodied itself in certain more or less fixed customs, or in the form of moral maxims, precepts, and regulations, or in the shape of something resembling a code of conduct defining what is to be esteemed right, what wrong, by the community. But even at this stage the multitude of individuals in their private ethical judgments only echo and reiterate, as they for the most part unquestioningly accept, the generalizations reached in some form by the generations of their predecessors in the moral life. In this stage, whenerer the attempt is made to give reasons for any particular judgment, such an attempt ends in a reference to the fact, as bare fact, of the conclusions already accepted by the majority. Thus most of the current "reasoning" on moral matters might be summarized in the one major premise for the standard ethical syllogisms: It is right to follow the custom; doing right is doing as the ancients have done and as people generally do now.

But eren this stage in the evolution of ethical judgment cannot come into existence, much less long continue to exist, without certain individuals at least making considerable advances into a third and higher stage. In this third stage, the science and philosophy of conduct become, to some extent, the interest and the attainment of the multitude of individuals of whom society consists. 
The history of ethical erolution by no means, of course, warrants us in making a clean-cut separation between these different stages of man's ethical progress. Other factor's and laws than those which are distinctly intellectual take part in this evolution. No community at any time can be regarded as stationary in either one of these three stages, to the exclusion of all examples of the other stages. Amongst the lowest savages are found some who, more than others, think for themselves touching matters of conduct; amongst the most highly cultured ethically, the majority, for most of their ethical judgments, trust to unreasoned feeling or accept the conclusions handed down from preceding generations. And it is well that it is so. For thus the "cake of custom" is formed; only thus could enough of uniformity be secured to constitute a safe and true social environment such as is the necessary presupposition of any ethical life or ethical development. But all the while the race - or at the least, that portion of it which is undergoing a real moral evolution - is learning more and more how to make up its mind, on the ground of an enlarging experience and by use of its improved powers of ratiocination, regarding the right and wrong of conduct. A progress in ethical enlightenment is certainly taking place with this portion of mankind; but whether this portion, or the whole of mankind, is growing better in disposition and in will in proportion to its increased enlightenment - why, this is another and a distinctly broader and more difficult question. 


\section{CHAPTER VIII}

\section{MORAL FREEDOM}

IN the preliminary analysis of the content of moral consciousness it was found that some degree at least of selfcontrol, superior to that possessed by the lower animals, is necessary to man's equipment for the moral life and for the development of character. The sphere of ethics is the sphere of conduct and character. But conduct and character imply choice - of one deed rather than another, of one course of action in preference to some other; and in their highest manifestation, the choice of an end, an ideal that shall largely subordinate and control the entire life. Hence the continued necessity for ethics of a discussion of the nature and extent of man's moral freedom. By "moral freedom " I mean such a kind and amount of self-eontrol as belongs, both in fact and in accordance with the demands of a sound ethical theory, to man's moral life and moral development.

It would manifestly be impossible, however, to bring the whole range of psychological and metaphysical problems which form important parts of this ethical problem ${ }^{1}$ within the reasonable limits of a treatise on the philosophy of conduct. To psychology appertains the deseription and, so far as possible, explanation of the phenomena of the voluntary nature of man. To metaphysics one might properly wish to

1 For a fuller discussion of these problems the reader must be referred to the other works of the author, especially to Psychology, Descriptive and Explanatory, chap. $\mathbf{v}, \mathrm{xi}, \mathrm{xxi}, \mathrm{xxvi}$; A Theory of Reality, chap. iii, vii, x, xiii, xix ; Philosophy of Knowledge, chap. $x$, xiv; and Philosophy of Mind, chap. iv, vii, viii, xii. 
relegate the discussion of the nature of Causation, in both the physical and the psychical fields; of the conceptions of Necessity, of Law, of the Indeterminate, and of the real Relations which exist between the different psychoses, or between the Body and the Mind of man; and, finally, the speculative treatment of the Absolute, the Infinite, etc., and of its relations to the Relative and the Finite. But how can ethics wait for psychology and metaphysics to solve all these complicated and profoundly difficult problems?

This entanglement of the problem of man's moral freedom with so many psychological and metaphysical problems has given occasion for certain intolerable attitudes toward the task of ethical philosophy. Against two such attitudes I wish to make an especially earnest protest at this point. The one is the attitude of indifference or of contemptuous dissatisfaction with all proposals for renewed discussion of so insolvable a problem. The other is the attitude of satisfaction and "cock-sure-ness" that the matter has at last been definitcly settled in the interests of a so-called strictly scientific conception of human nature and of its ethical, as well as of all its other development. It is difficult to say which of these two attitudes is theoretically the more unwarrantable and practically the more mischievous; it is certain that both of them should be challenged and criticised by every student of the philosophy of conduct.

Ethics can never cease to be profoundly and vitally interested in the discussion of the problem of moral freedom; for this problem, like a hanyan tree, although it affords friendly shelter or deadly shade for all sorts of common folk, sends its many branches down to take roots in the dark and hidden places whence comes its own life, and all Life. It is true that the problem has been attacked over and over again by minds of the keenest analytic powers, and left, after the attack, in nearly the same impregnable condition as before. It is also true that the sereral factors of the problem. the 
different considerations mainly influeneing the manner of its discussion, and the different forms given to its solution have customarily been thrown into the shape of fundamentally irreconcilable conceptions and conclusions. It has thus been left honeycombed with so-ealled "antinomies." And perpetually recurring antinomies inevitably bring about an attitude of discouragement or even of disgust toward the problems which are expressed in this fashion.

Now I have elsewhere ${ }^{1}$ diseussed in detail the subject of "alleged antinomics." What was there concluded as to such interesting products of ingenious dialectics in general is emphatically true of the hitherto current ethical antinomies. As a rule, they are not contradietions inherent in reason at all. "They are, rather, spurious contradictions which can always be got up when abstract conceptions of more or less doubtful empirical origin and of perverted or mutilated coustruction are hypostasized and brought into rclations that are themselves either fictitious or abstracted inconsiderately from the relations of real individual things." Such contradictions, that is to say, are not found actually existent or implied, either in the world of things or in the constitution of human reason, or between the world of things and the reason of man; they are the constructs of imperfect or self-deceived logical processes. The eure for such antinomics is neither indifference, nor contempt of thinking, nor despair of their removal. The cure for them is a more thorough, unprejudiced, and profound criticism of the conceptions involved. All this is true whether these antithetic conceptions are evolved by the plain man's thinking, or by the profound but perverse analysis of Kant, or by the brilliant and subtle but fallacious dialectics of Dean Mansel or Mr. Bradley. Limits of our knowledge may well enough, - nay! must of course be recognized; although they must not be too hastily fixed by the method of dialecties. In respect of

1 Philosophy of Knowledge, chap. xiv. 
the nature of moral freedom, and the relations to the World and to God in which man is placed by the possession or the derelopment of such freedom, there is doubtless much which the human mind does not understand. Probably there is much which never will be understood. But no one adequately acquainted with the history of the philosophy of conduct can assume that the conceptions involved in the phrase "Moral Freedom" have all received the criticism necessary to say the last words upon so involved a subject.

Nor can the student of ethics admit that theory here is of no great practical importance. Mr. Sidgwick, ${ }^{1}$ in his calm and measured way, undertakes to "dispel any lingering doubts ... as to the practical unimportance of the Free Will controversy." But, in his own discussion, he constantly confuses the question of the immediate practical results of Determinism with the question of the possibility of reconciling the theory of Determinism with the demands of practical reason, - that is, with the rationality of moral consciousness. But practical results of this sort are scarcely to be determined by a priori processes of reasoning; and there are two very potent influences at work which make it difficult or impossible to tell what the practical results would be of having no opinions, or at least convictions, respecting the questions in debate between the Determinist and the Libertarian. One of these influences consists in the patent fact that scientifie Determinism is an almost purely scholastic theory; and while the multitudes of men are perfectly well aware of, and constantly take account of, the facts on which the deterministic theory relies, they do not interpret these facts in terms of this theory. Therefore, until its advocates have managed thoroughly to convince the multitude of its truthfulness, we can never know by expcrience what would be the practical results of the unirersal adoption of this theory. There is absolutely no

\section{The Methods of Ethics, book I, chap. $v \mathrm{f}$.}


chance of ever converting the multitudes to a scientific Determinism. Fatalisin is, however, a religious doctrine generally accepted among millions of men; its practical results may be subjected to observation, and there cannot be much doubt about their baleful character.

The second cause of the difficulty of putting the fruits of the deterministic theory to a test of experience is that they who advocate it most strenuously as a scholastic tenet, as a rule, give it less scope in a practical way over their own conduct than do even the multitude of thoughtless men and women. For they who urge the speculative tenet, that all conduct is strictly determined, practise as though they were, what they really are, as free as the gods themselves. By constitution, by education, by circumstances, they are the highest specimens of responsible moral freedom. But to pursue the inquiry further in this direction would bo to cmploy a rather unserviceable argumentum ad homincm.

To say here in one word what will come up for notice subsequently:- those men who act as though they were "free" from all restraints of moral law or influences from their fellow-men, and those others who regard themselves as "slaves," strictly determined by either their own impulses and passions or by external influences, are ordinarily both alike bad and immoral. Both classes are customarily so regarded by the enlightened critic of conduct. They constitute, on the one hand, the gifted, high-born, and interesting rogues, and, on the other hand, the low-bred and often disgusting rogues, of human kind; - rogues are they both apt to be, and in such manner that license and slavery seem to meet in characters that practise according to either extreme of theory.

The attitude of undisturbed satisfaction toward any new proposal to discuss the problem of moral freedom is widely prevalent amongst present-day writers on ethics. It is virtually the assumption that further discussion is needless because, in sooth, the whole problem has been once for all 
definitively settled. Less speed and assurance would be not only practically helpful but more genuinely scientific here. To be sure we have writers - like Riehl, ${ }^{1}$ for example - who boldly assert that freedom is an "illusion" comparable to the illusion of the sun moving round the earth; and that "Morality is the cognitive ground of Determinism, while Determinism is the real ground of Morality." But to such offhand assertions the counter claim of Caspari, ${ }^{2}$ for example, is good enough as an answer; for Caspari claims with far more reason, that the phenomena on which Determinism depends are Schein-Phenomena, or illusions. Then there is the declaration of psychologists like Höfding: ${ }^{3}$ "Psychology, like every other science, must be deterministic; that is to say, it must start from the assumption that the causal law holds good even in the life of the will, just as this law is assumed to be valid for the remaining conscious life and for material nature." But, as I have ventured to say elsewhere: "Such an assertion as this may properly be met with the flattest kind of a denial. Psychology has absolutely no right to make any such assumption." Nor need the adrocate of moral freedom retreat before the encounter takes place through fear of such theories as that of M. Luys ${ }^{5}$ who regards all psychoses, including volitions and choices, as determined by the brain which dictates them to the conscious mind by a species of incomprehensible jugglery. Neither a metaphysical, nor a psychological, nor a psychophysical theory of the will is to be enforced or even made relatively acceptable by any such rash and wholesale statements as the foregoing. No student of ethics need hesitate boldly to call in question the somewhat too overbearing temper and self-confident tone of this current Determinism.

1 Philosophischer Kriticismus (edition of 1876), II, ii, chap. 3, $219 \mathrm{f}$.

2 Grundprobleme der Frkenntniss-Thätigkeit II, p. 131 f.

8 Ontlines of Psychology, p. $345 \mathrm{f}$.

4 Psychology, Descriptive and Fxplanatory, p. 627.

5 The Brain and its Functions, passim. 
In a word, although the world is old and the problem of so-called "free will" has often been examined, and always been found full of difficulties and dangers of misconception and of practical import, there is, possibly, still more light to be thrown upon it. At any rate, there is absolutely nothing in the most recent discoveries, either of psychological or of physical science, which compels one to regard the deterministic solution as the only valid and scientific answer to the problem.

Within the limits of the present treatise the best course to follow in discussing the nature and development of moral frecdom is, I think, the following: first, to recognize certain truths of fact emphasized by both the deterministic and the libertarian positions, and to criticise the views held by both these positions, when pressed to an extreme; sccond, to display briefly those principal data of moral consciousness on which an acceptable theory of moral freedom must be based; third, to examine the chief objections which may be brought against the theory; and, finally, to summarize the entire problem and harmonize, so far as possible, the conflicting elements and the subordinate conclusions.

Of preliminary considerations the following seem to me the most important. In the first place, the actuality must be admitted of certain relations between the successive states of the Self, and between each of those states and the bodily organism, as well as through this organism between the Self and the changing conditions of external things. Such relations are to be found at the very base of human experience; they are neccssary to the very constitution of any experience whatever. It may be said, the rather, that in these relations and in their effects upon the Self, experience itself largely consists. Different words are indeed employed by naïve common-sense or by psychological, psycho-physical, and metaphysical theories, to express these relations. Among such words are the following: "cause," "occasion," "in- 
duce," "influence," or even "make" and "compel." We "account for" one state or process of consciousness by referring to another preceding state or process; we refer, for example, our present choice or intention to the desire of attaining some coveted end. Men continually inquire as to the motives of deeds, the reasons and explanations of courses of conduct. They apply similar language to the relations in which they believe themselves as conscious existences to stand to the conditions of their own bodily organism; it is the arm or the tooth that makes one smart with pain; it is the condition of the eye or ear which determines whether one shall see or hear, well or ill. In all his social and civil relations man believes in the applicability of similar terms to describe what those relations are, and also how the experience of the individual is dependent upon the actuality of those relations. Society exists at all only on the postulate that human beings influence or affect each other, and that they are in their collective action and development influenced or affected by a great variety of external conditions. Upon such facts as these Determinism bases its theory; and in discussing the problem of moral freedom no such sophistical procedure with these facts as converts them into merely Schein-Phenomena can be adopted. Nor can the terms in use among men be interpreted by a scientific ethics otherwise than as bearing witness to the actuality of the relations which they signify. To interpret them, and not to deny or sophisticate them, is the task of the philosophy of conduct.

But, on the other hand, the actuality must also be admitted of certain relations between the Self regarded as emotional and impulsive and the Self regarded as willing and eloosing, and also between the Self and its own choices; and experience forbids our interpreting the foregoing words, when applied to these relations, strictly after the analogy of any relations which can exist between things and things, or between things and their own states. Upon this point the 
opinions and language of men, as well as their practice, are as clear as they are upon the point just preceding. The universal tendency of the untutored man is to conceive of the relations between things and things, and between things and his own states, pretty strictly after the analogy of his own experience with himself as influeneed by motives to choose or to avoid certain ends. This doctrine of Animism, with its langruage and practices, is all the more significant because, as says Tylor," "the conjunetion of ethics and Animistie philosophy, so intimate and powerful in the higher culture, seems scarcely yet to have begun in the lower." For the tendency shows how permanent and miversal is the naive conviction that the real relation between the man and his choices, or the man's choices and the man's desires, is not one to be expressed in terms analogous to a physical necessity. A similar anthropomorphism belongs to all stages of human development. Indeed, as 1 have elsewhere shown, ${ }^{2}$ the modern scientific view of the Universe as a strictly ordered and uniform system of causal connections, is no less anthropomorphic than is the Animism of the savages. It has the adrantage of projecting into things, for the explanation of man's experience with them, the higher as well as or instead of - the lower factors of man's cognition of the characteristics of selfhood. But modern science can validate its anthropomorphism only if it admits the postulate that Causation, or Influence, and Necessity, Contingency, and Law, mean something different when applied to man's experience with himself and to his experienee with physical things.

In this connection I will cite the sentence with which the author quoted above closes his discussion of the phenomena of Animism by bidding us "consider how the introduction of the moral element separates the religions of the world,

1 Primitive Culture, I, p. 427.

2 A Theory of Reality (passim, and especially, chap. $\mathbf{x}, \mathbf{x v i}$, xviii). 
united as they are throughout by one animistic principle, into two great classes, those lower systems whose best result is to supply a crude childlike natural philosophy, and those higher faiths which implant on this the law of righteousness and of holiness, the inspiration of duty and of love." 1 That is to say, the growth of culture and the development of morals does not destroy what is true in the one pervasive "animistic principle;" the One Life which manifests Itself in all beings is assumed to be both the Ground of a necessitated connection between Things and of a derelopment of such moral freedom in Selres as makes possible a keeping of the "law of righteousness and of holiness, the inspiration" (not mechanical causation) "of duty and of love." Of course, the language and conduct of men must be sympathetically and profoundly interpreted in order to find in them so much of superior privilege and of opportunity. But the most superficial interpretation shows that the universal type of psychical relations is not derived from man's experience with a merely physical mechanism.

The inevitable neecssity of combining in one's conception of moral freedom the two preceding somewhat antithetical considerations leads the mind directly to a third important truth. We may state the antithesis - which is after all more verbal than real - in either one of sereral ways. The Self is indeed influenced in its choices by its own desires and passions; but it is not thus compelled in the same way as that in which the action of one thing compels the action of another thing. Sometimes, and in certain pitiful cases almost or quite habitually, the Self is so strongly influenced, so overborne, as it were, in its consideration of all motives to pause or to resist, that men accept some such description of its action as the following: "I could not help it;" or "The temptation was too strong and sudden, was greater than I could resist." When asked: - Why did you choose 1 Tylor, lbid., ii, p. 361. 
thus and so? or, Why was your conduct so blameworthy, or impolitic? the answer sometimes is: "This passion or impulse mastered me; this consideration compelled me to act." And yet rarely does the explanation, taken at all literally, seem either to the one who makes, or to the one who reeeives it, quite satisfaetory or quite complete. The untutored moral conseiousness, the crude and swift justice of the savage, takes little or no account of excuses such as these. And the suspicion that the offender against the law or the custom is lying, when he pleads the exeuse of a causal and necessitated connection between his motive and his deed, is likely to make the retribution no less crude and swift. It is only the refined moral consciousness which modifies its feelings of reprobation and demerit, and substitutes somewhat of indulgent pity and compassion in their stead.

Now from such mixed and conflicting experiences as these it follows at once that moral freedom must be considered as a matter admitting of degrees, and as itself capable of development. In a word, human beings are not born free morally; neither do all men possess at any time, nor does any individual man possess at all times, equal degrees of moral freedom. The rather is such freedom to be spoken of as an acquisition, dependent upon repeated exercise of the so-called power of choice, under the principle of habit. Growth in moral freedom is the development of the Sclf's capacity for making ehoices.

It is also manifest at once, in the fourth place, that this "capacity of the Self for making choices" cannot be considered as the function of any one faculty or set of faculties. The possession of any degree of moral freedom, and the derelopment of its higher and more significant degrees, are dependent in all cases upon the possession and development of all the faculties which go to make up man's moral nature. The problem of ethics is therefore not decided, 
it is not even properly stated, when only the facts that concern the purely voluntary aspect of consciousness are considered. Neither mere arbitrariness of will, nor machine-like and necessitated action of will, can constitute the basis of a truly moral freedom. For, indeed, the problem includes much more than this. Choices to follow the ideal forms of that which is esteemed morally good cannot be made by a mere fiat of will, whether wholly unmotived or strictly determined; the presence in conscionsness of such ideals and the conseious eraluation of them from the moral point of riew is necessary to their choice. I cannot will to adhere to my feehing of obligation rather than yicld to my passion or desire, unless I have such fecling of obligation; nor can I choose that course of conduct which I judge to be right unless I am capable of a judgment which shall bring the conduct under the category of the right. And without the powerful influence from the feelings of moral approval and merit (and their opposites) it cannot be contended that men would ever attain to a genuine moral freedom. It is in the neglect of these considerations that some of the antinomies which are foreed into the problem of a so-called freedom of the will have their origin. "Freedom of the will" is, I think, a term which would better be abandoned by ethies. Moral freedom for the human Self; what is it in fact, and essentially, in spite of its many degrees of intensity, so to say, and its different forms of manifestation? 'This is the primary ethical question. And has moral freedom in fact such a character that, before the same moral consciousness which is its own most severe and, when well cultivated, intelligent critic, we may justify the conclusion that the present soeial system has in it at least the seeds of rationality?

Certain facts of indubitable experience exist, on the basis of which may be formed our conception of the nature of man's choices, and of the part which they play in the moral life and moral derelopment. But even these facts lose all their highest value and most of their significance, when we attempt to 
regard them as separable from the development of human life, in the individual and in the race.

One word more of preliminary cautioning seems desirable. This has reference to the chief fallacy in discussing this problem which affects those metaphysically inclined. The fallacy is that of mistaking conceptions for entities, functions for realitics, relations for pre-existent and effective causes. In a word, it is the fallacy of hypostasizing. For example, "Law" never docs anything, or accounts for anything, - no matter how imposing the eapital with which one spells the word. "Necessity" creates no real bond; and "Chance" and "Contingency"- whether whispered with bated breath by the frightened worshipper of the great modern WorldMachine, or boldly proclaimed by the arowed enemy of such a monstrosity - can 110 more injure the existing arrangement of things than the most inevitable Fate can conserve this arrangement by preventing man's interference with it all. Ghosts of abstractions, whether theological or scientific, whether redolent with the smell of the tombs in which they should have been buried ages ago, or emitting whiffs of the latest patent embalming fluid, can effect neither good nor harm outside of the mind of man. And when one is solemnly told that the Law of Causation forbids this or compels the other; that human Self-detcrmination would destroy the integrity of the physical Universe; or that the Conservation and Correlation of Energy does not admit of influences "passing over," etc., from the physical to the psychical realm, one may always demand a re-cxamination of the warrant in facts for such sweeping use of ideas whose whole force is only that of the highest potency of logical generalization.

What now are those facts of a well-nigh if not quite universal human experience, from which flows the coneeption of a real moral freedom for man, and to which this conception must be referred in the effort to determine more eritically its rational import? These facts may be dirided between two related 
but not identical forms of consciousness. They may be called the consciousness of ability and the consciousness of imputability, or the consciousness of the Self as active and the consciousness of the Self as responsible. As these facts appear in the stream of the individual's conscious life, and as they become data for the conception of man's moral freedom, they are expressed by such language as the following: "I can," and "I know that I can;" and because "I ought to have (or I ought not to have), I am worthy of approval (or of disapproval), and of merit (or of demerit)." In the one case, the Self contemplates itself as in the presence of its own deed and affirms that the choice to do, or not to do, in spite of all internal and external influence, is, nerertheless its very own. I make my choice; and the "I" that chooses is not simply the being that was yesterday, or eren a moment since; the rather is it the living, present, here-and-now-being of the Self. In the other case the Self contemplates its own deed as already done, and affirms that this deed of choice together with a certain greater or less amount of the consequences following from the deed, belongs to itself ; and, in consequence, so does also the blame or praise, the reward or punishment. $I$ did this thing, for it was my choice; and my living, present Self doth reasonably assume as its own the moral predicaments of its own choosing. Such, I maintain are the facts of human experience, when this experience reaches that stage of development which affords the clearest and most trustworthy data for a conception of moral frecdom. But with inferior degrees the same experience manifests itself as an almost ceaseless accompaniment of, and a substantial factor in, the unfolding of the moral life. Let us now examine somewhat more carefully these two classes of general facts belonging to man's ethical consciousness.

The general fact of self-activity, culminating in that highest form of such activity which is intelligent and deliberate choice, when taken - as it always should be - in connection 
with the equally general fact of limitations and inhibitions to this activity, is expressed in such language as "I can," or "I cannot." This form of language is appropriate before the choice is made. After the choicc, the appropriate declaration is "I could have," or "I could not have" - done otherwise (" helped" it, or not, etc.). The psychological analysis of the origins and derelopment of those complex conscious conditions which give the warrant to these forms of expression shows that the conditions themselves are continually present in human consciousness, and belong essentially to the rise and evolution of the very conception of a moral Self. To prove this we have only to eroke the aid of a descriptive psychology which is faithful to the facts.

In the infantile conscionsness there is neither knowledge of the Self as a doer, nor of other selves and things as external existences that excite desire and solicit or impel the will. But there is that mixture of sensations and feelings which stimulates the discriminating consciousness to master its environment both intellectually and practically, and which is of such a character as to compel the distinction between the Ego as active and the same Ego as passive, and so between the Self and the not-Self or other things. In the one everflowing and shifting stream of eonscious states there are changes which accentuate and define the conception of ourselves as agents; and there are other changes which accentuate and define the conceptions of things not ourselves by which our agency is limited, and by which we are made to suffer by being acted upon. This is no occasional experience for any man. This is the universal and necessary characteristic of all experience. Under the conditions of most supreme activity we are self-active only in a limited way; we are also solicited or deterred, impelled or inhibited somehow made passive - by the actions of other persons and other things. On the other hand, in our most abject submissions, in our most supine yieldings, we are often, if not gen- 
erally or universally, conscious of a certain measure of self-activity - of a resistance, which indicates the retention of at least a minimum of that inherent right and power of self-control which belongs to the very nature of man. When I suffer pain, after all it is I that, having borne up (sub fero) against it, now give way; and in the very giving way, I may assert my will not to hare it so. And if the total yielding happens to be an affair of ethical concernment; if I have yiclded because I felt I could no longer suffer for righteousness' sake; then - my conseience being well trained and still sensitive - I may feel most keenly that, after all, I really could have borne more; I was not wholly passive in being overborne. The ideal of a truly moral being is the conception of a Will which under certain circumstances, cannot be made to choose to do certain things by any amount of conceirable suffering.

The belief of mankind that human wills can by their activity modify the otherwise extreme conditions of passivity, is proved by their language, their judgments, and their behavior. "Do not mind it, and it will not hurt you (at all, or so much)" - this is what nurses and mothers tell their children. "You shall learn to bear up against that pain in the interests of some practical ideal " - this is the moral maxim which is fundamental with the North American Indian, as well as with that Christian tutelage out of which the martyrs came. Even the claim, "I eannot help it," or "I cannot do this," has no meaning unless it be interpreted in the light of contrast with the consciousness of power to do. The consciousness of potency is the indispensable postulate of the consciousness of impotency; "cannot" has no meaning except as the foil of "I can." 1

Neither past nor current theories of the physiological basis

1 For a full discussion of the beginnings and development of this consciousness, see the anthor's Psychology, Descriptive and Explanatory, chap. xi and xxvi. 
or of the psycho-physical connections of this consciousness of self-activity should be allowed in the least to modify our statements of the fundamental facts of experience, or to blur the conception of the import of these facts in their bearing upon the doctrine of moral freedom. That this feeling of self-activity, psychologically considered, cannot be wholly resolved into feelings of peripheral tension and strain, etc., I have elsewhere shown to be true. It is in these feelings that men have, the rather, the grounds in experience for the conception of an activity that is limited and checked. But the feeling of being active is not, as a mode of consciousness at least, the feeling simply of being inhibited in activity. I will, with difficulty, indeed; but the fact expressed by the words "with difficulty" is not the whole of the fact.

As far as available data exist for a scientific conclusion, it appears that the physiological functions with which these feelings of self-activity are correlated are not of peripheral origin. They are not modifications of the brain's states which arise wholly in areas of tense muscles, joints set together, skin stretehed tight, teeth grinding on one another, fists clenched, etc. The nervous correlate of these feelings is rather that ongoing chemico-physical life which belongs to the central organs, to the controlling centres of the cerebrospinal and sympathetic systems, and, through these systems, of all those bodily functions with which conscionsuess has, either directly or indirectly, anything to do. If this is so, - and, indeed, whether it be so or not, - the nature of the connection between the brain-states and the states of a conscious self-actirity is of so indeterminate and metaphysical a character that it should not be allowed to influence our preliminary judgment as to the character and import of the conscious facts. More sure than all theories of idealism, of materialism, or of psycho-physical parallelism, stands the indisputable and important datum of human consciousness. With rarying degrees of extension and intensity, howerer 
limited and checked by causes external or influences arising within, man earries with him an immediate awareness of his own potency. He expresses his inmost experience by saying "I can," although it may be with pain and difficulty, or even with doubt as to whether, after all, this potency will endure beyond a certain somewhat indefinite amount of strain.

The supreme exhibition of man's self-activity is given in the phenomenon of intelligent and deliberate choice. The wonderful and unique characteristics which this phenomenon may attain have been quite too little insisted upon in modern discussions of moral freedom. The consciousness of motives, the estimate of values, the appreciation of ends, have too often been converted into quasi-mechanical processes, whose effect in consciousness has been conceived of after the analogy of the action upon each other of the parts of a physical mechanism. But Aristotle long ago saw that intelligent deliberation guarantees, and itself is, the highest form of moral freedom. "When we say, this is chosen or purposed, we mean that it has been selected after deliberation." 1 An intelligent and deliberate choice is the very opposite of an impulsive or impelled deed of will. The Self choosing, after deliberation, is the Self determining and not determined. Even to say that "after reflection, I am determined," is to assert the highest conceivable potency of a finite self-determining being. Nor can any one imagine what larger amount of simple "power" of will" should be desired in the interests of man's moral freedom. More clearness of vision, more light on consequences, more pure and noble intentions, finer scusibilities, higher estimates of the more spiritual goods, - any and all of these acquirements render any man "freer" from the risks and dangers, the mistakes and errors, of the moral life. But I fail to see how the eonsciousness of self-activity which is expressed by the "I can," under the most farorable circum- 
stances, could be made any more convincing of the real nature of the transaction than it actually is.

The philosophy of conduct must, then, never omit to emphasize this most mysterious and, in some respects, most essentially incomprehensible of psychical phenomena, especially since so much of human experience inevitably leads the thought to different and even opposed conclusions respecting the nature of man, the nature of things, and the character of the relations actually existing between the two. The psychological characteristics of a deliberate choice are best understood by contrasting this supreme act of will with every form of impulsive volition. In view of the prevalence of the teleological principle in all mental as well as physical life, there is good ground for agreeing with M. Paulhan ${ }^{1}$ : "Every idea,. . . every sentiment, in brief every psychic system tends to complete itself by volitions and motor phenomena; every system has its own will." Now if this tendency itself were never subject to a conscious and voluntary check the phenomena of deliberate choice would never occur, and moral freedom could nerer develop. But deliberation is itself the conscious interposition of a check until two or more contending "psychic systems" can have their values estimated and one of them be adopted to the exclusion of the others. So that what is called " deliberation" is itself a mixture of intellectual activity and inhibitory volition; indeed, in all cases where the questions deliberated have a moral import, deliberation is a most significant piece of conduct. There are, indeed, not a few cases where every principle of morality leads to the conclusion that action ought to be preceded by deliberation, with its resulting clearer vision of the end to be aimed at and its more precise estimate of the values involved. The moral ideal is that of a Self roluntarily using its own intelligence to secure the ends of that conduct which is judged to be right. Deed without judg-

1 L'Activité Mentale, p. 59 f. 
ment, or impulsive judgment, is in these cases morally wrong conduct.

The very effect of the intervention of will and reason, or of the consciously judging and voluntary mind, is totally to change the relations in which the appetites, passions, emotions, and desires, stand to the fimal deed of will. So that the will to deliberate - " to reason with one's self," or " to let the roice of reason be heard," as men expressively say - often amounts in the issue to this: I will the influential ideas, feelings, and desires, rather than allow these ideas and feelings and desires to influence - not to say, determine me. "Nothing can well be more shallow and misleading, in description and explanation of the facts of conscionsness, as such, than to regard deliberation as a mere struggle for supremacy in consciousness of ideas and feelings and desires that strictly determine will." 1

Moreorer, the volition itself, when issued after deliberation is not psychologically the same. All the naive distinctions of degrees of responsibility and of guilt which men customarily make, and all the elaborations of acceptable ethical theory, agree in affirming this. The deed done with "malice prepense" is peculiarly one's own. If no deliberation intervene, then the feeling is rather that of being influenced or even carried away by one's own impulses; if deliberation intervene, then the feeling is rather that of a self-determining which one of two or more impulses shall be given the influence which it is judged to deserve. The culminating one in this series of psychical phenomena is that decision, or "cutting-short" of the process of deliberation, in which will expresses itself as the faculty distinctive in all making of choices. Or, to describe the experience in terms less abstract and technical: I myself decide which of the ideas and feelings and desires I will make definitively and finally my very own. The problem whose solution has thus far been only more or less highly

1 See Psycliology, Descriptive and Explanatory, p. $618 \mathrm{f}$. 
probable, is now for the time being solved; only the decision decides, only the resolution resolves the problem.

Undoubtedly, only a relatively small amount of any man's conduct results from, or consists in, those intelligent and deliberate choices which exhibit in a complete and supreme way all the characteristics that have just been described. But just as undoubtedly such choices are within the limits of man's capacity, and are actually made by many, if not frequently by all men. It is not the heroes alone who can truthfully declare with the Paracelsus of Browning:

"I have subdued my life to the one purpose Whereto I ordained it;"

or, again :

"I have made my life consist of one idea."

The plain men and women of the world, even in the more unfavorable conditions and lower stages of moral development, do frequently make choices which are of large subsequent effect upon their own lives and upon the lives of others. These concern their habitual employments, their places of residence, their marital and other social connections, the parts they play in the life of the tribe or larger community, and even the interests which affect the ongoing of the history of the race. "Will in the narrower sense, or rational will," says Paulsen," "is desire determined by purposes, principles, and ideals." But this is only the partial truth; Rational will is the Self regarded as determining its own conduct with a view to realize the ends that are conceived of as good.

The phenomena, taken in their entirety and surreyed as important factors in man's evolution, vindicate his claim to a conscious self-activity. The fact that this activity is itself dependent upon a development of the mind with all its powers, and the fact that it admits of a great variety of

1 System of Ethics, p. 220. 
degrees, varying from an impulsive and more strictly determined rolition to the most intelligent and deliberate choice, - these facts do not destroy but only modify and explain the nature and import of the claim.

In opposition to this view of the fundamental facts of experience another is sometimes set up, which regards the phenomena as analyzable into a consciousness of change plus a conscious ignorance as to the cause of the change. In a word, this form of Determinism sees an intellectual weakness in the very conscious experience in which we find a consciousness of power. But a potency of action is not to be resolved into an impotence of knowledge. Nor can the activity of a Thing be converted into the activity of a Self merely by assuming that the thing has become conscious of what it is doing, while remaining still ignorant of the reason why.

Some physical illustration is quite too often supposed, with a kind of Hindu logic, to prove the case against the adrocate of a real moral freedom. Let us suppose an arrow in its flight to become conscious of its own buoyaney, speed, and direction, and to feel the influences which really come from earth and air, without howerer knowing anything about the bow and the strong arm that set it in motion, or the forces and laws of gravity and of atmospheric pressure. Might not this conscious Thing imagine itself to be soaring aloft of its own free will, to be voluntarily going straiglit for, or deriating from, the mark with feelings and desires appropriate; and, finally, might it not rejoice in and esteem praisewortly its own suceess on hitting the "bull's-eye," or drop to ground quite short of the target with feelings of disappointment and moral shame? But, surely, it does not require a past master of psychology to prick this iridescent bubble, or a great interpreter of the language of the human soul to discover the fallacy of such mythological conceits. Let us make a complete Self out of this conseious arrow. And now under the principle of sufficient reason the "Thing" does account to itself 
for its own speed and direction as partially due to eauses that lic outside of itself; its tendency to decline from the straight course it ascribes to the pressure of the invisible wind; and the necessity to put forth more of its own effort to keep aloft it attributes to the down-pulling of the earth beneath. And yet this conscious arrow refuses to credit the conclusion that the wholly sufficient reason for its action resides outside of its own present, self-determining choice; and it maintains this refusal to the last, in spite of all the cogent pleadings of a deterministic philosophy. Add all these potencies of intellect and will, and not a few otlers, together with the ethical feelings of man, to this conscions arrow, and the conscious arrow has become a conscious Self, with all the rights, duties, and moral ideals of such a rational and free being. As to the possibility of so wonderful a transmigration of souls, I am quite willing to leave it to the most ardent and consistent adrocates of the theory of psycho-physical parallelism to diseuss.

But to drop so imperfect and even absurd an illustration; it distinctly is not true to the facts that ignorance of the precise influenees operative is any measure of the willingness to attribute to the Self the power of self-determination; or, on the other hand, that knowledge of the influences actually at work upon the man necessarily diminishes at all the wellgrounded belief in his freedom. Suppose, for example, that after much deliberation of the pros and cons I decide to take a certain journey. After making the decision, I know quite clearly the relatively narrow set of influences which tended to induce me to go abroad or to stay at home; I am still able quite accurately to describe the amount of consideration which I gave to them in making up $\mathrm{my}$ mind to the final choice; but, all the same, or even all the more, I remember that I was conscious of the ability to choose and that I did choose with this consciousness still pervading my deed of will. Now, on the other hand, suppose that I am inrestigating a 
complicated problem in cerebral physiology. For example: What are the causal influences that determine the production of so-called "protagon" in the human biain? I do not know. I have not the slightest doubt, however, that they are indefinitely more complicated than those which determined my choice to take the journey. I may doubt whether all the physico-chemical causes which enter into the production of protagon will ever be known to the student of physiological chemistry. But do I doubt that every atom and molecule in that compound, and the whole constitution of the compound, was strictly determined and did not anywhere admit, on the part of its elements or its totality any self-determining choice? Not for a moment; not in the least. Why, then, this difference? It is not a difference in amounts of knowledge; it is plainly a more fundamental difference. It involves all the enormous difference, based on indubitable facts of experience, between my conception of the nature of a Thing and my conception of the nature of a Moral Self.

The other class of facts upon which the conception of moral freedom is based has been called the consciousness of imputability. The bearing of these facts upon the eonception of moral freedom may be more briefly stated in riew of what has already been said tonching allied facts. Some one is ethically responsible for all conduct; some one is to be approbated if the conduct is good, or disapproved if the conduct is bad; and for every good or bad piece of conduct some one deserves to be treated accordingly. All over the world, when good or bad deeds transpire, search is at once made for the person, or persons, whose the deeds are, so that to them they may be attributed as their very own. And to ou'n the conduct - whether jointly or severally or exclusively - is to establish a sort of right to its appropriate treatment of praise or blame, of reward or punisliment; it is also to lay upon society the duty of this appropriate treatment. In a word, to the Self, in a special and peculiar way, belong such of its 
individual actions or habitual modes of behavior as constitute its conduct and character; this attribution of the conduct makes ethically proper the imputation of praise or blame, and the bestowal of reward or the infliction of punishment.

Few will doubt that men are in general ready to claim for themselves the credit and the reward which are due to the good deeds they are convinced they have done. Even the most genuincly humble Christian, in his most sincere ascription to God of whatever glory may belong to any of his own good deeds, still feels that his fcllow-men ought also to recognize in their treatment of him that these good deeds were indeed his own. If God did them, - and to I Iim be all the glory, - still they were done in and through himself. Just as little doubt is there that men generally disapprove and blame and desire to punish those who have wronged them ; and that they express with good conscience this disapproval and blame, if not a more explieit notice of demerit. And the fact that they are not, as a rule, so strict in their judgment, or so warmly convicted of the rationality of this universal mode of procedure, when their own selves must suffer thereby, is to be accounted for in obvious ways. In the case of those who have the highest degree of ethical culture, moreover, we not infrequently find the disposition to make the most unsparing application of this working of moral consciousness to their own casc. The bad things they themselves do are, of all bad conduct, the nearest and most intuitively disapprored and punished by themselves. They are of all men least disposed, in cowardly and self-deceitful fashion, to retreat before the condemnation of conscience or to throw the blame and the baneful consequences of their own wrongdoing off upon circumstances or upon other men. And such persons are the most trustworthy witnesses to those facts of moral consciousness which have this import. All conduct, with its accompaniments and consequences of approval and disapproval, merit and demerit, is imputable to some Self as to its author and source. 
The phenomena of ethical pride and shame, of the claim made by the pure conscience and the remorseful consciousness to be self-rewarded or self-punished, even if society neglect its duty, or fail through ignorance to administer reward or punishment, are not peculiar to any tribe or to any era of ethical devclopment. The man of honor in Old Japan committed hara-kiri, when his wrong conduct toward one of a lower class was not punishable as a crime in the eyes of the law. His honor called; he punished himself. On this point the sanctions of the religious consciousness reinforce the moral feeling of the imputability of conduct. Hence not only the $\operatorname{god}$ who is friendly should enjoy a saerifice as a gift, but the god who las become offended, must be propitiated by a sacrifice. Criminals have often surrendered themselres in order that the crarings of their own conscience for punishment might be appeased; and simners who become penitent get satisfaction in doing some sort of penance. Eren the Zulus have the prorerb: "When a fish is killed its own tail is inserted in its own mouth" (said of people who reap the reward of their decds).

The same riew of the imputability of conduct is taught by the unicersal customs and the language of men as related to one another's deeds. Whatever one may think about the morality of rerenge, one cannot forget the significance of the indisputable fact that men regard injuries done them by their fellowmen as demanding a different sort of treatment from that which is given to injuries done by things or by the lower animals. "Confucius made it a duty for a son to slay his father's murderer, just as Moses insisted on a strictly retaliatory penalty for bloodshed." I Among the Fijians the duty of revenge passes from father to son, and from the son to the nearest relation, according to the maxim: "Let the shell of the oyster perish by reason of years, and to these add a thousand more, still my hatred shall be hot." And

1 Comp. J. A. Farrer, Primitive Manners and Customs, p. 80. 
even the modern Italian extols the sweetness of rerenge and declares it a morsel fit for God. Bctween the tribes of the uncivilized North American Indians, and between the families of the scarcely less uncirilized portions of our own South, feuds and blood-rerenge illustrate this fact of imputability in the form which makes a sacred duty of rengeance. Nor is the strength of this fact diminished when the lower stare of morals has been transcended and the beautiful sentiment of Persia has prevailed, which makes it the sign of a mean spirit to take private revenge for an injurs, but a manly thing to return good for evil ; or when the yet clearer and more pronounced declarations of the sermon on the mount hare been adopted as the law of social life. On the other hand, the opinion grows with all the growth of the common moral status, that to withhold praise and approbation from him who deserves it, as well as to bestow them selfishly where they are not deserved, are trro kindred forms of eril conduct. Indeed, this may amount to saying that ingratitude (for public as well as private benefits - and every good deed is a public benefit) and sycophancy are among the basest of rices.

The same truth is even more clearly set forth by the existence and execution of the laws in all civilized states and nations; as well as by much of that appeal to force which is made to settle matters of conduct in dispute between states or nations, - the so-called " arbitrament of war." For men can scarcely fight as wild-cats and tigers do. Although there are few wars of human history where either party has had a clear title to a perfect righteousness of conduct in the matter under dispute, and no wars where both parties hare had such a title, yet there are fewer still where there has been made no pretence - howerer hypocritical or mistaken - of some right to be asserted or some wrong to be redressed. But all such claims bear witness to the same universal belief in the imputability of human conduct. The barest pretence of justice carries with it this same irresistible belief. 
There are, indeed, many curions customs and even laws which show through what various and shifting phases the conception of the more precise nature of man's responsibility for his conduct may pass. Most of these, however, may be explained as due to imperfect conceptions of personality, of the selfhood which the individual is considered to have. The history of man's ethical derelopment seems to show that belief in the imputability of conduct is even more constant than are the conceptions of selfhood which he develops. The conception of selfhood is a relatively complex affair. It undergoes important modifications with the growth in culture and in experience of the individual and of the race. Thus the individual Self may, on the one hand, become merged and almost lost in the vague notion of a selfhood for the family, the tribe, or the state. Since the other members of the body domestic, social, political, suffer sympathetically when any one member suffers, by a not umnatural and useful fiction they are thought of as sharing in the goodness or badness of each other's conduct and in "the desert to be treated accordingly." But the same conception may, on the other hand, become so contracted as to be identified with some one of its own good or bad passions, affections, and impulses; or eren with some one of those bodily members that are the natural instruments for executing the will as mored by these passions, affections, and impulses.

This vague and expansive conception of selfhood accounts in part for the custom of extending to the whole family or tribe the guilt of an individual member and of satisfying the demands of justice by exceuting the penalty upon any other member of the same family or tribe. Thus the Thlinkeet Indians, if they camnot catch the actual doer of a crime, kill one of his family or tribe instead. According to the native Samoan law a plaintiff might seek redress for the murder of one of his own relatires "from the brother, son, or other relative of the guilty party." Among the natives of Australia, 
when a crime was committed, and especially if the culprit escaped, only persons unconnected with the family believed themselves to be safe, until some one had expiated the crime. It is not Iong since the English law arenged itself on the successful suicide by punishing his relatives; and not so very much longer since it incarcerated or fined the husband for an assault committed by his wife. To-day in many Western sections of this country rengeance for a crime committed by some one or more Indians is executed by killing as many as possible, even innocent members of the same tribe or of other tribes, - and this not as a necessary but awful deterrent simply, but rather with the satisfaction of a good conscience. And do not the most Christian nations constantly disgrace their Christian name by treating the so-called inferior races with the same crude, selfish, and degraded, but awfully potent conceptions of personal responsibility for wrong-doing?

The thoughtful student of man's moral evolution cannot fail to find a certain basis in reality for these misguided ways of asserting the imputability of conduct. Some one has got to suffer, and some one ought to suffer, if any wrong has been done. And so much of a sort of solidarity is there to the connections of individual men, in the family, the tribe, the state, or the race, that the suffering calnnot be confined to the personality of the criminal alone. Moreover, it ought not to be so confined. Nor is the reason for this "oughtit-not" purely a matter of expediency or of social policy. In their social connections men act with a kind of corporate responsibility. This fact makes the precise manner of the just distribution of praise and blame, reward and punishment, most difficult; - so difficult indeed, that anything approaching perfect justice is an impossibility. The question of Cain: "Am I my brother's kceper?" has always been answered affirmatively by the prevailing judgment and actual practice of the race. As ethical enlightenment increases, and "good will" 
becomes more dominant, the eonception of Selfhood becomes truer and more definite, and the points for the just and beneficent attacliment of responsibility become more clearly discerned.

The important conclusion, therefore, from this general fact of the imputability of conduct may be stated somewhat as follows: The fact itself belongs to the most fundamental and unchanging phenomena of man's moral consciousness. It guarantees the individual and corporate responsibility of men to one another, for their conduct and, to a certain extent for the consequences of conduct. It implies the irresistible belief that conduct belongs to the Self, is the product of self-activity; thus conduct can be, must be, and ought to be, followed by praise or blame, reward or punishment. But these rational sequences of conduct are themselves justifiable at the bar of reason itself only in view of the postulate of moral freedom. And, in fact, these sequences are, by all men and everywhere, justified in this way. For they are universally regarded as belonging to the rery essentials of morality as a rational affair. Wrong-doing, since it is the product of a being possessed of moral freedom, ought to be blamed and punished; but right conduct is reasonably entitled to praise and to a reward of merit. For the total complex fact is not simply the fact of conduct imputed and treated accordingly; it is rather the fact of conduct imputable and so reasonably treated accordingly.

What now is the picture which these facts of universal moral consciousness both authenticate and require? It is the picture of Man as self-determining; it is the picture of man as a rational free Self. Negatively described, it is the picture of a being that is not wholly determined either by environment and external stimuli and impulses, or by his own emotional and impulsive states or past habits of action. Positively described again, it is the picture of a being that, under differing cireumstances and with varying degrees, 
derelops a power which reaches its culminating manifestation in its own peculiar form of intelligent and deliberate choice; and this power is the whole Self actively determining its own conduct. Perhaps nothing truer has ever been said upon this sulject than the following sentences of Aristotle ${ }^{1}$ : "Therefore virtue depends upon ourselves: and rice likewise. For where it lies with us to do, it lies with us not to do. Where we can say No, we can say Yes. If then the doing of a deed which is noble lies with us, the not-doing it, which is disgraceful, lics with us; and if the not-doing, which is noble, lies with us, the doing, which is disgraceful, also lies with us. But if the doing and likewise the notdoing of noble or base deeds lies with us, and if this is, as we found, identical with being good or bad, then it follows that it lies with us to be worthy or worthless men." "We are ourselves joint causes, in a way, of our (virtuous or vicious) habits.

Even those advocates of Determinism who venture to charge this universal opinion - We ourselves determine our conduct and help to make our own character - with being an illusion, cannot well controvert the fact that this "illusion" underlies and interpenetrates the whole moral structure of human institutions. It is an illusion of the race, a mutually tolerated and encouraged self-deceit that one cannot say afflicts, but the rather conserves the higher spiritual and ethical interests of all mankind. But no warning to the philosoply of conduct can easily be more significant than that which bids the reflective thinker beware how he passes lighltly over to the realm of illusion facts of experience like these. It might well seem far better to toss some of his own fixed ideas, some of his boasted scientific (sic) conclusions, over into "the deathkingdom of abstractions."

There are many of the transactions which take place between things and things, and between selves and things, that are

1 Nic. Eth., III, v, 2 and 20. 
certainly known not to be "free" in any of the several meanings which ethics can possibly attach to this word. Indeed, modern science has a well-founded belief that things, if left to themselves, uniformly behave in ways which are strictly determined by the natures and relations of the very things in whose changes the observed uniform behavior consists. I say natures as well as relations; the meaning of this declaration will be made clearer and the application of it more pertinent at a later stage of the discussion. For the very term "nature" is one which science is obliged to use in order to cover up a vast amount of ignorance, and as a sort of comfortable locus for that unavailable fund of mystery which investigation always leares on hand, no matter to what extent knowledge of so-called causes has been able to find its way. Or, to put the solution of the whole problem into one sentence: Science finds the total explanation of all the physical changes in the world in the assumption that all things are from the beginning strictly determined by their own natures how to behave each in its own same way - when in determinate identical relations with other things. This is not, indeed, the naîve, natural way in which men have always explained the physical changes with which their experience has made them familiar. It is not the way in which millions of men now explain these changes. It is, howerer, the way in which modern science insists upon explaining, at the rery least, all plysical changes.

It will be found that all the objections to that riew of moral freedom which I am adrocating hare their source in the socalled "principle of causation." But they come from its misconception and its consequent misapplication. The objections must be met by correcting the misconception and by determining the true application of the principle. And if we have to leave a large residuum of ignorance as to specific causes to be located in the mysterious nature of the Self; if we have, indeed, to end the controrersy by saying that the very nature of man 
consists largely in his developing the mysterious power of selfdetermination, still the confession is neither so extraordinary nor so damaging to a reasonable Libertarianism as it might at first appear. For the principle which controls the conscious and rational development of a morally constituted being is not the principle of causation in the complete mechanical form in which modern science applies it to the changes of things.

There are, however, two ways of eontroverting moral freedom with the principle of causation; and these two ways differ largely because they regard the principle itself as resting upon experience in two different ways. Thus the objections which arise may take either one of the two following forms: (1) empirical and inductive, or objections from facts ; and (2) deductive and a priori, or objections coming straight from the claim that the principle of causation - as interpreted by the objector - is of universal and demonstratively valid applicability. The one class of objections points to our experience with facts, and claims simply, It is so; the deeds of will, ineluding the most intelligent and deliberate choices, are all strictly determined by their antecedents and concomitants. The other class of deterministic theorists are bolder; they venture to affirm: It must be so; the universal and unalterable principles of reason are on our side; and we do not need to adrance convincing proofs in the way of facts. Let us, lowever, take each position in order, and advance to the citadel of what Kant would call an "apodeictic" stronghold over gaps in the walls of its empirical surroundings.

It is with no little amazement that, when one examines the Determinism which affirms for itself a solid basis in fact, one finds it hopelessly divided against itself on the most important matters, both theoretical and practical. Indeed, there is searcely need to call upon Libertarianism to disprove the very substance of the deterministic argument so long as these two schools of Determinists eontradict each other both in their affirmations and in their denials. The form which, without 
disrespect, may be called "Old Fashioned Determinism," maintains that the sufficient reason for all deeds of will must be found in antecedent states of consciousness. It cultivates an elaborate mathematics dealing with the dynamical theory of " motives," or those mainly emotional states of consciousness which hare different degrees of poteney to move (or determine in a quasi-mechanical way) the Will. Men choose always in accordance with - and so as determined by - the appetite, passion, desire, sentiment, or estimate of some form of the good, which for them at the time of choosing is the most forceful, the most of a real moving power. In a word, whatever form of expression may be selected to represent the facts of experience, the underlying assumption is this: All psrchoses, including deeds of will and even the most intelligent and deliberate choices, stand to antecedent psychoses in the relation of effects to causes. But the form of Determinism which I will venture to call "New Fashioned" (although its more appropriate name is the now almost universally rejected and opprobrious title, "Materialism") denies that psychoses can really influence, or cause, each other in any case or under any circumstances. For states of consciousness, say its adrocates, are not realities and cannot act dynamically upon each other. The real cause of them all is the succession of chomicophysical changes which goes on in the nerrous system; and especially, the succession of brain-states. Psychoses, whether appearing to us as motives or deeds of will, are mere phenomena - phenomena of the brain. And just as we do not say of the successive puffs of steam from the locomotive $-A, B$, $C, D, \ldots N$ - that $A$ causes $B$, and $B$ causes $C$, and so on until $N$ is reached; but we hold that the entire series, $A, B$, $C, D, \ldots N$, is explained by the succession of dynamical changes which go on in the boiler, steam-chest, etc., of the locomotive, under the influence of surrounding temperature, atmospheric pressure, etc., - so ought we to explain the succession of psychoses. Whaterer mas be their apparent character 
in consciousness, we must explain them by the only eausal chain of occurrences which can possibly be considered as effective in reality, - namely, the succession of cerebral neuroses. In a word, psychoses cannot cause or influence psychoses; all psychoses, as respects their nature and their order in the scries, are caused by neuroses.

Both these forms of the deterministic lyypothesis have certain undoubted facts of experience on their side ; and every theoretical construction of the conception of Moral Frecdom which aims to afford a sufficient explanation of the most patent facts must admit some truth from them both. For they are both right in much of what they affirm. But they are both wrong in much of what they neglect or deny; and they are both wrong in the extreme to which they push their own way of giving a theoretical construction to the phenomena. It should never be forgotten that Determinism always has been, is now, and must continue to be, a theory for explaining undoubted facts. As I have said, it is a scholastic affair. And now we discover that its two main forms are totally and irreconcilably contradictory with regard to the fundamental question: Do the psyclioses stand in causal connections with one another? Or, to state the same question in a more practical manner: Do men mean anything which corresponds to the reality, when they explain their own and each other's conduct by referring to the influence of passion, desire, estimate of the ideal good of truth, beauty, or duty; or to the tendencies of a mental and moral sort which are popularly summed up in the word, character? "Yes," says the Old Fashioned Determinism; "and by such influences we are to explain all choices as strictly determined, though by antecedent psychoses." "No," says the New Fashioned Determinism; "for all psychoses, and the subjects of them all, are mere phenomena; they can determine nothing; they, and their order of arising and setting, are strictly determined by the antecedent or concomitant chain of physical changes." 
Let us now ask for a brief re-examination of those facts of experience on which such portentous theories rely in order to rally around themselves their schools of adherents. That men are actually influenced by their emotional states of every kind in the matter of their conduct and in the development of character, has already been admitted as an indubitable matter of experience. That men do find the explanation of conduct - and an explanation which deals with causce verce - in their passions and desires, in their loves and hates, and in the various forms of impulse toward different kinds of good, is a truth of experience on which all society and all human life, as well as all science or philosophy of conduct, are based. And one may be pardoned for a sort of contemptuous impatience with any theory of moral freedom - whether deterministic or libertarian - which denies the reality of the explanation. But it is a long and blind road to travel which leads from this admission to the unlimited conclusions of what has been called the Old Fashioned Determinism. Especially is this true if one honestly proposes and faithfully endearors to follow the guidance of experience, and not to abandon the highway of Empiricism for the steep and dangerous paths of an a priori metaphysics of Causation. For, let the formula which is to embody the deterministic conclusion be framed as skilfully as possible, and it will be found that, unless it is made dependent upon some misconception of the metaphysics of causation, it cannot succeed, even as a formula, in covering all the facts of experience. When analyzed, the statements of every attempt at a purely empirical doctrine of the deterministic order prove to be either absurd, or tautological, or insufficiently founded.

What now is the position which must be proved to accord with the sum-total of human experience if we are to accept the view of the first form of Determinism? It is that all the self-determining activities of the Self are, contrary to its own impression, really determined by its own antecedent states, 
under the laws of association and habit. Shortened up and stiffened, this statement may be made to read: So-called motives are the sufficient and efficient causes of all so-called choices. And, in general, the whole series of psychoses which constitute the life history of a Moral Self are a causal chain in which each link is dependent in the most absolute fashion upon the preceding links.

In every deterministic but empirical construction of the principles of human mental and moral development there is much false as well as much true psychology. The two or three most important false conceptions of psychical life and of its meaning which are held by this form of the theory may now be noticed. In the first place, so-called "motives" are treated by it as states of consciousness that can themselves be considered independently of that power, or aspect, of the Self which we call Will. But even in the lower stages of man's life it is psychologically inexact not to regard him as an active Self, as a Will, which in some measure determines its own motives, and is not wholly determined by them. Especially when the power of intelligent and deliberate choice unfolds itself, and in some sort according to the extent and height of its unfolding, deeds of will begin to determine motives as truly as motives determine deeds of will. And as the development of moral being goes on, the phenomena of imitation, instinet, impulse, and desire, in unchecked and irrational form - all that goes to make up the push of mere motive in its lower stages - become relatively less distinctive; and the phenomena of will, with its principle of freedom under the higher laws of mental development, become relatively more prominent and distinctive. It is very largely this in which consists the manhood of man, the nature of Selfhood set with other selves into relations of domestic, social, and political kind. This espousal of the extreme and now obsolete "facultytheory" of the soul vitiates the old-fashioned form of Determinism. Its conception of a Self as a succession of strictly 
determined and causally connected psychoses is totally inadequate. For it must be substituted the conception of an evolving, conscious, and rational Life - depending for its original characteristics on its membership in the race, and for its more special characteristics on its ancestral inheritance, influenced constantly by education and environment, and developing under the laws of association and the principle of habit. But to say all this is not to give the entire account of this conscious and rational Life; for at every stage of its derclopment, and increasingly if it develops in accordance with its higher powers and better opportunities, the Self is, by its choices, constantly determining itself, and so manifesting a certain relative independence of its inheritance, its enrironment, and even of its own past development.

No particular deed of will, when analyzed in detail, can be resolved, on empirical grounds at least, into the mere effect of the antecedent motives. This is true above all of those choices which have the highest import for the moral life. There are choices where strong passions, desires, affections or selfish aims and impulses, come into competition with the estimate of the value of ideals and witl the gencrally nildmannered and low-keyed form of sentiment which accompanies and enforces all ideals. About the true psychological character and the ethical significance of such choices, the current English psychology and ethics of the seventeenth, eighteenth, and early part of the nineteenth centuries has been productive of much obscurity and misconception. This psychology set up a mechanical, a perfectly "wooden" standard, for measuring the relative weights or impulsire tendencies of those states of consciousness which it was pleased to isolate from the stream of consciousness and hypostasize as "motives."

Indeed, without admitting the full force of those facts of consciousness on which the conception of moral freedom is itself based, we have no ground in experience for the measurement 
of the relative intensities of "motive" states. It is true that there are certain conditions of mind in which the prominent factors call attention to the speed and inevitable nature of the transition from impulse to volition. In some of these conditions nearly the whole of one's consciousness is summed up in the fecling of being hurried away to an issue in action which one foresees, and yet is unable to aroid. But such conditions by no means constitute the whole, or the chief part, of any man's noral life. And even in them it is often, if not generally true, that the consciously active Self call, and does, modify the earlier stages of these strong impulses by, at least, a partial acceptance or rejection of them, - while it is more than probable that with the adult man no conscious action which has moral quality is totally passive. Moreover, when one tries to estimate the impulsive power of different motives even of the more passionate and cmotional kind, one discovers that there is little or no chance here for any near approach to a science of mental and moral dynamics. Nor is this fact due wholly or chiefly to ignorance; it is the rather due to the nature of the ease. The doer himself, no matter how shrewd in self-estimate he may have become, cannot weigh his own motives accurately, according to their intensity. How much less can any one external to the motives perform such a feat in spiritual mathematics. In the bare fact of experience, motives themselves are nothing statical; they do not appear and remain before the mind, side by side, in the same field of consciousness. And the mental image of a past (even of a single moment past) passion or emotion cannot, for the amount of its merely impulsive potency, be weighed against the now real motive, the present energetic urgency of passion or emotion. What determines in such cases, if all intelligent and deliberate choice is at any moment ruled out, is association and habit, - what is called character.

When, however, the more intense impulsive states of consciousness contend for the control of the purposes and deeds 
with the Self regarded as placing a sentimental value on intellectual, æsthetic, or moral ideals, the problem of spiritual dynamics becomes - not simply more complicated and insolvable, but eren intrinsically absurd. Here, again, it is true that one meets with examples of minds which choose what they estimate to be true, beautiful, or morally good, with an impulsive intensity of feeling which amounts to an overwhelming passion or affection. So the Russian Quecn longed to die, that she might learn what Leibnitz could not tell her; or, according to tradition, Martin Luther appealed to God to support his chosen position, for he "could not do otherwise" than follow his convictions as to the right. But such derotion to ideals is itself due to the repeated free choice of the same ideals in preference to other contending interests of a lower kind. In general, however, the so-called moving influence of ideals of truth, beauty, and righteousness, cannot be compared with that of the impulsive states of consciousness, in respect merely to the intensity with which both act upon the Will. Indeed, unless chosen repeatedly and made the somewhat consistent principles of conduct as defining the ends of life, and as regulating the means for attaining these ends, ideals in general have little or no motive power in them. They are the rivals of the motives to choose only as we prefer them, for their very quality's sake; and in this voluntary preference we move toward them with self-determination, rather than allow ourselves to be moved away from them by no matter how intensely powerful appetites, passions, and affections.

It is only by neglecting such plain facts of human experience that one can put any, even temporary, confidence in that pseudo-science of mental and moral dynamies which the psychological and political forms of Determinism cultivate. To convey knowledge which enables its student to make, either as respects the action of the individual, or with regard to the course of the community, any entirely trustworthy predictions for the future, it is confessedly feeble and incomplete. Its at- 
tempt to account for the facts of choice is often incapable of expression except in terms of a most notable circulus in definiendo. For example, Mr. $A$ chooses the conduct $X$; but Mr. $B$, under seemingly similar circumstances, chooses the con$\operatorname{duct}^{-} Y$. The choice was, in both eases, a matter of fact; and obviously it was an intelligent and deliberate choice. Why, now, did $A$ choose $X$, when $B$ chose $Y$ ? Why did $A$ choose pushpin or something similar, when $B$ chose poetry; or, why did the former elect to gratify a base passion while the latter determined, in spite of strong temptation from similar passion, to remain true to his ideal of the noble and the good? Because the one preferred the gratification of desire or passion; the other preferred fidelity to his conviction as to what was beautiful or righteous. But what is the precise meaning of the word "preference" in such cases? Does it mean that gratified passion was in the one case, and fidelity to truth and duty in the other case, esteemed the greater good; and that this mathematical phrase - " the greater" - refers simply to the impulsive magnitude of the affective consciousness, the mere bulk in the stir of feelings aroused by the mental image of the desired end? The facts of the moral consciousness eannot be handled with any such significance to one's language as this. For over and over again has it been true that $A$, who chose to gratify passion, has looked mpon duty as seeming very fair and attractive to him; and $B$, who has chosen fidelity to duty, has often formed and exceuted this deed of will in spite of passions as impulsively strong as those of $A$. Moreover, if preference means nothing more than the intellectual estimate of an apparent good, the choice which is the actual preference, has not yet been accounted for. What then remains that is empirically certain, but the empty declaration : $A$ chose $X$ because he did choose it (actually preferred it); and for a like reason, which is no reason at all, $B$ chose $Y$ ?

It must be confessed, then, that there is no fixed standard possible for the measurement of the various classes of so-called 
motives; that, where quantitative comparisons are at all posible one needs always to bear in mind a certain qualitative incomparableness between passions and affections as motives and the intellectual estimate of the value of ideals as motives; and that, practically, the mysterious problem afforded by the Self in its actual self-determination remains essentially unchanged. Nor is this problem the better solved by taking into the account the character of the person making the choice. $A$ chooses $X$, largely because $A$ is $A$; and $B$ chooses $Y$, because $B$ is $B$. Thus the inquiry becomes, not so much a problem in the dynamies of human personality, but rather in its chemistry. Just as a certain product necessarily emerges from the union under given circumstances of a definite quantity of definitively constituted atoms, so-Determinism claims - is essentially the casc with the human constitution. The nature of the constituents is the important statical consideration in attempting to account for all the combinations into which they are found to enter. Thus even writers on ethics who, like Mr. Leslie Stephen, are arowedly and consistently deterministic throughout, find themselves compelled to hold that the ethical feelings and ideas expressed in such words as " blame," " merit," "good," and "bad," etc., attach themselves properly only to the character of the individual, and not to his native endowment of passions and emotions.

No philosophy of conduct is possible which does not find room for the facts of experience, and the theoretical construction of moral principles, that are implied in a valid conception of character. It is under the laws which control the formation of character that man gains such moral freedom as he has, and uses this freedom in the continuance and development of a truly moral life. But, on the other hand, the conception of character cannot itself be formed without taking into account those conscious experiences in which the conception of moral freedom has its origin; and any such 
conception of character as contravenes and annuls the conception of freedom is itself unfit to command our intellectual allegiance and is injurious to the morals of mankind. In arguing this question it is especially necessary to heed the warning against hypostasizing. What men call character is no entity, no self-cxistent principle, capable of playing an independent part in the dynamics of the moral life. The character of any existence is merely the sum-total of those more uniform ways of its behavior by which we are able for purposes of knowledge and the communication of knowledge, to distinguish it from other existences. But the character of a Self is always a quite different affair from the character of a Thing. For the character of a Self always includes the choices, and the results of the choices, in exercising which it has been self-determining. What ethics seeks is not some hidden, statical core of reality which stands in the relation of unirersal and omnipotent cause to each of the individual choices ; the reality of the individual Moral Self is rather itself in a measure the constantly varying resultant of those choices. The man's character is not something external to himself, which, as a finished product of the past or an extra-voluntary determining force, gives the entire reason why he chooses as he does choose. On a basis of inherited potentialities, indeed, and under a variety of influences from the total, constantly changing environment, and in a certain subjection to the principle of habit, the Self, nevertheless, progressively determines its own character.

Habit is indeed strong, and its bonds are often difficult, sometimes impossible, to be broken. But, looked at from the historical point of view, habit itself is rery largely a rccord of self-determining choices, a child of moral freedom. Looked at from the present psychological point of riew it is the Self, tending more or less strongly to choose certain forms of conduct; and yet just now, perhaps, on the eve, by a choice, of interrupting the previous current of impulses and starting 
the formation of a new habit. Only the complete extinction of moral freedom converts any man's character into a purely impulsive cause, an all-sufficient determining reason, for each of the particulars of his action. Habit rules inexorably and unvaryingly, only when self-determination has wholly ceased.

It is important now to notice how the attempt to carry this form of the deterministic conception, with complete thoroughness of analysis and unbending rigidity of logic, to its last conclusion lands the mind in the most uncompromising Materialism. This surprising result is reached in the following way. All psychoses, it is claimed, are strictly determined by pre-existent psychoses, and these pre-existent psychoses by others still earlier: - and so on to the very beginnings of psyclical life. But what determines for the individual these beginnings and the channels in which they have flowed from the first until now? Any complete answer must appeal to the physical environment on which the psychoses are reactions; and back of all, to the atomic structure and physicochemical tendencies which were carried over in the impregnated ovum, - the one certain and fixed antecedent of the entire psychical development. Thus the deterministic mental and moral dynamies ends in a psycho-physical and chemicobiological dynamics. For it is the physical and chemicobiological forees which tie the conscious Self in with the course of Nature, and strictly determine for it disposition, character, and all the conscious states and all the pieces of conduct, - even those which find their account in disposition and character, for lack of a complete account in the shifting external environment.

Such, then, is the legitimate outcome of this form of the deterministic hypothesis. All psychoses, the whole ongoing of the life of the Self, with its illusory belief that It, by its own choices, can determine ought, as well as its beneficial but equally illusory conviction that it is somehow rationally subject to praise and blame, and deserving of reward or punishment, are 
only the phenomenal exhibition of the really effective forces of external Nature. At the last we neither determine ourselves, nor are determined by our own dispositions or characters :-

"We are a moving row of shadow-shapes," -

Our very shapes are shadows and the movement even is not our own, but Nature's, whose products through and through we are.

To this same conclusion the second form of Determinism leads by a more direct route. Into the arguments against its rude hustling of moral freedom quite off the whole field from the start, I shall not here enter in detail; and this, for two sufficient reasons. In the first place, I have elsewhere ${ }^{1}$ given them a detailed treatment, both inductive and speculative. In the second place, the slender basis upon which the theory stands renders it even more astounding than is the first impression made by its far-reaching consequences. The following summary of conclusions will, therefore, suffice in this connection to answer the assumption that all psychoses, including choices however deliberate, are strictly determined by the antecedent or concomitant brain-states: First, we are almost completely ignorant of the nature and relations of those chemico-physical changes in the brain, into the science of which it is proposed to resolve the connections of the mental states as they appear in eonsciousness. About the influences under which we choose, and about the conscious character of our choices, we do know much which has the appearance at least of the most certain kind of knowledge. In this sphere all adult human beings have seemingly trustworthy information; and upon its trustworthiness they plan and conduct and estimate their own lives and the lives of others. But no expert in cerebral physiology, knows anything worth calling by the name of "science" about the real nature of that chain of

1 Comp. Elements of Physiological Psychology, pp. 585-688; Philosophy of Mind, pp. 113-148 and 208-396. 
occurrences in the brain-states which is assumed to determine, without the interrention of a soul, the sequences of the conscious states.

And second: If we had all possible, eren all conceivable knowledge of the laws of the nature and established connections of the brain-states, this knowledge could never explain the actirities of the conscious Self, especially its self-determining choices. For, not simply is it true that physicochemical changes in the brain can never be conceived of as the sufficient explanation for changes in consciousness; it is also even more obviously true that certain factors and aspects of the more elaborate and developed mental and moral processes have no conceivable physical correlate - not to say, physical explanation. What can be meant, for example, by ascribing the feeling of obligation, or the estimate of the ideal value of a beautiful picture or of a noble action, or the feelings of potency and imputability which belong to moral frecdom, to some particular kinds of chemico-physical changes in the brain-states as their sole and sufficient explanation?

And, third: Abundant facts of experience furnish incontestable proof that, if we are to interpret the phenomena of the influence of the body over the mind as significant of a scrics of real transactions we are equally compelled to interpret the phenomena of the influence of the mind over the body as haring the same real significance. Feelings, ideas, and especially choices, considered as conscious processes, have quite as much claim to afford a satisfactory explanation of changes in the brain-states, as the latter hare to be made realiter accountable for the character and sequences of the feelings, ideas, and choices. If the theory which directs all the energy in one direction, after ascribing it all to a psychical source, comes into conflict with the physical hypothesis of the conservation and correlation of energy; so does the theory which finds only a physical source of energy, while scouting at the notion that con- 
scious states can be "causes" of nervous changes in any verifiable meaning of the words. The current resort to the absolutely unintelligible theory of psycho-physical parallelism helps out the one theory no more than the other. We know as much which may warrant the claim that the conscious Self is a source of control for the body as we know in favor of the proposition that the body accounts for changes in the conscious Self.

Furthermore, fourth: All human science of every sort, considered purely as psychological fact, is only man's way of explaining the connections of his own conscious states. Let cerebral physiology succeed in the most brilliant discoveries, the saying of the old woman in one of Fritz Reuter's novels will still remain true: "There is nothing so near to one as one's self." What is known immediately and indubitably is only this - the psychoses as influencing each other, and the relations in which they all seem to stand to what we call the Subject of them all, the conscious Ego. What men actually experience is the dependence of choices on perceptions, feelings, and ideas, and the dependence of feelings, ideas, and perceptions on choices. Only by remote, intricate, and often doubtful inferences do they reach any conclusions at all as to the connections between so-called brain-states, or between them and the sequences of human consciousness. Such inferences can never establish for themselves the scientific right to contradict and annul those more immediate facts of experience in order to explain which they themselves have been introduced as hypotheses.

Finally, fifth: When this second form of Determinism is carried to its extreme logical result, it, too, presents us with a picture of all Reality, including human life and human society, which undermines the entire structure of morality. The individual man becomes, absolutely and with no possibility of any qualification, a phenomenon of the blind and soulless play of physical forces. Human society and all the develop- 
ment of man in history must be explicable in the same way. Human history is the puppet slow of physical Nature; it is in no sense, at any time, the structure of man's building. The phrases which ethics so glibly employs when it discourses of " moral forces," " moral ideals," " moral standards," have no real applicability to the facts, when man has been reduced to the strictly determined series of conscious puffs, phenomenal of the partially known changes that, for unknown reasons, go on in that universal boiler and steam-chest we call the World of Reality. Surely man's condition is worse than that of the abandoned product of an illegitimate and unethical mixture:

"In die Welt hinausgestossen

Steht der Mensch verlassen da."

The truth, I think, is simply this : all Determinism, strictly constructed and logically carried to its issue, ends in Materialism. Why should its advocate be afraid or ashamed of the issue he has himself forced? Surely, the last thing to go in any system or practice of morals should be that honest manliness which stands upright in the positions which have voluntarily and deliberately been assumed. And to fcar being called a name which one merits is as cowardly as to call another an opprobrious name which is not appropriate or deserved. But the return to a study of the facts of conscious experience enables the student of moral consciousness promptly to throw off this nightmare of a materialistic Determinism.

I will now notice briefly the attempt to establish Determinisin inductively upon a basis of statistics. Here the argument is that the individual cannot have moral freedom, because there are facts to show that the multitudes of individuals frequently act alike under like influences. To every such argument may be opposed the undoubted facts that the validity of the statistics themselves is usually exceedingly question- 
able; that the interpretation of the statistics is generally doubtful ; and that other classes of statistics very severely test, if they do not wholly controvert, this form of the deterministic hypothesis. For example, if the number of illegitimate birtls in some district of Southern Europe suddenly suffers a great diminution, in close connection with the revival of wellpaid employment for the female operatives in its silk-mills, this does not prove that Maria or Angelica has been compelled or deternined to become virtuous thereby, or eren that she and her companions hare really become more virtuous. Probably, it simply shows that a larger number of couples are now financially able to comply with the legal restrictions which the State has unfortunately imposed upon marriage. But the virtue or the rice of sexual intercourse is not wholly, or even chiefly, determined by statute. Maria and Angelica, in that eternal conflict in which we are all placed betreen our moral ideals and our lower impulses and inferior interests, may choose according to their best light to be either good or bad, quite irrespective of the conditions of the silk market. Doubtless for them, as for us all, the external conditions and internal excitements, but above all the habitual past choices will make goodness, or badness, much easier or much harder in any particular case. But for either of these two souls, as for millions of others, there may come a moment in prayer, or reflection, or memory, when the worth of the moral ideal will be so revealed as to let it assert its more legitimate influence. Then the conscious self-determining Sclf will have its best chance to assert and to establish its riglit to a higher and more effective form of moral frecdom. For sudden reforms and complete religious conversions are, after all, not such rare and isolated phenomena in human society. And they constitute hard facts for any theory of Determinism that wishes to plant itself upon purely empirical grounds.

Let it be admitted, however, that good deeds and bad decds, virtues and crimes, tend to go in groups. This is only to 
reinforce a truth necessary to be taken account of by every attempt at a philosophy of conduct. Certainly men are influenced in their behavior as individuals by the social conditions under which they exist and develop. The obriously criminal population is always largely made up of a class that on account of discouraging environment, relatively great susceptibility to impulsire considerations, and a low degree of intelligence, has, on the average, a less degree of freedom. Moral freedom is always, indeed, a matter of degrees. The theory of morals, as well as the practice of enlightened men, takes all this into account. ${ }^{1}$ We expect that the final judgment and the ideally perfect judge will not fail to authenticate this truth. But especially in the most enlightened and civilized nations there are not a few who have fallen down from the ligher into the lower stratum; and some come up from the lower, in spite of all their burdens and temptations, into strata that lie far above. But falls, and reforms, and risings, in the ethical scale are significant of the same portentous fact; the character and destiny of the individual are not all strictly determined irrespective of the self-determination of the conscious, rational, and ethically-constituted Self.

We have, then, a most lamentably weak non-sequitur in the argument which, from a certain observed regularity in the external actions of a multitude of individuals, concludes that all the conduct of every individual in that multitude is strictly dependent upon influences which are, as it were, external to his own choice. That man is in some sort the creature of circumstances, and that many men are largely so - who would venture to deny this in full view of his experience with men? But that man is by deeds of will also in some sort the creator of his own character, and the moulder of society and of nature; and that many men are so in a somewhat large

1 Compare the pictures of some of these lower classes of society - much more sensible and true to the facts than the work of Lombroso and his followers - given by Josiah Flynt in his "Tramping with Tramps," and "The World of Graft." 
and impressive way - who would venture to refuse to admit this complementary truth?

During the entire previous discussion it can scarcely have escaped observation that the effort of a strict Determinism to keep close to the facts of experience is nerer quite successful. The Determinist cannot be content to argue that his case is true, - in fact he always covertly assumes it is true in fact, because he thinks it must be true. But this must be is itself the result of a misconception. It is due to a partial or complete failure to understand the conception of Causation. The philosophy of conduct, therefore, must undertake the criticism of this conception. Of this task also I shall now only briefly summarize what I have already said with great detail in several other connections. ${ }^{1}$

First of all, it is essential to bear in mind how exceedingly complicated and shifty is the nature of the conception of Causation, with its different forms of statement and of application. The very conception has quite generally of late been either hypostasized and made a god, or banished as a ghost from the realm of scientifically authorized abstractions. But it has neither the unity of intermal structure necessary for such metaphysical mythology, nor can it be got rid of by ignoring or ridiculing it. In any workable form Causation obviously involves the categories of Force, Relation in Time and Space, Law and Final Purpose; also a certain mysterious residuum which all our efforts cannot resolve, and which we are compelled to recognize in a general way as belonging to the inexplicable original Nature of things and of souls.

Now the narrow range of vision and the shallow insight of the current scientific Determinism consists in its attempt to handle and explain all experience as though it came completely under one type of the complex conception of causation, - namely, that of a Physical Mechanism. As we have just

1 Comp. Philosophy of Mind, chap. iii, vi, ix, x; Philosophy of Knowledge, chap. $x$, xviii ; A Theory of Reality, chap. iii, vi, vii, $x$, xiii. 
seen, the ultimate logieal consequence of the deterministic hypothesis in morals is this: The World, of selves, as well as of things, is a piece of mechanism in which ideas of value, as well as all the finer sentiments of art, morals, and religion, and the choices which have regard to such ideas and sentiments play no really effective part.

The psychological origin of the conception of causation warns us against any strictly meelianical way of interpreting our experience. This conception itself cannot be accounted for, or its real meaning understood and explained, without admitting the reality of that conscious and rational selfactivity which culminates in ethical, free choice. ${ }^{1}$ The processes in which the formation of this conception takes place follow somewhat the following order: I know myself to be active; I know myself to be restricted, inhibited in $\mathrm{my}$ actirity. In other words, my deed of will is generally, if not universally accompanied or followed by a feeling of effort.

* Hence arise the ideas of those mutually related and dependent forces with which we invest external things. But this experience of energy inlibited is, of course, connected with the more or less careful and intelligent obserration of the sequent changes in the relations of myself to things, and of things to one another. For I am interested in knowing how to carry out my will in effecting changes in things; and through the more immediately dependent changes which I effect, I find that more remote changes in other things can be brought about. Moreover, I soon develop an intellectual curiosity, which may become a burning passion and a practical self-derotion in the effort to discover how all the different realities stand related to each other in respect of their interdependent changes. How one may secure the ends one desires by using one's force in its dependent relations to other soulless or

1 The reader will please bear in mind that the dogmatic form in which this statement is here given would not secm justifiable to the anthor without the references already made to the discussions which have established it as their conclusion. 
soulful forces is of the utmost practical moment. But one's more purely scientific interest is not limited in this way.

So, then, from these beginnings within the Self and its most immediate environment, and with its own most pressing needs in view, the conception of eausation is objectified, and goes abroad to conquer the whole of Reality. For the most part, men understand the simpler sufficient reasons of their own actions, - the ideas to which they react willingly, and the passire conditions by means of which other men and the world of things limit their wills. Some of every man's environment - the other selves - is like his own self, influenced by intelligible motires, yet rather uncertain and freaky; but the things that are not selres, and that appear to him to have no conscious ideas, feelings, and choices, are relatively stable, uniform, and dependable in their modes of behavior.

And now, abstracting from all the social and ethical sides of human experience, it is possible to regard merely the way that things behave, when either beyond all recognizable infuence from the beharior of men, or when left to themselves to follow their own natural ways of behavior. In this manner is formed the scientific picture of a Mechanism, in whicl erery part is definitively limited, and strictly determined, not only as to the general course of its behavior, but also as to every minutest form of its movement, every slightest change in its own coustitution, or in its relations to the great Whole. With what confidence and joy, then, does the mind that is determined to be thoroughgoing in its scientific conclusions return, with this conception of a purely mechanical causation, to force it upon those very experiences of rational and purposeful choice, in which the beginnings of the conception are themselves to be found. Haring interpreted physical phenomena after the analogy of personal experience, with the most truly personal of the characteristies left out, science assunes completely and correctly to reinterpret personal experience after the analogy of a purely physical 
mechanism. Surely here is a fine case of matricide! The child, having learned bad manners in foreign lands, has come home to lay violent hands on his own mother.

But the truth remains forever unshaken that all interpretation of experience is an affair of the human spirit, and that physical seience itself is the construct of a rational and free will. The World of things is itself a quasi-personal affair. As such it gives to the observer no reasonable ground for denying to those beings whose experience is of a fuller and completer personal life, the more essential characteristies of personality which they know themselves to have. And among these moral freedom is not the least important, or the least clearly and forcefully evinced.

Repeated reference has been made, however, to a certain residuum of mystery, a trace or a large measure of the unknown, and the unknowable, to which every application of the principle of sufficient reason makes a tacit confession. Here is a consideration, to take account of which is very important for the philosophy of conduct. Let us begin with the case as the physical sciences deal with this principle. Suppose, for example, that I am searching for the cause of some chemical combination, and $I$ am told that it is to be explained in the following way: the elements, $A, B, C, D$, under definite conditions, and, in definite proportions, $N, \boldsymbol{M}$, have united according to the formula $X Y$. But now I will inquire: Why have these particular elements, $A$, etc., chosen to act and react in this particular manner, while - as we know - under similar conditions, other elements, such as $E$, $F, G$, and $H$, would behave in a markedly different way? The only answer to the question Why? in such a case must be found in the mysterious nature of $A$, etc., and of $E$, etc. But this is to say, that in all our explanations by means of the principle of sufficient reason, we leare certain factors unexplained. Nor is this true simply of those particular limitations of knowledge which further investigation may remore. It is truc 
by virtue of the very nature of all human knowledge as dependent upon the principle of sufficient reason, with its assumption of real causes, and real effects.

Suppose, next, that I am asking of biological science to explain, as fully as it can, some one of the simplest forms of life, - an amøba, for example. At present, we can only tell how, according to its own nature, this particular living form originates, develops, behaves, propagates its own kind, and ceases to exist. Suppose, however, that at some time the chemistry of life shall be so far advanced as to be able to ascribe all the changes in the amœba, and its own constitution, and even all the constitution and the development of every living germ, to the potencies of the atoms, still the truth for which I am contending will remain essentially unchanged. Indeed, this truth will be made the more astonishingly obvious. The increased knowledge of what the atoms can do, will only render the final explanation of their original nature - the potentiality in which all actuality resides - the more profoundly mysterious, the more hopelessly unknowable.

There is little reason, then, for surprise that the nature of man - itself, in its depths, unknowable - must always be made to account for so much in explanation of the important part he plays in the drama of his own historical development. We find abundant reason for believing that he is not always determined, either from without, or as a picce of psychical mechanism, after the analogy of a physical machine. We find abundant reason for affirming that he is also self-determining - by nature potentially so, and in fact often becoming actually so. $\Lambda$ nd if the answer to such inquiries as, How can he have this mixed constitution which thus differences him from all physical existences, and from the lower animals? or, Whence comes this gift of moral freedom ? must remain unanswered, still the student of the philosophy of conduct need not be ashamed; and he cannot be accused 
of any peculiar isolation in his ignorance. In the name of philosophy, he may even make bold to answer: Such is apparently the decision of that Absolute Will and Reason in whose Being man, as well as all other existences, has his life and being. In the name of religion he may say: God knows how it can be, and God's will is the ultimate sufficient reason that it should be so.

Finally, as the student of the philosophy of conduct makes over to Metaphysies and to the Philosophy of Religion the right and the duty to say whatever may remain to be said on the limits of human knowledge, and the possibility of a speculative solution of this mystery of moral freedom, he need feel no alarn at the cry that his view of human nature is injurious to the integrity of the physical or psycho-physieal mechanism. The stars in their courses hare greatly influenced the development of man. The greater chains of physical causation are too rigid for finite beings to bend aside to any appreciable extent. But that man's will does largely change the face of external nature is simply a fact of daily experience. The physical mechanism in the midst of which he derelops is more durable than steel where its own essential integrity needs to be defended; but it is as responsive in many particulars to human feelings, ideas, and choices, as is the most delicately constructed violin in the hands of its master. And to bring forward as an argument for Determinism the possible overthrow or the essential marring of the World-system, if moral freedom as inrolving selfdetermination in any virtual way be admitted, is to propose a speculative bugbear which any one, plain man or philosopher, may regard with a smile or pass by wholly unnoticed.

1 The way in which the criticism of the conceptions of Causation and of Freedom leads us back to the idea of that Absolnte whom religion esteems a Personal God has been finely shown by the Russian philosopher, Professor N. Ia. Grot, in a treatise called "On Freedom of Will," a written translation of which is in my possession. 


\title{
CHAPTER IX
}

\author{
THE MORAL SELF
}

WE are now prepared to see how extended and profound a significance psychological ethics imparts to the words which have been chosen for the heading of this chapter. They are synonymous with the entire nature of man when we regard him as equipped for conduct and for the derelopment of character. In a word, the so-called "Moral Agent," is the Self, so constituted and actually in action as to form by voluntary relations with other selves something quite different from a collection of interacting physical forces, or a herd of animals, or a mere multitude of human beings. As moral, the Self is a member of society; and society is the product of the correlated conduct of a multitude of moral selves. With a somewhat different but no less profound and important meaning than that which Aristotle gave to the saying, we may declare that Ethics thus becomes " a sort of political inquiry."

From the full and correct picture of man's ethical endowment certain truths of a general import follow which need at least a brief mention before proceeding to the next main branch of our inquiry. One of these truths concerns the too narrow use of the word " conscience,"- a use which has given rise to much not wholly fruitful (though by no means entirely unprofitable) discussion, and to no little practical embarrassment in the attempt to solve correctly the daily problems of right conduct. By all means "follow your conscience and keep it pure and good," has been the instruction and exhortation of moralists in all ages and places of human development. 
What, however, does it mean "to follow one's conscience;"what precisely, that has a definitive application to the conduct of life, as well as to the attempt theoretically to assign correct values to the different forms of conduct? Shall the appeal be made to unreasoned and unreasoning feeling, no matter how much crowned with sanctity on account of its associations with early memories, religious ideas, or its seemingly original and unquestioned spontaneity? In its cruder but not least intense and effective forms this may amount to a "feeling in the bones," or other bodily members, the heart, the veins, etc., as the language of men so significantly suggests. Or is it, on the other hand, consonant with the moral constitution, and wholly safe, to instruct men to disregard those sentiments of obligation and approbation which are, in respect of their attachment to certain definite forms of conduct, undoubtedly the results of education and social environment, and to leave each to " reason out for himself," on the basis of calculated consequences or in accordance with some abstract ethical theory (hedonism, e. g.), the forms of behavior which he will adopt for his own? Not infrequently, in practice, such instruction results in the formation of the disagreeable and self-conceited "crank," if not of the disorderly and dangerous criminal. Will the kindly and humane impulses, as well as all the tendencies to a prompt resistance of evil and the indignant infliction of penalty for unrighteousness, be improved by submitting themselves to the control of intelligent and deliberate choice. Or shall indiscriminate kindness and so-called charity, because they eroke the feeling of obligation and obtain the reward of approbation, while still commending themselves to the ethical judgment of the majority of mankind, be excused from deferring to the most rational and illumined investigation? Who can believe that the appeal to conscience as an ultimate authority can justify an affirmative answer to either of the last two inquiries?

The truth as it has been made apparent by our previous 
discussion, seems to be that conscience, as an authoritative guide to conduct, is synonymous with the total moral consciousness; and that moreover, this moral consciousness practically involves the entire distinctively human nature of man. Even thus understood, conscience provides no infallibility of authority. In his ethical, as well as in his more purely sentient and cognitive life and devclopment, man has an outfit of capabilities which quitc surpasses that of any of the lower animals. He is a really ethical Self - in feeling, intellect, and will ; and they are not even inchoate and undeveloped ethical selves; although they are, as man knows them, self-like in all their characteristics. Thus man is capable of self-conduct, of self-development. But neither in the form of " instinctive feeling," or of "innate idea," or of "rational principle," or of spontaneous and impulsive or delibcrate and intelligent "good will," has he an authoritative, in the meaning of an infallible, guide. The roice that is within him is often fecble and uncertain; it is always possible to dispute its authority, to gainsay its right, and to reject its rule. Just in this does man's imperfection and weakness, as well as his immorality and sinfulness consist. Nevertheless, this voice is the most precious possession he has, the most significant value of his whole existence. It is, indeed, entitled to be called "the voice of God." This voice calls man in every voluntary thought and feeling, and in every impulsive deed of will as well as every intelligent and deliberate choice, to strive after the realization of the ideal Self. Every form or particular exhibition of morally good conduct is - in however special and narrow a way - an item in this realization. The source of the authority of moral consciousness lies in the response of the actual Self to its own Ileal of self-hood. This is that anthority of conscience which thus reveals to religion a relation, that is dependent upon the total reaction of man's moral consciousness, between the human Self and God.

We note then how comprehensive is the study of conscious- 
ness as the source of ethical obligation, ethical relations and ethical development. The conception of the Moral Self includes all that descriptive and pragmatic psychology can discover and reveal respecting human nature, as well as all the sources for the most far-reaching and lofty conclusions of speculative philosophy. Moral self-hood is the all-inclusive nature of man. That all those activities of body and soul, whose stimuli and laws psycho-physics and psychology delight to make plain, are concerned in man's conduct is too obrious to need proof. No so-called scientific picture of his nature is completely drawn nor is the final significance of his constitution understood, until he is seen to be consciously, and in the exercise of his birthright of moral freedom adjusting himself to the morally right forms of actual relations to his fellow-men. Psychology, although it is primarily a study of the individnal, plainly shows that he is constituted for society; in social, that is, cthical relations, his entire being finds its supreme exercise, its most nearly complete satisfaction. The Self as fitted for conduct, and as actively engaged in the moral life, is the largest kind of a Self with which psychological science can deal. And all the investigations of psychology - "new" or "old" - have a certain unsatisfactory pettiness, if they do not somehow, either directly or indirectly, contribute to our knowledge of man considered as inrested with the power to constitute and control limself in manifold social relations with his fellowmen. In spite of the incessant claims of psychological science to consideration for its own science' sake, we cannot aroid asking ourselves: "What matters it, how many sigmas it takes to react to this or that form of stimulus; or, how the bonds of associated ideas are framed and broken; or, how intellect develops ont of what appears to be, at first, a merely mechanical sequence of mental images; unless, indeed, all our investigation tends to give us more insight into the nature of that life, three-fourths, or seren-cighths of which 
is conduct having reference to social interests and to the realization of the ideals of the race?" The psychology of the Moral Self includes all psychology, because the right and wrong of conduct compasses human life so inclusively, and because the values here concerned are so extensively present and so qualitatively supreme.

In this connection the significance of recent studies of the individual as psychically shaped by his social environment becomes apparent. Here two equally mistaken and dangerous extremes are to be avoided. They are alike unscientific in their disregard of each other's interests, however pertinent and helpful may be the positive suggestions of truth to which they succeed in calling the attention of the age. Properly speaking, there is no such consciousness as "social consciousness" and no such existence as a social individual. But if by the phrase we mean the individual man as influenced by his social environment, then we may say: The Moral Self encompasses the Social Self; and it is only by a clear conception of what is included in the former term that one can correctly estimate and discreetly judge the significance of what is often so vaguely connotated by the latter term. Of the two extreme views upon the subject one tends to sink the personality of the individual man in the indiscriminate mass of his social surroundings; the other tends to press so far the independence of the individual as to depreciate or neglect the influence of these surroundings. It is impossible for a true person to exist or to develop outside of a social environment. Against both these extremes the preceding analysis and discussion of man's moral self-hood has both warned us and provided us with a sufficient safeguard.

In the lower stages of ethical development the individual is, indeed, to a large extent the product of his social environment. He feels himself obligated to do that which this environment, by silent custom, or by spoken and written precept, or by more solemn priestly and legal decree, has 
decided for him to be the right thing to do. He is a dependent piece of the ethico-social mechanism. In all times and places very largely, and in some times and places almost universally (as, for example, even now in India), this " right thing" to do which the social environment enforces is, for the multitudes, not at all what flesh desires or heart eraves. Only for the favored few are the pleasant and the morally good things of life coincident in the view of the ethical authorities; among the millions the Social Self is either the unhappy or the morally bad Self, when viewed from the standpoint of the prevalent ethies. But as the truly Moral Self undergoes development, - or rather, I might almost be permitted to say, comes into being, - it wins more of that independence of judgment and of action which is essential to any considerable approach toward a realization of the moral ideal. Thus the conduct of the individual more and more freely takes up into, and incorporates with itself that rational regard for social considerations which stands at an extreme both from the blindly affective and unthinking acceptance of the social standards of conduct and also from the intelligent and deliberate but immoral departure from those standards.

A social being, in some sort, man might be, if he had no other equipment for the life of the community than a superior amount of those characteristies which belong to the lower animals, - if, in a word, he were not a Moral Self. But although in such a ease he might be, in some conceivable meaning of the word, "social," he could not be a social self. It is man's moral equipment, the essential potentialities of his individual personality, which makes him capable of forming a true human society. These potentialities, society, whether considered as an environment or as a continuous self-propagating force, can in some sort derelop, but can never originate or impart. The philosophy of religion has its theory as to whence come the germs of that moral self-hood which includes the true social self-hood. Neither ethnology nor psychology 
can inform us on this point. Or, rather, properly speaking, there is no such reality for these sciences as a social Self; the term is but a figure of speech, fitly enough designed, it may be, to remind one that the individual man could never be, or develop into a true personality were it not for the constant and most potent influence of other personal beings. When, however, ethics speaks intelligently of the Moral Self, it sums up in this term all that is true of the other term, and much more. And, moreover, ethics is using no figure of speech to endanger the understanding and the application of its terms, as do psychology and ethnology when they speak of " social selves," "social organisms," etc. For the Moral Self of ethics is the concrete reality of the individual man, regarded as equipped for the life of conduct and for the development of character, in certain definite relations with other selves equipped in substantially like manner. Were he not moral, man could not be social in the highest meaning of the word; and the very idea of morality as applied to man implies his existence, aetivity, and derelopment in the midst of society. I repeat: Moral selves constitute a true society; but social influences can never, of themselves, constitute or explain the existence or the total development of moral selves.

The conception of the Moral Self eontains within it the germinal thoughts and suggestions for a philosophy of the Ideal as well as of that to which science is so ready, sometimes quite too exclusively, to attribute the title of Reality: in this conception, therefore, must be found the data for reconciling all that belongs to man's scientifie tendencies, standards, and pursuits, and also his judgments of that which has value, his higher sentiments, the longings and obligations which bind him to an ideal Good. How to effect this reconciliation is, indeed, the burning question of this as of every other age; but it is the imperative and most difficult problem of this age beyond all other ages. No reconciliation 
can be accepted for longer than a brief breathing-spell in the hot chase after the final and satisfying truth, which leaves man divided into two incommunicable and unrelated parts, two spheres of interest and experience. Science, on the one hand, and ethics, art, and religion, on the other hand, cannot be allotted separate fields in the domain of human nature. No form of the dichotomy of man's being which has ever been devised, or that can ever possibly be devised, will long remain satisfactory. We camnot make the feeling and imagination responsible for faiths which run contrary to scientific conclusions that are forced upon us by the unfeeling and unimaginative intellect. We cannot believe in Ideals, whether of conduct, or of beauty or of worship, which contravene the known principles of Reality; neither can we know what those principles of Reality are, in their highest potency and completest significance, without crediting for their discovery and their explication, the authority of ethical, artistic, and religious Ideals. The Ideal and the Real must be a Living Unity.

The fundamental reasons for dissatisfaction with the demand of religion and etlics that we should believe and practise that which science condemns or doubts are not to be found in the undoubted weakness of the arguments of either of the two contending parties. The moral reformer, the artist, or the inspired seer, and the man of scientific claims and culture, are, as a rule, about equally partisan, equally insufficient as to information and illogical in reasoning, when they fall out with each other over the ultimate problems of existence and of luuman life. The fundamental reasons why they can neither of them be accorded a full satisfaction are deep-set and incradicable in the nature of them both. These reasons lie in the same unity of human Self-hood which is common to them both. You cannot array man against himself. A schismatic psychology is the original heresy, the root of all other schisms. Reason and Science so-called must listen appreciatingly to the feeling and judgment in their loving estimate 
of that which has value; and ethical, æsthetical, and religious ideas and sentiments must make themselves rational and ac. cordant with the truths of science. The possibility and the necessity for such a reconciling process are discoverable in the very nature of cognition and of the cognitive mind. ${ }^{1}$

It is, howerer, the conception of man's moral being which shows how a reconciliation may be effected between the claims of science and the claims of ethical, æsthetical, and religious sentiment and idealization. For all science itself is the pursuit and the product of the Moral Self. When we comprehend the entire extent of the ethical sphere and the full content of ethical principles and ethical ideals, scientific pursuits themselves become matters of conduct; and the scientific Truth itself attains to the condition where it has value in its relations to the life of conduct. The patience, candor, exactness of observation and carefulness of testing and attention to logical completeness, upon which scientific method so much insists, are an ethical procedure. These are the peculiar virtues of the man of science, quoad scientific. If his virtues in society, or on Sunday, are quite different from these, or eren if the more conspicuously social and religious virtues are lacking, his work-a-day and laboratory cxcellences are of a truly moral sort. The moral self-hood must go into any man's science or it is not his science at all.

Why, from the merely scientific point of view, should the human mind attach any idea of worth to truth or to its discovery? The animals, which are only partial selves and not really moral selves at all, give not - so far as I am awarethe slightest distinguishable token of regarding the acquirement of knowledge as a matter of ideal significance. They never exclaim : "I read thy thoughts after thee, O God;" nor do they strut about with the appearance of a conscious pride of possessing an ideal good as they do show pride in the suc-

1 This thought has been antieipated and wrought out in its preliminary aspeets in my work on the "Philosophy of Knowledge." 
cessful strife for sensuous goods. It is only a moral nature that feels the obligation, by a virtuous and painstaking self-denial, to attain the facts in each case; that appreciates in a quasiethical way the success of all scientific efforts; and that regards the Truth as worthy of being thus striven after, beeause - somehow or other - belonging to the domain of the " in-itself-Good."

Therefore, the more highly science estimates itself for its own self's sake, the more does it testify to the ralue of human conduct in the pursuit of an ideal Good. And inasmuch as the man who enters upon or pursues a so-called scientific career with an obvious regard only for his own selfish interests and an obrious disregard of the interests of "the canse of science," or "the public welfare," or " society at large," is blamed if not execrated for his badness morally, it is evident that the ideal interests of ethics are, in howerer indireet and concealed fashion, nerertheless supreme. One cannot, indeed, maintain that every failure to attain and state the truth of fact or of principle is blameworthy ; or that every manner and form of telling the truth is justifiable; but the highly significant fact is this: It is the ethical nature of man which makes him appreciate the ralue of the end at which science aims, as well as the morally worthy features of the mind's activity in pursuit of this end. Only the Moral Self is fitted to regard truth, and the effort to know truth, as an essential part of the ideal Good. Thus science becomes merged in the perfection of that supreme moral Ideal which is a society of moral selves. In the language of religion: The Kingdom of 'Truth becomes identical - reconciled - with the Kingdom of Hearen, or the ideal social community of morally perfect selres. This distinctly ethical way of regarding man's relation to all conceivable truth, which physical science appreciates only as the proper attitude of its students toward Nature, is, of course, only a bint toward the most profound and satisfying reconciliation of the ideas and judgments of worth with the spirit and achieve- 
ments of the scientific mind. But it is, at least, a hint in the right direction. The later speculative endeavors of ethics are surely bound to return again to the suggestion, and to carry the suggestion out to its rational conclusion in a declaration of peace between the domain of the Real in fact and the Ideals that have value for the moral life.

In all the foregoing analyses I have coupled ethics with æsthetics and religion as belonging, with them, to the same sphere of the Ideal. I have also spoken as though all the inconsistencies and seeming contradictions which exist, in fact and in the history of the race, between the ideals of conduct and the ideals of art and religion must find their reconcilement in the conception of the perfect Moral Self. With certain qualifications this is true. The interests and the idcals of art are by no meaus always obviously identical - not to say, reconcilable - with the interests of morality and the ideals of conduct. Neither can we in an offhand way force into coincidence the apparently diverging lines of ethical and of religious opinions, practices, and development. But, for all this, the conception of the Moral Self remains the most widely inclusive which the mind can form of human nature; and when expanded to its widest legitimate limits, this conception includes the suggestions necessary for reconciling all the conflicts amongst these three classes of ideals and of ideal values. Only this qualification must be added: - so far as the formation and the realization of the Ideal depends upon human conduct under any conceivable social relations.

The analysis of the moral consciousness has already shown us how many elements are common to it with that form of consciousness with which men greet the Beautiful, as well as with those closely allied forms of thought and feeling which lead to the life of religious worship and of obedience to God. Indeed, the artistic nature and the ethical nature of man have so many roots in common that it is difficult to separate them without stopping the flow of vital sap into both the life 
of conduct and the life of beauty. And it is only necessary to spread the mantle of one great Idea over the conception of ethics in order to give a religious signification and an "otherworldly" radiance to the whole subject. The somewhat uncouth compound "ethico-religious" is indicative of a profundity of experience as great as that in which such phrases as the "Beauty of Holiness," and eine schöne Seele, have their origin. In trying also to comprehend what, in essence, is common to all the kinds of the "in-itself-Good," and yet to keep somehow distinct the good of beauty, the morally good, and the All-Good, we found ourselves encompassed with the same Unity in variety. The metaphysies which grows out of such experiences belongs either to the more speculative part of ethics, or to æsthetics, or, finally, to the philosophy of religion. But the student of ethics must not fail at this point to feel the full weight of the impression that man is fitted and obligated to seek the Goods of art, and of religion; that the attainment of these ideal ends is, at least in a limited way, dependent upon his own conduct, both that of the individual and that of the race; and that in the general movement of human soeiety, what is achieved for the better appreciation and finer representation of the beautiful in nature and in human life as well as all the growing knowledge of God and the improved adjustment of human relations to Him, and, for His sake, of men to one another, is an integral part of the ethical development of the race. All this lies within the sphere of human conduct. And man is capable of it, responsible for it, successful or unsuccessful in it, only because he is a Moral Self.

Those great principles, however, which are true for the other main branches of philosophy are also true for the philosophy of conduct. These principles, as I have elsewhere ${ }^{1}$ said, group themselves about "two comprehensice conceptions which seem to us to be shaping the thought and the conduct of the present age. They are, of course, not new,

1 A Theory of Reality, p. 31. 
either in their total complexion or in any of their more important factors, otherwise they could not be so comprehensive and influential as they are. But they are receiving new and enlarged meanings; they are made to serve more extended and illumining uses. These are the conception of Evolution, of the principle of becoming, and the conception of Self-hood, especially as having its roots in, and as reaching out into, social connections." It is enlarged and truer notions of Personality and of Development which are sought by the reflective thinking of the age.

When, then, such fulness of significance and range of influence are claimed for the conception of the Moral Self, it must not be imagined that any of the legitimate rights of the other conception, the conception of Evolution, are invaded or denied. The history of morals, and the current opinions and practices of the time, as well as all the most profound and comprehensive of ethical principles, caunot be understood without giving due influence to both these conceptions. The Moral Self, in a process of Development toward the Social Ideal, - this complex of conceptions contains the whole domain of investigation for the student of ethics. What is the essential nature of the subject of conduct, the ethical being of man? It is moral self-hood; it has already been described. But for erery individual man, and for the whole race of men, conduct is some sort of a career; it is subject to the principle of continuity; it is a matter of history, and of the growth from beginnings toward ends, in the ongoing of time; it is something which can neither be described, nor even be conceived of, except as the individual is regarded in his physical, and especially in his social environment. The principle of Evolution applies, then, in ethics; but in no superficial or merely external way. The Moral Self is a life growth, and so subject - although on its own special terms, as it were - to a continuous development.

Here, howerer, must the word of caution be uttered which 
is confirmed by an analysis of the individual man, as well as by a study of the history of the individual and, so far as possible, of the race. The equipment which makes man capable of conduct at all, and which furnishes his first incitement to strive after the ethical idcal, as well as the feclings and resulting judgments that evaluate conduct, can never itself be accounted for as the mechanical resultant of an erolutionary process. The conception of endowment is the only one which will meet the facts in the case. The psychological study of the moral nature is competent to decide this question for the individual man of to-day; and such study does decide it. Ethnological study is not competent to give us the complete and trustworthy picture of the moral nature of the so-called "primitive man." It will probably, in spite of many interesting details which await observation respecting the customs and ethical opinions of rude and barbarous tribes, never be in a position to guarantee such a picture. But, as Wundt has well said: The one incontestable fact in this field of uncertainty and conjecture is that "however far back we push historical inquiry, and however low the stage of civilization that we choose for observation, mankind appears always and everywhere as subject to the same good and evil impulses which constitute to-day the sources of its happiness and misery." 1 Moreover, we may claim with equal confidence that man always and everywhere appears as giving a prefer. ence, for their own inherent value, to some kinds of conduct rather than to others; as feeling the bond of obligation which ties him to his fellows with common rights and reciprocal duties; and as appreciating those who voluntarily recognize the sacredness of this bond for their superior worth when compared with those who, in the pursuit of their own pleasure, or in the avoidance of pains for themselves, prove recreant to this bond. And if biology, invading the proper field of ethnology, and of history, and making bold to contradict all 
the conclusions of psychological ethics, chooses to please itself with the speculative conception of an ancestral, nonmoral man, the student of ethics must, on the one hand, confess his total ignorance of the existence of any such being, and, on the other hand, must insist upon the obvious truth that such a being is not capable of conduct at all, is not man in any meaning which ethics can attach to the word. In any erent, ethics does not deal with beings that are not already, potentially, moral selves; it finds itself compelled to take as its essential datum, the endowment of moral self-hood, as this endowment has already been described.

But after discorering and comprehending in a measure, the significance of this datum, ethics welcomes, because ethics imperatively needs, the conception of Evolution. This conception, as quite certainly applying both to the individual man, and also to the race, it expands and illustrates on the basis of experience in somewhat the following way. The three factors of feeling, ideation, and volition, enter into all the behavior and the development of man considered as a Moral Self. In the individual, and in the race, three stages of development may be, somewhat vaguely, and yet on the whole satisfactorily, distinguished as characterizing the life of humanity. The first and lowest grade of action which can be called conduct - or, at least, can be said to contain the germ of conduct - combines the idea of an action with a feeling of ought or ought-not, with reference to that action, and an estimate of worth or unworthiness for the person performing the action. In this complex, and often confused state of consciousness, which is always of necessity more or less painful or pleasurable, the moral life of man has its birth. The whole affair is concrete and individual, a hereand-now fact of experience which, as a conscious process, looks neither backward nor forward for its sanctions.

In the second stage of ethical development, that which 
was entirely concrete and individual, has become in some measure generalized and universal; but the same factors characterize this stage, although modified in form of manifestation according to those general laws which control the entire progress of the mental life. And now the improved discriminating consciousness, acting upon an acquired wealth of experience, estimates two or more actions with reference, either to their consequences, or to their seemingly inherent moral characteristics, approves of one, and disapproves of others, chooses and resolves in a way to bring into clearer consciousness the feeling of moral freedom; and thus the man takes the necessary steps in the formation of virtuous or vicious habits. By repeated actions of this sort, virtuous or vicious habits are actually formed, and the characteristically good or bad quality of the Moral Self becomes determined.

As I have already shown, during this second stage of evolution, the social influences are most directly powerful; although they operate with little accompaniment, for the most part, of any attempt to subject these influences themselves to a more purely ethical testing, by comparing them with ideals that appear to have for the enlightened consciousness a higher value than the current judgments and customs of society. Beyond this second stage, most men for the most part do not attempt to go. And for the multitudes of men everywhere, and in all times, this amount of ethical advance is usually satisfactory. Indeed, in the less highly civilized communities, through lack of the stimulus of intellectual and æsthetical as well as of ethical ideals, and also on account of an unfavorable physical and social environment, much progress beyond this stage is usually impossible, or at least extremely difficult. Yet vague glimpses of something more beyond and higher up in that scale of being by which the evolution of human morality is measured, come to the eyes and ears even of the multitude. Especially are such 
glimpses given to them in their religious experiences. The right beliavior toward the gods, is conceived of as something better and nobler than the best of the actions decreed to be right by luman society. If only men were gods, and dwelt with them in their more favorable surroundings, their ideals of conduct might be still loftier by far, and yet without transcending the possibilities of that moral freedom which is so strictly limited as their possession under existing circumstances. Let it, then, at least be an ideal which shall bring some further unification into human lives, so to conduct them as perchance, by and by, to go and live the diviner life in its more favorable environment.

And so, with all souls in some manner, and with some few souls in a most blessed and glorious manner, the last stage in the evolution of the Moral Self is reached. The various ideas of what is always and everywhere right - right here and under such circumstances, and right there and under differing circumstances - are gathered, or rather. (more frequently) gather themselves, into some shape of an Ideal. Under its influence the originally segregated, and somewhat spasmodic feelings of oughtness become unified; they develop into a more constant feeling of obligation, often passionate and yet rational, to strive as far as possible to realize for ourselves and for others this grand conception. Thus it comes about, that the entire practical life of the individual falls progressively under the controlling influence of the distinctively ethical ideas, and ethical emotions. The essential factors and prominent aspects of such a devotion may remain the same amidst a number of forms in which the Ideal assumes more definite outlines, and in spite of a great variety of concrete habits of action under varying conditions and changes in the social environment. This Ideal may be the idea of a so-called "moral law," or the idea of a perfected personality, or the idea of the Divine Will; or it may be some yet more inclusive form of a social constitution. With 
one good man the object which seems worthy of commanding him may be conceived of as an impersonal principle, an unselfish and unswerving obedience to which is recognized as summing up the entire obligation of man. With another, the conception of an infinitely worthy personal Being, in whose personal characteristics they may share who make the attainment of this ideal the object of their life endeavor, may be substituted for the conception of an impersonal principle. With another, the perfectibility, by human efforts, of society seems to furnish the good to strive for which with the strenuous life, is the whole duty of him who would attain the supreme moral Good.

Each of these, and all other forms of defining that Ideal which is the perfect satisfaction and permanent source of inspiration for the derelopment of moral Self-hood, is quite likely to be marred by deficiencies, or to include subordinate elements which wonld better be left out. The possibility of a sound speculative treatment of this Ideal will come before us for discussion later on. But I wish now to call attention to the truth that the very attempt to form any ideal of conduct in so comprehensive and lofty a fashion, and to place the ideal upon a basis of experience, while admitting the necessity for trusting the better sentiments and the artistic imagination, marks a high stage in the moral erolution of mankind.

But the Moral Ideal is itself the subject of Evolution,necessarily so, for it is the mental construct of the Moral Self, and therefore dependent for its very excellence upon the stage in its own moral development which the constructing mind has reached. And moral development here includes all kinds of development; for they all are dependent in a measure upon man's own conduct; and man's conduct is the sphere of morality. In reaching this conclusion, however, I have already gone far in advance of the position where the facts of psychological ethics can be confidently relied upon to 
defend me. We must, then, return to the study of experience from another allied but different point of view, and consider what habits of conduct men have agreed to call "virtuous," what "vicious," and how one may explain, justify, and properly apply such terms as these. 


\section{PART SECOND}

\section{THE VIRTUOUS LIFE}


"And he shall be like a tree planted by the rivers of water, that lringeth forth his fruit in his season; his leaf also shall not wither; and whatsoever he doeth shall prosper." Psald. i. 3. 


\section{CHAPTER X}

\section{CLASSIFICATION OF THE VIRTUES}

ONE of the most suggestive of ethical facts is the pertinacity with which men everywhere cling to a certain twofold division of the kinds of conduct. All conduct is in their judgment to be esteemed either good or bad, either worthy of approbation because it is right, or of disapproval and ill-desert on account of its quality of being wrong. Hence those habits of action which belong to the one class are called virtues; and the virtues have their corresponding opposites, the so-called vices of mankind. This distinction persists everywhere and under all conditions of moral evolution, in spite of all attempts to minimize or explain it away. To its significant truth and exceeding worth in determining all manner of human interests, the language, the customs, and the ethical opinions of men bear an indisputable witness.

It is true that increasing culture usually makes the mind, within certain limits, less prompt and self-confident in pronouncing upon the genuine qualities of particular cases of conduct. Quite too frequently it is ignorance or self-conceit which appropriates the title of "virtue" to one's own favored forms of behavior, and then assigns the opprobrious term of a vice to all departures from these forms. Especially does this appear to be true when we consider that all human means for testing the real qualities of conduct are so uncertain. In the case of others, particularly, the chances of mistake are threefold. There is, first, the chance which comes from the uncertain character of the sign to be interpreted. For 
example: did the attempted assassin of the Shah of Persia, in Paris, in the summer of 1900, at the precise moment when he pulled the trigger of the pistol still intend to commit murder, and was his failure due solely to a defect in the weapon; or did he at the last instant falter in purpose and thus make an ethically incomplete event of the final result? The expert in weapons can give only a probable answer to such a question, even when he has carefully examined the condition of the pistol and considered the external behavior of the assassin. But there is, second, the chance of mistake which comes from a defective or a prejudiced mind on the part of him who attempts the task of ethical interpretation. How difficult it is for the ordinary Occidental to estimate duly the virtues and the vices of the Orient; for the Anglo-Indian to understand the Hindu, the German the Chinese, and the American the Filipino! There is also, third, the special chance of failure to which even those best fitted to estimate conduct are always liable; and which comes from the quite generally complicated and subtle character of the thing to be estimated. Finally, we are reminded that all individual men, and all tribes and conditions of human kind, have their own somewhat peculiar virtues and vices; moreover that the virtues of one are esteemed the vices of another, and that the standards of virtue and vice are changeable from place to place and from age to age.

Such considerations as the foregoing must undoubtedly be taken into the account by any one who would draw a correct picture of the Virtuous Life as it is displayed and estimated in the moral evolution of the race. But they do not in the least alter the significance or impair the value of this distinction in the kinds of conduct. For the fundamental fact is that men universally make the distinction somehow; and that the distinction is always a twofold distinction. The distinction itself is always, thercfore, a germinal theory of virtuc, - an attempt, to appreciate the implications of which 
is an introduction to a valid opinion, based upon universal experience, as to the true nature of virtue and its opposite. It is, as well, a valuable hint for the application of the theory of virtue to the practice of the virtues.

In order, however, to form inductively a theory of the virtues and vices it would be desirable, if possible, to begin by taking the distinetion of good (or virtuous) and bad (or vicious) habits of conduct as it is found expressed in its lowest and, therefore, most unsatisfactory terms. Here all is vague and apparently confused; but it is spontaneous, naïve, and so the more valuable for the student of the philosophy of the moral life. One does not need, howerer, to rummage the field of ethnological facts with a view to discover precisely how many distinguishable virtues, how many vices, have received recognition by the whole race of mankind in all places of its existence and all stages of its derelopment. To consult philology as to the origin and meaning of the different words which have stood for the idea of virtue in general or for the particular virtues would, doubtless, be a more rewarding task. We may, with sufficient accuracy for our purpose, summarize the net results of both these lines of investigation in the following statements. And, first, as to the essential meaning of the words for virtue in general and for the particular virtues: they all evince some form of embodying the thought that certain ways of doing things are entitled to be considered preferable, more excellent, better, or best. To the unreflecting human consciousness, this does not seem to mean so much that it is better for a man to be virtuous than not to be virtuous; it, the rather, seems to mean that to be virtuous is to be the better, or the best, as respect one's conduct and character. In what respect "better" or by virtue of what peculiar advantages or special eharacteristics "best"? - this is a question about the answer to which the words that express the different particular virtues, do not, of themselves, by any means always clearly pronounce. Where, 
however, they do reveal the subtler thought and finer feeling that is in them, they call attention to the existence in human consciousness of an ethical Ideal.

The indeterminate but important answer which the instinetive expression of human thought gives to inquiry into the conception of the virtuous life is therefore this: The virtues are the habitual modes of the conduct of the person who is the better, the best, the most worthy and admirable, the noblest man. If then we ask: "In what sense are courage, constancy, justice, wisdom, kindness, generosity, better than cowardice, fickleness, injustice, folly, cruelty, meanness?" the answer is: "These are the ways of the behavior of the "better' men." Or, to translate into terms which further investigation must justify more fully: In the thought of mankind, the virtues are those habitual forms of conduct which realize the conception of the better and nobler Self. All naming of the virtues indicates a "constant and especial attention to the praiseworthy features of human personality." The rirtuous man is the good man; virtue is manliness and steadfastness of character; it is the best, because the fittest and noblest thing for a man to have. ${ }^{1}$

In the second place, the philosophy of conduct may borrow from ethnology the conclusion which rests upon its induction of facts: There are many startling dirergencies from the opinions, now current among the most ethically adranced eommunities, as to the correct list of the virtues; but these divergencies do not destroy, they rather make more impressive

1 Thus the Greeks used a a $a \theta$ obs to indicate the most manly personal characteristies, - especially, bravery in battle for the state and nobility of bearing. Virtus in Latin emphasized the same traits of good manliness. The connection of the English and German words for "good" with the German Gatte indicates the emphasis which these languages place upon personal "fitness" in the rirtuous


But the man is bal and vicions, he is no man worthy to be called a man, who is lacking in these fundamental qualifications. And where the influence of allicit religious eonceptions is listinetly felt, the idea of stain and defilement becomes more emphatic. The bad man has a darkened and soiled Selfhood. In Latin malus, and in Greek $\mu$ é $\lambda$ as (black), and in Sanskrit malas (from malam, dirt), seem to incorporate this way of thinking. 
a certain fundamental agreement. They are due chiefly to differences of emphasis, differences of application in dependence upon the existing physical and social environment, and differences in those wide-spreading moral and spiritual tendencies which, for lack of a more scientific account of their origin, we are often compelled to refer to as the "Spirit of the Age." If, however, one accepts the most general and unprejudiced estimate, and especially if one consults the opinions of the most thoughtful and pure-minded, one finds a substantial uniformity of view as to the leading characteristics of the proper life for man. Courage, constancy, justice, wisdom, kindness, generosity, - these and other allicd forms of the behavior of the manlier man, of the better Self, have always been esteemed to be ethically preferable to the opposite forms of behavior; they have always been accounted among the fundamental virtues. In a word: the one persistent utterance of moral instruction has been, "Yet show I unto you a more excellent way; " and, in the various forms of energizing wlich necessarily belong to every individual man in his social relations to other men, the different distingnishable virtues are the different allied forms of following this "more excellent way."

The relation of a preliminary classification of the virtues to the ends aimed at by a philosophy of conduct may, therefore, be described in the following way. We wish to discover the essential characteristics of the Virtuous Life; - and this both with a view to understand such a life and also to acquaint ourselves with the proper way to lead it. For the philosophy of conduct, although it deals so largely with a theory of values that are rather obscurely and changefully incorporated into an experience of facts, has its own supreme value as the trustworthy guide to actual right conduct. Ethics, considered as the scientific study of conduct, must introduce its student to the art of living virtuously. All the human estimates of virtue depend upon an experience involving ideas of value; and these values are all realizable only in the life of the 
better, the Ideal Self. But ethics is, of course, not satisfied to leave the current conceptions of the different virtues and duties so indefinite in number and so disconnected in principle. It aims to reduce them to allied species, to distinguish the more fundamental and inclusive, and, if possible, to bring them all under some one principle or idea. In its effort to accomplish this it must arail itself of the scientific method of classification and of reflective criticism with a view to unify its results.

Perhaps the most common mistake made by writers on ethics is to force a unification by exalting some one virtue or some one aspect of the virtuous life to a position of exclusive supremacy. But such a method inevitably results in several theoretical and practical evils: (1) The misinterpretation of the terms used by men generally to express the different virtues; (2) a narrowing of the conception of the morally most worthy manhood, either by leaving out of it certain virtuous traits, or by underestimating the value of certain aspects of the ideal of manliness; (3) a loss of roundness and harmony to the idea of the good man, which results from making him "over-good" on some sides ("too good for this world," as the somewhat misleading, yet expressive popular phrase would say); and (4) an excessive abstractness, - the completion of the task of describing the total Virtuous Life in terms that cannot be translated into the concrete lineaments and full-blooded structure of a living organism.

I would not have it forgotten then, that the truly virtuous life is the life of the whole man, body and soul, with all his appetites, passions, desires, and affections, involving all his capacities and constitutional or acquired forms of activity the total human being, feeling, intellect, and will.

How, more precisely, shall one describe the virtuous, the morally good man; - the man who performs all his duties, and possesses and exercises all the virtues? Shall one be satisfied to say: He is the man who does now this, now that; 
and who refrains from doing this on such an occasion, and on another occasion from doing that? Or may one affirm: He is the man who is courageous, constant, just, wise, kind, and generous; and who practises whatever other ways of conducting himself are to be recognized as virtuous by the social judgment of his fellow-men ${ }^{1}$ Or can one make a more general summary and rest satisfied with this: He is the benevolent man, the man of good will? On the answer which is given to these questions must depend in large measure the subsequent answer to the more speculative inquiry after the nature of the Right and the relation in which the human Moral Self and the social order of humanity stand to the order of the Universe and to the so-called "World-Ground."

In almost all attempts at stricter classification, in accordance with recognized scientific methods, the selection of a satisfactory principle of classification is a difficult task. In the scientific treatment of complex psychical phenomena, or of attitudes and aspects of the entire man as related to life and to reality, it is particularly difficult to find such a helpful principle. But when it is proposed to reduce to scientific ordering the voluntary adoption of ideas of value, in order to

1 The following list of virtues was written out at my request on consultation by two persons who are intelligent about matters of current morality and yet without tcchnical knowledge of psychological ethics :- "Temperance, paticnce, cleanliness, kindliness, good temper, uuselfishness, thoughtfulness, justness, trnthfulness, courage (moral and physical), righteousness, piety, uprightuess, forgiveness, purity, orderliness, sobricty, industry, perseverance, faithfulness, love to neighbor, honesty, chastity, adaptability (?), cheerfulness, prudence, selfcontrol, charity, hopefulness." The redundancy from one point of view and deficiency from another point of view, the lack of coördination, the comparative narrowness of some of these so.called virtues and the vast range over the "springs of action" which belongs to others of every such popular list are at once apparent to the trained student of psychology. But these same qualifications belong also to most of the lists which have been adopted by writers on the principles of morality. Even in the case of Martineau's careful and elahorate analysis of the "springs of action" with a view to a critical "I Iliopsyclological Ethics" (Part II, Book i. of the "Types of Ethical Theory"), it is difficult to make sure of agreement with the author, both as to the completeness of his analysis and also as respects the relation in which these primary and secondary springs of action stand to the different virtues and vices. 
place these ideas in control over all the varied and shifting springs of action, under every variety of the physical and social environment to which man's evolution is subject, then the selection of a principle of elassification is supremely difficult. Here the principle is necessarily defined by the nature of man himself - his total nature, including all the ends of Good he seeks - in his physical, mental, and social development. The opcrative principle, in actuality, is the unity in raricty of a Moral Self, frcely adjusting itself to the changing relations which it sustains, as a member of a society of moral selves.

Divisions of the virtues like that, for example, of M. Janet, ${ }^{1}$ into "devoirs stricts" and "devoirs larges," need not occupy our attention; for they can only serre the temporary purpose of introducing dispute orer certain subordinate problems in applied ethics. And these problems, so far as I intend to treat of them at all, will more fitly come up in other connections.

The classification into self-regarding virtues and social virtues is more worthy of consideration. This division is not infrequently, and always with a certain plausibility, employed to show how virtue ean be evolved from that which is nonvirtnous, or even vicious; how the morally good can come out of the ethically neutral, if not the ethically evil. It is a dirision of the virtues which is based upon the rclations sustained betwcen the motives for conduct and certain clearly conceired personal interests which are chosen as ends. The motive for some of the virtnes is the end of good for myself; the motive for others of the virtues is the end of good, for others. I have myself to look out for, - my own life, health, and happiness to secure; my own appetites, instincts, passions, and desires are in part self-regarding "springs of action." To conserve these self-regarding interests intelligently is right; and the different ways of doing this constitute, when they are rolun-

1 La Morale, liv. II. chap. iii. 
tary and habitual, the different so-called self-regarding virtues. But I lave also a certain part in society to play, - in the family, the tribe, the clan, the cirele of eomrades and friends with their opponents and enemies, if not in the larger community of the state, the nation, or the whole world of men. And I am constituted a social being, with appetites, instincts, passions, desires, and affections of a social kind. These latter, when voluntarily and habitually made reasonable and intelligent, become the social virtues. The two classes of virtues, when both are faithfully practised, fill up the whole orb of the virtuous man's life; he who has them both in full measure is the ideally good person.

Now it eannot be denied that some of the many so-called springs of action do have a more direct and forceful influence upon the eonduct of the individual as related to the interests of the individual self. Cleanliness, temperance, purity, industry, and prudence, as well as fortitude in resistanee to all lostile attacks upon the immediate interests of one's own bodily and mental life, are excellent forms of behavior, necessary habits for him who would lead the ideally good human life. And so are kindliness, honesty, justice, pity, cliastity, - words which have no meaning except on the supposition that the individual man is acting in social relations with others, and is shaping his conduct with their interests as well as his own in view. Moreover, both from the theoretical and from the practical points of view, he who has no regard for the cultivation of the excellences of the idcal Self in the concrete case of his own individual life - that which is nearest to him and most immediately, in all ordinary cases, under his control - cannot be an efficient doer of the socially right things; and to turn the statement about, he who disregards the practice of the so-called social virtues thereby shows a woful disregard of his own higher and more worthy Self.

It might be objected to this classification (so Sidgwiek) that it involves a premature and illogical denial of all the claims 
of every form of intuitionism; or, more forcefully, that it takes the spontaneity of ethical feeling, as well as the value of disposition and of habits of conduct, out of the sphere of ethics altogether. But there are objections to urge which are much more comprehensive and conclusive. They arise whenever one considers those psychological conditions on which, and those psychological principles according to which, the very conception of a Self has its origin and development; and they are greatly reinforced whenever one reflects upon the philosophical implications which the distinction itself is designed to support. Especially emphatic are these objections to this distinction between the self-regarding and the social virtues when it is applied to the nature and the qualifications of man's moral life.

For, in the first place, it is chiefly as the distinction between one's self and others is made, only to be disregarded and broken down, that the moral life of the liuman being enters upon its course of development. The very birth, so to say, of the moral Self, involves in some sort the voluntary abrogation of this distinction. In saying this, I do not intend to revire in new form an obsolete Hegelian abstraction; I intend simply to point out the obvious meaning of the most primary and crude but constant and significant facts of human ethical experience. The human being, as soon as conscious of a social environment, spontancously expresses all those springs of action which lead him both to seek from others for himself a variety of goods and to seek to give to others a variety of things which he finds to be good for himself. His self-legarding appetites, passions, desires, and affections, are shot through with sympathetic and other-regarding or social impulses; and the society of which he comes to recognize himself as a member, is an integral part of the conception which he comes to hold of himself as an individual to the securing of whose interests others as well as himself must pay regard. From the very inception of the moral life, and as a necessary incite- 
ment to the beginnings of such a life, the individual Self is the self-conscious Will seeking its own good, as one of many similar selves.

Thus, as I have already slown (p. $73 \mathrm{f}$.) the sentiment of obligation is ordinarily first aroused when the purely self-regarding volition receives its cheek from the social environment. The beginning lesson in right conduct is this: "Thou shalt not regard thyself to the exclusion of regard for others; thou shalt regard thyself only as society permits thee to regard thyself. And, willing or nilling, thou shalt conform in thy self-regarding, to the customs, the traditional and organized will of thy predecessors and superiors." Even in the gratification of the most fundamental and imperative of the appetites and passions, virtuous conduct imperatively requires that the regard shall not be, at least directly and ostensibly, directed upon the self. In no society, however low, can the individual eat and drink and indulge the appetite of sex, with even a show of virtue, and regard only himself. And that which is enforced in the lower grades of moral evolution by some form of appeal to civil, military, or religious authority, is freely adopted as the rational principle of conduct by those who have reached the higher grades of moral evolution. The essential thing about their morality is that, whether they eat or drink or whatsoever they do, they do it all - if not " to the glory of God" - with the good of society in mind as a matter of the virtuous man's constant regard.

While, then, the distinction between one's self and others, as a matter of self-conscious thinking, grows more and more clear with the growth of the individual's capacities, this distinction is from the first totally unfitted to be made the basis for a classification of the virtues. The more of selfhood any individual attains, the more does he become both able and entitled to distinguish himself, as having the unity of a personality, from all his own physical and social environment. 
But the growth in the ability to make this distinction cannot result in the development of a Moral Self, cannot even produce the first feeble beginnings of a life in which right and wrong conduct are distinguished, unless some sort of an attempt at harmony between the so-called self-regarding and the so-called social springs of action is brought about. The man who refuses to attempt this harmony, the purely self-regarding man, is the non-virtuous or bad man. His self-regarding excellences, in so far as they are purely selfregarding, are not esteemed virtuous at all. Even a king must do as kings ought to do-most of all, when he is regarding his own kingly dignity and power. The gods of Homer might be adulterous without blame; but if they were sneaking and cowardly in their gratification of selfish lusts, they did not beliave as gods should. But, on the other hand, at no time, whether in the naive and childish ethics of the Homeric Age, or in that most strenuous insistence upon regard for the social welfare which characterizes modern ethical theories, do we find men satisfied with the morality of the person who attempts to praetise only the so-called social virtues. In all our historical characterization of the Virtuous Life, the point now to be noticed is this: virtuous conduct eannot be merely self-regarding; it is, of its very nature and essence, an activity of the Moral Self in social relations; but then it is also something which belongs most distinctly and essentially to a self-respecting and self-controlled manhood.

In the second place, it may be objected to the distinction of the virtues into the self-regarding and the social, that most forms of virtuous conduct, so far as they are practised with an intelligent consideration of ends in view, are both selfregarding and social. For example, shall the man who, because he has respect for his own personality and its attitude of fidelity toward the truth as he understands it, refuses to lie, even when he is forced to believe that a lie might be useful in conserving the interests of society, be denied all 
claim to virtue on the ground that his conduct is motived by selfishness? Or shall the man who, with equal courage and consistency, always refrains from falsehood in the interests of social morals, be esteemed lacking in the essentials of a proper regard for his own personality? I do not believe that the virtuousness of truthfulness is destroyed or necessarily impaired by the acceptance of either point of view as its motive. Lying is bad for society, - a social injury, a social vice. Lying is degrading to one's proper self-regard, - an act unworthy and deeply injurious to the character of a moral personality. And they arc virtuous men, in this regard, who will not lie, whether their motive be regard for themselves or regard for society. The same line of remark is applicable to those who virtuously refrain from that vice which is specifically called "social."

That should be noted in passing, however, which will be made more obvious subsequently. The harmony at which all virtuous conduct aims may be expressed, not simply as an adjustment of the individual self to society, but as an adjustment which yoes on within the individual self. In the virtuous conduct, for the moment, at least, the whole being is brought into a harmony between the lower and actual self and the higher but ideal Self; and in this fact I find a suggestion of the ultimate Ideal of ethics.

Another classification of the virtucs which may receive a brief notice, adopts as its principle the difference of objects upon which the virtuous conduct terminates. In the division resulting, some three or four classes of virtues and corresponding duties are customarily enumerated. Thus, there may be recognized virtues that are (a) individual, (b) domestic, (c) social; and duties toward (a) Self, (b) the family, and (c) society; or again, four classes of duties and their corresponding virtues, - namely, toward (1) animals, (2) Self, (3) fellow-men, and (4) God.

But all proposals to discover the essential characteristics of the Virtuous Life by classifying the virtues according to 
the different objects on which the virtuous conduct terminates land us in hopeless confusion. Of the above-mentioned threefold division one may inquire, whether marriage is for all persons a necessary condition of living virtuously; and what particular form of it can be made, under all social conditions, so comprehensive as to include a full onc-third of all human duties. In what essential respect do certain virtues, - such as pity, kindness, justice, truthfulness, etc., - when exercised in the domestic circle, differ from the same virtues when they pass over into the class called social? As to the preceding fourfold classification, it may be questioned whether there are, strictly speaking, any duties and virtues having respect to the animals that are not included in those having respect to self and to fellow-men. And there can be no doubt whatever that the instant the existence of God is assumed as ncessarily connected with the philosophical treatment of ethical phenomena, the entire subject of morality changes front. All duties now become due to God; all virtues now become capable of being regarded as fidelity to Him, as a voluntary patterning of the individual man after the Dirine model and as "moments" in the life which is obedience to his Holy Will.

A third principle for a classification of the virtues lays emphasis upon the attitude in which the different impulses of human nature stand toward the Moral Ideal. This is at once the oldest and the most suggestive and convenient; it is also a principle which, when modified in accordance with the progress of psychological science, most directly and safely introduces us to a valid theory as to the nature of virtue. Its foundation rests in the belief that human virtues are those activities of the human Self which correspond to the Ideal of a Self. "A man's duties are due to his humanity."

By making this division, Plato, in spite of the uncouth physiology and psycho-physics which were then its accompaniment, showed a profound insight into the essential nature of 
the Virtuons Life among men. Three eardinal virtues there were; and yet a fourth which comprehended the three in a sort of divinely ordered harmony. The three were Wisdom or the virtue of the head ( $\sigma o \phi i a)$, Courage or the virtue of the heart (a $\left.\nu \delta \rho \in i^{\prime}\right)$, and Self-control or the virtue of the parts below the diaphragm ( $\sigma \omega \phi \rho \circ \sigma \dot{\nu} \eta)$. A certain Justness, or

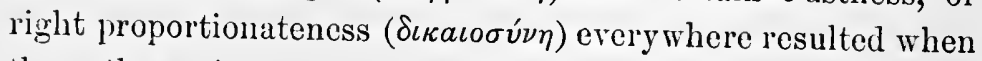
these three virtues combined to make the really "good man." And yet in some sort it is wisdom, or reason knowing the Reality, and so regulating the entire life, which, according to Plato, supremely characterizes the follower of the moral Ideal. But none of these virtucs can be merely self-regarding, althongh they are all attitudes of the ligher Self with regard to its own proper regulation. For with Plato, as with the ancient world generally, wisdom, courage, temperallee, and justice are essentially civic virtues, and have regard to the welfare of the State. This ideal of manhood is, then, the farthest possible from the brutal self-assertion of some of the modern adrocates of the so-called "strennous life." As Paulsen has well said: 1 "'The Republic is the very thing for young people whose thouglits are preoceupied with and confused by Nictzsche's Uebermensch."

Plato's great disciple, while not adhering to any consistent classification of the virtues, in his treatment of the nature of virtue in general and of the particular virtues accepts essentially the same principle. In his preliminary definition of the sphere of ethies Aristotle indeed proposes the distinction which, we have already seen (p. $106 \mathrm{f}$.), weakens, if it does not vitiate, one's estimate of the nature and supreme value of the virtuous life. The virtues of the head, the voluntary culture and right use of reason as a species of conduct, although it is a fundamental prerequisite of every cardinal virtue, he separates at the beginning of his treatise from the so-called " moral" virtues. Still "the rirtue or excellence that we are to consider is," according to Aristotle, "the excellence of man,"

1 A System of Ethics, p. 47. 
and by the "excellence of man" is meant "excellence not of body, but of soul." And in his deseription of each particular" virtue he finds himself dealing with the various springs of action and forms of activity, under the control of the will and in the pursuit of an ideal. Thus the various appetites give rise either to forms of temperance or to the vices of gluttony, mchastity, etc. ; and fear either begets an unworthy cowardice, or, being controlled, issues in a prudent courage or an imprudent rashness. In all this discussion it is evident that the author of the Nicomachean Ethics has constantly in view the fundamental principle of every psychologically sound theory of the nature of virtue.

Abundant examples might be drawn from the history of ethical discussions to show that every attempt at a description of the Virtuous Life must pay its respects to essentially the same principle for the classification of the virtues. And why should it not, as a matter of course, be so? For by the word, the "virtues," ethies does not mean to indicate some entity that can be abstracted and exhibited apart from the activity of the entire soul. Virtuousness for man is essentially man's Self in action as related to other selves.

With a view, then, the more conveniently to establish a ralid theory of the nature of virtue upon a broad basis of limman experience, I shall classify the virtues according to the current threefold classification of man's so-called faculties. We have thus to consider in a separate chapter, first, the virtues of the will, or those forms of conduct in which the excellent, the better manhood shows itself conspicuously by its selfcontrol, whether in the pursuit of its chosen ends or in resistance to those influences which inhibit and prevent the execution of the will. Second: we have to examine the virtues of the intellect or judgment, those excellences of the better manhood which give the distinctirely rational quality to human conduct. And, third, there remain the virtuous sentiments and affections, the virtues of the heart, 
or those excellences of conduct which do most sweeten the sourness, illumine the darkness, and cheer the otherwise hard and cold path to the higher Good of human life.

But before taking up in detail this discussion of the Virtuous Life certain explanations are necessary as to the use which it is proposed to make of this principle of classification.

First: no form of virtuous conduct can eitlier be understood or practised as though it were the product of any isolated activity of man's mental life. Strictly speaking, then, there are no virtues exclusively of either head or heart or diaphragm, or eren of either intellect, feeling, or will. For blind, unfeeling volition - if it were worthy to be called a man's will - has no ethical quality whatever; such volition is not a function of the Moral Self. In order to constitute any fact of volition a deed of will that has ethically good or bad quality, there must be a presentation of some form of good to be obtained and a feeling appreciative of its worth as an end to be voluntarily sought. But neither does mere judgment as to what is eudæmonistically or æsthetically or ethically good, howerer true and illumining in itself, constitute a virtuous action. Just judgment is a virtuous trait, and to be trained in such judgment is an essential for the truly good man. They who have in the lighest perfection this power of intelligently balancing conflicting interests, of sitting like gods for the evaluation of the moral worth of themselves and others, belong to the "good few" among men. But such power of judgment is always attained and exercised as the result of will, incited and suffused with feeling. It, too, is a function of the total Moral Self. Nor is mere socalled "fine feeling" a virtue, unless it be tempered with reason and then adopted as a guide to action.

The threefold classification of the virtues which I propose must therefore, like every other classification, be understood as not denying the unity, either of the soul or of the soul's virtuous liring, while at the same time adopting distinctions 
that are serviceable for the mastery of an almost indefinite variability.

For, second, there are different classes of virtues which do, both actually and in the average estimate of mankind, emphasize the excellences of man's self-control; and the corresponding vices are like laments over deficiencies in the lower of self-control. 'The courageous and consistent "bad" man illustrates the one; and the timid and fickle but "wellmeaning" man illustrates the other. So, too, there are virtues which depend chiefly upon a cultivated judgment; they are the virtues of rationality, in the narrow but popular meaning of the latter word. And no kindness of heart, or constancy of purpose, can suffice to fill the gap caused by a lack of these virtues. Tirtues indeed they are; for they result from the at least partially right activity of the moral self in accordance with its proper and obligatory ideal. On the other hand, the man of steadfast and courageous purpose, with no end of wisdom and the most exact justice, but without kindness of heart, sympathy with the weak, and pity for the oppressed and the fallen, is not the ideally good man. He lacks one essential third, at least, of the wholly Virtuous Life.

And, now in the third place, the two preceding remarks must combine in a conclusion, to make and apply which will relieve the mind of many practical perplexities, while, at the same time, throwing no small light upon the true conception of the essential nature of virtue. Is the courage of the criminal who is brave not wholly from a spirit of shameless bravado, but chiefly because of a sort of shame at betraying fear when he must face the foreseen consequences of his own chosen path of conduct, a virtue, or not? Is our admiration for Milton's Satan, however sneakingly confessed, a purely xsthetical and not also an ethical affair? Can the mind of man frame a picture of a devil, who is in any sense of the word and over any realm, the Devil, and make him wholly bad? 
To all such questions the naive moral eonsciousness of mankind gives no unequivocal answer. I believe that the answer of the student of philosophy must in the main accord with the answer of mankind. ${ }^{1}$

Courage and persistency of purpose, for example, are virtuous forms of conduct. They are forms of conduct, because they involve the activity of the whole Moral Self, - fecling, intellect, and will; they are virtuous, because they are such forms of conduct, chiefly a matter of steadfast will, as correspond with the Ideal of Selfhood. The self-eontrol of fear, 4 and steadfastness of purpose, even when given to the pursuit of some selfish end, do not thus become vices, being themselves vitiated by the quality of the end sought, or by the means employed. They remain what they essentially are,virtues of the will. But the choice of the inferior in preference to the better good is a most cardinal viee, the very essence, as it were, of all wrong-doing; and injustice to others in the pursuit of one's own ends, whether ignorant and thoughtless or designed and deliberate, is a flagrant moral evil. Selfishness and injustice are vices; but courage and constaney still remain virtues, even when enlisted in the behalf of selfishness and injustice.

It is this truth which gives ethical justification to the poetical expression of it in Browning:-

"Oh, a crime will do

As well, I reply, to serve for a test

As a virtue golden through and through.

The sin I impute to each frustrate ghost

Is - the unlit lamp and the ungirt loin."

Shall it then be said that it were better - more in accordance with the ideal of moral selfhood - to remain to the last courageously and constantly in the pursuit of the inferior good, rather than to ehange to the pursuit of the superior

1 Compare the remarks already made on p. 100. 
good? Certainly not. But timid and inconstant generosity, the spirit of kindness restrained and rendered fickle by cowardice, benerolence that has no "valiancy" to its "volency," are sometimes scarcely less elearly "throurh and through" vicious than is a courageous and consistent selfishness.

The reasons for this conflict in points of view, and the correct solution of the problems of ethical praxis that are concerned in the conflict, lie deep in the constitution of the human soul. They are due to its actual variety in unity, its real unity in spite of the actual variety of its activities. Thus all the particular virtues, or modes of conduct which the moral consciousness of man approves, may fitly be called "qualified" virtues. In order to liave moral quality at all, or - what is the same thing - in order to be species of conduct, they must involve the total personality. They must be forms of action that admit of voluntary control, and that are directed toward the attainment of some end which itself admits of being connected with ideas of worth and with feelings of obligation and of approbation or disapproval. Those particular activities of the man which correspond with the ideal of a Moral Self conducting itself in a variety of social relations with other selves are the so-called virtues. But, I repeat, they are all qualified virtues. They all inhibit and limit or supplement and complement each other in the totality of the complex Virtuous Life. For this life is the total life in conduct of that unitary being, with all the variety of its threefold nature, which we call a human Self. 


\section{CHAPTER XI}

VIRTUES OF THE WILL: COURAGE, TEMPERANCE, ETC.

From time immemorial and under all conditions of human development, the man of strong character has been quite generally admired and eommended. Nor can the admiration and commendation be declared, on a careful analysis of the motives and actions of men in this respect, to be by any means lacking in truly ethical significance. Doubtless some of this feeling towards so-called "strength of character" is connected with a sneaking sense of inferiority which may, on the one hand, lead the weak to prostrate themselves before the man of superior will, or, on the other hand, turn quickly into the expression of that base envy and hatred which always greet those of the strenuous, whether the obviously successful or unsuccessful life. Just as undoubtedly much of the universal admiration for men of strong character is quite purely æsthetical. The plucky bulldog or gamecock which puts up a brave fight and holds tenaciously on to the bitter end, is admired. Bravos meet the daring, if successful, rentures of the toreador or the prima donna. Exhibitions of strength, whether made by inanimate or by animate nature, tend always to arouse the rsthetical feeling of man. Weakness may be pitiful and pardonable, but it is never, as weakness, xsthetically good. But I beliere the facts of moral consciousness show that just as undoubtedly is the admiration which men so generally bestow upon strength of character also an ethical affair. Strong in character is what the good man ought to be, strength and constaney of self-determina- 
tion in this universe, where so many temptations to cowardice and fickleness are found and where such bulk of obstacles lies athwart the path to the right form of living are virtues which every good man must possess and cultivate. The approbation with which the strong man is greeted is the expression of a justifiable moral esteem.

And why should this not be so? The rather, how can this possibly fail to be so? For by the rery term, will, nothing else is meant in this connection than the Self regarded in its aspect of control of itself, of its own conduct, in the pursuit of an end esteemed to be good. This so-called "Will," then, is the very centre and core of his selfhood, in so far as man himself has anything to determine concerning what he shall be or aceomplish by way of influence orer his fellow men. So that, in some sort, the most essential thing about moral goodness is the way in which the self-control enters into the goodness so as to make it strong and constant. For, properly speaking, "good will," in this most fundamental, appropriate, and elearly intelligible meaning of the phrase, is not synonymous with benerolence, or wishing the good. It is, the rather, good stiff and sound, but not unintelligent and blind, self-control.

Inasmuch, then, as it is good psychology to hold that man is, primarily and most fundamentally considered, a Will, and good ethics to hold that moral freedom is an essential and integral part of his endowment for the life of conduct, it is also sound philosophy of eonduct to recognize that these good qualities of the willing Self, are cardinal virtues, fundamental forms of man's functioning in the Virtuous Life. $A$ "good will" $i s$, first of all and always, a Will that performs well its functions as a Will. And snch a will is what men chiefly mean whenever they note with admiration and commendation unusual "strength of eharacter" so-called.

The three cardinal Virtues of Will, or forms of self-control and self-determination which emphasize the correct function- 
ing of the voluntary Self in conduct, are Courage, Temperance, and Constancy. Courage is self-control in the presence of every form of temptation to fear; it is strength of purpose resisting the impulse to yield to cowardice. Temperance is self-control in the presence of every impulse to the gratification of the appetites and desires; it is strength of purpose to resist the seductions of the pleasure-giving and pleasurepromising activities. Constancy is persistent self-control in spite of resistance or obstacles to be overcome; it is strength of purpose resisting all impulses to turn aside from the chosen course of conduct, from the repeated if evell laborious use of ineals to reach the desired end. The vices or faults which are opposed to these virtues are cowardice, licentiousness or profligacy, and fickleness or sloth.

In some sort, however, Constancy best expresses the most essential characteristic of all the virtues of this kind, - constancy which when it exists in the interests of a high and noble principle, a rational end such as elicits the finest ethical sentiment, becomes Fidelity to the Moral Ideal. Than this word, no other, not even the word "benevolence," or the word "justice," is better fitted to call up and to embody the most inclusive characteristics of the truly Virtuous Life.

It is desirable in the interests of a tenable theory, as well as indispensable in preparation for the successful practice of morality, that these virtues of will should be distinguished from the shams of virtue with which they are most liable to be confounded. And perhaps confusion is easier here than with respect to any other class of virtues. Rashness, and the braggart spirit or the spirit of bravado, and insensibility to fear, are the shams of courage - the vices, which, although they have their own moral constitution, as it were, are most apt to be mistaken for the virtue of courage. Here, for cxample, the application, by Aristotle, to the case of this virtue of his well known doctrine of the mean ${ }^{1}$ does not quite satis-

1 See Nic. Eth., II, viii, 1 f. and III, vi-ix. 
factorily exhibit the exact nature either of courage or of those vices which are its most frequent and deceptive shams. For the virtue of which rashness is generally the apparent opposite vice is prudence; but this vice of rashness may be the expression of either one of several somewhat different forms of vicious motive; or whal seems rashness may even be the expression of a deliberate, intelligent, and virtuous resolve to throw all considerations of the prudential sort to the winds, for the time being, in the interests of some higher end. In this latter case we do, indeed, hesitate to speak of the violation of prudential considerations as rashness; and the conduct resulting, however imprudent, certainly cannot unreservedly be called vicious. It may amount to the sublimest kind of courage.

Not infrequently, howerer, it is some form of fear which furnishes the motive to the pretence of courage; and this is as true of what appears as an extraordinary willingness to face danger, a brilliant bravery amounting to rashness in the mind of the observer, as of what, in the case of weaker personalities is usually recognized as foolhardiness. The cowardice which exists in the latter case Aristotle recognizes: "And so your foolhardy man is generally a coward at bottom; he blusters so long as he can do so safely, but turns tail when real danger comes." But when one kind of fear impulsively overcomes another, the control of the weaker by the stronger impulse can scarcely be praised as an instance of the virtue of courage. The cowards are not only those who will not fight unless compelled " in Hector's fashion,"-

"Whoso is seen to skulk and shirk the fight Shall nowise save his carcase from the dogs."

but also those who dare not refuse to fight simply because they fear more some form of vilification, or depreciation by their fellows. It is moreorer often difficult to distinguish between insensibility to pain and that energy of will which overcomes not only the fear of pain but eren the feeling of pain. To 
which, for example, shall we attribute the heroic action of that Indian of whom Jameson tells in his "Winter Studies and Summer Rambles in Canada," who, when he was pinned by his arm by a falling tree, amputated the arm with his hunting-knife, crept to his canoe, and rowed himself home?

It would seem, then, that the virtue of courage needs a more thorough analysis than it has generally received in order to distinguish it from those vices or faults which sham its characteristies, and from those forms of virtuous conduct whose external manifestations are most similar. Courage, I repeat, then, is a virtue which includes all intelligent selfcontrol in the presence of every kind of fear. Cowardice is the yielding to fear, the allowing of fear to become an impulsive or a restraining motive in the pursuit of any end attainable by one's conduct. The Self afraid, and the Self controlling itself and putting down or setting aside the fear, - these are the essential elements of this cardinal virtue. It is fitly called a virtue of the will because, although it must be qualified by rational considerations and ethical sentiments in order to reach its most worthy estate, it is, nevertheless, eo ipso, a way of voluntary functioning which is a fundamental eharacteristic of the good Moral Self. Such a Self is designed to control itself, in the pursuit of its ends, in spite of every form of fear.

Man is a being made capable of fears and so environed that he is constantly, of necessity, subjected to various forms of fear. There are fears which are aroused by all manner of attacks upon lis physical well-being; and, as well, upon the physical well-being of those whose interests are nearest to his own. He cannot acquire any manner of possessions withont overcoming these fears; and for the primitive or savage man the daily fears that inhibit and scare backward his efforts for food and drink and gratification of the sexual appetite, are terrible and hard to overcome. Domestic, tribal, and civic fears hedge in and retrench his forth-puttings, the 
impulsive or more deliberate resultant workings of the different springs of action. 'The restraints of the current morals and of his religious beliefs largely multiply and enhance his fears. His primary moral law is chiefly a "thou shalt not"; his religion is largely a matter of terrifying superstitions and dreadful tabus. Only in this way, however, can the crude and dangerous primary impulses of his nature be held in check, and the most fundamental of all the particular virtues, the virtue of courage, be induced. As ethnology shows us $;^{1}$ "Prominent among the checks of savage life is the fear of the anger of the dead. Among savages the supposed wishes of their departed friends, or deified forefathers, operate as real commands, girt with all the sanction of superstitious terror, and clothing the most fanciful customs with all the obligatory feelings of morality."

Now if we examine this emotion of fear in the light of its psycho-physics we find its most primitive significance in the economics of liuman life to be (1) inlibitory and (2) retroactive in the meaning of furnishing the impulse to retreat, to move in the opposite direction from that in which lies the desired object. The scared child, like the startled animal, first, stops, stands still, remains in extreme cases " rooted to the spot" and trembling, but with senses alert to discover and estimate the object of fear; and then, second, if the fear is yielded to, impulsive or more deliberate flight results. But all human interests, all the ends of good which mortal man can pursue, including those that are most eranescent or purely ideal, are subjects of the struggle for possession, the fight that either wins or suffers defeat. For every kind of good and of impulse toward that good, there is a corresponding kind of fear. Without the inhibitory action and the impulse to withdraw, whether precipitately or deliberately, which are due to the various fears of human nature, neither body nor mind nor morality could be either conserved or 1 Farrer, P'rimitive Manners and Customs, p. $117 \mathrm{f}$. 
developed. For the checks and inhibitions and retroactions of every form of human life are quite as necessary to the preservation and evolution of that life as are the more positive and direct springs of action. He who has not all these fears is less fully equipped for life; indeed, he is less likely to have the genuine virtue of courage. For the virtue of courage consists in the self-control of fear; and insensibility to fear, even if we refuse to agree to Aristotle's view that "it is a vice which is one of the "extremes' of courage," certainly must not be identified with this virtue.

As the author of the Nicomachean Ethics pointed out, courage is, therefore, not to be confused with the sclf-confidence of the sanguine temperament or of the optimist; neither does it resemble that impulsive disregard of danger which extreme rage causes: "So we find in Homer, 'Put might into his rage' and 'roused his wrath and rage' and 'fierce wratl breathed through his nostrils,' and 'his blood boiled." " The sanguine man and the optimist may be courageous; and the angry man may also be truly brave. Both the sanguine temperament and the state of anger are, however, distinctly unfavorable to the genuine virtue of courage. Indeed, the virtue of courage is more apt to develop in the choleric and melancholic temperaments; and the exercise of the habit of courage is plainly for the time impossible when one is under the control of impulses due to an excessive and blind rage.

The truth is that the greater part of the courage of the world's bravest souls goes into their lives in quiet and unobtrusive ways. Invalids who meet with daily self-control the fear of pain and weakness, women who either calmly but intelligently await the terrors of childbirth or send their grown sons out to do battle in a just cause, laborers who pluckily fight for a decent maintenance and education for their families in the face of the new fears with which the modern organization of capital is surrounding them, the good few politicians (where there be any such) who stand for 
truth and justice in the face of a depressing and degrading dread of the "boss" or of "my constituency," the servants of God who plead for righteousness in spite of the fact that they may forfeit their positions, - these, and such as they constitute the multitude of those who have this cardinal rirtue of the will that chooses not to yield to fear. My friend, who pluckily fought to the end for the one hour and a half a day, which was all that the deadly disease would allow him, in order that he might worthily finish his good work of science, was amongst the bravest of men. Kant, working away and never minding but subduing the constant pain in his chest that he might, although " removing knowledge," "make room for faith," showed much more of genuine courage than some generals whose tombs adorn Westminster Abbey. And no more valiant hero ever died in battle than David Livingstone found dead upon his knees in Africa.

It is not strange, then, that the kind of courage most imperatively needed at any particular stage of man's development should be most highly esteemed and approbated by the ethical judgment of that age. Eren in the estimate of the ancient philosopher," "The term courageous, in the strictest sense, will be applied to him who fearlessly faces an lionorable death and all sudden emergencies which involve death; and such emergencies mostly occur in war." But a man, Aristotle thinks, would be "a maniac or quite insensible to pain" who should not fear "even earthquakes and breakers, as they say is the case with the Celts." Both these statements miss entirely the essential qualities of the virtue of courage. For fearlessly to face an honorable death is not courage unless the fear has been overcome by an act of will; otherwise it is the same maniacal rage or insensibility to pain of which the Celts are accused. But to control the fear of death by the sea or by the earthquake requires a rarer and a higher kind of courage than to face death in battle. Almost all kinds of men can,

1 Nic. Eth., III, vi, 10. 
as experts tell us, without great difficulty be trained to brarery in war; and that bragging over an exclusive claim to this exhibition of the virtue with which particular persons, tribes, or nations, so often go forth to battle is quite likely to take on a lower tone before the issue is fully decided. The Norsemen in their hardy and bold conquest of the sea have shown as much courage as did the founders of the Roman Empire. Moreover, as man becomes more truly civilized, less emphasis is placed by the thoughtful upon the particular manifestation of courage which Aristotle considered to belong to the concept in its strictest sense. In some far-distant future the time may come when even the less civilized nations will cease to agree with the Greek conception, because individual men and nations will have ceased to recognize the fearful necessity of appealing their disputes to the arbitrament of war, so-called. Then will be most highly esteemed the comrage of the man who would rather suffer wrong than do wrong, who is more afraid of not doing good than of not getting goods; and yet who is ever ready to facc even death in the interests of righteousness to be attained or unrighteousness to be opposed. For this virtue of courage will never be out of date; and the more subtle are the temptations to the vice of cowardice and the more deceitful the shams of courage, the more will the genuine thing be needed and the more highly will it be prized. Under such improved circumstances of nations so civilized as no longer to engage in war, there would seem to be still an opportunity for the ideally courageous man, as his praises are sung by Wordsworth in his Happy Warrior.

"Who, if he be called upon to face

Some awful moment to which Heaven has joined

Great issues, good or bad for human kind,

Is happy as a lover. . .

And, through the heat of conflict, keeps the law

In calmness made ...

More brave for this, that he hath much to love." 
But is it not true that to be influenced by certain fears is a mark of the Virtuous Life, and that the alisenee of these fears is a sign of stolidity or of shamelessuess rather than of the virtue of eourage? Are there not fears which a man ought to cherish and to control which cannot be called virtuous? These questions must doubtless be answered affirmatively, although in a qualified way. Susceptibility to various forms of fear is a natural characteristic of the human animal. And man, besides haring substantially all the same fears as the more intelligent of the lower animals, is also influeneed by many are that specifieally human. Moreover, some fears are so eonnected with the higher interests of human life that they appear to have, as fears, a real ethical character. For example, the fear of being disesteemed by one's fellow men, or of being deemed base, may become more potent, beeause it seems more ethically worthy, than the fear of the loss of property or eren of the loss of life. Higher yet in the seale of ralues, beeause of its connection with the virtuous life, may appear the fear of doing wrong, or that "fear of the Lord" which is the beginning of wisdom. There is also the curious anomaly of the man who is courageous because he fears more - not the being called, but the really being a coward, than he fears the thing that threatens seriously some physical or material interest. The fear of losing the conseiousness of honor has been a most powerful motive toward some of the noblest deeds of history.

It may be said, then, in some true and pertinent meaning of the words, that every eomplete man ought to feel all the kinds of fear to which man is subject, when his nature, his interests, and his environment are considered from the rational point of riew; and, furthermore, that he onght most of all to fear those things which make the most dangerous and effeetive attacks upon his superior interests. But from the ethical point of view the most fearful thing is whaterer tends to inhibit, or to make him retreat from, his following with all his will the moral ideal. 
The forms of conduct which arise through the influence of the different fears of man are certain so-called "prudential virtues." Prudence as a virtue frequently is the rational and voluntary yielding to fear in respect of the pursuit of ends for the realization of any form of the good; and the particular display of prudence has its place assigned in the scale of moral values according to the worth of the end in the interests of which the prudence is exercised. Self-control under the influence of fear may be called virtuous when the fear is of such a character that it may be regarded as obligatory upon the will. Prudence is, therefore, for all men an indispensable but most distinctly "qualified" and even subordinate kind of virtue.

It follows, then, from the very nature of both virtues and from the character of man's physical and social environment that courage and prudence are usually antithetic. They constantly qualify each other. Shall I run the risk - to life or health, to property or happiness, to the favor of men or to social or political advancement, or even to the interests of those dear to me - which is necessarily involved in the pursuit at this particular point, of the end which I have chosen? If I say, Yes, it is the courageous answer ; if I say, No, it is the prudential. When the end is one the attainment of which imposes the feeling of obligation, a conflict of duties, and a problem of moral values, is certain to follow. If the end is worth it, I am in duty bound to run the risk. The cardinal virtue of the will - courage - must win the das, or I am not worthy of moral approbation. If the end is not worth the risk - " not worth" that is, in the scale of moral values then I may be prudent; or it may be my duty to be prudent. It is noteworthy, however, that all yiclding to fear is apt to be accompanied by a certain feeling of weakness, littleness, finiteness. Thus that excellent Hindu gentleman who succumbed to the threats of the Brahmans through the fear of losing caste for his family, and did penance for having violated their 
rule against going abroad, even if it be admitted that his prudence was morally justifiable, suffered in the sight of men a certain loss of esteem.

But what if, it may he asked, as doubtless often happens, prudence is duty, and the man has no right to run the risk; shall we say that, in such a case, courage is virtuous; or may it not even be the crime of rashness, - not true courage at all? Here, I reply, is one of those psychological confusions with which the discussion of the nature of the virtues is so fraught. Courage, or self-control in the presence of fear, is always a virtue; but courage is not the only virtue; and, like all the qualified virtues, it is not always the virtue that should come to the front. In many problems of conduct there is, therefore, a chance for a seeming compromise between the antithetic rirtues of courage and prudence. This takes place oftenest, perhaps, in the form of a change of the chosen means for accomplishing the end; and conduct las frequently to do with the way in which men choose to realize their ends. If, then, without yielding through fear the chosen end, one can follow that end more successfully in some other than the chosen way, there is a chance to effect an apparent blend of courage and prudence. One may continue to be courageous in the following of the prudentially "more excellent way." Men who succeed best by such compromises get most credit for a kind of fairly courageous prudence, a judicious courage. But, unless there is something more of this cardinal virtue of will to these men, they have no fitness for heroic deeds, nor do they attain the sublimer heights of character.

In order to discover the key for unlocking this puzzle of seemingly inherent and unavoidable sacrifice of virtue to fear, we must turn to the positive side of the human soul, to the motives and inducements furnished by the moral ideals. Thus for every negative prudential virtue as an act born of fear, there is found a correlative virtuous act of a courageous sort. The prudential fear of death becomes the courageous guarding 
of life - but only so long as life ean be made to serve the ends that are set by the moral ideals. The prudential fears of losing property, position, publie favor, or even reputation and influence, are lost in the courageous defence and use of all these opportunities - but only so long and so far as they contribute to the realization of the moral ideals. Even the fear of doing wrong is transformed into a passionate and brave devotion to the ideal of duty; and that fear of the Lord which is only the beginning of wisdom is lost in the perfect love which easteth out all fear. How splendidly this cardinal virtue of the will, this courageous and positive devotion to the Moral Ideal, may shine forth in the expressions of finite moral consciousness is shown in a startling manner by the following declaration of John Stuart Mill 1: "I will eall no being good, who is not wliat I mean when I apply that epithet to my fellow-creatures; and if such a being can sentenee me to hell for not ealling him so, to hell I will go." So, what but the sublimest eonfidence in a moral ideal that is worthy of being bravely followed at whatever risk to interests not essentially and inseparably part of itself, could lave led that nobleman among my friends, in all modesty to say: "I do not believe there is power enough in the universe to make me tell a lie." But neither of these declarations ean possibly be explained in eonsisteney with a philosophy of conduct which makes any prudential principle supreme, either in the theory or the practice of morality.

How eardinal a virtue is courage in every form of its manifestation might also be shown by an historieal investigation into the place which it has always held amongst those forms of eonduct most esteemed by the moral eonsciousness of mankind. In the earlier and lower stages of evolution, whatever other virtues are lacking, eourage must be most insisted upon. All the immediate inducements of discipline and of praise, as well as the more remote social, political, and

1 Examination of Sir Wm. Hamilton's Philosophy, I, p. 131. 
even religious rewards of this virtue, tend to cultirate it. Of the North American Indian we are told 1 that, for him " death is rather an event of gladness than of terror, bringing him rest or enjoyment after his period of toil ; nor does he fear to go to a land which all his life long he has heard abounds in rewards without punishments." In the form of courageous endurance of suffering and scorn of danger in the interests of truth, early Christianity insisted upon this virtue; and it thus won for itself the admiration which the brave religious derotee has commanded in all ages and under all circumstances. Mediæval Germanic Cliristianity overestimated, or rather wrongly conceived, this essential virtue; and so - to quote from Paulsen: ${ }^{2}$ "The old Saxon poem of the life of Jesus (the Heliand) makes Christ a mighty lord and the disciples his retainers; the transformation shows how impossible it was for the Saxons to imagine the real Jesus and his followers." And in the modern Occidental civilizations, where the ordinary daily life of the multitude is all "sicklied o'er with the pale cast" of prudential considerations, the occurrence of war, riot, fire, pestilence, gives occasion to the spontaneous outburst of approbation which always, and fitly, greets any unusual display of this eardinal virtue of the will. In respect for this virtne man is essentially the same in all stages of the development of his moral consciousness.

Cowardice is, on the other hand, one of the most fundamental and mortal forms of bad conduct; it is essentially and eternally bad, because it ritiates and thwarts every kind of virtuous conduct by yiclding to the fears which stand in the way of the pursuit of moral good. No good can be gained for man without encountering pain. No virtue ean be exercised if the individual will cannot control the conduct in spite of the influence from the fear of pain. And here the current

1 J. A. Farrer, Primitive Manners and Customs, p. 39, quoting from Schoolcraft.

2 A System of Ethics, p. 119. 
distinctions between "physical courage" and "moral courage," or between " true courage" and "false courage," are for the most part mistaken and mischievous. There is no courage which is not moral ; and there is little use for courage that cannot control the bodily impulses which are produced by the various forms of fear. True courage is simply courage; and so-called false courage is simply the sham of courage, which may be only another and subtler form of cowardice. But cowardice is always and everywhere a vice; and it is often the most deplorable and harmful of vices.

The moral degradation from the vice of cowardice, as well as the mischievous results which follow indulgence in this vice, admit of being estimated by a sort of ethical standard or scale. What is the particular character of the fear, and with reference to what sort of good does it apply? The lower in the ethical scale stands the fear in yielding to which the cowardice consists, and the less worthy ethically are the ends at which the prudential considerations aim, the more degrading and, on the whole, more harnful, is the resulting vice of cowardice. The merchant who, through fear of losing property or of failing to gain it, consents to lies and bribery, the politician who does the same thing through fear of losing his place, the public teacher who flinches in telling the truth which it is his duty to tell, are all baser cowards than is the soldier who, in the panic fear of losing his life, turns his back upon his officer and precipitately leaves the field of battle. Yet, in these days, the one is surely disgraced as a poltroon; the other is perhaps commended for his prudence.

Another consideration which enhances the meanness and the dangerous character of cowardice is the number of other vices whose minister, or easy prey, the coward must become. For the coward is the man subject to fear and not the master of his fears. And almost every human vice, on certain frequent occasions, can appeal to our fears; while every antithetic virtue must often be practised bravely, if 
practised at all. Consider how avarice feeds cowardice and is responsive to the prudential considerations only. Consider how ambition - the more the baser - does the same thing. And how is lust made more despicable when allied with cowardice! What virtue can you expect, in an evil generation - and the generation is always prevailingly evil - from the soul afflicted with the incurable vice of cowardice? I believe it is quite warranted by the facts to declare that cowardice and avarice are the two worst, most mischievous, and most degrading vices of the nation at the present time ; cowardice that is begotten and nurtured in the rice of avarice, and avarice that is made all the more contemptible and pernicions because it is so cowardly. As one of our leading novelists has written: "We are a cowardly generation, and men shrink from suffering now, as their fathers shrank from dishonor in the rougher times. The Lotus hangs within the reach of all, and in the lives of many 'it is always afternoon, as for the Lotus Eaters. The fruit takes many shapes and names; it is called Divorce, it is called Morphia, it is called Compromise, it is designated in a thousand ways and justified by ten thousand specious arguments, but it means only one thing: Escape from Pain."

It is not without significance that, in the order of treatment suggested by our classification of the virtues, we now pass on to consider the virtue of Temperance. For temperance, like courage, is mainly a virtue of self-control; although, like courage and all the other particular virtues, it is qualified by other virtues as respects the rightful position which it holds in the Virtuous Life. But while courage is the enlightened and feeling Self in control of itsclf, in spite of fear, temperance is the same enlightened and feeling Sclf holding the control over all its own positive impulses to scek the various forms of good, - that is, over its own "springs of action" so-called. Temperance is a virtue of the Will, because in its essential nature it emphasizes self-control; but unless it be enlightened 
by intelligence, the control can have no moral character; that is to say, in a word, it is not control of the Sclf at all. Indeed, the very term signifies that virtuousness here requires the moderation rather than the total suppression of the impulses to action. It is the intelligence of man which furnishes the rules for this kind of self-control ; but it is the will that actually moderates, according to the rules of moderation which experience furnishes and wisdom dictates; I have, therefore, called tcmperance a cardinal but qualified virtue of the will.

Temperance, then, is the rational moderation by selfcontrol of every form of natural impulse, positive or defensive, toward all kinds of good. The germ of the complete conception is better giren (better, that is, than in the word

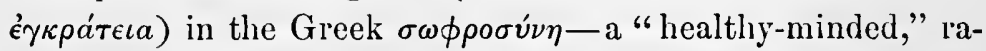
tional will. But even Aristotle, ${ }^{1}$ the most prominent scientific exponent of the conception, limits this virtue to "those kinds of pleasure which are common to the lower animals;" and, then, more definitely to "the sense of touch, alike in the pleasures of eating, drinking, and of sexual intercourse." It is more consistent, however, both with a profound psychology and with the interests of ethics to extend the conception to all the natural impulses of man. This extensiveness characterizes the view of the more distinctively Christian doctrine; the good Christian keeps all his appetites, passions, and desires, under strict control in the interests of the ideally virtuous life which he is trying to realize. The same fulness of conception belongs to modern ethics, in spite of the present unfortunate popular limitation of the word "temperance" to moderation, or even ascetic abstinence, in respect of one artificial form of a subordinate kind of the human appetites. The extent of the more comprehensive and refined idea may be seen in this declaration of "holy" George Herbert: "To put on the profound humility and the exact temperance of our Lord Jesus Christ, and to keep them on in the sunshine 
and noon of prosperity, is as necessary and as difficult, at least, as to be clothed with perfect patience and true Christian fortitude in the cold, midnight storms of persecution and adversity." Here humility, or the rational will in control of that impulse to haughtiness to which the prosperous man is tempted, is rightly coupled with temperance. For to temper, or modify, by self-control, all the natural impulses is a cardinal excellence of will which is demanded in the pursuit of the moral Ideal.

Further insight into the nature of this particular virtue, as bearing upon the general theory of virtue is gained by considering the fundamental relations in which the varying intensities of the impulsive elements of liuman nature stand to the cultivation of a genuine strength of character. It is customary to speak - and this accords with universal experience of different degrees in the strength, naturally, of the various appetites, passions, and desires. One man is said to be born with "strong" and another with "weak" appetites or passions, - either including the general outfit, as it were, or selecting some one or more examples. $A$ is naturally "passionate" (meaning a man born with tendencies to anger which rise above the average level of intensity); but $B$ is "lustful" (in the narrower meaning of the word ) ; and as for $C$, the desire to aequire property has been espeeially foreeful and controlling from almost the beginning of his conscious life.

Two things are to be observed touching the psychologieal relation in which this so-called strength of the impulses stands to the acquirement of strength of character, to the Virtuous Life in so far as it consists in energy of self-determining Will. First: strength of character is dependent upon a certain natural inheritance or endowment of intensity to the appetites, passions, and desires; the man who is weak in respect of all these springs of action can scarcely become a man of strong eharacter. But, second, the reverse or complementary truth is this : unless these appetites, passions, and 
desires are tempered by self-control-unless, that is to say, the virtue of will which is called temperance, is called forth and cultivated-their very intensity becomes a source of moral weakness. For the centre of the Moral Self is apt to become occupied by some dominant impulse, which from this centre controls the courses of conduct to the impairment or the destruction of a genuine moral strength. Such a thing as a maximum intensity of all the varied and numerous forms of impulse is, of course, impossible of realization; for they sway the will of the morally weak man in different and often in contrary directions. The strength of the maniac is the nearest approach to the resultant in character, when all the impulsive forces of the soul are trying, since they cannot rage together, to get their turn in the control of the will. But strong appetites, passions and desires, when tempered by selfcontrol, are constituents of a strong and effective and morally admirable manhood. Thus Temperance becomes a cardinal and indispensable Virtue of the Will.

The same thing, in a way, is true of the appetites, passions, and desires of man, which was seen to be true of human fears. There is a general outfit of such impulses which all completely constituted human beings possess in varying degrees of intensity belonging to each. To be deficient in any of them is to lack some of the qualifications of manhood, and so to be incapable of certain forms of the virtue of temperance. These different impulses are themselves capable of being arranged in a scale of values, corresponding to the relation which they sustain to the Self in its pursuit of the moral Ideal. Thus, to control the appetites in the interest of almost every form of desire - the desire for property, the desire for estcem of one's fellows, the desire for knowledge, or the desire to succeed in one's profession - is recognized as a species of the virtue of temperance. But desires themselves have different values by reason of their relation to the values of the ends desired, if not by virtue of their own inherent 
worth. Nor can one stop with this admission. For the various affections, the loves and hates of mankind, make different claims upon the voluntary powers to exercise this cardinal virtue, self-control, in the interests of moral ends. For example, it is one's duty to control one's appetites, so far as their gratification interferes with the desire for property or for professional success, which desire in its turn ought to be tempered in the interests of one's affection for one's family or for the community of which one is a member.

'Thus the mind is led around to the same point of starting again. There are springs of action, desires and affections and longings, which ought to be allowed to control the conduct in preference to other springs of action. The perfectly moral man, in respect of this virtue of temperance, will not be the man without passions and desires; much less will he be the man without strong affections and intense enthusiasms. The coldblooded, unaffectionate, imperturbable man is not the Ideal Self. The exaltation which the ancient Stoical picture of the "good man" gave to this virtue of temperance was often itself intemperate, and therefore unsatisfactory to the most highly developed moral consciousness of mankind. Ardent desires for the various kinds of good, warm affections toward men in the different social relations, intense hatred of unrighteousness and of those who make prey of their fellows, and passionate devotion to righteousness, - these are not inconsistent with a virtuous self-control. But the full-orbed virtue is the Moral Self controlling its own springs of action in accordance with a rational pursuit of the Moral Ideal.

In the general evolution of humanity there are three forms of this virtue which are most imperatively demanded by the very constitution of soeiety, and in the interests of its perpetuation. 'These are the self-control of anger, of sexual appetite, and of the desire for property. Among the most undeveloped peoples ethically, the restriction of anger, lust, and avarice is necessarily provided for in some mamner. Other- 
wise there could be no eommunity life, no most rude and primitive organization of the family, no aequirement of property either by the individual or by the commune. Enforced control as respects these three forms of impulse nourishes the beginnings of the virtue of temperance. The various conerete forms of this edueative control by the community have, indeed, so often been at variance with all the modern ideas of truth, justice, and good sense, as to conceal and perhaps, seemingly pervert their real ethical significance and value. But the real point which must be insisted upon as of importance in framing a theory of the Virtuous Life remains fixed and luminous for the eye of the student of ethies whose insight is keen and penetrating. It is simply this : under all circumstances, and in all grades of human development, the good man must in some prescribed ways and to some obviously appreciable and worthy extent, voluntarily temper his anger, his lust, and his avariee, by consideration for the interests of others. Temperance or self-control in respect of the appetite of sex, the passion of anger, and the desire of property, is a virtue prescribed as necessary for even the most imperfect correspondence to the lowest eonception of an ideal manhood.

The natural passion of anger is part of the equipment which man has, in common with the other higher animals, to defend his interests of every kind against every species of attack. In its crudest form it expresses itself as the impulse to strike at once, to strike hard, and to maim or destroy the being which makes the attack. If, however, this passion cannot find such expression because of inability to get at the offender, or if it is restrained by some form of fear, it beeomes the spirit of hatred and the desire for revenge. The indulgence, or rather the exercise, of anger becomes a matter of moral action, an affair of good or bad conduct, when it acquires those ethical qualifications of will, feeling, and judgment whiel characterize all forms of conduct properly so- 
called. A being deficient in every phase and degree of this passion would, indeed, scarcely be capable of defending against attack any one of the many human interests; but a being incapable of developing the virtue of temperance in the control of anger would reinain still beastly in this respect. The higher in the scale of values stands the interest which is attacked, the more reasonable and even praiseworthy the anger may become; but always only if it is tempered by the will under the influence of the appropriate motives. These motives may lie either in kindly feelings, or in some form of just judgment respecting the merits of the case, or in regard to the consequences upon ourselves and others of either the indulgence or the repression of the anger. But all these so-called motives represent aspects of that selfhood which corresponds to the moral ideal; and into that ideal Moral Self temperate anger must enter as an important phase of its Virtuous Life. Even the Personal Absolute cannot be conceived of as an ethically Ideal Self without laying emphasis on his voluntary and affective resentment at whatever attacks those interests that are of the highest worth.

The crudest and most primitive way of bringing about the initial steps in the self-control of anger is the punishment of its expression by returning the consequences in kind. Life for life, an eye for an eye, and a tooth for a tooth. And amongst peoples of the lower stages of ethical development, - savages of the twentieth century B. C., or of the twentieth century A. D., and whether situate in ancient Egypt or in modern England, in ancient Mexico or in America of to-day, - the punishment for indulging anger, like the original indulgence in the anger, is a matter of good or bad conscience. That is to say, the deed is approbated as obligatory by the ethical judgment of the doer, or it is disapproved and rewarded accordingly.

Nor is the ethics of these complex reciprocities essentially altered by all manuer of startlingly false conceptions of per- 
sonality and personal responsibility. Where the passions are hot and unrestrained by refined moral motives, and where human life is cheap, one deed of blind, impulsive rage may kindle a bloody feud which will involve scores of men, and last through generations as yet unborn when the deed was committed. So in ancient Germany, whose poet Béowulf treats the punishment of Cain for Abel's murder as a divine act of blood-revenge. Here " came the great step of civilization which compounded a murder by the payment of a definite price" (the wergild, or man-price). ${ }^{1}$ The very unutilitarian method of expressing the disapproral of one angry killing by more of vengeful killing now gives place to a method which tends to make a prudential virtue out of the self-control of the passion. Thus, the impression is deepened that such conduct does not pay. In other cases, as in the Hebrew law, for example, ${ }^{2}$ the custom of blood-revenge was tempered by introducing the distinction between accidental killing and deliberate, malicious murder, and by interposing some representation of the public sentiment and authority between the culprit and his punishment (in this case, "the elders of his city," who were to "send and fetch him thence, and deliver him into the hand of the avenger of blood"). "Besides spiritual terrors," says Farrer," "secular punishment has a well-defined place among sarages, to check the extreme indulgence of hatred or passion. It is doubtful whether any tribe is so indifferent to the criminality of murder as to be destitute of customary penal laws to prevent or punish it."

There are not wanting traces, however, even among those low down in the scale of ethical development, of a more enlightened judgment and a better sentiment as to the wrong of intemperate anger. In the same Deuteronomic code which enjoins the slaughter of women and children in the city

1 See Gummere, Germanic Origins, p. 178.

2 See Deut. xix.

8 Primitive Mianners and Customs, p. 106. 
which resists the Israelites, is found not only the injunction to love one's neighbor, but the command, "Love ye therefore the stranger: for ye were strangers in the land of Egypt." While the sarage blood and ferocious customs of the ancestors of those races which consider themselves "superior" are still frequently shown in lynchings and other brutalities at home and in shocking barbarities in foreign war, it is fair not to forget what Buddhism has done to temper anger and to encourage pity, gentleness, and kindness amongst millions of the so-called "inferior" races. And if the modern Italian still extols the sweetness and commends the duty of revenge, the Yorubas of Central Africa may certainly extend to him a fit invitation to reflect upon the ethical spirit of some of the maxims current among them: "Ashes fly back in the face of the thrower." "He who injures another injures himself." "Anger benefits no one." "We should not treat others with contempt." "He that forgives gains the rictory."

It is instructive to notice how these "savage (?) proverbs" touch at a vital point almost all the motives which may be pleaded in behalf of the virtue of temperance as the selfcontrol of the natural passion of anger. It should be cultivated as a prudential virtue; for intemperate anger injures him who indulges it as surely as ashes thrown against the wind fly back in the face of the thrower. And society receives no benefit from such anger. For although the rational and tempered anger of the good man is an indispensable and priceless safeguard of social interests, a prime social virtue, savage rage "benefits no one." Men generally regard others as like themselves, worthy of being treated otherwise than in blind rage or sullen contempt; while the dignity and worth of not only the restraint of anger but even, and especially, of the spirit that goes beyond and stands ready to pardon the injury which has caused the anger, belong to the man who, by virtue of his own rational Will, has made a conquest of his lower self. To conquer thus one's self is better than to take a city. 
While, then, this particular form of temperance has a hard lot amongst men in their lowest, and still low, stage of moral evolution, the germinal ideas and sentiments from which the virtue may be developed are widely sown in human minds, if they are not everywhere present. And the ancient Scandinavian who boasts: "I have walked with bloody brand and whistling spear, with the wound-bird following me," has perhaps not more truly submerged this virtue in his false ideal of bravery than his modern descendant, who is ready to kill or to refrain from killing, in accordance with his idea of the interests of trade, lias lost sight of the same virtue in a dominant avariciousness.

Some kind of self-control of the sexual appetite also is exacted by the prevalent customs, laws, and ethical ideals, under all conditions and in even the lowest stages of man's ethical development. But the great variety of customs, laws, and ideals which give sanction to the relations of the sexes as dependent upon this appetite has already been noticed (p. $120 \mathrm{f}$ ). "The morality of the family is varied and changeable"; and, indeed, as the writer from whom I quote this sentence, ${ }^{1}$ and others have sufficiently shown, there is no other matter of morals upon which such widely and startlingly different judgments and practices may be adduced as upon this : What relations of the sexes are right, what wrong; or how shall the sexual appetite be controlled in the interests of the truly virtuous life?

On the one hand, we find the most refined Christian morals of to-day limiting the gratification of the appetite of sex to a chaste monogamous marriage, and still, although somewhat doubtfully, defending the limitation by reference to some moral intuition or even to some primitive divine command. But, on the other hand, the student of liuman history discovers almost every kind of license permitted at some time and somewhere - in respect of the limits of consanguinity, of

1 Schurman, The Ethical Import of Darwinism, p. 258. 
the number of wives or husbands, of the period during which the relations ought to hold good, of the grounds on which the relations may properly be severed, and of frequency of indulgence, etc. In Milton's apostrophe to marriage,

“ Hail, wedded love, mysterious law, true source

Of human offspring, sole propriety

In Paradise of all things common else,"

poetical expression is given to one form of thought as to what is commanded by the virtue of temperance in this regard. Standing at the other extreme are such views as those of the Mexicans, who held the possession of a large number of wives to be a proof of superiority; or the Ashantee law, which allowed the king three thousand three hundred and thirty-three wives; or the right yiclded to the king of Yoruba to have as many wives as, linked hand in hand, would reach across his kingdom. Somewhere between stands the tempered indulgence permitted by custom to the patriarchs, or to their descendants by the Mosaic law; and, indeed, the ethical theories, and practices of the multitude amongst modern Christian nations. And then there is the position taken by the Confucian ethies in Old Japan, which, apparently, attached no moral significance whatever to the intercourse of the sexes in itself considered, but only as it became dependent upon the supreme virtue of personal loyalty.

The reasons for such great divergence in the riews and practices of men as to what ought to be the temperate, rationally self-controlled indulgence of the sexual appetite, although in certain respects obseure, are in the main not impossible to appreciate. They may be touched upon in the following line of considerations. The appetite of sex is, with the exception of the appetite for food and drink, the most imperative of the bodily impulses. In the language of Schopenhauer, " in this act the most decided assertion of the will to live expresses itself." The general gratification of the appetite in some form 
is essential to the very continuance of the human specics. "Therefore it is this act through which every species of living creature binds itself to the whole and is perpetuated." Inasmuch, however, as there is an obvious connection between this voluntary act and the origin and perpetuation of life, that eternal and inscrutable mystery, the exercise and the control of the function have always been closely connected with the religious ideas and practices of mankind. The phallus was worshipped by the Greeks; the lingam is worshipped by the Hindus of to-day. But man, in this respect as in other respects, has much more decided preferences and choices than have the lower animals: and the very physiological characteristics of the human offspring necessitate some at least rude and inchoate form of the family. Moreorer, the interests of society become immediately and deeply inrolved in the union of the sexes. Of necessity a community of human beings cares more, because it has more raried and vital interests involved, how its males and females are paired than do flocks of birds or herds of cattle. But chiefly is it because the higher, tenderer, and nobler affections of man are most powerfully enlisted in connection with the exercise of the sexual functions that their control is of the highest import, not only as a matter of social custom and morals, but also as a matter of essential morality.

It is not strange, therefore, that an almost bewildering difference of conceptions and customs should characterize the judgments of men as to what constitutes the virtue of temperance in sexual intercourse. Even the practices and the sanctions of man's religious life throw littlc clear light upon the path of virtue in this regard. It is plainly the will of God that the will to live should be satisfied, by some form of uniting the sexes. But if man looks to the various forces and processes of nature for guidance, the utmost confusion of conceptions is the inevitable result. Quite commonly an important part of nature worship is phallic worship; and 
when religious erolution has reached the stage in which the gods are conceived of as persons similar to heroic and kingly men, their example is an encouragement to unbridled lust rather than to its temperate control. Such was the case in ancient Greece; such is the case in India to-day. Indeed, in the latter country the British Government is still compelled to make an exception to the laws prohibiting obscene literature, in favor of religious (!) books; and the sacred interests of morality and religion are continually pleaded by the most orthodox of the Hindus against the attempts made by their own reformers to promote the increase of sexual temperance and sclf-restraint. Nor does it appear, until after a lengthy, complicated, and even conflicting experience, what forms and limits of the control of the sexual appetite are actually productive of the best results. The consequences of the immoral indulgence of this appetite are often most remote and difficult to trace. And then, how irregular and fitful do these consequences secm to be! Relatively gross indulgences are not infrequently concealed or their bad results lie latent; while quite as frequently the least immoral, or even a small legitimate indulgence, is promptly followed by the most appalling evils.

Yet the other side of this universal human experience must not be neglected. Some self-control, a measure of tempering for this form of desire, is universally demanded of the man who will lay claim to the title "good." For the formal and legitimate union of the sexes the barrier of some sort of ceremony must in almost all instances be passed. Among savages it is a common rule of etiquette that a proposal for marriage shall be approached indirectly; generally it is deemed right that the male shall show his insistence by pursuing or even violently carrying off his bride, and that the female shall show her modesty by some, at least pretended, form of coyness or resistance. The limits within which marriage may lawfully take place are everywhere 
somehow fixed, although the manner of their adjustment varies indefinitely. The Hindu Kooch incurs a fine if he marries a woman of another clan; the Abors consider marriage out of the clan as a sin to be washed ont only by sacrifice; but among the Thlinkeets the young warrior of the totem of the Wolf must seek his bride among the maidens of the totem of the Raren. Almost everywhere adultery on the woman's part, if without consent of her husband, is punishable with death. Amongst the Germanic nations "the church has the credit of forcing law and sentiment to take cognizance of the husband's crime as well!" Slowly, and more especially among these same nations, the standard of sexual virtue has, at least as far as the sentiments and open practices of the majority are concerned, been rising. And there are few indeed now whose judgment is worth respecting, that do not identify the virtue of sexual temperance with monogamic marriage, and with such indulgenee of appetite in this relation as is consistent with the ligher interests involved.

It appears, then, that the regulation of the appetite of sex is a species of temperance in the larger meaning of this word. It is, that is to say, a form of the voluntary control of a natural and legitimate desire within the limits rationally permissible in accord with the pursuit of the ideals of a Virtuous Life. These limits are themselves the result of a historical evolution which has defined them more and more clearly, and has enforced them by more and more powerful sanctions, as the gathered experience of the race has yielded more light upon the right path. But prominent among the different forms of this experience is the teaching and example of the Christian Church and the teaching of its founder: "Moses because of the hardness of your hearts suffered you to put away your wives; but from the beginning it was not so." All other extensions of the limits, whether by way of legality or of custom, are thus declared to be concessive; but the dirine 
ideal for the human species is a pair, faithful to each other and chastened by those ends that have ralue and are dependently connected with the married state.

Another of the historically more prominent forms of the rirtue of temperance is self-control over the desire of possession, the impulse to acquire property. The desire "to hare and to hold" for one's self all the rarious forms of good is natural and unirersal with man; it is also indispensable for his material evolution and for the development of morality. No form of Communism is conceivable - not to say possible of actualization - which is not based upon the desire of property and the distinction between the ricious and the rirtnous ways of gratifying this desire. Therefore some measure of the external habits of honesty is esteemed good conduct under all conditions of human existence; and much as men may differ as to what stealing is, or as to how much and what kinds of stealing are permissible, some formal regulation of the indiridual's tendency to appropriate the goods of life exclusively to himself is always provided for by the customs and laws of the community. Even the robber castes of India recognize this virtue as reciprocally obligatory upon the other members of the caste. With them, as with our wreckers of railroads and other plunderers of the public, eren thieves must divide the spoils amongst themselves with some show of honesty; and if brought before the standards of the prevailing moral consciousness of their own class, they must show reason why their conduct was not essentially dishonest after all.

Here again the multiform curions discrepancies in the prevalent customs and opinions regarding the nature of the virtue, the weird and strange ordeals to which suspected culprits are subjected, the startling differences in the forms and degrees of punishment inflicted for crimes of dishonesty, do not change the essential nature of the transaction, whether subjectirely or objectively regarded. Thus if " the Guinea Coast negroes thought it reasonable to punish rich persons guilty of robbery 
more severely than the poor," they did not necessarily show themselves less appreciative of the crime of dishonesty than do the English of to-day, with their theoretical principle of impartiality before the law, for all ranks and degrees of wealth. The rich, argued the negroes, deserve more punishment, because they are not urged to steal by necessity, and can better spare the fines of money laid on them. "The thief catches himself," and "Stolen goods do not make one grow," say the Basutos of South Africa.

But the virtue of self-control over the desire of possession is not confined to matters of property in the narrower meaning of this word. Among the less civilized, the wires of any man are, of course, regarded as his rightful possession; and the crime of adultery is punished not so much - or not at all -as an impurity, but rather as an act of robbery of that which bclongs to another by right. So also to take another's picture, or to use his name, seems to many savages a similar sort of crime. To gain power over others by witchcraft or incantations and so to rob them of self-control or of the dues of service may also be regarded in nearly the same way. In our complicated modern life, where the "possessions" of man have became so much increased in number and magnitude, the various concrete forms of virtuous control over the desire for that which is not one's own, have themselves greatly increased. But the virtuousness of the virtue romains always the same. And the viciousness of the vice, too, - this is essentially identical in all times and under all circumstances ; it is the gratification of the lust of possession without regard to the moral ideals. When, as, alas ! so often happens in modern times amougst the most highly civilized nations " civilized," that is to say, in the interests of commercialism and for the purpose largely of protecting the property rights of the individual and of the community - this lust can be gratified under the protection of the laws, it may become legalized and respected indeed, but it is no less essentially 
immoral until it submits itself loyally and completely to the demands of moral principle. The custom and the law do indeed assist in defining the limits of a virtuous self-control. But if the self-control is not really exercised in the interests of the ideal of a virtuous life, compliance with custom and law is not morality. Indeed the custom and the law may combine to encourage this vice. For a time - but only for a time - the custom itself may be a species of robbery; and the laws may be enacted in the interests of robbers.

Many other forms of the virtue of temperance than these three might be mentioned and shown to be important parts of the Virtuous Life. For example, the rational self-control of the natural emotion of pride is the distinctively Christian virtue of Humility. But this virtue has been much misunderstood, - not only by the ancients, who found difficulty in detaching it from the suspicion of a certain baseness of spirit, but also by many modern writers. The genuine virtue of humility consists in the rational self-control of pride, primarily before God and chiefly with reference to one's own attainments and merits as measured by the standards of a perfect Moral Ideal. But before men, and in the face of every attempt to bribe or to threaten the soul away from derotion to its supreme spiritual interests, genuine humility is closely akin to, if not identical with, a certain noble haughtiness, or at least quiet self-reserve. And this is a virtue which, although distinctively Christian in the sense that it is a cardinal thing with the spirit of the true believer and was especially enjoined and needed in the early times of the Christian faith, has always and everywhere been recognized by the most thoughtful students of ethics. It is true that humility cannot easily flourish amongst those savage tribes whose successful struggle for existence depends upon the practice of the tougher and more strenuous virtues. But, as I have just said, humility is not essentially inconsistent with courage; in the long run, and in its more intelligent and refined forms, it is often the twin of 
courage in the successful struggle for the higher life. "Blessed are the meek : for they shall inherit the earth." When, where, and how? these are questions which it will take a long time for the race to answer in a practical way. Still, even amongst the Ojis, one may find such a suggestion as gleams through the proverb: "If you can pull out, pull out your own gray Ihairs." In happier circumstances the moral truth has been more reflectively and fully expressed in such wise sayings as follow: "As the tulip that is gaudy without smell, conspicuous without use, so is the man who setteth himself on high, and hath not merit." "Wherein art thou most weak? In that wherein thou seemest most strong; in that wherein most thou gloriest; even in possessing the things which thou hast; in using the good that is about thee." 1 Or, as the sacred saying of the Vaiṣnara Dharma is: "That man truly pronounces the name of the Loving Lord, who is in fortitude like the trunk of a tree, and in humility like a blade of grass."

Temperance in eating and drinking are, to a certain extent, enforced upon those tribes and communities whose conditions of living are most nearly primitive. With them the meagre and fitful supply of food confines the vice of gluttony within narrow limits; and the vice of drunkemness is also likely to be spasmodic rather than habitual. It is scarcely to the credit of any claim to superiority in rational self-control of these appetites, on the part of the most civilized peoples, that they have come to limit the popular meaning of the word temperance to the self-control, or the enforced external control, of the appetite for drink. The history of the matter shows that habitual over-feeding and improper drinking are more particularly the rices of a civilization where luxury and want exist side by side in extreme forms, or where some lardy race seeks relief in these ways from the monotony or

1 Taken from a book called "The Economy of Life" and purporting to be translated from an ancient manuscript discovered in Thibet and written by a Brahman. 
the severity of the conditions imposed upon it by its environment. The opposed virtues can never be widely and successfully cultivated except as the result of a more intelligent self-control under the influence of an exalted moral ideal.

That other Virtue of the Will which I have called Constancy is yet more cardinal - were this possible - than are the virtues of courage and temperance. By constancy I understand that intelligent and steady habitual action of the will which follows in strong characters the commitment of the whole self to the pursuit of a deliberately chosen end of good. "Consistency," says Lotze, " is demanded in conduct: only that which flows from such a constant character - rather than inconsequent ebullitions of fine feeling - experiences our moral approbation." "We demand that every single action be not at all times dependent on a hazardous struggle between character and the impulse of the moment. Rather does the moral habit, which makes the correct conduct seem like a second nature, appear to us a much higher ideal of morality and as somewhat toward which, among other things, education lias to strive." The virtues, according to Aristotle, are all "habits or trained faculties." Constancy, then, is the essential of every virtuous character, in so far as virtue is a matter of will. It is that interpenetrating and all-suffusing quality of moral selfhood which every form of the so-called virtues must have, in order to the realization of any even imperfect ideal of the Virtuous Life. In chosen courses of conduct it secures uniformity and dependableness; in the service of one's superiors, of one's country, or of humanity, it manifests itself as faithful obedience; in matter's of sentiment and of behavior towards others, it is the much-prized characteristic of loyalty; in devotion to the rational life, it is the very bone of veracity. On the contrary, every virtue is either

1 Outlines of Practical Philosophy, p. $30 \mathrm{f}$.

2 Nic. Eth., II, passım. 
marred or spoiled by the rice of fickleness and inconstancy. Of Reuben, said Israel, - though he was his firstborn, his might, " the beginning of strength, the excellency of dignity, and the excellency of power": "Unstable as water, thou shalt not excel." Steadfastness of purpose is, psychologically considered, the one indispensable condition of virtuous character, the rery core of right and dutiful manhood. It is justly admired under all circumstances, and in every stage of moral derelopment. Even bad men are given for this type of character a credit and an admiration which are not merely æsthetical but are also ethical. And the verdict of the populace, as well as of all writers on ethics, accords with the declaration of Seripture (Jas. i. 7 f.): "A double-minded man is unstable in all his ways." And "let not that man think that he shall receive anything of the Lord."

It is scarcely necessary, however, to call attention at length to the danger of mistaking the psychological nature of this virtue of the will. Constancy is certainly not to be confounded with obstinacy, or with "blind will" (provided even that we admit the propriety of any such term as blind will). Indeed, although constancy in any particular course of conduct may easily enough be accused of obstinacy by the opponents of this course, the two are so different that obstinacy cannot even properly be regarded as the shamming of constancy. The man who will not hear to reason is unwise, the man who prefers to listen and commit himself to the inferior good is morally foolish. Such refusal is the essence of obstinacy, and is not to be confounded with the virtue of constancy even when this virtuc, like all the other qualified virtues, is enlisted in a bad cause. Neither can persistence in an evil course of conduct convert that conduct from the one ethical category of "bad" into the other of "good" conduct. None the less, however, is constancy always a genuine virtue of the will. The solution of such a seeming paradox is to be reached in the following way: Particular pieces of 
conduct or aspects of character are called good or bad, ethically, according as they do, or do not, correspond to the Moral Ideal. Repetition of these acts constitutes, therefore, either a good character and a virtuous life or a bad character and a vicious life. For the principle of habit is fundamental in the growth of character, and the laws of development extend over the entire life. He, then, who at any time shows that power of will which induces a change from a bad to a good course of conduct makes the kind of a choice which is a highly important initial step in the path of all virtuous living. But constancy of will is essential to the fuller realization of this life. He who has hitherto been bad, because he has applied this essential characteristic of the virtues to vicious ends in vicious ways, is the more sure thereby of a successful issue when he changes his conduct to the pursuit of the higher ideals. Steadiness of purpose, although attained and exercised in vicious ways, when converted, gives more assurance of success than do the fitful yicldings of the ficklc man to the demands and persuasions of a disapproving conseience, even if continued through the whole life.

In all moral concernment, however, Habit is powerful over all; the bad man will necessarily become the weaker in respect of the possibility of changing to virtuous courses, and hardened in his commitment to vicious courses. But however it needs to be "qualified" by all these considerations, steadfastness of purpose, planful and constant self-control, remains a cardinal virtue of will.

There are scveral particular subordinate phases or complex combinations of these cardinal Virtues of the Will which are themselves recognized as separate virtues, in some sort within the scheme approved by the moral judgment of mankind. Such are patience, endurance, sobricty, industry, perseverance, etc. The exercise of all these virtues makes draughts upon the power of self-control under the hard circumstances, or in the presence of the seductions and temptations which every- 
where and inevitably belong to human life. The patient, enduring, and perserering man must have a steady, temperate, and couragcous self-control. The industry and sobriety which are chosen in the interest of the legitimate ends of life, and which bring satisfaction to the moral consciousness, are therefore entitled to be considered virtuous forms of selfcontrol ; for the temptations to laziness, impatience, and selfindulgence are pervasive and strong. But there are relatively narrow limits to all these subordinate virtues : there are wrongs before which patience is not the cardinal virtue; insults and attacks that ought not to be endured; innocent mistakes in chosen courses of conduct in which one ought not to persevere. There are also ethical as well as physical limitations to industry; and recreation and play may become imperative duties. Neither can it be said that the good man will be always "sober," unless a very generous interpretation be given to the word. If it be not true, as Aristotle taught, that a "refined and gentlemanly wittiness" is itself a rirtue, it is certainly permissible to be witty in consistency with the limitations set by other forms of virtuous conduct. And perhaps one may fitly end such a discussion by saying, as does Orsino in Crawford's Corleone: "I believe that the chief real wickedness is in doing nothing at all ;" or, "Sloth is one of the capital sins," as Vittoria observed, who knew the names of all seven.

When all these virtues of the will are combined in good proportion and fair mixture in one person, and that person is in their exercise fully committed through a long life to the realization of lofty and morally worthy ideals, we behold a character which the cultured moral consciousness approbates and thinks most worthy of reward. This is also the character which, under the conditions of human life is likeliest to succeed in doing the work of life. A loyal and a royal man, - brave, temperate, constant, and with an unchanging courage and moderation of his own desires committed to his 
highest ideals, - a faithful soul; such is he whom others esteem to be, so far as will can make one, the man of the virtuous life. He it is of whom they say:

"Languor is not in your heart, Weakness is not in your word, Weariness not on your brow." 


\section{CHAPTER XII}

VIRTUES OF THE JUDGMEN': WISDOM, JUSTNESS, ETC.

THE considerations which justify and explain the title of this chapter have already been presented with considerable detail. They show that certain kinds of conduct which men agree to call good, and which are indeed essential characteristic forms of the Virtuous Life, depend upon the culture and use of the judging faculty. It will be well, however, before proceeding to determine what these forms are, and how it is that intelligenee takes its place as an essential element in all noral goodness, to subject some of the most important of these considerations to a brief restatement. I shall do this, emplasizing the following four points :-

First: Judgment about matters of conduct is itself a species of conduct. And inasmuch as most judgments have some either direct or remote reference to eonduct, most judgments are liable at any moment in human experience to be brought under the rubrie of conduct. By a man of "good judgment," then, is fitly meant what the popular speech usually means, viz., one who uses his judging faculty in a morally worthy way.

Second: In all the language and usages of men which have a bearing upon this subject, this true and profound psychology of the judgment is implied. Judging is not conceived of as a mere getting together, much less as a mere sequence, under the laws of association, of memory-images or products of the phantasy. Neither is judgment regarded by men generally as a merely formal and, as it were, passive 
collocation or connection of conceptions or of so-called abstract ideas. I judge ; and this has reference to a voluntary and synthetic activity. The judgment is mine, as belonging to an actice Self. The ideas or conceptions, which logic regards as somehow being together, the language of men agrees with a rital psychology as regarding under terms of a connection effected by a living Will. What wonder, then, that the inclination of mankind is strong to hold - each one, the other - responsible for his judgment. The exhortation, then, to take heed how one judges is deserving of regard, not simply on prudential but also on more distinctively ethical grounds.

Third: The part which judgment takes in the conduct of the Virtuous Life is integral and essential. Judging well is not simply preliminary to virtue, or merely accessory to good conduct; neither is the part of judgment in morality fully discharged ex post facto, as it were, when the virtuous or vicious act comes before the bar of the intellect to have its moral quality estimated. Intellect judges conduet; how and why it judges at all, and judges as it actually does, has already been made elear in the discussion of the origin and nature of ethical judgment. Plato was, indeed, wrong when he went so far as to make virtue always coincident with knowledge; it contradiets the facts of experience to hold that men do wrong only because they do not know the beauty and the real worth of the higher good. Neither as accordant with facts, nor as tenable theory of the right and wrong in conduct, is it true that "all men are always involuntarily bad." 1 It is not even true that the cardinal rirtues of judgment-as, for example, Wisdom - are wholly identical with "thought on moral subjects" ( $\phi \rho o ́ \nu \eta \sigma \iota)$. Feeling and will enter into every species of conduct; and without these aspects of the moral self participating no virtue is possible. But, on the other hand, the same thing is true of intellect. In its supreme function-

1 Laws, p. $860 \mathrm{C}$; and on the Ethics of Plato see Sir A. Grant: The Ethics of Aristotle, I, essay III, and Thos. Maguire, Essays on the Platonic Ethics. 
ing by way of judgment, it is necessarily a participant in every rirtuous or vicious act. What is done blindly - wholly blindly - loses all the characteristics, both intellectual and voluntary, of a genuine piece of conduct. What is done deliberatcly is more particularly ethical in its characteristics; but deliberation is itself a voluntary exercise of the judging faculty. What is done with the whole Self - this it is which bears to the fullest possible extent, the stamp of the coin that is either genuine or counterfeit in the kingdom where right and wrong doing are matters of the supreme value. Voluntary judgment, feeling motive, deliberate choice, - thus the entire unitary being of the Moral Self commits itself to the consequences, internal and external, subjective and objective, of what is the expression of its own deepest life.

Fourth: But while all rirtues involve intellect, fecling, and will, and some virtues are chiefly of the will, some other virtues may properly bear the title "virtues of the judgment." Whererer the relation which the judging function bears to truth and reality is the prominent characteristic of the good or bad conduct, there the virtue or the vice may properly be spoken of in this way. It must be remembered, howerer, that we arc treating of real virtues and not of their appearances or of the opposite vices which so often are the shams of the real rirtues. For just as seeming courage may often result from real cowardice or from insensibility to some particular kind of fear, so seeming wisdom may be due to real timidity or to a selfish reserve of one's strength, or to neglect of onc's opportunitics. Just as temperance may be only the expression of another form of uncontrolled desire (like the miser's abstinence from food and drink), so what men call justice is not uncommonly the expression of merely prudential or positively selfish impulses.

The Virtues of Judgment, then, are those forms of conduct whose goodness or badness, in the ethical meaning of these words, depends chiefly upon the character of the judg- 
ing function which enters into them. Of such virtues the following three are most cardinal and comprehensive; namely, Wisdom, Justness, and a certain other form of good judgment which I will call, Trueness.

Wisdom as a virtue is moral, and therefore voluntary, judgment having reference to the ends of life, and to the means of attaining these ends. It is the Moral Self exercising its power of judgment in conduct regarded as the pursuit of some form of good. The virtue may either terminate in the act of judging, or it may require for its completion and manifestation some further motor elements. Indeed, since wisdom is essentially a judgment with reference to conduct, there is usually something to be done by somebody in order that the virtue may not spend itself in mere judgment as it were. When the action which is necessary to realize the wise conclusion devolves upon the very same person who has reached the conclusion, the failure to act certainly detracts from the popular estimate of the original virtue. Indeed, those who are wise to counsel others to virtuous conduct, but who do not conduct themselves in accordance with their own wise counsels, are apt to be esteemed bad, rather than good men. Here, however, as usual, what is needed in order to understand the psychologieal nature of this virtue is a more diseriminating analysis. To adjudicate wisely the value of ends, and the means of attaining ends that have ralue, is a virtue - not merely an intellectual excellence, but a species of morally right conduct. But habitually to disregard in thought the ideal ends of life may not improperly be said to be essentially vicious. "Frivolity," says Humboldt, "undermines all morality and permits no deep thought or pure feeling to germinate; in a frivolous soul nothing can emanate from principle, and sacrifice and self-conquest are out of the question."

To act in accordance with wise judgment usually requires courage, temperance, constancy, and all the other virtues of 
the will. To be lacking in these is to be not virtuous; it is to be, on the contrary, guilty of certain vices that are themsclves contrary to, and destructive of, the higher wisdom. Moreover, that principle of moral derelopment must be reckoned with which makes the habitual failure to do what judgment dictates ought to be done, react upon the judging faculty so as to render it obscure and blind. For the mind, in conduct and in the development of character, is such a unity of interdependent functions, that its vicious or defective working in any one important respect makes itself felt in all respects. For example, if courage should be wise, wisdom should be courageous, in order that both may be at their best.

The most important respects in which the virtue of wisdom needs to be excrcised are three in number : (1) the evaluation of ends, with a view to determine their relative worth; (2) the estimate of means, with a view to determine their effectiveness (often relative also) for the realization of ends; and (3) the appreciation of those limitations which concern both the ends and the means, but which belong to the natural and social environment of man. Wisdom in the evaluation of ends is sometimes called the "higher" wisdom; in the estimate of means the same virtue may be considered as a practical wisdom, the quality which belongs to the deliberate judgments of the expert. But a due appreciation of the limitations of life is the intellectual essential of that rare and holy complex of virtues which may fitly be called a wise Resignation. I shall consider briefly these three forms of exhibiting the virtue of wisdom.

In each of these three forms of wisdom one may discover what is the essential difference between knowledge and wisdom. Knowledge, too, culminates in that activity which is the supreme expression of man's intelligence, - namely, in the judgment. But wisdom always implies an estimate of some kind of value; and the judgment into which the quality of the virtue enters has reference to something conceived of 
as dependent - in some way and to some extent - upon personal will. If nothing which comes into our human lives had worth in human estimates, there could be no virtuous judgment, no wise man; and even when men discuss the wisdom of a constitution of the universe over which human wills have no control, the very problem - Is this constitution of the universe wise or not? - implies the conception that It is dependent upon the Absolute Will.

The highest conceivable manifestation of wisdom consists in the right, because rational, evaluation of those ends of life which can be, at least partially and approximately, reached by courses of liuman conduct. We have already seen (Chap. III) that men recognize different goods to be pursued; and that these goods are recognized as not only differing in degrees within themselves but also as differing between themselves in kind. The good which morality exalts is the Moral Self realizing its ends in the Virtuous Life. When, then, any problem arises concerning the end toward which it is wise to direct one's energies, this general principle will always be giren the chief place: it is always true wisdom devotedly and unswervingly to follow the ideal of the virtuous life. It is true wisdom always to set the problem of conduct before one in the following way : what is right and best (as having most moral value) to be done? The problem being proposed in this form, the syllogism along which the wise man's intelligence proceeds to the judgment, may be naïvely expressed thus : major premise - It is always wise to do what is right; minor premise - This is right; conclusion - Therefore this is wise. Certainly, like all other general principles and like all the devices of a so-called "pure" logic to advise men what conclusions they shall arrive at, this syllogism settles nothing as to what is right, and therefore nothing as to what is wise. But it describes the attitude toward his ideal of a virtuous life in which every man persistently and intelligently stands, who is truly wise. This attitude of soul is itself a virtue of the highest degree of 
excellence. It succeeds, when perfect, in making the higher wisdom appear coextensive with the entire rational content of virtue.

Nor can it be claimed that this relatirely abstract form of the virtue of wisdom is of little or no practical value. Questions as to what conduct is wise, what not, are often complicated enough. Many such questions can never be solved by a judgment which is quite clear and self-confident; and the entirely clear and wholly self-confident judgment of one man will not infrequently be exactly the opposite of that of another equally trustworthy judge. God pity us all if we are habitually tempted to think our wisdom of the highest and most complete! None the less, for the man who is in process of that discipline which alone can give the conquest of the Virtuous Life, the supreme obligation is to choose the end that seems to him to have the highest worth, to remain unswervingly faithful to it, and so to be wise, - howerer many faults of judgment he may commit in his decisions about the means of realizing this end. Neither is it true that such wisdom is not definitively practical. For in the majority of instances men know well enough how to supply the middle term and so to form the minor premise. They know what is right. But they think to be wise enough to make what they know is not right serve fairly well in the place of the right. To do this habitually is to be really unwise; it may in the end amount to the rankest and most mischievous folly.

The ends of truly virtuous living are themselves manifold and admit of being arranged in some sort of a scale of values. Hence many complicated and perplexing problems arise with respect to the subordination of these ends. To be always just is one such end; to be always kind is another. To make others happy is a virtuous thing to choose ; but to make others strong to resist temptation and able to fight manfully the battle of life is certainly no less virtuous. Which of the various ends it is wise to emphasize most, whether habitually or on 
any particular occasion, demands some special wisdom of judgment; and no so-called moralist can give rules which will dispense with the patient mastery of the details that belong to the preparation for wise judgment. Heuce, the higher wisdom is the steadfast attitude of one's moral self, as a judge, toward one's moral ideals.

Practical wisdom as a virtue, in the narrower meaning of the phrase, has reference chiefly to judgments concerning the right means to be employed in attaining the ends of life. But these means are far more complicated and intricate than are the ends themselves. Furthermore, so far as they are the objects of the wise man's judgment, the employment of them is a matter of conduct. In not a few instances, too, certain means involve action which is prejudicial to some form of good, or even destruetive to the securing, by others, of the things on which they have set their hearts. Hence the questions, What means shall be selected? and How far shall the particular means once chosen be pushed forward against the wishes or the rights of other's? become exceedingly difficult ethical problems. The solution of such problems of conduct requires the application of a large and varied stock of knowledge in the form of wise judgments. For moral judgment about appropriate means for the realizing of one's chosen plans has to consider - not simply what means are best, because likeliest to bring about the desired result, but also what means are permissible in accordanee with the principles of a virtuous life. The good man may not realize all his closen ends by the use of any kind of instrumentality. This would not be wise, with the wisdom of virtue, although it might be shrewd, masterful, and successful.

More and more, as the experience of the individual accumulates and the scientific knowledge of the race gives to it increased mastery over the resources of nature and over the gathered results of past discoveries and achievements, do problems of the use of means demand special and expert 
information. At the same time, many means for achieving desirable results which were wholly lacking in past times, are now ready at hand for general use. It is the part of wisdom to know what these means are, and to know how to use them. One can heartily sympathize then with the indignation which I have, in a clinic, heard a surgeon pour upon the parents of a boy allowed to grow up with an unstraightened spine or an uncorrected club-foot. He who, when important human interests are involved, will take no pains to know what course of conduct to pursue, or, in case he cannot himself judge fitly of the means, will not even try to know who the judges are, is foolish in an immoral way. In modern life, therefore, the place of the expert is destined to become increasingly important. It is wise, it requires good moral judgment, to provide pure water, clean streets, effective protection against crime and fire, and to organize schools and other institutions that make for good citizenship. It is unwise, it is distinctly immoral judgment, and wicked conduct, which disregards the opinions and counsels of those who know, and who are therefore entitled by their wisdom to decide in the interests of the people. That king is saved by his wisdom who, knowing himself to be a fool in need of counsel, is wise enough to choose wise counsellors and to follow their advice. But woe to the nation that is guided either by its own unintelligent impulses, however brave or generous in themselves, or by counsellors and legislators that, however shrewd in political manipulation, have little or no true wisdom! Courage and generous expenditure of treasure and blood may save that people from some of the effects of its folly, but courage and generosity can never take the legitimate place of that cardinal virtue of good judgment which is called Wisdom.

In those communitics which are low in the scale of ethical evolution practical wisdom occupies a most important place amongst the cardinal virtues. The man who is wise in council is the running mate of the man who is brave in war. That 
tribe or nation is well equipped with the most essential excellences for its existence, and for its welfare, which has its young men courageous warriors and its old men wise, " not in part nor in any particular thing (as Homer says in the Margites -

' Him the gods gave no skill with spade or plough, Nor made him wise in aught'),

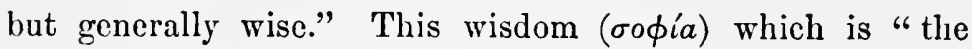
union of intuitive reason with scientific knowledge, or scicntific knowledge of the noblest objects with its clowning perfection added to it," "has always been a rirtue highly prized. In its very nature it is a mixture of the higher wisdom and practical wisdom (but not necessarily the knowledge of a specialist in any one line). It was for this that the Sophists were, so far as admired at all for wisdom, justly admired. It was this which Socrates, as not wise but a "lorer of wisdom," wished to substitute for the sophistical pretence of wisdom. It is this kind of wisdom which, no less rare, is no less to be prized and is even more difficult in our complicated modern life. Who is the wise man of to-day? He who, adjudging to the various ends of life the value which really belongs to them, judges correctly also as to the means to be employed in realizing these ends, - and all in consistency with the ideal of virtuous living.

But wisdom, like courage and temperance, has its imitators, the shams that sometimes seem the same with the virtue, but are often really the vices most unlike its genuine form. One of these shams of wisdom is the unfounded conceit of knowledge, which is all the more effective if the supposed content of the knowledge be something wholly esoteric and lidden from the common herd; and if the knowing subject be shrewd enough to be chary about exposing his wisdom to the tests of reality or of the sound judgment of other men. It is recently

1 Nic. Eth., VI, vii. 
reported that a new Grand Llama has been proclaimed in 'Thibet; and he will be worshipped by the people as incomparably wise in matters extremely occult and of the highest import; but it will doubtless be the better for him not to talk too freely, but to allow his owlish look and dignified silence to be mistaken for the supremacy of wisdom. To this class of the pretences of a noble virtue belong most of the theories and practical judgments of what goes under the name of theosophy, "Christian" and not a few other forms of "science falsely so-called," together with the practices of palmistry, fortune-telling, oneiromancy, and what not. In saying this I do not mean, of course, to deny that all or any of these subjects admit of investigation with a view to determine knowledge, and of that sound moral judgment respecting the conduct connected with them which is the essence of the virtue of wisdom. But most undoubtedly the far greater part of this sort of wisdom is only a pretence of virtue which either arises from ignorance and folly, or is more positively vicious on account of the large admixture with it of mental laziness and of falsehood. Most pernicious, perhaps, of all the shams of wisdom is that low-lived shrewdness in business which stands ready to abrogate or avoid every principle belonging to the higher wisdom, if only the chosen end of commercial prosperity can be secured.

From the cardinal virtue of the judgment which is called Wisdom flow several subordinate but important forms of right conduct that are themselres entitled to a place in any complete catalogue of the virtues. These may more properly be called the genuine prudential virtues. Here we return to a subject already touched upon (see p. $240 \mathrm{f}$.), and are prepared to regard it from another and higher point of view. What is popularly called prudence is not a virtue, but is rather the vice of cowardice, when it consists merely in the yielding to some unworthy form of fear. But, as we have just seen, it is not easy to gain one's lawful ends, however worthy, or even 
to gain the use of the means which are likely to be most serriceable in the pursuit of these ends. Espccially do the virtues of justice and kindness toward our fellow men hedge in and move athwart the path along which seems to lie the way to suceess in attaining the aims of life. Indeed these rirtues are essential parts of human life; all virtues are social and have regard to our fellow men. Therefore wisdom in the form of prudence, or, rather, wisdom showing intrinsic excellence as moral judgment in various forms of prudent conduct, is a marked characteristic of the truly good man. Wisdom itself, although a cardinal virtue, is qualified by the other cardinal virtues of justice, kindness, etc. But it, in turn, qualifies them; kindness and eren justice, must be wise, in order to reach their highest estate. And thus the wise man will be cautions in action, where the virtue of caution is demanded; and he will be deliberate and fair minded in making up his opinion, where the virtue of deliberation can fitly be secured. He will be provident with respect to the present and future risks of life, considerate of the feelings and interests of his fellows, judicious in selecting his associates and in respect of the trusts which he reposes in other men, and discreet in his selection of means for realizing his own plans and in his adaptation of these means to their appointed work.

Nowhere else is the virtue of wisdom as a matter of politics more forcefully commended than in these words of the Hebrew law-giver: "Keep therefore and do them (i. e., the divine statutes and judgments); for this is your wisdom and your understanding in the sight of the nations, which shall hear all these statutes, and say, Surely this great nation is a wise and understanding people."

Perhaps the loftiest, and often the most pathetic, exhibition which the truly wise man can make of his wisdom is in the form of Resignation, or voluntary and intelligent judgment in riew of the limitations which belong inevitably to the life of the individ* ual and of the race. Ideals of every kind, the more they are 
contemplated and subjected to thoughtful consideration, the more do they rise and expand themselves before the mind. The more passionately, enthusiastically, and hopefully they are pursued, the more bitter the strife becomes to attain them, the more inevitable the disappointment over the very partial character of the realization of them which human efforts can secure. But the nature of morality requires the deroted and unswerving pursuit of one of the loftiest and most unattainable of all human ideals; this is - to speak only, for the present, from the point of view which I am holding - the reality of the Virtuous Life, in its perfection as an Ideal. Speak as one may of moral freedom, and exalt as one will the lower of man to realize his noblest ambitions, the Koran is truer to experience in declaring that a man miglit as well lope to cross the gulf of hell on a hair as to live a life wholly without wrong-doing, than he would be who should claim the ability, in fact, to realize this ideal of perfectly virtuous living. 'To relinquish the pursuit of the ideal is to drop down from the demands of the higher wisdom to the level of a wrong tolerance of vice: but to fail, in one's plans and in one's use of means, of all recognition of the inevitable limitations of the Moral Life, to continue vainly to "kiek against the pricks," is also a fatal wrong toward the counsels of practical wisdom. If patience, endurance, and courage are virtues of will which must characterize, unremittingly, the pursuit of the ends of morality, resignation is a habit of mind toward the suceess of such pursuit which is one of the noblest and most necessary forms of wisdom : - most difficult, too, for the most noble and aspiring souls, whose temptation and failurenot to say, whose vice - is to be not resigned.

Resignation is then, a virtue of rational judgment which leads to a certain yielding of will before the inevitable limitations of the moral, as of every other form of life. It results in the no less patient, enduring, and passionate pursuit of the moral ideal, though with a constant attitude of mind that 
is rationally adjusted to the fixed conditions of that enrironment in the midst of which this ideal must be pursued. For, as says Lotze: " "Neither ought conduet to be fruitlessly directed toward what is in itself impossible, nor ought a contest to be waged against what is unavoidable. This is the thought of Resignation, by which all our activity is limited to real and attainable ends."

In its highest exereise this kind of wisdom almost imperatively demands the support of the religious motive. It is, possibly, conceivable that a man may still retain his devotion to moral ideals and practice, and also gain the pure virtue of resignation before the limitations of life when these limitations are regarded from an absolutely fatalistic point of view. But the shikata ga nai ("it cannot be helped") of the careless Japanese servant, and the erect head and unbending will of the ancient Stoic philosopher, before the destiny of pain and defeat, are scarcely on a level with this form of wisdom. The roluntary bending of our wills to a Will in whose wisdom we have a reasonable confidence is a great support, if it be not the indispensable condition, of the virtue of resignation.

The vices which are the opposite of this virtue are somewhat manifold. Among them are the discontent, the peevishness, and fretfulness which men whose lives are full of disappointed plans for realizing worthy ideals so often share with the men of selfish and unideal lives. There is also that "high-flying extravagance" of aims and plans which often characterizes the fanatic or the megalo-maniac. Saddest of all is the rebellious spirit with which the proudest and most incorruptible souls sometimes meet the inevitable result of their honorable struggle for the supremaey of truth and justice. Hence comes the moving spectacle of a Prometheus Vinctus, - a man who has striren heroically for the good of humanity, now bound and suffering to have his vitals torn

1 Outlines of Practical Philosophy, p. 27. 
by the rultures that have hitherto been restrained by fear in their desire to approach. That purifying function of tragedy which Aristotle recognized is exercised when reflection reveals the moral lesson of human experiences like these.

The second cardinal virtue of judgment is Justness; and in treating of it we have a more complicated and difficult conception before us than has been presented by any of the previously considered forms of virtue. Courage and constancy are comparatively simple aflairs; their psychological nature and the historical conditions which have enforced them and which have determined their several principal forms of manifestation are comparatively easy to describe and to estimate. Since temperance has its range of control over so many different and often conflicting impulses and desires, its psychological description, historical evolution, and practical application furnish somewhat more difficult problems for the student of ethics. But none of these virtues, as respects its complexity and the obscure problems it presents, equals any one of the several virtues of judgment.

Justness is a term which covers a group of forms of rirtuous conduct whose psychological origin and character, and whose historical evolution, are very complicated and obscure. Whocver has to take the part of the judge, and to pronounce judgments that must scem fair and fit to the critical moral consciousness, knows that he can seldom be sure of securing more for these judgments than his own just intention. Subjective justice, - what is it, as respects its origin and character from the psychologist's point of view? Objective justice, the spirit of justness realized, where in the universe shall the man find it who has not either already lost the red blood from his conception of the ethical Ideal; or else has answered with a faith far transcending sight the pressing inquiry: "Shall not the Judge of all the earth do right?"

This complexity of psychological nature and historical 
development requires recognition. In the effort to cover all that virtuousness which seems to give their characteristic good quality to an entire group of the most fundamental and universally commended virtues, I have thercfore adopted the word "Justness." By this I do not mean mere compliance with the customs and laws, whether common or statute, which regulate the relations of men, - in business dealings, in civil and criminal procedures, or in the freer intercourse of friendship or the family life. Nor simply by dealing out rewards and punishments according to one's ideas of the merit or demerit of others' conduct, together with the wise insistence that one's self shall be treated justly by others, does one become perfectly just. On the contrary, submission to a large amount of injustice from others, and no little treatment of others which it is impossible to make consistent with the conception of a strict distributive justicc, seems inevitable in erery good man's life. Even in legal administration, the abrogation or ameliorating of justice, in the narrower meaning of the word, is at least occasionally demanded in the interests of the higher virtue of justness; just as the higher wisdom sometimes makes it necessary to disregard all ordinary prudential maxims. Mere justice, for its own sake, may become a horrible fetish; its worship may result in conduct that, from the higher standpoints of moral consciousness, seems thoroughly defective in respect of virtuousness, if not positively criminal.

There is undoubtedly, however, an entire group of virtues which appear most fitly to fall together under one term, and which cannot be resolved into "benerolence," in any properly restricted meaning of the latter word. Such are, for example, honesty, honor, equity, fairness, and much truthtelling and enlightened kindness. In some sort, too, it may be said of justness that it includes the essence of all virtuousness. The author of the Fifth Bouk of the Nicomachean Ethics recognizes a kind of general justice, including 
the legal and the fair: "Justice, then, as so defined, is complete virtue, although not complete in an absolute sense, but in relation to one's neighbor." This justice, which is the exhibition of the spirit of virtue toward others, "is not a part of virtue but the whole of virtue." Thus understood, it is, of course, worthy of the highest praise. Justice and virtue are one and the same character differently riewed. "On this account it is often spoken of as the chief of virtues, and such that ' neither evening nor morning star is so lovely.'"

This high estimate of justness, as well as its complex character, cannot be considered as due chiefly to the evolution of law and custom. The eonception and the practice certainly were far enough apart among the Greeks of Aristotle's time. In general, however, it may be urged that where the discomforts and disasters of unjust judgment are most abundant, the praises of the virtue of just judgment are apt to be most loud. But where ii is assumed in the rery structure of the government and of society that a large measure of equality belongs by right to every individual, and where the laws are trusted to regnlate both distributive and retributive justice, the difficulties of actualizing this theoretical equality, and so the actual failures in fairness and equity, are less easily made obrious. Yet the essentials of this virtue are probably as highly prized among savage peoples as among the most elaborately constituted and highly eivilized communities. The cirilized praetice, however, is about as far below the eurrent ideal of this most important rirtue as the practice of ancient times and of sarage peoples has ever been below their lower ideal. "Perhaps," says one author, " "no description of savage character is fairer than Mariner's of the Tongan Islanders. 'Their notions,' he says, "in respect to honor and justice are tolerably welldefined, steady, and universal; but in point of practice both

1 Farrer, Primitive Manners and Customs, p. 127 f. 
chicfs and people, taking them generally, are irregular and fickle, being in some respects extremely honorable and just, and in others the contrary, as a variety of causes may operatc.' But the justice of such remarks is lost in their vagueness, and their impartial generality would render them of world-wide rather than of merely local or insular application." Who that knows "the chiefs and people" of the United States or of Great Britain could claim for them anything better respecting their notions of justice, or anything less bad respecting their practice of this entrancing virtue? It is -

\section{"This even-handed justice}

Commends the ingredients of our poisoned chalice To our own lips."

And the cry of the ages is: "There is not a just man upon earth, that doeth good, and sinneth not" (Eccles. vii. 20). Where justice is supposed to reign, it is little appreciated. Where it is most lacking, it is most praised.

An analysis of the virtue of Justness shows that the appreciation which it receives is due to the rery nature of the Moral Self in its social environment with other selves; while the immense variety of customs, laws, opinions, and judicial decisions which have given concrete realization to this virtue is due to the varied nature of man's moral evolution. Only some such distinction as this will help us solve this paradox of experience. That one ought to be just, and to require justice of others, - this comes out of the moral constitution of man which is at the same time sclf-regarding and social. What constitutes justice, under certain definite circumstances or in every special case needing determination, - this is a question, to answer which requires an immeasurable fund of historical information and illimitable tact in forming particular judgments. The spirit of fairness, ready at all times to infuse the judgment, - one can understand, appraise, and cultivate this. The actually fair 
apportionment of the goods and evils of life, so far as these depend upon one's just judgment, - no one can hope to accomplish much of that. The psychology of the virtue, though complex and somewhat obscure, arises out of the depths of personal existence; it springs from the permanent nature of moral and social beings. The account of the various forms which the virtue has assumed, although interesting and helpful to the understanding of its intrinsic nature, is due to environment and historical conditions.

By Justness, as a cardinal virtue, I understand the voluntary judgment which duly apportions to men their share of the goods and the evils of life, so far as these goods and evils are dependent upon human conduct. Injustice, popularly so-called, is indeed customarily regarded as some deed which either violates the rights of others by taking from them what they already possess, or else prerents them from receiving what they have a right to possess. But even in such matters it is recognized that the person who cannot in any way effect the result by his action is as capable as another of being, in his judgment, either just or unjust. Men demand just judgment of their fellows, even where the bare satisfaction of being justly judged is the only appreciable result. Indeed, in many cases, if it is justice, for its own sake, which they demand, and not the " pound of flesh" for its sake, men prefer just judgment even when it is, from the nature of the case, not possible to carry the subjective virtue into objective realization. And as for the case of the man who judges virtuously but will not act according to his own judgment, his failure and vice are everywhere severely condemned.

The good things and the evil things of man's life are, to a certain increasingly large extent, disposable according to the decisions of men themselves. It is within the sphere of such things that justice mores. Where men, whether in the lower and coarser or in the higher and more refined forms 
of religious faith, regard this distribution of good and evil as dependent upon the Divine Will, they bring eren the judgment which guides that Will before the bar of human judgment. ' They argue with themselves and with one another as to the justice of the gods, or of the One Supreme God. But this working of the religious consciousness only confirms the conception of this virtue which I am adrocating. In the distribution of the evils of floods, cyclones, and strokes of lightning, they do not demand justice of their fellow-men unless, as in the case of the disasters at Johnstown and Galreston, the results can somchow be traced back to responsible human action. But earth and air and water, with their common stock of bane and blessing, are disposable by the will of man, according to fair or unfair judgment; ard so are the fruits and deposits of the earth, the breezes of heaven, and the contents of river, lake, and ocean. And He who made men in his own image commanded: "Let them have dominion orer the fish of the sea, and over the fowl of the air, and orer the cattle, and over all the earth, and orer every creeping thing that crecpeth upon the earth."

It is not material goods alone whose apportionment depends upon the conduct of man. Honor in the eyes of one's fellows, reputation, political place and influence, social position, intellectual attainment, opportunities for moral and spiritual welfare, are also among the things for the distribution of which the virtuous judgment which we call justness is imperatively demanded. This dependable character of those goods which all men desire, and of those evils which all men wish to avoid, upon man's conduct is the fundamental and universal fact which makes human justice and injustice possible.

Within the consciousness of man, therefore, there arises

1 For a discussion of some of the curious implications regarding the nature of Reality which this involves, see Philosophy of Knowledge, chap. XVII and A Theory of Reality, chap. XIV and XVII. 
what may be called an instinctive sense of justice; and with the development of moral self-consciousness there comes a sort of sacred apperception of the worth of personality. In its lower and beginning forms, this so-called "sense of justice" is ehiefly protective and retributive. It has its foil in the animal consciousness; but injustice does not cut deep with the lower animals as it does with man, and it is doubtful whether anything resembling its dullest human appreciation is to be found with them. Wolves that liunt in packs do indeed contend with one another for a share in the captures of the hunt; and ants have a semblance of organization in which each member has its duly allotted place, and suffers the just penalty of being found derelict in duty at that particular place. In fact, however, the consciousness with which all this is done probably does not even remotely resemble that of the Homeric heroes when they dispute over the spoils of war, or the places of honor and of leadership. There are seemingly authentic stories of animals - notably of elephants - cherishing the spirit of revenge and punishing those who had excited their anger, even after considerable intervals of time. But it is doubtful whether the sense of being wronged, and of righting the wrong in accordance with the satisfactions of moral consciousness, such as the lowest savages manifest, is back of any of these analogous actions on the part of the lower animals.

Adult human beings generally resent attempts to deprive them of good, or to inflict evil upon them, not merely in the spirit of instinctive anger, but with the approving consciousness of protecting their rights. We believe also that Lotze $^{1}$ is true to the psychological facts, when, in discussing " the simple moral ideals," he declares: "Retribution is agreeable to conscience; that is to say, the returning of a corresponding measure of reward or of punishment to a will,

1 Outlines of Practical Philosophy, p. 29. 
which has occasioned a definite measure of weal or woe." Every man, by virtue of his normal moral consciousness, is capable, not only of feeling spontaneous anger or prolonged resentment, but also of feeling "wronged" and of cherishing the desire to see the wrong somehow righted. Therefore, the virtue of temperance in the form of the self-control of anger only limits but does not extinguish the sense of justice. On the contrary, it requires justness, - the submission of the feeling of anger to rational considerations in order that all the interests of the Virtuous Life nay be the better conserved and promoted. Here also justness itself, in the higher form of this virtue, intervenes to correct the tendency to an unjust excess of merely protective and retributive justice. For the man who invokes even the most primitive sense of justice is always a member of some sort of a community; and he is necessarily restrained by the enforced obligation to remember that the man who has wronged him is still also a man unless, indeed, he be an outlaw, or a beast of a man. Retribution itself, therefore, must also take on the garb of justness, must be measured according to custom or to law, whether it be between members of the same tribe, or between different tribes.

It would take the discussion too far afield to examine thoroughly the psychological origin and historical evolution of the doctrine of human rights. It is enough for the present purpose to know that the consciousness out of which this doctrine develops is strictly universal; it belongs to man everywhere and under all circumstances, to man as man. Every normal adult human being claims for himself some rights, and also acknowledges the obligation to respect some of the claims made by others for the satisfaction of their rights. Every man believes that certain of the good things of life are his dues, and is irrevocably committed to the conviction that he ought to be exempted from certain evils at the hands of his fellow-men. What precisely are 
these goods and evils, and what the measure of them, which justice demands for every man, is a question whose answer admits of no general agreement. The Javanese servant will not resent fines and blows from his master, if they are "nominated in the bond" which the customary relation executes; but he will kill you with good conseience, and as a duty, if you call him certain opprobrious names. The "grafters" and "strong-armed" thieves of our modern American cities are ready enough to insist upon what they call the "fair thing" in their iniquitous partnership with the police. Nor do they have any less respect for the justice of the authorities that arrest, imprison, and hang them, if only such is their fate in the result of a "fair" fight between themselves and the public good.

In some sort, then, every developed moral consciousness places all individual moral selves on a basis of equality. The goods and the evils of human life are manifold; the former are somewhat uncertain, yet on the whole abundant enough for all to hare some share; the evils are inevitable and of such nature that every one must have some share. The distribution of both goods and evils depends largely, either directly or indirectly, upon the will of man. Every Self, because of his selfhood, is morally entitled to his own proper share; to this he has rights, and he is in duty bound to leave to every other the share that is his own. If in human society there is a failure here, and the failure is due to human conduct, wrong has been done. Justice demands, originally, the avoidance of all such wrong; it requires the positive virtue which assists in the equable allotment of both good and evil. But when the wrong of injustice has been committed, justice demands that punishment should correct the wrong. That curious mixture of highflown talk about esscntial rights, and of intense fecling with respect to exacting and rendering justice to these rights, with what we should regard as the most flagrant injustice in the work- 
ing of the existing customs and laws, and with the most confused and inadequate notions of personal responsibility, of which human society is capable, is perhaps nowhere else so well illustrated as in China. ${ }^{1}$

The case is not, then, as though man, like the other animals, simply wanted the satisfaction of his desires; for his social life rests upon the ethical demand, as a right, of a due proportion of the common good. Why this universal demand? and, Why this concession of the rightness of a similar demand by others? Some crude estimate, at least, of that personal worth in which each individual has a share must be at the bottom of the demand. It is this which in part (but only in part) accounts for the satisfaction which all mankind feel in retributive justice. Pain suffered by the offender and inflicted by the offended may satisfy the passion for rengeance. Punishment regulated by custom or legal enactment, and proportioned duly, makes for the peace and order of the community. But outraged sense of justice puts in its roice at this point with a claim for satisfaction that is of a deeper sort. Only in accordance with this view, it secms to me, can we account for such ethical phenomena as the frequent self-punishment of criminals (sometimes even with death); or where, as in "Old Japan," the corporate conscience was sensitive and the conceptions of personality vague, and the man of honor voluntarily assumed the penalty needed to satisfy the demands of justice as against the community at large.

Although compliance with custom and observance of legality cannot be identified with the virtue of Justness, and although regard for the current forms of behavior and for obedience to the laws cannot explain the attitude of men toward their criminal fellows, yet this virtue can never get concrete expression in action irrespective of custom and legality. Ignorance, or seorn of custom or of the existing 1 See Chinese Characteristics, by Arthur H. Smith. 
legal enactments, makes distributive justice difficult; it makes protective or punitive justice well-nigh impossible. For the measure of the rights to which most men think themselves entitled is that afforded by either one, or by both, of these two standards. All the others have this good fortune, why cannot I? None of my fellows are treated so ill, why should I be? These are questions which children and childish men and women are forever asking of themselves and of one another. If they cannot get a satisfactory answer from human sources, they will have it from hearen. Thus struggles for precedence at courts and at all manner of functions, and for the enjoyment of all the trivialities of life, are gloried orer and made seemingly to have a certain cthical respectability, by an appeal to this universal and eternal regard for what is fair and just. Each rank, each circle, each social class, makes in this way its attempt at the fixing of some accepted standard.

But as, in the evolution of moral selfhood the tenct of the equality of all selves, in some respects at least, becomes more widely extended, and the corresponding sense of justice and the demand for the recognition of rights expand, the customs and the laws which regulate the concrete expressions of the virtue of justness undergo constant changes. What was once very just has now become the most rank and unbearable injustice. What is generous rather than simply just in one place, and under one set of circumstances, seems intolerable when change of place and of circumstances must be taken into the account. Practical justice is, therefore, doomed ever to shift and alter both its grounds and its character. Custom and law camnot confine it, although custom and law are so largely the expressions which it has given to its own inner spirit and intent.

On the other hand, as there is a higher wisdom, so there is a higher justness. This higher justness judges the customs and the laws themselves and condemns or approbates 
them in accordance with its own ideals. In order to be just, and so true to its own higher nature, this supremely virtuous judgment must keep free from the temptations of Fanaticism; it must always bear in mind the inevitable limitations under which all human ideals of virtuous living are progressively realized. At the same time, and especially in the case of those more highly complex civilizations where the forms of justice have become registered in prevalent customs and accepted laws, one is made painfully aware that often these same customs and laws are most blameworthy and pernicious from the point of view of the higher justness. Alas! that this judgment should be so emphatically true of the most advanced nations at the present time. Nothing else can possibly be so disturbing to the public morals, or so threatening to the public welfare, as the enactment of laws which the multitude of the people governed by those laws feel to be unjust and unfair. This, however, is the inevitable result of class legislation especially under a republican form of government. Here the very laws and the whole structure of society become chargeable with the dreadful crime of a deliberate, wilful, and protracted disregard of fairness. It is not individual acts of injustice, however frequent and violent, that most threaten the virtuous quality or even the stability of the national life of any people; it is, the rather, the organized and customary and legalized unfairness which is most dangerous. And what awful retribution has more than once in human history followed a long-continued disregard of this essential characteristic of a virtuous National Life!

What, then, can the individual man do in order to merit the title of the "perfectly just"? He can (1) cherish always the spirit of fairness; (2) hold ever before him an estimate of the worth of every individual man (no matter to what race or social rank the individual may belong, and irrespective of the relative grade or the total mixture of 
human characteristics which constitute the individual); (3) diligently inform himself as to the relative values of the ends of life and the means of obtaining them; (4) study those customs and laws which are so influential over the interests of men in the use of means for the pursuit of every form of good; and, then, finally, (5) fuse all these elements of justness into judgment whenever any concrete question arises concerning the share of the common stock of good and evil which shall be borne by any individual self - himself, of course, included. He who with courage and constancy, and with the spirit of tempered kindness, always acts under the control of such judgment gives to the world the best possible cxample of perfect Justness. But a perfect objectire justice-a wholly fair distribution of earth's gocds and evils in accordance with the merit of each individual man is an ideal toward the realization of which one man, with his highest wisdom and most strenuous endeavor, can do little enough.

As Plato long ago taught, justice is the reality of which all the division of life's labors and acquisitions is the semblance; - "dealing, however, not with the outward man but with the inward, which is the true self and concernment of a man." 1

\footnotetext{
"Say, what is honour? 'T is the finest sense Of justice which the human mind can frame, Intent each lurking frailty to disclaim, And guard the way of life from all offence Suffered or done."
}

Closely allied with the virtue of justness is that other cardinal virtue of intellect which I have rentured to designate by the somewhat unusual title - Trueness. Indeed, so close is the alliance between the two that the latter might almost be called a species of the former. There is, however, an important difference between them; and that quality of ideal 
manhood which appears as sincerity in conduct and genuineness of character is not altogether the same as that which gives birth to the virtues of fairness, honesty, equity in dealing with others, etc.

By Trueness as a cardinal virtue of judgment I do not understand mere truth-telling, or speaking what is believed to be either true in facts or to be in theory accordant with a large number of facts. Much less ean one properly define this virtue so as to approve unthinking bluntness of speech, or that openness of conduct which reveals the thought and feeling without regard to effects upon the thoughts and feelings of others. Undoubtedly, justice and kindness both require much concealment, and sometimes even what is ineritably misinterpreted so as to construe a voluntary deceit; much of this same thing is also apparently necessary to a proper self-respect and to the maintenance of any ground of standing for the exercise of the social virtues generally. Mere truth-telling, for its own sake and without regard to consequences or to the inquiry, whether the truth ought to be told at all and who is the proper person to tell it, may become criminal; and such truth-telling often shows a defect in respect of the virtues of wisdom, justice, kindness, or eren courage and temperance and constancy.

On the other hand, it cannot be claimed either in view of the patent facts of universal opinion or of the course of moral evolution that there is no such cardinal virtue as a regard for truth - in some sort, "for its own sake." On the contrary, "being true" in conduct and in character may be esteemed the one indispensable condition of all rirtuousness, the core of all right and dutiful character. Limited as is Aristotle's conception ${ }^{1}$ of the virtue of trueness, he is unstinted in his praise for "the plain dealer" who is truthful both in life and speech. "Falsehood," says Aristotle, who makes "irony" in dealing with one's inferiors the

1 Nic. Eth., IV, vii. 
rirtue of a gentleman, - " falsehood is in itself base and censurable; truth is noble and laudable." And whaterer one may think of Paulsen's teleological theory of virtuousness, neither the popular nor the eritical estimate of the nature of all virtuous living can encourage us to follow him in exempting examples of infidelity to truth in practice, like Schopenhauer, Rousseau, and Petrarch, from the charge of falsehood in the most intensely moral meaning of the word, on the authority of a motto like this:- "The man who rings the bell eannot march in the procession."

The student of ethics must not hastily fall in with the too prevalent opinion that the virtue of trueness is not even recognized in the lower stages of moral evolution, or among peoples where lying and all forms of deceit are habitual and persistent. It is true, indeed, that ignorance, falsehood, and craft interpenetrate the whole life of almost all savage, as well as of many eivilized peoples. In the case of the savages, unceasing eraft and deceit are so indispensable even to continued existence that the conduct in which they find expression is esteemed an essential kind of virtue. Yet even in such cases the virtue which is really recognized and esteemed is, after the notion of these same people, a sort of wisdom or prudence. Only the man who is in the position of independence and power can be - so it is assumed - habitually frank and truthful. It would not be easy to show, however, any essential difference in respect for this virtue between the most immoral peoples and those who most pride themselves on their superior morality. All men reeognize how eomparatively difficult it is for one to practise truthfulness at the cost of, rather than in the maintenance of, the desirable and good things of life. Eren the Ojis have a saying: "When a poor man makes a proverb it does not spread;" and in Acera it is cleverly declared: "A poor man's pipe does not sound."

But the persuasion is tolerably widespread and embodied 
in maxims among mankind, that it is poor policy to lie. "The liar is short-lived," says the Arabian proverb. "Lies, though many, will be caught by Truth, as soon as she rises up," is the Wolof way of expressing the general experience. "Even in Afghanistan, where it is said that no disgrace attaches to lying per se, and where lying is called an honest man's wings, while truth can only be spoken by a strong man or a fool, there is also a proverb with the moral, that the career of falschood is short." As long ago as Herodotus it was known how the Persian moral philosophy held, what the Persian gentleman practised, namely, "that the man who speaks truth is always at his ease; that men never suffer from speaking the truth; that it behoves them to speak their minds unreservedly, for there is no hill in front of the tongue." Probably, nowhere else in the world is falsehood in all its shades of gray, from that which is a little off the pure white of truth to the blackest of lying, more prevalent than amongst the Hindus of India. Nowhere else is deceit of every kind more ingenious or more tolerated. Yet when the Hindu can free his judgment from the temptations of poverty, fear, greed, and superstition, he shows the same appreciation of the value of trueness which belongs to others; and with the high-minded Hindu gentleman, truth, as he understands it, is as essential a part of the Virtuous Life as it is with the high-minded English gentleman. In the Hindu moral philosophy truthfulness is one of the sattwik gunas, or principles that introduce harmony "by controlling self or by sacrificing self to higher forces;" and as such, it is daivik (or divine). "Of the good man in the Rig Veda," says Professor Hopkins, " "are demanded piety toward gods and manes and liberality to priests; truthfulness and courage." That this virtue of judgment is connected in the Hindu system of thinking with a true apprehension of the great religious and philosophical verities is not to be

1 Religions of India, p. 148. 
urged as a mark of its depreciation; but rather of the opposite, - while, as I have already said, the prevalence and the tolerance of the breaches of this virtue are in India, as elsewhere, due to ignorance, superstition, cowardice, and greed. As says the base Iago:-

"O monstrous world! Take note, take note, $\mathrm{O}$ World, 'To be direct and honest, is not safe."

Trueness inrolves, essentially considered, an appreciation of the value of Reality and of the correspondence which may be established between it and the Self by way of its own act of true judgment. This appreciation it is which inspires the noblest minds with the love of the truth for the truth's own dear sake. Such a passionate affection, however, when subjected to psychological analysis and then, as far as its residuum is concerned, to further reflective thinking, loses its abstract character, but gains much thereby in actual ethical significance and importance. The love of Truth for its own sake turns out to be an affective appreciation of the value of true judgment for the Self's own sake, and for the sake of other selves; and, finally, for the sake of fidelity to that Supreme Selfhood who is the source and the guardian of all truth - " The Truth," as well as the Life, of man. ${ }^{1}$

By this virtue, accordingly, I understand that voluntary judgment which corresponds to the facts and principles of Reality as these are made known to the Moral Self. In perception and self-consciousness we stand face to face with certain actual facts. By reflection and reasoning we proceed from the apprehension of those facts to the knowledge of principles, or to the belief, varying all the way from timid conjecture to unshaken conviction, in facts and principles that cannot be immediately apprehended or (as often happens) empirically verified. It is in the judgment that this

1 Compare the chapters on "Truth and Error" and on "The Ethical and Fsthetical 'Momenta' of Knowledge," in the author's Philosophy of Knowledge (XV and XVII). 
total activity so culminates as to come under the rubric of the true and the false. It is the actual judgment which, as a species of conduct, merits the title of being either good or bad, not only from the logical, but also from the ethical point of view. This is only to say in other words that the Self, when voluntarily pronouncing judgment, is virtuous and meritorious or vicious and blameworthy, according to the relation which it thus assumes toward the facts and principles that appear to have reality.

Undoubtedly somewhat the same obscurities and perplexities encompass this inquiry which were found surrounding the discussion of the virtues of wisdom and justness. The sceptical questions: What is Truth? and, How can any one assume that his representation of it does correspond, and that of his fellow-man does not correspond, to Reality? need not embarrass us at this point. Let it be granted that " real" truth in this connection means what seems true to each mind; that it is the individual's own seizure of the fact or of the principle. Without attention, memory, insight, thought, and the fair spirit, there is no satisfactory judgment of either fact or principle possible. So that getting the judgment into a form which shall appear to ourselves clearly and fully to correspond with reality is a complex piece of conduct which always has either a certain good or bad moral quality.

But truths, like other forms of good, have different degrees of worth and are therefore capable of being arranged in a scale of values. Their place in such a scale, so far as either they or it can be the proper consideration of philosophy, must be determined by two things: (1) by the relation in which the truths, as respects the possibility of their attainment, stand to human conduct; and (2) by the relation in which the truths, when partially or perfectly attained, stand to human welfare.

It will not do dogmatically to pronounce upon the irre- 
movable limits of human cognition. The folly of attempting this after the fashion of the Kantian or other agnosticism is made clcar by a consistent theory of knowledge; and the history of the particular seiences is full of instructive instances of discoveries which have brought to nought the agnostic declarations of the men of seience themselves. Yet the inquiry, whether the "game is worth the candle," when judiciously put, always has an ethical import. And to spend energy and time that might be given to the solution of solvable problems in the search for unattainable mysteries, or in the hair-splitting discussion of abstract propositions, or eren in almost hopeless attempt to unearth matters of fact buried too deep for human industry, may savor of an immoral lack of wisdom. For the spirit of trueness is, after all, opposed to the exploiting of mere fact or barren theory, for the "truth's own sake" so-called. But ethics must be very liberal upon this point. And a due humility before the great realities themselves strengthens rather than diminishes the faith that the door into the innermost chamber of Reality is never wholly shut to man; and that each fact has some worthy place and important signifieance in the structure, as it were, of that Reality. Here it will appear to the thoughtful mind that fidelity to the virtue of Trueness approaches, and in a sisterly way embraces, the virtue of Resignation.

It is a more obvious remark in the interests of a fuller exposition of this form of virtuous judgment, that truths themselves stand in different relations to human welfare. Our conception of "The Truth" may, perhaps, properly be such as to sanctify in some measure every seemingly insignificant fact. Thus scientific exactness, in all its pettiness of details, may come to have a decidedly ethical quality and may even be worshipped with something of the fervor of religious derotion. And accepting the correct psychological view and metaphysical estimate of the virtue of trueness, 
one can readily see how such exactness meets a moral de- mand; since all truth is for some self's sake. Let then the "man of science" pride himself on having counted exactly the petals of some new species of flower or the seales of some hitherto unknown species of fish, and on having correctly derived the one from its true plant progenitor or pieced suecessfully together the skeleton of the other, - and all the more, if both be extinet and of no practical interest to either pharmacist or fisherman. For his own patience, industry, intellectual control, are features of good selfhood; and he is so far virtuous in this piece of conduct, although the truth he has obtained prove of small value to other selves. While, of course, God knew it all beforehand. What, however, shall be said of the man who spends his energies and risks his life in finding the way to the North Pole, or the best plan of spanning with a bridge some river, but refuses eren earnestly to inquire whether there be any God, or no, or what is the better way to adjust one's own conduct to the exigencies of the higher life and to the attainment of its supreme values?

It is, of course, not possible for a philosophy of conduct accurately to scale the values belonging to every form of truth; it is sufficient here to point out that the virtue of trueness, since it is a species of conduct, must always recognize its object as a thing of worth. And this good value, which the object has, is a matter of degrees. Like every species of good, therefore, this good which belongs to truth has reference to human welfare-to the welfare of persons in their manifold social relations. So that the highest truthfulness, like the highest wisdom and the highest justice, will be exhibited in the forms of judgment that concem matters of the highest worth. Although, perhaps, nothing can be further from the spirit of an age that values truth chiefly from the commercial standpoint, and even estimates the truths of science in dependence solely upon the worth of the 
profit that is in them, it nevertheless remains an invincible conclusion from the inmost nature of man: He has most of the virtue of Trueness who most painstakingly and sincerely adjusts his judgments to the realities that have most of value in relation to the supreme ends of the Virtuous Life. The reverse of this is also true: to exalt, either theoretically or practically, either in education or in life, so-called scientific truth or those forms of knowledge which minister to success in trade or in warfare, above the truths of morals and religion, is immoral; it is distinctly disloyal to the inmost spirit of the virtuc of trueness itself.

The vices which oppose this virtue are manifold; but they do not consist chiefly of the different kinds and degrees of lying - a form of evil conduct that is oftenest the expression of the rices of cowardice, greed, love of notoriety, etc. They are chiefly of the following three varieties: (1) Thoughtlessness, whether taking the form of carelessness, indifference, or sloth in forming judgments; (2) Dogmatism; (3) Partisanship. Man is made to be thoughtful; and the idcal selfhood is not to be attained, or successfully pursued, or even most distantly approached, without painstaking thought. It is chiefly thought that makes judgment true; and he who, for any reason, will not think, is essentially untrue to his manhood. Carelessness, however, inevitably results in untrue judgment; but taking care is a voluntary matter, an activity of the willing Self that is essential to the formation of all sound judgment. Indifference, too, is destructive of sound judgment; for, while carelessness is likely to err through haste and lack of prolonged and concentrated attention, it may sometimes by good luck hit the mark more or less near its centre. But the vice of untrueness which is due to a cool and delibcrate disregard of the value of truth shows a more deeply seated and repulsive character. Especially is this so, when the indifference has for its object the higher ethical, social, and 
religious truths. Let it be said again, then, that the man who claims that such truths have no interest in his sight, and who treats them with a practical neglect-not to say contempt - is, as respects the virtue of trueness, one of the most immoral of men. He is untrue to the highest derotions - the principles of conduct, the welfare of the race, the attitude of the human soul toward the Supreme Good - of which his manhood is capable.

Dogmatism, too, is untrueness, a species of immorality. But by dogmatism I do not, of course, mean either positive knowledge which has subjected itself to the scientific tests of valid cognition, or reasoned opinion which is held firmly, as opinion, in view of the rational grounds on which it reposes, or warm conviction concerning moral issues where wisdom and justice are difficult to secure, or eren the faith which reposes, somewhat ignorantly, in the judgment or the authority of others. All these forms of judgment may evince, under differing circumstances, the various shades of the virtue of trueness. Dogmatism is the arrogant and unreasoning attitude of mind, in judgment, toward the facts and principles of Reality. No doubt, the dogmatist habitually has his reasons to offer; and they may appear convincing to him and to his coterie, if to no others. And to be alone with The True One in one's judgment may be more virtuous than to agree with the world's multitude against Him. But he who is in this position of seeming isolation from his fellow men, or in any position resembling it, escapes the vice of dogmatism so long as lie keeps free from arrogance, however firm in bis opinions, and remains ever willing and striving to know the truth, however this new truth may disturb or contradict his past opinions.

In polities, and in all the judgments which prevail among the different classes, Partisanship is the most mischievous form of the vice of untrueness. Lies here and there are 
mischievous enough; no one but an all-sceing Providence can foretell how long and how far their mischief will spread over the sphere of the liar's selfhood and over the sphere of society. Habitual tolerated trickery, when it permeates the multitude, is worse in its effects. But, sometimes in amusing as well as appalling ways, the evils of this form of the vice come almost constantly to correct themsclves. In parts of the Orient everybody knows that everybody else is lying; but everybody has come pretty eorrectly to conjecture what everybody else truly means by the lie that he is telling. To escape from the practical evils of the rice without taking part in it requires time and patience; it is, indeed, quite impossible for the inexpert foreign traveller. But in its practical mischicf the vice of partisanship is worst of all. It is bitter in spirit and coupled with all injustice of judgment. It incritably expresses itself in methods of action which join all the vices of eowardice, unwisdom, and unkindness, in one amalgamation of baseness. Inasmuch as it unites men in masses, so that each individual rather accentuates than corrects the untrue judgments of every other, it is of all forms of falsehood the most dangerous to the civic welfare and to the national life. On the other hand, it is the man who remains true to his ideal of manhood, and, while benevolently inclined to join with others in every good eause, steadfastly refuses to join with any, or with all, in efforts to debase this ideal, - it is such a man, who is both most truly virtuous in his own Self and most truly valuable in his social relations.

The forms of expression which the true judgment reecives, whether in speech, or in gesture, or in more elaborate action, are manifold; they give rise to many complicated and difficult ethical problems. The virtue which we have been considering is a virtue of judgment; it is the virtue of trueness, and its opposite is found in the different forms of untrue judgment. But what is eustomarily understood 
by deceit, falsehood, or lying, has to do with the voluntary failure to make the expression correspond with the judgment itsclf. These failures are, of course, a species of conduct. But as has already been pointed out, the vices which the failures really evince are often, perhaps ordinarily, of another kind; they are cowardice, greed, some unlawful desire, love of applause, etc. It is most important, then, briefly to notice how dependent the form and number of such vicious actions is upon the civic and social environment. Attention has already been called (p. 296 f.) to the fact that, in Aristotle's scheme, truthfulness appears as the virtue especially of the gentleman, the man of honor who does not need to degrade himself by telling a falschood. Truthfulness goes with wittiness and modesty. It is the consciousness of superiority which makes the man outspoken. ${ }^{1}$ In fact there is much truth in this view. Many powerful influences, both direct and indirect, may be traced between the civil and political constitution of any community and the character and amount of falsehood prevalent in the community. Between the tyrant, or the irresponsible government and its subjects, falsehood is inevitable; thus Oriental intrigue and lying are largely due to wrong civic relations. In a constitutional but aristocratic government, the gentry are in general truthful; they have little temptation to be false, and truthfulness is a primary virtue and point of honor with them. In a mercantile community, a certain amount of truthfulness is necessary; but as the spirit of greed grows, and rivalry becomes more intense, the various forms of deceit grow more elaborate and seductive; until the experience of the race in its efforts to get the start of the great, abiding, and worthy realities repeats itself, and the Arabian and Wolof proverbs come true again: "The liar is short-lived;" and "Lies, though many, will be caught by Truth, as soon as she rises up." So far, however, as the

1 Nic. Eth., IV, iii, 29. 
essential spirit of Trueness, as well as of Justness, is concerned, the modern Commercialism, when unmodified by the, at least, indirect influences of Christian benerolence, is every whit as cruel, false, and unscrupulous as was the ancient or mediæval greed of Empire.

What kinds and degrees of deceit, if any, are consistent with the Virtuous Life? and, Is lying ever justifiable? these are questions which it belongs to casuistry to raise and to discuss. But the essential nature of that virtue of the judgment which is called trueness enables one to make the following observations looking toward the success of any attempt to answer them.

1. Trueness, in the higher meaning of the word, is one of the most unqualified of all the virtues. Indeed, if one considers that all right conduct, and all estimate of the rightness of conduct depends upon true judgment, one may affirm that this virtue is of all most absolute. All the virtues are essentially various forms of the voluntary conformity of the Self to its Ideal; they are all, therefore, different ways of being true to some type or principle, - so far as such trueness depends upon ourselves.

2. But trueness, as a virtue of the judgment, requires courage, temperance, constancy, wisdom, justness, kindness, in its own expression, - whether the expression be in the form of speech, or in some other form of action; and trueness does not require intemperate, unwise, or unjust expression of its own judgment. So that to secure its own proper influence, and even to make its own essential excellence apparent, this virtue must somchow be combined with, and qualified by, certain other virtues. Concealment of the judgment may, then, either be a virtue, or it may be a contemptible form of vice; and only good judgment, which is a form of conduct, and oftentimes equivalent to natural or acquired tact, can decide between the reasons for concealing, and the reasons for revealing, any true judgment. 
3. The true interpretation of any expression of judgment, the understanding of the speech or other action of another, is always a somewhat doubtful, and often an extremely difficult matter. No amount of trueness in one man's judgment, or fidelity and care in the expression of the judgment, can furnish security against other men's blundering, mistaken, or perverted interpretation. There is often wisdom, too, in "answering a fool according to his folly," if you answer him at all. To a certain extent, moreover, which can never be determined antecedently, and can never be determined at all with much approach to accuracy, all good and truthful men must allow themselves to be falsely interpreted, whether they speak or remain silent, whether they act upon their judgment or think fit to suspend action while remaining in the same true judgment.

4. 'There are certain matters, and many times, when one's conduct camnot be altered on moral grounds in view of the fact that it is certain to be misunderstood. One cannot be decent or virtuous, in a social environment constructed as that of man actually is, without concealing many things; and concealing in not a few instances is tantamount to decciving.

5. Where those who carry the utilitarian or teleological conception of the virtue of truthfulness to its extreme are ready to justify deceit, or even lying, this justifieation, so long as it is in any sense of the word a moral affair, consists in qualifying this particular virtue by some other virtue. In wisdom or kindness or justice toward others, they hold, one may deceive or tell lies; perhaps sometimes one eren ought to tell a lie, or two, in the interests of these other virtues. But few moralists in any age have been found ready to claim that those popular sayings which praise the benefits of untruthfulness to the seeker for the goods of life have any standing at the bar of a refined moral consciousness. We have here, then, in another form, a question of casuistry, a problem arising from a seeming conflict of duties. 
6. Once more, there undoubtedly is always a certain feeling of moral degradation attaching itself to the personality of one who, for any reason, however praiseworthy the reason in itself may be, has told a lie. The more exalted the virtue of truthfulness has been in the estimate of such a person, the more violent the wrench, the more pitiful the feeling of self-depression, which follow yielding to the most approved motives for lying. It is the nun who has never lied, who, in Victor Hugo's Les Misérables, becomes the heroine for her self-sacrificing benerolence in telling just this one lie in the interests of another person. The angels drop a tear on the record to wash it away. Moralists debate and perhaps end by justifying it; at any rate all pity the doer and perhaps condone the deed. But none glory in it as we glory in the conduct of the man who dies himself rather than tell a base and selfish lie.

The man, then, who uses all his powers of judgment in the interests of good conduct, is the man of the Virtuous Life, so far as qualities of judgment can go. In his estimate of the ends of life, and of the means for their attainment, he is wise. In his apportionment of the goods and evils of life to the different individual selves with whom he has relations, he is just. In his own mental attitude of judgment toward all the facts and principles of reality, he is true. Being wise, and just, and true, in all matters of judgment, he $i s$ the good man whom the universal moral consciousness of his fellows must approbate and esteem "worthy of being treated accordingly." 


\section{CHAPTER XIII}

VIRTUES OF FEELING: KINDNESS, SYMPATHY, ETC.

The virtues of the class which await consideration differ in some important respects from those of the two classes which have already been diseussed. The differences are, for the most part, due to two causes; first, to the character of the psychological source or mainspring of these virtues; and second, to the relation which the virtues themselves, considered as forms of conduct, sustain to the individual's social environment. Certain modes of behavior originate mainly in the affectional and sentimental nature of man ("the heart," das Gemiith); and these modes of behavior, coming under the guidance of judgment and the control of the will, institute and sustain a great variety of powerful and valuable relations, of a general character called friendly, among men. Such virtues are, therefore, preeminently social in the narrower mealling of the word. I say in the narrower meaning of the word social : for we have already seen that, in the broader and truer meaning of the same word, there neither are, nor can be, any virtues or vices which are not social.

It should be observed, first, that the affectional and sentimental origin of this class of virtues makes difficult, if not quite impossible, any clear definition of their characteristic marks. It is now, for example, almost universally acknowledged in the ethically more highly developed communities, that kindness is due to men generally, and that it is to be morally approbated and deemed worthy of reward for its meritoriousness. But what is it to be kind? The feeling to which one must appeal in order to get any basic fact in 
human experience for an answer to such a question as this, does not admit of definition. It is what it is, as feeling; and to know what this particular feeling really is, it is necessary that it should actually be felt. But the theory of morals as applied to the description of every cardinal virtue refuses to regard mere feeling as coming up to the full standard of those characteristics that are required of erery claimant to the title. This theory very promptly and properly introduces a distinetion between merely having kindly feeling and being truly kind, - or exereising the full-orbed grace of virtuous kindness. For such kindness, judgment is necessary; and, as well, the volition which, as it were, appropriates and makes the Self's very own, the spontaneous kindly feeling. " Good nature," for example, is a potent and praiseworthy source of virtuous conduct; but he who good-naturedly tosses a coin to a beggar is not, as a matter of course, virtuous, - especially, if he owes that coin to his family or to some other cause. It is necessary that the natural feeling of kindness should be roluntary and subjected to rational judgment in order to convert it into the cardinal yet qualified virtue which it may become.

That there are natural feelings of kindness, sympathy, benerolence, and self-sacrificing lore, scarcely need be questioned anew at the present time. Aristotle was, like all the ancient Greck and Latin world, far enough from recognizing the highest form of the virtues of this class, such as the enthusiasm of humanity, the principled lore of all mankind. But lie was too keen and observing a psychologist not to notice how "Lore seems to be implanted by nature in the parent towards the offspring, and in the offspring towards the parent, not only among men but also among birds and most animals; and in those of the same race toward one another, among men especially — for which reason we commend those who love their fellow-men. And when one travels one may see how man is always akin to and dear to man." 1 That

1 Nic. Eth., VHI, i, 3. 
outeome of sensationalism and egoism in psychology which prevailed at one time among certain English and French writers on ethics, and which thought to show that all these obriously kindly, sympathetic and friendly forms of human feeling are only sly and indirect forms of selfishness, and that the different species of conduet to which the feelings give rise are only concealed ways of seeking one's own good, - jejune and unproductive as it always was - is now so deservedly extinct as to require only a passing reference. It is interesting to remark, however, how the suecessors of this psychological system are at present among those most interested to make out that certain spontaneous feelings belonging to our common human nature are distinctively (and eren exclusively) altruistic. Indeed, "sympathy" is the term which some of these writers employ as fit to summarize all those impulses of humanity in which the social virtues have their origin and their support.

Kindness, sympathy, and various forms of affection and friendship undoubtedly belong by birthright to the nature of man. They are as essential impulses in his soul as are the impulses to anger, fear, pride, and jealousy. Indeed, the two classes of impulses, when one attempts to classify them as two, and apart, appear so to interpenetrate, modify each other, and fuse together in complex emotional states, as to be practically indistinguishable, if considered as furnishing motives to deeds and courses of conduct. The affection of the sexes, for example, often manifests itself as jealousy; and, indeed, in not a few instances it feeds upon this passion. Much anger and pride are sympathetic, and belong to the social life of the community, whether domestic, tribal, or national. The various affections of family, tribe, and state foster no little anger and pride. To be proud, without sufficient reason, of the object of our love, is quite as natural as to love that which ministers to our pride. And there is no fiercer, as well as more rational anger, than that which burns against 
the person who attacks a beloved member of one's own social or friendly alliance. These kindly outgoings of the human spirit belong as truly to man in a "state of nature" (if by a state of nature be meant any condition in which human existence is historically recognizable, or even conceivable in view of an accurate psychological analysis) as do any of his passions, emotions, or desires.

On the other hand, it cannot be denied that, in some respects, the virtues of the heart are not so fundamental and essential to mere existence, or to the carliest stages of man's moral evolution, as are the cardinal virtues of the will and of the judgment. Courage, a certain amount of temperance and of wisdom, and some rude justice, can perhaps less easily be dispensed with, when man is making his first start toward the ideal of virtuous life, than can kindness, generosity, or the love of man as man. To be sure, one cannot fail to recognize a certain large truth in Aristotle's ${ }^{1}$ declaration: "If citizens be friends, they have no need of justice, but though they be just, they need friendship or love also; indeed, the completest realization of justice seems to be the realization of friendship or love also." But eren the truth of this declaration seems to confirm the truth of what has just been said. Man cannot exercise the virtue of the higher justice without rendering to other men that kindly, sympathetic, and friendly service which is their due. And friendship is needed to satisfy a yearning which is native to every human soul, - except, perhaps, the most callous and degraded. There is, moreover, a profound and powerful ethical truth in the declaration that "Love is the fulfilling of the law," in its essence and its entirety. But it is also true that the virtues of the heart flourish upon a basis laid by the sterner and less lovable virtues of courage, prudence, and a rude but sturdy form of protective and retributive justice.

It is true, however, that some degree and form of the 1 Nic. Eth., VIII, i, 4. 
virtues of feeling is found and appreciated at all the lower levels of moral evolution. A certain prizing, and even a relatively large amount of practice, of these virtues is often found among savage peoples. For no savages are all the while engaged in hating, killing, and abusing others - including those of their own household or tribe. Many sarages are, on the contrary, quite habitually kind, generous, and friendly, not only to those of their own tribe, but also to strangers. One of the saddest things about the effect of contact with the evil representatives of peoples who have attained an adrance of civilization that permits so-called "benevolence" largely to take the place of protective and punitive justice is this, it too often destroys the more simple and confiding forms of friendly feeling among savage peoples. What M. Rose says is true of his own countrymen with respeet to their influence upon other sarage virtues is too often true of so-called superior races generally in their influence upon the hospitality, generosity, and kindliness of inferior races: "The people are simple and confiding when we arrive, perfidious when we leave them. Once sober, brave, and honest, we make them drunken, lazy, and finally thieves. After having inoculated them with our vices, we employ these very vices as an argument for their destruction." 1

Among the more warm-blooded races, however low in the scale of cirilization, there is usually a large amount of the various forms of natural affection. Even where polygamy abounds, or concubinage is most unrestricted, affection between the sexes is not wanting. Nor do abortion, the exposure and murder of children, and other similar kinds of erime against offspring, do away with that instinctive and powerful love which binds the parent - especially the mother - to the child. But particularly is hospitality comted to be essential among the virtues of manhood; and the ties of friendly feeling every where bind men together - master and servant, chief and

1 Quoted by Quatrefages, The Human Species, p. 462. 
retainer, old man and youth, tribesman with member of the same tribe - in a way to mitigate and sweeten the hardships and eruelties of the struggle for existence and for the possession of the goods of life. The Tongan chiefs, according to Mariner, were familiar with the value of " the agreeable and happy feelings which a man experiences within himself when he does any good action and conducts himself nobly and generously as a man ought to do." "A good name makes one sleep well"; and "A lent knife does not come back alone" (i.e., a good deed is never thrown away), say the Basutos of South Africa, - while the lofty ancient morality of the Persians proclaims: "The liberal man is the friend of God" ; and, "Practise liberality, but lay no stress on the obligation." Even our own sarage and cruel ancestors who, not many generations ago, spared "the bairn that is on the floor" (is born) only when the father had caused it to be lifted up, prized the "pure virtue" of hospitality and enjoyed no little of "romantic love" in the marital relations of the sexes.

It has already been said that kindness as spontaneous and natural feeling cannot be further analyzed or, strictly speaking, defined; but its various manifestations, as these depend either upon the social relations under which the feeling comes into play, or upon the condition of the object toward whom the feeling goes out, require some separate mention. Of such relations the following three deserve chiefly to be considered : (1) the relations of the family; (2) the relations of the tribe, or other form of social community; and (3) the peculiar relations which come under the term of friendship, in the narrower meaning of this word. In adopting this order I do not intend to raise the question whether the family or the tribe is the oldest social organization.

The physical and mental constitution of man and woman is such that any sexual union, when continued and repeated, necessarily develops feelings either of affection or of repulsion. So true is this that it is only under the most un- 
farorable conditions, and where sexual intercourse is most unregulated by law or custom, and most brutish, that the human pair do not feel the happy impulse to some degree of distinguishing kindly feeling toward each other. Were it not that so many other influences, both among sarage and highly civilized peoples, tend to counteract this impulse, it would probably be quite generally true that husbands and wives would love each other, - and this, whether the affection were left to follow upon marriage or were made to precede it. Mothers naturally tend to feel a peculiar kindness toward their offspring; and amongst the crucllest of savages the pride and affection of the father in his son, whenever this son has grown to an age to reciprocate the simpler forms of intercourse, manifest themselves in not a few important ways. Members of the same family - brothers and sisters, daughters-in-law and mothers-in-law, etc. - doubtless quarrel frequently and bitterly enough even in the most refined and Christian communities; but, after all, membership in the same family, however the family may be constituted and howerer much its confines may be enlarged, is the one form of affection which ties society together at its rery base, so to say. Witness the amazing strength of the mixed and ill-defined Hindu family, both for offensive and for defensive purposes, in spite of the wide-spreading evil of family jealousies, bickerings, and strifes. In China, too, the cement which unites the various heterogeneous interests of the social fabric is a sort of loyal affection for the family and the clan. I have heard it said by one of those most familiar with Chinese character that one can nerer judge the indiridual by himself as either so good or so bad as he seems to be. He is always, in his most fundamental and effective characteristics, a member of the family or clan. In spite of the large amount of insincerity, jealousy, and even eruelty which are prevalent among the different members of the same family or clan, "filial piety," as they understand it, continues to be both the- 
oretically and practically a force which mitigates the selfish struggle for existence among the Chinese. Every one familiar with the history of "Old Japan" knows how much of virtuous conduct, in spite of exceedingly loose notions of the morality of sexual relations, came from the reciprocal affections of those who bore the same family name, or who owed allegiance to the same Daimyo.

To ethnology and the history of ethical development the student of the philosophy of conduct may confidently appeal to show how valuable, and how universal and effective, are these kindlier affections, and the rirtues which grow out of them, among the different tribes and other subdivisions of the human race. When the common social life and social interests have spread themselves over the larger and ever widening cireles of men, the power of the friendly feelings, in general, is yet more obvious. It is never merely selfish interest, and rarely, if ever, the merely natural reaction of courageous anger against attack, which enlists the members of the same tribe or larger community in a common cause. It is rather also because they have sympathy with one another; because even they, in some rude and imperfect fashion, obey the Divine command, as brethren to lore one another. The idea of brotherhood, however, extends only to the one bound up in the same bundle, in respect of his notions, customs, language, lores, and even prejudices and hates. But, alas! how few in the most Christian nations have really any higher conception of the brotherhood of man than just this!

There is something yet more imposing and in some sort mysterious about the love of friendship in the more restricted and positive meaning of this word. This peculiar form of love, although it is by no means identical with the affection which ties together the members of the same family, clan, or tribe, may be added to domestic or tribal affection, and so constitute a double cord for human souls. Where it exists between husband and wife, it may outlast, and outstrip in self- 
denying service and in mutual reward, the relations peculiar to the two sexes; where it binds brothers and sisters together, it is a much more durable and purer bond than mere consanguinity. Where it exists in its noblest form, as between good souls who desire to have, and are able to have, suitable converse with each other, and whose motive for love is pure, friendship is the finest and most elevating of human affections. The mysterious nature of this bond, as respects both its origin and also the character of the persons between whom it can properly exist, or exist in fact at all, has been the subject of debate for centuries. Aristotle was forced to say:" "There are not a few differences of opinion about the matter." In his day some said the principle of choice is "Like to like," as "Crow to crow;" but others even then reminded the inquirer how "Potter quarrels with potter, and

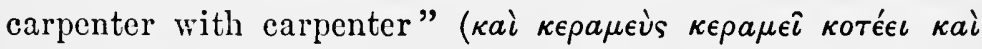

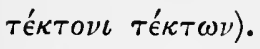

With all the psychological analysis which has been given to the causation of friendship, and all the instruction and exhortation which the duty of carefully choosing one's friends has very properly received, little more is known about the subject than was recognized in the writings of Plato and Aristotle. The former makes Socrates say at the close of the Lysis: "Here is a jest; you two boys, and I, an old boy, who would fain be one of you, imagine ourselves to be friends, and we have not as yet been able to discover what is a friend."

In spite of the truth of Jowett's remark ${ }^{2}$ that Socrates allows himself "to be carried away by a sort of eristic or illogical logic," the notions which "appear to be struggling or balancing in the mind of Socrates" are not yet easy to harmonize: namely, "First, the sense that friendship arises out of human needs and wants; Secondly, that the higher

1 Nic. Eth., VIII, i, 6.

2 Introduction to the Lysis, The Dialogues of Plato, vol. I. 
form or ideal of friendship exists only for the sake of the good." What more does this amount to, however, than the opinion that, if one considers this form of friendly feeling between human beings, one finds it capable of becoming either a vicious and injurious or a virtuous and most beneficent form of conduct. It is also a form of conduet which is all the more powerful for weal or for woe in the development of morals, whether in the case of the individual or of society, because it so grasps hold of all the springs of action and brings them all to bear together either toward, or away from, the ideal of the Virtuous Life. Witness the frequency in all times with which friends have sacrificed themselves for one another, whether in a good cause or in a bad one, have committed suicide together, or have cheerfully laid down their lives in common devotion to the same end.

Satisfactory off-hand explanations cannot be given as to why two human beings come to acknowledge the ties of friendship in their more or less binding form. Learned and unlearned, master and slave, royalty and peasant, man and man, or man and woman, or woman and woman, youth and youth, or youth and age, those of kindred blood and common country, and those as alien as possible in blood and of countries hostile to each other, have become faithful and devoted friends. For the forces in human nature that induce friendship are an exceedingly complex affair; and whether in any particular case the existence of intense friendly feeling is due chiefly to contiguity, or to likeness of interests and tastes, or to the need of being supplemented, or to the quite common yearning for appreciation or for affection, or to something that is either too fortuitous or too profound in character or in circumstance to be reached by external inspection, ean never be determined a priori. Nor should much importance be attached to rules for defining the duty of the individual in respect to the making of friendships; especially, perhaps, if such rules are conceived in a spirit 
too narrow and Puritanic. For the casuistry of fricndship, too, is rery complex. Bad characters are by no means always helped, even if they can be induced to form a sort of self-interested friendship with good men. Characters with bal tendeneies already established may be either improved or injured by unselfish friendships with others not much better than themselves. Good men are undoubtedly sometimes made worse by friendships with the vicious; but, on the other hand, there is no so potent human influence to make the vicious better as to make them feel the friendship - not the formal "benevolence" or the so-called " charity" of the good. In a word, the beneficial or deleterious results of friendships depend in general upon the relations which the friendly alliances themselves sustain to the pursuit of the ideal of the Virtuous Life.

Among the forms taken by kindly feeling, as dependent upon the condition of its objeet, in the lower stages of man's ethical development, the more prominent are Hospitality and Pity. The former is undoubtedly partly of a utilitarian origin and character, and partly comnected with the gratification of either a noble or an ignoble pride. It is in eating and drinking together that men's friendly feelings are apt to be aroused and enhanced, and their hatred cooled and ameliorated. Quite unirersally the stranger and even the enemy, when received as a guest to the $d$ welling-place, tent or house, is considered to have the most saered claims to protection from injury. And, for whatever motive (the honor of Jehovah, or the good of his people, not excepted) to do as Jael did to Sisera (Judges iv.) is a most heinous crime. When the host is himself poor and needy, he feels the virtue of his hospitality all the more keenly beeause he is sharing with his guest the small portion of food and the meagre lodging which is the just and rightful property only of his own family. But where the host is rich or princely, a liberal and even magnificent display of hospitality, al- 
though it does not enhance the virtuousness of the friendly feeling, ministers to a not wholly ignoble kind of pride. Not to treat one's guest according to one's ability to comfort and to please him would be, in such a case, a positive and mean vice. As regards the practice of this virtue also I may refer to ethnic and historical studies to show in detail the many curious and interesting customs which have grown up in various communities from the root of this friendly feeling; and, as well, what great benefits have accrued from the ancient and wide-spreading practice of hospitality, in the way of ameliorating the condition of men and of cultivating the spirit of humanity and love. Even among sarages this virtue is esteemed. As Wundt has said: ${ }^{1}$ "In the Greek world this high regard for hospitality goes back to the very earliest times. The Odyssey counts Ulysses' unrivalled hospitality to the coming and the departing guest as one of his chief virtues." The duties of hosts ( $\xi^{\prime} \mathrm{v} \nu \iota$ ) are placed by Aristotle among the virtues of "accidental friendship." Among the Germanic peoples Grimm quotes ancient ordinances which imposed a penalty upon the household who refused shelter and fireside to the traveller. "Even if the guest had slain the brother of his host" - no matter; le must come and go in safety. This hospitality was in time extended so as to cover the travelling merchant; it thus became the early protector of commerce. Of Chaucer's franklin we read that his

\section{“. . . table dormant in his halle alway \\ Stood redy covered al the longe day."}

This virtuous friendly feeling, when combined with a sense of honor, has led to such heroic deeds as those of the Gepidae, who refused to give up a guest at the command of Justinian and so suffered themselves to be ruined. At the

1 Ethics, I, p 286, f. ; and comp. Buchholz, Homerische Realen, II, 2, pp. 38 ff.; and III, 2, pp. 361 f., as cited by Wundt. 
present time, in the more civilized communities, the preralent commercial spirit has produced everywhere the attitude which makes the traveller the legitimate object of every kind of plunder; while the progress of the humanitarian spirit consigns the tramp either to the station-house or to the "charities' home." This may be just; it is perhaps inevitable. But it should not lead the student of morals either to flatter unjustly his own generation, or to overlook the part which the ruder forms of the virtue of hospitality have formerly played in the development both of commerce and of benevolence.

Pity is the form which kindly feeling takes when its object is suffering. The feeling of pity is natural; and in spite of the curse of, and almost the necessity for, unspeakable crueltics in all the earlier stages of the evolution of the race, there are never and nowhere wanting traces of this feeling. The physically lower and sarage peoples undoubtedly show an astonishing indifference to suffering. Physiologically considered, they are relatirely incapable of suffering; they are from their earliest existence inured to bear it, and to take pride in concealing or eren in despising it. Of this hardened attitude toward the sufferings of others, which is largely conditioned upon the absence of nerves and the custom of secing and bearing what to more highly sensitive nervous organizations would be intolerable, the Chinese are perhaps the most conspicuous example among civilized peoples. But where the human heart becomes sensitive to the pain or misfortune of others, unless selfishness or hatred interpose to pervert or alter the natural feeling, pity is the emotion which is spontaneous for man toward man, and eren toward the animals. Anger, jealousy, desire for revenge, as well as insensibility, prevent the feeling and its expression. The cultivated virtues of courage, wisdom, and justice, not infrequently hare to control and divert it. But pity itself, in turn, powerfully modifies them. 
And when, chastened with wisdom and tempered by justice, the virtue of pity takes its highest possible form, it is one of the most divine, as it is always one of the most difficult, of all the human virtues.

The use of the word Sympathy suggests a conception which seems too comprehensive and fundamental to fit well any particular form of virtuous conduct. Indeed, the principle of sympathy, when joined with the principle of imitation, gives the psychological explanation of a considerable portion of the experiences witnessed in the earlier stages of the ethical development of the individual and of the race. In action, whether merely expressive or designed to accomplish some ulterior end, men imitate each other; in feeling, whether their own interests are quite direetly or only in an imaginary way involved, men sympathize with each other. Imitation and sympathy co-operate with each other to impel in certain common directions all the emotional impulses and motor activities of groups of men. Thus are secured the more spontaneous and unthinking forms of conduct common to considerable multitudes. All wise, just, and truly benevolent co-operation with one's fellows, in good eauses, represents a later stage of ethical development; but it is rendered by his nature inevitable that man, on learning to interpret and to employ his motor powers through the principle of imitation, should be instructed and quickened in all the different forms of sympathetic feeling with others.

Indeed, by a not unwarrantable and suggestive extension in the applieation of this principle it is possible to make sympathy serve as the explanation of all the so-called altruistic side of human nature, and of the whole extent of the foundations upon which human society rests. Among the lower animals similar influenees seem to prevail. The "feeling of the kind," the feeling with the species, is everywhere a generie rather than a particular form of feeling. It is that broad yet subtile emotion of kinship which, while it 
is no one specific form of emotion, is the emotional basis for all the specific forms. If ants will not tolerate ants of another hill, or bees those of another hive, because they do not smell or otherwise seem like those of their own kindred, the sympathetic attractions and repulsions of the higher animals, and especially of human beings, are more complex and decisive as to terms of friendly intercourse. Where the physical features of different peoples, or their habits of dress and of behavior, or their manner of gesture and their written and spoken language, are markedly unlike, it is the more difficult to persuade both mind and heart that this feeling of sympathy is legitimate - not to say, virtuous. A monkey, or a fox, or a bulldog, or some one of another species quite different from one's own; - why ought one to sympathize with it as though it were of one's own kinship? Thus, even until the present time and in spite of all the experience of travel and commerce, and all the instructions of art and of philosophy, and all the commands and exhortations of religion, the Oriental and the Occidental fail to exercise the virtue of sympathy with each other; and black, white, and yellow, Englishman, Frenchman, German, and Russian, find it difficult to extend over one another the mantle of a just and sweet kindliness of feeling.

But in the narrow confines within which the natural fecling of kinship - sympathy, in the broader meaning of the word-exercises its legitimate power, the specific virtue of sympathy springs up and extends itself toward all those who share the title to be considered of one kind. And as men come to know that man is essentially the same on whatever hemisphere you find him, and of whatever color, and to whatever nationality his allegiance may belong, the virtue of sympathy follows in the path of the natural feeling of kinship. Thus this virtue leads the way to the supreme form of virtuous feeling, - namely, a courageous, just, and wise benevolence. 
The natural feeling of sympathy tends to bring men into accord along all the different lines of the particular forms of feeling. I have already remarked that anger, fear, pride, etc., are subject, in general, to the influence of the principle of sympathy (see p. 75 f.). The same thing is, of course, true of pity, love, admiration, joy, hope, and all the loftier and fincr sentiments and aspirations of humanity. To "rejoice with them that do rejoice" is as truly a mark of sympathy as to "weep with them that wecp." Indeed, there is a certain truth in Perty's remark" that "it is no fine feature of our nature that most men are much more inclined to sympathetic suffering with others' misfortune than to sympathetic joy with others' good fortune." As respects both the psychological nature of this virtue and also the cultiration and exercise of it, the feeling of sympathy depends largely upon a cultivated imagination. One can feel with others only when one is able to imagine how others feel. And here is one of the screral points at which the feeling comes, so to say, into relation to the will. For the cultivation of the imagination so as to be able to "put one's sclf into the other's place," if done with a view thus to realize the ideal of virtuous living, is itself a virtuous action; and it also makes possible the virtue of a more complete sympathy. Nor can the connection of such culture of mind and heart with the virtue of justice be long kept out of sight. Without the virtue of sympathy the "higher justice" is impossible.

That the natural feeling of kinship, the feeling of the species, develops among the rudest sarages into the virtue of sympathy, there can be no doubt. The range of the virtue may be narrow, the limitations obvious, but the reality of the manifestation is unmistakable. "Primitive man," says Wundt, " ${ }^{2}$ can be sympathetic, helpful, even self-sacrificing, when his comrade is in danger: he is incapable of an action whose results will not benefit some one of his acquaintance,

1 Anthropologie, I, p. 298.

2 Ethics, I, p. $263 \mathrm{f}$. 
still more of conduct that does not aim to assist any individual whatever." But this concrete, personal character of the earlier manifestation belongs to all the virtues; and the reasons for it will appear more clearly hereafter. It is largely, however, caused by the narrow range of interests to which the so-called "primitive man" is susceptible, and by the limited character of his knowledge and the imperfect working of his imagination.

Out of a half-savage hospitality toward the stranger, pity toward the suffering, and sympathy with those most closcly $\mathrm{kin}$, the noble and inclusive virtue of benevolence has been erolved. The influences which have chiefly contributed to this evolution are two: philosophy and art, on the one hand, and, on the other hand, religion - especially Christianity. Thus as the range of human acquaintanceship extends, the reasons, motives, and sanctions for the extension of the natural feelings of friendliness and sympathy are provided; and what is with primitive and savage man possible only over an exceedingly narrow circle of his fellow-beings, on account both of his ignorance and of his own low grade of moral development, becomes possible over the ever widening circle of mankind, and even of other personal existences in whose capacity for fellowship man comes to believe.

Philosophy and art have undoubtedly rendered a real service in the evolution of that supreme virtue of the fecling which is called Benerolence. This service has becn accomplished by elevating and expanding the conception which man holds of his own nature and destiny. Philosophy and art have been powerful historical forces to teach mankind to recognize the better and the worthier Self. They have always, on the whole, emphasized the permanent values of life. True, they liave in not a few instances ministered to what is sensuous and opposed to the interests of moral development; but religion has also - even more frequently than philosophy and art - had this same ethically degrading 
effect. For a degraded ethical condition will pull down and abuse the ministrations of all the otherwise illumining and elevating energies of man. But, in general, and in the historic process of unfolding human life, all these three philosophy, art, and religion - have powerfully co-operated to raise and reinforce the ideals of the spirit.

Philosophy, as soon as it applics its instrument of reflective thinking to man himself - his origin, nature, and probable destiny - begins everywhere the search for the universal and the permanent. It sceks the universal and the permanent amidst the individual and changeable facts of experience; and it finds what it seeks. It makes the discovery that slaves, strangers, and even barbarians are also men; it discerns in them also those marks that are common to the members of the philosopher's own houschold and nation and circle of friends. Before this conception of man as unan has been formed in some intelligent and comprehensive fashion, the spirit of kindliness and sympathy has no sure dwelling-place. It wanders like the dove over the face of the dreary waters and returns, tired out, to its own little ark. Philosophy, whose spirit is - quite contrary to notions that are always widely popular but are based upon ignorance and prejudice - not proud and exclusive, but always more genial and condescending than that of the unreflecting crowd, reveals man to himself as a being of worth. Philosophy customarily estimates the value of man much higher than does commerce, or the civil government, whose officers arc ever ready to sacrifico the multitudes to themselves, or to the popular opinion. Even in the case of those religions which have contributed so much to the awakening and spread of bencvolent feeling, it is the conceptions of man's origin, nature, and destiny, which they share with philosophy, that give to this feeling, and to the beneficent works which flow from the feeling, the sound and permanent rational basis they possess. Indeed, unless the 
philosophical basis of any religion is sound and its spirit and efforts are directed to right ethical ends, that religion increases hate rather than good will among mankind.

Through art also, and especially in the form of poetry, man comes to a knowledge and appreciation of his own higher selfhood. The feelings awakened and nourished by the poetical representations of those hopes and fears, those interests and activities, those insights and mysteries, which are the common heritage of mankind, tend foreefully and effectively toward the extension of the friendly and sympathetic side of human nature. Poetry, and in a less degree other forms of art, has indeed done much to stir and to foster the warlike spirit, the courage and the enthusiasm which must become popular if the tribe or the nation is going to engage heartily in strife against a common foe. But the war-songs, like the love-songs and the cradle-songs of other tribes and nations, show to us how essentially like ourselves these others really are. This truth I will illustrate by reference to the exploit of a former pupil and friend of mine, who, after mastering the dialects of the inhabitants of sundry South Sea Islands, and becoming recognized as a friend among them, translated into one of these dialects a book from the Odyssey and read it to their assembled chiefs. These savages found the hero of the Homeric poem a man after their own heart, and greeted his sufferings with pity and his triumphs and his escapes with sympathetic joy.

It is also instructive to notice how poetry and philosophy have combined to call attention to the conception that all existences recognize the principles which bind together as well as those which result in contention and strife. Lore, as well as Hate, or Friendship and Yearning for one another, as well as Strife and Contention (

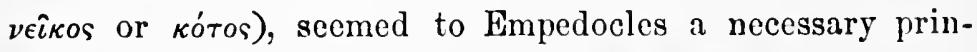
ciple of all natural objects. And in a sentence quoted by 
Aristotle, ${ }^{1}$ Euripides sees in natural phenomena the apt illustration of the principle of friendships among men:-

"The parched earth loves the rain, And the high heaven, with moisture laden, loves Earthwards to fall."

From a yet higher ethical point of view did Menander sing:

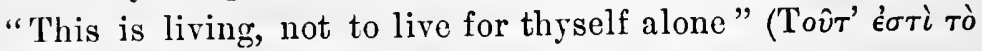
$\zeta \hat{\eta} \nu \mu \grave{\eta} \sigma \epsilon a v \tau \hat{\varphi} \zeta \hat{\eta} \nu \mu o ́ v \omega)$. If modern chemistry finds itself obliged to recognize the attractions as well as the repulsions (which are, after all, only superior attractions) of the atoms, doubtless modern biology will come to see that eren the "struggle for existence," which it has hitherto made so exclusire, is actually modified among the lower animals by the mysterious far-reaching power of sympathetic feelings and affections. In the human race, these latter have always been so influential that we can never consider the erolution of man as falling in any unqualified way under the current biological rubric; while, with erery extension of the knowledge of what is of common nature and common value to all men, the natural feelings of friendliness and sympathy have tended to expand themselves so as to cover yet wider spheres of human nature. In the present intercourse of the so-called "superior races" with those whom they choose to consider "inferior," there is testimony, though of a mixed pathetic and ludicrous character, that the former are beginning to raise again the debate whether the latter are indeed "luman" in the fullest sense of the word. Those whom greed and rerenge prompt the enlightened (sic) of the race to treat as though they were not men, the enlightened will try to make out really are not men. It would not be civilized - not to say, Christian - to harry and hunt men like squirrels and rabbits, or tigers and wolves!

It is religion, however, which has been the mightiest ${ }^{1}$ Nic. Eth., VIII, i, 6. 
power over the minds of men to foster the growth of the virtue of benevolence. It is true, but only in the sense in which we have explained it, that "philanthropy is utterly foreign to the savage mind." And when the author just quoted asserts, "Humanity in this highest sense was brought into the world by Christianity," we must carefully guard our accord with this assertion so as to make the assertion itself accord with the facts of history. "Humanity in this highest sense" is "the sacrifice of self for others, without regard to difference of class or race." It was undoubtedly the early Christian religion which raised this virtue of benevolence to the height of a supreme moral principle and made it effective in the morally decadent condition of the ancient Roman Empire. We find the same moral principle, however, recognized and proclaimed by both of the two most widely influential religions of the Orient; - recognized and proclaimed, indeed, but not alive and effective in any such Inanner as to compete successfully with its working among modern Occidental and Christian peoples. Buddhism in its earlier days was a most powerful humanizing influence. It proclaimed a doctrine of friendly feeling and helpful conduct, of pity for, and sympathy with, all the suffering and needy, quite irrespective of differences of class or race. And in those earlier days it did a vast work for the Oriental World in spreading a genuine and helpful, if not wholly enlightened and judicious, spirit of active well-wishing for all men.

It is true that the religion from which Buddlism was a revolt contains, in a germinal way, some recognition of the virtue of benevolence, as self-denial and well-wishing toward all sorts and conditions of men. In a measure, too, it connects this human virtue with "the power to realize the loving presence of an individualized Personal God (?) in everything in the creation." Even in the extreme case when

1 Wundt, Ethics, I, p. 291. 
the individual, whose character must determine our actire relations to him in carrying out our well-wishing, is suffering the inevitable consequences of his own wrong-doing, the feelings of universal fellowship should not wholly be extinguished. "When one person suffer's the consequences of his acts," asks an expounder of the Bhagavad Gìtā,1 "should his fellow-brothers stand by and enjoy the spectacle? Certainly not. They should, led by feelings of universal fellowship, do their duty disinterestedly towards the person suffering." In spite, however, of those nuggets of gold that are hidden in the various strata of the writings which the Hindu religion has produced, the practically unbroken reign of caste, with all its ideas and practices so contradictory of the virtue of benevolence and of the beneficent practices belonging to this virtue, will remain for a long time the answer to any claims which its devotees may advance in rivalry of the claims of Christianity.

An active well-wishing toward all men, with a consistent self-sacrifice in their behalf, "without regard to difference of class or race," is made by the Christian religion a cardinal and quite indispensable duty - a virtue that is the gift of divine grace, and not to have which is contradictory of the essential spirit of the religion itself. In a treatise on the philosophy of eonduct there is little or no need, therefore, to argue the point. But in any treatise on distinctively Christian ethics there is little else to be done than just this, - namely, to show how the Christian conception of man as a child of God, and of God as the loving Father and yet just Judge of all men, makes rational as an ethical tenet, and peremptory as a moral command, the virtue of benerolence toward all mankind. Thus religion unites all men, as brethren, in a common service and a common destiny. In judging, Christianity in this regard, there is no need of

1 Mr. Kishori Lal Sarkar, in The Hindu System of Moral Science, commenting upon chap. xi, 26 and 27. 
doubt. In judging Christian nations, one must encounter the spectacle of many departures from the Ideal of the Virtuous Life, which are all the more conspicuous, sad, and blameworthy, because of the nature of this ideal itself.

It is customary to claim for modern commerce a large share of influence in spreading the spirit of humanitarianism among the nations. But this influence, where it is favorable to the extension of friendly feclings and sympathy among men, is mostly indirect; its more direct and powerful effects are mostly unfavorable. Commerce with one another on the part of foreign peoples makes them acquainted; and no one can lore the man as his fellow whom he does not know as his fellow man. Thus the virtue of benevolenee is made able to take a wider range. But the narrower spirit - of commercialism is, in the main, distinctly opposed to the spread of the spirit of well-wishing. If it were only the fairest of "fair trade" which modern commerce sought to secure, the result of its efforts would probably continue only negative or indirect at best. It is not in the interests of universal well-wishing that men engage in trade with one another. And when so much of the trade is distinctly not "fair trade," as is still everywhere the case, it is indeed questionable whether the indirect benefits, by way of fostering benevolence, compensate for the direct mischiefs to benerolent manifestations which commerce constantly works. The past and the present state of the commercial relations between the Christian nations and China is a fruitful and a frightful commentary on the charge of moral ineffectireness and mischief-making which $\mathrm{I}$ am bringing against commeree. At any rate, one cannot praise commerce, as one can praise art, philosophy, and religion, for its services in extending the natural virtues of pity, sympathy, and all manner of friendly feeling over into that principled love of all mankind for which the word "benerolence" is now made to stand. 
What has already been seen to be true of the other cardinal virtues now appears emphatically true of the virtue of benevolence. What, indeed, can society require of the individual more than that he should wish well to all his fellows; and, of course, carry the well-wishing out into conduct, wherever and whenever the opportunity offers? In opposition to that selfishness which certain ethical theories make the essential root of all wrong-doing, benevolence appears as the most attractive and pervasive principle of all that doing of the right which the most refined moral consciousness approves and commands. Who is entitled to be called perfectly good, if it be not the man whose supreme motive is wishing the welfare of all? It is doubtless possible so to expand the conception of this virtue as to make it seem to embrace all the other virtues so-called. Of this effort I cannot wholly approve, as will be made clear in another connection. But the very grounds on which the effort is based point toward some meeting-place for all the virtues when each of them is raised to its highest potency.

Both the counterfeits of this class of virtues and the vices which are the opposites of the virtues, are peculiarly offensive to "good taste." This fact is significant as to the nature of the virtues themselves. They flow spontaneously from good feeling for others; they are calculated to awaken corresponding good feeling in others. Their extended practice makes kindliness itself to be widely extended among men. Kindness begets kindness in others, and sympathy begets sympathy; the case is not the same with courage, wisdom, and justice. But the shamming of friendly feeling for purposes of gain or ambition or pride is distinctly disagreeable. Fawning, flattery, and fickle, shallow friendship, are æesthetically and ethically nauseating to the refined consciousness. Such is the natural and normal reaction against a peculiarly affective and emotional form of vice. But harshness, censoriousness, and kindred manifestations of a lack of friendly 
feeling are also vices that excite answering feelings of a like disagrecable character. That sickly sentimentality which is sometimes praised as "loving everybody," irrespective, not so much of class or race as of moral character and good or ill desert, instead of carrying wisdom, justice, and truth up to the heights where they are lost in a common halo with lore, too often degrades and perverts these three cardinal virtues in its foolish effort to reduce them all to a subordi. nate position under its control. Such benevolence is no substitute for justice even of the sterner and more punitive kind; nor for courage of one's convictions; nor for the wisdom that fears the consequences of breaking natural or Divine law more than of disturbing, however deeply and long, the smoothly running current of social good feeling.

Of all the vices which militate against good feeling none is baser than ingratitude; and perhaps none is more common. Indeed, this vice seems to combine unkindness and injustice in a peculiarly heinous fashion of mixture. For there is no other good which every individual man has so perfectly at his disposal for a just and equitable distribution as his own "good will," the sincere well-wishing, the friendly feeling for his fellow-men. There is no other good which, when convineed of its sincerity, men prize more highly, if onee they rise to the moral point of view. Now while the nature of benerolence is such that it does not seek a return in its own kind, or refrain from the beneficent deed through fear that it will not meet a reward, it is still true that friendly feeling, if genuine, and however manifested, merits friendly feeling on the part of its recipient. Such reciprocity is one of the most essential characteristies of the distinctirely social virtues. So that ingratitude adds injustice to unkindness, and both of the most inexeusable kind. No doubt the temptation to ingratitude comes chiefly from the dislike of being obligated to another, and of the feeling of inferiority which such obligation implies. But such a motive 
to ingratitude adds to its already great load of meanness. One of the most false touches in all the writings of Aristotle is the passage in the Nicomachean Ethics, ${ }^{1}$ where he says of the high-minded man: "It is his nature to confer benefits, but he is ashamed to reccive them; for the former is the part of a superior, the latter of an inferior. And when he has received a benefit, he is apt to confer a greater in return; for thus his creditor will become his debtor and be in the position of a recipicut of his favour." 2 This spirit is, however, quite the opposite of high-mindedness or even of ordinary friendliness on the part of the superior; carricd into effect it discourages, if it does not make utterly impossible that fine mixture of justice and benevolence in which the virtue of gratitude consists. Of all the virtues gratitude is the fittest and the easiest for the inferior to exercise toward his superior and benefactor; and when thus exereised, it partakes also of the virtue of fidelity and so makes possible for the poor and dependent a highmindedness of their own. All such relations presuppose, of course, that the good deed, the faror done or the help rendered, is a manifestation of genuine and unfeigned kindly friendship - a sound fruit from the beautiful root of humanitarian feeling.

In conclusion, attention should be called to the pleasuregiving quality of many of the subordinate forms of these virtues of feeling; this renders them more influential for good, or more seductive for misjudgment and even mischicvous consequences, than any of the colder and harder virtues. Much is readily forgiven to the kindly, sympathetic disposition, to the "good-hearted" man or woman. For, however the judgment may condemn a somewhat habitual lack of wisdom or an occasional brcach of justice, the heart responds to his heart in kindly and sympathetic fashion. It is on the whole well that this is so. For cowardice, greed,

I IV, 3, 24.

2 IV, iii, 24 (Translation of F. H. Peters, p. 117). 
ambition, and lust are still among men so excessively infiuential for suffering and want, and so productive of hardness of heart and misery of life, that the sunshine and cheer which kindly feeling brings can scarcely be overestimated. Yet your man who is thoughtless, fickle, and not altogether careful of truth and of the rights of others, can be the cause of much misery, - sometimes of even more than the more selfish and deliberately cruel man. And it is not to be forgotten that, neither in human physiology nor in human conduct, is it always the most obviously comely and graceful manifestation of life which is the most essential and effective of good results. 


\section{CHAPTER XIV}

\section{THE UNITY OF VIRTUE}

ThERE is little donbt that the foregoing description of the Virtuous Life would, in its main features at least, seem fairly satisfactory when brought for judgment before the bar of current popular opinion. It would accord substantially with this opinion, and it would seem to carry its own explanation, proof, and sanction, with itself. There is considerable historical ground also for the conclusion that if an essentially like description could be adapted to those differences in language, customs, and physical and social environment, which characterize the different stages and types of man's ethical evolution, it would gain a general acceptance in all times and in all places. Who is the good man, - the man who conducts himself as a man ought, and so meets with the approbation of the universal moral consciousness? He is the man who is brave and constant, wise and just, hospitable, generous, and kind. To explain further than this or even to seek for the proofs and sanctions of so much as this, seems to the multitude of men to belong to interests of a purely academical sort. Plain common-sense is satisfied to take its ethical judgments and opinions on a basis of life and reality.

The scientific student of conduct, however - its origins, derelopment, sanctions, and ultimate principles - cannot be satisfied with a merely deseriptive history of the virtues, no matter how true this history is to the facts of individual or ethnic psychology. As said Socrates to Meno: "When I ask you for one virtue, you present me with a swarm of them." 
Science seeks for some principle of unity; and the argument which gives a warrant and a guide to this scientific impulse may be stated in somewhat the following way. Here are nine-more or less - so-called cardinal virtues; and yet cach one of the nine is confessedly of an order which needs to be qualified by one or more of the others. For courage that is not wise, even if still entitled to be called the rirtue of courage, is eertainly not virtuous when considered as folly; and kindness that plainly violates the prineiples of justice, however well intentioned, is not to be commended from the higher ethical point of view. Moreover, we have discovered that whenever any of the more fundamental of the virtues is considered in its highest purity of excellence, and in its widest range of application, it begins to show a kind of eapacity to embrace, as it were, a large number of other relatively subordinate virtues. If, then, all these forms of conduct are virtues, there must be some characteristic which they all share in common, so as to entitle them all to the same name. What is this characteristic in which all the types or kinds of virtuous conduct share? What is that essential quality which gires their virtuousness to the virtues?

The endearor to discover a unifying trait, or principle, for the virtues is undoubtedly born of the scientific spirit; and whaterer its practical ralue may be, or eren its success in the research which it stimulates, it cannot be disregarded by the plilosophy of conduct. Two considerations, howerer, should always anticipate and constantly accompany such research. And, first, it must be remembered that in the order of experience and reality the manifold and various

- precedes; it is the actually experienced, the real; and the so-called unity is only abstract and conceptual. Virtues exist; they are the actual, concrete forms of the Virtuous Life. Virtue does not exist, except as a conception abstracted from the existent specimens of the virtues.

Second: in certain similar cases we find our keenest psy- 
chological analysis much puzzled, if not completely baffled, in its endeavors to discover the essential, unifying marks of to similar conscious states. Men speak, for example, of different pleasures and pains; and then, again, of pleasure and pain, in the abstract and yet as though the intention were to appeal to a universal experience. But pleasures and pains are of an indefinite variety; and neither pleasure nor pain is ever experienced, or can possibly be experienced, except as some concrete, definite kind of $a$ pleasure or a pain. But what is common, for example, to the anguish of having a firmly rooted tooth drawn, or an attack of neuralgia of the stomach, and the melancholy memory of a neglected opportunity, or the grief of haring offended one's invisible Divine Friend? Both experiences are painful, to be sure; but what construction shall be given to the conception of what is common to both - quoad pain? How, on the other hand, shall science depict the common essence of two pleasures - one of which is the gratification of some appetite, for example, and the other the memory of some deed of gratitude in return for help rendered to another, or the appreciation of the present Divine favor? In answer to such questions as these the current psychology is accustomed to give either evasive or inadequate answers. Evasive - distinctly soare all such theories as those which, since the day when the close of the Serenth Book of the Nicomachean Ethics was written down to the present hour, have defined plcasure and pain by reciting their physiological or psychical antecedents or accompaniments. Such theories, at best, only describe, in a lame way some of the known or conjectural conditions under which pleasures and pains of ecrtain sorts are experienced, and then confuse the conditions with the experience of pleasure or pain itself. $\quad$ More misleading still, and decidedly mischievous

1 For a more detailed discussion of this subject compare chapters ix, "Feeling: its Nature and Classes" and x, "Feeling, as Pleasure-Pain," in the author's Psychology, Descriptive and Explanatory. 
in the field of ethies, is the psychology which identifies the entire fecling side of human nature with the pleasure-pains, then proceeds to strip the remainder of its contingent judgments and estimates of value, and then propounds a theory of a wholly abstract and unreal gross quantum of pleasure and antithetic pain which it can distribute by weight, as it were, among the different concrete experiences of human lives. This is seientific unification and simplification with a vengeance; but its simplicity is a delusion, and its unifying a snare. And the pieture of the individual or social Self which it thus completes, as seeking with a pair of phantom scales in its hand to weigh out larger portions or smaller driblets of the current pleasure-pain commodity, no more resembles the infinitely rich and varied affective experiences and judgments in estimating the goods of life which belong to the real, living man, than the rude sketch of his bodily appearance, as drawn by the child or the sarage, resembles the histological structure and physiological action of man's actual bodily organism.

Another example of the same difficulty might be taken from the condition in which psychological analysis finds itself compelled to leave the search for the unifying essence of man's sensuous experienees. Light and color, noise and musical tones, the various smells and tastes, and the sereral modifications of consciousness cansed by stimulating the areas of the skin, are all classifiable together as "sensations"; and the psychologist knows beyond doubt what are some of the conditions and concomitants, as well as some of the characteristies common to them all. It is another and much more difficult problem, however, to frame a conception of sensation, as such, which shall include only the common characteristies and negleet all that belongs exclusively either to sensations of smell, or of taste, or of sight, or of sound.

It will not be an unexampled failure, then, if the student, of ethics fails to discover in what consists the virtuousness 
of the different virtues. For virtues - I repeat - as actually recognized and concretely practised by men, are the antecedents in the order both of experience and of reason; but to discover the "essence of virtue" involves an academic quest which may not be destined to end in complete success.

There are two forms, closely allied but by no means identical, which have been taken by the customary attempts at unifying the particular virtues. Both of these are, in my judgment, unsatisfactory in their method as well as in their result. One of them consists in selecting some single feature or aspect of conduct, and then identifying the virtuous or vicious quality of all conduct with the goodness or badness of this one feature or aspect. The other consists in selecting some one of the more important of the virtues, and then identifying with it the entire essential content of the virtuous life. Thus if one follows the trail of the first argument in one's seareh after the unity of virtue, one will discover the virtuousness of virtue to consist in either good external behavior, or good motive, or good intention. But if the second method of solving the problem be adopted, then it will be claimed that all the virtues are, in the last analysis and essentially considered, either wisdom, or justice, or benerolence, or some other one among them all. The first method of unifying the particular virtues results in a narrow and perverted conception of conduct, as conduct has already been described in aceordance with the opinions and practices of mankind. The second method results in so modifying and expanding the conception of some one of the particular virtues as that it loses all its conerete and valuable particularity in a vague and shadowy generalization as to the nature of virtue. The result in both cases is similar to that obtained by a similar method of treating the allied phenomena of man's religious life. Thus in answer to the question, What is religion? one may locate its "essence" in feeling, or dogma, or behavior; or one may 
attempt the answer by so manipulating some one religion as to include under it all "true" religions and exclude all other religions on the ground of their being "false."

The one essential characteristic of virtue is not the character of the external behavior; the science of ethics cannot bring about a unification of the virtues under the conception of Conformity to the customs and laws regulating such behavior. It has already been shown that without regard for those customs, laws, and precepts, which give external expression to the dereloping moral consciousness of mankind, there could be no concrete standards for the social testing of conduct and of character, - no society even as an affair of ethical influences and ethical significance. But, on the other hand, nowhere and never do we find the merely external conformity to custom, or law, or moral precept regulating behavior, identifiable throughout with the essence of virtue. For "virtuous" or "vicious" is an epithet which men apply to conduct; and conduct is something more than mere conformity to any rule, however set, of behavior. It is an activity of the conscious Self, and not an affair of muscles, bones, and tendons chiefly. Men call the bow strong and good which, when drawn by a strong arm and directed by trained visual and muscular sense, speeds its arrow truly and well toward the far-distant mark. Men do not, except in a figurative way, demand of the bow the feeling of fidelity, the resolve to try to hit the mark, the judgment of the distance at which the mark is set, of the resistance from the currents of wind, or of the downpull of gravity. In the ease of the lower animals, unless we endow them with quasi-moral qualities, we are satisfied if their behavior is satisfactory, whatever the motives and intentions which initiate it, or the judgments which guide it, may chance to be. We prize affection, fidelity, sound judgment, courage, etc., on their part; but we do not demand these states of consciousness as in themselves commendable so long as we consider the animals to be merely conscious machines. 
In man's case, howerer, the very locus in which resides the virtuous quality of the virtue is the conscious feeling, judging, and willing Self. It is this conscious Self which is good or bad, virtuous or vicious, deserving of approval or of disapprobation, and of punishment or reward. Whenever men have reason to believe that it is cowardly, they do not call the action brave, however it may conform externally to the requisites of the virtue of courage; or wise, if the motive and intention be those of a fool, in spite of all the more obvious semblances of wisdom. We cannot, then, adopt any view which, like that of Locke, ${ }^{1}$ regards the whole essential quality of morality to be the conformity of action to a rule.

It is a much more frequent temptation and consequent error to merge the whole of conduct in the so-called Motive merely. Or if the motires be taken collectively and regarded as fairly stable in eharacter and habitual in their impulsive effect, his "disposition" may be counted upon as summarizing the virtuous or vicious character of the individual. The good man is, then, as the popular phrase expresses the thouglit, the "good-hearted" man; he is the man who always means woll. One will therefore have to say that conduct is virtuous whencrer the motive which issues in the conduct is virtuous. And it would seem to follow that the one thing which he who would lead the Virtuous Life must do is to make sure that his motives are good. For are we not assured by those who invoke the sanetions of religion in behalf of morality, that God has regard to the motives only?

Now although I cannot for a moment admit the adequacy of this attempt to simplify the eonception of virtue, I have no desire to hold it to the strictest account for the language which it sometimes employs. The word "motive" does not once occur in that collection of books (the Bible) to which this view of the essential nature of all the virtues most frequently appeals. The word "heart," however, does occur

1 Essay Concerning Human Understanding, book II, chap. xxviil. 
there hundreds of times; and although the heart includes, in that vague and unscientific way which distinguishes the psychology of the biblical writers, activities of intellect and of will, it undoubtedly emphasizes more particularly the side of feeling and of the emotions. Since the mishaps which arise in conduct, as well as the more heinous sins and crimes of humanity, have their origin so largely in selfish and disordered appetites, impulses, and desires (the motive elements of human nature); and since the inducements and disciplines to improved conduct which ethical praxis aims to employ must reach man so largely through his feelings; there is good reason for emphasizing the supreme importance of purity of motive in all attempts at virtuous living. All this, however, does not alter the essential facts of the case; good judgment is as necessary to virtuous conduct as is good disposition; and the same is true of the courageous, strenuous, and constant will.

Nor are matters helped in the interests of unification when it is urged that, of course, the motive to inform one's self and to form good and wise judgment is a part of the general good motive required by the demands of virtue; and as well that one must cherish the motive to be, and to grow, more courageous and constant in self-control, to get the mastery over one's Self, so to say. To all this the reply is obvious: the disposition to cultivate wisdom is doubtless a species of wisdom, and so is the disposition to cultivate courage or that species of self-control which results in temperance. But if the actual aequirement of the wisdom, the courage, the temperance, or the kindness, does not somehow result from the motive, then the quantum of virtue and as well the particular qualities of virtuous conduct are so far forth lacking. The ideal of virtue can no more excuse this lack than the common moral consciousness of mankind actually does excuse it. And experience shows that good disposition, and commendable motives, when they fail of the moral strength and the wise 
judgment necessary to realize themselves in courageous and wise conduct, may be excused in part and for a time, but they are finally, and rightly, visited with increased moral disapproval and even contempt. For although it is necessary for the heart to go into the decd in order to impart to the deed its quality of life and moral vivacity, the heart that yields only motives which are not guided by good judgment and set into reality by strenuous will, is so far from being the summary of all virtuous living as to incur for its owner the greatest risk of being quite seduced away from the paths which lead toward the attainment of the Moral Ideal.

The science of psychology, then, sets certain limits to the ethical theory of virtue when this theory attempts to confine the essential nature of virtue to the character of the motive. For, in psychological language motive is any impulse, desire, or wish, which tends to induce a definite form of volition. Motives that are "good," in the ethical meaning of this adjective, are such impulscs, desircs, and wishes, as tend to induce the choice of good, or virtuous, action. And, if all morality consist in the motive alone, to desire or wish to be perfectly virtuous is equivalent to being perfectly virtuous. But such an extreme conclusion is quite inconsistent with the moral consciousness of men, as this consciousness expresses itself in the feelings of obligation and ethical approbation, in the complex conception of conduct and of the virtues, and in the most satisfactory attempts at the speculative construction of the conception of the Right.

If, however, to this conccption of motive as mainly emotional, we add the elements of "reason" as an inducement to ccrtain forms of judgment, we confess in a covert way the inadequacy of our conception, by introducing into it from the outside, as it werc, what does not properly belong to its psychological character.

"By motive I mean," says Jonathan Edwards, "the whole 
of that which moves, excites, or invites the mind to rolition whether that be one thing singly, or many things conjunctively." It is now only nccessary to couple this conception of motive with the Edwardean theory of a strictly determined will in order to complete a machine-like theory of the nature of virtue and of the virtuous life. But it cannot be too often repeated that conduct involves - nay! it is - the entire Self, feeling, judgment, and will, functioning together in relation to a Moral Ideal. When, and only when, this total functioning corresponds with some portion or aspect of this ideal are we warranted in calling the particular piece of conduct virtuous. To quote from the Nicomachean Ethics:1 "If the purpose is to be all it should be, both the calculation or the reasoning must be true, and the desire must be right."

Similar objections may be urged against identifying the virtuousness of the virtues, the "essence" of all virtue, with the so-called Intention. This word ordinarily includes elements which do not so strictly belong to the motive; and such elements are partly of the intellectual and partly of the voluntary order. The man of habitually good intentions might perhaps be distinguished from the man of habitually good motives by his larger measure of thoughtfulness in planning his conduct, and by the increased certainty with which the plans get themselves actualized in the choices and their sequent courses of action. As said Locke, in his naire, common-sense way of stating the conceptions of the popular psychology: "Intention is when the mind, with great earnestness, and of choice, fixes its view on any idea, considers it on every side." An ethically good intention, then, may seem to include an earnest desire to do the right thing, a voluntary direction of the judgment upon the problem of determining what that right thing is, and the suspension of action during a process of deliberation which enables the 
mind to regard all the elements entering into the problem. In this way, of course, the cvaluation of the end of conduct becomes more completely rational; the estimate of the most effective and appropriate means is gained; and the increased chances are securce that the final choice will be satisfactory from the moral point of view.

Intention apprehends and comprehends the probable consequenees of conduct far more than does mere motive. For this reason it is ordinarily held that the responsibility is increased and the blameworthiness heightened if the conduct is wrong, the praiseworthiness if the conduct is right, according to the intention. Morcover, to intend evidently gives more of distinctively moral quality to the entire process; for it involves and commits to the process more of the entire Moral Selfhood. To be in the habit of framing good intentions (it is well to notice at this point that one speaks of creating or forming intentions and of indulging or encouraging motives) is undoubtedly a virtuous habit; it is a most desirable species of wisdom, and a duty, as well, to which the power of rational intending obligates every man. It must also be admitted that in ecrtain cascs good intention is by far the greater part, and it may become the whole of virtue. Finally, if one insists on so extending and modifying the word intention as to change quite completely its own primary meaning, one may make a brave show of identifying it with the virtuousness of all the virtues. I must, however, object to this, and for the following, among other reasons.

First: if under "good intention" it is meant to include the best possible functioning of the Moral Self, as feeling, judging, and willing, in the interests of the moral Ideal, good intention is ecrtainly identical with the morality of all the virtues. The man of perfectly good intentions would then be the man of the perfect Virtuous Life. But this would only change titles without simplifying the subject. 
Morally good conduct would remain just as complex an affair as before; the virtues would not be unified; and for the very good reason that we should not be at all enlightened as to the nature of their unity.

Sccondly: The forming of good intentions is often the best possible exercise of virtue; sometimes it is the only way of virtue possible under the circumstances. But there are eertain forms of feeling to which the moral conseiousness of men quite generally responds with approval that are not so consistent with the fixedness of view upon an idea, and the consideration of it from every side. These feelings seem to lose somewhat of their moral beauty, or effectiveness, when they lose their spontancity; and spontaneity belongs to them rather as motives than when they beeome transformed into fixed and deliberate intentions. Still further must it be remembered that often, if not ordinarily, time for the consideration of consequences and for the contemplation of the ideal of virtue, eannot be secured previous to action; to attempt to secure time would result in racillation and delay and even in loss of opportunity for any fit action at all. The Puritanic virtues may be ealled the virtues of good intention. But there are other virtues of good impulse and good feeling more particularly. Sueh are all the subordinate forms of kindliness, hospitality, generosity, etc.; and as well much of courage and temperance. Nor am I at all sure that so-called "righteous" anger, if righteous at all, is always improved by being converted into the virtuous intention to punish or eren to reform. Its outburst and expression is not infrequently a token of the virtuous heart of the angry man; and the effect of such anger is seldom, if time and form of expression be appropriate, otherwise than morally purifying. On the contrary, the infliction of punishment, and the attempt at reform, without more or less of such spontaneity of feeling, seem to lack something of right moral quality. And men resent, rather than appreciate 
highly, all intention to be kind or generous toward them, which is not largely a spontaneous feeling.

Thirdly: there are some of the most cardinal and important virtues of each of the three main classes which do not seem reducible to good intentions merely. For example, there is that virtue, mainly of the will, which was called constancy. To be sure, it may be affirmed that in order to be always a man of good intentions one must constantly be framing and keeping the intentions good. But this bit of sophistry does not meet my objection. For it is just that necessity of being constant, of having a roluntary fidelity to the chosen ideal, which must be introduced into our accounting for the habit of intending well, in order to complete the picture of the ideally virtuous life. To a less degree somewhat of the same necessity applies to the virtue of courage. The best of intentions need to be carried out with courage in order to perfect the system of virtuous forms of conduct. Shall we say that the intention always to be courageous is equivalent to the unfailing virtue of courage? We can scarcely elaim that the man who fully intends to do any particular brave and virtuous deed, but who fails through fear in the hour of execution, is as good and meritorious a man as he who both intends to be brave and courageously carries into effect the brave intention.

It seems, then, that the virtue of habitually intending well is a kind of deliberative and voluntary wisdom; and that this virtue properly emphasizes the duty of man to plan his conduct, wherever this is possible, so as to put his moral reason and right resolve into appropriate action, when the time for action arrives. But the conception which the ethical use of the word "Intention" covers is of comparatively little assistance in our search for the bond of unity which unites all the virtues into one idea of Virtue.

The second way of unifying theoretically the virtues maintains that some one among them all is so comprehensive in 
character, and so supremely magisterial, that it includes and dominates all the rest. Such a claim may be pushed so far as to assert that some one Virtue $i$, essentially considered, all the virtues in one. Thus he who has that one virtue to perfection exercises them all in perfection;-not, indeed, because he can dispense with any one of them, but rather because he already in essence possesses them all. In modern systems of ethics the virtue which is thought most fit to be intrusted with this comprehensive supremacy is, of course, Benevolence. Thus this particular virtue is converted into a gencral, all-inclusire virtuousness. And if a somewhat theological caste is given to the conception, the word Love may be adopted in its stead. The summary of all the virtues is then expressed in "The Law of Love and Love as a Law." For are we not told on the best of authority that the two commandments on which "hang all the law and the prophets" are: - "Thou shalt love the Lord thy God with all thy heart, and with all thy soul, and with all thy mind;" and, "Thou shalt love thy neighbor as thyself"? Love, then, is the fulfilling of the whole moral law.

But before adopting somewhat too rashly the ethical theory which identifies the virtuousness of all the virtues with the one virtue of benevolence, one may profitably consider the exact nature of the proposal. If "the law and the prophets" be themselves inquired of in order to determine more precisely their own most elevated and comprehensive conception of morality, they return such answers as the following: "And now, Israel, what doth the Lord thy God require of thee, but to fear the Lord thy God, to walk in all his ways, and to love him, and to serve the Lord thy God with all thy heart and all thy soul ;" ${ }^{1}$ and, again, "He hath showed thee, 0 man, what is good; and what doth the Lord require of thee, but to do justly, and to love mercy, and to walk humbly with thy God." 2 These are the utterances of a monotheistic

1 Deut. $x, 12$.

2 Mic. vi, 8. 
religion in which the Deity is conceived of as the Source, the Arbiter, and the Ideal, of perfect righteousness. No wonder, then, that an attitude of loyal and passionate devotion to his scrvice, conceived of as an intelligent and principled personal affection, should seem to be a sufficient motive to the practice of every form of that which ethics conceives of as the Virtuous Life. It should not be forgotten, moreover, that the first of the passages just quoted has reference particularly to the keeping of the Mosaic Law with its elaborate "commandments and statutes" having reference to domestic, social, and civil relations, and appealing to every cardinal virtue in the entire catalogue current at the time; while the exhortation of the prophet especially emphasizes the justice, mercy, and humility, which were at the time - as always in human history - particularly needed, and conspicuously lacking, on the part of the rich and the powerful. For it was a time when men devised iniquity at night and executed it with the morning light: "And they covet fields, and take them by violence; and houses and take them away: so they oppress a man and his house, even a man and his heritage ". . . "because it is in the power of their hand." 1 Here is surely a tolerably comprehensive list of virtues and vices, the former of which would be motived and secured by the love and fear and obedience of Yahveh, the god of righteousness, and the latter of which would be obstructed and prevented by the same love, fear, and obedience.

Finally, it should also be borne in mind that the entire list of concrete and particular virtues, with the illustrative examples given in the Sermon on the Mount, is summarized by their author in the exhortation: "Be ye therefore perfect, even as your Father which is in hearen is perfect." As to the truthfulness and value of this religious doctrine of perfect morality, I shall have occasion to refer hereafter. But surely this is a very different tenet from the identification,

1 Mic. ii, 2. 
in ethics, of the virtue of benevolence with the virtuousness of all the virtues.

Is benevolence properly conceived of as the one absolute and all-inclusive virtue? The affirmative answer to this question either compels us to extend unwarrantably the meaning of the term "benevolence," or else leaves us with the same complex and confused eonception as to the essential nature of virtue, and as to the bond of unity among the different virtues. In the most expanded form of its proper ethical significance, this virtue is an active well-wishing, a desiring and planning for the good of our fellow-men (comp. p. 331). When this virtue is represented by the word "love" and identified in its essential virtuous quality with that attitude which religion considers to be due from man to God, an almost complete change of its psychological characteristics is silently but suggestirely introduced. For it is decidedly not a virtue for any one to love all men alike, or with the like kind of affection (e.g., the domestic, friendly, admiring, etc., sort of love). Nor is it virtuous for me to love any human being with all my mind and soul. On the other hand, there seems something quite inappropriate and savoring of the æsthetically, if not of the ethically, unseemly, to regard it as a virtue in man to cultivate "benevolence" toward God.

What, moreover, is this good which I ought to desire and plan for every man, if I am to exercise benevolence in such a way as to include in it all the other forms of virtuous living? Eudxmonism, even in its most refined forms would hare to say: It is happiness; for happiness is, first and last, the only and all-inclusive good for every man. But justice and wisdom often require me not to desire and plan for this kind of good, either for myself or for some one else, so far as the concrete and individual case is concerned. And if the modification is added - "for the greatest number and in the long run" (a general benerolence or "love of being in 
general "); then the vagueness and worthlessness of the entire conception are made apparent as soon as it is brought to the actual test of a working principle. Distinctly, I am not going to desire and plan to have all my fellow-men happy, unless they themselves fulfil the fundamental ethical conditions of a limited happiness; and I an very sure that these ethical conditions themselves are going, so long as they are not essentially and even inconceivably altered, to set unavoidable limits to human happiness.

Even Lotze is hopelessly confused and unintelligible in his conception of benevolence as affording the unity of all the virtues. For, after defining this virtue as that piety which "considerately allows" the undisturbed devclopment of spirits in their relations to spirits, he regards retribution as also agreeable to moral consciousness. And, then, having shown that pleasure-pains as the consequences of conduct are essential to all moral judgment, he appeals to an intuition of conscience to show "that it is not the effort after our own, but only that for the production of another's felicity, which is ethically meritorious; - and, accordingly, that the idea of benevolence must give us the sole supreme principle of moral conduct." 1 But I do not so read moral consciousness; at least, I do not so read its conclusions in any such off-hand manner. As is customary with all advocates of this theory, Lotze's conception of benevolence is quite too vague to correspond to any definite manifestation or attitude of the Moral Self toward others; and his identification of benevolence, on the authority of conscience, with the virtuousness of all virtues is not in accordance with the universal moral feeling and judgment, even when considered from the higher point of view to which man is rising in his moral evolution.

The best possible case is, however, made out for the allinclusive nature of benevolence when the object of its wish-

1 Outlines of Practical Philosophy, p. 28-34. 
ing and planning is the welfare, including especially the moral derelopment and perfection, of all mankind. I may not virtuously wish the bad man to be happy. On the contrary, I may be, in fidelity to virtuous principle, bound to wish and to plan to make him very unhappy. But I may virtuously wish him to become good, that we togrether, as brethren in one high purpose, may follow, each in his own individual appointed way, the Moral Ideal. The highest benerolence will include-will chiefly be, just such a wishing and planning as this. What more than such an habitual temper of bene-volence, or well-wishing, as this can the complete Virtuous Life demand or even suggest?

I have elsewhere (p. $326 \mathrm{f}$.) referred to this lofty spirit of wishing and planning for the highest welfare of all sorts and conditions of men as the choicest result of poetry, philosophy, and religion in their influence upon the moral evolution of the race. Such so-called "benevolence" includes the uplift of imaginative insight, - the far-away look into the future of the race, the acquaintance with the history of its past evolution and with the conditions of its future improvement, and, above all, that estimate of the great worth of the individual soul and of a human society which shall consist of multitudes of such souls when morally improved and perfected. The most kindly and sympathetic savages are $\star$ quite incapable of all this. Eren Plato and Aristotle, with all their noble conceptions of the virtues of friendship and of philanthropy failed to rise to such heights as those where these conceptions and ideals are powerful.

Yet the same difficulties recur when the effort is made theoretically to reduce all the particular virtues to this one virtuous attitude of well-wishing and planning for the highest welfare of mankind. And the difficulties seem to be due to the very nature of the Moral Self; they persist, in part, because wishing and planning, even when extended and organized into choice of a course of conduct, do not 
corer properly all the functioning of such a self. Nor does the whole of virtuous living consist for any individual in planning and wishing for the most desirable end of others' happiness or welfare. In order to the perfection of benevolence itself the moral judgment of men requires all the other most cardinal virtues, both of will and of judgment. All these other cardinal virtues qualify benevolence, as benevolence employs, consecrates, and qualifies them. Bcnevolence itself must be courageous in its expression where the beneficent conduct which it motives is destined to encounter any kind of fear. Especially do we require of this virtue that dependableness which is the product of the virtue of the will ealled constancy; and for which, as such, there is not wanting a certain ethical admiration, even when it becomes a steadfast commitment to a wrong cause. Even the wishing and planning for the highest welfare of mankind in general-nay, just this especially - needs indomitable courage and steadfast fidelity to make it complete. No advance is made, however, when the claim is raised that only courageous and constant benevolence is real benerolence. For the answer is at the same time suggested and justificd by the question: benevolence, then, plainly needs courage and constancy in order to become perfected in its own reality, and this seems the same thing as to say that the latter virtues qualify and complement the former, in the unity of the Virtuous Life. As says Hegel: "True character involves on the one hand an essential import in its purpose; on the other hand, adherence to that purpose such that the individuality would be robbed of its whole existence, if forced to desist from and to abandon it." "This stability and substance constitute the key-note of character." 1

It is doubtless easier to make a fair show of proving that such virtues as temperance are only applications of the one all-inclusive virtue of benevolence. Yet I am by no means

1 See Hegel, On Fine Art, Bosanquet's Translation, p. 129. 
sure that some fallacy is not lurking in the argument here. Many virtuous acts which fall under the general notion of self-control over the impulses, appetites, and desires, are certainly relative. Their virtuousness mainly, if not wholly, depends upon the character of the social consequences which follow from them, as a rule. In the narrower meaning of the word chastity, for example, as involving virtuous control over the sexual instincts and passions, the actual limits of such control are, in fact, exceedingly indefinite. In the large they may be said to be determinable only by consideration for the welfare of society. In the regulation also of one's appetite for food and drink, and in the matter of sccuring and maintaining bodily health, the law of regard for the highest social welfare is very properly emphasized. Why, however, shall one say that preserving health by chastity is always a virtue; and that sacrificing health sometimes - as in the case of the faithful mother, nurse, or physician - is also a virtue? How far rightfully may the demands go for sacrifice of Self in the interests of society? These, it seems to me, are questions which the benerolence theory can never answer with a complete satisfaction. For at a certain point the theory is always met by certain limitations which moral reason imposes in the name of the other virtues, - even such as temperance, wisdom, and justice.

Benerolence itself may become an absorbing passion. The enthusiasm of humanity, like the scientific zeal for truth, may carry the soul and body of the enthusiast beyond the limits of a temperate and wise self-control. And then the student of ethics who wills to face steadily its most profound and dark philosophical problems may return to ask of it anew certain pressing, though perhaps unanswerable questions. After all, am not I, too, a Self? - only one, among a rast multitude of other selves, it is true; and yet one Self. And is there not that in me, and belonging by right of my very selfhood to me, which I am not virtuous, not true to the 
nature of a Self, if I surrender or disturb? At times this devotion to the good of others seems to threaten the supreme and inalienable rights of one's own soul. In view of this threat, as well as in view of the highest ideals before the individual soul, Aristotle and other philosophers, both ancient and modern, have made reflective thinking or philosophy itself the highest form of virtue. In view of similar considerations, not only the Hindu and Buddhist derotees but also many Christian ascetics and monks have withdrawn from society in the interests of the higher ethics - the spiritual life of the individual soul. The lonely Jew Spinoza, isolated so largely from all social interests, concludes his Ethic with the demonstration that the intellectual love of God, which is blessedness, is "not the reward of virtue, but is virtue itself." It is "the highest good we can seek according to the dictate of reason;" and although it is "common to all men and we desire that all may enjoy it," the virtuousness of this virtue does not consist in the desire for others but in the intellectual love itself. ${ }^{1}$ Such theoretical constructions of virtue as these are, indeed, quite foreign to the spirit and the doctrine of the Modern Occidental World; and they are not mentioned here in order wholly to commendmuch less to rehabilitate and reinstate them. But they represent a side of the truth sought by the philosophy of conduct which is perhaps too little regarded at the present time. Every man must save his own soul; nor can he surely and wholly save it by the utmost of wishing and planning for the welfare of others.

And now the proposal is made so to extend the conception of benevolence as to have it apply, on terms of personal equality as it were, to one's own self as well as to other selves. The perfect exercise of this virtue would then secure the wishing and planning for one's own highest welfare as included in the welfare of mankind generally. Such a pro-

1 Ethic, Fifth Part, Prop. XX and XLII. 
posal certainly strikes the common-sense of mankind as a somewhat fantastic modification of the current and appropriate meaning of ethical terms. Indeed, on examination it also appears to conceal a kind of twist to the conceptions themselves. If by welfare one simply means happiness, then the desire and planning for one's own happiness is only doultfully to be called a virtue in any case. Have we not been told by Lotze (see p. 353) that benevolence, considered as the one all-sufficing virtue, is " not the effort after our" own, but only that for the production of another's felicity?" Suppose, howerer, that by welfare one means also, and especially, the highest welfare, which from the purely ethical point of view is the attainment for the Moral Self of the perfect Virtuous Life; then indeed one may say that wishing and planning for this is the most comprehensive of virtues and, in some sort, includes all the virtuous quality of all the other particular virtues. Only now we have arrived, by a process of enhancing the content of the conception of benevolence, at a result which essentially alters its entire meaning. Properly, the virtue of benevolence consists in wishing and planning for the welfare of other men; in this meaning of the word, benevolence is the powerful corrective of the too exclusive wishing and planning for one's own welfare. All of which paradox will have to be resolved, so far as its resolution is possible at all, by considerations connected with the fundamental truth that an isolated Moral Self is a monstrosity, - impossible eren of conception - and that society is an essential condition of the individual's moral life and moral development.

Once more, then, the discussion must return to the thought that wishing and planning for the welfare, whether of ourselves or of others, is not the whole of man's virtuous living. Benerolence, even in its most comprehensive exhibition as a virtue, must be infused with the cardinal virtues of judgment. It must be wise, and just, and conformed in a voluntary and 
rational way to the facts and principles of Reality. Indeed, so far as human wishing and willing have reference to the higher welfare as their object, they imply the reference also to some standard which shall determine a place for each form of good in a scale of values. The best benerolence desires what is best for every self in its various changing relations to a social organization of selves. But who shall determine that which is best - either in general, or in any ease of a particular and concrete problem for the judgment? If the problem be one concerning the ends to be chosen, or the means to be sclected, then the virtue answering to its morally satisfactory solution is wisdom; if the problem be one of distributing good and evil among men according to their desert, then the corresponding virtue is justness. Bencrolence wishes to employ justness and wisdom in carrying out its supreme desire and plan to secure the welfare of all mankind. Benevolence, then, has need of wisdom and justness in order to complete its own virtuous quality. The idea of rational measure is required as an added ethical qualifcation in connection with benevolence itself. That justice which is "half of honor - and honor and justice are two-thirds of purity" - is a necessary supplement to benevolence, and cannot be merged in it. It is this fact which has led so


the complete and all-inclusive virtue. The same thing is true of the wisdom which Plato exalted to the place of supremacy. But in the ethical theory of Old Japan, benevolence, justice, and wisdom all yield the crown to the consummate virtue of Fidelity.

The relation of trueness to benevolence in the system of the virtnes is somewhat similar to that in which temperance stands to benerolence. But it is even more fundamental. Is trueness, as it has already been described (p. 295 f.), a species of conduct whose virtuous quality can all be resolved into benevolence? Certainly not. I am not now about to dis- 
cuss the more casuistical question whether a lie, under certain prescribed circumstances, may be consistent with, or even demanded by, the virtue of benevolence. Nor is it proposed to criticise such statements as the following from $\mathrm{Mr}$. Leslie Stephen:1 "If in some distant planet lying were as essential to human welfare as truthfulness is in this world, falsehood might there be a cardinal virtue." I only interrupt the argument to suggest these three inquiries: (1) What would distance or difference in the physical constitution of its enviromment have to do with the moral nature or the social effect of lying, in case the nature and the spiritual relations of moral selves remained the same? (2) If we agree with Mr. Stephen in making the end of conduct - namely, "human welfare" - synonymous with happiness, do we not find ourselves obliged to admit that an immense amount of falschood is "essential to human welfare," - almost as essential as truthfulness is, in this world even? And (3), how can falsehood be regarded as a "cardinal rirtue" - however permissible or pardonable as a species of kindness or politeness - without so undermining the very structure of the rational sclfhood, and of society as a community of moral selves, as to render all virtue nugatory and inconceivable? In a word, the hypothesis of Mr. Stephen seems to me to resemble that of John Stuart Mill with reference to some conceivable condition in which space is still three-dimensioned, but parallel lines are habitually scen to meet. Even in the philosophy of conduct, however, analytical axioms must not be unwarrantably converted into synthetic judgments a priori. You cannot at the same time keep your three-dimensioned space, and your Euclidean geometry, and also utterly destroy its essential characteristics. You cannot posit Moral Selves in a social community and then suppose them to be transmuted by some change of place or physical environment into a totally unlike Moral Selfhood. 
The adjusting of one's rational position by an act of judgment to the facts and principles of Reality is, I believe, for a rational and moral being a virtue which can never be resolved into any form of well-wishing toward other beings. Granted that falsification may sometimes be a virtue; and if the motive be regard for the well-being of others, call the falsehood an act of benevolence, if you please. And still, it secms to me, you have not essentially altered the state of the case; you have not at all changed the principles involved. Benevolence may be the virtue which, in the conflict, gets the victory, while a particular manifestation of the virtue of trueness temporarily gocs to the wall. But the duty of rational man to frame his judgments according to the facts and principles of Reality remains unchanged; and the cardinal character of the virtue of doing this remains unimpaired.

In a word, the argument always seems to come circling around to the point of starting again. Benevolence is indeed an important and cardinal virtue; but it is only one of the virtues, and it must itself be supplemented and completed by the others - by constancy, wisdom, justness, and trueness if ethics is to depict in its perfection the Virtuous Life.

This circle in the argument has, however, its own most important suggestion to make. The suggestion is this: the student of the philosophy of conduct should concentrate his regard upon the one conception corresponding to that unitary being about which the circle has been drawn. This is the being of the Moral Self. It is the conception of such a being in which he must find the true principle for the unification of all the virtues. The unity of the virtues is due to the unity of a personality, in active and varied relations with other per8ons. This is a unity of no mechanical or merely conceptual sort; it is neither like the unity of a piece of mechanism nor like the unity which the process of logical abstraction prepares in order to cover an entire species consisting of 
individuals. One sheep is like another, although one may be white and another black, one with long wool and one with short. But wisdom is not like courage, temperance is not a species of kindness, and justness and trueness are not to be reduced to benerolence. This many-sided being called man is the virtuous or the vicious one; his possible virtues and vices are as many as the forms of his action that are in any measure subject to intelligent control. $\mathrm{He}$ is set in society as the incitement and environment of his moral development; and his social relations are as indefinite in number as they are variable in kind. Now he is angry, and now he is pleased; now he loves and then again he hates; now he is called upon to summon courage, now to exercise wisdom, and now to let himself melt with the spirit of kindness. He is parent or child, brother or sister, subject or ruler, employer or employed - a companion of friends, a fighter with other comrades against a common foe, connected with many societies and guilds, citizen of some State or member of some tribe, and always potentially a citizen of an invisible and heavenly community.

In all these varying relations, and on all these many sides, the Moral Self is seeking many different forms of good, and is trying to escape or bravely to endure many different forms of evil. In all this search and effort the individual man is only one of many, a unit in a larger social multiplicity, which is itself also a sort of unit relatively to other higher unities. No one virtuous quality will suffice on all occasions, or for the satisfactory discharge of all the functions belonging to these differing relations; nor can any man, however wise, always tell which one of several virtues it is fitting to display.

Shall we, then, abandon all hope of discovering any principle of unity among the virtues? Shall we confess that, while we can confidently declare, in accordance with the common consciousness of mankind, our adherence to the 
virtuous character of courage, constancy, wisdom, justice, and kindness, yet we are quite unable to say in what the virtuousness of them all consists? Must we conclude with Meno: "Every age, every condition of life, young or old, male or female, bond or free, has a different virtue: there are virtues numberless, and no lack of definitions of them; for virtue is relative to the actions and ages of each of us in all that we do?" Or, must we all "confess with shame," as does Socrates: "I know literally nothing about virtue; and when I do not know the 'quid' of anything, how can I know the "quale'?" Not so; or, at any rate, Not yet. But the search for the ultimate unifying truths and conceptions, if any such are to be found, must go much deeper down into the heart of Reality, much further abroad in the kingdom of Truth.

One unifying conception of great significance and power has, however, already been attained. All the discoverable virtues are partial harmonies, or single notes accordant with the Moral Ideal. And that ideal is a Self living the Virtuous Life in social relations with other selves. The effort to realize this ideal furnishes to each one in a fragmentary way his bit of the principle of unification which, so far as it is adopted and applied, tends to bring his own inner life, at any rate, into the unity of a harmonious whole.

The alleged unity of virtue thus becomes the fidelity of the one and total personality - the unitary being called a Moral Self - to the Moral Ideal. But this unity is subjective and lies in the nature of moral personality rather than in the nature of virtue - as though "Virtue" could represent anything more than an abstraction from the characteristic tendencies and conscious states of this Self. For any objective unity we must look, not to the nature of virtue, but to the Nature of Reality. But the subject still awaits further and more satisfactory discussion.

It should be joyfully noticed in this connection how much 
opportunity for the derelopment of Individuality this view of the unity of virtue permits to every man. Virtuous living is not living in conformity to any one pattern of conduct. It is no dead monotonous agreement in a sort of common stock of virtues, from which each man may win more or less for himself. The Virtuous Life has all the variety which belongs to the beings who lead the life; and of them no two are alike. No man's list either of virtues or of vices precisely resembles that of any other man. Indeed, no man's anger, or pride, or courage, or wisdom, or justice, or kindness, is preeisely the counterpart of the same qualities in another. For the unity is in and of each individual selfhood. And this is a unity that emphasizes endless variability - even in the Ideal toward which it strives. 


\section{CHAPTER XV}

\section{DUTY AND MORAL LAW}

THERE are certain aspects of man's moral consciousness, the experience and the contemplation of which give rise to conceptions that are in important ways different from those already considered. Of such conceptions the two most suggestive and fundamental are Duty and Moral Law. According to the modern enlightened conscience, at any rate, the life of virtue can be led only by the man who does his duty, and is obedient to the moral code. Indeed, the question may be raised whether the complete doing of one's duty, and perfect obedience to that law which commands the right and forbids the wrong, would not be tantamount to attaining moral perfection. The value of the animus which attaches itself to these two conceptions can scarcely be overestimated; and to trace the history of their evolution and elevation in human moral consciousness is equivalent to following along the main lines of the moral progress of the race. For it is in respect of improved and enlarged conceptions of Law, and more severe and exacting conceptions of Duty, rather than of altered appreciations of the virtues, that the moral progress of man has consisted hitherto.

It must be admitted, however, that the moment one begins the effort to derive a theory of the virtues, or a theory of the nature of the right, from men's notions of duty or of that which some writers are pleased to call the moral law one becomes involved in manifold embarrassments, - not to say, hopelessly insoluble puzzles. The reason for this is not 
difficult to discover. Duty and moral law are extremely abstract and intangible conceptions. They summarize a certain complex attitude of the Moral Self toward one of its own ideal constructions, rather than the definite marks of some class of concrete objects or the common factors of definitely similar experiences. They are themselves comparatively late developments; although the basis for them is, of course, laid in the most universal and fundamental facts of human experience. Here again, the particular and the concrete, with all its variety and subtile texture, comes first; and the abstract, the formulated, the attempt at a generalization which shall embody all the essential elements of the changing actuality, is a later product of reflection. Just as virtues precede virtue, so are duties prior to duty; and so do many individual and conflicting commandments antedate the idea of a unity of moral law.

To understand the nature of the conception of Duty it is necessary to discover the facts in moral consciousness in which it has its origin. These facts all, in a word, refer to the excitement of the feeling of obligation in connection with certain definite relations of the individual man to other men. 'Two sets of factors are thus bronght to our attention by this conception: (1) that conduct is an obligation; and (2) that the obligation has personality - the Moral Self in relations to other moral sclres - for its objective aim or point of attachment. In this way the significance of the very word "duty" becomes apparent; it is the conduct that is owing, is due (debitum), because the mental image of it arouses the feeling of "oughtness" or moral obligation. A duty is a formulated oughtness.

I cannot, therefore, quite agree with the statement of Professor Dewey: "1 "The consciousness of an end to be realized, the idea of something to be done is, in and of itself, the consciousness of duty." It is rather to be said that the con-

1 Outlines of Ethics, p. 192. 
sciousness of an end that ought to be realized, an idea of something that ought to be done, is in and of itself the most fundamental content of the consciousness of duty. But no particular conduct can be regarded as a duty without the added conception, or mental picture, of some one whose duty the conduet is, and also of some other one to whom the conduct is due. Who owes this "something to be done"? It is I (or some other one) that owe; it is my duty, my debt, my obligation to be met by a corresponding deed of will. To what, or to whom, is the debt, the duty, the obligation due? To some other person, to another who stauds in some definite and particular form of relations to me.

It is not likely to be disputed that the conception of duty would never originate, were it not for that feeling of obligation which has alrealy been discussed as the most unique phenomenon of the moral consciousness of mankind. For the conception is essentially an abstraction from this unique form of feeling. And when it becomes the more definite conception of some particular form of conduct, $-a$ duty, or the duty, for example, of reverence to superiors, pity for the suffering, courage in danger, or justice and friendliness to all mankind, - it cannot be disconnected from the feeling which is its source. Only forms of behavior having reference to what we feel either ought or ought not to be, ean be conccived of as duties.

There is more chance for question, however, with reference to the statement that all duties are due to some Self conceived of as standing in social relations to other selves. For do we not hear of duties to the animals, and even to inanimate things; and especially in these later days of somewhat extreme refinement of ethical theory, of duties to one's own person, and above all to a code conceived of as a sort of impersonal unity, called the Moral Law? How, then, can one affirm - as I certainly wish to be understood to affirm - that the conception of duty implies as an integral and ineradicable 
moment of itself the reference to persons existing in social relations to one another?

It is, indeed, possible to maintain the duty of eultivating a spirit of kindness and of the unwillingness to eause unnecessary pain toward the lower animals. The rationale of this duty may be differently regarded by different systems of ethies, or when brought to the test of the explanation afforded by the ethical judgments of different individual agents. Thus $A$ may refrain from abusing another man's dog, because he recognizes the right of its owner to protect his property from injury; $B$ may refrain because he dislikes to experience the sympathetic pains which the sufferings of the animal would cause him ; $C$ may recoil from the feeling of moral degradation which he would thus bring upon himself; and $D$ may shrink from the social opprobrium inrolved, or from the danger of arrest by the officer of the Society for the Prevention of Cruelty to Animals. In each ease, however, if reason is sought to justify the feeling of moral obligation, the reference will be either direct or indirect to that which is due to a being answering to the conception of selfhood. It is my duty to my Self, or to my fellow selves among the social community, or to the quasi self-like being of the dog, which forms the point of attachment for the feeling of obligation.

In this connection it is worth while to notice how different is the attitude of moral consciousness toward animals which are distinctly hostile and dangerous to man, when it is possible to strip them as nearly as possible of all self-like qualities. In India, for example, most Europeans do not feel it to be a duty owed to the cobras or the man-eating tigers, to treat them with kindness; however unwilling many individuals may be to demean themselves by subjecting these pests to unnecessary torture. But the devout and superstitious native will continue to leave the deadly serpent where the European may, at peril to his own salvation, destroy it; while he himself feels the obligation not to harm the animal be- 
cause his own ancestor may be embodied in the cobra or becausc he would thus impair his own chances of improving his future condition in Karma. At the other extreme of refined sentimentality stands the example of St. Francis of Assisi who delighted in doing his duty by way of loving our dear brethren in the Lord, the birds.

Any form of conduct, then, whose mental representation calls forth the feeling of obligation toward some Self or self-like being is properly called a duty. "I am bound to every act of duty." And where the relations which define the different classes and different eircumstances of mankind are suffieiently permanent, we find arising out of them some specific formulas that prescribe the corresponding duties. For example, the relations of the family bear upon the conseiences of the different members of the family in different ways. Husbands and wives owe each other some duties; but between the chief of the tribe and the tribesmen, or between the common members of the same tribe, other duties are owing. In the narratives of the Homeric era we have a picture of a varicty of obligations under which gods and men stand to one another, and gods and goddesses to ono another, and all to Zeus; while the different elasses of persons among the allied Greek forces acknowledge peculiar duties as belonging to each one of them; nor are even Greeks and Trojans so alien that no duties whatever are felt to be incumbent upon both in their reciprocal relations. In our modern commercial civilization it is the duties of men and women that grow out of their various business relations which are chicfly emphasized; and even domestic, social, and religious duties are either relegated to the background of privacy or else are themselves discharged as matters of contract and of commercial justice. Indeed, there seems to be danger that in England, America, and Germany all human duties will be regarded from the commercial point of view, - while in the Orient, and especially perhaps with 
the Hindu and the Mohammedan, duties have chiefly to do with religion and social relations; while commerce and trade are matters that are conducted with an appalling lack of any consciousness of being bound by moral law.

This brief analysis of the conception of duty may enable us to discern how much of truth, how much of fallacy, there is in a theory which - like that of Paulsen, for example regards duty as in origin essentially negative, and uniformly arising in the form of a limitation of impulses. ${ }^{1}$ According to this theory the feeling of obligation is itself a derivative moral consciousness, caused only and limited by, that clash of impulse with custom which always gives the idea of the right to the individual. That the feeling of obligation is not a derivative form of moral consciousness, that, on the contrary, one cannot even speak of moral consciousness of morality at all as prior to this feeling, has already been shown in detail. ${ }^{2}$ It is then necessary at present only to point out the fallacy of regarding the notion of duty as purely negative and limiting of natural impulso. It is true that the dawning of all moral experience is largely due to the negation and limiting of natural impulses; being inhibited and checked by the social environment acts, in the early instances, to stir most vohemently the consciousness of right and wrong, of good and evil, in the ethical significance of those terms. But to say this is quite a different matter from characterizing the conception of duty as purely negative. The "duty-to," psychologically considered, is quite as positive, and it often becomes quite as spontaneous, attractive, and influential, as the "duty-not-to." The reason for this has its basis in the moral nature, and in the most nearly primitire moral experiences. For eren under a very low degree of ethical and social culture, but preeminently as this degree rises to the condition attained in

1 A System of Ethics, p. $346 \mathrm{f}$.

2 Compare the discussions, especially chapters $\mathrm{V}$ and VII. 
the ethically most developed communities, the feeling of obligation and the pleased feeling of self-approval together become most closely associated with identical forms of conduct. So that, in all degrees of social culture, ethically considered, while there is much which custom enforces against inclination and in the interests of duty, there is also much which custom does to secure a union of inclination with the feeling of obligation. It may even be said that men are naturally inclined to do at least some things which they are determined by custom, law, or their own reflections, to judge that they ought to do. Instances of this sort, taken from the less developed forms of social organization, are the pleasurable duties of courage in battle, hospitality to strangers, and many of those forms of conduct to which are attached - as even the Tongan chiefs knew (see p. 315) "the agreeable and happy feelings which a man experiences within himself when he conducts himself nobly and generously, as a man ought to do."

The conception of duty must, then, be held to include all those forms of behavior toward others with which the feeling of obligation becomes bound up, whether they are farored or opposed by impulse and inclination. One's impulses and inclinations, whether natural or acquired, may coincide with, or they may stand in the way of, one's dutics.

From the conception of duty there have arisen a number of subordinate conceptions and connected problems, the discussion of which has quite too often resulted in a rather unproductive logomachy. For example: Are the duties and the virtnes co-extensive? Can a man, by, being virtuous, do more than his duty? More particularly: Can one properly speak of such experiences as the duty of being happy, or of thinking correctly, or of any other form of self-control over feeling and intellect?

So far as such questions as the foregoing are of general interest and have a bearing upon the philosophy of conduct 
and the practice of the virtuous life, they are illumined in a measure by such considerations as the following. Both words - Duty and Virtue - are used sometimes with a chiefly subjective, and sometimes with a chiefly objectire and external, reference. That is to say, they either signify conscious and voluntary attitudes of the Self, considered mainly as such; or they indicate definite forms of behavior which are observable by others and so can be considered with referenee to their conformity to the prevalent eustom or other social standard. Not only in all discussion about matters of conduct, but also in the very transactions which constitute these matters of conduct, the consciousness of men is subject to rapid and frequent transitions between these two points of view. To illustrate this let us consider two examples of exactly opposite kinds; and let the first example be the doing of a duty to which one is very much disinelined, - the administering of a punishment, the disclosure of his faults to a friend, the bestowal of a faror likely to be abused, the performance of some tiresome social function, or the casting of a vote for a candidate who is "the lesser of two evils," etc. Here the external act is a duty; and its performance eren against inclination would be considered by most men to be a virtuous deed. In the objective aspect of the transaction virtue and duty coincide. How stands the case, however, with the mental attitude, in spite of which, one forces one's self - so to say - to perform the external act? Is one virtuous in having this attitude of disinclination toward one's duty? On the contrary, would not one be more virtuous if one were less in need of using the motive of duty to orercome disinclination?

If the same point of view is steadfastly maintained during the entire inquiry, I am confident that we must answer $Y_{C S}$ to the first question and No to the second question; and that we may get confirmation from both the questions and their appropriate answers for identifying throughout the 
sphere of the rirtues and the sphere of the duties. For supposing that the mental attitude to the external act may be considered as a piece of conduct, - and so it ought to be considered if judgment and will enter into the feeling here; then the disinclination itself is either virtuous or not virtuous, either a duty or not a duty. In many cases disinclination to do one's duty is virtuous and is itself a duty. I ought to be disinclined to administer painful punishment, to find fault with a fricnd, to bestow favors likely to be abused, to use strength needed for work in social functions, and to vote for unworthy candidates, no matter to wliat party they belong. In a word, both disinclination to the duty and doing the duty to which we are disinclined, may be both virtuous and dutiful. Virtuous living consists for man in large measure in cultivating certain disinclinations and yet in acting in ways that are contrary to the same disinclinations. This any student of ethics must admit who takes ethical facts and truths as they exist in their finest manifestation, - namely, the reactions of intelligent, sensitive, and disciplined moral consciousness upon the inevitably hard eonditions, both physical and social, of human life.

In the other class of cases the good man refrains, for duty's sake, from doing what he is more or less strongly inclined to do. Sometimes, in such cases, the inclination may be virtuous and the failure to perform the external act may seem to other's to be wrong; at other times, the inclination may seem to others to be wrong, but both it and the refusal to do the thing to which the inclination points may really be both dutiful and virtuous. For example, he who has the virtues of kindliness and pity cannot see the suffering and $\sin$ of others without the inclination to relieve both. This inclination is virtuous; it is a duty to which the feeling of obligation binds the mind, and from which we ought not to desire to free ourselves. So, too, there are certain inclinations to the mutual enjoyment of one another's wit, poetic 
imagination, seientific information, or other friendly and sympathetic intercourse, without which the life of virtue and of duty-doing does not easily flourish or even keep its head above the mire of despondency and the dust of oblivion. Yet oftentimes in view of inevitable limitations and of the consequences of indulging them, these kindly, pitiful, and friendly inclinations have to be denied. The denial is both dutiful and virtuous; it is what the good man ought to do. But it is also both dutiful and virtuous to do what one ean to keep alive these generous and kindly impulses. 'To refrain from giving to a beggar may be a duty; but it does not follow that it is also a duty not to feel the pitiful inclination to grive.

Similar considerations help to solve those cases where the moral consciousness of mankind seems the more highly to commend the virtue of those who have done "more than their duty." For here, too, the very idea of a surplusage which is transferable from the credit side of the ledger where the accounts of "Duty" are kept to the same side of the page over which is the headline "Virtue," is a mistake due to a lack of clear thinking. If one will look at the two aceounts without changing the point of view, one will find their debits and credits to coincide; and both accounts stand always with the same defieits on the eredit side. No man can be more than perfectly virtuous; no man can do more than his whole duty. It would not be virtuous to exceed in any direction the domain of known duties; it is not doing the whole duty to be wanting in any particular of virtuous conduct.

'Two forms of the confused thinking on this subject which results from the unconseious transition between different points of view need especially to be noticed in this connection. First: The evolution of morals in the individual and in the race does for the so-called duties of mankind what it does for the virtues; it reduces them to some sort of order, 
formulates them, and incorporates them into certain commonly recognized modes of external behavior. It is in this way that there come to exist those rules of conduct which it is decmed obligatory for all persons to observe toward one another under definite sets of relations; these are the duties owed by one person to another, as they are associated in rarious ways. Morals are satisfied if these debts are paid, whatever be the inclination, the motive, or the preceding struggle in consciousness. But morality is not satisfied in this way; and, in some crude and imperfect fashion, mankind demand morality as well as morals of one another. This they have always done; this, to an increasing extent, they will do as the social and ethical evolution of the race goes forward. When, however, any individual makes an exhibition of morality in some form that notably transcends the limits of morals fixed by the social standard - whether this standard be custom, law, or opinion - he is said to "do more than it was his duty to do." But here again is concealed the same ambiguity which arises from shifting the point of view. This ambiguity may be emphasized in the form of a paradox: It is every one's duty to do a great deal more than he and others esteem his duty; and yet no one can do more than his duty; and, finally, if one were to do more than his duty, he would not, in this doing, be doing his duty at all.

Second: It is customary for writers on ethics to debate whether the merit of well-doing is enhanced or diminished by the amount of conflict through which the mental attitude finds its way to the external action. Is a man's virtue, and his corresponding merit the greater if he does his duty in spite of inclination, or if his inclination sets strongly in the direction of his duty? Here, once again, a careful analysis of the problem exposes the vice of constantly shifting the point of view. For example, the question is raised: Is the man who is strongly tempted to indulge the appetite for 
drink and yet who, out of proper motives, controls that appetite, more virtuous, dutiful, and meritorious than the man who is not tempted to drink at all? The answer is, Yes, or No, - according to the point of view which is taken, and the character of the virtue which is emphasized. More viltue of will goes into the external act of temperance in the case of the man who has the appetite. But the appetite for drink itself is, in all normal cases, a resultant of an habitual vice of will. In its beginnings and early developments, this appetite is due to a lack of rational control over imagination, thought, speech, social environment and influences. On the other hand, unless the case has passed beyond the limits of recovery by the practice of self-control, repeated acts of virtuous self-denial will erentually undermine the vicious appetite, and restore the man to a completer state of virtue. To take another example: Is the grasping man when, with painful reluctance and yet for duty's sake, he bestows his property upon some good cause, more rirtuous than that "cheerful giver" who is the beloved of God and man? Yes, and yet No, - according to one's point of view, may be the answer again. The araricious man practises more selfdenial; and this self-denial is certainly virtuous, if it be wise and in a good cause. But the kindly, generous feeling of the cheerful giver is a virtue also, - a meritorious attitude of soul toward others which seems to belong to a somewhat different category. Nor is it much easier to weigh over against one another virtues and duties that do not belong to the same class, than it is to estimate the relative intensities of the different forms of sensations, or of the pleasurepains. Especially is this true when the standard itself is constantly kept shifting between the subjective and the objective points of view.

It appears, then, that the conception of the duties, like the conception of the virtues, arises from the way in which men contemplate the different aspects of moral life and 
moral development. The two conceptions lay emphasis upon somewhat different aspects of this life and of its development. The virtues suggest less of the feeling of obligation, more of that which is relatively spontaneous and impulsive. The duties lay more emphasis upon the feeling of obligation, in its frequent attitude of counteracting or restricting the impulses; but especially do they recognize the various social relations in which men are placed toward one another as limiting and defining the forms of their mutual obligations.

'Thus the conception of duties leads naturally and necessarily to the conception of rights. What I am owing to another, that it is his right to have: what is due me from another, to that $I$ am entitled as to a right. And as the conceptions of duty and of virtue take a wider range and extend to more manifold and intricate relations among men, the idea of universal moral laws comes into prominence and power. This growth in these conceptions introduces and nccessitates a philosophy of conduct that is political and social rather than so exclusively psychological.

It is quite impossible, however, to do the scantiest justice to the conception of Duty without noticing how forceful is the grasp which it lays upon the ethical imagination, when it is sublimated and apostrophized to the highest possible degree. Nor is the quickening and elevating influence of the conception lessened by the extremely vague and indefinite nature of its content. On the contrary, the continually expanding demand made upon human thought and imagination to frame an Ideal of that which shall express all which the Moral Self feels itself obligated to be, and to do, becomes the cause of more and more strenuous efforts to realize all the conerete virtues and duties which make up the Virtuous Life. Thus Kant, although he seemed to make the coneeption of duty synonymous with subjection to an abstract principle admitted that men properly ascribe a certain "dignity 
and sublimity to the person who fulfils all his duties." I In his celebrated apostrophe he addresses the bare conception as "Duty! Thou sublime and mighty name." In Coleridge and Carlyle and in other writers whose thoughts upon ethical topics are infused with more of emotional warmth, a similar treatment is given to this impersonal conception. In not a few of those lives which are actually keyed to the highest pitch of moral endeavor, the idea to which this "sublime and mighty name" corresponds, imparts to the person who follows the idea a certain great "dignity and sublimity" of personal character.

How shall this manner of speech be taken out of the realm of poetry and myth and given the garb of scientific truth? It seems to me that only one way is possible. The ideal of duty-doing, which is a mere abstraction until it is translated into terms of personal experience and personal character, is really the ideal of a Moral Self perfectly adjusted, by his own response to the feeling of obligation, to all other moral selves in the various social relations. What, then, is the whole duty of man? It is the constant, courageous, wise, and loving devotion of one's powers to the realization of this Ideal. Positively expressed in terms of religion, the exhortation which sets before man his whole duty is this: "Be ye therefore perfect even as your Fatlier which is in heaven is perfect." Negatively expressed, and as contradieting all the impulses, endeavors, and ideals which lie in different directions, human ethical experience may be summed up in these closing words of Tourgueneff's Faust: "Not the fulfilment of cherished dreams and aspirations, howerer lofty they may be - the fulfilment of duty, that is what must be the care of man. Without laying on himself chains, the iron chains of duty, he cannot reach without a fall the end of his career. But in youth we think - the freer

1 Fundamental Principles of the Metaphysic of Morals, Edition of Rosenkranz and Schubert, p. 64. 
the better, the farther one will get. Youth may be excused for thinking so. But it is sliameful to delude one's self when the stern face of truth has looked one in the eyes at last."

Closely connected with the conception of duty as an obligation upon impulse which is felt like "iron chains" is the coneeption of moral law in its origin and development. On this subject the analysis of moral consciousness confirms what an historical study of moral development suggests; only at a certain stage in his progress does man (the individual and - in a somewhat figurative way we may say - the race) find himself face to face with this legal conception of morality. It is indeed doubtful whether any distinct epoch in ethical evolution is to be discerned "when the idea of obligation held in the general consciousness has been taken by the obligatory norm of law." The rise and growth of the thought that the pursuit of the Virtuous Life may properly be conceived of as obedience to a universal code has been natural and yet manifold in character, and oftentimes subtle and concealed. Especially is this true of that exceedingly vague and intangible conception which undertakes to express itself in such phrases as $a$ moral law, or the Moral Law. Laws, themselves impersonal, which are concrete enactments regulating the relations of persons, and which owe their origin to the action of persons, can be understood. Laws that have only the significance of the more or less regular observed modes of the behavior of impersonal things, are prima facie intelligible, even if we cannot understand their souree. But what can be meant by the Moral Law, if all personality, all Selfhood, is to be left out of the account which ethics attempts to render of its origin, its validity, and the enforcement of its penalties?

In their effort to understand the origin and nature of such a mental construct as the conception of an impersonal moral law writers on ethics are found shifting their points of view 
in the fashion against which warning has already been uttered repeatedly. That is to say, these writers take at one moment the subjective, or plainly personal point of riew; and at the next moment they are found stationed at the more objective and tentatively impersonal point of view. I say "tentatively impersonal;" for no point of view from which to regard any ethical conception can possibly be more than apparently and momentarily ("for the sake of the argument," as it were) separated from considerations that are realizable only in the conditions and social relations of moral and personal beings.

Subjectively regarded, the conception of Moral Law is the conscious apprehension of some rule or maxim, adapted to regulate conduct, which actually excites the feclings of obligation, approbation, and merit, and which actually offers a mandate to the will. Subjectively considered also, the very formation of this conception implies a work of learning these rules and maxims from other persons, or of generalizing them for one's self by processes of observation. The primary data for its formation are such as have already been discovered by our analysis of man's moral consciousness. They are the "I think," "I feel," "I desire," "I plan," etc., all of them psychoses, which have reference to forms of good and bad conduct. Objectively regarded, howerer, the so-called moral laws are certain forms of conduct that have-by whaterer historical processes and in accordance with whatever true or false traditions - become actually embodied in customs, maxims, statutes, or other institutions; they are the commonly accepted formulas which assume the right to regulate human behavior under a great variety of conditions and relations. But such laws, thus objectively and impersonally regarded, cannot be regarded as moral laws, without a return to the personal and subjective point of riew. And here the simple and ultimate fact is that they appear before the individual consciousness as binding; they actually arouse the 
feeling of obligation, and offer a mandate, an imperative to the will. Their being consists in the recognition which they obtain in the minds of personal beings.

Noral laws imply, then, law-giving moral consciousness, which is their only actual, and indeed only conceivable, source. So much of universality as they can attain is dependent upon those characteristics of moral consciousness which belong to human nature and are exereised semper, ubique, et ab omnitus. So much of objectivity as they possess, of injpersonality as they appear to have, is due to the conditions and nature of the various forms of social organization. But social organization is itself a product of morally constituted selves. In all such social organization the primary, universally present fact is found to be that certain ways of behavior, rather than others, are recognized as biuding upon human nature. As far back as one can go in human history, trusting in genuine historical sources, one finds society of some sort already organized upon substantially the same ethical basis as that now existing. The person makes the laws that take on the objective form of custom, maxim, common law, or written statute; and the person responds to these objective forms with the feelings, thoughts, and rolitions, which make them to be, in reality, moral laws.

The prevalent conception of moral law, and the influence of this conception over the practical morals and virtuous living of the men of any age, are, therefore, always closely connected with the development of the conception of law in general. In modern times this connection has been made especially close with thoughts and feelings which are the product and the embodinent of the regnant scientific spirit; and the fact has been, in some respects, most unfortunate for ethics. What, in reality, is to be understood by the word "Law," as this one word is made to cover experiences so unlike as the generalizations of the physical sciences, the enactments of legislative assemblies, and the formulas 
to which the nobler impulses to action respond in moral conscionsness?

As I have elsewhere shown, ${ }^{1}$ the ethical nature of man directs, colors, and everywhere interpenetrates his scientific rescarches and conclusions. It is in his moral being that all the current notions of the sanetions, of the quasi-ethical import and obligatory character of natural laws, have their origin and source of strength. From the same fountain flow the feelings with which the modern student of nature so highly regards his oftentimes really unimportant discoreries, and with which he magnifies his office and the worth to the race of his own personal services as a so-called man of discorery and research. Only for a being with moral conscionsness can such conceptions as "the reign of law," "obedience to the laws of nature," etc., hare any power to awaken ideas of obligation or sanctity. Indecd, if one $\checkmark$ will think clearly, one will come to see that all that terminology of science which implies ideas of sanction, obligation, worth, etc., is utterly meaningless except as applied to the states and relations of personal beings. On the other hand, any attempt to set up the conception of an impersonal rule, or a formula derived from obserration and generalizations on a basis of mere fact, within the moral realm results in a species of fetish-worship which is as unthinking and degrading here as fetish-worship is within the kindred realm of religion. The same personal being who is expected to regard with a feeling of sacredness and admiring approbation the uniform modes of the behavior of impersonal beings - the so-called "laws of nature" - cannot be expected, without these feelings of a personal sort, to conform in his own conduct to the idea of an impersonal rule, when it calls itself by the name of a "moral law." Why, indeed, should man show the fundamental characteristics of his moral selfhood more plainly when he is regarding the behavior of

1 In Philosophy of Knowledge, and A Theory of Reality - throughout both books. 
things than when he is regarding the behavior of human beings?

Of all the several forms which the conception of law can assume, that which it wears within the sphere of ethics is most distinetly an affair of personality. Natural laws are, indeed, only the observed or inferred uniform ways of the behavior of things; the things themselves are not regarded as consciously conforming to the laws. The whole representation terminates in the mere fact that so the things behave. But human laws are objectivcly formulated rules, to which conformity is expected and enforced by an appeal to interest of some sort. Both natural laws and human laws become moral, and obedience to them becomes virtuous and disobedience becomes a vice, only when the external expression of the formula presents itself within the eonsciousness of some Self as a form of behavior which ought to be rendered, under certain social relations, to other selves. Thus the idea of an "external imponent," - to borrow the expressive phrase of Professor T. H. Green ${ }^{1}$ - is undoubtedly connected in the imagination of mankind with the sanctions belonging to most laws that are conccived of as distinctively moral.

When the point of view properly held by the student of ethical erolution is assumed, it is seen how the idea of universal obligation arises from the experience which the individual actually has of the laws imposed upon him in connection with the growth of socicty. Formulas of conduct that are embodied in customs, common laws, statutes, and institutions, do really and inevitably bind men as with "iron chains." But on the other hand, the laws thus actualized in the social organization, and accorded sanctions by society, have themselves arisen from the more primitive ethico-religious conscionsness of mankind. The profound import of all this ean only appear later on, when we come to deal with the relation to ultimate realities which

1 See Prolegomena to Ethics, p. 354. 
is sustained by this ethico-religious consciousness in whose development lies the source of the very laws which it regards as haring an "external imponent," and to which it accords the right to command and a certain character for sanctity. It is enough now to note that the conception of some one all-comprehending Law which, having an impersonal origin, comes to claim the right, as mere law, to bind the conduct of the individual, or of society, is a conception which can find no legitimate place either in the philosophy of conduct or in ethical praxis. Of all ethical abstractions this is the most untenable.

Among the influences which have worked upon the thought and imagination of man to develop, elevate, and enforce the conception of moral law, that of religion has been much the most potent. Indeed the very nature of religion is such as to serve most effectively the two principal ends reached by this conception;-namely, (1) that the feeling of obligation should attach itself to an "extermal imponent" instead of remaining a merely inexplicable subjective stirring of consciousness; and (2) that the formula should assume the shape of a command issued from a person to a person and defining right personal relations. All the secming impersonal laws, whatever may be the form of manifestation which they have taken, lack something of these important characteristics. But the priest, the prophet, the soothsayer, or the sacred writing, eomes with words from those who are like the noblest and most powerful of human kind, with definite formulas, in the shape of a command - "Thou shalt" or "Thou shalt not;" and this command is enforced by promises of reward and threats of penalties. In the lower stages of ethical and religious evolution this is especially true of the essence of tabu, which is, as Jerons has said, ${ }^{1}$ the conviction that certain things must be avoided, because it has been so commanded-absolutely, and not on grounds of

1 Introduction to the History of Religion, p. Ilf. 
experienee with them or of "unconscious utility." Tabu is the objective eategorical imperative, the law that is imposed from without as a "Thou shalt not" - "the first form assumed by social and moral obligation and by religious commandments." In the same direction of ethical evolution those religious codes have been powerful which, like the laws of Moses, or the laws of Manu, have preseribed forms of ritual, or other forms of conduct, to mankind. Their general formula is a "Thus saith the Lord," - a commandment that has divine sanctions, is more direct and usually more explicit than the impersonal custom, and that appeals to all those feelings which are the more powerful because the objects toward which they are evoked are invisible and mysterious.

It is significant of the most important ethical truths that no release from the "iron chains" which give these truths the character of laws follows upon the setting free of the intellect from its superstitions, so long as the commandment itself retains its moral character. The inner obligation - the feeling-bound to keep the commandment as though it were an "external imponent" - still abides in the morally worthy consciousness; still does this voice of conscience seem as though it were a voice from an invisible and supreme source of moral laws, a true Voice of God. Hence when those who do not believe in God as a Moral Self, or in God at all, personify the conception of the sum-total of ethical obligations, they are fain to spell the words with capitals and swear allegiance to this purely abstract conception. They hypostasize and deify an abstraction as though it were itself existent and divine.

“ Der Aberglaub', in dem wir aufgewachsen, Verliert, auch wenn wir ihn erkennen, darum

Doch seine Macht nicht iiber uns. Es sind Nicht alle frei, die ihrer Ketten spotten." 1

1 Lessing, Nathan der Weise, line $2755 \mathrm{f}$. “The superstition in which we have grown up, even when we come to recognize it, does not lose its power over us on this account. They are not all free who scorn their chains." 
I shall undertake to show in another connection that this high regard for the conception of an impersonal formula, or system of formulas, - that is, for the Moral Law regarded as not having its ground or sanctions in the Absolute Moral Self - is a continuance of a similar more refined, but no more logical, form of superstition.

It appears then that our conception of the law of morality is itself an evolution which is due to the action and reaction of two correlated but not identical sides, or aspects, of man's ethico-social derelopment. Of these one is objective and historical; it includes the progressive formation of all those legal or quasi legal institutions, of whatever kind, which present themselres as external to the moral consciousness of the individual, because they prescribe formulas for his conduct that have rewards and penalties attached, and represent with social sanctions the collective will and judgment of the social organization. These are the laws furnished by the current morals regarded as externally imposed. But this historical evolution is accompanicd by a development of the ethico-social consciousness within the individual members of the social organization. Such consciousness consists in a clearer mental grasp upon the significance and value of the external institutions, and a response to them with the distinctively ethical feelings of obligation and of approbation (or its opposite). It is this subjective erolution which, having more or less unconsciously produced the objective, now determines the question whether the existing laws shall be acknowledged to be truly moral laws. Thus humanity comes to a higher degree of moral consciousness with reference to its own morals. Thus there is developed an idea of laws that, from the point of view of the present enlightenment, correspond better with the Moral Ideal than do the cxisting legal institutions and externalized moral formulas. Indeed, in the interests of this ideal every ethically progressive social organization is continually condemning and so 
improving or wholly rejecting its own past attempts to legalize the different forms of the Virtuous Life. What it has imposed upon itself in an external way it now regards as an unwarrantable imposition; and so it changes the external manifestation of some phase of its own ethical construction.

In adopting this conclusion, however, the philosophy of conduct is by no means left to those shiftings of opinion and of conviction which seem to threaten its very foundations. Laws many there have been, as there have been gods many and lords many. And the moral laws, sacred as we must regard them, seem to be much less stable than are the laws of nature so-called. Well, why should they not be - at least in some sort, and when regarded from a higher point of view? Even physical reality is not a matter merely of keeping a few unalterably fixed laws externally imposed. It, too, when regarded as having value, appears to be the manifestation of the unfolding Life of the World; and natural science, as well as ethics, needs to recognize the higher import of the very system of laws which it has already discovered. What has already been seen to be true in a limited way, when shown to be true also in the larger spheres of conduct, suggests to the student of ethies a higher and more unchanging point of view. It is chiefly religion that has connected all these predicates - such as personal source, supreme authority, inviolable sanctions, meaning that lies in the very heart of Reality - with the conception of an inviolable and unalterable ethical code. Whether we shall not be forced either to leave all our philosophy of human conduct in a state of perpetual flux, or else to substitute the conception of a personal Life for the abstract conception of an impersonal Law remains to be considered.

At any rate it is absolutely certain that philosophy cannot logically justify, as anthropology cannot historically authenticate, the conception of a Code for Conduct, that, irrespective of the moral character of its personal source and of the 
moral consequences which its keeping or breaking has upon a society of personal beings, possesses the right to rule orer men. Especially in respect of its moral consciousness, society is always superior to the laws to which it has given the place of "external imponents." For moral consciousness, curiously enough, always allows itself glimpses of a character for the individual, and of a condition for socicty, which is better than that already existing, and to which man is bound - somehow, but why? or by whom? - to struggle forward and upward. To try to justify this obligation by deifying Humanity and joining the few remaining disciples of Auguste Comte, would only be another way of conforming to the clinging superstition(?) which regards the Moral Ideal as having essentially the character of an "external imponent."

We may note, in elosing this chapter, how the conceptions of Virtue, Duty, and Moral Law, stand related in moral consciousness, in many interesting ways. Virtue is a generalization from particular virtues, or kinds of conduct to which, as due chiefly to moral reactions of the social environment, the feelings of obligation, approbation, and merit have become attached. Duty is a generalization from concrete particular duties, each one of which implies the same feelings as connected with forms of conduct dependent upon our special relations with others (an "oweness" of something to be done to some person). Law is a generalization of the maturer consciousness of the individual in his race development and more extended social environment. It is two-sided, and implies validity ("thatness") and content ("whatness"); - an imperative which has reference to some external authority, although existing as a mandate within the human mind. 


\section{CHAPTER XVI}

\section{UNIVERSALITY OF MORAL PRINCIPLES}

Corresponding in some sort to the unification of virtues and duties, and to the development of the conception of moral law, is the growth in universality of moral principles. Before we can comprehend the nature of this growth, however, it is necessary briefly to consider for what the word "principles" is entitled to stand in any system of ethics, as well as in the actual pursuit of the Virtuous Life. Of the conceptions whose import has already been examined, that of moral law comes nearest to the content represented by the word now to be cxamincd. For the essence of rules and formulas in morals does not consist in an unconscious and involuntary uniformity of action, but in the relation in which the rules or formulas stand to the judgment, feeling, and will of moral selves. Moral principles, too, have reference to conduct, and conduct is something more than mere habit of action.

In ethics, then, laws when subjectively regarded become in most respects the equivalent of principles; for both are the self-understood and self-accepted formulas for regulating the behavior of persons in their relations to other persons. There are, nevertheless, two respects in which the conception of moral principles carries us beyond the conception of moral law. First: the word "principle" lays more emphasis upon the recognition by the reason of the rule, or formula, and less upon those factors in moral consciousness which make it possible to regard ethical rules and formulas 
as originating in some impersonal source, and so as having a large irrational element in their character of "external imponents." Thus the will seems to bow to laws; the reason acts upon, or in the light of, principles. Reason is more in conscious agreement with the principles of right conduct than with the laws that define the limits of such conduct. Laws cannot become principles in the sphere of ethics without making an appeal to the rational side of human nature. Laws, - only when rationally apprehended, become principles.

With this eharacteristic difference between the two conceptions another is closely and even necessarily allied. Principles, in order to be entitled to the name, must be capable of becoming the points of starting from which by processes of reasoning to conclude something concerning particulars. Moral principles are, then, in the second place, such rules, or formulas, as being apprehended by the reason may be made the grounds of a syllogism, or argument, by means of which to reach a particular judgment concerning the right or wrong of conduct. They are starting-points for ethical judgment.

This view is justified by the eurrent usages of speech. It is customary in some circles to speak of certain persons as "men of good" (or, again, of bad) "principles;" and by the adjective used in this conncetion with the word principle the usage indicates clearly enough that it is an ethical meaning which is had in mind. Mr. A may be trusted in general, and expected to do right in each particular emergency calling for action, because he is a man of good moral principles. But of Mr. B one is obliged not to expect too much by way of resisting temptation or acting with good judgment; bccause Mr. B is not well grounded in moral principles. In all such cases the emphasis is plainly not put upon mere difference in that habit, or fixed state, of the affections and will which, in the Aristotelian meaning of the words, is 
called a virtue or a vice. In the man of moral principles, grood or bad, reason recognizes its own grounds of action, and stands ready to make them the points of starting for a conclusion that is - at least in the opinion of the individual himself - justified by these grounds. Moral principles in general, therefore, may be said to be those formulas that are widely accepted by human reason and made premises for conclusions as to the right and wrong of conduct.

It is obvious from the very nature of moral principles what must be the nature of any universality which such principles can attain or continue to possess. Principles, in general, have no existence outside of the rational consciousness in whose apprehension aud mental emplorment of them their very being consists. They are not entities to dwell in mid-air or in material things, or to be "lying around loose," as it were. Moral principles can exist only in the consciousness of rational and ethical beings, in moral selres, and as apprehended and employed by these selves for the determination of concrete cases of moral judgment. Their universality, therefore, can never be abstract merely - like the laws of pure logic for the plain man's consciousness; nor can it be, like the law of gravitation, simply the uniform way of the behavior of beings that do not comprehend the grounds on which their behavior reposes or the ends which this behavior is fitted to procure. Moral principles can really become universal among men, only when more and more living individuals actually adopt the same rules as the points of starting and of control for the intelligent determination of what they ought to do, and what they ought not to do. Such increase in the universality of moral principles depends upon the growth-nay! it is equivalent to, and identical with the growth - of the rational and ethical self-consciousness of mankind. It is, to speak somewhat figuratively, a moral coming to itself, to a self-understanding and a practice that grows out of self-understanding, on the 
part of the race. The progressive establishment of moral principles is an evolution, a march toward the Universal which must have its grounds and its laws in something that is common to mankind.

If, then, a discussion of moral principles as having universal validity is to attain any basis whatever in experience, or eren in that which is intelligible because it states itself in terms of experience, this discussion must discover some real historical grounds for this progress toward the Universal. For, so far as man is concerned, the universality of moral principles is a progress and not an accomplished fact.

Let it be noticed that I am not proposing to inquire into the grounds and laws of the total moral improvement of the race; nor do $I$ even assume that there has been such improvement. It is not as though ours were the historical inquiry whether, on the whole, a larger proportion of mankind are becoming virtuous; or whether the "good few" are becoming more virtuous; or whether the general level of the race at large is being raised as estimated by the scale of virtuous living about which men generally agree. Our inquiry is in some respects more simple, although perhaps in others more complex and difficult than any of these inquiries. I assume that at least a considerable portion of the race is beeoming more intelligent and self-conscious as to the laws, the consequences, and the import, of both natural and social erents - is, in a word, making progress in its mental grasp upon those forces, formulas, and results that enter into its own experience. Moral principles, as a part of the increasing knowledge of the world, are becoming more universally accepted and understood. In spite of the appalling fact that, reckoned by numbers mercly, such a large proportion of mankind appear to be making no progress of any kind, it is still true that the progressive part of the race is in the way of forcing or carrying along the unprogressive part toward some kind of agreement upon moral truths, as upon 
other forms of truth. A not inconsiderable advance toward the universality of moral principles is thus established as an historical fact.

More than two thousand years ago Aristotle declared $;^{1}$ "There is no human function so constant as the activities in accordance with virtue: they scem to be more permanent than the sciences themsolves. Among these activities, too, it is the most honorable which are the most permanent, as it is in them that the life of the fortunate chiefly and most continuously consists." Now it is in these permanent functions that the grounds of the universality of moral principles are laid; and it is in the growth of human knowledge as to the laws which these functions follow that all actual realization of the universality of these principles, thus grounded, must consist.

It is not necessary to add to what has already been said in support of the proposition that certain permanent and fundamental forms of moral functioning belong to man as man - are the common, the universal characteristics of the race. These are the forms of fceling, judgment, and volition, which are the characteristic constitution of man as an ethical being. The study of human nature from the anthropological point of view shows the truth of Wundt's contention: "Man has always had the same kind of moral endowment." To say that these forms of functioning are, so far as man is concerned, universal in their validity and applicability is, therefore, either tautological or superfluous. So essential are they to every conception of morality itself that all other rational beings - inhabitants of some distant planct or more distant star, angels, disembodicd spirits, and God himself - are in thought necessarily endowed with these same forms of functioning. It is in these universal forms of functioning that the immediate grounds of man's moral development consist.

1 Nic. Eth. I, $x, 10$. 
Moreover, there is a limited number of more definite rules and principles declarative of what is right that arise from experience under the most general, or even universal forms of human life and human development. To this class belong those most primary and widely applicable ethical formulas, or conscious generalizations, that are based upon a few simple and universal relations, such as those of the family, the tribe, or the somewhat more claborate social organization. For example, that children owe some sort of service and obedience to their parents, and parents some sort of protection and nurture to those whom they freely adopt as their children; that subjects owe some sort of fidelity to rulers, and of service to the social organization of which they are members (courage in battle for the tribe, etc.); and that members of the same social organization owe a certain amount of friendliness to one another; - these, and some similar judgments of worth of a primitive sort, may be said to have had a nearly, if not quite, universal existence. They cxist because they have been consciously accepted by adult human beings, and made major premises in their inferences about the right and wrong of conduct. They are judgments of worth which all men recognize - proximate moral principles of an actual and practically universal validity. Their universality is due to the fact that they grow out of the very constitution of moral selves as related to one another under the simpler, and therefore more universal and permanent forms of social organization. About them the infantile race must be more or less cnlightened and self-conscious.

In accordance with this definition of the words it is difficult to find in reality - that is, in the actual social life and social development of humanity - much that answers to the conception of strictly universal moral principles. Indeed, principles seem to be less universal than are the virtues. For the latter, to be effectice, must be practised much more spontaneously than would be possible if every one were com- 
pelled to arrive at them by way of deduction, so to say, from accepted general formulas. Men are also more at one in their opinions as to what are the duties befitting most of their different relations with one another than in their opinions as to the way in which the rational grounds of those duties should be stated and applied by processes of reasoning to concrete cases. It is, then, primarily through their common feelings of appreciation for the different forms of the Virtuous Life, and of unreasoned obligation arising under the impulses of the different social relations, that the multitudes are bound together, and are made loyal in their attachment to any universally valid Ideal. Bad as the conduct of the race has hitherto been, and still is, and important as are the moral failures of most of its members, it is true of the race as of the individual: It "las builded better than it knew." $\Lambda$ chievement, in respect of particular virtues and duties, everywhere lags behind knowledge as to what those particular virtues and duties are. But knowledge of universal principles from which knowledge of particular virtues and duties may be derived by a logical process lags behind the achievement of those same virtues and duties.

In this respect ethical science and the philosophy of conduct do not differ from all forms of science and all branches of philosophy that get their principles incorporated into human living. For example, there are few men who do not indulge their appetites in ways which they well enough know will be injurious to health; but they are even fewer who know enough about the principles of physiology and hygiene to regulate the practice of individuals deductively, and irrespective of those experienees in which individuals do not agree. Again, there is much which is defective in all existing forms of social organization; but there are few students of sociology who can enunciate principles that are adapted for a universal applicability by all members of any particular organization. 
On the other hand, as respects their appreciation of virtue and their opinions as to what are the cardinal virtues, there secms to be comparatively little progress among men toward the universal. This is partly because - as I have just said they are already "universalized" in such matters. The true nature and significance of the principal virtues are substantially the same for all men, in all stages of moral development. The emphasis is different; the mode of manifestation greatly varies; the external actions and prevailing customs are bewildering, changeable, and confusingly unlike. But the good man generally knows his own brother and acknowledges the kinship, as soon as he comes to an understanding of his character. And the ethical characteristics which it is necessary to take account of in classifying any individual - whether virtuous or vicious, good or bad - remain essentially unchanged. Thus it is easy to belicre that the African Bakwains were sincere in their declaration that "nothing described by the missionaries as sin had erer appeared to them otherwise, except polygamy." The "natural virtucs" attributed to the Tongans include "honor, justice, patriotism, friendship, meekness, modesty, conjugal fidelity, parental and filial love, patience in suffering, forbearance of temper, respect for rank and age." Of the ethical side of the Brāhmanas we are told: " "The list of virtues is about the same as that of the decalogue - the worship of the right divinity; the observance of certain seasons for prayer and sacrifice; honor to the parents; abstinence from theft, murder, and adultery. Envy alone is omitted."

An historical and anthropological survey of the ethical development of mankind seems, then, to establish some such conclusions as follow, regarding the grounds and the laws of this development. Men are constituted substantially alike in their moral natures. This common constitution of men is the basis of the universality which moral obligations and

1 Hopkins, Religions of India, p. 204. 
the accepted forms of eonduct hare in their sight. The sanctions and sources of moral principles, so far as they can be subjected to an historical investigation, lic inherent in that moral Selfhood which all men share. Moreover, inasmuch as we find men from the first existing in certain fundamental but relatively simple relations, - such as the family and the tribe, we find them largely in agreement as to certain judgments of worth which they eonsciously recognize as binding for the control of all who live under those relations. These are eliefly the relations of the family and the tribe; but also, always and everywhere, the relations of man to the gods of the family or of the tribe. On this universal basis his moral life depends; and, resting upon this basis, the moral evolution of man gocs forward. An important part of this moral evolution is the spread of an improved and enlightencd consciousness of moral principles. About the way in which this growth of the universality of moral principles takes place, I wish now to make a few suggestions that would seem to bear the light of history.

The reciprocal reactions which go on between the moral consciousness of the race and the moral institutions which this consciousness has builded are exceedingly important in the evolution of universal moral principles. These reactions follow a law which I will venture to call the law of the redintegration of judgments of worth through ethical institutions. In explaining this law it must, first of all, be noticed that the moral progress of the race (and of the individual as farorably or unfarorably affected by his membership in the race) consists almost wholly in two classes of particulars. Both of these are pre-eminently social; they emphasize the aspect of growth toward the universal. They are (1) the development of a great variety of institutions of a beneficent and morally helpful sort, and (2) the discovery and extension of those principles, properly ealled moral, which are won for the intelligence of the race through experience 
as to the consequences of different forms of conduct. In a broad and loose way, then, it may be affirmed that the moral evolution of man consists chiefly in the development of right institutions and in the coming to consciousness of rational and sound principles of conduct. The mental recognition of good moral principles, and an environment of good institutions, even when operating together, will not suffice to make the good man; but they do make some kinds of goodness easier, the possible sphere and influence of most goodncss larger, and all goodness more rational and enlightened. On the other hand, ethically improved institutions also make some kinds of badness easier, more common, more farreaching, and also more essentially bad; because the badness knows so much better what it is about and what its direful consequences are certain to be.

It has already been shown that the primary factors in the moral development of mankind consist of the practical recognition of particular virtues and duties, togetler with those simpler judgments of value which give the rational sanctions and grounds to these virtues and duties. These are activities of moral consciousness. But next stands, both in the order of time and of logical independence, the objective forms of morals - the customs, laws, common and written, and other institutions which are the products of these activities. As a rule these institutions precede the moral prineiples which become, when they are discovered, the rational justification of the institutions. For men, in general, do not derive their customs, or enact their laws, or rear the other institutions which have ethical import, because they have previously reasoned out the conclusion from some consciously recognized principle, that such customs, laws, and institutions ought to be adopted. Human institutions, as a rule, spring up suddenly, or more slowly come to be, - the men who build them not knowing either why or to what really good purpose. And the same thing is 
true in ethics, which is true in language, in every form of art, in religious cult, and in all the practical life of man. Moral principles follow the institutions, and are mainly due to reflection upon institutions that already exist. Man first acts, builds, and achieves; then by observing what he has done, builded, and achicved, he comes to an understanding of his own, hitherto hidden, laws of behavior.

Ethical laws become moral principles through ethical institutions. In other words, the lower, more restricted and less self-conscious judgments of worth develop into consciously accepted premises for all conduct by means of reflection upon the nature and effect of existing institutions. For customs and laws must themselves inevitably be made the objects of critical observation from the moral point of view; and, as judged from this point of riew, they must either be approbated or condemned. As long as any custom or law conflicts merely with the irrational impulse or desire of individuals, it holds its position of a sanctioned "external imponent." But all morally progressive communities are constantly "breaking the cake of custom," repealing and changing the laws, and building anew their various institutions. The custom is judged bad; the law must be broken or changed; the institution must be modified or replaced. Thus by noticing the effect, and reflecting upon the rationality, of its own work, the moral consciousness of man recognizes better the character and import of this work, as surveyed from a higher and more enlightened point of riew. The recognition is made possible only because experience of the work has resulted in elevating the arerage judgment of moral value to the point of view held by a morally more enlightened reason. The formerly vague and fluid factors of the social consciousness become redintegrated into a higher and more rational form by means of experience with the results of its own constructions. The moral stagnation, if not degradation of China is chiefly due to the fact that for 
centuries nothing has been effected there toward this form of moral redintegration.

This point of view may serve to show, in part, how much of truth there is in the contention of Mr. Balfour: " "The general propositions which really lie at the root of any ethical systcm must themselves be ethical, and can never be either scientific or metaphysical. In other words, if a proposition announcing obligation require proof at all, one term of that proof must always be a proposition announcing obligation, which itself requires no proof." So far as this declaration means that physical science can nerer, of itself, furnish the explanation of either the origins or the sanctions of moral principles, it seems to me undoubtedly true. But general propositions do not "lie at the root" of ethical systems, nor are "propositions announcing obligations" dependent for their proof on other similar propositions that require no proof. The rather are more and more general propositions the flowering of any ethical system that would take human ethical experience into its confidence; and those propositions themselves, thus actualized by the reflection of the race upon its own experience, have no satisfactory explanation, and no proof at all, without resort to metaphysics.

In illustration of the law for which I am contending, let one attempt to trace historically the manner in which a general principle respecting the morally right use of names is coming to be established in the consciousness of mankind. No name of any person ought ever to be cmployed thoughtlessly or maliciously: perhaps one may venture in this way to state a moral principle which would serve as a raluable major premise for innumerable more particular judgments of worth, and which also shows some signs of progress toward the position of a real universal. How has this moral evolution of so valuable a principle been going on? In obedience to the law of ethical redintegration as already explained.

1 A Defence of Philosophic Doubt, Appendix, p. $337 \mathrm{f}$. 
In tracing this development one would hare to observe how the instinctive feeling of possession and of rights, which goes with the name of the individual even among the savages, has combined with superstitious fears to produce customs and laws designed to guard and enforce respect for the names of others. Another allied branch of historical study would show how crimes of forgery, or of perjury in the denial of one's own signature, have become widely recognized as serious breaches of morality. Just now in India the low moral consciousness of the natives is being educated toward a somewhat higher plane by the use of "thumb impressions" to identify their signatures beyond all dispute. Doubtless, the enforced guardianship of the seals of the nobility in Japan is destined to have in connection with the rapid lifting of commercial morals, a salutary effect in this respect upon the moral consciousness there. The history of the customs and laws relating to the libellous or insulting use of others' names reveals another side of an essentially similar experience. There is at least a hope that the application of the same generalization to the habits of the gossip, and of the good-natured but thoughtless signer of ill-judged recommondations, is destined to attain more and more of general acceptance. Major premise: The name of a person-my own or that of another-ought never to be employed thoughtlessly or maliciously; minor premise; in this case the name of some person has been so employed; ergo, etc. It is surely encouraging to think how much of wrong-doing and of consequent misery will be done away when this moral principle comes to be clearly established in the moral consciousness of men.

Another law which seems to be made obvious by a study of the history of moral development may be called - The universalizing of moral principles through the abolition of limiting distinctions between classes or individuals. In the practice of the virtues, the difference between the lower and 
the ligher stages of moral development is, oftentimes, chiefly a difference in the range of the relations under which the obligation to the virtue is felt. For example, no other form of morality secms so loose and shifting, so difficult to establish upon a basis of clearly recognized principle as that which concerns the sexual relation. In general, if one simply consults the historical derelopment of the race, it will be found that the rules for the virtuous conduct of the male differ flom those supposed to be binding upon the female; those for the ruler are not the same as those for the subject; those for individuals of especial gifts or attractireness often permit what is forbidden to ordinary mortals, etc. But, on the whole, the tendency is manifest, wherever there is pronounced progress in moral enlightenment, to bring both sexes and all classes under the same general principles.

Again, in the Nicomachean Ethics, although justice is regarded as the whole of virtue ${ }^{1}$ and friendship is held to do away with the need of justice in the case of fellow citizcns, ${ }^{2}$ it seems incredible to the author that there can be any talk either of justice or of friendly feeling as obligatory on the part of masters toward slaves. For "the slave is a living tool, and the tool is a lifeless slave." 3 But as soon as all men, not excluding bond-servants, are apprehended under the conception of a common citizenship in the heavenly kingdom, the universal prineijles of justice and kindness are applied even to the fugitive slave "not now as a servant, but above a servant, a brother beloved." 4 So, too, are certain principles of ethics clearly enunciated in the Brāhmanas which are prevented from any approach to a general application by the distinctions of class and caste still current in India. All over the world similar distinctions continue to oppose the actual universality of the moral principles of justness and kindness; - that

$1 \mathrm{~V}, \mathrm{i}, 19$.

8 VIII, $x i, 6$.
2 VIII, i, 4.

4 Philemon, 16. 
is to say, not simply the universal practice of these virtues but also the recognition of the rational title of the principles to be universally applied.

It is beyond doubt that, on the whole, the distinctions between classes of men, which are founded upon what is more adventitious and accidental, are slowly being cast out of the controlling place they have hitherto held in the moral consciousuess of the race. Unfortunately, a plutocracy is taking the places of power formerly held by an hereditary aristocracy, or by rulers distinguished for merit in war, in council, in character, or by rirtue of some peculiar relations with the unseen and divine powers. Probably, a plutocratic aristocracy, although less stable, will prove itself as disagreeable, unsatisfactory, and even dangerous, as a military, a landed, an hereditary, or a priestly aristocracy. In spite of this, the distinctions between men, as made by wealth or otherwise, are less and less considered when questions of the supremacy and inviolability of moral principles are put before the social consciousness. The ethical spirit which is winning its way all over the world is democratic; men are becoming more and more clearly and intelligently pronounced in the opinion that distinctions of class and rank do not count for so much when the sanctions of judgments of worth are concerned.

Growth toward the universal on the part of moral principles is powerfully affected by all the influences and institutions which tend to give increased solidarity to the race. Growth in the size and power of the social units themselves is of great efficiency here. The old Roman Empire never attained a true social unity. Its spread tended in a certain way, indeed, to unify the race. But the cement which held together the different heterogeneous parts was not of the moral quality; neither was it distinctively social. Some of the mighty empires and growing imperial enterprises of today are undoubtedly running the same risks as those which 
ruined the ancient structure. On the whole, however, there is far more of intelligent moral principle (far more, although still, alas! far too little) which gets itself applied with some logical consistency to modern social and political affairs than was possible two thousand years agro. Nor is it the development of states that are based upon an improved democratic morality which is the only cause of the tendency of moral principles toward a more universal acceptance. Intercourse of every kind - and especially the interehange of ideas and sentiments - between different states is assisting the universalizing of moral principles. As men know each other better, they come to understand how essentially alike all men are; and if this is so, why should not the same general rules of conduct apply alike to all? In language and religion, in needs and hopes and fears, in proverbs and wisdom, and even in customs and laws, they discover so much of fundamental resemblance as to justify the opinion that common principles ought to govern the conduct of all toward all.

Especially, howerer, does the spread of the essentially Christian idea of brotherhood, and of responsibility to the Father from whom all come and to whom all go, powerfully operate to secure growth toward the universality of moral principles. How ean one set of moral laws have sanction for the male and another for the female, one code apply to the ruler, the mighty man, the rich, and another to the subject, the weak man, or the poor, when one Creator is the Lord and Master of all; and when the destiny of all is subject to the same eternal and unchanging ideas?

This growth toward the universal by abolishing distinctions between particular classes and persons is itself met, however, and in a measure checked by other connected facts in the moral evolution of the race. The resulting complex experience introdnces the third of the laws that control the unirersalizing of moral principles. All tendency toward a 
practical solidarity of the race is accompanied by an increase in the complexity of life, and therefore in the difficulty of applying moral principles, however clearly recognized and constantly kept in mind, to the actual solution of concrete cases of conduct. When the social organization is relatively simple, even though different sets of moral principles apply to the different classes and different relations of those classes, the practice of the Virtuous Life needs less of thought and enlightenment. If, for example, one's servant is to be treated as a "living tool," one does not need to trouble one's self so much about the precise manner of treating him as a servant. Treatment of him is no longer a matter of moral concernment. If the male has no obligations to sexual fidelity toward his wife, or other female, then the virtue of temperance in this regard needs no thought for its application to concrete cases from some well-conceived moral principle. If one is morally bound to love only one's friend, and to hate one's enemy, then one is comparatively well prepared for a prompt and uncomplicated discharge of obligations toward both friends and enemies. And it cannot be denied that a soothing simplicity is imparted to the problem of conduct, if your principle is - "The country, right or wrong" - when you are trying to govern your behavior toward the Chinese or the Filipinos according to accepted and universally applicable moral formulas.

While, then, the moral evolution of the race has witnessed a tendency toward the simplifying of moral principles, by abolishing certain distinctions between social classes and between individuals in the same society, it has also witnessed an increased complexity of the relations in view of which the principles must be applied to the concrete cases constantly arising under the new conditions. This increased complexity of relations, in turn, makes necessary an increase of skill in forming judgments of moral values; it requires a development of "moral tact." Such a change is well illus- 
trated by the difficulty which is experienced by the individual under modern conditions in respect of the treatment of beggary. Under certain widely prevalent forms of social organization, the professional beggar, especially if he have some intimate association with religious hopes and fears, as the fakir or yogi in India and the begging friar in mediæral Enrope, is dutifully dealt with as a class apart. The spontaneous and morally acceptable custom is to give a small dole; and the feeling of satisfaction at having done right is the normal accompaniment of the action. When, however, the whole experience of giving to beggars is subjected to rational reflection, and especially in view of changed social conditions, the problem before the man of cnlightened moral principle is made much more complicated. For him every beggar is, indeed, one of his fellowmen, to "count as one" with himself in the universal society of mankind. But changes in the social conditions of the race have made more complicated the problem to be solved in each particular case, even after one's moral principles have been reduced to this highest degree of generality.

What, now, is the effect upon moral development in general, and upon the growth of the particular toward the universal, which arises out of this conflict between increased simplicity of principles and increased complexity of relations? In the first place, the repeated effort to frame particular judgments as to the right and wrong of conduct, by referring these judgments to universal prineiples, constitutes a most important form of moral discipline for the individual and for the community. The effort forces intelligence into conduct; it compels action to be more enlightened from the point of riew of moral reason. It is by the habit of solving problems of practical morals that skill in judgments of moral values is gained.

But, second, the reactionary effect upon the moral principles themselves is the matter of chief concernment in this 
connection. The conflict which has often seemed to spring up between two principles, because each of them has appeared to apply to some particular case, constitutes of itself a problem that demands a rational solution. Such a conflict shows plainly that neither of the principles involved can claim the sanctions necessary to render its use obligatory as a ground for drawing conclusions fitted to cover every individual case. Some higher principle must, then, be discovered; and its discovery marks an important step in the march of mankind toward the knowledge of those supreme principles of morality that have an absolute and universal validity. The result of reflection upon such an experience is an expansion of ethical intelligence, a growth toward the universal in the only way in which moral principles, and their sanctions, can be actualized among men. This, as we have already seen, is through their conscious acceptance and use as grounds of inference by a larger and larger number of the human race.

This process, or law, 1 will call the universalizing of moral principles through the practical necessity of establishing a rutional connection between particular forms of conduct and those universal principles. Illustrations of the working of this third general law are so numerous that they may be derived from almost any form of human experience. Indeed, the kaw itself is only an application to problems of conduct, of the same method which characterizes all growth of human intelligence. In the physical, the linguistic, the psychological sciences, the constantly increasing complexity of the phenomena demands always an enlarged knowledge of those universal principles which are thought to be in control of the phenomena. But in ethics, the phenomena themselves are human conduct - behavior of men toward one another, as moral selves socially related; and the principles are nothing else but the generalizations derived by reflective thinking with regard to those rules that have sanction in moral consciousness, and that are adapted to serve as points of starting 
for a deductive argument in the solution of concrete cases of conduct.

One more general experience regulating this species of moral evolution may be called The law (?) of learning universul moral principles from particular individuals, by precept and by example. In all forms of human development the influence of remarkable individuals has been far too much underrated or neglected by modern theories of evolution. Especially is this true in human ethical development. For such development consists in conduct, in opinions about conduct, in institutions that embody the results of conduct, and in principles that have the authority and sanctity which belong to ideals of conduct. These are all the products of individual selves. In effecting these products the gifted and favorably circumstanced individual is the principal factor.

I turn aside for a moment in order soon to return with added reasons for my conclusion, to protest against the whole machine theory of the world and of human life. Everywhere it scems to me that this theory is so loaded with the very facts which have been discovered and substantiated in its behalf that it is destined soon to break down under the load. It has been my welcome task, in preparation for this study of the philosophy of conduct, to show in detail that all the most fundamental conceptions which science has used to state, defend, and expand, the theory of mechanism, are themselves derived from instinctive experience with, or elaborate reflection upon, the life of the self-conscious and rational Self. These scientific conceptions have no validity, no intelligible meaning even, except as they are interpreted into terms of that selfhood. But when we give scientific consideration to this Self we discover that it is not possible satisfactorily to describe it, or even superficially to state its numerous performances, in terms of a psycho-physical or psychical mechanism. The * Self is not simply a more elaborate mechanism; the rather are 
all mechanisms conceivable only as incomplete and partial selves.

The individual will, whose the conduct is, and which undergoes a moral self-development bccause it is a rational and self-determining will, can in no case be considered as merely the product of pre-existent substances and forces, whether physical or psychical. Individuals, indeed, enter upon their historical career under conditions which they cannot alter. But individuals are never merely the resultants, or the expressions, of historical conditions. Individuals make human history by a complicated set of reactions upon the existing physical and social environment. Great individuals have much to do with making history. On their career, which is more than ordinarily the effect of their own free and rational selres, the subsequent history of the race is dependent to an unusual degree. This is pre-eminently true of the moral evolution of the race. If out of its ethical experience there were taken a few score men of great ethical influence, the moral condition of mankind would be changed indeed. No other influence has had so much to do with shaping human history as the influence of a few great moral and religious teachers. Moses and the Prophets of the Old Testament, Confucius, Sakya-Muni, Zoroaster, but above all Jesus and his disciples, with the greatest among the succession of the moral teachers and reformers which the Christian religion has produced, have exercised a quite incalculable force for the elevation and universalizing of moral principles. This they hare done both by teaching and by example. It is doubtless true that in the case of none of these teachers has the enunciation of moral principles been something wholly new and foreign to the most enlightened moral consciousness of their predecessors in the great function of teaching morality to mankind. Eren in the case of him whom Christianity recognizes as having supreme authority among these teachers, it is not to be forgotten 
what was the special talent for ideas and ideals of righteousness shown in the previous history of the people from which he sprang.

But, on the other hand, he minimizes, not to say distorts the indisputable facts who is not ready to admit that a few individuals have thought out into clear consciousness before their own and following generations those truths respecting the right and wrong of human conduct that have been, previous to their coming, only discerned in a relatively partial, fragmentary, and hesitating way. I am not, then, uttering a mere figure of speech when I maintain that in such individuals the supremest moral consciousness of the race culminates in a most surprising way. Nor is it a wonder that has no justification in reality if the multitude comes to regard these individuals when they speak of standards and ideals that are above the accepted standards and the hitherto conceived ideals, as having the sanctions of not only an external but an absolute and divine authority.

In every age, even among social organizations that have reached a fairly high degree of moral development, individuals are to be found whose discermment and use of moral principles rises much above the level of the multitudes. Such individuals refuse to take their principles of conduct, ehiefly and in uneriticised form, from the prevalent customs, laws, opinions, or institutions. And so long as they maintain this position, the prineiples which they do adopt as their own have for them the authority and tho sanctions which belong to all moral principles. Indeed, withont this authority and these sanctions, the rational grounds of action conld not be esteemed moral at all. When such persons inquire into the sources of these principles, and of the right to control them which the principles seem to themselves to assume, they are accustomed to refer either to a livine Origin, or to Reason (a source in the higher rational Self), or to some impersonal origin to which they give quasi-personality under the rubric 
of Law. In either ease the moral principles are regarded as coming from a source which is higher than that of the custom, law, opinion, or institution, over which they constitute themselves as an authoritative judge.

Those moral principles which are either discovered or more clearly enuneiated by the moral leaders of mankind are, as a rule, apparently so merged in the general level of outward forms of the morals of society, as to be lost. We cannot, however, believe that they really are ever wholly lust. They contribute something toward raising the standards and the ideals for all judgments of moral values; they do something in the behalf of the march toward the Universal of moral Prineiples and toward the realization of the more ultimate moral Ideals. There are a few individuals in every branch and epoch of the history of the race who have done much for its moral development. They have voiced most clearly the Universal Moral Reason; they have seen most clearly the Ultimate Moral Ideal.

By reflecting upon its own experience as embodied in institutional forms, by abolishing fictitious and incidental distinetions between individual persons or particular classes of persons, by education in the actual application of accepted rules of conduct to concrete cases of conduet, and by favor of the teachings and example of preferred individuals, the growth of moral prineiples toward the Universal has taken place. This is to say that the actual advance of such principles is ehiefly dependent upon the derelopment of social and political institutions, upon the spread and intensifying of an intelligent democratic and Christian spirit, upon the culture that comes from the effort of individuals to live more virtuously according to conscious rational rules, and upon the leadership of the foremost spirits in the discernment, enunciation, and employment of these principles.

It should be added that the more speculative efforts of great thinkers like Plato, Aristotle, Aquinas, and in more 
modern times Kant, Hegel, Locke, Hobbes, Hume, Bentham, and others, have been of no inconsiderable influence in the same direction. The great preachers and teachers of religion have also, always and everywhere, been prominent in moulding the moral consciousness of mankind. At the same time, it must not be forgotten that probably those who have by their own speculations been most successful in reaching universal principles satisfactory to themselves have by no means contributed most toward the actual unirersalizing of moral principles; and the work of religious preachers and teachers has had more effect, for good or for cvil, on the practical life of men than upon the acceptance of those higher generalizations that should serve for the rational and self-conscious governing of that life. The philosophy of conduct sharpens the critical faculty and makes the mind more self-conscious; but it operates within a comparatively narrow circle in its influence upon the growth of moral principles for the race. But good religious teaching makes men better, morally, and bad religious teaching makes men worse, without in either case necessarily putting them into possession of the rational grounds of conduct.

All the forces which concern the growth of moral principles toward universality have their reverse side; they may tend to narrow and degrade rather than to expand and to elerate. To live in the environment of customs, laws, and institutions, that no longer represent the higher levels of the popular moral consciousness, tends to check the growth of moral principles. The continuance or the re-establishing practically, of distinctions among men that are only of a superficial or even unethical character, has a similar effect upon moral progress. The increase of the plutocratic spirit over the whole world, and its allied development of the spirit of commercial imperialism and of race-hatred, is probably doing more at the present time than all other antagonistic forces combined to retard and degrade the moral evolution of 
mankind. But the increased complexity of modern life and of modern social organizations and social relations is wonderfully sharpening the wits of men by the demands which it makes upon them for principles of conduct that will apply to the solution of such complex ethical problems. Here again, howerer, if the truly moral solution of these problems is not diligently sought and somehow found, then this very social evolution itsclf reacts to blind and blur and degrade the rationality of moral consciousness. For men cannot come to act habitually without regard to moral principles and yet continue to hold their mental grip strong upon their principles - not to say, advance socicty to the intelligent apprehension of improved and higher moral principles.

All the while, the individual - every individual in some degree, but in the greatest degree those most favored intellectually and socially - is contributing something either toward the advance or toward the retrogradation of moral principles. For it cannot be too often said, if one has the practical ends of morality in view, that moral principles do not dwell in heaven or in mid-air, or in the merely speculative dreams of theologians and philosophers; they exist, only as they really are; and the only reality which they can have is in the rational consciousness of the Moral Self.

Any student of the philosophy of conduct who reflects in a serious and prolonged way upon the conclusions of this and the preceding chapters will detect in them a sort of concealed postulate, if I may so say, which is of the nature of a problem demanding further consideration. As the course of moral evolution flows onward, whether objective or subjective, whether in the consciousness of the individual members of the social organization or as given some institutional form, the code of moral laws and the body of accepted moral principles always seem to hold a certain position of authority, - claiming sanctions from somewhither, and sitting in criticism over what has already been accomplished 
for the social realization of the ideals of morality. Moral reason is critic and judge of its own accomplishments in such a way as to be always dissatisfied with them; it manifests itself as endowed with power and authority to command their modification and improvement. Its voice has the characteristics of an "external imponent." This fact accords with the view that the grounds and the satisfactory type of man's universal moral principles must be found in the nature of his ethical Ideal. And it implicates the problem of accounting for this Ideal by bringing it into relation with the nature of the Ultimate Reality. 


\section{CHAPTER XVII}

\section{CASUISTRY: MORAL TACT AND CONFLICT OF DUTIES}

THAT eminent good sense which characterizes the Nicomachean Ethics leads its author to declare respecting the solution of cases of conflicting duties: "To lay down precise rules for all such cases is scarcely possible; for the different cases differ in all sorts of ways, according to the importance or unimportance, the nobility, or necessity of the act." 1 But Aristotle immediately adds that one principle is tolerably obvious, namcly, no one and the same person can reasonably make claim to all of another's obligations. In the complicated relations of modern society this ancient cautionary remark is more than ever needed; and the tendencies which this society so plainly shows toward a certain equalization of claims on the part of all individuals, and toward the universality of moral principles in the manner already discussed, have made the ancient principle somewhat more than "tolerably obvious"

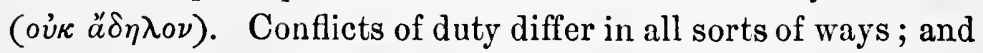
all the members not only of that particular social organization to which each modern man more especially belongs, but also of the race of which all the different social organizations are parts, make increasing demands upon one anotlier for the discharge of a variety of moral obligations. Precise rules for the solution of these conflicts are therefore becoming constantly more difficult, not to say impossible, to give. The sphcre of casuistry seems to be expanding; it seems likely to burst through excessive expansion.

1 Nic. Eth., IX, ii, 2 f. 
For the Moral Self, lowever, the practice of casuistry is, always and essentially, a truly rational discipline. Excessive punctiliousness over minutiae of behavior is, indeed, not approved by the enlightened moral consciousness; and delay to act at all, through doubt over the way in which to act, is often a loss of opportunity for some good deed; not infrequently, the delay itself is immoral and mischierous. A certain spontaneity in mental movement, especially of the affectional sort, seems essential to the practice of the Virtuous Life; and the promptness of action which depends in large measure upon such spontaneity is certainly felt as an obligation, and is approbated and rewarded when the demand for promptness is successfully met. Even wisdom and prudence cannot always adrise - strictly in their own interest as cardinal virtues of judgment-the examination of reasons and the making from the reasons, of deductions affecting particular cases. For such wise and prudential performances too often have the effect of rendering the other cardinal virtues of courage, justice, and kindliness quite impossible of realization. Persons who are extremely fussy over details of behavior - cren if it be "for conscience' sake" - are not, on that account, virtuous beyond the ordinary man; indeed they may be quite the opposite; for manly virtue must always retain something of the proportion and largeness of spirit which rationality commands and guarantees.

On the other hand, disregard or carelessness of details of conduct is not approred by a refined and enlightened moral consciousness. In the business of living wholly virtuously - that business which is always on hand with the truly good man, whether he be at work or at play, and eren if he be not at all thinking about the business - details cannot properly be neglected. Indeed, here as in all business matters, much good or evil depends upon how prorision is made for the details. He who thinks the manner of doing little things does not count in character is the servant who is unfaithful in 
that whicl is least; he thus shows his unworthiness to be trusted with matters of greater import. Indecd, human judgment as to what is great, what small, what is most or least important, is far from being infallible. At any rate, the spirit and habit of unfaithfulness, the temper and practice of disregarding duty, are of the very essence of immorality.

Modern pathological psychology recognizes both these extreme forms of moral consciousness as morbid and inhuman. The one is characteristic of a certain form of insanity; the other of what is bestial and monstrous. They who attach enormous importance to petty details, and who make error in these details a matter of moral life or death, may be preparing themselves for the retreat of the mentally unsound, rather than for helpful social intercourse with their fellows. But they who scorn to concern themselves about all so-called " mattcrs of conscience," and arrogate to themselves the right, in the name of might or of genius, to disregard moral principles and moral motives, may read the description of the brotherhood to which they properly belong, in the following words of the scientific psychiatrist: ${ }^{1}$ "To persons of this 'moral colorblindness,' this perversion of the altruistic feelings, the entire prerailing cult, the whole moral and eivic order has only the significance of a restricting limit for their egoistic feeling and effort, which must lead them, as of necessity, to the negation of the sphere of others' rights and to attack upon them." Even when such unfortunates have more than usual gifts of an artistic, logical, or inventive order, their true place is not in human society but in the madhouse; and there in certain notable instances they have ended their misspent lives.

Casuistry, regarded as " the science or doctrine of cases of conscience," is therefore entitled to rational consideration from the philosophy of conduct. For it is a species of ethical disciplinc. Nor can any valid reason be given why the

1 Krafft-Ebing, Lehrbuch der Psychiatrie, II, ii, chap. 3, p. 118. 
attempt should not be made to put this discipline into something resembling systematic form. The indiridual, since the consequences and even the moral worth of his behavior has reference to others, may properly enough communicate with other individuals belonging to the same social organization in the common effort to establish some such quasi-science or doctrine. Men may teach and learn from one another in the common effort to solve the problems of conduct as well as every other manner of problem. Incitement, guidance, instruction, are possible in the moral sphere as in crery other within which a multitude of selves are socially organized with reciprocally determining limits, and mutually limiting interests. Only it can never be forgotten that, since the rirtuousness of conduct resides in the attitude of the Self, and since each Self, while following in common with all other selves a certain universal Ideal, must have his own jdeal which it belongs to himself to realize, particular problems of conduct can only be solved by actual conduct; and conduct forerer remains the individual's own affair. The motire, the intention, the execution, the responsibility, the reward, are all primarily and pre-eminently the property of the individual. No individual can do for any other what that individual ought to do for himself. No man can usurp the place of conscience for any other man; none can lay off his duty of deciding upon any other.

All that it seems further necessary to say upon this subject may arrange itself as a brief discussion of the following three topics: (1) The Sources of Casuistry; (2) the Splere of Casuistry ; and (3) the Conflict of Duties. In the dictionary definitions of this term there are frequently enumerated three sources of casuistry, - namely, "Scripture, the rules of society, and the principles of equity or right moral reason." Now, if the first of these be extended so as to include all the books esteemed authoritative in matters of ethics by the devotees of the different religions of mankind, and to these 
be added the injunctions and instructions of priests and other religions teachers, this thrcefold division is fairly exlanstive of the actual sources from which men do derive their help in the solution of cases of conscience. But to regard either Scripture or the rules of socicty as a primary source for solving problems of conduct is to depart from the rery conception of casuistry as a truly ethical disciplinc.

It is the moral consciousness, the "right moral reason" of some Moral Self, which is the only source of ethical judgment, with whatcver of authority and sanctions such judgment may possess. Sacred writings are, at most, only chamnels and not true sources at all. So, too, must the "rules of society" either be received as merely the customs which embody forms of action that "right moral reason" las already sanctioned; or else they must themselves be subjected to the criticism of moral reason in their application to erery so-called case of conscience.

Undoubtedly, the moral precepts and more particular rites and cercmonies prescribed by the sacred writings, and by the expounders of the various religions of the world have hitherto been the most important practically, of all the influences employed for the settlement of cases of conscience. Indeed, in the case of millions of mon, these influences hare largely taken the place of the activities belonging properly to the moral consciousness of the indiridual. But this they have done in the name, and by the alleged authority, of other moral reason than their own;-e.g., in the name and by the authority of the gods or the One God conceived of as a Lawgiver, or of some principle of Universal Reason, etc. Wherever the necessity for applying any moral principle to the concrete case has been lifted from the conscience of the individual, the casuistical procedure has ceased to be a genuine ethical discipline.

As to the relations in which so-called "moral reason" stands to its own products in the form of the rules of society, enough 
has already been said to justify the denial that it ean ever look to them as an independent source for the solution of problems of conduct.

If, however, we affirm that moral reason is the only source for solving problems of conscience, we are at once reminded that the coneeption of the process used in dealing with these problems must be something different from that of arguing one's way from general principles to particular cases without violating the rules of the syllogism. Nor can this process be guided exclusively by that "logic of feeling" about which so much has of late been written in the effort to free judgments of worth from the hard and fixed lines of evidence and proof by which scientific judgments ought to be bound. In saying this, the rery language reminds us that any difference between the two classes of judgments is by no mcans absolute. In ethical affairs, judgments of feeling, however subtle and emotional, must have some rational grounds; but judgments of the more scientific and strictly logical order must have and command some feeling of their truth and worth.

I will say, then, that a sort of Moral Tact is the source of such practice of casuistry as can rightly commend itself to the seeker after the Virtuous Life. This form of tact it is the good man's duty to cultivate. Thus will he save what can be saved, under the hard conditions of human living, of the spontaneity, grace, and beauty of virtue, without unnecessarily sacrificing the rational quality which should always characterize virtuous conduct. In this way, if morality is always devotion to duty, it may also generally be good sense ; if duty is essentially an inner principle which compels each man to strive after the ideal of selfhood, it is also commonly a very practical and noighborly affair.

The psychology of tact is an extremely difficult subject to treat scientifically. This is ehiefly due to the two following reasons: first, the factors which enter into any judgment of tact are exceedingly subtle and evanescent; and, second, the 
complexity of the combinations of these factors in the individual judgments of tact is very great. It is the rapidity and immediacy, combined with a certain sureness and appropriateness of his conclusions, which gives to the tactful person his admirable ability to act aright under complicated conditions. This judgment has the characteristics of a judgment of first intention, as it were; we are inclincd, therefore, to call it "perception," "intuition," or " insight," rather than a conclusion reached through any conscious recognition of the grounds on which it is placed. Indeed, the factors which enter into the concluding mental state, the decisions that determine what is to be done in the particular cases, arise so little way above the threshold of consciousness (if they come up out of the sphere of the psycho-physical mechanism at all), and blend together or disappear with such rapidity, as fully to warrant that view of the nature of tact which the popular language implies. The How, and the Why, this particular judgment, rather than another, was actually reached cannot generally be assigned by the person whose judgment it is. Now in matters of conduct it is those who actually have moral tact who are the true teachers of casuistry; but they teach by example rather than by a display of logic and didactic machinery. In order to be genuinely moral, howerer, the tactful judgment must be the expression of a trained and refined moral consciousucss.

It will be seen, then, that the thcologian, the priest, or the moralist, who is not himself a man of genuine moral tact, a person with a "trained and refined moral consciousness," can scarcely become a trustworthy casuist. And systems of casuistry emanating from ethically impure sources are not only devoid of value theoretically, but are practically mischicrous. Indecd, the solution of cases of conscience $q \cdot e \cdot d$. fashion, by one moral consciousness for all other moral consciousnesses, is a snare and a delusion. But moral tact, like the ability to form with unusual rapidity, immediacy, and yet 
sureuess and fitness, other kinds of judgment, is susceptible of cultivation; within certain limits it can be both learned and taught, although the rather learned by practice and tanght by example, than learned by rule and taught as a pseudo-scientific system.

In the cultivation of moral tact four things are chiefly necessary. These are (1) sensitiveness of moral feeling; (2) insight into the motives of men in general and especially into the motives of those composing one's social environment; (3) experience as to the consequences of different kinds of conduct; and (4) subtlety of ratiocination, or skill in the drawing of detailed inferences. That sensitiveness of moral feeling can be cultivated, although the original susceptibility for it differs immensely with different individuals, there can be no reasonable doubt. It must be borne in mind, however, how exceedingly varied is the play of feeling appropriate to all the varied situations of the life of conduct. In the settlement of perplexing cases of conseience it will not do wholly to rule out any legitimate form of human feeling, from the most deep-scated but righteous indignation, or the most heroic disregard of suffering in the realization of a ligher good, to the most refined sentiments of pity and of tender regard for the feelings of others.

The knowledge of the way others think and feel also admits of cultivation. For the great multitude of human beings these "others" are, indeed, a very small number; of the most of the race, and even of the men over the nearest mountains, or across the nearest river, not to say, across the seas - they can imagine little correctly, and can know surely almost nothing at all. But even this narrowness to the range of their acquaintanceship has certain adrantages. It makes the more possible an insight into the thoughts and feelings of others which is sufficient to enable the individual, if he will, to put himself into the place of the others. Without this insight one cannot obey the golden 
rule and love one's neighbor as one's self. With regard to the consequences of good or bad conduct all the range of human foresight and human calculation is, at its widest, narrow indeed. But crery one can watch and be thonghtful here. And to act without any regard to consequences is as immoral as abstinence from doing our duty is impossible, until we have calculated precisely what the consequences are going to be.

To cultivate subtlety in ratiocination is also possible. There are undoubtedly dangers comnected with all attempts at such a form of cultivation; and these dangers are somewhat akin to those which attend the too great refinement of the moral sentiments. Feeling may become too exquisite for the best service of virtuous living under the actual conditions in which men have this life put before them as an ideal for achievement. And reasoning as to what is one's duty may be habitually conducted through such winding paths of considerations pro and con., and with such an array of "but-ifs" and "notwithstandings" as to result in the partial paralysis of those powers that best carry men forward in straight and direct courses toward their chosen ends. At the same time, it cannot be denied that life is increasingly complex; and this increased complexity seems to make necessary an increased skill, amounting to subtlety, in the use of that discursive reasoning which, for the modern man, must often take the place of the animal craft of the untutored savage.

Fortunately for the interests of the man who is heartily deroted to the realization of the Moral Ideal in the Virtuous Life, there is a certain economics of casuistry which appears the more elearly when we consider the sphere within which move the attempts to teach in a systematic way the right solution of particular problems of conduct. I have already said that the rules of society cannot constitute an independent sonrce of casuistry. They do, however, shape a certain sphere within which casuistry may most conveniently and 
safely receive recognition from the virtuous man. Broadly understood, the sphere of casuistry is coextensive with the entire sphere of conduct. Or rather, in any particular case the two spheres may at any instant come to coincide. For the otherwise most trivial detail may at any instant become of the greatest ethical import; and all the powers of intellect, stirrings of the heart, and energy of will in self-determination, may be called forth in the interests of morality as respects this detail. But ordinarily the general submerged purpose to do right, in connection with the habitual working of moral consciousness under conditions that are familiar, best meets the demands of virtuous living. What to do in order to do one's duty, how to act in order to act virtuously, are questions which would better appear only comparatively rarely in one's conscionsness. It is ordinarily better to go ahead and do one's daily prescribed duties, without thinking of them as duties; simply to live virtuously, without raising casuistical inquiries as to the virtuous or vicious character of one's living. That is to say, the moral tact which is the source of the practice of casuistry is working with a satisfactory smoothness. Magnanimity, and other of the nobler virtues, are very desirable to sccure in conjunetion with a minute regard to the details of one's own daily conduct; but this is nearly impossible where the mind is much given to regard for the details of the conduct of other people. It is right ordinarily to lower the window or open the door, without attaching any moral import to the transaction; or to put on a dress suit as a matter of course in compliance with etiquette when accepting an invitation to dimner. But thoughtlessly to let a dangerous draught upon some invalid would be a grave fault; and deliberately to lower a window upon a relative in whose death we were interested might be no less a crime than murder. Nor are occasions wanting where no little thought is necessary to determine how one ought to dress in order to dress virtuously. 
In the vast number of cases the rules of the socicty with which he is either temporarily or more permanently conneeted have settled for the individual the manner of his behavior in respect to details of a certain sort. These rules are themselves, to be sure, constantly changing; and their changes are largely due to elianges of judgment and feeling respecting the moral propriety of the rules themselves. Some of these rules are almost sure to violate certain principles of morality recognized by those who are sensitive to ethical considerations and bent on realizing their ideal of moral sclfhood. Thus the kecping or the breach of these rules may beeome a problem in casuistry - difficult to solve and of no small cthical importance. But ordinarily, and in the large, the man who aims at being wholly virtuous will let the rules of society decide for him what he should do, will simply comply with those rules; he will thus set free his more distinctively moral consciousness for better business than making compliance or non-compliance with petty details of beharior a case of conscience. He considers that it is as irrational, and may be as unethical, to make wearing no buttons a matter of conscience as to malse wearing a particular number and kind of buttons a matter of pride at being in the fashion.

The eommitment of his conduet on the part of the individual to the rules of society rather than to his own moral judgment is most rational in matters of etiquette, in matters of professional and technical behavior, as it were, and in certain classes of personal habits. In such matters, unless there exists some special reason to the contrary, one may hold that the moral quality of the action varies with the custom and derives itself most directly from the custom. In these matters, when in Rome one docs as the Romans do. What would be indecent and lewd under some circumstances would be prudish under other circumstances. To omit what would be servile and lacking in proper self-respect in some communities would be rudeness and deficiency in due respect 
for others, in other communities. In all such cases the true casuist tries to find out what are esteemed good manners and then calls into exercise all the refinement of feeling and sureness of judgment he can command in the desire to conform to the current standard of good manners. For although manuers are not synonymous with morals, and morals are not all that is most important in morality, thoughtlessly or deliberately bad manners are usually immoral. Where departures from the rules of society are due to an cxcusable ignorance, the enlightened moral consciousness makes light of them; and in general, in the case of others, one should be careful not to err on the side of excessive punctiliousness. But that habitual disregard for polite manners, which, for example, Occidental nations show in their treatment of Oriental peoples is something worse than pardonable boorishness; it is the expression of an immoral haughtiness and unfriendliness which is most certainly none the better because it is also coar'se and vulgar.

In the majority of eases, amidst the freer social organizations of modern civilization, he who dissents from the rules of society on moral grounds can save his good conscience by not consorting with others in the more objectionable forms of organization. Rarely does the "good conscience" require that the individual should join the society whose rules he intends, "for conscience' sake," habitually to set at naught. It might have been necessary for the newly converted captain of the host of the king of Syria to provide against a serious misinterpretation of his behavior as both a servant of the Syrian king and a believer in the foreign god, Yahveh: "In this thing the Lord pardon thy servant, that when my mastel. goeth into the house of Rimmon to worship there, and he leaneth on my hand, and I bow myself in the house of Rimmon: when I bow down myself in the house of Rimmon, the Lord pardon thy servant in this thing" ( 2 Kings, $v, 18)$. It may also be doubted how far Elisha intended to approre 
this bit of casuistical subtlety, when he bade Naaman "Go in peace." But there are at present relatively fewer cases where the applicability of the rules of society is not a matter dependent upon the will of the indiridual. If the visiting American objects to kissing the hand, or receiving the blessing, of the pope he need not seek admittance to the pope's receptions. And he whose conscience is offended by having to bow low three times on entering into and departing from the presence of the Mikado ought not to allow others to ask the imperial audience for him.

In not a few cases, however, where the rules of socicty and the moral conscionsness of the individual come into conflict the settlement of the path to be followed is not so easy. For the good man cannot go entirely out of society. In the more proper meaning of this word "society," to attempt to withdraw from it altogether would, if it could be successful, take the individual totally out of the sphere of ethics. This would be a solution of all possible cases of conscience indeed; but it would also be to make social morality impossible. To keep any restige of moral goodness in the most pronounced solitary ascetic, God and he must constitute a sort of society. Nor can it be denied that in most cases no little of what is popularly called "sociability" is conducive to the highest development of the Virtuous Life. But in all this the Moral Self must retain its own integrity. Hence there arises the necessity of being always ready to refer the right of society to control the individual back to the source of all rules, to the moral reason; and thus the need of moral tact is made prominent again.

The minor and relatively unimportant cases of the Conflict of Duty usually occur in the sphere of social details. But conflicts of duty are apt to arise which are of a far more portentous character. And to such experiences some reference is now in place.

Many writers on the philosophy of conduct - and among 
them eren Professor T. H. Green ${ }^{1}$ - have denied the possibility of such an experience as a genuine conflict of duties. On the other hand, others have claimed that, inasmuch as the entire tendency of moral development is monistic, and toward a unifying of the entire life of conduct under the control of some one principle, conflict is a nccessary result of all effort at moral development. According to Simmel, for example, the eonflict of duties arises, as an essential moment in the progress of ethical monism, in either of two ways: first, when a higher prineiple comes down from without, as it were, upon two or more contignous and litherto concordant classes of duties and forees a choice between them; or else, second, when the more internal development of two related duties forces them further and further apart until they become antagonistic. A marked instance of the first class occurred when, in the fourth eentury, the Christian bishops were ordered to put away their wires, and fidelity to the office beeame ineompatible with fidelity to the family relation, because the authority of the Church dominated both relations. Instances of the second class are constantly occurring where Chureh and State interfere with each other in matters that have customarily been controlled exclusively by one of the two. ${ }^{2}$

The abstract way of treating this subject is, I think, inappropriate to its character; it is also inconsistent with the riew whieh finds the unifying prineiple of so-ealled "monistic ethies" not to reside in any form of a moral law but in the unity which belongs to a Moral Self following its individual Ideal. Duties are not entities ready-made with corresponding or antagonistie characters between which one must choose as one chooses which pattern of cloth one will have made into a suit of clothes. Nor are duties fixed coneeptions of what ought to be done by every individual in accordance

1 Prolegomena to Ethics, p. 355.

2 See Simmel, Einleitung in die Moralwissenschaft, II, pp. $380 \mathrm{ff}$. 
with unalterable laws. Duties are concrete individual forms of conduct which must realize themselves in the individual moral consciousness, and which are continually liable to change the form of their expression. The problem of conduct is therefore always capable of statement somewhat as follows: Is this particular conduct my duty, at this particular time, under these particular conditions, and as something owing from me to this particular person? Every factor of the problem is particular, and dependent upon a variety of accordant or conflicting particulars. Moreover, ethical conflicts are not clashes of material entities or of physical forces that take place outside of moral selves; they are not mere conceptions of the meeting of such entities or forces. Ethical conflicts are conflicts of soul. Conflicts of duty are just this - namely, actual struggles of the feelings of obligation because the ethical judgment cannot be made clear. They, therefore, certainly do exist with the only kind of existence which they could be conceired of as having. To deny their existence is about as inane and comfortless a "psychological fallacy," due to excessive abstraction, as can possibly be derised.

Moreover, there seems to be much truth in the view that the very nature of man's moral derelopment makes necessary a conflict of duties. Certainly the fact appears to be that, under existing conditions, the more developed ethically any individual bccomes, the more are the chances increased of the occurrence of many such conflicts. To avoid conflicts of this character it would scem necessary never to make one's conduct a case of conscience at all. Bluntness of sensibility and incrtia of judgment on moral matters is most favorable to that quictness which consists in frecdom from the perplexity of asking one's self to settle troublesome ethical questions. But this is moral conseiousness asleep, not moral consciousness at peace with itself. Always to be cock-sure what is duty, and always to be satisfied in retro- 
spect that one's duty has been done in the best possible manner, does not prove a superior moral insight or rational soundness of judgment; it may the rather show a meagre ethical nature and a defieiency of interest in the real values of human life.

Still further does it scem true that, after all, human life is greatly enriched, made more interesting and better worth the living, by these battles that are best worth the fighting; for they are battles in the interests of that which has the highest worth. And certainly, from the asthetical point of view cases of conflict of duties, where the struggle is of the life-or-death order and the stakes at issue are the salvation of the higher Self, are the sublimest things in human history. The noblest tragedies celcbrate such conflicts. There is Antigone with all her soul's affection and her most cherished sense of obligation committed to the act of putting the necessary three handfuls of dust upon her brother's corpse; and in conflict with this command of sisterly affection and duty are the duty of obedience to the highest external authority and to the wise counsels of the experienced old men of the chorus. What shall one poor girl do when torn apart in two directions by moral forces so mighty as these? It is the necessity for answering such a question as this, in which the tragedy of many a humble human life consists.

Conflicts of duty that are real and that call upon the individual for much painful but disciplinary and improving use of his ethical powers may arise in any one of several different ways. In one class of cases moral feeling and ethical judgment are found in conflict. The rational and intelligent conclusion from moral principles as to what is duty stirs up feelings of obligation and of approbation or disapprobation that conflict with the conclusion. Then the mind knows it ought to do what it feels ought not to be done; or knows it ought not to do what it feels ought to be done. This sort of conflict belongs necessarily to all the 
more intelligent and deliberate changes of habit in matters that are made distinctively moral (comp. p. $90 \mathrm{f}$ ). In all such cases the problem before the man who would live virtuously is this, - how to develop rationality in conduct upon a basis of larger experience, without losing that tenderness and sensitireness of moral sentiment which it is so beautiful and praiseworthy to retain.

Another class of conflicts of duty arises when two or more persons, or groups of persons, require from us modes of behavior that are incompatible. Every individual life is fnll of this kind of conflicts. Within the circle of the family the husband may have to decide between duties owing to his wife and those owing to his child, and the wife may have a similar decision to make; the child may have to choose to which of its two parents it will remain obedient, eren when the matter of conflict would not of itself originate the conflict unless it were commanded by two authorities. Either of the parents may require that which the child cannot in conscience perform, and so give rise to that choice which, when viewed from the religious point of view, is so often called choosing between obeying God and obeying man. So, too, do duties to one's family - especially for the overburdened man whose entire life is a doing of duty to somebody by conducting conscientiously his business or profession - not infrequently conflict with duties to society. The different social circles which surround every individual, and the different social organizations with which he is more or less closely connected, all make their demands upon interest, time, strength, and property; and these demands are in almost perpetual condition of conflict. Here, especially, the more the sphere of one's conduct expands, and the more the quality of one's conduct becomes a matter of moral concernment, the more numerous and severe the conflicts are likely to become. And then there are the demands of the religious nature with its longings, at least occasionally, to get away 
from all social obligations, to commune with one's Self and be still; and to know something more of the "peace of God."

Still another class of conflicts of duty arises when the very virtues themselves - and, in extreme cases, those of the mest cardinal order - fall out with one another. How shall one always, in a practical way, be both courageous and prudent, angry and sympathetic, just and kindly, truthful and polite, loyal to one's higher selfhood and actually helpful to society, at one and the same time. Shall one insist on punishment or on pardon for the offender? Shall one throw one's life into the breach at the risk, or with the eertainty, of losing it, or shall one save one's life for other battles? Shall one speak and act out the truth that is most offensive and disagreeable to the populace, with only a possibility that it will be salutary; or shall one wait in silent hope that some other tongue will speak the same truth in a more agreeable and salutary way? Life is made up, to no small extent, of such problems of practical morals as these; and to deny that they are real conflicts of duty is to offer empty phrases for the instruction and consolation which all attempt at goodness so much needs.

Feeling conflicts with judgment, and custom often conflicts with both; the demands of individuals and classes confliet and no one ean erer satisfy all their demands; even the virtues themselves seem at times to be rariant. What shall the good man do? In what consists the truly virtuons life? The good man must stand up to the conflict and do the best he can in it; for in this consists the rery essence of the virtuous life itself. And here the principle of individuality as a relation of every Moral Self to its own Moral Ideal, although cach individual ideal is worked out in a social organization of similarly constituted selves, shines forth again to guide our thinking by the right path. For morality is not the mere keeping of a law; it is not the mere doing as others do, have done, and are going still to do; although without 
consideration of enstom and of consequences no morality can be attained. Morality is the achievement of the indiridual person who, by dutiful exereise of all his powers, frames - each for himself - an ideal of what, as regards conduct and character, he ought to do and to be; and who by dutiful exercise of these same powers progressively realizes this ideal.

Both the moral ideal, and the virtuousness which consists in the realization of it, are individual; both the formation of the ideal and the realization of it are progressive, never finished, always growing in wealth of content and in difficulty of attainment. But neither ideal nor realization ean crer come into being otherwise than in a social environment. Indeed, in their very nature both ideal and its realization, although individual and ceaselessly variable, are also just as essentially social. Conflict here, as through every form of life, is a struggle for existence. But since virtuous liring is something more than mere existence, or merely fortunate existence, this struggle is of a nature to involve all the moral ralucs. It is a struggle to apprchend, to comprehend, and to realize a Moral Ideal. There is no help for it then; every man who desires to be virtuous must endure this kind of conflict. His claim to virtue consists largely in the way in which he conducts the conflict.

This brief casuistical discussion may fitly be brought to a close by a few words regarding one elass of eases of eonscience which has given the easuists of all times no small amount of trouble. These cases are those in which the duty of truth-telling comes into eonflict with some other form of duty that claims to be equally eardinal, or eren more fundamental. Here our view of the nature of morality does not permit us either to say with Kant that untruthfulness is always "by its mere form, a crime of man against his orn person, and a baseness which must make a man despicable in his own eyes;" or with Fichte: "I would not break my 
word eren to sare humanity;" but even less to hold with Paulsen " that "veracity may be regarded as a form of benerolence" and that lies may be told with good conscience if they seem likely, in particular cases, to benefit others. It would scarcely seem necessary to controvert the extreme views of Kant and Fichte, in these days when the utility of truthfulness is so emphasized by most writers in commending it as a virtue. Moreover, I have already indicated ( $p$. $296 \mathrm{f}$ ) in what sense trueness is a cardinal, an absolute virtue, - not as the mere keeping of a law but as an act of fidelity to the nature of moral and rational selfhood. Nor is it necessary to dwell long upon the necessity under which Paulsen (with every other student of ethics who does not place this virtue upon its own secure foundations) finds himself of covertly reintroducing considerations which his very conception of the virtue has appeared openly to exclude. For if the sole answer to the question, Why is lying wrong? is this: Because it destroys faith and confidence among men, and consequently undermines human social life, the other question still recurs: What about human social life is it that lying undermines which has the worth to make the happiness given by, and derived from, much lying, disapproved as inconsistent with the ideal of personal morality? In trying to answer this question we actually find Paulsen disapproving, on the one hand, of the theologians who deceive men in the supposed interests of the salvation of their souls, and commending physicians who deceive them in the interests of their bodily health or of recovery from disease!

When the conflict is on between the duty of truth-telling and the duty to exercise some contrary and opposed form of virtue, only the individual whose conflict it is can decide which of the two shall control his action. But the conflict must be fought out on grounds of duty, and the eye must be

1 A System of Ethics, p. 66+f. 
kept steadily fixed on the moral ideal. Otherwise, whichever way this particular problem of conduct is practically settled, duty is not really done, and the moral ideal has been riolated. In most cases it will be found, I think, that the conflict is not between duties at all. For example, if the question seem to be, Shall I tell the truth and be unkind or speak falsely in a benevolent way? there are several questions that deserve an answer which lie still back of this one. Must I speak at all? Will the truth be really unkind? Will the falschood or deceit be rcally kind; and if a kindness to this one person, will it be a kindness to society? And, indeed, am I bound to be kind in this case, etc., etc. ?

He who values trueness at its own intrinsic worth, as belonging to the most essential qualities of rational and moral personality, and as situate at the very foundations of all social intercourse of the moral sort between selves, but who has come to the pass that he must either deliberately surrender this precious thing for only one moment or else do a great wrong by way of injustice, unkindness, or other harmful conduct to his fellow-men, is in a hard case indeed. $\mathrm{He}$ is in one of those tragic situations for the relicf from which no system of easuistical rules, and no code of moral principles, can amply provide. He must settle his own case of conscience as best he can. But he must settle it as a moral problem - keeping himself free from cowardice, injustice, enmity, and hypocrisy or self-deceit. If he thus settle it, good men will commend his devotion to his own ideal of duty, and pardon and pity him if he seems to them not to have settled it aright. And what the Judge who knows the whole truth will cause to erentuate from this human decision is in this Judge's hands. The struggle itself has its own value, although its place in the realization of the Moral Ideal may be a mystery hidden from man. 


\section{CHAPTER XVIII}

\section{THE GOOD MAN}

The previous discussion of the nature of the Virtuous Life has prepared the way for a correct and fairly complete answer to the following question: Who is the good man, and how shall we describe, so that we may know him? This answer must, however, always remain of a rather general sort, the details of which hare to be filled in with a variety of eontents dependent upon indiridual circumstances and upon the differences inherent in individual selres. Moreover, the description must employ terms of the recognized rirtues rather than the more abstract terms of moral laws and moral principles. Thus we may say without fear of contradiction that the good man is brave, temperate, and constant; he is also wise, just, and true; and he is not lacking in kindness and sympathy but, the rather, guides himself in his relations to others by a principled and broad benerolence. In a word the good man is he who realizes the virtuous life in all his varying relations with other men in society. This "realizing" consists in the actual practice of the different virtues, - the virtues, namely, of courage, temperance, constancy, wisdom, justness, trueness, kindness, sympathy, and benerolence, - each duly and in its own place, as occasion demands and as circumstances make possible. This "realizing" is not so much the mental recognition of a law, and the patterning of conduct after the law, as it is the actual living of a life according to an Ideal.

But the ideal itself, since it is a moral ideal, appears as a 
command which elicits the feeling of obligation and which gains respect for its own sanctions by its own nature and manner of appearance in consciousness. The good man is the man who actually lives in the progressive realization of the virtuous life. In other words, and since every man is a concrete individual, in social relations with other individuals, the good man conducts himself according to his ideal of what his Self ought to do and be, in its intercourse with other selves. Every piece of conduct which lias these characteristics is entitled to be called virtuous, or morally good; every person who habitually conducts himself in this way is entitled to consider himself, and to be considered by others, as a truly good man. And should any mortal and finite person succeed in doing this to perfection he would be entitled to be considered by others an entirely good man. As says Professor Laurie: " "The Good Will is that Will which habitually subsumes moral ideas as motives of its willing or volition."

In order, however, to adapt this description to the facts of experience and also to the uses of the student of ethics, whether from the more purely speculative or the more purely practical point of view, it needs to be modified and further cxplained by a series of remarks. These remarks are themsclves only brief summaries of conclusions which have either becn definitively reached or less clearly indicated by the previous discussions of the nature of the Moral Self and of the Virtuous Life. Among them I place first the following: Morality does essentially consist in conduct shaped according to an ideal; but this ideal need not be either conceived in its entirety, or followed with a full consciousness of its significance and worth, or even always followed with any conscious recognition of it at all, in order that conduct may be moral.

That morality does consist in conduct shaped according

1 Ethica, The Ethics of Reason, p. 21. 
to an ideal standard, and that moral judgments regularly and naturally bring all actual conduct into comparison with this standard, has been made increasingly apparent by the entire trend of our discussions. The power to frame ideals by joint activity of thought and imagination, and that emotional response to the ideal which the consciousness of man returns, are fundamental and universal conditions of all his moral as well as asthetical development. He who cannot in any wise be indueed to conceive of that which is better than the actual, and to feel some preference for this better, some drawing or obligation to it, cannot be a moral being. The good man must conceive of a Self, to make his own, which is morally superior to his own present self; and he must feel the impulse and the demand to realize that superior self.

At the same time, for the multitude of men in all their transactions with their fellows, and for the best men in the multitude of their transactions, the moral ideal is not present in consciousness in any distinct, not to say complete, form. With most men and women - even good men and women - the daily and yearly round of duties is filled out with comparatively little conscious intention aimed at the end of it all, and with only rare and fragmentary pictures of the better selfhood which is either being won or being lost. Indeed, with the millions of earth - and not simply among the savages, or in the eivilizations of China and India, but as well in Europe and America - life is lived with a concentration of encrgies upon the problem of bare existence which leaves little of thought, imagination, and feeling, for problems that lie in any measure above, or outside of, bare existence. And yet, everywhere that any form of social organization constitutes an environment for the individual - and man's environment, as moral, is neeessarily some form of social organization - the shadow of some feature or fragment of the moral ideal is constantly being thrown across his path. His barest existence is a 
social affair, and to secure it involves the practical solution of questions of conscience. Shall he now be brave or be a coward? Shall he in this case indulge his anger and the spirit of revenge, or control it? Shall he act with forethought or let this particular matter slip by without his careful seizure of opportunity? Shall he treat another in this special instance unjustly, or allow himself to be treated unjustly in case he can avoid it by resistance or outcry? Shall he swear to his own hurt and change not; or shall he aroid the keeping of his word? Shall he be kind and helpful toward a fellow, even at the cost of self-sacrifice? In the solution of all these concrete questions, there is an opportunity to exchange glances betwcen the Self that is and the Self that ought to be? The former is very real and insistent with its appetites, passions, and desires. But then it has its kindly and sympathetic impulses as well. And the latter, the Self that ought to be, is always, in respect of this one piece of conduct in hand, or perhaps in respect of the entire class of actions to which this action belongs, at least somewhat better - ideally so - than the actual Self. It has certain appreciable values, and the sanctions that go with these values, on its side.

There are, moreover, in the very structure and personnel of the existing social organizations concrete representations of that Ideal Self which the individual is obligated to realize. There are the customs, laws, and institutions, which have moral significance and which result from the past experience of the race in its own experimenting to find out the right ways of conduct. And there are the older and wiser members of society, the individual selves that are looked up to by the multitude as embodying, in some important features at least, the ideals of a selfhood which is better than that now realized by the average development of the immature and unskilled multitude. There are the stories of the heroes of old, and of revered ancestors, and of the gods that have 
their home on Olympus or dwell nearer the hearts and hearths of men. Thus the individual member of the social whole is led to feel, in this or that respect at least, and here in one way and there in another way, that the selfhood of these superiors is an example of the Ideal Self which he should make his own.

But no matter how much the individual may subordinate his moral reason to the social type, and in spite of the lazy and abject willingness to be, not simply no better man than the custom and law demand, but even as little of a good man as the custom and law will permit, problems of conduct are apt to arise which make still higher demands upon the joint work of thought and imagination in framing his moral ideal. Whether I will or not, I must be my self. My virtuousness or viciousness must be, in some respects, peculiarly my own. For the working of the principle of individuality is imperative here. The great majority of men and women are undoubtedly, in such ideals of the life that ought to be as they cherish at all, very largely, perhaps almost wholly alike. Yet in all countries and stages of social evolution, good and bad men are recognized as existing side by side in the same social organization. And the very words, "good" and "bad," indicate clearly enough which of the two classes is recognized as entitled to give the picture of moral perfection to the community for their example and imitation. There are also some "very good men" in almost all multitudinous communities. And such is the rery nature of moral goodness, that these leaders of the ran must have an ideal for themselves to follow which is raised by themselres consciously above the low level of the average morals. As to the influence of this ideal upon the moral development of these individuals themselves, and, not infrequently, through them upon the race, it is not necessary to add to what has been already said.

Nor can this relation of the ideal Self to the actual Self, 
in the case of all who are entitled to be called good, be understood without taking into account those psychological laws which control all human development. Among such laws are chiefly those which enter into the growth of habit and which deterinine all the immense influence of habit over the character and achievements of the individual. Repeated activities of the order that constitutes good or bad conduct, like all repetition of similar activities, tend to the formation of habits. The formation of habits is necessarily connected with important changes in the character of the thinking, fecling, and willing, which enter into every single instance of the habit. What was formerly done, when the habit was in its earlier stages of formation, only with a definite consciousness of the end to be attained and of the proposed method of its accomplishment, with more or less of specially appropriate feelings or with a certain conflict of feeling or resistance from feeling, and with an appearance of deliberate willing and self-determination, comes to be done in a seemingly unintclligent, non-emotional, and automatic fashion. But the good man morally, according to the age and maturity of his goodness, is emphatically the man of good moral habits. He is, therefore, good in general, as a matter of course. He is habituated to follow a certain ideal; and for this very reason he, in his habits, follows it actually, but oftenest without consciously setting it before him as an ideal. In the main he has solved the problem of conduct by deciding what sort of a man he ought to be; and he has settled himself into an habitual but relatively unthinking, unfecling, and oncc-for-all determined career in pursuance of his ideal. It is chiefly when such an one awakes to the consciousness of having been unfaithful in some particular to his standard of moral selfhood, or when some more than usually difficult case of casuistry comes up for a practical decision, that he makes conscious reference to his moral ideal. It is, as a rule, only in a case of doubt, that the 
good man inquires: How, under these particular circumstances, shall I act in order best to realize my ideal of a Moral Self?

Conduct is a sort of high art; and truly virtuous living is not a theory to be accepted, but an habitual practice of the several virtues that flow from the rery nature of the obligations of moral selves in their reciprocal relations as members of a social organization. Like all art it recognizes the ideal. But its ideal is realized not in idea merely or chicfly, but in conduct which implies much more than correct and exalted ideating activity. And like all life the virtuous life, the life of the good man, is an habitual way of living that conforms to a norm without, by any means, constantly holding that norm before itself in the mirror of consciousness. Moral self-consciousness - no matter of how intelligent and exalted a type, and notwithstanding the great need of self-comprehension which the noblest living requires - is never the chief end of conduct, or the principal criterion of the moral quality of conduct.

Another remark necessary to characterize properly the good man is, I think, somewhat like the following: The different degrees of moral goodness depend, both upon the excellence of the moral ideal adopted by the indiridual, and also upon the perfection with which each individual's ideal is realized in the actual conduct of life. That some good men are better than others, and that good men may generally continue to grow better, are propositions which only a captious and pernicious metaphysics or theology would think of disputing. Most human beings have some morally good puints about them; eren those justly called bad men have some virtues, some fragments or traces or promises of moral excellence. Not infrequently men who are decidedly vicious, when their conduct is compared with the standard set by certain of the cardinal virtues, are conspicuously good if measured by the standard of other cardinal virtues. But 
the good man is he whose ideal, chosen and followed, is the for him virtuous life; or, in other words, he is the man who is actually shaping his conduct according to the ideal of manhood he belieres he ought to attain. As is the case with ail other ideals, so with the moral ideal; the different individual standards get compared with one another, get tested by the comparison which often becomes a conflict, get preferentially selected as the result of such practical testing; and gradually, if not suddenly, in the experience of the individual and of the race, the more excellent are made plain. It is not strange, then, that there is much difference of opinion among different indiriduals as to the most excellent type of manhood, morally; just as there is much difference of opinion concerning the ideals of the happy life, or of any of the principal kinds of art. And every one must "work out his own salvation" in ethical, as well as in eudxmonistic or æsthetical affairs. For it is the spirit working in the man, the spirit of devotion to the moral ideal and the constant working to realize it, which are the chief distinctions between the good and the bad.

Nevertheless, the moral development of the race, which is in this respect eminently dependent upon its intellectual development and upon its entire growth in experience, has made it possible in good measure to adjudicate between the different ideals of moral selfhood. The influence of the Christian religion has been especially prominent in this development, through the ideal of manhood which it has favored and established in favor amongst mankind. I cannot believe that this ideal differs, in so far as it is ethical and not distinctively religious, so radically from the best Greek conception as Paulsen and others would have ns to suppose. But the description of the ideal good man as given in the Sermon on the Mount, and as realized by the preacher of that Sermon, with its implied exhortation to strive to be perfect after the pattern of the Divine Ideal of Selfhood, is 
undoubtedly entitled, even when judged by the standards of historical and ethnological and psychological criticism, to be considered the most excellent of ideals. This ideal, however, cannot be adopted in a vague general way; it must itself be individualized by every good man; and, in its concrete realization, it is dependent upon a host of constantly changing circumstances comnected with each individual's social euvironment. It must also be a practicable, a progressively realizable, ideal. For nothing is more destructive of virtuous living than to make virtue consist in holding and pursuing a type of manhood that could not possibly maintain itself in any existing, or even conceivable, kind of a social orgauization. One's ideal may be-nay! should be - as high and noble as the strenuous and persistent effort to copy the godlike man can possibly raise it; but its realizing is no mere act of mental apprehension; and living in accordance with the moral ideal can never be a mere copying.

So, then, it is not simply the holding of the higher and lower degrees of the ideal of moral selfhood which makes the difference in the goodness of different men; although they are the better morally, who, other things being equal, have espoused the best ideals. The "high-flyer," the Idealist (as the word is usually understood when spelled with a capital and applied to the sphere of ethics), is not likely to be the best of good men. For besides the general impracticable character of the ideal he cherishes, we may have to note that he is too frequently and too contentedly unfaithful to his own ideal. No good man - much more, no best among good men - realizes his own ideal of a Moral Self. But any man renders suspicious, if he does not altogether forfeit, his claim to being a loyal follower of the Virtuous Life, if he habitually and obviously falls far short of the very elements of the ideal which he considers so strictly applicable to all his fellow-men. He may be grandly right, as Jesus was, in 
leading a little group of followers, or in going alone to martyrdom, because the standard he raises and would have others accept is so obviously contrary to the interests of the ruling classes or the impulses of the multitude. But, I repeat again : Every moral ideal which is binding on the individual involves the conception of a Self set into actual relations with other selves, in some existing social organization, and conducting itself virtuously in those relations. The most really good man is, then, he who in his daily life habitually, by the employment of all his encrgies of mind, heart, and will, moulds himself according to that particular ideal of morality which seems to him most worthy. This ideal of morality is always, on the one hand, concrete and individual; but it is also, on the other hand, social and having reference to the part which every individual takes in the community of moral bcings.

Another remark - almost too obvious to deserve making, were it not for its practical importance, is this: The goodness of the good man is always a growth, both of function and of performance; and this growth is eminently dependent upon the development of the ideal toward which the growth is directed in each individual case. Being good is no general undefincd sort of a thing; functioning virtuously is not an abstraction. The good man is a good father, a good son, a good brother, and a good citizen or member of the particular social organization in which his daily life is placed; and, as such a good member of society, he is a good daylaborer, a good shopkeeper, a good teacher, lawyer, doctor, or what not-using the word "good" always in its ethical significance. Into this kind of moral goodness he must grow by experience, just as truly as into the excellent skill or learned technique of his particular calling or profession. But back of, and down below, all this is the fact that the very functions in which every form of virtuous living consists are all subject to development. 
The more specific activities in which the essential morality of action consists are apt to develop later than those necessary to the mere form of the action itself. The feeling of obligation, for example, is necessarily preceded by a considerable development of the pleasure-pains and of the lower and less complex forms of affection and emotion. The appreciation of the worth of resisting the impulse to steal an orange comes later than the appreciation of the value of the orange for its pleasure-giving sensuous qualities. It requires more growth in self-determination to resist the tendency to cowardice in consideration of motives presented by the idea of a virtue called courage than to let one's self be determined by the struggle for supremacy of two conflicting forms of fear. And the stage at which intellect and imagination must arrive in order to construct even a relatively low type of the Moral Ideal is a higher stage than that which makes possible the anticipation of pleasure or pain on account of some imaginary condition of a physically ideal sort. Cinderella and Blue Beard, or any of the tales of the Arabian Nights, awaken the picture-making faculty at a much lower level than that to which the spiritual purity of the Virgin Mary, or the self-sacrifice of her Son, the Christ, appeal. Whoerer throws himself wholly into the arms of the Virtuous Life, whoever makes his constant aim the realizing of so exalted an ideal, must endure a strain upon his Time-consciousness and Self-consciousness, in order to find rational justification for such a deed of will, which considerably surpasses that required for the mastery of the higher mathematics or the physies of the solar system.

To these less obvious considerations may, of course, be added the entircly commonplace remark that growth in virtue comes only through the practice of virtuc. Of course, as everybody knows, the only way to be good is to become good; and the only way to become good is to practise being good. 
Scarcely less important but much less obvious is the truth that the Ideal of conduct and character toward which the good man shapes his course, is itself a matter of growth and development. No other forms of psychoses are so manifestly subjective as are the ideals of men. Their perceptions are popularly thought of as copies of somewhat permanently existing extra-mental realities; and there is warrant for this mistaken thought in the very nature of the mental processes which are called perceptions. So, too, are those conceptions which are formed by logical functioning upon a basis of concrete experiences considered to have some correlate in the world of actual existences. But how stands the case with human ideals? Are they not mere dreams of what might be, entirely unlike perceptions and conceptions in that they are devoid of all correlates in Reality? Must it not be confessed of the good man, as of the Idealist of every sort: -

"That type of Perfect in his mind

In Nature can he nowhere find,

He sows hiniself on every wind?"

I am not seeking at present the answer to so vast and difficult a question, although it raises the ultimate problem of a philosophy of conduct. The existence of the ideals which are formed by the conscious activity of good men is at any rate a fact of experience. Moral ideas are persistently recurring facts, - of such a nature, too, that without them and what they imply as to man's constitution and history, there would be no problem of conduct for ethics to try to solve. And for every individual his own ideal-howerer low and fragmentary or lofty and relatively complete - is subject to change and development. Besides all this, it is truth of fact that the good man finds his ideal growing faster than his own growth in the ability to actualize it. To other good judges and, if he will only be reasonable in judgment, to himself, he may appear to be making no inconsiderable 
advances in the practice of the particular virtues; his motives may be growing purer and his intentions wiser; but at the same time he is likely to seem further than ever from realizing his own ideal. This is because his ideal of the Self to which lie owes allegiance has advanced faster than has his real Self in the actualization of that ideal. Hence the beautiful and profoundly true words of Rückert:-

Vor jedem steht ein Bild des, das er werden soll;

So lang er das nicht ist, ist nicht sein Friedte voll.

Doubtless something similar, as applied to the different social organizations and eren, in a way, to the entire race must be recognized as true to the facts of history. Certain large sections of mankind - notably, the Chinese, for example - have remained for centuries well satisfied with the moral ideal which has "set the pace," and marked out the path, for the people in their ethical development. All nations show their national characteristics respecting the self-satisfaction of an ethical sort which they habitually feel. But neither in the case of the multitudes, nor in the case of individuals, can this satisfaction with the existing ideal be considered as a sure sign of moral advancement. Neither for the people, nor for the individual, is the habit of patting one's self upon the back and congratulating one's self on one's own virtuousness a sure sign of the real possession of a rirtuous character. A certain noble dissatisfaction belongs, the rather, to the best among individuals and among nations. And at the present time, the large amount of pessimism current among the most enlightened and conscientious of the morally most progressive peoples is, undoubtedly, a sign of two truths which are seemingly, but not really, antagonistic. First: The Moral Ideals of humanity are rising, and this is the canse of that noble dissatisfaction with existing moral conditions which they who do not feel, have no right to be considered good men; but, second, the actual conduct of men 
is far below their ideals, perhaps farther below now than ever before; and this, too, is the cause of a sad but not discouraged dissatisfaction. The former is a hopeful sign, a forerunner of a coming age of ethical improvement. The latter may mean either Yes, or No, to the question: Is the world growing better? according to what part of the world one regards and how one estimates this "growing better." Everywhere and in all times, for the individual and for the race, the growth of the Moral Ideal is an indispensable cause and accompaniment of all moral progress.

And now it would seem inevitable that every psychological and ethnological discussion of ethical problems must have a most astonishing conclusion. And, indeed, the inevitable logical conclusion of empirical ethics is most astonishing. For the whole discussion leads to apparent practical contradictions, if it does not end in confusion. Indeed, if the word were not so certain to be misunderstood and its implications abused, I should not hesitate to maintain that the psychological and ethnological study of the problem of conduct ends in "antinomies." These are not, however, real metaphysical antinomies of the Kantian order, because neither one of the apparently contradictory propositions which compose them can, in any case, be given the form of law (a nomos) that is founded upon a truly scientific handling of the facts. Let us say, then, that unless philosophy can in some way get behind, or underneath, the conditions in which a descriptive and historical survey of the Moral Self and the Virtuous Life leave the subject, the good man, when he sceks in ethics a guide to conduct, is left hopelessly in the dark as to the real significance and worth of the Right, and hopelessly at odds with himself, with his fellows, with his environment, and with the World of Reality.

I will now briefly state several of the principal forms of conflict, or antithetic situations, which have been disclosed by the detailed study of ethical facts and ethical laws. 
First, there is the conflict between the sentient self and the moral self. Man is constituted so that his pleasure-pains have value for him; indeed, it is difficult, if not impossible, to conceive of any form of conscious existence in which pleasure and pain should not be constituents of, or essentially connected with, ideas of value. Conduct, for the worth of its own which it seems to possess, is dependent in large measure upon its concomitant and sequent effects in the way of pleasure and pain. To be regardless of the happiness of others, if not of my own happiness, is ecrtainly immoral. Justice, wisdom, kindness, sympathy, and benerolence, if not also courage and truth, would have no meaning in a world composed of non-sensitive beings. But man is not simply a sentient self, he is also a moral self. And whaterer the most subtle and refined arguments of Hedonism or Utilitarianism may have to advance, the interests of the two selves, or two sides of the one Self, are by no means obviously identical throughout. Indeed, everything that psychology and ethnology have had to disclose regarding ethical facts and laws has gone to show that, neither by the individual nor by the race have these two elasses of interests been regarded as essentially and always the same. On the contrary, the history of the individual and of the race is full of conflicts between the two classes of interests. The essential characteristic of the good man has come to be that the moral self shall largely triumph orer the sentient self. And yet the sentient self remains - always an integral part of the moral self. Hence the eonflict ever remains; it must be perpetually renewed until some sort of a reconcilement can be effected.

But the sentient self and the moral self are both perpetually in danger of dereloping an internal conflict. I take pleasure in seeing others happy; but if I am to have this pleasure I must often - perhaps usually would be the better word for most persons - gain this pleasure at the expense of 
other pleasure. But for the sentient self to calculate its own interests in terms of the value of pleasure-pains brings about many a conflict; whereas a perpetual calculation of this kind is distinctly prejudicial to all genuine morality. Again, if I am to be truly moral, I must often regard in others something much more highly than their happiness;but frequently nothing is more disagreeable for both parties to the transaction than for one human being, no matter how wisely, to undertake to improve another's character.

Second: There are almost unceasing conflicts among the virtues themselves. All the most eardinal virtues have been found to be relative and necessary to modify or supplement one another; and yet it seems quite impossible to discover any one supreme virtue entitled to absorb them all. Hence life is full of conflicts of duties which are as real as any of the most intense but indubitably human experiences can be, and which are not to be escaped by resort to abstract theories that a priori demonstrate their impossibility. And, besides, although we refused on good grounds to accept the common division of virtues into the self-regarding and the altruistic, there can be no doubt that constant conflicts arise between a dutiful regard for one's own interests and a dutiful regard for the interests of others. It is vain to deny the fact of these conflicts; it is a kind of solemn mockery to offer, in solution of the problem they afford, a mathematical theory which regards the whole of society as so many in number, "each to count as one," or any abstract conception of the race as a lump-sum of spirits, so to say, of which each individual forms only an insignificant portion. I may be in duty bound at one time to consider myself as worth more than a hundred others of my fellow-men; at another time I may be bound to sacrifice my life freely in the behalf of one poor specimen of this common humanity.

Much as is now being said - some truth, some travesty of truth, and some horrible falsehood - about the social organ- 
ism and its worth, etc., the side of the individual's duty to guard against the encroachments of socicty his own higher and nobler Self can never be neglected without grave danger to the most fundamental moral interests. The "good few" have rights; and they are bound to guard these rights even in the interests of the few good. And nowadays, when the popular sneer is so often against those who will not lower their staudard of ethical excellence in the interests eren of society, the individual may be compelled to stand alone with God, as "holier" than they, against the multitude of his fellow men. No matter; for the good few always represent the ultimate Moral Ideal better than do the majority. And in this and all kindred cases, how shall the good man know whether, in his supreme regard for his own better Self and for the absolutely Holy One, he is not also acting in the best interests of society? His ideal must be his own highest and best Self; his ideal must be one that is practicable in the actual society of which he is one member. Will he do harm by opposing the majority, and perish for his presumption, or lose all influence on account of his seeming arrogance? Or will he succed in doing something worth while for other men while regarding so highly his own absolute standard? God knows; but who among men can tell? The conflict is inevitable in the good man's life; and no form of socialistic theory, and no amount of respect for the rules and opinions of society, or even of more rational regard for the higher social interests, will enable him to escape this conflict. Indeed, the good man's own high ideal of what he himself would be, constitutes at times an almost irresistible temptation to disrespect for the "herd" of men, with their low estimate of moral values, and their yet lower practice of virtuous living.

And, finally, there is the eternal contrast, which so often issues in conflict, between the actual realization and the real Ideal. Why should the torment of the ideal be so felt 
by the men who would seem least to need it? Why should the whole race seek a moral good, which they do not understand or really appreciate, but which comes to them in fitful glimpses of fragmentary shapes?

\section{"Heaven opens inward, chasms yawn, Vast images in glimmering dawn, Half shown, are broken and withdrawn."}

For this ideal is not one of bodily comfort merely; it is not the Utopia where all are rich, and healthy, and wise enough not to desire more than is neecssary for a happy life. It is an ideal that takes conduct and character into the account, in such fashion as to make its realization without righteousness intrinsically absurd. But as material, and even moral conditions go on improving, the Moral Ideal scems little or no nearer realization under the improved conditions. For IT has risen while the conditions have been rising; its demands, therefore, now seem more difficult of fulfilment than they were beforc. Or, at least, they would seem more difficult, and even impossible of fulfilment, were it not for that strange hopefulness which somehow characterizes most of the individuals and the peoples who are most bent on setting moral principles into realization as a practical affair.

Such conflicts as these lie athwart the path of the good man - the more frequent and intense, the higher his ideal and the broader and more influential upon society his sphere of action - in his effort to lead the life of perfectly virtuous conduct under existing natural and social conditions. Such difficult questions of a practical character come before him for solution by his moral tact. The attempt at a theoretical treatment of these ethical antinomies (?), and of the problems which grow out of them, is the task of speculative ethics in the form in which we now turn to it our attention. 



\section{PART THIRD}

THE NATURE OF THE RIGHT 
"From Thee all things come; in Thee all things subsist; to Thee all things return. And so I say of the World: Dear City of God."

Marcus Aurelius. 


\section{CHAPTER XIX}

\section{THE ULTIMATE PROBLEM}

WE enter upon this final stage of the investigation of topics in ethics with a number of questions still unanswered which appear to be of the most important theoretical, if nut practical, character. It would seem highly desirable to gather these questions together and to give them a sort of unity, which may serve as a guide and a goal to further investigation. Can the problems which an empirieal ethics leaves unsolved be so stated as at least to constitute the terms of an ultimate problem in the philosophy of conduct? And if such a statement be found possible, what method of research may be most hopefully employed in the effort to find a tentative and fairly satisfactory solution of this ultimate problem, - "tentative and fairly satisfactory," I say. For, if biology is constantly finding the lower life, with all that it implicates as to its origin, laws, and destiny, more and more of a mystery, and the wonderful array of new facts is so far outstripping the utmost energies of science in its effort to give the facts a complete explanation, it is small wonder if the higher life of the Moral Self, and the evolution of morality in the race is found to be equally mysterious. If the biologist or anthropologist confesses with becoming modesty his inability to deal with the origin and nature of physical life, no student of ethics need be over-confident in his attack upon the ethical problem, or scorn and underestimate the help which metaphysics and religion have to offer. For, indeed, biology, psychology, and anthropology, by their combined efforts, seem scarcely com- 
petent much to illumine this ultimate problem. Indeed, we shall soon see that our only hopeful resource is to metaphysics and to religion.

In this chapter I shall make the attempt simply to state the ultimate problem of the philosophy of conduct, and briefly to describe the means which offer themselves for its best possible solution. In a word, the ultimate problem of ethics concerns the essential and permanent relations in which the ethical life and ethical development of the individual man and of the human race stands to Reality; and the conception of reality here referred to must be the most comprehensive and ultimate which it is possible for philosophy to construct. The method of investigating these relations must be that method of reflective thinking upon a basis of all the data of experience concerning which philosophy uniformly employs, and in which, indeed, philosophizing essentially consists. In this particular case it will be found, I believe, that those data which are gathered from all the ideals of man and especially from his religious nature, must be chiefly taken into the account. In a word, then, only general philosophy borrowing largely from the philosophy of religion can give any, cven tentative and fairly satisfactory solution of the ultimate problem of ethics. A few words of explanation regarding each of these two claims will suffice the purposes of this introductory chapter. Their justification is the task attempted in the entire Third Part of the book.

When I say that the ultimate problem of ethics concerns the essential and permanent relations of human morality to Reality, I am using the latter term in no empty or abstract way. Above all must the mistake be aroided of setting the conception of reality orer against the actual and historical development of man in its moral aspect, or of excluding from the conception this moral development itself. Indeed, the central and essential permanent reality in ethics is this same actual moral life and moral derelopment. The progressive 
ethical life of man is the reality whose psychological characteristics and historical career form the subject-matter of ethics. This life is real; and it does not borrow, or need in order to be real, a reality outside of itself.

The fact that the Ethical Life of Humanity is really a succession of psychoses, and so, from the psychological point of view, a subjective affair, does not render it less real. Indeed, what kind of reality but a subjective and spiritual reality could morality possibly have? The dreamer, the student of the phenomena who is guilty of useless and unmeaning abstractions, is not the thinker who conceives of ethics as really an affair of the mutually dependent conscious states of selves; lie is rather the so-called "scientist" who considers morality to be really an affair of extcrnal customs and institutions, or even an affair of stone, bronze, iron, and steel, of clubs, spears, cross-bows, and ironclads. That vague conception which anthropology dubs by the title "civilization," and which it is accustomed to describe as chiefly made up of things visible and tangible, is undoubtedly both cause and effect of the ethical evolution of the race. But civilization itself is chiefly - at any rate, in its highest and most important factors - an habitual manner of the intercourse of selves with one another, and of their construction and use of those means for such intercourse which have been put at the disposal of the present generation by the achievements of past generations. Now it is just in this social intercourse that we have found the sphere of morality to lie; for morality is essentially an actual conscious life of the Moral Self in social relations with other moral selves.

But the reality of the actual moral life which history discloses, whether of the individual or of the race, is not the whole of Reality. Looking backward and outward, if not looking inward and forward (although I believe we shall have to cancel this "if not" too), the history of man's moral life is not the Ultimate Reality. Such a declaration 
is certainly true of the individual Moral Self. Character and conduct we have agreed to leave subject to the self-determination of the individual in a limited way. But the ethical constitution which makes the conducting of hinself and the acquirement of character possible for the indiridual, and makes possible as well the social and physical environment in which his moral life is begun, do not originate with the individual. All these he receives as a dependent member of the race. The race itself, however, cannot be conceired of as carrying in its life history the whole of that reality on which this history is dependent. However we may work out our problem of the descriptive history of man's moral evolution, we come to a theoretical beginning when this history is dependent for its institution upon realities that lie beyond itself. Let it be atoms, ape, or (pardon the seeming irreverence!) God, the case for philosophy is not essentially changed. The Reality, which is from the point of view of time-consciousness more Ultimate, must be thought of as containing within itself the potentiality of all the surprising moral evolution of mankind. The origins of that reality which is the actual moral life of the race must either be left in mid-air, or found in the atoms and the lower animals, or credited to the Absolute Self. For this real life is a part of the larger Life; this reality of man's moral life and moral development begins in, and is encompassed by, a larger Reality.

Nor do I believe that it is necessary to follow the dull, mechanical "rattling of the chain of causation," physical and biological, back in imagination to the beginning of things, in order to feel the imperative, the supreme need of grounding one's ethical theory in a certain conception of Ultimate Reality. It is confessedly an impossible kind of a task to try to discover the satisfactory reasons for a feeling of obligation, and for a judgment that bears in itself a claim to authority and to incontestible sanctions, as a part of the most ultimate conceivable knowledge (if we had or could ever hope to have 
such knowledge) of the nature and laws of physical existence. Nor do I see llow the difficulty of the task is lessened by putting in between ourselves and the material elements countless generations of animals with pleasure-pains resembling ours; albeit with more or less likeness of appetites, impulses, desires, and social interests, besides. But whether the holy light which surrounds the sanctions of the Moral Ideal began in a twilight that was indistinguishable at first from the darkness in which all things are black, or struck into the world of real experiences at some instant like a faint flash of lightning, the ultimate problem of ethics remains unchanged. How shall the world of moral life-human or animal - be accounted for as a dependent part of the world of Reality? This moral life is an actual psychological and historical development. How shall it best be interpreted and explained in its relations to the Totality of which it is an undoubted part?

Inasmuch also as this moral derelopment, like every other development, looks forward as well as backward, and raises problems as to its goal, as well as problems as to its origins, etlics cannot aroid questions of the destiny of the individual and of the race, if it wishes to treat satisfactorily its own ultimate problem. All explanation is teleological and has reference to an end to be realized. Especially and most obviously true is this of the phenomena with which ethics deals. Its end to be realized is a form of the Good, which is most intimately related in all the systems of interconnected real existences and actual events with every form of good realizable by man: and yet the ethical good seems to have its spccial characteristics and its own conditions and laws of realization. How then can ethics solve its most fundamental problems in a satisfactory way unless it consider the ends that are sought, attainable, and actually attained, by human conduct. And here what is true of the individual in the small is true of the race in the large. It is impossible to explain the 
ethical meaning and the forward-running effect of the good or bad conduct of the individual without reference to the relations of the individual to the future generations of men. Yet to justify the individual, from the point of view of moral reason, in sinking his own immediate and more pressing interests in the future welfare of others, some sort of an appeal must certainly be made to a teleology which rises to a higher plane than that upon which stands the merely sentient nature of man. Besides all this, moral reason demands that one should raise some such question as the following: What sort of good for others in the future am I bound to seek, or even justified in seeking, at the expense of good to myself? And what pieture shall I frame of that Ultimate Good, for myself, or for others, or for all, that will connect the entire moral evolution of mankind with the unceasing and universal ongoing of the World of Reality? Or must one leare both ends, the origin and the goal, as well as all that is most interior, of the moral evolution of man in the darkness of doubt and nescience? Must the philosophy of conduct end with this confession?-

"There was the door to which I found no key, There was the veil through which I could not see, Some little talk there was awhile of Me and Thee, And then no more of Thee or Me."

But since the essential thing about morality is its peculiar judgments of worth, and the way these judgments arise, assume a position of command, and define for the Moral Self the course and final purpose of the Virtuous Life; and since such judgments radiate from, or concentrate themselves upon a certain Moral Ideal - the truly right conduct of personality as a member of a social organization - the ultimate problem of the philosophy of conduct may be said to concern the origin, sanctions, and teleological justification of this ideal. This is, however, to say that some rational and eternal relation must be established between the Moral Ideal and the Ultimate Reality. 
Put in the form of a question, the ultimate problem of ethics reads as follows: May that Being whom philosophy knows as the Absolute or the World-Ground be so conceived of as to afford the source, the sanctions, and the end of Morality? Or, more brienly, how shall the Moral Ideal be so united with the Uitimate Reality as to find in IT its Ground? The same problem which the metaphysics of ethics proposes in this way, religion solves by affirming (rod to be the source, the judge and defender, the goal and guaranty, of that virtuous living which has for its aim the realization by moral selves of the moral ideal.

Surely the answers to such questions as these constitute an important problem for the student of the philosophy of conduct. And whoever carries on his study of this branch of philosophy with the moral earnestness and scientific thoroughness which befit the theme cannot consent to be satisfied with that state of practical antinomies and consequent theoretical agnosticism in which psychological and anthropological ethics. inevitably leave the mind. Above all other forms of life the moral life should serve to impart a desirable unity to experience. To have either the theoretical consideration of moral principles or the honest attempt to set them into practice result in a permanent and hopeless schism in human nature would be a discouraging and sad result indeed.

$B_{y}$ what mothod, then, may one most hopefully proceed in the further treatment of this so-called ultimate problem of ethics? The very nature of the questions which combine to constitute the problem suggests the method. The questions have to do with the evolution of moral selves in their natural and necessary relations with one another, under the different forms of social organization. Whence does the moral life come? Whither does the moral life tend? What sort of real world must that be in which such a striving after an ideal good has its so important and essential place? And what, as further described or defined, is the larger nature of 
that ideal, the Ultimate Moral Ideal toward which the moral evolution of the race is on its way? These questions concern the origins, the authority and sanctions of the regulating laws, and the destiny of man's ethico-social development. Their answer requires such a conception of Reality as furnishes to reason the most satisfactory form of knowledge - or, if knowledge be impossible, the most rational form of belief - respecting this development. These are questions of general philosophy, and especially of the philosophy of religion; and they must be attempted by the method which is legitimate to philosophy. This is the method of reflective thinking upon the broadest possible basis of experience as scientifically construed.

The different so-called "schools of ethics" have from time immemorial dealt with one or more of the features of the more comprehensive problems of human conduct. Some of them have attempted simply to confine their consideration to what experience tells us concerning the ethical development of the individual, or of the race; they have been satisfied with such a descriptive history as could be told in terms of fact. With them the most important inquiry has been, whether happiness is the one form of good that must be sought by human conduct in accordance with the constitution of human nature and its conscious reactions upon its environment; or whether virtuous conduct should be sought as having a worth of its own. But this is chiefly a psychological question; and it should never be confused with the more ultimate metaphysical problems which psychology and anthropology leave unsolved.

A genuine and comprehensive metaphysics of ethics seeks to ground in Reality a rational basis for the origins, sanctions, and results of conduct and of moral development. It is this in which even the multitudes of common men are truly interested. For them the disputes between Utilitarians and Intuitionists are matters of merely academic concernment. 
They recognize the truths to which both appeal; and they can detect those misses of the truth of which each school justly accuses the other. What they most want to know abont, however - or, at least, to have some opinion or faith about - are such problems as these: Is the world a moral order, or a machine driven onward by blind forces, and blind to its own fate? Whence come the sanctions of the so-called moral laws, and who is going to enforce those sanctions, if I can manage to disobey and to escape my follow men, or even to profit by disobedience? Who but a lot of impracticable theorists issues the demand that I shall do what I do not want to do? And, what is going to come of it, any way, in the long run, in the far-away future, for me and for the race? But these are the questions of a metaphysics that must pay regard not simply to the physical and natural, or to the psychological sciences, but also and chicfly to the faiths, fears, and hopes, of the religious nature of man. They are proposals to extend that essential, rational, and inevitable anthropomorphism, on which all scientific knowledge of the World is based, over into the sphere of ethics and religion, with a view to unify one's entire working theory of nature and of human life. 'That is to say, they are inquiries as to whether what psychology and anthropology fail to do for ethics and religion, the spheres in which man's realest interests move, cannot be accomplished in some other way? The popular demand is for a view of man's origin, nature, and destiny, which will do something worth while in the way of bridging the chasm between truths of fact and those ideals that seem to have an absolute worth.

And the people are right - and by "right," I mean both rational and ethically justifiable - in making this demand. Moreorer, no matter how much of studied effort the schools of ethical theory may make to keep their contentions clear

1 For the proof in extenso of this, see my Philosophy of Knowledge, and A Theory of Reality, throughout. 
of general philosophy, and of those problems with which the philosophy of religion concerns itself, they never succeed in doing this. Some view as to the nature of the Absolute, and as to the relations toward the Ultimate Reality in which the moral life of man stands, as respects its origins, laws, development, and destiny, every theoretical treatment of ethical problems must either explicitly avow or implicitly involve.

While, then, I shall make no pretence of an effort to avoid the discussion of topies which compel one to go beyond where ethics, empirically considered, would counsel one to stop, I shall take the path to this discussion which lies through a criticism of the different schools of ethical theory. To classify these schools at all strictly is impossible; their points of agreement and of disagreement are nowadays too numerous, and the paths that connect or diverge from them are too complex for a strict classification. For purposes of convenience they will be considered under three classes, namely, Utilitarianism in Ethies, Legalism in Ethies, and Idealism in Ethies. The criticism of these schools and the establishing of my own conclusions positively will compel me to borrow - often without ealling attention to it - much from what seem to me truths of general philosophy; as well as to anticipate some things which a detailed treatment of Asthetics, but more especially of the Philosophy of Religion, would be necessary to establish. 


\section{CHAPTER XX}

\section{UTILITARIANISM IN ETHICS}

THE modern ethical theories which go by the name of "Utilitarian" differ from the ancient Hedonistic theories, whose descendants they are, in two or three important particulars. Of these the most important, perhaps, consists in the modification which they have received from their connection with modern views as to biological evolution, and from the application of the principles of such evolution to the phenomena of human life. But, as will appear in the eourse of discussion, whatever light of truth the biological doctrine of evolution can throw upon man's ethical development is really no more favorable to the hedonistic elements of Utilitarianism in Ethies than to other distinetly antithetic forms of ethical theory. Indeed, writers who, like Mr. Herbert Speneer, insist most strenuously upon a close amalgamation of Utilitarianism and Evolution often seem singularly deficient as to insight into the real difficulties of the problem they are trying to solve.

Modern Utilitarianism also differs from both ancient and more recent Hedonism as respects the way in which it is accustomed to eonstrue such coneeptions as pleasure, happiness, the good, ete. And this difference is largely due to a historical growth in the complex conditions of what men generally regard as necessary for comfortable and happy living, or even for an existence that is deemed barely tolerable. Here again, however, there is not infrequently apparent an inerease of confusion, rather than of elearness, 
in the psychology of pleasure-pain states (or of happiness in general and in particular), which grows out of a failure to seize and hold fast the permanent elements that enter into a problem of so much complexity. The relatively large importance and range given by the current Utilitarianism to those virtues of feeling so-ealled, which have a peculiar relation to human pleasure-pains - such as kindness, pity, sympathy, ete. - may be said further to characterize certain changes in the prevalent ethical opinion.

But in spite of these important differences, and of all the conceivable as well as actual minor differences, the essential contentions of a certain school of ethies have remained unchanged throughout. I have given to this school the name "Utilitarian" rather than "Hedonistic," because the former term seems better adapted to include the latter, than does the latter to include it; moreover, there are some writers of this school who object to being called Hedonists, - as though something not so exeellent ethically were implied in this word. ${ }^{1}$ But Hedonists, Utilitarians, and certain writers who adopt still different terms for their theories, hold essentially the same view respecting the answer to that ultimate problem which it is proposed now to diseuss. They hold that the life of man, whether of the individual or of the race, is an end in itself; and that its own happiness is its final and all-inclusive end. In a word, they all maintain that the criterion, the sanctions, and the rational end of conduct and of character are to be found in human happiness. From this conclusion it follows, first, that the reason which entitles any particular kind of conduct or type of character to be called morally good (virtuous) must be found in its useful-

1 Professor Watson is undoubtelly true to the facts of history when, in his treatment of "Hedonistic Theories," he includes J. S. Mill and Spencer with Fpicurus, Uobbes, Locke, IHume, and Bentham; while Thilly (Introduction to Fthics, p. 72 f.), in grouping together writers who accept some form of the Evolutionary Theory, has included with Spencer, Leslie Stephen, and von Gizycki, those who differ so widely from them as Wundt, Simmel, and Alexander. 
ness as a means to happiness; second, that the obligation to right conduct depends upon its utility as productive of happiness; and, third, that the rational ideal, set up and striven for by the individual and by the race, is the utmost possible of happiness. In a word, moral good is instrumental; it is good because it is of utility toward the attainment of other good.

To the student of the philosophy of conduct, who traces the history of the utilitarian view, the cardinal and decisive importance which belongs in its arguments to the conception of happiness is the most impressive phenomenon. But no other point in psychology, whether popular or scientific, has been left after so much discussion in a state so indefinite, so unsuitable to serve as the basis of a theory, as the conception of happiness. Indecd, I am inclined to doubt whether the academic notions which are generalized under this term have not often stood for experiences which mankind can scarcely recognize as having any considerable influence upon their actual lives. It is true that as a stricter psychological theory of human pleasure-pains has gradually been erolred, and has come to be more insisted upon by those critically disposed toward all ethical theories, a certain tendency toward general agreement has appeared. Thus, to quote from Paulsen," "In his Ethics Gizycki modifies the hedonistic theory as follows: The highest subjective goal of life, he says, is the satisfaction produced by the consciousness of having done the right, or the fecling of a good conscience. Döring agrees with him when, in his Gïterlehre, he defines the highest good as the proper regard for self, or the satisfaction of the desire for individual worth. - We see thus that the difference between the various conceptions of morality may be practically insignificant or may entirely ranish, The question is a purely theoretical onc." What we do see is, the rather, that practically significant and theoretically

1 A System of Ethics, p. 286. 
important questions in ethies may be handled with so much lack of psychological analysis, and so much confusion of terms, as to identify things essentially different, and make imposing distinctions in things essentially the same.

While, then, it is, of course, impossible to discuss the entire psyehology of the subject, some remarks seem indispensable, from the more disinterested and purely psychologieal point of view, upon the coneeption of pleasure or happiness, and upon the relation sustained by pleasurable and painful conscious states to that total activity of the Self which ethies considers under the name of conduct.

And, first, when men speak of Pleasure or Happiness, they are always dealing with the feeling aspect of conseious proeesses or states; and this constitutes a factor of human experience that can be actualized only in a subjective and strictly individual way. This universal psychological truth must not be overlooked or covered up in the interests of any theory, hedonistic or anti-hedonistic, eudæmonistic or utilitarian. Pleasure, happiness, enjoyment, even bliss - whichever one of these words is employed, and whether other terms are derised to suggest and secmingly to warrant some modification of the coneeption, or not, an element which remains substantially unehanged in them all must be distinetly recognized; and this element must not be confused with other essentially different elements that are quite too often introdueed in order to produce a false appearance of breadth and depth to the foundations of the ethical theories based upon them. This element, always substantially unchanged, is that purcly subjective feeling-tone which psychology treats under a theory of pleasure-pains.

But pleasure-pains are not entities; neither are they general notions, whether academic or popular in their logical construction. They have no existence except in concrete, individual experiences; to be actualized, or brought into being, they must be experieneed; to be experienced, they must 
be - not thought or thought about, but felt. For one man to tell another that he ought to be happy is not to make him happy; nor does assuring the wrong-doer that he ought to be unhappy necessarily increase his unhappiness. To proclaim the comforting (?) doctrine, "Be good and you will be happy," does not alter the matter-of-fact experience of every man that, in his own case, and in multitudes of other cases moral good: ness and happiness really do not go hand in hand; - while to say to men who are consciously unhappy that they are really happy, or to those who feel their own lives to be a suecession of pleasant states, that they are really miserable, is, so long as one does not covertly introduce distinctions of another order, a performance which would be always amusingly impudent were it not so often desperately embittering. All conscious states, quoad their pleasure-pain qualification, are essentially of one order; and that order cannot be determined by the advice of the moralists, or altered by the pronunciamento of the psychologists. It really is what it is to the one whose state it is - pleasure or pain, happiness or unhappiness, enjoyment or misery ; and no one else's conception of "ought" or "ought not," of "real " or "illusory," so long as it is simply the character of the fecling, and of its pleasure-pain tone which is under diseussion, has anything to do with the true nature of such experiences.

From this it follows, in the second place, that any judgment as to the intensity and the value (as pleasure or happiness) of all pleasurable or painful, happy or unhappy, experiences, is also subjective and individual. As the feeling itself cannot be rendered into conceptual form so as to transfer it from one consciousness to another, so the quantitative and qualitative estimate of the feeling cannot be made permanent and universal by another's thought. Every soul knows its own joy as well as its own bitterness - how great it is, how unsatisfying or otherwise it seems; and which form of either joy or sorrow is most approved or most 
dreaded in its own sight. As long as the observer maintains the strictly hedonistic or eudæmonistic position, all questions of preference and of estimated value are questions strictly of fact. Without abandoning this position one has absolutely no right to say for another that the pleasures of poctry are preferable to push-pin, or that the happiness of a life of wise self-sacrifice exceeds that of a life of not too excessive but morally unscrupulous indulgence of the sensuous appetites. One must somehow get out of the hedonistic or utilitarian position; or else one is compelled, in the seeming interests of eternal moral truths, to be constantly telling lies about the actual experience of mankind. If $\dot{A}$ actually prefers drinking beer to psalm-singing, or getting and spending money immorally to leading a poor but honest life, or pandering for success to the lower standards rather than preserving the consciousness of laving followed a high professional or artistic idcal, $B$ can never persuade $A$ to truly virtuous living simply by reciting the greater and superior pleasures that charactcrize $B$ 's consciousness. The judgment which prefers the pleasure a to the plcasure $\mathbf{x}$, quoad pleasure, is a subjectire fact, and that is all there is of it as belonging merely to the sentient self. When the indiridual intelligence attempts to stick by the standard of happiness, its quantity or kind merely, and at the same time masquerade as rational and talk about what is unirersally noble and what is ignoble, it makes itself ridiculous.

And, third, so far as personal experience and observation of others ean teach one, it does not appear that the habit or quality of men's moral consciousness is ever the chicf determining factor in their experience of pleasure-pains. One may not be greatly tempted, indeed, to adopt off-hand the cynical maxim that the chicf conditions of human happiness are, like those of the pleasures of the lower animals, "no conscience and a good digestion." But as the arerage man is constituted and situated in the present world environment, the 
conditions of happiness are, so far as they reside in the individual, undoubtedly physiological and temperamental rather than ethieal and spiritual. When men of widely separate elasses or stages of derelopment contemplate each other objectively they are apt to form entirely crroneous conceptions of the pleasure-pain experiences of onc another. Anthropology is just now depicting the desperately miserable condition of primitive man, as he struggled perpetually for a scanty existence against the forces of unsubdued nature, against horrid cold and leat, wild beasts, and the invisible terrors with which his imagination peopled the air and waters and skies. Undoubtedly this wholesale conversion of external conditions into conscious miseries is largely weak sentimentalizing. The modern anthropologist writes all this, sitting in his well-warmed room and in his well-cuslioned chair, and with the pleasurable anticipation of the renown and reward in royalties which his labors will bring to him. Perhaps he reads his finished paper before a group of "society" ladies who, before they go to their elegant luncheon, add this small bit of Weltweh to their accumulated stock of sufferings, at once sympathetic and self-complacent. But his brother man who dwelt with the care-bear and the rhinoceros as his constant companion would probably, could he read the anthropologist's book, not at all recognize the picture as corresponding to his subjectivity, however objectively valid. It is altogether likely that he would find more of kinship to his own soul's actual states in the words of Browning:-

"Oh, the wild joys of living! the leaping from rock up to rock,

And the sleep in the dr. $\cdot$ the hunt of the bear,

How good is man's life, river channel

All good is man's life, the mere living! how fit to employ

Of one such tribe of men, at any rate, a modern writer says: "Given freedom from disease, and a slain antelope, and there could be no merrier creature than a Bushman." I

1 Theal, The History of British Colonies, II, South Africa, p. 6. 
Eren in these latter days and more highly cirilized eonditions which are generally (but by no means surely) supposed to furnish the individual with such improved opportunities for happy living, we do not find that those who are most governed by moral considerations are necessarily the happiest. On the contrary, the healthy performance of the physiological functions of respiration, circulation, nutrition, reproduction, ete., and that cheerful but not too careful way of taking life which is so largely a matter of inherited temperament, are the possessions which, whaterer else a human being may have or fail to have, contribute most to his happiness in living. And why should one dispute those who, having all that wealth and honor and social distinctions ean confer, testify so emphatically that these goods of external living do not make them happy. If now the rery important exception be made of that inspiration and consolation which most really conscientious people get from religious faiths and hopes, I am sure that the bare consciousness of haring striven to do one's duty and to live up to one's moral ideal, taken together (as it must be) with all the conscious failures and mistakes of such a life of striving, suffices to make exceedingly few men very happy. People who are happily satisfied with their own conduct and character are usually easily satisfied. They are really getting their pleasure out of their temperament and their surroundings rather than out of their proper moral consciousness.

It would doubtless seem to most observers of modern life in the better conditions of it, a difficult and perilous thing to maintain that the good people in any particular large social organization are not as a rule the happiest; and even that their very goodness stands much in the way of their happiness. But I should be quite willing to maintain this proposition if there were any feasible way of bringing it and its counter proposition to the test of an empirical standard. Certainly the vulgar Utilitarianism which maintains that it 
is the good man's own fault if he is not happier in his own goodness, is quite often enough rather a mean way of adding insult to the injury which any form of an extreme hedonistic theory does to moral consciousness, strictly so-called.

But, in the fourth place, it is an incontestable psychological fact that all men recognize different degrees of intensity and of value in their different pleasure-pains, or happy and unhappy conscious states. Pleasures succeed pains, and then themselves give way to other pains; and mixed states, in which one can scarcely tell whether there is more of pleasure or of pain, are common enough as human experiences. Both tones of feeling rise suddenly or more slowly to a maximum and then suddenly or more slowly die away. Pleasures, as such, although they are not the original and primary objects of desire or ends of conduct, when once experienced are, unless there be some reason to the contrary, essentially desirable. But they differ in their desirable quality with different individuals and with the same individuals at different times, in an almost unlimited and seemingly lawless manner. Indeed, when we come to inquire into the grounds of this difference we find that they cover the entire realm of the objective, the physical and social, as well as of the subjective, the psychical and spiritual, conditions and aspects of the conscious life of man. Why are some persons most happy under conditions that render others most miserable? Why are all individuals so liable to change as respects the things and the activities that bring happiness and unhappiness? The Esquimaux in Central Park is scarcely less wretched than the dweller on Fifth Avenue would be if consigned to live in Greenland. Aristotle tries to commend his Eudæmonism with the conclusion "that happiness is a kind of speculation or contemplation." 1 "In this way also, therefore, the wise man will be happier" than any one else;" for "the wise man is the most beloved

2 Nic., Eth., X, viii, 8. 
of heaven; and, therefore, we may conclude, the happiest." But the arerage good citizens of England or America, and not a few of its so-called "educators," consider this sort of activity most useless and unsatisfying; and nothing would make them more miscrable than to have to spend their lives as men should who are made wise by philosophy. "Blessedness," says the "God-intoxicated" Spinoza," "consists in love towards God, which arises from the third kind of knowledge, etc. Blessedness, therefore, is virtue itself." No wonder that the philosopher closes this Proposition and his entire Treatise on Ethic with the dcclaration: "But all noble things are as difficult as they are rare." It is not with rare and noble experiences, however, that the psychology of pleasure-pains has to deal; and the Spinozistic Ethic has arrived at its conclusion by a way which the disciple of Hedonism, in its most refined form, cannot possibly follow without losing sight both of his point of starting and of his goal. For they are rare individuals, indeed, who are getting this blessedness which is virtue by liring persecuted and solitary, grinding lenses to sccure a barc subsistence, and meanwhile enjoying the contemplative love of the Absolute. And who conld ever claim to be so at home in the inmost soul of either Aristotle or Spinoza as to know that either moralist was actually enjoying the proof of his theory?

When an appeal is taken to pragmatic psychology with the inquiry after the causes of this endless rariety and ceascless changeableness in the degrees and kinds of hapyiness which different men experience and appreciate so variously, all its resources have to be ransacked to provide an answer. Prominent among these causes are the following: The inherited characteristics of body and mind, or the temperament; the physiologieal and psychical changes which depend upon age, sex, and external physical and social influences; the varying moods and fancies of the individual

1 Ethic, Fifth Part, Prop. xlii. 
or of society, so strange, unaccountable, and often whimsical, as they appear; the crer present mighty force of the habits which are, nevertheless, themselves subject to more or less sudden and often unaccountable changes; all the quick and the dead associations that cither lie close to the surface and are ever ready to rise above the threshold of consciousness, or those more deeply buried memories that a symbolic and poctical psychology is fond of ascribing to a "subliminal" or "secondary" or eren "tertiary" Self; and those profound transformations of the tastes and aptitudes, the loves and hates, and of such sourees of happiness or unhappiness as result from the most fundamental choices or from the influences of the wind that "bloweth where it listeth, and thou hearest the sound thereof, but canst not tell whence it cometh, and whither it goeth."

That happinesses and unhappinesses do differ in degree and in kind, as purely subjective and individual, there can be no doubt. Doubtless then, also, one may properly speak of different kinds of happiness that have more or less of value in the estimate of their possessors. But this difference in the kind of the pleasure, quoad pleasure, is a differenee due to the complex characteristics of the conscious state or process whose feeling-tone it is; and the estimate of the value of the pleasure, quoad pleasure, like the pleasure itself, is purcly subjective and individual. So long, then, as the criterion and the end of conduct are made to consist solely in any kind or degree of pleasure, the "wise man" is he who trusts his own estimate of what is most and best (that is, in fact, preferred by himself) among the attainable kinds of pleasure.

Accordingly, fifth: From the hedonistic or utilitarian point of view, so long as one remains faithful to the actual facts of human experience, one can never make distinctions in pleasures or happinesses that have in them any other worth than that which they actually derive from the prefer- 
ence of the individual whose states they are. To speak of higher and lower pleasures, or of noble and ignoble pleasures, or of pleasures in which one ought or ought not to indulge, is at once either to falsify the psychological facts or to overleap the utilitarian point of view. And here ethies must beware particularly of the confusion which results from introducing distinctions of moral worth into terms that are to be employed subsequently for the express purpose of dissolving or changing the nature of these same distinctions. For this reason I cannot approve even of the very guarded remark of Professor Seth:" "But we must distinguish, as Aristotle did, between happiness and pleasure." For Aristotle failed to carry out this distinction, as indeed from the nature of the case, he was sure to do; and the very effort to make the distinction introduced a confusion into his entire ethical system which his pupils and critics have never been able to eradicate; nor will they ever be able to eradicate it, because the confusion is an integral part of the system as it was left by its author. Nor can I approve of the distinction which the author just quoted borrows with approbation from Professor Dewey 2: "Pleasure is transitory and relative, enduring only while some special activity endures, and having reference only to that activity. Happiness is permanent and universal." For one would tell the truth of fact quite as well if, in these sentences, one interchanged the words pleasure and happiness; and it is not true of either happiness or pleasure that they are separable, in fact, from special activity, or ever "permanent and eternal." And when the theory goes on to say that "happiness is the feeling of the whole self as opposed to the feeling of some one aspect of self," it substitutes mysticism for both psychical facts and ethical prineiples. Aristotle's conception of happiness is particularly guilty of the same confusions as those

1 Ethical Principles, p. 209.

2 Psychology, p. 293. 
which distinguish modern Utilitarianism. With him, happiness is equal to the excellence of the Virtuous Life plus a considerable amount of such pleasures as to Aristotle's mind seemed indispensable and inseparably connected with the practice of some of the more imposing of the virtues namely, liberality, large hospitality, magnificence, and an independent position with reference to the "common herd

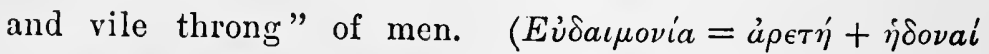
dependent upon external goods of a certain kind.)

But ethics can divide pleasures into higher and lower, noble and ignoble, or difference pleasure from happiness or even from blessedness, only by introducing into the psychological conception of pleasure-pains something from the outside. That something is a standard of moral values. In a word, the hedonistic standard must be subordinated by reference to another scale of values. Another kind of good must sit in judgment over the worth of the good which men call pleasure or happiness. This judgment indeed changes the kind of satisfaction. It changes its kind so radically that now we are no longer considering the value of the subjective condition as due to, or consisting in, any kind of pleasure or happiness merely, but as relative to the demands and the satisfactions of a higher form of consciousness. And these demands and satisfactions do not have primarily to do with amounts and kinds of happiness as such, but with the relation in which the proposed conduct stands to the ideal of a Moral Self. That the good measured by this standard actually is, and is esteemed by men to be, another species of good, and by no means wholly identical with, or subordinate to, happiness, has already been shown in detail (see especially Chapter III). That the satisfactions of the sentient self in various relations are not identical with those of the Moral Self in social relations with other moral selves, but are rather in large measure antithetic and incompatible, has come to be the problem, in part, with which all ethical theory has to deal. 
It is scarcely necessary in this connection to discuss the relation of desire to happiness. Indeed, the historical erolution of the Utilitarian School has made clear to its own adrocates that happiness is not, as was often formerly assumed, the primary object of desire; neither is there any such psychical experience as "general happiness." Desire itself is a complex and rather highly developed psychosis. ${ }^{1}$ Its affective roots are in blind impulsive feeling. Experience is necessary of things that actually produce pleasure or pain in order to make desire definite and to guide the mind toward the ends of desire. The psychical states that are more properly called desires are therefore definite; they are desires after some particular kind of satisfaction; unless, indeed, they are species of that vague sort of dissatisfaction which is popularly called, - "Wanting something, one knows not what;" - or unless they are those primary forms of appetency with which nature has provided the human animal and which serve as eauses for his earlier impulsive movements toward some form of external good. It is by the latter class of desires, less appropriately so-called, that the infant is controlled before it has had concrete experience of the definite place of its various active functions in meeting the needs of life, or of their more precise value as connected with life's pleasure-pains.

The old-fashioned conception of man as a being that seeks happiness as his one obvious, definite, and comprehensible ain, and that differs from the lower animals chiefly in his superior equipment of ability to calculate more accurately the amounts and kinds of obtainable happiness, has perished of its own simplicity. It took no sufficient account of the many sides, obvious and hidden, of man's natural equipment, and of the many motives, springs, and estimates of value that show him to himself as a being, complex, mysterious, and suggestive of the Infinite as the Source and Goal of

1 See my Psychology, Descriptive and Explanatory, chap. xxr. 
his life. Man, as modern anthropology knows him, is essentially and universally artistic, moral, and religious. And although these qualifications of his nature do not relieve him from the demands of his sentient nature for a variety of happy experiences, but rather reinforce these demands at many points, they are significant of other claims that are never to be met and satisfied by any quantity or kind of such experiences.

If now one will keep steadily in mind the truths just stated regarding the psychological doctrine of the pleasurepains, and also what has earlier been said concerning the naturc of the Moral Self, one may, without injustice, make short work of every form of Hedonism, however subtle and well-fortified with argumentation. In its most refined form of modern Utilitarianism, it cannot explain the simplest facts of moral consciousness and moral development; nor can it help us by its conclusions and its postulates out of those distressing practical antinomies into which ethics is conducted by the survey of these facts.

From the very nature of happiness as an actual experience it follows that the assertion which makes the value of morality consist in its being instrumental to happiness cannot be maintained in an indefinite and merely general way. Utilitarianism cannot be declared satisfactory as an ethical theory, after it has established a relation of cause and effect between happiness in general and morality in general. It must, the rather, be held strictly accountable for a definite answer to the three following particular questions: (1) Whose happiness furnishes the eriterion, sanction, and rational ideal of morality? Is it the happiness of the subject of the conduct solely; or also the happiness of a few others - most closely connected with him; or of the whole of society; or does it perhaps also include the happiness of invisible sentient and rational beings? (2) When is this happiness to be conceived of as realizable, in order that it 
may afford the desired criterion, sanction, and ideal? Is it more immediately, or in the near or more distant future, or eren in the life that knows no ending? (3) What is the nature of the happiness that stands in such an essential relation to morality? Does it include all manner of pleasurepains, as these are measured only quantitatively and by the conscious estimate of the individual whose pleasures or pains are under consideration? Or does the answer provide for the establishment of a selected judicature composed of "wise men," who are authorized to decide what pleasure-pains ought to be preferred? And once more, for what reason ought others to prefer the pleasures which moralists recommend, even when these pleasures are so mixed with pains and sometimes so submerged and lost in pains that they can scarcely be distinguished as pleasures? Is the obligation to prefer them due to the inherent superiority of their pleasuregiving quality merely; or is it due to the nobility they possess on account of their connection with the consciousness of moral demands and moral values?

All these three sets of questions are differently answered by the different modifications of Hedonism, from its most crass and morally shocking forms to the forms that are most refined and captivating. I begin at the lowest levels. Egoistic and quantitative Hedonism elaims that the amount of the pleasure which the individual can get for himself out of life is the sole eriterion, sanction, and rational end of his conduct. "Quantity of pleasure being equal, push-pin is as good as poetry." It is now well-nigh universally admitted, however, that this form of Hedonism is incapable of any theoretical construction whaterer. And, indeed, it is doubtful whether any class of individuals, ${ }^{1}$ even in spite of their boasting such purity of selfish calculation, do actually make

1 As Carlyle has declared; "In the meanest mortal there lies something

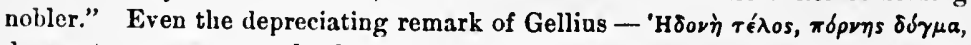
does not express correctly the truth of fact. Few prostitutes are so vile as actually to be Hedonists of this order. 
the sole principle of their conduct, the obtaining for themselves the maximum of pleasure, with a total disregard of the pleasures and pains of others except as affecting their own.

If, however, any considerable number of persons should be discorered whose consciousness gave no response to other intcrests than those represented by the amount of the subjective feeling of pleasure attainable by themselves, such persons could never serve as an empirical basis for any form of an ethical theory. All that ethics could do with such monstrosities would be to note the fact of their existence. Whereas Aristotle and Spinoza considered the noblest happiness to consist in the activity of the speculative reason, these creatures find their utmost quantity of pleasure, presumably, in some other way. But from such comparisons no principle emerges for the determination of the goodness and badness of conduct. For the point of starting shifts with every individual's experience; and, indeed, with the shifting cxperience of every individual. No criterion is attainable that even approaches the secure position where it can make a claim to generality. Much less can any sanction or ideal of conduct be obtained in this way. To tell any man that, in fact, by behaving in a certain manner toward others, he will obtain the maximum of pleasure for himself, when the same man finds himself obtaining more pleasure for himself by behaving in a quite different way, is hard enough doctrine to enforce. But to give sanctions to such adrice, and to issue it in the name of duty and for the purpose of arousing feclings of moral obligation, is to involve one's self in an absurd circulus in arguendo. And, finally, how can there be rational justification for placing the grounds of moral obligation in the maximum of each individual's own happiness when the moral consciousness of those whom the ethical judgment of mankind has agreed to call morally most worthy has been foremost in renouncing this standard of morality? 
When Hedonism lays aside its more pronounced egoistic features, while retaining the measure of mere quantity of pleasure, it presents indeed a distinctly improved appearance, but it still fails to answer the demands of a satisfactory ethical theory. The investigator can now, on the basis of experience with large numbers of men through long periors of time, make some approach to a defensible view as to what kinds of conduct and types of character conduce to the maximum of pleasures in the greatest number. Yet the standard is exceedingly, and even increasingly, complicated and difficult of application; and he is constantly in danger of falling under the fallacy that the natural conditions, the kinds of bchavior, and the constitution of society, which are conceived of as fitted to make him happy, or to make his set happy, are of like applicability to all the successive generations of men, in all grades of social progress and under all elasses of social organization. Hence, in part, the significance of the disputes that arise in so-called social science. Difficult of nice comparative estimate as the virtues of men are, their happinesses are eren in worse case in this regard. The traits of the good man are easicr to deseribe than are the conditions and circumstances which make all men happy. Persons most envied for their happy estate not infrequently commit suicide to escape from misery; and in the excrcise of the virtues of courage and fidelity, not a few have ealmly taken their own lives, or submitted them to be taken by others.

It would not be fair, indeed, to demand of this altruistic but quantitative Hedonism that it should provide ethies with such an exact standard of measuring happiness as to facilitate the prompt solution of all cases of conflict of duties. As I have already shown, such a readily arailable standard can be afforded by no system of ethical principles or code of moral laws. But the attempt to apply this particular form of the hedonistic standard-namely, the amount of so- 
called "general happiness" which the particular conduct in question will produce - is something in which no one can possibly become an expert. The rule for the ordinary man must be an uncritical following of custom or external forms from which the genuine moral quality has largely departed. In this way all the so-called virtues tend to become merely prudential; and the wider the ranges of time and greater the changes of conditions which are taken into the account the more uncertain docs all realization of the ideal of conduct become, if this ideal is so conceived as to correspond with the phrase "the greatest happiness of the greatest number."

Even more difficult is it for this altruistic, but still quantitative Hedonism to justify itself in view of the immense influence which the discipline of struggle and pain has always exereised over the moral development of the individual and of the race. In view of this influence the theory shows us the spectacle of an interminable series of somersaults which never allow the person turning them to light anywhere upon his feet. Let us suppose some good and wise man to train his family of children or his pupils and wards exclusively upon this principle. Certain virtues must be enforced by painful discipline, otherwise the entire scheme will certainly go wholly awry. This enforcement bears heavily upon the suseeptibilities for current pains and pleasures of each member of the community. What is the warrant for this disciplinary suppression of the pleasures and increase of the pains of this small community? It must be found in the interests of their relations to a larger community. But this larger community, this present generation of men and women, cannot pursue virtuously its own maximum of pleasures and minimum of pains, if the pursuit is conducted without any regard to the next generation who are to be its successors in the ethical evolution of the race. The next generation are in their turn restricted in like manner in their pursuit of the maximum of pleasures 
for them. But will the whole happy result culminate in those far-off generations of men who, having entered into the reward of the self-discipline and self-denial of us and of all their other ancestors, have attained the purely quantitative and hedonistic social ideal - the maximum of pleasures for the greatest number? Will they be able to contain, as it were, - even if they attain all they can contain, - enough of the ideal end to compensate for the accumulated pains of moral discipline and altruistic selfdenial which all the preecding generations have endured in their behalf? Who can say? And who would be willing to have the worth of his own moral selfhood, or of the present virtuous living of men, as a good-in-itself, estimated in this uncertain way? It seems to me that we are all entitled to a release from the obligation to suffer so much as respects the attainable maximum of our own happiness, if this suffering is a mere form of functioning in the interests of the happiness of others; especially where the factors of cur calculation are so remote and uncertain. And, indeed, how can we speak of obligation as resting on such a basis as this? For even if this form of Hedonism furnished an approximately useful measure or criterion of the moral quality of the individual's conduct, it utterly fails to afford a sanction for morality. As Professor Dewey has said: ${ }^{1}$ "Because all men want to be happy, it hardly follows that every man wants all to be happy." Still further: If it could be shown that all men would actually be happier, if every man wanted all, irrespective of their conduct and character, to be happy, it would by no means follow that every man ought to want all to be good, and to be happy in and through their goodness. But it is just in this form that the desire to promote the happiness of others receives its highest and most unquestioned sanction from the educated moral consciousness. The right-minded and rational regard

1 Outlines of Ethics, p. 55 f. 
for the happiness of others expresses itself in crery one of the cardinal virtues; $-i n$ courage, temperance, and constancy, in wisdom, justice, and truth, in kindness and benevolence. But the unrestricted desire to get the utmost quantity of pleasure for ourselves or to furnish it to others, regardless of moral considerations and of the effects upon the moral life and development of one's self and of society, is a vicious and not a virtuous desire. To admit such a conclusion is at once to break down all the claims of this form of Hedonism. It is to admit that, if mere quantity of pleasure distributed among the greatest number is to be regarded as the sole measure of the morality of conduct, all attempt must be abandoned to find a rational ground for that feeling of obligation with which moral consciousness regards even the most painful and disagreeable of human duties.

In a word, you cannot appeal to my reason, and get its sanctions in behalf of my denying to myself and to the little circle of friends in which I am especially interested, the most of pleasures attainable simply on the ground that future generations of unknown individuals will possibly, or probably, thereby have made a greater amount of pleasures obtainable for themselres. When, therefore, the advocate of Hedonism affirms, ' "The fact that 'I am I' cannot make my happiness intrinsically more desirable than the happiness of any other person," he is guilty of a most astonishing fallacy. For what does "intrinsically" mean in such a strange connection? Does it mean to speak of "my happiness" as abstracted from the consideration that "I am I ?" Then the statement becomes either absurdly tautological or wholly unmeaning. Or does it mean that to me, in fact (actually), my happiness is no more desirable than that of any other person? In this case the statement contradicts the psyI Compare the entire argument of Professor Sidgwick on this point, in his
"The Methods of Ethics." 
chological basis on which all forms of the hedonistic theory repose. Or perhaps - and this is the only intelligible meaning - it is the intention of the author to remind us, that in a social and moral system, where those rational considerations which are appreciated by the Moral Self are prevalent, the individual may not worthily or rightly regard his own happiness as more desirable than the happiness of " any other person." But in this case, every trace of an hedonistic position has been completely abandoned, and the altruism has been carried to an extreme which may be irrational and dangerous. Much more truth than in the sentence just quoted is there in what Crawford says in his Corleone: "Happiness that is solidly founded is itself a most negative source of the most all-pervading virtue, without the least charity for unhappiness' sins; happiness suffices to itself; happiness is a lantern to its own feet; it is all things to one man and nothing to all the rest; it is an impenetrable wall between him who has it and mankind." That is to say: The estate of Eudamonism which even Aristotle makes the end of virtuous conduct tends to separate men from sympathy with the unhappy lot of the multitude of mankind.

The irrational and even ludicrous extremes of sentiment to which the mind is driven by a merely quantitative Hedonism receive ample illustration in the history of literature. The ancient Epieureans set up the elaim that the wise man, even on the rack, is enabled to say: "How sweet," - a declaration which rivals the most extreme statements of the most ultra Stoicism, but is quite impossible to interpret from the merely hedonistic point of view. In the last scene of Victor Hugo's Hernani, where the two lovers, who have so long been separated, are at last united in death, - and this, a death of the most frightful agony, - a bystander, Don Ruy Gomez, cries: "How happy they are!" The exelamation may bear witness to an isolated fact; but if the problem of determining the virtue of such constancy as 
that shown by these two lovers were proposed to this form of Hedonism, and were decided by a calculation of the greatest amount of happiness to be got for the greater number by similar conduct, the sum in proportions would not be likely to be worked out by any sane mind to a satisfactory result. ${ }^{1}$ Over against such perversions of fact by sentiment we may set the facts that the worst criminals are rarely troubled by remorse; and that a sensitive nature like that of Heine could declare he would rather suffer a life-time of such pain as a disapproving conscience could give him than endure the pangs of tooth-ache for a single hour.

The hedonistic view of ethical facts has in comparatively recent times been made much more plausible by being complicated with two important improvements. These are (1) the proposal to establish some standard of the higher and lower values, some measure of the worth of different kinds of happiness; and (2) the addition of the theory of evolution in order to account for those actual modifications which have taken place in men's estimates of these values, and for the corresponding changes in ethical judgments, and in the accepted rating of the particular virtues and vices.

Now it cannot be denied that if one does not criticise its conception too closely, modern Utilitarianism as thus modified and fortified, is able to answer certain objections that are easily shown to be fatal to the older forms of quantitative Hedonism. Modern Utilitarianism also makes it more probable, upon an empirical and historical basis that in the long run and in the large way, a coincidence may be

1 Of the principle adopted by Hedonism of the mixed social and quantitative order, as a rule of conduct admitting of practical application, Dumont says in the Discours preliminaire to his Traités de Législation the following: "Pour avoir une connaissance précise du principe de l'utilité, il a fallu composer une table de tous les plaisirs et de toutes les peines. Ce sont là les premiers éléments, les chiffres du calcul moral. Comme en arithmétique on travaille sur des nombres qu'il faut connaitre, en législation on travaille sur des plaisirs et des peines, dont il faut avoir une exacte énumération." What a hopeless task such a table offers to psychologist or to legislator! 
established between the welfare which the Sentient Self craves - namely, the welfare of happiness - and the welfare which the Moral Self demands and appreciates, - namely, the realization in conduct and character of an ideal personality. This is indeed a very ancient truth, and has of old been tanght with relatively little parade of scientific apparatus: "Say ye to the righteous it shall be well with him;" and "It is righteousness that exalteth a nation;" - these and similar expressions emphasize the connection of the ethical with the eudrmonistic aspect of human experience. But what utilitarian theories of every sort really prove is not what they set out to prove; neither is it, strictly speaking, what they claim to prove. To show that happiness and virtuous conduct are, for human beings in their historical evolution, largely interdependent is quite a different thing from showing that the virtuousness of virtuous conduct consists solely in its utility to produce happiness.

A philosophy of conduct which is founded upon experience may even be led to believe that the ultimate goal of human striving is a social life in which all the forms of what the mind esteems as "in-itself-Good" unite to constitute a complete and total Welfare. But we cannot entertain this picture of complete happiness and perfect righteousness, combined and objectively realized for mankind, without holding to principles and postulates which can by no means be placed upon a merely psychological and historical basis. What is at once evident, however, in view of the relations which psychology and history establish between human happiness and the evolution of human morality, is this: just so far as modern Utilitarianism explains these relations it abandons its purely hedonistic positions. Every one, even the most high and dry Rigorist, like Kant, admits the psychological and historical connections of the two forms of "the Good." Nor is the utilitarian claim established when it is shown that the happiness which follows directly from morality - 
whatever there may be of it - is actually more highly prized in the conseious estimate of good men than are the pleasures of sensuous gratification.

In brief, Utilitarianism in Ethies claims that the criterion, the sanctions, and the rational end of conduct are all to be found wholly in the relation which conduct sustains to human happiness. Conduct is, in fact, a function productive of happiness or of unhappiness; this is one truth of experience. But men call conduct "good" or "bad," meaning by these terms to designate the eharacteristics of conduct in relation to another ideal standard than that of happiness. This is another truth of experience. These two truths cannot be united in the theory that conduct is to be considered, from the ethical point of view, solely as a function productive of happiness or unhappiness; that the rationality of the demand made upon moral consciousness for right conduct is based solely upon the value of its eudæmonistic tendency; and, finally, that the ideal end at which moral self-culture aims is solely the end of happiness.

To review the problem of conduct as it now comes before us for solution: We are secking for some rational account of the origin and grounds of that quality of "rightness" which men attribute to some conduct in preference to others. We are seeking not so much to explain the facts of particular preferences, but to discover a universal basis which our rational nature may approve for the fact of this kind of a preference. In the course of the search, the admission has bcen forced from the advocates of the hedonistic theory that men do not actually regard the preference of morally right conduct as identical with the choice of the course which seems to bring the maximum of mere happiness. The admission has also been forced that men do not regard themselves as obligated to seek happiness, nor do they claim the sanctions of conscience for seeking happiness, in the same way as for the effort to do right, and for the striving after the reali- 
zation of the moral Ideal. The admission has also been forced that, in the practical reason of mankind, the ideal of happiness and the ideal of a Moral Self functioning perfectly so far as its own conduct is concerned, in social relations to other selves, are not absolutely identical ideals. What more is needed to constitute the admission that the criterion, the sanctions, and the ideal end of conduct, as regarded from the point of view of ethics, are not to be found in happiness alone?

Now, howerer, a last attempt is made to escape from the full force of the objections to Utilitarianism by claiming a special dignity and worth for certain happy experiences, for those - namely - that accompany or follow such conduct as is esteemed morally right; especially, perhaps, if it be of a somewhat rare and heroic character. Why, however, even if it could be shown that, in fact, the better men are, the more they have of this especially choice kind of happiness, is the happiness entitled on rational grounds to be invested with such a peculiar worth? Only because this worth is imparted to it by the moral conseiousness of mankind. In other words, we note the fact of man's moral consciousness functioning so as to dignify a certain kind of happiness; and, indeed, imparting a remarkable dignity and worth to this kind of happiness. The Moral Self appears to raise some of its own rarer happy experiences to a limit of value which makes them quite orer-reach in worth all other happy experiences. But this is the benediction of righteousness bestowed upon pleasure, and not the functioning of morally right conduct for the production of pleasure.

To make the theory of Hedonism depend upon distinctions in the rational worth of certain happinesses is, it seems to me, a complete abandonment of its fundamental position. For the rightness of conduct is no longer located in its energy as productive of happy states of consciousness; its worth is no - longer estimated according to the measure of its hedonistic 
utility. On the contrary, the rational worth of certain pleasurable states of consciousness is now found to consist in the appreciation which the moral nature of man gires to them on account of their connection with right conduct. The sentient Self is no longer authorized to dictate the supreme and final purpose to the moral Self. The right of the moral Self is now acknowledged to set its own stamp of values upon the pleasure-pain states of the sentient Self.

The refusal to regard morality as having either its criterion, its sanctions, or its ideal, in happiness merely, has been so complete in the world's best literature that one scarcely need cite examples to show this truth. Dramatists, pocts, biographers, and historians, who have taken the ethical point of view, as well as the surer insight of the highest class of modern norelists, have refused to depict or to estimate the values of human life in terms merely of pleasure and pain, of happiness and suffering. The necessary discipline of pain, and the moral worthiness of disregarding the purely hedonistic standard have so impressed the minds of the poets generally as to evoke many passages like that one often quoted from Browning's Rabbi Ben Ezra:-

"Then welcome each rebuff

That turns earth's smoothness rough,

Each sting that bids nor sit nor stand but gol

Be our joys three parts pain,

Strive, and hold cheap the strain;

Learn, nor account the pang ; dare, never grudge the throe."

The same relation between morality and the pleasurepains is recognized by George Eliot in the Epilogue to Romola: "We can only have the highest happiness, such as goes along with being a great man, by having wide thoughts and much feeling for the rest of the world as well as for ourselves; and this sort of happiness often brings so much pain with it, that we can only tell it from pain by its being what we would choose before everything clse, because our souls 
see that it is good." But such discourse connects itself far better with Stoicism than with any form of Hedonism, - not excepting even the hedonistic side of a Eudæmonism like that of Aristotle.

When combined with elements of a quasi-religious character, this anti-utilitarian morality may take utterance in words like those of Marcus Aurelius : " "What, then, is that about which we ought to employ our serious pains? This one thing: thoughts just, and acts social, and words which never lie, and a disposition which cheerfully accepts all that happens, as necessary, as usual, as flowing from a principle and source of the same kind." Or, as Bacon in a somewhat hyper-sentimental way ${ }^{2}$ states the ideal of conduct to be striven for under the existing conditions of human life: "Certainly it is heaven upon earth to have a man's mind move in charity, rest in Providence, and turn upon the poles of truth." But all such testimonies point to an Idealism in Ethics which sees moral goodness and æsthetical sublimity illustrated, the rather, in a face like that given to Jesus in Raphael's "Bearing of the Cross."

Hedonistic Utilitarianism, then, if consistently carried through, contradicts, rather than explains, many of those facts of man's moral consciousness which have been most conspicuous in the analysis of the Moral Self, and in the discussion of the Virtuous Life. Neither human nature, broadly and profoundly regarded, nor the nature of virtue, when regarded either from the point of view of the more common consciousness or from that attained by the heroes and the seers among mankind, consents to the theory which places the criterion, the sanctions, and the end of morality

- in that feeling-tone of certain subjective states which we call happiness.

I have already said that the considerations which the

1 His "Reflections" (English translation by Long), IV, 33.

2 Essay I. 
modern theory of evolution has brought to bear upon the older forms of Hedonism are important; and that their admission into the theory produces certain improvements in the current forms of Utilitarianism in Ethics. So far as the theory of evolution is applied to the explanation of the changes that have gone on in the attitude of the moral consciousuess of the race toward different customs and practices, it throws a flood of light upon ethical phenomena. Undoubtedly the experience, both of the individual and of the race, with the pleasurable or painful consequences of the current customs and practices is always changing, and often profoundly or even completely, the attitude of men toward those customs and practices. The typical morality is uniformly, to a large extent, the construct of the physical and social forces that enter into the total evolution of human life ; and hedonistic considerations are, of course, powerful amongst those forces. But they aro by no means the whole of the forees which shape the moral crolution of mankind; and the history of this evolution shows that they are not. It is, therefore, necessary again to remind ourselves of that fallacy to which the advocate of the theory of evolution in ethics is constantly tempted, - the fallacy, namely, of identifying a partial and defective history of moral derelopment witl a complete and satisfactory account of its causes and its principles. But I have already made sufficiently clear what are the limitations within which the theory of erolution moves in its attempts to account for the Moral Self and for the Virtnous Life; and its powerlessness to deal with that ultimate problem of morality which we are now approaching, I shall hope to make clear later on.

After making the necessary restrictions and explanations there are few real reasons left for the present close alliance between Utilitarianism and Evolutionary Ethics. The just claims of both, as based upon facts of experience and upon fair conclusions from those facts, can be the better admitted 
and incorporated into a satisfactory ethical theory, if this alliance is severed. Those complicated and distinctive forms of functioning which make man a moral being, cannot, strictly speaking, be explained as evolved from any less complex and more vaguely general forms of functioning. His moral endowment being once assumed, however, the various modifications which it undergoes are explicabletheoretically at least - in terms of the theory of Erolution. On the other hand, the important part which man's susceptibility to an increasing variety of pleasures and of pains plays in his ethical development cannot, of course, be denied; nor should it ever for a moment be lost sight of by the student of the philosophy of conduct.

Indeed, it is to these considerations, which admit the value of happiness and yet deny that happiness is the sole criterion, sanction, and ideal end of morality, that we must attribute that unsettled and antithetic condition in which the ultimate problems of ethics were left at the close of the Second Part of this treatise. And, surely, Utilitarianism in Ethics does not promise any measure of deliverance from such painful dilemmas. On the contrary, it widens the gulf, intensifies the strife, and perpetuates the schism, between the Sentient Self and the Moral Self. It tends to make a hopelessly divided manhood. No amount and no subtlety of intellect, when employed in calculating amounts, kinds, durations, and ideal values, of happiness merely, can so equip man as to fit him to conduct his entire life toward a rational and rationally worthy end. We must look to some other form of theory for help in the further solution of the most pressing problems of morality. 


\section{CHAPTER XXI}

\section{LEGALISM IN ETंHICS}

IT would seem intrinsically improbable, if not quite absurd, that a conception which concerns itself wholly with the characteristics of personal beings and with their relations to one another in society should be capable of reduction to impersonal terms. And yet this is what is virtually attempted by all the theories which, either in whole, or in part, fall under the heading of this chapter. The attempt itself is honorable; it is the issue of the resolve to discover some principle in ethics that shall be free from the charge of being dependent upon the subjective changes of the finite individuals who constitute the social organization. For, in truth, there is something entirely unsatisfactory, and indeed almost shocking, in the assertion that the nature of the right has no fixed characteristics, either as regards its criteria, its sanctions, or its ideal. Must the philosophy of conduct confess that whatever any man thinks or feels to be right is really right; that each fleeting state of the individual's moral consciousness contains within itself the true measure and final goal of morality? Or is it the end of the matter to assign an absolnte authority and unchanging value to the ethical opinions of any generation or age?

But where, on the other hand, are to be found criteria, sanctions, and ideals, of the sort that ethics seeks, except in some one's conscious processes? To escape from this dilemma of a complete subjectivism, resort is had to some conception which seems to offer a permanent and universal 
ground for ethical judgments; and such a conception is that of a Moral Law, or a Moral Order.

In cthics, as in physical science, the mind scientifically inclined is apt to be captivated with its own generalizations; and forgetting that the conceptions formed by generalizing (itself a mental activity) are only conrenient summaries of the habitual manner of the behavior of things in their manifold relations to one another, the derotee to science includes in his conceptions all that belongs to the reality of the individual things themselves. Then, on spelling these conceptions with their proper capital letters, he secms to recognize in them an absolute authority and power; but all this has been fictitiously imparted to abstractions, as though they were entities. In this way Law and Order appear as real beings that rule over particular facts respecting individual things and their relations; they, at least, are immutable and unchanging, however transitory the things are, and howerer continuously changing the relations. Such a fictitious manner of regarding the phenomena is much less inappropriate, and less mischierous too, in the science of physical beings than in the study of the phenomena and principles of human conduct. For things are impersonal; and their qualities and relations must be conceived of as having some sort of a reality that is independent of human conscious states.

But the case is not at all the same with ethical affairs. Ethical facts are all personal - distinctly, and essentially, and exclusively so. What kind of applicability to them then, can conceptions have like that of an impersonal Law or an impersonal World Order? Yet there is not a little of ethical speculation, and some of it of a very exalted and moving character, which employs language that, strictly interpreted, implies an impersonal character and origin for the criteria, the sanctions, and the ideals of human conduct. Do we ask, for cxample, after the standard of the right and the wrong of man's behavior? It is asserted that this standard is obedience or 
disobedience to moral law. Do we further inquire after a rational ground for the obligation to obey? We are referred to the exalted and inviolable character, or the benefit-producing energy of this same law. And, finally, if we crave an ideal, according to which we may persistently and progressively shape our conduct in the interests of the perfect moral life, we are bidden to devote ourselves unflinchingly (and, sometimes, without regard, it would appear, to ourselves or to other human interests) to the keeping of the Moral Law. For, otherwise, the great Moral World Order, impersonal and one would suppose, blind as it is, will grind us small ; it will, at best, somehow sadly put us out of sorts, if we do not observe its sacred formulas.

Now for my part, I have less respect for this fetish of "Law" or "Order" (when personified and spclied with a capital, although represented as impersonal) in ethics than I have for the corresponding fetish called "Nature" in physics. It would seem that a sentient being might reasonably entertain certain vague fears and hopes that are aroused while in contemplation of a system of mysterious impersonal entities and forces. But to ask a thinking being to have a moral respect for any merely impersonal formula or to recognize such a formula as a rightful source of authority and of binding obligation, is to ask for an irrational rather than a rational procedure. Our demand upon every ethical theory, however, goes much further than this. For we are seeking some help out of a dilemma caused by a series of painful, practical antitheses, all of which originate in personality and have reference solely to personal relations. It is difficult to believe that real help is to be found from any manipulation of conceptions that are impersonal and, therefore, foreign to the interests with which ethics deals.

That all the offers of help which Legalism in Ethies makes are really unavailing will the more readily appear after what has already been said in the chapters on Moral Law and on 
the Universality of Moral Principles. Indecd, these previous discussions render unnecessary in this connection anything more than two or three brief observations. Of the two forms taken by the theory that the essential nature of the right is to be described as obedience to some impersonal norm or law, one has already been considered in detail. This form seeks to place its conceptions of moral criteria, sanctions, and ideals, upon a basis of experience. The other form appeals to some statement that can lay claim to be established as a rational intuition. In the one case, the resulting conception of "The Moral Law" is empirical and historical in respect of its origin and of the proofs to be advanced in faror of its validity. In the other casc, the conception is said to be $a$ priori; and it refuses to appeal to experience, because it does not admit the need of making so uncertain and doubtful an appeal.

It has already been clearly shown that the nature of all empirical laws and principles respecting judgments of ethical value is purely subjective and personal; and that the objectivity which they appear to have - the qualifications which impart to them the character of "external imponents" - is in its origin also suljective and personal. This form of Legalism in Ethics amounts then to saying that mankind, in its moral evolution, has somehow embodicd in its social organizations certain ways of beharior, and types of character, which actually excite the feelings of obligation and of approbation; and which, therefore, appear to hare a right to command the will, with the majority of the individuals forming these social organizations. The criteria, sanctions, and ideals of conduct are in this way left, just where they ought to be left by all merely descriptive and historical ethics, namely, in the conscionsness of the multitude of the individnals that respond to the stimulus of external conditions, with the appropriate ethical feclings and ideas. Nothing is learned in this way, however, as to how the source, the rational justi- 
fication, the profounder significance or final purpose, of this expericnee of mankind must be conecired of, in relation to Ultimate Reality. Somehow or other the fact emerges that man finds himself bound by one side of his nature to principles of conduct that do not get themselves approved as by any means wholly favorable to another side. The moral norm is his own unaided, unbidden construction; but in spite of the fact that it is his own construction it commands him as though it had celestial authority and celostial sanctions. It rises gradually in his consciousness; and yet it seems to rise above him, and largely to contradict that external Nature of which he is, physically considered, so insignificant a part, as well as to divide and set at hopeless odds against itself his own selfhood, or internal nature.

The case is somewhat different with the other form of Legalism in Ethics. This theory asserts that the moral law is revealed in liuman consciousness, and in such manner as to be independent of any form of historical or experiential proof. The Moral Law has the force, it maintains, of an unquestioned rational principle; whose peculiarity, however, consists in this, that it does not simply offer a statement of truth which has demonstrable and universal certainty, but that it also makes upon the will a demand for obedience which is equally exempted from all the questionings of human scepticism. The moral law is thus, on account of its origin being purely in reason and without any admixture of empirical elements, both an apodictic proposition and a "categorical imperative."

That we cannot speak of any one all-inclusive and complete moral law, any proposition that shall summarize all the essential judgments of mankind with respect to ethical values and all the maxims esteemed right for realizing these values in a virtuous life, has already been demonstrated in great detail. The very nature of ethical judgment, the plainly heterogeneous character of the moral code accepted by the best judges, the actual course of man's ethical evolution, show 
that this conception of an intuitire all-embracing moral principle, as set into the original constitution of liuman reason, or even as having evolved itself in the progressive formation of human reason, is a chimera. Eren more unwarrantable have those attempts been found to be which disregard the personal influences and interests involved in all moral values; and which repeat the vain proposal to free the mind from its natural, necessary, and rational tendency, to consider all these values as rendered unthinkable and wholly without value as soon as they are treated from the point of view of impersonal laws and impersonal ends.

Our contention against the possibility of an a priori inpersonal law as offering the solution of the more difficult problems of the philosophy of conduct may fitly be illustrated by a few words of eriticism of Kant's attempt in this direction. In his profoundly philosophical mind the ineritable connection between ethics, on the one hand, and epistemology and metaphysics on the other hand, is obvious and impressire from the very first. To found more securely the principles of conduct and the postulates and faiths of religion was his purpose from the beginning of his eritical examination of human reason. His criticism of so-called "pure reason," or man's cognitive faculties so far as they are native and constitutional, leaves these faculties embarrassed and thwarted wholly, whenever they attempt to extend knowledge beyond the confines of phenomena. Within these confines the same faculties operate to give to all kinds of experience, both constitutive and regulative forms that are themselres quite independent of experience. And when Kant comes to treat of the moral ideas, he demands for them, too, an origin that is not empirical but wholly supersensuous ; he remains true to the presuppositions of the Platonic ethics. He is eren forced into the position where the very moral worth of every right action consists in its being done against resistance. Nothing but a bare law, unrelated to experience and arising in a world 
quite apart from the one which we know, is left of the essence of morality. This abstract formula, thus derived by a critique of man's moral consciousness and independently of all empirical data, is called by Kant the "Fundamental Law of the Pure Practical Reason." And it is stated by its author in the chief one of its several slightly different forms, as follows: "Act so that the maxim of thy will can always at the same time hold good as a principle of universal legislation."

Further examination of this Law, to which Kant gives a perfectly unquestioned authority and an absolutely universal applicability, and which he conceives of as a mandate of reason entirely free from all considerations as to the consequences of conduct and as to the feelings with which men unavoidably contemplate those consequences, shows that it is neither a priori, in any strict meaning of the term, nor properly speaking impersonal. Indeed, whatever this Law has which commends itself to the human feelings of obligation, or to the reasonable judgment of man, is dependent upon a vast and variable evolution of human experience; and all this experience consists in forms of intercourse between persons, and in readjustments of opinions and practices due to such intercourse. That is to say, all the validity which the so-called a priori and impersonal formula possesses comes from centuries of the use of human powers of reflection upon ethical and social phenomena.

This criticism of Kant's "fundamental law of the pure practical reason," might, if it were necessary, be supported by a detailed examination of the very terms in which the socalled law is stated. Every word of it palpitates with warm, concrete, human interests that appeal to the emotions cominon to humanity, and to the experience of men with the cunsequences of their different forms of conduct. How otherwise is the possibility (the "can always") of applying the maxim of my will to others, to be tested? How otherwise can the adaptability (the "holding good") of the rule of one 
person's conduct to the case of others be presupposed, deroid as it would be, of a parity of ethical experiences and of a certain uniformity of results from similar forms of conduct? And is it not so self-evident as scarcely to need exposition, that any absolutely unexceptionable law ("principle of universal legislation") over all human beings must take account of the various kinds of concrete relations in which all human beings stand to each other, under the different forms of social organization? If it were worth the while in the present connection, it could be shown that all of Kant's own exposition of this law answers thesc and allied questions in a manner distinctly unfarorable to his claim of a strictly a priori character; in a word, he cannot himself regard a Moral Law as free from all dependence upon common and wide-spreading, and eren upon concrete and individual, forms of human personal experience.

Were such attempts as that of Kant much more highly satisfactory from the standpoint of universal reason, they would still remain of comparatively little practical importance or eren convenience. For taken in its full import erery such "Moral Law" is impossible of application to the solution of concrete cases of conscience, not to say conflicts of duty. How can the plain man discover whether the particular maxim of his will, in a given instance, is such as to "hold good as a principle of universal legislation." Instead of its being true, as its author asserts, 1 that in this way "the commonest intelligence can easily and without hesitation sce what . . . requires to be done," quite the reverse is truc. Nothing could be more complicated and doubtful of issue than this appeal to fitness for "universal legislation." And nothing else so much requires, as well as produces elcration of mind, as to consider carefully the nature of each thing, and thus - to quote the wisdom of Marcus Aurelius-decide,

${ }^{1}$ Critique of Practical Reason, Part First, Book I, § VIII, Theorem IV, Remark II. 
"What virtue I have need of with respect to it, such as gentleness, manliness, truth, fidelity, simplicity, contentment, and the rest."

There is much, however, in this lofty maintaining of the claims of universal reason to have somewhere hidden in its depths the eternal truths and unchanging principles of all morality, which excites the enthusiasm and commands the respect of the reflective mind. The most unchanging truths, we feel, are moral. The profoundest insights into the heart of Reality are born of the ethical nature. Man's kinship with the Infinite and the Eternal is most intimate and strong, only when he has arrived at the maturity of a moral selfconsciousness. Things may be in an unceasing flux, and all the physical structures of human skill may crumble away. Eren the elements may melt with fervent heat, and the heavens themselves be rolled up like a parchment scroll. But the obligations of duty can never be abated; the good of righteous living does not fade; the moral ideal loses none of its awful beanty, or of its unconditioned value. Over and beyond the last dim and fading vision of the things that minister to a sensuous good, there rises the spiritual vision of a good that is lasting and supreme. And in this Good virtue is not the least, but rather the most important factor; for it is the Ideal which lures on and enconrages and commands the moral consciousness of humanity.

This the philosopher, enamored of his own rational construction, has always felt and spoken regarding his Ideal of the morally Good. That profound stirring of feeling, which Kant designates "respect for the Law," is itself a fact; and so is also the movement of imagination and thought which accompanies the feeling. These facts show in an undoubted empirical way that, if not otherwise, at least in his moral nature man is -

"Formed to rise, reach at, if not grasp and gain The good beyond him, - which attempt is growth." 
It is the source, the significance, the value, the warrant, and the outcome, of this "formation" to which men generally respond, in some measure at least, as they are related to the sum-total of Reality, which offer to the philosophy of conduct its ultimate problems. These problems, which Utilitarianism in Ethics disregards, are not solved by Legalism in Ethics. But the latter theory emphasizes and reinforces them as the former theory does not. We therefore turn with an inereased sense of their important and pressing character to consider other attempts at their solution. 


\section{CHAPTER XXII}

\section{IDEALISM IN ETHICS}

IT is obvious from the previous course of our examination into the problems of ethics that the attempt to solve them, if this attempt is carried through consistently, must terminate in some form of an idealistic theory. Indeed, all the facts, opinions, and tendencies with which the philosophy of conduct is concerned have reference to human ideals; and only in so far as the average "plain man," or even the hypothetical "primitive man," is conceived of as a creator of ideals can he be considered moral in any tenable meaning of this latter word. Thus it was found necessary to introduce a corresponding phrase into the very first preliminary description of that sphere of human experiences which ethics claims as peculiarly its own. This sphere was defined to be the sphliere of conduct not as mere fact of behavior, but of conduct "as related to a rational ideal." In the analysis of the Moral Self also, it was shown how indispensable to moral life and development are those activities of thought and imagination which result in the formation of the moral ideals; that these jdeals themselves are indubitable psychic facts, actual forms of the functioning of human minds; and that they are, moreover, very potent and influential facts, which no student of human history, ethically considered, can safely overlook.

It was further discovered that the different cardinal virtues, although they are actual forms of that personal life which men agree to call good, are all conceived and prac- 
tised under the guidance of certain typical notions of what a person onght to be. In their superior or more perfect manifestations they are construets of thought and imagination - each one being some phase or aspect of that moral selfhood which represents for the ethical aspiration of the individual the goal of his striving. To try to be "a good man" is the naire, popular way of expressing the aspiration and the effort to attain a moral ideal. And when, by the further process of abstraction and generalizing, the most comprehensive conceptions of morality are cvolved in human consciousness, this idcalizing tendency, and the dependence of human conduct and ethical development upon the tendency, are still further illustrated and enforced. The conceptions of a universal Moral Law, and of a System of moral Principles whose sanctions and values and authority extend over all men, if not over all personal beings, are of an exccedingly abstract and non-empirical character. Indeed, so purely abstract are they that the desirability was strongly felt of calling even the philosophical mind back from its high-flying excursions to consider again more carefully the details of the ground from which it took its flight, and the probable construction of the territory on which it would be obliged to alight.

And, finally, our empirical investigation found itself confronted with a puzzle of antithetic positions and opinions, of inconsistent and contradictory demands upon the strivings and active life of the mind. This was the puzzle of human moral life - of an existence in which each individual feels himself bound to seek a kind of welfare which is so often incompatible with the cravings of his pleasure-loving nature, and in which he thinks it reasonable and even obligatory to legislate, in thought and heart at least, for all his fellow men for all time, and under all cireumstanees. On turning to the various schools of ethical theory for the solution of these problems of conduct, they were all found either to admit or to 
emphasize the essential importance of the Moral Ideal. The first of these schools to be examined, the Utilitarian, did indeed change the character of this ideal. For the ideal of a Moral Self living in accordance with his conceptions of a virtuous life in social relations with other selves, Utilitarianism in Ethics, substitutes the ideal of a Sentient Self, shrewdly or even wisely calculating the conditions and consequences of conduct as affecting a certain sum-total of happiness. But the criteria, the sanctions, and the ends of conduct are still placed outside of, and above the actual, in the realm of what ought to be. And although the ideal of the lower and grosser forms of Hedonism is itself relatively low and gross, the ideals of the more refined modern forms of Utilitarianism are among the most difficult to frame by human thought and imagination. For they require the mind to pieture a condition in which happiness and good conduct shall be actually related in such a way as that seeking the former will afford a sure criterion and rational sanction for, if not a goal identical with the latter. This is a hard task for the idealizing faeulty to combine with the cool judgment which retains a strong grasp upon the actual forces and laws that have to do with physical nature and with human society. Certainly no actual form of existence sustains any very close resemblanee to the ideal of any form of hedonistic theory.

Those forms of rationalism in ethics which resemble the attempt of Kant to derive from the so-called practical reason, by a eritical process, some general proposition that may demand unhesitating and unquestioning acceptance and obe. dience, eertainly tax sufficiently our deference to human ideals. Indeed, they have a superb confidence in the results of the reflective thinking and lofty imaginings of the individual mind of the philosopher; this confidence more than meets the demands of a tenable idealistic theory. This rationalistic ideal must be some principle, that may be pronounced obligatory upon all rational beings, even upon God himself, 
and infallibly applied to particular cases of conscience by any plain man's judgment, if he be a "man of good will." No more noble and inspiring exercise of human ideality than this could possibly be imagrined. But alas! when tested by experience the facts of experience do not support the theory. The dream of rational Legalism is quite as beautiful as that of the most refined Hedonism; and it is, ethically considered, much more stimulating and ennobling. But the actuality of man's moral nature and ethico-social derelopment do not justify the dream. Its very existence in the human mind gires a grave additional emphasis to the conclusion that only as man is an idealist is he a moral being; and that all satisfactory solutions of ethical questions must make large demands upon the idealizing activities of the human mind.

Thus does the problem of conduct begin, indeed, with the attempt at a purely empirical investigation, and with the promise to regard only such facts of ethical import as the sciences of psychology and anthropology appear to justify incontestably. But the investigation leads on irresistibly to the speculative contemplation of the highest and most comprehensive of human ideals. For these ideals themselves are found to be-however fitfully and fragmentarily constructed by the multitude of men - the most momentous and influential of the phenomena of men's moral derelopment. In spite of our earlier warning (see p. $9 \mathrm{f}$.) against making ethics, as Professor Sidgwick charged Mr. Spencer with doing, the science of the "double ideal," it appears now that, in close connection with the study of the life of the Moral Self in its manifold relations with society, the mind is almost inevitably carried away toward a sort of triply ideal Utopia. In this Utopia all ideal good is to be realized - the good of happiness, the good of beauty, and the good of morality.

Some form of Idealism in Ethics is, then, the only consis- 
tent and tenable ethical theory. Indeed, I am quite ready to say that there is possible only one form of ethical theory - namely, some form of Idealism. But such a conclusion as this, while it follows from what has already been discorered to be true in the domain of ethics, does not afford the further truth which we are seeking. It suggests that truth, however; and I will now state it in the form of an alternative hypothesis:- Unless our human Ideals - and I am now speaking of the ethical ideals, the ideals of moral personality and of a society of morally good persons - have their ground, their sanction, and their goal, in the nature of Ultimate Reality, they are merely subjective, without rational ground, or sanction, and without sure promise of a satisfying end. In other words, that Unity of Reality which science calls Nature (including in this term the nature and evolution of the human race), and which philosophy calls the Absolute or the World-Ground, must be so conceived of as to be the source, the authority, and the guarantor, of man's ethical development, or else all ethical theory must be left, where a carefully restricted empirical and historical investigation leares it, in a condition of distracting and hopeless antitheses. But I am anticipating a conclusion which will more fitly be reached by slower approaches under the guidance of patient reflective thinking.

Idealism in ethies, like Utilitarianism in ethies, bas certain definite answers which it must propose to the subordinate problems of conduct before it can claim to have established itself upon an empirical basis. These are elicited by questions like the three following: (1) With whose ideal does the nature of the right in conduct and the good in character correspond? Can the functioning of any individual's intellect and imagination, "plain man" or philosopher, be trusted to furnish the criteria, the sanctions, and the end, of morality in such a way as to entitle its result to claim authority for all human beings under every form of 
social organization? (2) When is this trustworthy ideal of conduct actually produced by human mental activity? Does it originate in the presence of every particular piece of conduet, or every special conflict of duty, as a sort of cllvisagement of the rational and the universal in the conerete and individual conscious state? Or has the ideal rather the nature of a result from a long process of evolution, during which it slowly emerges in the consciousness of the race, or at the end of which it suddenly springs into the mind of some member of the race who has a genius for morality? What kind of an ideal is this which is said somehow to contain within itself the rational account of the criteria, the sanctions, and the goal of human conduct? Psychologically considered, is it chiefly a suggestion of the emotional nature, an ideal of faith, hope, and aspiration; or is it a pure product of processes of ratiocination, or a principle of judgment adapted to regulate the activity of the rational powers whenever they are applied to the problems of conduct; or is it, the rather, something discoverable only by a historical generalization based upon centuries of racial experience; or is it not, perhaps, a combination of feeling and intellect working according to rules preseribed by the very constitution of the human mind?

To many of the inquiries subordinate to the three questions just raised, as well as to the three questions themselves, more or less satisfactory answers have already been given. These answers have shown in large measure what shape any idealistic theory of morality must take, if it wishes to found itself upon the psychological and historical "data of ethics." But brief summaries of the conclusions already reached by the psychological and historical method will prepare the way for that more speculative extension of the idealistic theory which, while it bases itself upon other facts that are closely allied with these data, extends the conclusions of ethics over into the domain of a theory of 
Reality that takes into its account also the resthetical and religious nature of man. For even in those ideals of his which depart furthest from his experience with concrete realities, man eannot wholly disregard the facts. And no wise man, no reflective thinker on the problem of conduct, would wish to disregard them. But there are other classes of facts than those which concern man's experience with conclete realities; and these are the facts which solicit and require the mind to form ideals. There are other ideals than the ideals of morality; there are the ideals of art and of religion. These asthetical and religious ideals are so involved with the moral ideals that, in fact, the experience which ereates and supports all three eannot be wholly separated. And thus the need is manifest that the rsthetical, and especially the religious nature, should be consulted in connection with the moral nature, when it is proposed to construct such a theory of Reality as shall satisfy the entire being of man.

Concerning moral ideals, as affording the criteria, the sanctions, and the goal of eonduct for the individual and for the race, the following elaims of Intuitionism - a form of Idealism in Ethies - have already been found to be true: First, in multitudes of cases, in all forms of social organization, the average adult promptly and apparently intuitively decides for himself what is right and wrong in conduct, by comparing the concrete action with his own ideal. He also habitually judges the conduct of other men to be meritorious and worthy of being rewarded accordingly, or the opposite, by comparing it, too, with the same ideal. If the judge be a man of particularly "liberal mind," he can make ecrtain allowances; he can at times remember and take into his account the patent fact that men and circumstances differ and that no one man ought to make himself the measure of all things moral. But after all, this amounts simply to saying that the liberal mind is able and willing to picture 
the ideal of Selfhood which it has made its own, in a somewhat more than ordinarily facile and, as it were, elastic way. Every judge and critic of another's conduct, in his very judgment of others, still holds fast to his own idcal; his real inquiry is: How should I feel and think that I ought to act, if only $I$ were not $I$ in these circumstances that are mine, but if $I$ were he in those other circumstances that are his? It would, however, be contrary to faet to affirm that men at all frequently deliberate whether this or that way of behavior will produce the maximum of human happiness; or whether the particular action accords with some maxim that can be made to hold good as a principle of universal legislation. Indeed, more frequently, perhaps, the multitude do not deliberate problems of conduct at all. To this extent, at any rate, the simplest form of that idealistic theory which is called "intuitive" secms to correspond with the facts of experience.

And, second, this intuitive application of the moral ideal to problems of conduct, this prompt and secmingly infallible activity of so-called conscience, in multitudes of cascs carries the entire being of the man along with itself. Thus the man in action is not a divided mall. Or if he is a divided man, the division of his being is not orer the moral problem; but is rather a division over some question of expedieney. The problem of the man who doubts about conduct is usually hedonistic and not strictly ethical. Cases of doubt customarily arise as follows: The individual las a feeling of obligation which binds him to some definite course of action; this is the course which he judges would be right, while not to follow it would be wrong; and he also experienees in the same direction ccrtain elementary and primary impulses of will. If, however, action does not follow, then the feeling of a divided Self emerges; doubt as to what is duty creeps on apace and grows with deliberation. When the man begins to reason with himself, the seemingly infallible 
authority of conscience becomes obscured; the subjectire ideal no longer seems to afford the sure criterion, the sufficient sanction, the worthy end, of the particular conduct. Indeed, a conflict of duties may arise, according as one course of conduct appears to satisfy one phase of this ideal, and another different and antagonistic course makes its appeal to a different phase of the total complex ideal. The seemingly infallible nature of the moral standard as a commitment of the entire man to one line of action, gires place to a condition in which feeling contends with judgment; or the more inmediate emotion and intellectual estimate are confronted with a contradictory conclusion that results from a course of argument with one's self or with some other person.

Such complex and conflicting phenomena have very naturally operated to divide the members of the Intuitional School into subordinate classes. Some intuitionists have given precedence to the immediacy of fecling, and have accordingly developed a theory of "moral sense" or - more particularly - a "taste theory." Others have relied rather on intellectual processes and have mistaken the prompt mental recognition which follows according to well-known psychological laws from the habitual ways of carrying through these processes, for the immediate dicta of practical reason. The ideally right is thus made a matter of "insight" or of "perception," after the analogy of our most obviously immediate cognitions of material objects and their relations.

Still other writers on ethics have emphasized the need which the average man must acknowledge of help from those of his own species who have the gifts and the culture of the moral philosopher. "Intuitions" of that which is infallibly and universally entitled to be called right may, therefore, be had by the human mind; but in order to reach them, long and severe processes of reflective and analytic thinking must be gone through; - somewhat, for example, after the pattern of what is necessary to attain the geometer's intuition of the 
abstract gcometrical properties of space, or the physicist's intuition of the indestructibility of energy or of matter. Such a so-called "intuition" is plainly about as far as possible removed from that envisagement of the concrete, individual object, of which sense-perception is the type. It is none the less, however, beliered to have a superior excellence on account of its alleged a priori character. It is definitively a rational intuition, and therefore necessary and universally applicable. And just as all men hare, or may develop, the ideal of a perfect triangle, or of those parallel lines that (unlike the appearance of the parallel rails of the steamroad), however far produced, can never mect, and may compare with these geometrical ideals all actual triangles and pairs of lines, so all men may test the purity of their actual conduct by comparing it with the moral ideal. For practical reason affords to all rational beings an "intuition" of the unchanging standard of right conduct. Such an intuitionist of the pronounced rational type was the same great thinker, Kant, whom we classified as a legalist in Ethics, when considering his ethical philosophy from another point of view.

It is instructive to notice in this connection how one-sided are all these forms of idealistic theory; just as the practice of the Virtuous Life is by most nere one-sided. Considered from the point of riew of their disposition, education, and habits, some persons are obviously better fitted to conduct themselves properly and to attain the goal of virtuous living, if they act very largely in pursuance of their spontaneous good feeling, their natural kindliness, sense of justice, and courage in speech and deed - the sum-total of which constitutes for them the emotional ideal of a morally good man. It cannot be denied, however, that the "intuitions" of such persons are peculiarly liable to do mischief through lack of that cool judgment and habit of reasoning logically from premises, coupled with that self-restraint, which makes the will refuse to yield to morally good impulses until the duty 
of foresight has been exereised in the effort to determine how the conduct is going to result. Certain other persons, in their turn, not at all infrequently fail to be good according to the ideal standard which the more emotional intuitionists would set up; the intuitions of cool judgment too often end by suppressing all goodly emotions in the interests of prudential considerations. In fact, the course such "cool judges" habitually follow results in immense loss of the opportunity to do good, even through the fear of doing harm, - not to take too much account of the undoubted fact that what society especially needs for its betterment is often more spontaneity in the brave expression, by deed and speech, of sympathetic kindly feeling and of that highly emotional sense of justice which characterizes so many somewhat fanatical minds.

In regarding all this human experience from the point of view offered by a properly constructed idealistic theory, the explanation comes promptly and aluundantly from considerations already supported by abundant facts: Every good person actually has, and from the nature of morality as belonging to personality must have, an ideal of his own peculiar Self. Men generally do not like peculiar selves, at least, not those which are too peculiar. But the peculiarity of the Moral Self which I am commending, and in which I insist the moral ideal for every individual human being must reside, is not the peculiarity of the "crank." Even less is it characterized by that pernicions determination which tries to reduce all the rich individuality of the Virtnous Life amongst the multitudes of the human race to the utmost possible uniformity in the details of opinion and of practice. On the contrary, its maxim, while it recognizes all the worth of social influences and the close connection of custom and law with essential morality, is a very generous "Live and let live," so far as virtuous living is concerned. Each individual, in order to be moral, must commit himself, such as he is by inherited disposition and under the eircum- 
stances which make his physical and social environment, must commit his very own Self to the ideal which this same self progressively constructs, of what he ouglit to be.

Individuality is, therefore, of the very essence of morality. In the social organization which is composed of a multitude of individuals there is always abundant demand and ample room for a great variety of moral selves; just as we have reason to believe (a faith about the justification of which more will be said in another place) that the Absolute Self designs and has regard for all the particular manifestations of moral selfhood, in whose common practice of the virtuous life and development of character, - each in his own somewhat peculiar way, - the fulfiment of His plans takes place.

It must be further acknowledged, in the third place, that in every form of social organization many of the laws, customs, moral maxims, and opinions about matters of conduet, are accepted so unquestioningly by the moral feeling and ethical judgment of the community as to make the impression of an intuitive cognition. In other words, the actual forms of conduct prevalent in any society have the appearance to the members of that society of corresponding with the absolute ideal of morality. So far forth, then, the social ideal, as it has actually established itself by historical process, is, for the time being, the accepted ideal of the multitude of indiriduals. For the multitude this ideal is, in its main features, entirely satisfactory. And in many eases of conscience, eren those indiridual members of the social whole who are most disposed to frame their own ideal of conduct, and to act somewhat independently of the common practices and opinions, yield to the almost irresistible foree of these embodied and entrenched "intuitions" of what is right in conduct and in character. Indeed, a certain large conformity, which would better be made with the utmost possible of good conscience, is essential to any ethico-social 
organization among moral selves. Many matters, accordingly, are treated by persons who are inclined to dissent, or who would prefer different laws, eustoms, moral maxims, and opinions about matters of conduct, as morally indifferent. The good man may conform, and still hold to his own ideal. In other matters a certain large conformity takes place which is not altogether with good conscience; and in still others, revolt arises against the demands of society upon the individual to suppress the feelings of obligation that bind him to his own peculiar ideal.

And now appear facts of ethical experience which contradict Intuitionism in Ethics. Soon the history of the moral erolution of any progressive community shows that the common ideal which has undertaken to enforce itself within the mural consciousness of the individual members of the community is, after all, only a "rough and ready" affair. At its worst it cannot wholly exclude from the place of respect and command the more particular ideal of any individual Moral Self. At its best, it cannot wholly be accepted as a substitute for this particular ideal. Aristotle hell, indeed, that a slare conld not be a person, and could not hold or follow any ideal of a virtuous life for his own Self. But we know, that even under the limitations of ancient slavery, slaves could cherish their ideals of goodness, and could make a fairer show of realizing them than could many of the Greek warriors, statesmen, and philosophers. Morcover, all the while the process of change is going on in the social ideal; and not infrequently the multitude comes around to the "good few," if the latter will not eonform overmuch to the multitude. So that every man may say, "If in the last resort I cannot follow the type of conduct, in general or in any concrete case, which corresponds with the prevalent and commonly recognized moral ideal, and if I choose, at whatever risk of social unpopularity, or loss of social influenee, or even suffering of penality, to 
follow my own more personal ideal, it may be-God knows whether it will be - that sooner or later the conception of the right which the multitude hold will be exchanged for the conception which I now hold; at any rate, when my ideal has been purified and clarified as best I can, to that, and to no other, must my Self cling, or I am false to the absolute and universal moral good."

When now, in view of these conflicting considerations we ask for the secret of that idealistic theory which explains "the Nature of the Right," the psychological and historical suggestions are not so difficult to discover. Certainly, "The Right" is by nature both subjective and individual, on the one hand; and, on the other hand, it is objective and universal. It is both, at one and the same time, when considered from two different points of view; - from both of which points of view, however, it is necessaly to consider its proper nature. Every example of morally right conduct is, by its very nature, subjectire and individnal. It is some person's conduct; and, as conduct, it is an affair of conscious fecling, judgment, and volition, considered in relation to an ideal. This ideal, too, is subjective and individual. It is the product of that same individual's judging and imagining activity. But "the Right" appears also as objectified and universalized. For all men have, in order to constitute them moral and capable of living together under ethico-social relations, a certain constitutional equipment; and certain common relations, like those of the family, the tribe, or the more complex social organization, belong to men everywhere and at all times. Therefore, the conduct of the individual is never solely his own affair; it has constantly to measure itself by this more objective and generally accepted standard; and its ideal can never be achicved, nor even approached, by those

"Who, trimmed in forms and visages of duty,

lieep yet their hearts attending on themselves." 
Moreover, these two ideals - both the indiridual and subjective, and the objective and unirersal - are never framed in any approach to a complete independence of each other; nor can they be kept apart in their application to the theoretical solution of the problems of conduct, or in their effect upon the feelings and deeds which correspond to the ideals. Not infrequently the two seem struggling together; the one to enforce laws and rules, and to realize in the social organization the conception of an eternal and absolute character for that which is esteemed right; the other to introduce exceptions and to break down existing laws and rules by an appeal to some superior interest or higher authority. Especially is this apt to be true in all rapidly transitional stages of the development of ethical opinions and practices, whether with the individual or with society at large. Such a period was passed through in old Greek life when the Sophists were prominent; such a period is now being passed through in Japan, and indeed all over the world. Repeatedly between the ancient history and the present time has "the cake of custom," and all that goes with it, been breaking into fragments and forming anew, so as greatly and speedily to modify the particular ideals of many individuals, and thus to modify the common ideal. Always, indeed, some kind of conduct is considered morally to be preferred; always virtue is praiseworthy and vice is blameworthy; always there is some mental picture of what a man ought to be and of what society ought to be, that awakens feclings of obligation and of moral appreciation, because it corresponds to the rising, if not to the setting sun of the Ideal Moral Good.

It eannot be said, however, that the doubts and oppositions over the problems of conduct which characterize all human experience, and which especially characterize those epochs of transition to which reference has just been made, affect the fundamental "Nature of the Rightt." Nor can it be 
asserted that the antagonism, or even the twofoldness, which seems especially to develop at these periods, exists between the individual's ideal of his own Self and the social Ideal. For, in truth, the ultimate moral ideal is always necessarily social; it is invariably conceived of by every idealistic theory, which has any claim to critical consideration, as including the moral good of the one and the many, of the individual and of the social organization. What precisely this ideal good may be, and how it is going to harmonize in particular cases, or in the final result, the interests both of the individual and of society, no one may be able to describe a priori. Certainly, no theory which confounds all morality with the prudential virtues can frame a solution for the problem which the conflicting interests of society and of the individual presents. But so far as one attends strictly to the moral ideal, the difficulties and antagonisms between the individual and society are of another order.

From the point of view of my personal selfhood, and its moral ideal, I am bound to be faithful to it; but this fidelity cannot be, if I am carcless of the social good, and do not take my part in realizing the ideal of a community composed of upright moral selves. On the other hand, he who urges upon me to conform to the generally accepted ideal, if his urgency be upon moral grounds, camnot disregard the fact that my moral welfare is involved in my fidelity to my ou'n ideal. As a moral adviser, therefore, he may try to make me see that by conformity to the more general judgment of the social organization as embodied in its customs, laws, maxims, and opinions on matters of conduct, I shall be doing my duty, fulfilling my obligation to the moral ideal which is reasonably mine under the existing circumstances. But he cannot exhort me to go contrary to my ideal of what I ought to do, without abandoning the ethical point of view. The damon of Socrates can be enlightened or persuaded, but it cannot be forced. My friend who differs from me, 
although quite radically as to how a man ought to act under a given concrete set of circumstances - and here in the word "action" we are to include motives, intentions, and feelings, as well as external bchavior - may still remain $\mathrm{my}$ true friend, standing with me on the higher grounds of genuine morality, if each of us is faithful to his own moral ideal in each particular case. Indeed, my friend's moral ideal, as an individual and subjective affair, may differ from mine in not a few important ways, and yet, in the larger and more comprehensive meaning of the words, we may both be secking the same Ideal.

This more inclusive ideal is undoubtedly social; and so it is adapted to include the particular ideals of the individuals composing society. But the social ideal itself is decidedly not the ideal of a social organization in which the customs, maxims, laws, and opinions, that are for the time being most popular and dominant, assert and enforce the right to control absolutely the individual in the pursuit of his own moral ideal. Such a social organization would not correspond to the Ideal of a society of moral selves. Indeed, the ecclesiastical and civil organizations which have - no matter with what pretence of a good conscience, or with what show of reasonable grounds - endeavored so to dictate moral ideas and laws to their individual members have usually turned out most mischierous and abominable tyrannies. The present day proposals, which are more subtle and indirect, whether of the more pronouncedly imperialistic or socialistic order, to force conformity to some common ideal, when the Moral Self is not intelligently committed to it as its very own ideal, will undoubtedly turn out just as disastrously. The two prominent existing and contending types of social organization - Imperialism and Socialism - are both characteristically immoral and fatally destructive of genuine morality. For, the moment you conceive of your social organization as successfully framed after the pattern that com- 
mends itself to the ethical judgment, and that stirs moral feeling and the imagination in appreciation of its excellence, you have rejected for the individual the supreme authority of the prevalent customs, maxims, laws, and opinions.

An ethically ideal society is essentially such that it can be constituted only of ideally grood persons living together in social relations. But the good person is the Moral Self who shapes his conduct in conformity to his own Ideal of what a Self ought to be. He is deferential to society; he conforms oftentimes to its customs and laws, and often remains silent in the presence of its maxims and opinions, although they do not represent satisfactorily the ideal which he has made his own. Ile is deroted to the best interests of socicty, as he conceives of these interests; for them he may wish to live and, on occasion, be quite willing to die. But he can conscientiously do this, and so maintain in integrity his own moral selfhood, only in so far as his own moral reason will permit; and when the necessity arises, he appeals to something within himself, or above himself and above all men, for the warrant to disregard and even to transgress the standard of morality which has become objective and generally accepted. He may call this something his deemon, as did Socrates; or he may style it the Moral Law and spell it with a capital, as do those devotedly good men who wish to free morality from all taint of religion; or he may call it the voice or the law of God, as the religious conseiousness has always done, and will always continue to do - the conclusions of ethical societies to the contrary notwithstanding. Or the individual man may even have no other name for it than just simply this: - What $I$ feel, or think, that $I$ ought to do. But however he may denominate this marvellous something, and whether he locate it within or without, in the soul alone or also in heaven and in the World-soul, if he remain a truly moral man, he will die rather than be false to this ideal. 
Let it not be overlooked that I have said "he will die rather than be false to his ideal." I hare not said that he will consign others to death; or indirectly work to do them any inferior harm, because they differ from him as to the nature and application of the moral ideal. Nor will he necessarily hate, and fight, the multitude who demand from him either conformity, with the sacrifice of his ideal, or else the loss of other forms of good. In this respect the true moral spirit is at one with the method of $J$ esus and with the genuine spirit of Christianity. In this respect, most of the world's present plans for forcing upon unwilling subjects foreign ideals of the ethical order - whether of the more obviously civic and social or the more private and domestic kind - are both immoral and un-Christian.

The further developments of Idealism in Ethics and its adjustments to the facts and laws which an empirical inrestigation of the data discloses, are significantly aided by the conception of evolution as applied to the sphere of human conduct. Our use of this conception has already shown how both the ideal of the individual in its more purely subjective form, and also the more objective and general form of the social ideal, are constantly in a process of change. For the individual in the lower stages of human life, and in the earlier stages of the highest derelopment of this life, the moral ideal is fragmentary, fitful, and largely dependent for its more special characteristics as well as for the strength of its influence over the conduct, upon the physical and social environment. This is only to say that any child of man, and all childlike men, think and imagine with respect to what they ought to do and to be, in a relatively strict dependence upon their parental inheritance and total environment of things and of other persons.

What has been shown as to how the individual's ideal of morality develops, and how this ideal stands related to his actual conduct, need not be repeated here even in the 
most summary manner. It need only be said that the idealizing activity itself depends in a most important way upon its own effect on the actual moral life of the individual. The man who - to use the popular expression - "is as good as he knows how to be," knows the better for this very reason how to be good. In other words, the ideal of a Moral Self is itself really developed by the practice of the Virtuous Life. But this ideal, if practically disregarded and thwarted, fails of development. He who follows with patience the path of virtue learns how more suceessfully and firmly to walk in that path. But he who, whether through carelessness or yielding to temptation, habitually departs from that path, loses both the instinctive appreciation of its worth and the ability to mark it out for his own feet with a sure and intelligent judgment. The very nature of virtuous living, and as well the nature of morality, is such that it cannot be defined in detail for any individual. This path - the path of virtue, the right course in life-must be always in a process of defining itself. The virtuous man is a perpetual "path-finder."

The same changeable character and susceptibility of constant growth belongs to the moral and social ideal of every community of men and, indeed, of the entire race regarded as in a process of development. Change characterizes this Ideal, - whether it exist as a sort of vague general presentment, a certain prevalent type of thinking and feeling as to what the social organization of human beings ought to be and what of good it ought to realize for its members, or take the more objective and fixed form of popularly aceepted customs, laws, maxims, and institutions.

Idealism in ethies, then, if it wishes to adjust itself to all the data of ethies, as these data are gathered from the widest and most varied sources by the psychological and historical method, and are subjected to philosophical reflection, must make large use of the theory of evolution in 
morals. This it can properly claim to be able successfully to do in the following way. The ethical theory which best satisfies all the facts does indeed locate the Nature of the Right in the relation which conduct sustains to an Ideal. For every individual this ideal is the ideal of his own Self as living and acting in social relations with other selves; and for society the more objective and seemingly universal ideal is that of a multitude of such sclves - a social organization of human beings that are living together and acting, each one, in aecordance with his own moral ideal. The reeiprocal influence of the indiridual and society upon the growth of moral ideals is secured by the very nature of moral selves socially organized. I have said that every individual forms his own ideal of the Self which he ought to be; that, for the most part, this is donc in a very fitful, fragmentary, and unsuceessful way; and that it is always done under the predominating influence of the prevalent social ideals. Each individual, however, contributes something to the formation of the prevalent and typical social ideal. This is true, althongh only to less apprcciable extont, of the lorest sarages in respect of the origin and change of their tribal customs and ideas; it is true also of the countless hordes of a decadent civilization, the multitudes like those at the present time of India and of China. As the entire race of men comes to experience, in more prompt and sensitive and impressive ways, its own solidarity, the reciprocal influences of the different subdirisions of the race become more appreciable and significant. Let him who thinks that savages are incapable of producing individuals which powerfully influence the prevalent ethical type of conduct and of character, study, for example, the history of mon like Tschaka and Moshesh among the Zulus. On the other hand, to suppose that the Anglo-Saxons, or any other most considerable portion of mankind, can remodel the morality, private and social, of the so-called inferior races without being themselves remod- 
elled by these races in a significant way, is to fail of an understanding of some of the plainest lessons of history.

Man, then, I conclude, in his psychological and historical development, creates his own ideals of conduct and charaeter, - each individual moulding for himself in particular the idea, and yet all for each one and each one for all. The Right is defined for every individual and for every age by the fidelity with which the individual and the age actualizes in conduct this its perpetually growing Ideal.

We are now prepared to summarize the more definite answer given by Idealism in Ethies to the three questions which it was declared at the beginning of this chapter every idealistic theory must be able to answer. The three questions, Whose? When? and What kind? must, as we have seen, be answered in the following way.

1. For every individual his own ideal of moral selfhood furnishes the eriteria, the sanctions, and the end of morality in such manner that if he conforms his conduct to this ideal he is entitled, at the bar of universal moral reason, to be called a good man. By such conformity the individual realizes in his own personal experience the nature of that which is eternally and unchangeably right. For it is the spirit of devotion to the ideal of personal being in social relations which constitutes the very essence of ethical rightness. Only it must nerer be forgotten that this spirit itself inrolves and absorbs the entire Self, - involres all the functions and activities of moral personality in its serrice daily and momently, and absorbs them all in the rational pursuit of its more and more perfect realization.

Whatever objections may be urged against the subjective and rague character of this conclusion will be found, I think, to have been answered, either directly or indirectly, while considering in detail the nature of the Moral Self and of the Virtnous Life. The following, howerer, may seem to demand a few words additional. How is it, then, to be explained 
that so much of error in ethical judgment and of practical failure to kecp the recognized moral code may be charged against those who seem the most pronounced in their claims to pursue faithfully their own ideal of the right? To this question the reply is obvious: Claims and appearances are by no mcans sure tests of the entire, sinccre attitude of the person toward his ideal of personality; and the theory of the virtuous life shows how essential is good judgment and intelligent regard for the welfare of society, both to the con. struction and progressive improvement of every individual's moral ideal, and also to his progressive realization of that ideal. In further reply, it might be asked: How can any onc judge what is right except with his own judgment; or form a conception of what he himself, or others, ought to do or to be, except by activity of his own thinking and imagining; or feel regard for the welfare of others, otherwise than as a morement of his own affections? For me, there is no morality but my own, which can assert or decide the claim to be classified with that which is universally and oternally right. Moreover, the objections which arise from the shifting nature of the moral ideal itself are to be answered by recurring again to the conception of moral development. It is the direction and the goal of life which chiefly determines its character at any particular stage in its evolution. This is true of every form and aspect of life; but it is pre-eminently true of the moral life.

In a more figurative way perhaps, but still in accordance with empirical data, we may say that the same declaration is true of any particular society or stage in the moral erolution of the race: its own ideal furnishes for it the criteria, sanctions, and goal of morality, so that a practical correspondence with this ideal tests the rightness or wrongness of the prevalent customs, laws, and maxims. Here, again, however, the conception of development and the acknowledgment of the important and dominating part which the 
most enlightened and pure members of the race play in its moral evolution is necessary to save the idealistic theory from hopeless confusion. Of such moral leaders, moral seers and prophets of the Absolute, known or imagined as perfect Moral Personality, we may say in the words of Matthew Arnold:-

"Beacons of hope ye appear!

Ye fill up the gaps in our files, Strengthen the wavering hands, 'Stablish, continue our march."

It is by those who, standing in the front ranks on account of the position which they have attained for their own ethical ideals, reveal the advanced stages of human moral development, that the more nearly absolute criteria, sanctions, and goal of morality are set for the race. These "good few" are, indeed, children of their own age, and are never able wholly to free themselves even in the formation of their most exalted mental pictures of what human society ought to be, from the influences which are ancestral and environmental. Nor is it best, whether we consider the moral value of their own conduct or the magnitude of their influence upon others, that they should reach such an extremity of idealism as to discourage and confuse, rather than encourage and confirm, their fellow men. In them, however, the highest ideals of what a Moral Self in social relations with other selves should do and ought to be liave come to consciousness, as it were. It is pre-eminently their ideals which answer for erery age the first of our three questions.

2. The answer to the second of the three questions, proposed to Idealism in Ethics by an empirical inrestigation of the phenomena of man's moral life and moral derelopment necessarily admits only of a somewhat rague and indefinite answer. When is this ideal brought into the only existence which an ideal can have, in order that it may serre as the 
criterion, sanction, and end of morality? In multitudes of cases we may give the answer which the ordinary intuitional theory of ethics gives. The ideal is constructed at the time that the problem of conduct arises in consciousness and by the same active consciousness in which the problem arises. Thus the problem itself is solved by the very appearance of the ideal; the man envisages or intuits his duty in an intelligent and whole-hearted way. This duty is his, whatever might have been the duty of others under similar circumstances. The criteria, the sanctions, the more immediate end to be secured, are all there present, so to say, in the one transaction; and for this particular picce of conduct no further justification of its rightness is necessary than that which the present experience of the individual sceures. This is spontaneous morality; but it is no less ideally moral conduct because it is so spontaneous. In other cases, however, the actual must be brought, as it were, into comparison with the ideal by way rather of reflection and thoughtful judgment based upon the opinions of others, or upon the social requirements, or upon the calculated consequences of the conduct. In such cases the nature of the right may be either revealed in consciousness, at the end of the period of reflection, in a surprisingly sudden and clear manner, or it may come only slowly and doubtfully after all. Or, again, some logical connection of the particular problem of conduct with a law or principle which embodies for the intellect a relatively permanent phase of the moral Ideal may be indispensable in order to realize the right.

Especially must the principle of evolution be taken into the account in every attempt to answer this question both for the individual, and for the race. When do we arrive at the absolute and infallible criterion of all conduct? When is the soul's search for the morally good rewarded by discovering those sanctions of morality to which an appeal may always be made as to something universal and unchanging? 
When do we get in all its grandeur and beauty the picture of the final end which all development of moral character, at whatever cost of suffering and struggle by the way, aims to secure; and which the final moral judgment will pronounce worth all the suffering and struggle which its pursuit may have cost? Now, always, or nerer, - according to the point of view which the inquirer takes. The criterion, the sanction, the goal, is now and always with us. The criterion is our own best present moral consciousuess; the sanction is in the authority of that same conscionsness; the goal is realized every time we actually make a piece of conduct conform to our ideal of just what that conduct, here and now and under these definite circumstances, ought to be. And this statement is not vitiated in the least by the fact that, not infrequently, we are in doubt and cannot see clearly what we ought to do. For to doubt, and to act in doubt, or to refrain from acting because of doubt, - all this is what for man the highest criterion, the most imperative sanction, and the most desirable goal, of his present existence require him to do.

And, making the necessary changes in one's language, without neglecting the increasingly figurative character of those conceptions which necessitate the change in language, one may maintain that what is true of the individual is true of society at large. Nations as well as individuals, when they wish to do the right, sometimes see it clearly in an intuitive way, and do it spontaneously; sometimes they act rightly only after reflection; and then either with a clear moral judgment or in moral perplexity and doubt. Oftener, of course, they do wrong because they refuse to be moral at all.

3. In answering the third question which empiricism proposes to Idealism in Ethics, the entire course of our examination comes to a concurrent and accordant termina - tion. The ideal of morality is a Personal Ideal. As such 
it involves all the characteristics of personal being and personal life. These are the characteristics of a moral Self, living and acting in social relations with other selves. In every individual case this ideal is dependent for its construction upon the combined activity of feeling, thought, imagination, and will - the activity, namely, of the idealizing human mind. In every individual case this ideal is dependent for its partial and progressive realization upon the same activities of the same being that constructs the ideal. It is only as this Self functions according to its own nature in its different social relations that the eriteria of right conduct come into existence. These criteria themselves are the reactions of the moral personality upon the mental representations of its own behavior, or of the behavior of some other person, toward other persons in the same society. The sanctions of morality, too, have no existence other than in personal existence; they, too, are the rational and emotional responses of the same human nature. Man judges his own morality, and feels the inestimable worth of it, when he comes to moral self-consciousness. And the goal which he sets before himself for attainment by the activity of the moral self is the realization of the ideal of that same Self, - the actual, perfected personal Life in social relations with others. The idealistic answer, then, to the question, What kind of an Ideal is this which you propose as affording the criteria, sanctions, and end of right conduct? is this: It is a personal ideal, the conception of the life of moral and social Selfhood, in its whole range of constitutional activities progressively attaining the perfection of its being. In a word, it is -

“... all our rarer, better, truer self, That sobbed religiously in yearning song, That watched to ease the burden of the world, Laboriously tracing what must be, And what may yet be better." 
Two remarks may fitly bring to its close this part of the discussion. First: In determining the Nature of the Right two conceptions are of paramount and even of unique importance. These are the conception of Personality and the conception of Development. In other connections ${ }^{1} I$ have shown how the conception of a Self is needed to be understood - its genesis, nature, and unfolding - in order to describe the actual meaning of all other descriptions, and to explain all other explanations. For the world is, in all its lower individual forms of being and so-called purely physical relations, a self-like World; it is understood by science, and can be understood by regarding it, from whatever point of view, only as the manifestation of the Absolute Self in a system of self-differentiating and sclf-relating objects. And now a psychological and historical study of man's moral nature and moral development has shown that the philosophy of conduct builds itself securely upon foundations of experience only as it extends and further emphasizes this - same conception of Selfhood. To things and to the lower animals, even in our very most immediate cognition of them and of their relations to us and to one another, we attribute self-like characteristics. We do not, howerer, feel warranted in recognizing them as moral selres. But men are moral selves, and thus are capable of the truly moral and social life and derelopment. In a word, they are persons. And all the understanding of ethical phenomena in their "first intention," as it were, as well as all further results due to reflection upon the implications and the significance of these phenomena, require ethics to emphasize and comprehend the conception of Personality. The kingdom of moral realities and of moral values is a kingdom of personal beings socially related and socially organized.

Equally necessary is it to any semblance of a satisfactory ethical theory that emphasis should be laid upon the concep-

1 In the Philosophy of Knowledge and in A Theory of Reality, passim. 
tion of Derelopment. The full definition of the individual person or of the social organization is not attainable by the mind that studies only the germinal stages of personality or of society; or that confines its attention to any one, or to any group of the past stages of evolution. Clearer and clearer has it become at every step of our investigation that, for each individual person, the sourecs, the criteria, the sanetions, and the goal of his own personal life must be accounted for by what lies outside of that life; the individual cannot be regarded as separate from the great whole. And what is true of each individual person is true of every portion, and generation, and stage, of the ongoing moral life of humanity. To understand and appreciate that life the better, then, we must strive to grasp together the parts under the conception of the totality. And this the ideas and laws of the general theory of development, in a measure, enable us to do ; but only "in a measure," for another remark is needed to prepare our conclusions for the further considerations which they seem to require.

This most defensible and comprehensive idealistic theory of man's ethical life and development is far enough from being complete in itself. It shows, indeed, how the criteria, the sanctions, the laws, and the goal of conduct are all included in the ongoing life of that personality, when multiplied in numbers and socially related, which man is. But it leares us with the picture of a race of moral beings, coming we know not whence, devoting itself to the realization of ideals whose origins and sanctions are not otherwise explained, attaching a kind of absolute and unchanging value to actions that neither promise nor, so far as experience goes, actually secure any appreciable external reward; and, as set into reality by its own morally most worthy examples, pursuing to the death or even beyond death a goal that can only be very vaguely imagined, and yet that somehow incites endeavors and elicits hopes and fears quite out of all corre- 
spondence to a reasonable interpretation of man's workaday experiences with the consequences of his own conduct. In the words of a recent Chinese writer, the practice of the highest morality is not due to interest, or because of any form of natural affection merely; it is "because of the spirit of nobility in the Superior Man, strong enough to break in pieces stone and metal, and which mounts to the clouds of Heaven." This is an engaging picture; but it is as mysterious as it is engaging.

I have already said that undoubtedly the Nature of the Right must be explained in accordance with our knowledge of human nature in its moral and social development. But I have also said that unless one is willing to leave human life thus isolated, as it were, from its own ultimate grounds and thus irrationally unconscious of its own profoundest significance and supreme destiny, one must so expand the conception of the Being of the World - the World-Ground, the Absolute Self - as to find in this conception the perfection of the task undertaken by the Philosophy of Conduct. I shall, therefore, go on briefly to show how all conceptions of man's actively produced welfare involve his moral life ; and how the grounding of this moral life in Reality requires the ideas, faiths, and hopes, which the philosophy of religion alone can furnish. 


\section{CHAPTER XXIII \\ THE ETHICAL SCIENCES}

Tre value of many of the positions, whether assumed or reached by a course of reasoning in the preceding chapters, so far as their application to human life is concerned, depends largely upon the extent of the ground they are permitted to cover. It has, indeed, been constantly maintained that the sphere of ethies is coextensive with all human conduct; and that fitness for conduet is the most valuable possession and most distinctive excellence of man. With the unfolding of the total life of the individual and of society, therefore, the domain of morality is constantly widening; and there arises an ever increasing obligation and opportunity to make the practices of men serve the ideals of the moral life. All the analysis of moral selfhood and the descriptive and speculative study of the nature of virtuc, its interests, and its aims, has tended to confirm the claim of a certain supremacy for these moral ideals.

The fact cannot be overlooked, however, that other branches of the study of human life, in the most comprehensive meaning of the phrase "human life," have their more or less distinct points of view; they feel themselves entitled to insist upon the seientific rights, and both the scientific and the practical benefits of this study from their own points of view. Indeed, the different sciences of man in action have struggled hard to separate themselves completely from ethical considerations; just as ethics itself has tried to get free from the influence and the implicates of religion and of metaphysics. 
This effort has, of late, been urged on by a strong combination of practical and speculative influences. The economical, political, and social organizations of men have rapidly undergone an enormous derelopment. All manner of financial combinations - companies, trusts, syndicates - have grown big and grasping beyond all precedent in past time. The aims of these combinations are, as a matter of coulsc, as purely financial as it is possible to make them. Their "legitimate" business is to produce wealth and to distribute it to their promoters and stockholders. Their primary interests and their distinctive points of view are economical only; and they are not at all, or in very scanty fashion, ethical as well. To promote the public wclfare, or to secure the ideal purity of their administration, enters scarcely to a perceptible extent into their estimate of the ends they wish to serve.

What is true of the financial combinations of men is also, to a large extent, true of their political combinations. Everywhere, the rulers of the nations, and all the forces that chiefly control the relations of nations, are eager to make their political combinations strong, and prosperous commercially, with an almost complete disregard of the bearing of moral considerations upon the means to be employed for the accomplishment of their ends. Interest in ethical theories of the state, or in the serious consideration of the application of moral principles and moral ideals to the relations of nations, is relatively languid and ineffectire, where it is not wholly wanting at the present time. Socicty itself has recently shown an almost overpowering disinclination to regard its own more lasting and larger interests and aims from any distinctively ethical points of view. With the increase of material prosperity in certain quarters of the globe there has bcen no corresponding popular increase of inquiry into those principles of conduct upon which all social organizations have their basis, and according to which all real social progress 
must take place. With the standing still or the decline of material prosperity in certain other quarters of the globe, there has gone on a corresponding stagnation or decline in the moral standards.

This condition of human affairs, economical, political, and social, when regarded from the point of view of actual practice, has been related as both cause and effect to the pursuit of the sciences of economics, politics, and sociology so called. The scholastic students and recognized authorities in these subjects hare for the most part come to regard the problems confronting them, in a totally unethical way. Ethics, we have seen, cannot be made an exact science; perhaps - for I have shown how little I care to claim any right to the term - ethics, as the philosophy of human conduct cannot be made a science at all. Certainly, in so far as the handling of its phenomena can be subjected to scientific tests, the problems of ethics do not admit of a satisfactory solution by the empirical method. But it has been the pardonable, though forever unattainable aim of economics, politics, and sociology, to take their place among the sciences which can claim to have employed the empirical method in the more exact forms of this method. The semblance of deductive and demonstrative method which the older treatises on these subjects affected has very properly been abandoned. Its results never even attained the trustworthy semblance of science. The inductive and historical study of the economical, political, and entire social aspects of human life and human development is a very distinct advance beyond anything which the older method could hope to attain. But, in their attempts so to catch and represent the spirit of the age as to give scientific character to their conclusions with regard to the economic, political, and social life of man, without taking also into account the pervasive and permanent character of his moral and spiritual being, the students of these sciences will continue to labor largely in vain.

The individual man in action, however his action is diver- 
sified and to whatever end it is directed, is a psychical unit, a Moral Self. And society, however we may contest the propriety of regarding it under the figure of speech suggested by the word "organism," is composed of such units. The growth of society, the progress of so-called civilization (whatever that may be thought to signify), and all the development of human institutions of every sort, are the resultants of the reactions of moral selves upon one another and upon their environment. The human individual and human society can, then, no more escape from the sphere of ethics than (to borrow an old figure of speech) the greylound can outrun his own shadow. Nay more: human society cannot exist or continuc, in any one of its varied forms of existence and development, otherwise than as the construct of ethical beings living together in all the varied relations of which their ethical being makes them capablc.

Economics, politics, and sociology, are, therefore, psychological and ethical studies. If they are erer to attain the corcted distinction of being called "sciences," it must be with the same allowances made for inexactness, doubt, and growth upon the basis of accumulating experience, which belong to all the attempts to formulate the principles that control the nature and development of man, as placed within, and active in, his historical environment. These sciences can never dispense with psychology and ethics. They can nerer advance far beyond the points of successful and permanent construction provided for them by psychology and cthics. Indeed, one might properly add the study of the religious nature and religious development of man to the list of prerequisites for the more successful cultivation of economics, politics, and sociology. Certainly in India and China no one can begin to comprehend the economic, political, and social problems which there require theoretical and practical solution, without understanding the ethico-religious views and practices of the people. Nor have America and Europe 
yet become so free from superstition or so little religious that the same thing is not true of their peoples also.

The attempt to render the other principal sciences of man's life and development independent of ethics must, therefore, always and inevitably result in failure. The claim to have succeded, cven partially, in this attempt, is a shain. The continuance of the attempt is likely to be fraught with balcful practical results. It has already worked a certain evil amongst the multitudes of men. The race will never play "Hamlet" with the passions, fears, faiths, aspirations, and speculations of the hero left ont. The whole of human history is predominatingly ethical and religious in its motif, its tendencies, its guiding forces and ideals. It is a mixture of tragedy and comedy, in which, in every act and every scene, gods and godlike men and devils and derilish men, are taking their part. In the production and distribution of wealth, in the formation, disintegration, and reformation of states, in the construction, improrement, and deterioration of social organizations, the ethico-religious being of humanity is always seeretly or openly at work. Therefore, no historical and empirical study of man's economic, political, and social constructions and developments can be trustworthy or - much less - complete, which does not take this ethico-religious being into account.

The objection may be urged against the foregoing view that, although the sciences of economics, politics, and sociology, deal with the description and explanation of phenomena which are facts of human conduct, and which therefore belong to the proper sphere of ethical inquiry, they deal with these same phenomena from quite different points of riew. In a word, these sciences consider conduct as cause and effect of economic, political, and sociological conditions, but without any reference to its more distinctly ethical or unethical character. They are sciences of actual facts, as fact; but ethics has been defined as a study of what 
ought to be in human conduct, and of the relations which facts of conduct sustain to a developing ideal. There is a certain measure of foree in this objection. But after all, the distinction here introduced is more fietitious than real, more purely theoretical than practicable in the concrete work of establishing these allied sciences. For - not to be continually reiterating the statement of fundamental positions and of conclusions long ago sufficiently established - the ethical feclings, judgments, and moral choices of men, with all their unique psychical characteristics and reactions, are pervasive and powerful facts affecting the whole of human life and human development, in all manner of human relations. As such, these phenomena determine, and are indeed integral parts of all those activities of men in the relations to which the sciences of economics, politics, and sociology give their attention. The relations themselves, I affirm, are essentially and indissolubly connected with, and dependent upon, the ethical nature and ethical development of man.

The more detailed working-out of the applications of ethical principles to economic, political, and social conditions, belongs to the appointed task of the students of those conditions. A general treatise of ethical sort, or more especially a philosophy of conduct, cannot attempt this task. After dismissing as fallacious the general assumption that these three seiences-economies, politics, and sociology - are capable of treatment without the assistance of ethics, and that their ideals are realizable apart from the ethical ideal, I shall therefore content myself with a few remarks upon each of the three.

The development of the resources of any country or smaller social unit, and the distribution of the wealth thus produced, is necessarily always a matter in which moral forces, moral principles, and inoral values, are deeply concerned. For, in the first place, a large basis of fact and law, physical and physiological, underlies and controls the 
actions of men in those relations which are dealt with by economies. These same facts and laws furnish the absolutely rigid, or more elastic conditions, under which the conduct of men shapes itself into the eustomary forms of morals and of moral development. For example, there is the entire sphere of the sexual relations in which the close eonnection of economies and morals may be illustrated; and here this connection is made close and permanent because the same physical and physiological facts must be eonsidered from both points of view. The ethics of sexual intercourse and the economics of sexual intercourse are, to a large extent, made one by the structure and functions of the sexes. Those same natural differences of man and woman which determine their relative values in the economieal seale decide also, in large measure, the right and wrong of their conduct in their mutual relations. The relative helplessness of the human infant, and the relatively long time which it needs in order to develop to a fitness for self-help, is also of both economic and moral significance. Thus the same group of unalterable and indisputable physical facts determines both the ethics of the family life, and also the economics of the family in its relations to the production and distribution of domestic and national wealth. And in spite of the present vast and far-reaching disturbance of old-time views concerning both these aspects of the relations of the sexes, there are unmistakable signs of a preparation on the part of the natural laws to reassert their supremacy. No economical changes can be lastingly successful, from the point of view of economies, which violate those ethical principles regarding right relations of man and woman, and of the family life, which the race has won through centuries of experiment and struggle in its pursuit of ethical ideals. This is because both the ethics and the economics of family life rest upon the bed-rock of unalterable physieal and physiological preconditions. 
Were it necessary - as, indeed, it would be if one were making a detailed study of the ethics of economies - it could be shown how the same principle admits of varied illustration and application in many of the relations which men, as moral selves, sustain to one another. But it will serve the present purpose better if we invert somewhat the terms of the proposition and consider, in the second place, how impossible it is to make the conduct of men ethically correct, or to secure a progressive correspondence with the rising and changing moral ideals, without regard for the facts and laws appertaining especially to that experience of the race with which the science of economics deals. Men are universally and unchangeably obligated to the virtues of wisdom, prudenee, fidelity, justice, and kindness. But, as has already been shown with abundant illustration and argument, there is no infallible and a priori way of determining just what conduct is wise, prudent, faithful, just, and truly kind, in any particular combination of circumstances. The rather is it true that, in the effort to put into practice the disposition toward these virtues, some of the sererest confliets of duty arise. Now these same virtuous forms of conduct have also the very highest economical value. Judged by historical and empirical standards, and without neglecting well-founded deductive arguments, the most suecessful development and the most satisfactory distribution of any country's resources depend upon the actual exercise of these virtues by the people themselves. Nothing is more foreboding of economical evils, or more certain to be disastrous in its final results, than the too prevalent impression that individuals or nations may attain the highest lasting economic prosperity without the assiduous practice of the cardinal virtues. Over and over again has it been demonstrated in the history of the race that nations must, in the long run, pay back erery dollar of treasure and every drop of blood of which they have possessed themselves in disregard of fundamental ethical principles. 
This close and permanent relation between ethics and economics makes the two reciprocally dependent. Ethics prescribes for economics those ideals of the virtuous life, that pattern of dutiful moral selves living together in a variety of social relations which has been for unnumbered centuries rising and gathering clearness and strength in the consciousness of the race. Economics teaches ethics by what more precise forms of conduct, and under what particular kinds of physical environment, the means may be secured and employed, for the better realization of these ideals;but this, only in a given class of human relations, viz., those which concern the development and distribution of material resources. Thus it comes about that, to disregard the influence of the ethical ideals which are set by such conceptions of the virtnous life as answer to these words, wisdom, prudence, fidelity, justice, and kindness, - is bad economical policy. But how to make these virtues effective requires that good men should hare some knowledge of economical principles. Ethics must inspire economics with its ideals, must soften and vitalize its otherwise hard and even brutal formulas, must inform it of the higher obligations which rightfully assert an ever-increasing supremacy over the lower passions and desires. Ethics must rebuke and chasten economics when, as so often happens, it tends to forget that selves can never be treated as mere things; and that there are loftier considerations for individuals and for nations than the unrestricted increase of their material prosperity. On the other hand, the virtnes which secure material prosperity cannot be practised in those relations with which economical science deals without instruction from this science as to how the practice is to be shaped and is most successfully to be secured.

There is probably no other land where the reciprocal relations and influences of economics and the ethico-religious life of the people are so curiously, and in such a complicated 
matter, intertwined as among that conglomerate of peoples called India. How shall the improved sanitary and economical condition of the multitudes be brought about in social organizations where the power of the money-lender and of the grain-merchant is chiefly conferred through the dominant and oppressive regard for quasi-religious functions ; where, for example, millions would rather die of starvation themselves than kill a cow for food; where the management of the sewers is likely to set the entire body politic aflame with a quasi-ethical zeal for rebellion; and where bubonic plague runs riot, and the crops of the starving are allowed to be ruined, because the extermination of rats is forbidden by established moral and religious principles? But what is true in such exaggerated form of India is essentially true of all peoples in all ages. The development and distribution of their material resources cannot be considered irrespective of the influences constantly exerted by moral forces. Nor can the peoples themselves develop the higher qualities of ethical judgment and sound moral practice without instruction as to economical laws and economical conditions.

The great economical problem of the present age is most distinctly an ethical problem. In the more prosperous nations, and between all nations, this problem concerns the distribution rather than the production of the world's resources. The development of physical means for effecting this distribution makes the problem more distinctively ethical. And all the subordinate problems - for example, of the tariff, taxation, reprisals and wars for commereial aggrandizement and supremacy, are great moral questions. That they are so little considered from the ethical point of view, and in the light of the practicable ideals of the virtuous life, is the principal economic shame and menace of the present age.

What has been said of ethics and economics, in respect 
of their relations to each other, is also true of ethics and. Politics. Politics, or the science of human conduct under the relations of "statehood" (including municipal and all other forms of governmental organization), has its own basis of physical facts and physical laws. And right conduct for the citizen, whether ruler or subject, in all the various relations under which men are organized politically, is impossible in disregard of this basis of facts and laws. The same environment forms the inescapable conditions of the moral life and of the political life. The same physical eonditions surround the individual, and determine the quality and the consequences of his conduct, whether he be considered as citizen of a state or as one of many moral selves in the looser relations of society so-called.

If, moreover, we consider the psychological and social origins and development of the state, the necessarily ethical character of the science of politics becomes yet more obvious. It is not by the enactment of contracts which are motived and controlled by purely utilitarian conditions, and even less through the pressure of force and necessity in a purely physical or brutal way, that men come to associate themsclves together politically. The rather does the state have its origin in obedience to a command that is respected as divine, in filial and deroted affection toward the head of the family or toward one's dead ancestors, and in loyalty to the leaders of the tribe. ${ }^{1}$ But these feelings and forms of action spring from the nature of the moral Self in its social relations with other moral selves. The origin of the state is, then, distinctly ethical. So, too, does the character of its development depend in a very important, if not absolute way, upon the moral status and moral progress of its individual members; even more upon those prevalent customs and current standards of opinion which represent the moral eulture of the people at large.

1 Comp. Wundt, Fthics, I, p. 279 f. 
That the seientific treatment of political phenomena is pre-eminently an ethical discipline has aways been acknowledged. So truly, and to such an extent, is the connection between ethics and polities to be maintained that it is difficult, as well with respect to their history as their conecption, to separate between the two. Plato's Republic is a discussion of Justice "writ large." Now "Politics," says Aristotle, " seems to answer to this description," - namely, that of the "master-science" of the final ends of all action, of human life itself. Ethies is, then, "a sort of political inquiry." The Confucian ethies, as it has developed in China and Japan, is political. And Christian ethies, in its conception of the divine Family including all men, or of the Kingdom of God, obviously and in a very pregnant manner extends the doctrine of responsible conduct over all the relations which are covered by any of the sereral forms of statchood among men. Indeed, "the self-acknowledgment of the state that it is a moral institution" ought to be so firmly established as nerer again to be questioned.

The ideals of human political organizations are also ethical ideals. The moral ends of statehood hare, in fact, been progressively more clearly defined and more emphasized during the political evolution of mankind. Any tendency to dispute or to depreciate this profound truth is, however much such a tendency may refer to the "illumination ideas" of the eighteenth or any other ecntury, a distinct retrogradation in political theory. Neither commereial prosperity, nor the spread of intellectual enlightenment, can serve by itself to suffice the final purposes of political organizations among men. And Japan, which still insists upon ethico-political instruction for the citizen from the earliest to the latest periods of his education, is clearly entitled in this regard to serve as a model for other nations.

It is by no means elear that there is a science which may 1 Nic. Eth., I, ii, 5, 9. 
properly be called "sociology," or "societology," or by some similar term. If the intention is to apply such terms to all attempts at a scientific treatment of the conception of human society, or of the actual historical development of human social organizations, or of the physical and psychological conditions of their origin and evolution, then we are met at the beginning of all such attempts by these essential facts: (1) all the physical sciences which relate to man's environment upon the earth serve as introductory or essential parts of the so-called science of "sociology;" and all the sciences of human nature are allied branches of it. But (2) defined in this way (which is almost equivalent to its not being defined at all) sociology seems to lose all clain whatever to a definite scientifie character, and to merge itself, so far as it is scientific at all, in certain other mure particular and definite sciences; and, finally, (3) so far as it remains sociology, the result degenerates into propositions of a very indefinite and disputable, or purely speculative character. A specific seience, deserving this particular name, can therefore scarcely be said to claim either existence or raison d'être.

The term "society" properly applies to a number of persons who are associated together for whatever purpose or by whatever connection or bond. In the very conception the two important words are persons and association; associated selves constitute every kind of a society. The conception, therefore, is essentially psychological and ethical. Human society, of every description and in every stage and era of its development, is constituted by moral beings who conduct themselves in common relations to some environment, and in reciprocal relations toward one another, for the attainment of some end. Of socicties there exist in fact innumerable kinds; and the several kinds, as well as the multiplications within the area of the same kind, are ceaselessly coming into existence, running their more or less brief 
course, and passing to their end. Society, spelled with a capital $S$, has no existence, and no chance for existence, except in the theoretical imagination of the individual man. In the wider significance of the word "social," all human life and human activity, under anything resembling normal conditions, is necessarily social. At his birth, in his training, in his activities and aims, the human being is constantly forming and breaking these different associations with those of his own kind. But all this falls within the sphere of conduct. Therefore, whatever one may mean by the science or theory of Society - whether it be a study of the abstract conception connoted by the term, or of the actual physical and psychical conditions which environ all the different associations of men, or of the historical derelopment of some selected few of the many forms of human social organization - this science or theory cannot separate itself from ethics.

As I have already said, a general treatise of the philosophy of conduct cannot expound or vindicate in detail the ethical character of economics, politics, and so-called sociology. They are, indeed, all ethical sciences, or studies of the conditions, laws, results, and ideals of men - of moral selres in their various relations of a more particular or a more general social order. It is enough for my purpose at the present time to have indicated how wide and inclusire is the sphere, how theoretically and practically important are the principles and ideals, of the moral life and moral development of man. Neither in his economic, nor his political, nor in any of his other varied social relations can man escape the necessity, or deny himself the high privilege of paying regard to the laws and ideals of morality. As a tradesman, as a citizen, as a member of many forms of society, he is always a Moral Self; and not the pursuit of happiness for himself alone or for others, or the mere keeping of a Law, however austere or lofty, can wholly take the place of the 
supreme Ideal of conduct. As Mr. Shadworth Hodgson has said: ${ }^{1}$ Ethics is "a science which is supreme over the whole of human practice." Economics, politics, and sociology, are therefore ethical studies; and so far as the ideals which they hold up before humanity are realizable as results of human conduct, they are subordinate parts of the Ideal of Ethics.

1 Metaphysics of Experience, III, p. 214. 


\section{CHAPTER XXIV}

\section{MORALITY AND RELIGION}

What Pfleiderer ${ }^{1}$ calls the "positivist view" - namely, "that at first religion and morality had little or nothing to do with each other," he declares to be contradicted by everything we know of the early history of mankind. Indeed, the same authority has previously ${ }^{2}$ asserted the truth of exactly the opposite proposition: "The historical beginning of all morality is to be found in religion." In a more qualified and cautious way we find Wundt affirming in his treatise of Ethics: ${ }^{3}$ "History shows that almost all, and especially all the more significant forms of life have their root in religious motives that have disappeared from the consciousness of a later age; and thus teaches that man's self-education in custom and morality begins with the development of religious worship." And Waitz, ${ }^{4}$ who speaks from the standpoint of the most sane and accomplished student of anthropology, declares: "There is hardly a more trustworthy sign and a safer criterion of the civilization of a people than the degree in which the demands of pure morality are supported by their religion and are interwoven with their religious life." That admirable little book by Roskoff ${ }^{5}$ shows how, in the natural order of the development

1 See The Philosophy of Religion (translation from the second edition by $\Lambda$. Menzies) IV, p. 238.

2 lbid., IV, 230.

8 I, p. 134.

4 Anthropologie der Naturvölker, IV, p. 128.

5 Das Religionswesen der rohesten Naturvölker, p. 175. 
of human life, "Custom and the Law receive divine sanction, the connection between religion and morality is placed in elear light, and the two appear in their reciprocal relation."

The historical facts which compel some such conclusion as the foregoing are undoubted. The current anthropological teachings which either overlook or minimize the conclusions that follow logically from these facts deserve the severest testing, if not the promptest rejection. There are two riews, however, about the more important and permanent relations of morality and religion which must be regarded as representing two about equally unwarrantable extremes. In treating briefly of them, and in proposing the true opinion, which mediates and reconeiles these extremes, I shall continue to take the ethical point of view. The more full discussion of the entire subject belongs to the historical and theoretical study of the phenomena of man's religious life to the so-called philosophy of religion. But its importance as bearing upon the ultimate problems of a philosophy of conduct, and especially as affecting one's views of the origin, sanetions, and final purpose of morality, and of the nature of the moral Ideal, cannot be overestimated.

Of the two extreme views one advocates the complete separability of morality and religion; the other, their complete identification. The former is not held solely by those who incline to that philosophical point of view adopted by the Positivists which Pfleiderer controverts; it is held by a certain select few who are purely and somewhat passionately devoted to the Moral Ideal, but who find themselves more or less unwillingly agnostic concerning the fundamental verities of the religious life; and it is also held by an increasing multitude who tolerate the customary and conrentional opinions of their class respecting moral problems and moral practices, but do not bother themselves at all about religious affairs. The opposite view which identifies morality and religion throughout - the ground, the sanc- 
tions, the meaning, and the ideal of both - has customarily been promulgated by two classes of thinkers and writers; these are the theologians and certain idealistic moralists. The former ordinarily choose to identify morality and religion by making religion absorb morality. They find in their conceptions of God and of his relations to humanity the full, and the only account of the origin, sanctions, worth, and ideals, of the moral life and moral development of man. But the latter identify morality and religion by making morality absorb religion. Religion as theoretical, as a metaphysics or a reasoned system or a faith, is with them nothing more or less than an ethical view of the worldorder. And God, if he is not Himself identified with the moral world-order (the "power not-ourselves that makes for righteousness"), is of use, so to say, only as the postulate, and the vindicator of the moral consciousness.

It will be found, I think, that most of the confusion and the antagonisms over the problems involved in defining the relations of morality and religion arise in too narrow and one-sided views of human nature and of its complex interests, activities, and forms of development. In a technical word, they are primarily psychological. Here, as everywhere, philosophy goes back to the full and rich knowledge of the Self, if it would escape the severest pains of disappointment and the direst disasters of controversy. "Know thyself"the full, richly endowed Self, sensuous, intellectual, artistic, social, but also both moral and religious, and jet always a unity of selfhood in a course of development; it is because they neglect, or are ignorant of the choicest deliverances of self-study that so many go astray over this subject. ${ }^{1}$

The historical facts of man's moral and religious derel-

1 If theologians, moralists, and anthropologists alike were only also psychologists, and familiar with the hroader fields of those sciences that treat of the soul of man, there would be less of unjustifiable assurance on some points, and more of certainty and agreement on others, in their average discourses about the relations of morality and religion. 
opment lay the basis for that psychological theory of the relations between morality and religion which must itself serve, in turn, as an important part of the basis on which to rest our conclusions respecting the ultimate problems of ethics. The nature of these historical facts has been indicated in the opening paragraph of this chapter. It is desirable that they should be presented here in somewhat more of detail.

But, first of all, it should be understood - what a serious study of the nature and development of human religious consciousness establishes beyond doubt - that man, as man, is essentially and everywhere a religious being. $J$ ust as surely as all men are speech-making and speech-using, are instinctively and naïvely metaphysical, and are moral and social in their nature and in their institutions, just so surely are all men also religious. Religion is, with man, no adrentitious or temporary thing; it belongs to man as man; it is implanted in his constitution, that he should seek after and believe in the "Over-natural," which is the hidden Spirit and Life of all that appears in his experience. And, furthermore, the roots of man's religious nature, and the sources and sanctions of man's religious experience, are not exhaustively to be found in any single form of natural functioning, or in any one aspect of his unfolding life. Not intellect alone, or feeling alone, or the necessities and outcome of the practical life alone, but all together as allied forms of the activity of the one soul of man, furnish the sources from which his religious experience arises, and in which it finds its sustenance and growth. No wonder, then, the nature and origin of religion being such, that morality and religion are so closely and even indissolubly allied in the experience of the individual and in the history of the race. But all the more because both morality and religion spring out of the complex being of man as reacting in manifold ways upon its physical and social environment, and 
because both derive their discipline and their culture from the same complex history of man's development, do they differ in a variety of secondary but by no means unimportant ways.

The history of humanity shows that morality and religion have, in fact, to a large extent a common origin. As I have already said, the opinion of Saussaye and others, which was always based entirely on a priori grounds, that morality and religion had a separate origin and were later forced into union by the environment, as it were, is disproved by many facts of history. The nature-myth, for example, has always served as a common root for both. In this myth, some natural power or natural phenomenon is deified and made the object of religious feeling and religious worship; but man's welfare, as dependent upon his own conduct, is necessarily more or less connected with every such myth. Hence morality and religion find in every such work of thought and imagination a common root. Nor does it even hold true, as Wundt seems to suppose, ${ }^{1}$ that the separation of the naturegod from the natural phenomenon is necessary before ethical ideas can be connected with him. exemplified in different divinities, because these divinities have themselves been idealized in different ways. And thus the hero-legend may become a root out of which grows a closely connected development of religion and morality. In this way respect for the virtues of courage and courageous efforts in behalf of others became connected with legends of the god Heracles. Where the idealization is more complete in the interests both of religion and morality, we may have some important aspect of the divine Being represented, and its corresponding form of virtuous life commended and enforced by a particular divine example. Thus the merciful and pitiful side of God, and the duties and blessings of 1 Ethics, I, p. 86 f. 
mercy and pity, are presented by the Buddhistic conception and worship of Kwannon. The same thing is seen in the worship of Mary as the embodiment of the motherly tenderness of God.

Wherever reverence for ancestors, and the continued feeling of filial piety toward them after death, are prevalent and influential - and this is the case among many peoples - these feelings furnish a vigorous common root for morality and religion. Cruclty to one's aged ancestors uniformly marks the lowest depths of barbarous immorality. And, as especially among the Japanese and Chinese, fidelity to the Emperor, the daimyo, the head of the clan, becomes the central principle of morality. Whenever the bodily presence on which it is concentrated is removed from sight, this reverence takes to itself more of that feeling of mystery, that respect for the invisible, that veneration before the worth of unsecn realities, which is of the very essence of the religious life. In support of this vicw reference might be made to the standing which the genii, the manes, the lares and penates, of ancient Rome had in the moral and religious development of its people. In this way the deified ancestors or idealized human beings of any people become moral ideals and set the standards of accepted customs and moral laws, either by depressing or elevating or otherwise modifying them.

In these and numerous other ways the close historical connections between morality and religion, which may be traced from the recorded beginnings of human history, have been brought about. Thus it has been made true in fact that no system of religious doctrine, or set of rules and observances for the practice of religion exists, which does not involve ethical principles, enjoin duties, and inculcate virtues. On the other hand, it is difficnlt, if not impossible, to live virtuously in any social organization without giving some practical recognition to the current religious beliefs 
and practices. But this truth, which is merely the expression of historical facts - a sort of general fact of anthropology - has its own explanation in considerations that are permanent and lie deep down in human nature. It is all the more necessary to insist upon this conclusion because it is often assumed that, whaterer may have been the case in the earlier and cruder stages of man's social evolution, the progressive divoree of morality and religion is sure to be accomplished and greatly to be desired. This assumption cannot be justified. It is made improbable, or eren impossible, by what we are constantly learning as to the origin and laws of the development of the total moral and social selfhood of man. A long treatise would be needed even summarily to present in its full force the argument for our contention, but it can be maintained. We may not identify morality and religion; we must not absorb either one in the other, or cultivate one to the exelusion of the other; but, on the other liand, we can never divoree morality from religion, or safely fail to recognize both theoretically and practically the dependence of morality upon religion.

We have seen that the cssence of morality consists in an intelligent and voluntary devotion to an ideal of conduct; and that this ideal of conduct is the conscious life of a Moral Self which is functioning in all its relations toward other selves in the social organization so as most perfectly to realize this ideal. But religion, in its more primitive forms, is belief in the real existence of superhuman beings, of the "Orerman;" this belief is joined to the feelings of fear or reverence, dependenee, trust, and love or dread, which arise out of the belief; and it expresses itself in certain acts of worship, allegiance, and obedience. In both morality and religion the Ideal is a personal affair, and one which ealls for an adjustment of relations toward it that involve in a large way the entire sphere of human experience. "But that which is a demand in morals becomes a reality in religion." And 
other important differences between the two attitudes of mind and of life toward their respective ideals might be noticed. What most impresses the student of the philosophy of conduct, however, is the essential likeness of the two.

For, in the first place, morality and religion have much the same psychological origin. The truth is not simply that they are both outputs of the same soul of man, as he is surrounded by the same physical and social environment and develops within the one general course of human history. Morality and religion have yet more profound and sensitive connections in human nature. The roots of the two are intertwined in similar instincts, feelings, faiths, and other experiences. Nor can the whole case be summed up by saying with Paulsen:1 "Both spring from the same root, the yearning of the will for perfection." This is too vague and mystical. There are, at least, two specific forms of human feeling - constitutional and universal even in the lowest stage of social relations - which form a twin root for uniting morality and religion. These are fear and piety. The former is the more simple in structure, but is exceedingly varied in its manifestation; the latter is more complex and includes elements from several primitive forms of emotion, such as admiration, sympathy, respect, and even the more refined forms of fear itself - namely, reverence and awe. The very nature of the invisible and unknown powers which are symbolized by material or personal forms is such as to excite feelings of more or less lively fear. Their wishes ean be only imperfectly learned; their commands must be received and interpreted in a somewhat mysterious way. Hence the more potent is the fear they inspire, and the greater the need of man's care that their mandates are understood and obeyed. God, or the gods, cannot be rendered intelligible to human understanding without conceding the essential likeness of divine and human selfhood; but God,

${ }^{1}$ See Paulsen, A System of Ethics, p. 419. 
or the gods, cannot inspire the religious feeling without being conceived of as superior to man. How excedingly similar in both respects - in respect of its likeness to man and in respect of its superiority to man - is that ideal Moral Self which each one somehow, and to some extent, fears and reverenees; whether this Ideal takes the subjective form of the mandate of conscience, or assumes the more objective representation of the better part of socicty commanding the individual's allegiance and judging and punishing his misdeeds!

In the broader meaning of the word, howerer, it is some kind of piety which most allures men to righteousness and also deters them from vice and crime. In spite of the cold and hard impersonal character to duty upon which Kant and the legalists in ethics generally insist, it is a loyal and affectionate regard for personal considerations which secures both the lower and commoner, as well as the higher and rarer, forms of morality among men. Domestic loyalty and domestic affection, the courageous and faithful allegiance to the interests of the tribe or other social organization, the trusty and loving service of others, in a word, Piety, is the summing-up of all virtuousness for the multitude of men in the majority of their daily transactions. But when this personal interest is concentrated upon the deified ancestor, or the gods of the tribe, or of the particular tribal or national religion, but - more especially - when it becomes a supreme and passionate devotion to the serrice of the one true God, although such serrice is called "religion," its moral character and influence over the life of conduct is not so essentially changed.

Nor are the character and the influence of that complex attitude of soul toward personal interests, which $I$ have called piety, essentially altered by the most thorough culture and supremely worthy derelopment of both the moral and the religious life. Regarded as morality, the culture of 
piety extends the affectionate respect for personal life far beyond the narrow cirele of the deceased members of one's own tribe or family, into the wider circle of all sentient and rational being. The truly pious heart of the cultured good man fecls the obligation to virtue as having for its object the whole of mankind. Such is in large degree the true thought which Kant reaches when, in the Seeond Section of his Metaphysic of Morals he changes his point of view and his theory besides: for, having before made the essence of morality to consist in a too unfeeling and purely rational (in the narrow meaning of this word) respect for an impersonal Law, he now recognizes the truth that morality is essentially an intelligent and rational regard for the interests of a Kingdom of Selves, an ideal of personal dignity and worth. Personality is the only true splere of ends that are absolute and final. But regarded as religion, the culture of piety reaches substantially the same point of view, the same temper of mind, the same spirit of devotion to an essentially identical ideal. For the deified ancestors, or the gods of the tribe, or the nature-gods, let us substitute the cultured monotheistic conception, and consider the attitude toward the World and toward Life, which properly aceompanies this coneeption. Now the supreme motive to goodness beeomes the adoring and loving service of the One Personal Absolute who, although $\mathrm{He}$ is the alone Absolutely Good, shares his goodness with all finite sentient and personal life, and thus assigns to them as well as to Himself the fceling and the exercises of piety, in the religious meaning of that word.

The close relation between morality and religion, and yet the infelicity of a complete identification and the complete impossibility of a divorce of the two, may now be made clearer in a somewhat different way. Let us, then, raise and briefly answer the following question: What effect, if granted, do the postulates of religion have upon the concep- 
tions and principles of ethics? That the great majority of men have always acepted, and to a certain extent acted upon these postulates, is one of the plainest general facts of luman history. Nor is there sufficient reason extant - no matter how enormous one may estimate the opposing influences to be - for believing that any considerable number of the human race will snceed in divesting their minds or their lives of the influence from these postulates. The question we have just raised is, therefore, most important for the student of the philosophy of eonduct who wishes to understand its profounder and more difficult problems while, at the same time, not removing his point of view from the ground of actual human experiences.

The ease may be briefly stated as follows: Man is, as a matter of fact, a moral being. Man is also, as an equally sure matter of fact, a religious being. But $m a n$ is, considered as an individual, a unique kind of unity. And the human species, considered in its speeific characteristies and specific development, is a looser but no less real kind of a unity. Now in human history these two aspects of human nature and of human derclopment have always been most elosely allied, most powerful in their reciprocal influence. Suppose that the inquirer professes - and to this there is perhaps no objection, but sereral considerations in its faror - to be a man of faith, or even of alleged knowledge leading to indubitable convictions, in matters of morality; and that the same inquirer has little aptitude, and perhaps no taste and scanty respect for religious truth, and for the life that grows out of such truth; at any rate he must be prepared to face the facts, and all the facts, of a human experience which is always, in the large, both ethical and religious. Let such an inquirer consider, then, certain religious truths as mere postulates; and let him also consider the practices which, in fact, grow out of these postulates as concessions to the faiths, fears, hopes, and 
aspirations of humanity. What follows from these postulates within the more definite and special sphere of human conduct as studied from the moralist's point of view?

In answer to such a question as that which has just been raised one may confidently say, first: A certain considerable class of new duties and of new ethical problems are now forced prominently upon the attention. These duties and problems are not "new" in the chronological meaning of the word; on the contrary, they are as old as the history of the race itself. They are logically new only to the mind which has accustomed itself to separate the faiths and practices of the popular religious life from all its own conceptions and principles regarding what are the essentially right and wrong forms of human conduct. These duties and problems of duty which uniformly arise out of the current religious faiths and practices, cren when one considers the latter as merely postulated, are too complex and varied to admit of easy elassification. I shall, howerer, mention three classes which will serve, at least, to illustrate my meaning.

And, first, religion, as both faith and practice, creates a multitude of associated members within the larger social oryanization, whose duties, when considered from the religious point of view, become special; and who, by their very cxistence, also creatc a special class of duties toward themselves on the part of the other members of the same social organization. Such persons are the priests, prophets, ministers, acolytes, and religious devotees; as well as preeminently the authorities and rulers in the different religious associations whatever the character of the religion in question may be. The situation is rendered more perplexing ethically by any sort of union between Church and State. Granted only the existence of any class of specialized persons, - such existence is everywhere a fact that must be reckoned with, - and the treatment which they receive from the individual, from society, and from the government, 
becomes a complicated problem in morals. It is utterly vain and unhistorical - whether it be impious, or not - to reason theoretically, or to practise as though this class were, under any existing circumstances or under any circumstances likely to exist, to be treated precisely like all other classes. All morality, as we have repeatedly seen, is special in its application. The outcry against priesteraft and against the domination of the ecclesiastic is indeed warranted by the facts of history. The throes of the governments of the nations in their efforts to rid themselves of this domination are indeed pitiful. The hatred and despite of it are largely pardonable, if not wholly justifiable, in view of human experience. But the throes and the woes of the peoples in their efforts to obtain freedom from all special obligations to the classes which represent religious ideals and religious authority are no more severe and pitiful than the throes and the woes of those who imagine themselves permanently to have effected at least in this more external regard, a complete diroree between morality and religion. To establish this conclusion, witness the French Revolution. And it is unwise, with that unwisdom which is saddest of all because it overlooks or despises the teachings of history, for either France or the United States to-day to think it possible to treat the religions associations of the former country, or the religions orders in the newly acquired territory of the latter comntry, otherwise than as affording a very special and complex ethical problem. The individual man who prizes and cultirates the pious life, whether from the dominatingly moral or the religions point of view, is sure to lose something from his morals without gaining anything for his claim to superior intelligence, by refusing practical recognition to any sincere and faitluful representative of the religious organization and religious development of humanity. Nor can the student of the philosophy of conduct fail to sympathize with the advocates of a freer course for the religious life and of more recognition for 
spiritual authority in any fair and reasonable contest with the rule of "blood and iron."

In the second place, by far the majority in the different larger social and political organizations of men recognize their obligation to perform certain acts as so-called religious duties. This is to a great extent true in the most "irreligious communities." Impicty toward the gods and impiety toward man show essentially the same spirit; they march hand in hand; they grow strong and insolent in each other's company. But in many communities the sphere of conduct orer which these more definitely religious duties spread themselves constitutes a large portion of the practical life. The example of the Hindu religion in India may be referred to again in this connection. "He," says the Egyptian "Book of the Dead," - " he who blasphemes the king, his father, or his god, he who lends his ear to evil and remains deaf to the words of truth and righteousness, he who liurts his neighbor or despises the gods in his heart, he cannot cuter into the dwellings of the blessed dead." Such sins as these are violations of piety in both its moral and its religious aspect. And although this code is largely negative - a forbidding of immoral conduct in the name of religious authority and with religious sanctions - there is abundant evidence to show that the same relation maintains itself between the more positive injunctions of religion and the equally positive injunctions of morality. In the lower as well as the higher stages of ethico-religious derclopment human experience is essentially the same. The tattooing of savages, for example, is in many instances a quasireligious rite made obligatory at puberty as a matter of practice. Who can fail to regard the practice as much more respectable on this account than when indulged in by the modern English lady or gentleman - the motive being in this case a fashionable fad? Again, are the lascivious dances which are so widely prevalent in connection with 
certain forms of religious cult any more reprehensible from the ethical point of view than are the scarcely less indecent recreations of much of so-called "polite socicty"?

Many similar illustrations, although important, are comparatively trivial when contrasted with those more profound and pervasive obligations that command certain forms of conduct and forbid others, which grow by necessity out of the accepted religious faiths and religious cult of any community. In China to-day, the binding relations to the family and to the clan, which are the most powerful factors in determining the characteristics and consequences of the national life, are of a quasi-religious sort. The whole structure of society reposes upon the foundations that are cemented by these obligations. The case of ancicnt Rome was not unlike this. In Russia at the present time it is a pious devotion, showing itself in manifold forms of conduct, of suffering and of self-denial toward the "Holy Church" and the Czar, the ruler and father of his people, which holds the social structure compacted together. Even in Western Europe and in America the conduct of the daily life of the multitude in all their economic, political, and social relations, is either dictated or commended and reinforeed, or else restrained and rebuked by the presalent religious ideas. And whoever determines to live a purely moral life, and yet keep himself free from the influence of these ideas and the practices corresponding to them, attempts a wholly impossible task. The popular faiths may not be his faiths; the prevalent cults he may despise; the common practices he may regard as of doubtful validity and usefulness from his own ethical point of view. But he can scarcely aim to live the virtuous life - much less, meet with any satisfying success in the realization of this aimwithout making some of these faiths the practical postulates of his own inorality.

Yet further, in the third place, the influence of the prevalent religious faiths and practices over the duties and prob- 
lems of ethics is felt when one considers how the religious point of view modifies the scope and the character of ethical opinion and ethical discussion. If there is a God, and if the religious life is to be considered essential to all morally right living, then human opinions and points of view respeeting many an ethical problem are liable to undergo important ehanges. The influence of the religious postulates is enormous here. The very conclusion of the Kantian criticism is this : opine, believe and act as though God were, and as though He were the absolute Moral Reason, the Guardian and Judge of rigliteousness among men. In the field of pure reason this criticism leads to a most thorough-going agnosticism; in spite of which, however, the fundamental ethico-religious faiths of humanity in God, Freedom, and Immortality, are reinstated in the form of necessary postulates of the universal practical reason. One may accept, or not, the critical method of Kant and his followers. One may feel warranted, or not, in rejecting the agnostic conclusion. But one cannot wholly fail of respecting and adopting the practical postulate: Opine, reason, and behare, as though the origin, sanctions, principles, and sure evolution of man's moral life and moral ideals were not in himself alone or in the structure of material things; but, the rather, as though they had their ground in the Being of that Personal Absolute whom religion believes in, and worships as God. And, indeed, to do otherwise than this, to make more than a pretenee of the total rejection of this practical postulate, in the large and for any long time, would seem to be impossible for the luuman race.

Nor is the explanation hard to find of the remarkable tenacity with which the mind of man clings to opinions and theories which imply that man's moral life is neither alien nor indifferent to the superior Spiritual Being in which religion believes. Men have hard work to withhold the religious nature from all influence over their opinions in the more purely scientific fields of experience. The particular sciences 
do, indeed, deal primarily with what is considered to be mere truth of actuality; their so-called laws are descriptions of the general facts of human experience. But the shadow of the Ideal which is at the same time an illuminating centre, is over them all. In their orderly behavior, and in the conceptions of sublimity which they incite, "the heavens declare the glory of God and the firmament showeth his handiwork." Art and ethics, however, when we attempt to treat thoughtfully and methodically their phenomena, reveal themselves as belonging to the spheres into which reach upward the ideals of man. But the supreme and all-comprehending Ideal-Real, the Reality which stands as the correlate, in the thought and imagination of men, of all their loftiest and worthiest ideals, is the object of their religious faith, contemplation, and service. So that their opinions as to the verities of art and of morals cannot possibly escape all important influence from the religious life.

In scores and hundreds of small practical ways, and in a manner closely fitting to the details of daily life, what men believe and feel about the faiths and practices of religion influences their judgments and practices in matters of conduct. Of this it is scarcely necessary to give illustrations; and to the fundamental principles involved in these related experiences I shall return in other connections. The rankest atheist, the most confirmed agnostic, cannot judge himself or others, and behare toward others, as though there were absolutely no "soul of truth" in the religious faiths and practices of his fellow men.

What is true of ethical views and moral practices, respecting their dependence upon the postulates of religion, is emphatically true also of the sanctions of morality. The sanctions of conduct become profoundly modified, and greatly reinforeed by taking the religious point of riew from which to regard them. Standing in fear and awe before mere mystery the ancient Hebrews could speak of the thunder as the "voice 
of Yahreh." The more interior and penetrating view of the sources for that mandatory character which the moral consciousness not infrequently assumes has led to the popular regard of conscience as the "voice of God." Questions of casuistry, as wcll as questions of profit and of destiny, have often enough been relegated to diriners and priests who settle them by declaring the divine will. Not only does the Chinese merchant try his prospective luek, in lottery fashion before the idol in the temple; but the devont worshipper who doubts as to what in some particular emergency his duty may be, asks, "Lord, what wilt thou have me to do?" If the pious soul can discover the divine will it is satisfied that it has the right side of the problem of conduct; - and this, oftentimes, even when the judgment of the multitude or of the wise men is on the other side. There are few things at once more pathetic and more dignified in human history than the position on questions of right and wrong which have been taken, in loneliness, by the always few deroted followers of the Lord, when the popular declarations were all the other way. On God's side stood the Hebrew prophets when his people were against Him respecting the moral issues of their day. On God's side stood Socrates, satisfied that the sanetifying testimony of the dæmon within him was ideally better to follow, even at the cost of life, than the judgments of the Athenian demos. On God's side stood Martin Luther and felt that it was enough that he could do no otherwise. But in less conspicuous and in historically unimportant ways thousands of plain men and women are constantly trying to invoke the divine sanctions upon their conduct of the path of life. And these are by no means they who are least intelligent or least successful in the practical solution of those questions of right eonduct which so frequently perplex us all.

The undoubted fact that many crimes against the moral ideal have been committed in the name of religion does not diminish but rather increases the force of our argument. 
Crimes innumerable hare also been committed in the name of freedom. This statement is true, whether such crimes arise out of ignorance or out of more purely immoral inpulses. Human experience shows, in a historical way, that neither religion nor political freedom can safely be estranged from a cultivated intelligence and a sound moral consciousness. Where, as so frequently happens, the breaches of the moral code are indefensible when viewed in the light of the moral ideal, but are made under the impulse of a sincere religious zeal, the whole phenomenon illustrates anew the elose relations which exist between morality and religion so far as the sanctions of both are concerned. Saul, when he persecuted the followers of Jesus, thinking thus to do God service, is as forceful an illustration of this relation as Paul when, the most notable follower of the same Jesus, he is ready himself to be "offered up for his sake." Immoral religion and irreligious morality - if one may be tolerated for the time in forming such conjunctions of words - are inept rerbal linkings together of different aspects of human nature which, in their more fundamental relations, are somewhat indissolubly united.

Connected with the same considerations is the almost world-wide experience that a certain purity of heart and purification of life is deemed necessary by religion in approaching the gods, and in all manner of divine service. This purity is, indeed, too often merely formal and ceremonial; and the external purifications are too often made the substitute for a real improvement in the motives and principles of conduct, if not a corer for positive immoralities to hide themselves behind. It is true also that an exeessively emotional religious experience not infrequently, instead of warming and vivifying the sources of right conduct, makes the more pliable or fluid those barriers which sound judgment, and the erolution of morally superior customs hare erected against wrong conduct. In all such cases, howerer, it is doubtful how much, what can 
properly be esteemed religious faith, and even what can properly be called religious fervor has to answer in its own right for that lowering of moral tone and those excesses of license which have become connected with it. Phallic worship and the vile practices in the name, and to the honor of the gods, which are its accompaniment, have undoubtedly in various places been an almost integral part of the worship of nature. In Syria, Assyria, and Old Japan, this was so. In India today there are religious rites and religious festivals not a few, as well as surviving customary privileges of the Brahmans, which are the occasions of gross and bestial immoralitics. The presence of the lingam lingers everywhere in the land. But it is by no means easy in most of these instances to determine how far the real causes for the lowering of the standard of the public morals ean rightly be attributed to the prevalent religion. The worship of Krishna has undoubtedly been the patron of debauchery. But the existing debauchery in the hearts and lives of both priests and people accounts, in turn for the impurities of the god Krishna.

However, then, one may be disposed to distribute the responsibility for a degradation of the popular conduct between morality and religion - the two aspeets of the one moral and religious Selfhood of man in his social relations and social organization - one cannot fail to be impressed chiefly with another and opposing current of influences. In general, religion has stood for a more or less sincere purity of heart, and for a more or less serious and effective attempt at purification of the moral life. In all forms of religion which have passed beyond the very lowest stages in the evolution of man's moral life, it has been held that purity of soul is necessary for acceptable worship of the gods; and the effect of this adınission has been most powerful over the historical development of the popular morals. For as the bard who sang thousands of years ago in the Odyssey (III. 48) well knew: "All men long after the gods." The tribute paid by 
the chorus in Sophocles' "King Oedipus" to the power of religious feeling is as rational philosophically as it is poetically beautiful

"Oh may I live

Sinless and pure in every word and deed,

Ordained by those firm laws that hold their realn on high!

Begotten of heaven, of brightest ether born,

Created not of man's ephemeral mould,

They ne'er shall sink to slumber in oblivion;

A power of God is there, untouched by Time."

The gods are, indeed, always, in respect of some of the forms of the virtuous life, above man as he actually is; they belong to the "Overman," to the kingdom of human ideals. Thus, the desire of intercourse with these divine beings, the wish to stand well with them, and the fear of their disfavor, all of the motives belonging to the more especially religious experience of humanity, - are essentially and permanently enlisted on the side of a higher than the prevalent standard of morality among men.

Were examples needed, they might be given, almost without limit, of the powerful influence which religion has exereised in purifying morals and uplifting the moral ideal. India, the land where religion remains so largely identified with mere form and ceremonial, and so largely deprived of its legitimate good influences over the popnlar morals, is by no means an exception to this rule. On the contrars, its best religious teachers have always held that without purity of heart no man shall see the Lord; and that unless religion shows itself in a real improvement of the moral hife, it is spurious and vain. According to Hindu doctrine, the "holy man" is indeed Sattwik ("having a healthy taste") as respects his diet; he "likes food that promotes longevity, tranquillity, strength, freedom from discase and cheerfulness, - food that is palatable, soothing, nourishing, and cheering." He has also been tanght precisely how to regulate his breath- 
ing, his dress, his gestures, his entire life in its details. There is bondage in all this. But the Hindu doctrine also teaches, that "there is only one kind of bondage in the world, viz., the boulage of passions and no other. "Freed from the control of desires, like the moon emerged from murky clouds, the man of wisdom, purged of all stains, lives in patient expectation of his time." And the summing-up of all the morality which grows out of true religion is this :

"I. Let not adversity and temptations bend you.

"II. Divest yourself of stiffening pride and hardening selfishness.

"III. Do not seek your own glory, but the glory of your fellow brothers."

Summarized and translated into the hortatory principle of religious derotion, these maxims become: 1 " Do all works and at all times under His shelter, and then by His Grace you will be saved."

I am sure also that the practical insufficiency of morality to sustain and elevate its own principles without support and help from religion can be shown by an appeal to almost all the human experience which illustrates this subject. How convincing is the testimony of history to this truth has already been made the subject of remark. The dependence of the morals of the state on the popular teachings with respect to the nature of God and of man's relation to Him is emphasized and illustrated toward the close of the Second Book of Plato's Republic, althongh in a negative way. If lies and lying vanitics are not to be tolerated among the citizens, all men must know that " the superhuman and divine is absolutely incapable of falsehood." Later (III, 391) Plato declares that stories about the immoral conduct of the gods "are likely to have a bad effect on those who hear them; for everybody will begin to excuse his own vices when he is convinced that similar wickednesses are always being perpetrated

1 Compare the Bhagavad Gĩtā, chap. xviii, verse 56. 
by the kindred of the gods." That is to say, such false opinions in religion are the equivalent of a lowering of the moral ideal in its effect upon the morals of society.

But more positively we may say, and may place our declaration upon an empirical and historical basis: Human morality has unecasing need of religion for its better support and more effective triumph orer all the weaknesses and temptations which assault and try the very foundations upon which it reposes its rules for the practical life. It is cold, hard work for the human soul, and frightfully difficult and unsafe for human socicty to try to lead the virtuous life strenuously and perfectly, and to hold up and adrance the moral ideals, without the faiths, consolations, and cheer, which religion has to offer. Who can deny that, if we may heliere in God as the Righteous One, as the Vindicator and Guardian of righteousness and at the same time the pitiful and gracious Father of men, and if we may hold to the hope of the triumph at the last of his Kingdom, as the reign over all rational spirits, of righteonsuess, truth, and peace, then living according to our lights upon moral principles, and pursuing tirelessly and loyally the highest Moral Ideal, is a less distressing nay! a far more hopeful, sure, and joyful thing? The strongest in the race for moral perfection get weary and even discouraged at times. The most loyal suffer, in certain moments of defeat, the almost irresistible temptation to strike the colors which they have held up in the service of their lord and master, Duty. What if humanity goes all the more to the dogs, or to the devil, because I decline to bear extreme hardship or stand in my post as a suffering soldier in its behalf? Why should I concern myself? Whence comes this unceasing and unsparing obligation to an Ideal that grows the more exacting for the individual and the race, the more the indiridual and the race rise through sweat, and toil, and infinite loss of treasure and blood, toward its alluring embrace? How can the moral Law dare to impose upon 
the quivering flesh and sensitive soul of the world's best and noblest, the scemingly unreasonable sanction of its imperative demands? Surely the thoughtful man must find in such questions as these the true metaphysical riddles of the universe. Not in the nature of space, or of matter, or of the hypothetical atom, do the most puzzling of all problems lie concealed. They consist rather in the practical antinomies of the moral nature and moral derelopment of the race. And yet the enlightened moral consciousness somehow feels that the last thing which the rational Self can afford to let slip, or even to loosen its firm grip upon, is the Moral Ideal. This Ideal is vague, changeable, and elusive; it partakes of the nature of the Infinite from which it comes. But it is both alluring and commanding; and wholly to let it go is damnation for the individual and for society - sure and swift, and already well on the way to completion.

To one whose position toward the moral Law and the moral Itcal corresponds, whether very occasionally or more frequently and even habitually to any of the points of view just described, religion certainly offers itself in a most inviting way. Let its faiths and alleged knowledges for the present be considered merely as practical postulates. To examine reflectirely these postulates, and to criticise and harmonize these alleged knowledges is the task of the philosoplyy of religion; and the psychology of the religious being and life of man must be invoked to consider in detail how it is that religion supports and helps the moral life of man. I can only indicate a few thoughts upon the subject here.

Religion imparts warmth and vitality to morality. Let it be supposed that one is trying to lead the virtuous life, without faith in God, Freedom, or Immortality. We need not take the position which Kant expounded, and thus institute the claim that these tenets of religion are indubitably implicate in a moral law that needs no appeal to human experience, no other sponsor than the pure practical reason, 
in order to authenticate itself. We will only ask: What effect on such a worthy strife for the Moral Ideal is had by the absence of all these faiths of religion? The irrationality — not to say, foolishness - of roluntarily subjecting one's self to a mere impersonal law, remored from all concrete, personal interests, has already been sufficiently exposed. But without belief in the reality of God, and in the immortal life regarded as dependent upon man's voluntary relations to Him, certainly much of the most important of these personal interests is remored from the place of power. Derotion to the practical concernments of a system of physical and psychical existences that can never attain title to the worthiest conception of personality, or of a kingdom of personal ends and so of the supremest dignity and worth, is surely a difficult attitude of mind consistently and persistently to maintain. Some few - good few, if you will are perhaps equal to the task. But the multitude of men are not so strong. And there is reason more than to suspect, that it is the only half-conscious but profound hereditary and environing influence of the religious nature, which contributes no little accession to the strength of these "good few."

How the baser fears of a religious sort reinforce the fear of the consequences which follow the disregarding of moral obligations imposed by custom, or by the statute, or even by the moral consciousness of the individual, it is scarcely necessary to show. A reverent attitude toward the Divine Will and an awesome regard for the consequences of giving offence to Deity, is closely akin to that respect for the Moral Law in which Kant thought to find the only emotional factor in true morality. The hopes of religion, - not so much the hopes of reward which it holds ont, but rather the hopes of success in making some small contribution to the eternal blessedness of the world, - reinforce the courage with which the devout soul meets the problems of the moral life. Thus one finds the more satisfying practical solution of many of these prob- 
lems. We are "saved by hope," both in morals and in religion, - while faith in the effective goodness of God is so closely akin to the practical and influential belief in the supreme worth and final supremacy of moral interests, that the two seem quite identical. Both require, at any rate, that constancy of confidence in the higher ideals of human reason which is the "sustaining grace" of all who cultivate any form of that which is conceived of as "in-itself Good." 1

It is everywhere assumed, as a matter of course, that morality and religion are together, and in their relations of reciprocity, subject to development. Savagism and brutality, where they exist, show themselves in both the moral and the religious beliefs and practices of any social organization. The characteristic temperament of the individual, or the prevalent temper and established habits of any age, furnish conditions to the manifestation of both forms of human consciousness. The culture of one at the expense or in neglect of the other may efiect a temporary sehism between the two. Nor is it quite possible to tell how moral any indiridual or nation may become, after the religious development has been allowed to lag far behind; or, vice versa, how intelligent and sincerely religious a man or a people may be, while as yet their ethical progress has not been in any marked way promoted. The "conversion" of the Saxons by Charlemagne was no more and no less bloody than his other imperial performances. And if one Capitulare (that of Paderborn, 785) decreed death for him who refused baptism, or wantonly ate meat during Lent, or burned a corpse after the custom of the heathen, this was no more immoral surely than the inflietion of the punishment of death upon the man who, to satisfy the hunger of his children, knocked down a hare in the forest of some English nobleman. The latter immoral and legalized

1 Compare the declaration of Carus, Moralphilosophie, p. 169 : Vorausgesetzt wird vor jeder Religionspflicht, die Pflicht ein moralisches Interesse zu erregen für den Glauben an die wa!ıre Gottheit und das sterbliche unendliche Ziel. 
cruelty can scarcely be eharged to the influence of the Christian religion. The horrors of the wars in South Africa and the Philippine Islands are eertainly not intensified by the genuine Christianity of the nations that are waging them.

To return, then, to the fundamental truths regarding the relations of morality and religion, so far as these truths can be based upon human experience with both these aspects of human nature in its social workings. $\Lambda$ reflective study of the phenomena fails to identify the two. Religion is not the sole ground, nor does it afford the only sanctions, of morality; nor does religion wholly correspond to morality in respeet to the ideal which it presents. But the roots of the two are largely the same, - both those that strike down into the nuchangeable constitution of man, and those that spread widely in the underlying strata of all human domestic and other social conditions. Both the similarities and the differences are rather too manifold and subtle to admit of offhand analysis or easy-going enumeration. 'The faiths, fears, hopes, sanctions, and ideals of the two merge into each other, and interpenetrate in myriads of ways. It is the many-sided nature of the one moral and religious Self which is expressing itself in both ways, - inseparably allied, never to be divoreed, but always to be accorded those items of special worth which belong to each, and never in a crude and ineautious manner to be confused or identified.

Morality and religion need each other in order to secure the perfect and more blessed and worthy ideals of life; or, rather, in order to live up toward our growing and rising conceptions of this blessed and worthy life. If, on the one hand, morality needs religion in order to impart to it warmth, comfort, and the assurance of faith - needs, in a word, the divine Life and the divine Grace - none the less does religion customarily slow itself inferior to morality in clearness of vision, in rational eharacter, and in practical adaptability to 
the exigeneies of the present life. As says Dr. Laurie: " "A system of moral ends has an opportunity of eorrecting itsclf from day to day by the perceived results of human activity, while in the region of pure idea, which may always be disconnected from the actualities of life, there is no such contimnal correctire of the false and the inadequate." I cannot, indeed, agree with the proposition that the "region of pure idea" may "always be disconnected from the actualities of life"; nor is the plirase an adequate description either of the domain of speculative thinking upon the great philosophical problems of religion, or of the practical and emotional experiences which enter into the religious life. But man undoubtedly has more of solid and indubitable experienees connected with the sources, the sanetions, the principles, the development, and the consequences of conduct, when considered from the ethical point of view, than with the corresponding problems in the domain of religion. There is more of racial solidarity, of historical rerity, of experimental truth, and immediate practical import, in morality than in religion.

It is not necessary to enter into the reasons for this practical superiority of the ethical over the religious sanetions and principles. Man feels, indeed, the obligation to conduct himself aright in all his many and raried relations to his total environment. So far as the proper adjustment depends upon his own conduet, the obligation is ethical; the adjustment is a moral problem; the processes and results belong to the sphere of ethics. If divine beings, in any of the many forms simulated or faithfully represented by human coneeptions, really exist, then the adjustment of human relations to them, and of the relations of men to one another and to their physical environment, as coming under these divine beings, is a matter of ethical concernment. The postulates of religion place the conduct of men toward the Divine within the domain of moral sanctions and moral principles. But in-

1 Ethica, p. 189. 
asmuch as these postulates do not in most cases attain the same position of clear light and intelligent comprehension which belong's to the faiths, knowledges, and practices, of morality, religion remains inferior to, or rather dependent upon, morality in certain important respects. In certain others, as I have already shown, the relation is reversed: morality depends upon the acceptance of the religious postulates; and religion becomes the most desirable and helpful companion, and even supporter and inspirer of the rirtuous life.

In this connection mention should be made of that one great and perpetually recurring danger which arises ont of the inherent natural and historical connection of morality with religion. I refer to the dangerous heresy of a doulle morality. Such a two-sided ethical system only makes confusion worse confonnded; it debases religion and loads down morals with an added weight of practical and theoretical contradictions. Nevertheless, this doctrine of a double morality has been somewhat variously held. Sometimes it amounts to having one code for duties eonnected with religious faith and worship, and another for those forms of conduct which it is convenient to regard as not belonging to the religious life. At other times, the distinction is made between essentially different principles and sanetions of conduct, - some having reference only to the members of your own religions caste or sect, others which are to be brought into play when dealing with the adherents of other religions. Or, yet again, within the sphere of the religious life itself, the distinction is set up between a ligher and a lower morality. The lower is, perhaps, the morality of the laity, the higher that of the clergy; or the lower is the morality of duty merely, and the higher that to which the merit of some special divine favor is attached. In this way picty and morality, instead of being drawn together and made to impart each to the other its peculiar strength, are further separated. The two ideals are rendered antagonistic rather than complementary and recipro- 
eally assisting. Thus the great Church Father, Thomas Aquinas, in his effort to combine "ecclesiastical supernaturalism" with the ethical riews of Plato and A ristotle, made a sharp division between the cardinal virtues of the Greek ethics - wisdom, justice, self-control, and courage - and the three supernatural virtues of faith, love, and hope. It is easy to see how this dirision may be used to withdraw from the virtue of wisdom the support of faith in the Divine goodness, to take away from justice the warning and vivifying influence of the Divine lore, and to withold from self-control and courage the support, which they so sorely need, of a cheering religious hope. But religious faith should inspire wisdom; love should infuse, justice; and hope should sustain courage.

Here again, however, it is not religion and morality which contain in their own nature, or by virtue of their more legitimate influences are responsible for, so sad a mistake in ethics, so dangerous a doctrine in religion. To-day, under the baleful domination of commercial greed, and notwithstanding the plainest teachings of the world's most highly developed moral principles and the most potent exhortations and motives of the Christian religion, this detestable heresy, this most perilous enemy both of pure morals and of sincere religion holds sway over the multitude of minds. In national and international politics, the current morality is double. The combined forces of morality and religion must be invoked to grind into powder this brazen and hideous two-faced idol of the age. To shape the material into the image of the new man, whose moral consciousness suffuses and illumines his religious faiths and religious cult, and whose religious consciousness warms, consoles, and supports in the struggle with evil his moral conduct, both sets of influences must work harmoniously. But there is much truth in Martensen's statement ${ }^{1}$ that "abstract autonomic morality only appears at those seasons when there is also religious decay." It is when both morals 
and religion are decaying that the practice of a double morality is likeliest to be rife. Its prevalence at present is one of the most foreboding signs of the times.

We are now in a position to sec more clearly what is the bearing of this profound and many-sided connection between morality and religion upon the ultimate problems of ethies. In attempting to pursue these problems, our way was blocked by certain antinomies, or puzzles which seemed to baffle all attempts satisfactorily to solve them by employing only the material which empirical and historical ethics could furnish. The theoretical handling of this material had forced an inquiry into the nature, origin, sanctions, and derelopment, of a rational Ideal; and the very constitution of this Ideal, so to speak, had come to appear of a superhuman, not to say supernatural, character. Moreorer, the moral Ideal appeared to make demands upon the life of conduct which were difficult to reconcile either theoretically or practically with the interests of other sides of human nature and other forces in the historical evolution of human society. Hence, finally, arose those theoretical and practical antinomies, which it was found impossible to solve either by substituting some other ideal for the moral ideal, or by debasing the character of the ideal itself. The extent of these problems was seen to be coincident with the entire sphere of human conduct, and of the development of the race as dependent upon its own conduct. Such sciences as economics, politics, and sociology, which deal with men as associated and interacting, upon a basis of their tutal physical environment in a great variety of ways, are all ethical. But the solutions which they offer only emphasize anew and extend still further these distinctively ethical problems, these antinomies of the practical reason as the responsible ruler of the life of man.

We are now also in a position to affirm that religion does offer much needed assistance toward resolving the antinomies of ethies; that it does throw light upon the puzzling problems 
with which the student of the philosophy of conduct finds himself confronted after he has used up all his empirical data, and has lent his ear to all the different theories regarding the nature, sanctions, principles, and development, of what men call "the Right" in conduct and in character. The help from religion to morality is real though not complete; it should be respectfully considered and gratefully receired, eren if it is only partial. I will, then, put my contention into the following form: If those postulates of religion which the constitution and history of man seem to warrant him in accepting be made the faith of the soul and the guide of the practical life, many of the practical antinomies of ethics are either completely solved, or much reliered. These postulates themselves may be so stated as to appeal to a rast amount of experience which evinces the close and indissoluble connection, but not identity, of morality and religion as they grow out of the personal life of humanity and derelop in their historical interrelations according to the nature and goal of this life.

In order that the truth $I$ am presenting may appear in more convincing form, let us take for a moment both morality and religion at their best. On the one hand, the best morality approves such a view of life as regards the moral ideal to be abore all other ends of conduct most inspiring and most worthy to enlist the efforts of the rational mind. But this ideal is personal; it is rich in all the concrete virtues which the Moral Self feels obligated to endeavor to realize. The virtues of self-control are necessary factors in this ideal; but they do not enable the good man to dispense with the virtues of judgment. And strong and constant self-control, even when well eoupled with wisdom, prudence, and truthfulness, cannot boast itself to be quite independent of sympathy, kindness, and benevolence. Nor is this ideal stationary; and so capable of being approached without itself undergoing any improvement. Were it not the subject of development its 
own imperfections would soon become too manifest to admit of its being longer regarded as a worthy ideal. Nor does the ideal encourage an exclusive devotion to one's Self - not even to one's own better and ideal Self, as though this could possibly be realized in independence of devotion to the interests of the social organization. On the contrary, the moral ideal is so distinctively social that one cannot even begin to consider the existence, or much less the hopeful development, of the individual moral Self as possible apart from other selves who constitute with it a moral association, a kingdom of persons in which personal interests and personal ends are regarded as the only realities of supremest worth. This tenet is true, although the most difficult practical problems of ethics often arise in the attempt to know just how to adjust the higher interests of the individual Self with the higher interests of the social organization. But, then, here is one of the practical antinomies which religion may help us to relieve or even to solve.

What, on the other hand, may the best religion be said to maintain? In answering this question it is not proposed to make any selection among the different religions which contest with one another the claim to occupy the first rank in the respectful consideration of mankind. Nor is it proposed to try to enumerate those tenets of religious faith in which the best religions may be supposed substantially to agree. I wish now only to state briefly what are the propositions, as regarded from the ethical point of view, which appear to represent what is highest and best in the religious faith of mankind. The best religion as related to ethics is, then, the faith in an ldeal Personality, whose real Being affords the source, the sanctions, and the guaranty of the best morality ; and to whom reverential and loving loyalty may be the supreme principle for the conduct of life. This ethically best of the religious tenets lies slumbering in the exhortations which so many religions make that their followers should 
purify their hearts and lives, if they wish acceptably to approach the Divine presence and find favor in the Divine sight. This it is which is symbolized in the mirror of Shinto, and more clearly expressed in those doctrines of Hinduism to which reference has already been made. This is the substance regarding the gods, and the relations of men to them, of that which is taught by much of the Egyptian Book of the Dead. This it is which the religious experience of that people who had a special genius for religion embodied in the coneeption of Yahreh as the God of righteousness. But preeminently is this the central ethico-religious tenet of Christianity; the way of riglt conduct is the way of salvation; it is the way of man's being perfect after the pattern of his Father in Ileaven; it is the "imitation of Christ."

And now, bringing together these two clusters of best conceptions, - one from morality and the other from religion, - we may see how they unite to furnish the most illuminating, and as well the most inspiring, comforting, and hopeful attitude toward the problems of morality and the conduct of the practical life. In other terms, the postulates of the best religion, when they are joined to the choicest conceptions and principles of the highest moral development, solve in a way the practical antinomies which non-religious ethics leares in the dark. From these two higher points of view, - - the ethical and the religious, - or rather from the one ethico-religious ground of standing which covers and occupies them both, the so-called moral laws coincide in their principles and in their sanctions with the religious commands. All duties become for the true believer due to God as the ideally perfect Person, and to men as his children, as "Sons of God." All rirtues become, essentially considered, right attitudes toward the King whose kingdom includes as its members all sentient, and especially all rational and personal life. All doing right becomes interpretable as loyalty to the will of God, as keeping the Divine Law, or as being a true 
son of God. This is the exaltation in its ethical aspect of the words ascribed to Hippocrates who coupled with the inclusive "all" the adjectives "divine" and "human" as well ( $\pi \dot{a} \nu \tau a$ $\theta \epsilon i a$ кai à $\theta \rho \omega \pi i \nu a \pi a ́ v \tau a)$. Thus man's faith toward the Moral Ideal falls into line with his Way of Salvation; the antithesis between the Moral Self, with its law and ideal of life, and the sentient Self, with its strong craving for satisfaction of desire and personal happiness, is softened; and finally, it is made to vanish wholly away. The hard setting together of the teeth and tense straining of the muscles in the effort to run well the race of duty in the sight of an impersonal and forever unattainable ideal gives place to a no less strenuous, but more hopeful and joyful service, because it is a loyal devotion to a personal master and friend. The social instincts and other more crude and non-rational motifs which evoke a regard for the interests of others are found to be only anticipations of that rational recognition of kinship which entitles every member of the race to a share in the blessings of a social ideal, of a true Kingdom of God.

'This is the truth in its sublimated form which Plato teaches by way of exhortation at the close of his most masterly Dialogue — "The Republic":

"Wherefore my counsel is, that we hold fast to the hearenly way and follow after justice and virtue always, consideringr that the soul is immortal and able to endure every sort of good and every sort of evil. Thus shall we live dear to one another and to the gods, both while remaining here and when, like conquerors in the games who go round to gather gifts, we receive our reward. And it shall be well with us both in this life and in the pilgrimage of a thousand years which we have been reciting."

In the previous discussion the faiths and practices of religion have been regarded simply as postulates which have an undoubtedly important effect in modifying the practical antinomies of ethics. These postulates have been for the 
most part accepted as they are to be discovered in operation among men, and exerting their matter-of-fact influence over human conduct and over human opinions respecting the right and wrong of conduct. It remains necessary for the completion of our attempt to throw light upon the ultimate problems of ethics that we should inquire into that course of reflective thinking by which these postulates are best justified. And this I shall do under two heads, - namely, first, the identification of the ground of morality with the WorldGround, or the doctrine of God as the Source of the moral law, its sanctions and its development; and, second, the justification of the hope that the ultimate moral ideal will be realized in the establishment of the Dirine Kingdom. 


\section{CHAPTER XXV}

THE GROUND OF MORALITY AND THE WORLI-GROUND

A certain natural and naïre, but strong and indissoluble bond between morality and religion has been seen to be the explanation of much of the ethical history of humanity. Although morality and religion are not throughout identical, but, the rather, express and emplasize different complex aspects of human nature and of the development of man, they constantly draw upon the same sources and rereal similar ideal conceptions and ideal aims. But more especially is it true that religion furnishes to morality the much needed, and even indispensable, support of its faiths and its motires, - indeed, of its entire affective and practical attitude toward reality and toward the conditions and ends of life. And, finally, if one will but accept the postulates of religion, and shape his conduct in accordance with them, some of the most trying of the antithetic and scemingly contradictory positions in which the empirical and historical study of ethics leares the mind are either greatly relieved or wholly transcended. The soul, aspiring after the ideal of a rirtuous life, and finding the way so difficult and the goal set by the ideal so unattainable under existing circumstanees, is quicted and encouraged, incited and cheered, by the faiths and hopes of religion. Indeed, in its most approved form, the belief in God and the service of God become the fundamental and controlling principles of the life of conduct and of the development of character.

In the historical evolution of humanity - both ethically and religiously - this natural and naïre connection between 
morals and religion must give way to a more sure and broad comprehension of the common basis upon which both repose. But such a comprehension can be obtained only through philosophical reflection. Here, as everywhere, philosophy seeks to discorer, to criticise, and to harmonize those universals which hare their existence for experience in all the phenomena of man's life. These "universals" in ethics which have already been discorered and discussed, - chiefly from the psychological and historical points of view, - have prored, in general, to be of two orders: (1) certain functions of human nature and their products, - the various kinds of right and wrong conduct and of opinions about conduct, - which belong to all men, in whatever stage of moral evolution you may find them; and (2) certain ideals which, although rariously conceived in respect of their details and always conceived imperfectly, are sliared in by all men, and which influence most powerfully the entire derelopment of humanity so far as this development is dependent, either directly or indirectly, upon the results of human conduct. These two orders of so-called "universals" are not, lowever, spoken of as two, in the meaning of being dirided or separated by exclusion of cither class from the other. The moral ideals have themselves been shown to be the functions of man's idealizing mind, and thus dependent in their own development upon the historical changes which have gone on in the actual nature of his conduct and of his judgment concerning the right and wrong of conduct. But, on the other hand, it has also been shown that the actual practices of men and the prevalent opinions as to the nature of the moral life, are themselves dependently connected with these idcals. In other words, man creates the norm-the universal and necessary ideas, the so-called "moral law," or "categorical imperative" - which itself, in turn, forms his actual life of conduct and gires shape to his entire moral and social evolution.

The ultimate philosophical problem in ethies becomes, 
then, the inquiry, by critical reflection, into the real ground for the existence and development of human moral life; and for the progressive realization of the moral ideals of humanity. IIow does the ground of morality stand related to the Being of that which philosophy knows as the "World-Ground"? Or to put the question more concretely and definitely in the terms of religion: Can the mind frame a rational system of ethics without admitting (either as tenct of faith, or as postulate, or as reasoned knowledge) the Divine Being, so conceived of as to be the Source, the final Sanctioner, and the Guarantor of morality among men? I believe that this last question must most emphatically be answered, No. Or, to turn the answer into an affirmative proposition: The Ground of Morality for man must be found in the World-Ground conceived of as an ethical personality, as the ideally righteous and holy God. Thus, and thus only, ean that which the multitude of the race have always done naturally and nairely - namely, establish a more or less vital connection between their moral conceptions and practices regarded from the ethical point of riew, and the faiths, feelings, and practices which constitute their religion - be made consonant with the conclusions of the philosophic mind. Thus, and thus only, can the total interests of humanity, as they are represented by both morality and religion, be merged in one view of the world and of liuman experience which, although it may be far enough from solving all the rexed problems set for reason to solve, certainly affords the highest attainable satisfaction for the rational as well as the practical life of mankind.

In this case, as elsewhere, plilosophical reflection elaborates into metaphysical eonceptions, and defends, those instinctive or unreasoned beliefs and practical postulates upon which the life of humanity bases its derelopment and eren its very existence. In truth, the ultimate questions of moral philosophy are not problems for ethics alone to solve. They acquire 
the nature of imperative demands upon ethics to take into its confidence the conclusions of the philosophy of nature and the philosophy of mind; but most especially do they constitute an imperative demand upon the student of the philosophy of man's religious life. These ethical problems start the discussion of certain yet more fundamental and universal conceptions and relations; thus the reflective and critical treatment of ethical phenomena connects the metaphysics of ethics with the entire domain of metaphysical philosophy. As was said at the beginning (p. $29 \mathrm{f}$.), and as has been implied all the way through, ethics camnot dispense with metaphysics. On the contrary, its metaphysics comprises all metaphysics; because ethics itself is concerned with all the most essential interests, and deals with all the conscious life, of man considered as a true person, a moral Self.

It will be noticed, however, that this conception of the true place and province of the metaphysics of ethics, and of the proper and only successful method of its pursuit, is quite different from that of the immortal author of the "Fundamental Principles of the Metaphysic of Morals." Kant assumed the existence in human reason of a universally ralid and necessary principle (a practical synthetic judgment a priori) which was virtually admitted by every reason, and which by philosophical criticism could be explicated, and held up for the most unquestioning acceptance and transcendent respect. We have followed the lowlier and more humble, but, as I firmly believe, much surer and safer path of psychological and historical inquiry into man's actual experience with himself as a moral being, in social relations, pursuing and owning allegiance to a moral ideal. This empirical path, howerer, conducts us irresistibly to the presence of the ultimate metaplyssical problems. What sort of a World is that in which a race of beings, constituted moral selves and following moral ideals, can originate, struggle, organize themselves socially, and derelop institutions founded 
wholly or in part on ethical principles? It is God's World. In what sort of a being must we conclude that such a world, and such a race existing in such a world, and having to run such a course of development, has its real explanation, its Ground, if our explanation is to maintain any claim to a consistent rationality? It is the Being of the ideally righteous and holy One, whom the highest religious conscionsness believes in and worships as God.

In support of such a metaphysics of ethics as is outlined in the declarations just made, the temptation is strong to maintain a polemical, if not a purely dogmatic attitude toward those who dispute or cren doubt. I believe tlat the statement made, for example, by Professor Watson ${ }^{1}-$ "To a man in our day who thinks, and who insists upon having a connected view of things, it is apparent that individual, political, and social morality, are one and inseparable, and that law and morality as a whole ultimately rest upon and are explained by religion" - is substantially true. But merely to affirm this, or even to prove the affirmation by an appeal to current thoughtful opinion, is not enough to satisfy the legitimate demands of a mind which seeks to find a firm rational basis for a system of ethical principles. Such a basis, as has already been said, must seck in its formation all the help that can be rendered by general metaphysical philosophy, and especially by the philosophy of religion. Ethics can ill afford to dispense with any of these offers of help. Neither the high-and-dry, autocratic, a priori method of Kant, nor the hortatory and scntimental method of the current theology, are satisfactory to meet the demands of reflective thinking upon the ultimate problems of conduct.

The profoundest and ripest conclusions of philosophy, when firmly founded upon the survey of the experience of liumanity, belong to that branch of metaphysies which deals with the grounds in reality of man's moral life and moral developmcnt.

1 Iledonistic Theories, p. 12. 
Philosophy can render no greater service than this to humanity. Even if it can only make somewhat more acecptable to reason that metaphysical tenet which finds the Ground of Morality in the ethical Being of the World-Ground, this is no small gain. Anything in the way of sound reflcctive thinking which scems to harmonize the discordant elaims of the sensitive and scnsuous nature of man, with the claims of moral conseiousness and its ideals of duty and estimate of judgments of worth, is itself beyond all price as measured by physical good. Indeed, when considered from the point of view where the values of different truths are sufficiently taken into the account, such practical, reconciling, and invigorating work of philosophy is that in which the attempt at a systematic and rational treatment of all our ultimate problems most properly culminates.

The attempt at a justification of the theory which identifies the Ground of Morality with the World-Ground, by conceiving of this World-Ground as the ideally righteous and holy personal God, must borrow much from general philosophy and anticipate no little from the philosophy of religion so called. In the form in which I shall now present it, the argument is an extension of the "theory of reality" which I have elsewhere ${ }^{1}$ discussed in detail; and it rests upon a riew of the nature, validity, and limits of human knowledge, and of the essential reality of mind, which I have also advocated in separate writings. ${ }^{2}$ From these three related branches of philosophy I therefore gather together the substance of the conclusions which their independent study scemed to justify.

And, first, man knows Reality and knows something which is beyond all doubt and all dispute as to what this Reality is. It is not true that knowledge is "of phenomena" only; or that all the assumptions and implicates of that form of the

1 In a work called A Theory of Reality, published in 1899.

2 Philosophy of Knowledge, 1897, and Philosophy of Mind, 1895. 
mind's functioning which we dignify with cognitive titles is forever open to scepticism, - much less to either dogmatic or critical agnosticism. On the contrary, reality is implicate in all knowledge; and in every exercise of the knowing faculty the testimony plainly is - I, the actual, am not afar off, but nigh thee, even within, an integral part of thy Self, the knower. The doubt of this truth - the truth of all truths - is so irrational, so absurd, that it does not even admit of a consistent and intelligible statement by one mind to another, or by any one to one's own conscious mind. This attitude toward reality in which knowledge consists - call it what you will, enrisagement, intuition, belicf, inference, or what not, or better all combined - does not come by one sudden leap into conscious life; nor is it the result of the functioning of some one selected class of the so-called faculties of the human mind. On the contrary, it is the choicest development of the complex Self functioning in all its three, not identical nor yet distinct and separable forms of functioning-namely, intellection, fecling, will. In this, its complex and dereloped active and passive life of relation to other selves and self-like things, which we denominate its growing knowledge, the mind constantly exists in a living and fruitful intercourse with reality. Thus the artificial analysis of the Kantian criticism, with its hard and fast gulf between the bounds of pure reason and the domain of reality, with its firm and divisive separation between phenomenon and noumenon, - as though actuality were forever outside of the mind's life and could never show itself in conseiousness otherwise than as the shadowy suggestion of a great unknown That-somethingreally-is - totally misrepresents the indubitably experienced truth of the case. On the one hand, the philosophy of knowledge teaches as that "Thing-in-itself" there is not - to be either known, or imagined, or tlought; but, on the other hand, it teaches also that the really-existent is implicate in all human knowledge, is indeed its inseparable correlate in perpetual 
communion with the active mind. Noumenon apart from phenomenon cannot indeed become the object of cognition; but in every phenomenon of the cognitive sort noumenon stands present and self-revealing.

Moreover, the philosophy of knowledge shows that of all the different kinds and degrees of knowledge the type of perfection is that which the developed cognitive Self experiences when it knows, in trained and ripened self-consciousness, the reality of its own Self. Such self-consciousness is the integer, as it were, of cognition; all other knowing is fractional and relatively imperfect. The same thing is true in respect of moral consciousness which is true in respect of all the conscious manifestations of the Self. That $I$ myself feel the binding foree of duty, the attractiveness and obligation of the virtuous life, that $I$ make judgments of right and wrong which are followed by feelings of approbation or disapprobation, and of merit or demerit - all this neither needs proof nor admits of disproof. I know my own moral selflood with this immediate and indubitable eertainty. More indirectly, and with a lower degree of certainty, I know other selves to be constructed ethically in a large and substantial agreement with my own moral selfhood. This substantial agreement is not essentially impaired, much less is it abrogated, by many and varied differences in judgment over what is right in conduct or most commendable in character.

Nor can it be said that the Moral Ideal is itself wholly removed beyond the limits of human knowledge. Like all other ideals, it has a marked kaleidoscopic character. As the hand of time turns it, the colors arrange themselves in different patterns. The realization, too, of the moral ideal is neither to be known nor achieved as though it were some simple fact of experience, or some one deed of will that could be undertaken and finished once for all. But to speak of this ideal as illusory, and to regard human experience with it as deroid of all truly cognitive activity, is to introduce a 
schism in human nature which is quite unwarranted by the facts. For each moral being the force and value of his own moral ideal may be made a matter of knowledge in the same way as any of the other of the individual's complex experiences. And in the broader fields of history there is knowledge to be gained touching the progress which the race has made in the past by way of forming and reforming, and of progressively realizing its moral ideals.

The philosophy of conduct may, then, avail itself of all the positive conclusions of the philosophy of knowledge with reference to the possibility and trustwortly character of man's knowing faculty when applied to his ethical experience. Neither dogmatism nor agnosticism, neither the attitude of unquestioning and thorough-going certainty, nor the attitude of a scoffing or a despairing scepticism, becomes the student of the problems which the ethical constitution and development of humanity has to propose. The nature, the guaranty, and the limits of knowledge, when the effort to know is directed upon the phenomena and principles and ideals of the moral life, are not essentially changed.

If we may borrow from philosophy a theory of knowledge which secures the highest interests of ethics from becoming a wreck in full sight of the eyes of reason, the same thing is true of a theory of reality. General metaphysics may be summoned to prepare the way for the more special metaphysics of ethics. As to the propriety and the method of this summons I do not need to repeat what has been either said or implied, over and over again. With us, metaphysics - of whatever name or sort-is never wholly a priori in conception or in method. The rather is it the critical and speculative treatment of the conceptions and principles which are discoverable in experience. So then, if one raises the problem which is before us at the present time-namely, May the ground of morality be found in some rational conception of the World-Ground? - one can properly revert to the 
inquiry: And what does metaphysics, as a theory of reality, have to tell us of the characteristic marks of that Being which it calls the "World-Ground" (or by some similar term)?

When this question is asked of metaphysics, regarded as a eritical and systematic theory of reality, its answer is not equirocal; although the answer has, of course, been given by different philosophers with varying degrees of clearness and comprehensiveness, and in spite of the fact that certain names may be quoted in denial of the possibility of systematic metaphysics at all. Among these names the greatest - anticipating or following the example of their most illustrious leader, the "astounding Kant" - have, after all, found some way, either by faith, or revelation, or philosophical intuition, of introducing more or less covertly the very knowledge (or its equivalent) the possibility of which they had previously denied. And when such fragments, or rather grudging acknowledgments, are pieced together, and illumined by further reflective thinking, they are wont to arrange themselves into a form, having a certain consistency with the same permanent and unalterable view which the common reason of man holds respecting the nature of all that is Real. This statement is about as true of Mr. Spencer and Mr. Bradley as it is of Jacob Boehme or of Schleiermacher. Small wonder if it is so; for no immersion in modern physical science, or academic exclusiveness, or sceptical disregard for the common opinions and faiths of humanity, or special respect for the extra-mundane, or belief in the value and validity of belief, essentially changes the nature of the reason of man. They and we all are finally brought around upon our knees before the same confessional : homo sum - not a god or an angel, nor yet a mere phenomenon or sum-total consisting of a series of phenomena that never attain any reality beyond the extra-phenomenon of a certain appearance of quasi-reality.

There is, then, a well reasoned and defensible answer which 
a general and systematic metaphysics ean deliver to the metaphysics of ethics, when the latter cries out for assistance in the effort to answer its own more ultimate and profound inquiries. What are we warranted in affirming as defensible knowledge regarding the Being of the World-Ground? In few words it is this: What philosophy calls the Absolute or the World-Ground is Will, informed and guided by Reason, and immanent as progressively realizing its own Ideas in all that of which we have experience. As I have elsewhere ${ }^{1}$ saic, in summing up the conclusions of a lengthy discussion of the problems of metaphysics, our liuman way of knowing the World-Ground is " a way of conceiving the 'Being of the World' after the analogy of the Life of a Self, as a striving toward a completer self-realization under the consciously accepted motif of immanent Ideas. The principle, as a postulate of all reasoning, and so of all science, implies (1) some sort of unitary Being for the really existent; (2) that this Being is Will; (3) that the differentiation of the activity of this Will, and the connection of the differentiated 'momenta,' - the separate beings of the world, is teleological and rational like that of our own Self." In one word, the Being of the World, the World-Ground, is a rational Will, everywhere and always energizing for the realizing of its own ideas. The Absolute is a Self: all the seeming separate beings and happenings of which man has experience have their ground in this Absolute Self.

And now when it is objected that this is an anthropomorphic riew of the so-called World-Ground, that it is, if not avowedly at any rate covertly, a purely human and limited way of

1 In the treatise already referred to I have shown this to be true, with more of detailed and constant appeal to the conceptions and prineiples adopted by the particular sciences, than, so far as I am aware, has hitherto been employed by any similar treatise. All the so-called "eategories," as they are actually embodied, so to say, in the very structure of every form of science and involved in all the growth of science, have there been given a thorongh critical treatment. To this treatise, therefore, I must refer the reader who asks for further proof in support of the propositions made above. Compare $A$ Theory of Reality, p. 54i. 
conceiving of a hrpothetical Reality, the objection must be admitted. But on taking it back to the philosophy of knowledge for re-examination, this objection does not appear to have either the bearing or the force which is claimed for it. For it is seen that, as an argument for scepticism or agnostieism, it dwells only upon the negative and limited aspects of human knowledge, and largely or wholly neglects its positive and constantly extending guaranties and triumphs. Moreever, its psychological analysis of knowledge is markedly defective; its logical outcome is the destruction of the conceptions and assumptions which enter into all the particular scieuces, as well as into all human practice and social intercourse; and, finally, the more consistent logically it aims to become, the nearer does it approach the point where it is obliged, by a kind of intellectual hara-kiri, to destroy itself and all its own works as integral portions of human thinking and knowing.

On the contrary, the philosophy of knowledge and the theory of reality supplement and confirm each other, in all those forms of both which have been advocated by the reflective thinkers who have managed somehow to escape the results of a scepticism that ends in agnosticism rather than in a critical reconstruction of the conception answering to the term, "the World-Ground." Taken together into our confidence, these two branches of philosophical discipline show how all man's cognitive processes and achievements of knowledge whether practical, scientific, or speculative - culminate in substantially the same view. They all assume that the world in which man lires is a manifestation of a Reality of Will and Reason - a Mind-World. They all contribute proofs toward the progressively clearer and better establishment upon grounds of experience, of the very assumption upon which experience itself is grounded. This basic circular constitution of human experience, which grows out of those relations to reality in which the cognitive powers of man's mind place 
him, instead of being a vicious circle in argument, is itself the foundation upon which the validity and the value of all argument must always rest. As knowledge grows, man's conception of reality becomes more comprehensive and more profound. The assumption which underlies all knowledge itself becomes the better understood, the more obvionsly proved true, by the growth of human knowledgre. The postulate is immancut in all science; all scientific derelopment confirms and illustrates the postulate. This World is known by man as the manifestation of Will and Reason. The Reality made apparent by all man's experience is Personal; the WorldGround is rightly and rationally conccived of as an Absolute Self. If now, more of trustworthy knowledge is required respecting the fundamental characteristics of that Being which the World-Ground is known to be, it can be obtained only from a study of the philosophy of Mind. This branch of philosophy undertakes to discover and expound what may be known as to the nature of a Person; or - to use a term which may possibly scem less ambiguous - of a Self. The reality, the unity, the identity, and whatever other characteristics may be discerned as belonging to the essential nature of a Self, are all revealed-however imperfectly grasped and hazily conceived - with an indubitable certainty in the experience of every human life. What it is to be real, to be one, to be sclf-identical, as all sclies are, man docs not need to go to the heavens above, or to the depths of the scas, or to the inter-stellar spaces, to find out. What he does find, so surely that it reaches the acme of conceivable knowledge, is not correctly summarized either by the shallow positivism which reduecs the Self to a scries of phenomena which conceal instead of revealing reality, or by the scemingly profound but always unclear ontology which assumes an unknowable and inconccivable "substance," a sort of dead Ding-an-sichheit, that cannot break through the phenomena. The reality, the unity, and the identity, of every human Self 
are just such actual characteristics of its own living and conscious activity as sererally answer to these words. And to affirm that man does not know for what actual characteristics these words are warranted to stand is another of those distressing and self-destructive absurdities into which the sceptical attitude toward experience is constantly leading astray the devotees of metaphysical philosophy.

Nor is there better reason for the conjecture that the characteristics of Reality, Unity, and permanency or Self-identity, when attributed to the World-Ground, have reference to some unknowable and inconceivable quasi-dead core of its Being. To be real, to be one, to be self-identical, is, for the Absolute Self, essentially the same as for every finite Self. To be a Ding-an-sich, in the Kantian meaning of the word (if elear meaning there be which can be fixed upon all of Kant's uses of these words), is surely nothing for the gods to covet. Dingan-sichheit is poor "stuff" out of which to make Divinity. The rather is it especially important, as it were, for the Absolute Self that he should hare in its most unlimited and highest degree of perfection that self-realizing, self-unifying, selfidentifying power, which is to some degree possessed by every finite Self.

What, then, a critical and systematic study of man, and of the world which constitutes his environment, contributes to the philosophy of conduct is this : The World-Ground must be conceived of, and may (speaking broadly and generously) be said to be known, as an Absolute Self. IT is real, unitary, self-consistent and self-identical, as a self-conscious Will and Mind alone can be. Thus much by way of foundation for a metaphysics of ethics may be fairly borrowed from other more fundamental branches of philosophy.

The philosophy of conduct inquires, then, whether any of the characteristics of the Moral Self which man knows himself to be, can properly also be attributed to the World-Ground. By this latter term ("the World-Ground") we express a general 
notion of metaphysies. Can the attributes of personal Being be so extended in their application to this notion as to find in its reality the ground for all the phenomena, the laws, and the history of man's moral constitution and moral development? The full answer to this problem requires a critical surrey of nearly the entire sphere covered by the philosophy of religion; indeed the sphere covered by this survey is common to this branch of philosoplyy and to the metaphysies of ethies.

In the very brief sketch of an argument which will follow, two lines are seen to converge upon one conclusion. Of these two lines one is ehiefly negative, the other positire. The former tends to show that without admitting that conception of God as the World-Ground which the most mature reflective conseiousness of humanity presents, the foundations of morality are left totally unexplained. The otler tends to show that the truths involved in this conception furnish the mind with the best available explanation of the fundamental facts and truths of ethies.

The non-religions, not to say the irreligious, view of man, his origin, constitution, history, and destiny, cannot suggest any explanation of the admitted facts and truths of his own ethical experience. The failure of the ethics of "Naturalism" to explain itself, or in any satisfying way to answer, or eren to attack, the ultimate problem of the philosophy of conduct has been emphasized by no one more strongly than by Professor Huxley. According to this authority on the processes and laws of so-called "Nature," all modern as well as ancient scientific effort has utterly failed "to make existence intelligible;" but it has especially failed "to bring the order of things into harmony with the moral sense of man." I The "injustice of the nature of things" is quite "unfathomable;" "the cosmic process has no sort of relation to moral ends;" the "ethical process" involves a checking of the "cosmic process" and the substitution for it of something radically

1 Erolution and Ethics, 1893, and the Prolegomena, 1894. 
different; the life of virtue is opposed to that which leads to success in the cosmic struggle for existence. And to $\mathrm{Mr}$. Spencer's question, "If the ethical man is not a product of the cosmic process, what is he a product of ?" the naturalistic riew of ethical phenomena has, of course, no sufficient answer.

Now, as I have elsewhere shown, ${ }^{1}$ the merely naturalistic riew of so-called "Nature" itself leaves all the most pressing of our questions unanswered; it is indeed, quite unable to justify or even to explain the conception which it endeavors to embody in this capitalized word - the nature spelled with a big N. "Except in so far as it is known by having additional characteristics of Spirit, Nature is as 'brute and inanimate' as was the old-fashioned but now extinct coneeption of matter." "The genetic and architectonic power" which modern science puts into the word is all spiritual in its origin; it is the result of that inevitable and legitimate construing of the world of things after the analogy of our indubitable experiences with the world of Self. It amounts, in the last result, to affirming that "Spirit is the true and Essential Being of so-called Nature." Certainly no explanation of the moral nature, moral life, and moral development of man can be derived from this, the naturalistic conception of nature; this conception may even be said to be opposed to any morality at all, and more especially to any such view of the nature of moral sanctions and moral ideals as a fair study of ethical phenomena establishes in a matter-of-fact way. But then, no values of any kind, notling that has worth, whether from the artistic, the ethical, or the religious point of view, can gain the least credence in the creed, if it is consistently maintained, of such a form of Naturalism.

It is not Nature, truly conceived and profoundly known, which is antagonistic to morality, so much as the wholly inadequate and largely false conception of nature held by the naturalistic philosophy. One cannot, of course, claim that

${ }^{1}$ Especially, A Theory of Reality, chap. xvii : Nature and Spirit. 
the nature of things, when man's ethical nature is left out of the account, will serve to account for the origin, sanctions, principles, and development of morality. But when this inadequate view of Nature is itself transcended, one cannot, on the other hand, so bluntly affirm the total opposition of the "cosmic process" and the "ethical process." From the higher point of view, one may even attain glimpses, if not a full vision, of the truth that both processes are parts of one great and all-inclusive process, and that both lead to one and the same "far-off divine event." If Morality asks Nature to show how she could come from nature's womb and be nature's offspring, the question may only evoke the return of the question:

"' Ah, child,' she cries, 'that strife divine,

Whence was it, for it was not mine?'"

And yet the ceaseless, seemingly immoral, "struggle for existence" with which all Nature is laden may have the same ultimate ground and ultimate goal before it as the ceaseless and by no means less painful strife of Humanity after the moral Ideal. The inquiry after the origin and the sanctions of both may thus elicit the answer:

"'Twas when the heavenly home I trod, And lay upon the breast of God."

It would scarcely seem necessary to assume the obligation of showing the failure of Naturalism to furnish a metaphysies of ethics, after its failure has been so emphasized by the students of the "cosmic process" themselves. The truth seems to be that we have here one of those problems relating to the comparison of incomparables, which answer themselves in the very asking. Cosmic processes, conceived of in the purely naturalistic, or - what is the same thing - the totally unspiritual and non-theistic way, are asked to originate beings who believe in the value, who respect the sanctions, who safeguard the principles, and who secure the derelop- 
ment of ideals of conduct, not only of the individual but also of the social kind. That the belief is often weak, the respect ineffective, the safeguarding violated, and the security incomplete does not essentially change the conditions of the problem. For the problem is just this: How can conscious conceptions of worth arise as the resultant of mere blind happenings in fact? How can such actual happenings produce a respect for that which is conceived of as claiming the right to be in spite of the fact that it is not? How can the clash of irrational and impersonal forces produce a tender and pious regard for personal interests - especially when these are the interests of others that must be secured by a more or less complete surrender of one's own lappiness? The old-fashioned metaphysical saw, ex nihilo nitil fit, may not scem sufficient to put a check upon such eroluting of the moral from the non-moral, or the positively immoral, as all the attempts of Naturalism in Ethics to answer such questions obviously require. But if ever there was an explaining which did not explain, a borrowing of tenets which are not current coin and which have no power to pay anything back, such a transaction is that which goes on whenerer a naturalistic metaphysics undertakes to solve the metaphysical problems of ethics. Far better to be frankly agnostic than to accept such answers to one's inquiries for ultimate trutl. Far better to cling without light or hope to the dark shadow of a form we call our Duty than to explain its origin and sanctions in so absurd a manner as Naturalism in Ethics offers.

The quite complete incompetency of that view of the historical evolution of morality which does not recognize the personal character of the Moral Life and the Moral Ideal, as to both its origin and its sanctions, has been pointed out many times in our past discussions. It was, indeed, the confession of this incompetency which threw upon us the necessity of resorting to a more fundamental philosophical discussion in 
order to get light for the solution of the ultimate ethical problems. That Positivism in ethies which merely notes the facts of certain historical conditions of the development of morality is as unsatisfactory as is Naturalism in ethics. Again we are obliged to say that it is better frankly to confess our agnosticism than to make the phenomena of man's moral constitution and moral evolution, by a skilful but always hypothetical rearrangement according to some preconceived theory, seem to explain themselves. He should have no difficulty with any of the stories of the wonders wrought by Aladdin's Iamp who professes to understand how a World absolutely indifferent to distinctions of moral worth could give rise to an ethico-social being like man, and to his etlical and social derelopment.

And now, before turning to the more positive answer which the philosopher has, at his best estate, to offer for the solution of the ultimate problem in ethies that concerns the relations of the ground of morality to the World-Ground, let us once more endearor clearly to see what the problem is. The existence of morality amongst men is a fact. Anticipatious, forecasts, preparations for its coming may be detected in the animal kingdom lying lower down than man, and even in the systematic arrangement of things. For although neither things nor the lower animals secm to be wholly equipped with moral selfhood, they do possess certain basic qualifications for moral derelopment in common with man; and both things and the lower animals undoubtedly hare important functions to perform in furnishing the physical basis and the plyysical and social environment for man's moral life and moral development. In spite of Mr. Huxley's low estimate of the moral value of the "cosmic processes" - which, with him, include all the different lower stages in the erolution of animal life preceding the time when man became a Moral Self - there are good reasons for the belief that these processes, too, cannot be illumined fully or understood aright until they are regarded from the ethical point of view. They, too, participate, 
in a way, in a system where ideas of value, and ideals of moral development, have the highest sanction and the most universal sway. At any rate, such has been the confidence, not only of the multitudes who do not think, but of the poets and the philosophers of the human race. In a certain Sanskrit drama, for example, ${ }^{1}$ a wicked prince endearors to persuade a parasite to commit murder by assuring him that there is no one to witness the act. Pariah as he is, he faces the prince in confidence that the last foundations of morality are not subject to human influences, and thus replies in indignant language:

"All nature would behold the crime, The genii of the grove, the sun, the moon, The winds, the vaults of heaven, the firm-set earth, Yama, the mighty judge of all who die, Aye, and the inner conscience of the soul."

And that tried liuman soul, the girl Antigone, ${ }^{2}$ when called upon to decide between her loving sense of personal obligations and the mandates of the supreme liuman authority reinforced by the ripest human wisdom, is made to say by the tragedian whose insight into the springs of human life has never been surpassed :

"It was not Zeus who heralded these words, Nor Justice, helpmeet of the gods below, 'T was they who satisfied those other laws, And set their record in the human heart. Nor did I deem thy heraldings so mighty, That thou, a mortal man, couldst trample on 'The unwritten and unchanging laws of heaven.

They are not of to-day or yesterday ;

But ever live and no one doubts their birth-tide."

This confidence, thus poctically expressed, was the ground of the philosopher Fichte's assertion: "The world-order is in the last analysis a moral order." Or, again, as another writer

1 See Talboys Wheeler's Short History of India, p. 63.

2 See also CEdipus, 846 f. and p. 572 of this book; and comp. Pfleiderer, The Philosophy of Religion, iv, p. 240. 
has expressed the same truth from another point of riew: "Man's consciousness of himself as a member of society inrolves a reference to a cosmic order."

Doubtless it will be objected to all this that we are here dealing only with the projecting of man's moral Selfhood into the phenomena of the World, in the midst of which this Selfhood somehow finds its origin and its development. The objection is true in fact; but the fact to which objection is made is the rery thing which demands explanation. Why do the multitudes, and the choicest of the poets, and the wisest of the philosophers, find themselves impelled to regard with this moral sympathy that system of things in which their own existence and derelopment have their ground? Of course, it is because they all are themselres moral beings. But the very thing to be accounted for is the existence and progress of moral beings, as arising out of such a ground and existing in such an environment. Certainly, man's moral nature, the experience of the individual with himself and with other men and with things, must be recognized as containing the sources, the sanctions, and the principles of his own moral development. All the more necessary is it, therefore, so to conceive of the origin of this human moral nature, of its reactions upon its environment, and of its progress and its achievements, - so to shape, in a word, the explanation of all that is distinctively ethical in human experience, - as to bring it into the fullest harmony with all our other most trustworthy conceptions of Reality. This, I assert, can be done only by identifying the Ground of Morality with the World-Ground. And such an jdentification is possible only if the World-Ground be conceived of as the absolute moral Person, the ultimate Source of all the ethical life and ethical development of humanity. I shall now present this general position very briefly as it appears to me defensible from several closely related but somewhat different points of view.

And, first, in God, or the moral personality of the World- 
Ground, we discuver the more ultimate souree of whatever common standards of conduct have prevailed, so far as investigations can inform us, in all ages of the ethical history of humanity. Certain of these standards are, indeed, more especially of a purely utilitarian character. They spring up every where as the result of that striving for freedom from pain. and for the obtaining of pleasure, in which man joins all sentient life and in which he employs his superior intellect. But this merely utilitarian explanation of the prevalence of common standards of morality will not apply to all cases, nor is it the complete explanation of any of the forms in which a moral code establishes itself. An inner motive is especially necessary to account for some of these standards; indeed, some inner motive seems necessary to supplement the explanations of an external utilitarianism in order to account for the origin and prevalence of nearly all of them. This inner motive uniformly appears to involve a recognition of values that are not wholly of the utilitarian order. For example, in some eases the gods are deemed worthy to be pleased; or their fear restrains the would-be wrong-doer. This, or some other form of impulse, which, like whisperings from another and invisible world, compels men to the recognition of the more subtle spiritual connections of their own selves with a mysterious and invisible Selfhood, has always - to quote the words of another - added " incalculably to the power of religious ethics to hold its own against the tendeney to an external utilitarianism which springs so easily from a purely objective consideration of moral phenomena."

It has been by means of both the co-operation and the antagonism between inner spiritual motives and the more external utilitarian considerations, in action and reaction with the "cosmic processes," that the human race has established in authority over itself certain common standards of morality. These standards, psychologically considered, are the forms of mental activity that are everywhere regarded as right and 
that together constitute the virtuous life. Historically considered, they are the forms of external behavior, the manners and customs, the laws unwritten or written, which, however they may differ in respect of many details, still bear witness to the essential universality of the conduct that is recognized as valid for man as man. But the historical process which derives its factors from all three sources - namely, from spiritual influences, from utilitarian considerations, and from physical processes - and which somehow manages to work out a planful structure of an ethico-social kind, challenges philosophy to furnish to it a satisfactory account of itself. This account philosophy must bring into accord with its conclusions upon cognate subjects. Its account reads as follows: Any historical process like the moral decelopment of humanity is proof of the presence in the World of a rational Will, which is working in the interests of moral values, and which is establishing over all moral selves the regency of moral standards in the only way in which such establishing is possible. For, in the progress of morality, man must accomplish the Divine Will by making that Will man's own; in other words, the Divine standards of righteousness and of virtuous living must be made universally effective by the work of God in human ethical history, as mere "cosmic processes" or "external utilitarian" considerations alone cannot make them, even although working in conjunction with influenees from these processes and these considerations.

This same thought is still further emphasized and enforced when humanity is considered as actually experiencing a real moral progress. This manner of progress implies, on the one side, the elevating of the currently accepted standards of morality; and, on the other side, it implies the spreading of these rising standards over a larger and larger portion of the race. That there is a moral progress of this sort actually taking place, historical and anthropological data would seem to show. The race may not, on the whole, be 
growing better men. But the current standards acknowledged as obligatory are being raised; and a larger number of mankind are being made acquainted with what those higher standards are. This is a work similar to that which religion assigns to Divine Providence and to Dirine Selfrevelation. If the response to this self-disclosure of the Infinite Moral Spirit is effective in actually securing among men, not only intellectual enlightenment and improved judgment upon matters of conduct, but also the purcr leart and the nobler life, then religion speaks of this result as due to Divine inspiration. Thus religion regards the raising and the spreading of the standards of morality among men as due to the efficicnt activity of God, in providence, revelation, and inspiration.

Making a sufficiently large allowance for over-confidence in details of argument, for excessive naïveté in expression, and for a somewhat too frequent and often dangerous neglect of modifying considerations, a truly philosophical Theory of Reality can receive the conclusions of the religious consciousness as worthy of a high place in its system of philosophical truths. Any completed theory of reality has the realities of morality to take into its account. Ethical facts are no less facts because ethical. Among ethical facts not the least important is the actual existence of the accepted standards of conduct and of the current judgments upon matters of conduct. The explanation of their existence cannot be found wholly in any purely cosmic process, or in any historical process of a purely utilitarian character. Ethical facts come into such supreme importance and beeome of such tremendous import in the development of the race, through a sort of progressive synthesis in which cosmic processes, utilitarian interests, and spiritual ideals and motives all co-operate to a common result. We, therefore, find this synthetic power in the Divine Will ; we ascribe this complex historico-ethical evolution to the Divine Plan. In it God, the ideally righteous 
and holy Person, is realizing his immanent ideas as to what standard liumanity ought, by its own co-operative responses to this rational and holy Will, to set before itself as the law of its life in the conduct of moral selves with one another.

In this sense, then, does the metaphysics of ethics find the origin of moral laws in the will of God. Such a philosophical tenet is by no means to be identified with that tenet of theological ethics which finds the ground of the right in the so-called "bare will" of God. Of bare will, whether in physical nature, in man, or in the Absolute, a discerning theory of reality discovers no trace at all. Schopenhauer's contemptuous phrase — " wooden iron" - for the justifiable conception of an "ought-to-will" may properly be turned against lis own attempt to identify the one central attribute of the World-Ground with the being of bare will. In physical nature, in man, or in God, nothing is "bare" - neither will, nor reason, nor feeling, nor any of the other psychological aspects or attributions of the unitary being we know as a Self. But the moral laws which men create, as the expression of their higher ideas of unseen worth, and their experience with the uses of things, are at the same time the offspring of the righteous and holy Will of God. Here, that is true which was seen ${ }^{1}$ to be true of all finite beings and finite erents; they, too, share in the will and wisdom of the Infinite; they, too, are "moments" in the self-realization of the personal Absolute. They are not lost in Him, beeause they exist in Him; nor, because they do really exist in Him, are they able to affirm or maintain their existence in independence of Him.

Man creates his own moral standards. This is true. He makes, in the progress of his own ethical evolution the moral laws which he either does well in keeping or suffers

I Compare a Theory of Reality, Chap. XIX. "The World and the Absolute." 
by disobeying. He is pre-eminently his own law-giver in the moral, as he is not in the physical or purely mental sphere. God created the sun, the moon, the stars; God created the world of man's physical environment; and He constituted the laws of man's mental life, - those constitutional and inescapable limitations of man's thinking processes, of his sensuous observations, of his handling and moulding of things. But did He have aught to do with the constitution of those invisible spiritual influences which co-operate with the more visible and material inducements to form the mandates of the moral law? Most certainly; and none the less truly because so true is it that man forms and adopts, without being under the same stricter compulsion, his own moral standards and moral code. For, in the last analysis, human thinking must find in the World-Ground the efficient and the final cause for the development among men of uniform and improved standards of conduct, and for whatever real ethical progress our historical and anthropological studies enable us to claim for the race. The continuous illumination of the human race by the everywhere scattered lights of the Moral Law has its source in the Sun of Righteousness, the ideally holy and righteous Will of the World-Ground.

But, second, the argument is again reinforced when we consider the character of those sanctions which are everywhere found attributed to the moral standards of men. These data of all morality, too, must find their ultimate source in the same World-Ground. There is no more puzzling problem before the philosophy of conduct than is involved in the seareh after the ground of the inviolable sanctions, the sources of the indisputable obligations, of the moral selfhood and moral development of man. That humanity believes in some such sanctions and acknowledges the existence of such obligations, the psychological analysis and historical survey of the phenomena of moral consciousness plainly show. It is, indeed, possible to find in the social environment and even in the 
" cosmic processes" a partial account of some of the particular sanctions which belong to human morality. But this account, at its best, is only partial.

All views which do not find the feeling of oughtness, as uniquely human among the most original data of ethics, have already been adjudged unsatisfactory. This fecling cannot be regarded as the outcome or expression of any purely cosmic process. It cannot be explained as a resultant solely of the working of social influences upon the mind of the individual. On the contrary, it is itself a basic and ultimate fact with which every attempt to account for the origin of social organizations among men must always reckon. Social organization among men presupposes the feeling of moral obligation; it is built upon the reeognition of sanctions belonging to particular kinds of conduct; social organization as mere fact, then, cannot form the entire satisfactory account of the existence of this fecling or of the most original sanctions, to which the feeling responds. It is true, however, that the direction and concentration, so to say, of the sanctions of moral consciousness upon particular courses of conduct are often to be explained by the character of man's physical and social environment. These environing influences often answer, chicfly or in part, the question why the soul of man recognizes as ubligatory just such, rather than other, forms of conduct. This general historical fact explains why moral laws appeal to a sense of obligation; only by making this appeal do the customs of society, or its more deliberate statute enactments acquire the peculiar sanctions of morality. So, then, whenever certain eustoms or laws appear to be due to the fortuitous or the regular operation of physical or social forces, the sanctions of these same customs and laws also appear to be derived from the same physical or social forces. What the social organization commands becomes a truly moral mandate, and has all the sanctions belonging to such a mandate. Even Nature, in a more uncertain way and often 
by a kind of dumb, pantomimic gesture, indicates to man her orders as to what he shall feel himself obligated to do as her creature and the subject of her laws.

Doubtless, the recognition of the right of Nature and of human Society to issue mandates to the individual man, and of the duty of the individual to respond by obedience to the feeling thus aroused - in this way acknowledging the moral sanctions inherent somehow in these mandates - is an inestimable benefit to humanity. Without it the individual would speedily make wreck of himself by antagonizing both nature and society, either in a blindly mechanical way or else in a no less dangerous but wrongly conscientious fashion. Indeed, it is just this failure to credit the cosmic processes and the social customs and institutions with the amount of moral character which is their due that constitutes the arch-crime of Insolence; this crime is the essence of tragedy; it is the wrong-doing which the Divine Will as Nemesis, is wont so surely and frightfully to avenge. The opposite of this crime is the allinclusive virtue of the judgment to which the name of a pious Resignation was given. Doubtless it is in general right for the individual man to obey the so-called "laws of nature," so soon and so far as he can discorer what those laws actually are. Doubtless also a man will not generally be in the right, if he flouts at and contemptuously disobeys the customs and laws of suciety.

But so much concession as this, and even many times as much of concession, does not make it clear that either nature or society can furnish the ultimate and complete ground of moral sanctions; nor does it explain precisely how they can scrve as an ultimate ground at all. It is in the endeavor to clear up the origin of that right to command which all the moral standards - howerer historically derived - seem to elaim, that the course of reflective thinking leads the mind again to the identification of the ground of morality with the WorldGround. Let us consider the argument as briefly stated. 
With regard to Nature, considered merely as a complex of more or less coherent " cosmic processes," one can really find no rational account for any sanction attaching itself to her so-called "laws." That some at least of these processes dominate man and determinc his weal and his woe-will-he or nill-he - is undoubtedly matter-of-fact. This matter-of-fact lies at the basis of all his moral life and development just as it forms the indestructible basis of his very existence. In certain other cases, not a few in number or unimportant but always of a restricted character, man can say whether or not he will act in obedience with nature's laws; he can take the conscquences of disobedience, if he cannot, as not infrequently happens, mitigate these consequences by action that falls under other natural laws. In still other cases, his moral development depends largely upon improving Nature's unrestricted ways of behavior, and so, by natural forces, helping himself to a better estate than nature, without this self-help, would ever furnish to him.

All such human intercourse with natural forces and natural laws belongs, howerer, to the domain of the actual. So it is: Nature encompasses me, hems me in, assists me at times and thwarts and punishes me at others. I must obey her laws, because without this I cannot even exist, much less attain any of my ends or enjoy any of her privileges. But suppose that She, or some moralist who has come over from physics into ethics, speaking in her name, attempts to add the sanction of an "ought" to any one of her many ways of treating human kind. Suppose that the endeavor is made to impress the individual man with the ethical sacredness, the truly obligatory character, of any of the so-called natural laws. It is proposed to put an obligation upon man's ethical nature to do as the cosmic processes compel or solicit him to do. The voice that issues from this mysterious mother of us all is now no longer " Thou must," or "Thou shalt," in order to this or that end, and in view of these favorable or unfavor- 
able consequences; her voice now is, "Thou oughtest," and "so only wilt thou secure the satisfactions of an approving conscience." But what right to command - right, such as belongs to the very idea of an ethical sanction - can be conceired of in the name of a purely cosmic or natural process? Suppose that I choose to disobey nature; you may threaten me with impersonal cosmic processes, but you cannot appeal in their name to my feeling of obligation. The ruling natural forces may grind me to powder, but they shall not make me bow before their right to command. The laws of nature may compel my obedience, but they cannot compel a moral respect for themselves. By the appeal itself, "Holy mother Nature" is already transformed from an impersonal source of cosmic processes into a personal and Ethical Spirit, in order that she may serve the better as a sort of World-Ground. This is really only another way of bringing in covertly the postulate of God as the ground of morality.

As the moral development of man proceeds, accompanied as it necessarily is by his intellectual progress, the conscious worth of man's nature superior to the sum-total of the underlying cosmic processes, becomes more and more obvious to himself. From the very beginning, indeed, he finds much in those processes which is neither to his mind nor in accordance with his dawning and ascending sense of what is just and wise and kind. The schism between the natural and the ethical tends to become more apparent. The struggle with these natural forces and laws into which man's ethical nature impels him becomes more intense and more oppressive. His moral consciousness comes to assume the right of moral judgment over these very "cosmic processes ;" and, as in Professor Huxley's extreme case, it accuses them of the breach of all those proprieties and obligations under the sanction of which man's moral development flourishes best. A saner and profounder view of Nature follows, in our judgment, upon taking a higher point of view ; but this is 
true only if one confess that the cosmic processes themselves issue from the same personal and spiritual source as that to which, in the last resort, must be attributed the moral nature and moral development of man. Certain it is that, without some such way of unifying the explanation of all man's experience, the schism between his moral life and the existence, action, and evolution of physical forces and laws is certain to go on widening and deepening to the end. Accept such an explanation, however, and it at once becomes apparent that - if not wholly how - the quasi-obligatory character of natural law is due to this: The source of this law and of the human consciousness which endows it with sanctions is to be found in the same World-Ground. But this is in a way to identify Nature with the ideally righteous and holy Will of God.

There is undoubtedly more reason to be found in man's naive moral consciousness for asserting the right of society to issue morally obligatory commands to the individual, than can be discorered in the nature of any of the mercly cosmic processes, or in any of man's natural relations to these processes. Such is the very constitution of socicty that certain of its members ineritably appeal to the multitude of men with a sort of sanetion for their claim to authority and allegiance, in matters of conduct. In the family, this is true of the relations between parents and ehildren, during all the earlier development of the latter; true also of certain of the relations which exist between husband and wifc. In the tribal relations also, the ehiefs, or head-men of the tribe, its leaders in war, its wise men in council, and its teachers and priests who carry on the religious functions of the community, are naturally clothed with an authority which appears to be of no merely external sort. The moral consciousness of the inferior multitude of the tribe acknowledges the commands or injunctions of the superior few as reasonably acquiring the obligation of a spiritual and ethical bond. 
Mere fear of force, unmixed dread of physical consequences or desire for the pleasant rewards of obedience, can in no case account for all the strength of the tie which binds men together; -even in these simplest forms of social organization, or in the lowest stages of their moral and rational development. What is true of the simplest forms and the lowest stages is pre-eminently true of the nore complex forms and higher stages of the ethical development of humanity. In these higher developments, the will and ethieal judgment of the social organization have expressed themselves in a great variety of customs, precepts, laws, and regulations, all of which are themselves the resultants of a long process of historical development. In other words, we find the individual Moral Self everywhere, within certain limits, acknowledging the sacred and obligatory character of the customs and laws which express the moral development of the community of Moral Selves. Thus do the historical and social processes, in which the moral life of humanity manifests itself, seem to stand in a relation to the sanctions of morality which is much superior to anything that can be claimed for what Professor Huxley denominates the "cosmic processes."

If now inquiry be made into the reason why the ethical judgments and choices of the various forms of social organi. zation appear, under ordinary circumstanees, to carry with them their own indisputable sanctions, the answer must undoubtedly be found in the very constitution of man, and in the nature of the social organizations which he constructs. To draw out this argument in detail would only take us again over the same ground which we have already covered in considering the nature of the Moral Self, and the doctrine of the Virtuous Life, its eharacter, and its aims. Man is, in fact, so built that he respects his own building. Becanse of this mysterious inherent dominance of the feeling of obligation, the judgment and practices which have, for various reasons, come more or less continuously and persistently 
to call forth the feeling, appear to the subject of that feeling as having an inviolable authority. In one word, the sanctions of the prevalent standards of conduct have their origin and their explanation in the same sources as those in which these standards themselves originate.

Let no inquirer, however, be deceived by the appearance of lucidity and finality which all such explanations as the foregoing may be tempted to assume. For this circle in argument, however interesting and able to illuminate its own complete circumference, or even its own entire area, nevertheless still leaves unsolved the same problem in the metaphysics of ethics. It is the historical behavior of the race in its construction and acknowledgment of these very same moral sanctions for which a more fundamental and ultimate explanation is sought. Just as the ministration of the cosmic processes to the moral derelopment of man does not seem to be satisfactorily accounted for when it is referred to Nature, conceived of as a complex of blind forces devoid of all Spirit and conscious Life, so does the work of so-called human society, in creating and sanctifying those bonds which are in their very character spiritual and personal, appear unequal to that of a self-existent and self-explaining Absolute.

And, indeed, there are other ethical phenomena which are current and indisputable, but which are of a startlingly different character. For sacred and full of self-consistent sanctions as much of social morality may seem to be, there has always existed in the human breast a strong and sometimes irresistible and outbreaking tendency to overleap the regard for all such sanctions. The great moral reformers and prophets of humanity have always felt this, and have acted according to the feeling. Call a crime if you will this revolt against the current social morality; and perhaps society is compelled thus to designate and to punish every such revolt. But the fact is that the most enlightened and pure-minded individuals have never been willing uncondition- 
ally to submit their moral consciousness to the most highly sanctioned exterual regulations, however enacted and enforced by the social organization. In studying the phenomena of man's moral development in a large way, attention is constantly called to this interesting and startling fact. Other sanctions, and another more spiritual and mysterious source of authority, have always been appealed to in critical moments by the morally most advanced members of society itself. Nor do I think that any reasonable critic of man's moral life would be satisfied with finding no higher and more final sanctions to which an appeal may be taken than those that belong to the actually existing mandates enforced by the customs of the social organization.

I should understate the case so greatly as quite completely to misrepresent it if I left this subject with the impression that we are here dealing only with a rare phenomenon, or one that may be accredited to the class of ethical eccentricities. On the contrary, it has always been true that a possible distinction, usually lying latent perhaps, and yet always ready to emerge, exists in the moral consciousness of the race, between the sanctions which the will of man imparts to the moral law and the sanctions to which an appeal may sometimes, at least, be made as though they belonged to the moral law itself. I know that there is much about such human experience which is vagne and shadowy. I confess that it is difficult to take the fact out of the figurative and symbolical character with which it is clothed in human experience, and then reconstruct it in such a way as to give it the force of a convincing argument. But the fact is there; it cannot properly be overlooked; its import is sometimes most astounding. Very timid animals, when driven and cornered, will sometimes fight most desperately. Very subservient multitudes of men, after long years of suppression under the dominance of forces of social organization that have every claim to moral sacredness which society itself can impart, 
sometimes appeal, regardless of results, to another than the human social tribunal. The appeal is generally dim-sighted or blind. Seldom, or never, do these multitudes clearly know what they arc about. Rarely, if erer, do they succed in escaping from the infliction upon themselves of evils more grievous than those which they endeavor to abate. But in some dim-sighted or blind way they hold the indestructible confidence that there is a justice superior to all human justice; that there is a court of appeal to which the individual may resort when the last earthly court of appeal has giren its sanctions to essential wrong-doing; in fine, that the moral law is above all the human laws which enact what shall be estecmed moral; and that its sanctions are so decply founded in the bedroek of Reality as never to be shaken, even when all human institutions of the most time-honored and sacred order seem tottcring to their final fall.

It is not, howerer, in this quasi-nililistic or revolutionary fashion alone that the moral consciousness of man secks satisfaction in the confidence that the Ground of the World itself is the source and ground for the sanetions of morality. There have always been many quict workmen who have held this confidence in less obtrusive and disturbing ways. More or less habitually these persons have been able to do right, and to enjoy the sanctions of an approring conscience, even when the "doing right" brought them into disesteem as wrong-doers among thuse of their fellows whose standards of moral judgment were of the more conventional sort. That some of these workmen have displayed a somewhat immoral spirit of contempt and bitterness toward conventional morality and toward its sanctions must be confessed; it is to be deplored undoubtedly. The disposition to let socicty "gohang," as it not infrequently deserves to do, is never lovely or morally to be approbated. But the testimony of the men who, whether indulging this spirit or keeping themselres free from it, have cherished that respect for morality which is not 
founded merely in respect for the enactments, practices, and opinions of the social organization, is, it seems to me, a valid arcument for the identification of the ground of the sanctions of morality with the World-Ground.

Nor should one fail to notice another cognate class of related phenomena. Not simply in times of open and violent recolt against the prevalent moral order, but in their daily moral judgments multitudes of men frequently exhibit their confidence in God as the source and sanctioner of a more ripe and essential justice than that which society approbates, - not to say practises and enforces. This they often do in querulous ways. And among such complainers the most pronounced skeptics as to the Being of God, the Ethical Spirit, are not infrequently most prominent. Things have not gone right with them; socicty has not dealt fairly with them. And yet things have gone on stcadily treating them with that indifference to merely personal considerations which belongs to the very nature of things. Socicty has quite uniformly given them just the same chance for success which others have had; and neither the social customs, nor the courts of law, nor the popular opinions and judgments, have ever brought any peculiar hardship upon them. They who least of all believe that there is any Providence are often most bitter in the judgment of the behavior of Providence toward themselves. They who do not credit any existing ground for the sanctions of morality above or beyond the cosmic processes, or the enactments of society, are frequently most dissatisfied with the character and working of these sanctions. To claim their respect, things and society "ought to do better;" because things and society are somehow not up to the standard to which they ought to rise! Surely one may call out with Schopenhaver, "Wooden iron," when one hears from such lips about what that is not, really ought to be. Or the rather, may one say in the words of the Apostle Paul: "Whom therefore ye ignorantly worship, him declare I unto you." In 
contrast with this multitude stands the multitude of pious souls who quietly and faithfully trust God, the Ethical Spirit, as the original source and final sanctioner of all morally right conduct. By the standard of his mandates they constantly test, as best they can, all the most sacred standards both of the natural and the social sort.

By these and many similar experiences it may be shown. that there is a necessity laid upon reflective thinking to find somewhere back of, and beyond, man's moral constitution and the historical evolution of his moral life the ground for the sanctions which he recognizes as essential to all morality. Collective humanity, in and through a historical process, gives itself the moral law. And yet lumanity gives itself the law, because humanity itself is constituted a child of that Ethical Spirit in whom are all the sources of its own moral life and moral development. Man recognizes the inviolable authority and indisputable sanctions of morality, because he is himself an ethical and social Self; and thus is empowered and compelled to respect his own moral constructions. But just as he is not the author of his own physical being and physical development, but perpetually derives this from the World-Ground, whose life and vital energy are immanent in the race, so is he not the author, in the last analysis, of the authority and the sanctions which his Moral Selfhood acknowledges.

I believe, then, that no satisfactory account is possible for the reflective and speculative treatment of the sanctions of human moral life which does not find the ground of these sanctions in the World-Ground. If they originate, as they certainly do, in the ethical reactions of man himself upon his own physical and social environment, still this very procedure of man must find its explanation in our theory of reality. Both the environment - social as well as physical - and the constructive work of man in his own ethical crolution must be referred for their more ultimate explanation to the Per- 
sonal Absolute. In order that this Absolute may serre as an explanatory principle of such a complex cvolution - namely, of the development of man's confidence in, and respect for, the sanctions of morality it must be conceived of in terms of Ethical Spirit. The ultimate Ground of moral sanctions cannot be bare Will, or blind Will, or Will indifferent to all the Ethical as well as sentient and esthetical interests of humanity. The rather is it an omnipotent and omnipresent energy devoted to the final securing in reality of those interests. In other words, the ultimate sanctions of morality must be located in the authority of an ideally righteous and holy Will that is realizing its own Ideas in the historical process of human moral development.

Such a conception as that just expressed imparts rationality to the sanctions of morality. When the demand is made that $I$, the individual person, shall sacrifice my immediate or more distant sentient good in the interests of the common good, an underlying substantial Ground seems necessary in order to justify the obligatory character of such a demand. All through the previous treatment given to the problem of conduct, transcendental references have been implied to a Personal Bond among the individuals whose life in social relations affords the content of morality. One may not be ready to accept the claim that no sanctions for an altruistic etlics - $i$. e. for genuine morality at all - are tenable which do not found themselves in belief in God, and in the oneness of all finite souls in God.1 "All persons are mutually exclusive . . . yet they are one in God. Hence the Good for the whole is the Good for every separate member." But if such a form of stating the truth seems somewhat too abstract and otherworldly, this is no legitimate reason for overlooking the plain facts in the case, or for refusing to face the mysterious and profound problem which the attempt to explain the facts presents. In some dumb and inchoate fashion the universal

1 As made by T. H. Green, and compare D'Arcy, Short Study of Ethics, p. 102. 
moral consciousness makes confession to the belief that men - the wise and the ignorant, the superior and the inferior individuals and races - are bound to acknowledge the authority over them all alike, of a moral government which is only faintly and imperfectly typified and realized in the sanctions which they confer upon the mandates of their own devising. And this confession points the finger of reason in the direction of this truth: The ultimate Source and Guarantor of all moral sanctions is that Ethical Spirit to whom all men thus, more or less unwittingly, confess that their allegiance is due.

Pre-eminently true, however, is it that the moral Ideals of humanity must find their explanation in the Being of the World-Ground. And this they cannot do unless this WorldGround be conceived of as Itself an Ethical Spirit, the One Ideal-Real of a righteous and holy rational Will. As a modern writer has said: 1 "The moral World-order regarded as an active Principle is God as Spirit. Only the Self, only Egohood, is the home of all that is Ideal." In human morality, its life and its development, the presence and influence of ideals is the greatest and most mysterious of experienced facts. Man is, indeed, an idealizing energy. His dissatisfaction with his physical and intellectual conditions and attainments is a mighty potency for accomplishing the improvement of these conditions, the enlargement of these attainments. In all stages of his development, at least abore the very lowest, he forms a picture of something better than the actuality and makes more or less strenuous and determined efforts to realize it. This ceaseless reaching out beyond the domain of lis present possessions to grasp after imagined goods characterizes the course of humanity in its upward history. It is, however, in the ethical sphere of his liring and acting that the influence of man's idealizing potency is most mysterious and profoundly significant. He is indeed a poor specimen of human nature who has no ideal of a Moral

I Moriz Carriere, Die sittliche Weltordnung, p. 405. 
Self in any respect or degree better than his own actual attainments; who esteems himself in all respects as largely and comprehensively virtuous as is necessary to satisfy his own conceptions of what he ought to be. I am not now referring to the theological doctrine of the consciousness of moral imperfection as a consciousness of sin. But, in fact, man is naturally determined to compare the facts of the moral life of himself and of other men with a standard which is set higher than the reaches of that life itself.

In a still larger way are men found picturing to themselves a social status which is an improrement morally over any existing social organization, and then acknowledging, however feebly, the moral obligation to move onward toward the realization of this Ideal. Thus it is only a seeming contradiction in terms when I assert: the moral Ideal is the great, mysterious, and permanent Reality in the moral constitution and moral development of humanity. This same Ideal assumes almost innumerable forms as it appears before the individual consciousness and as it changes its character in the different ethical epochs and stages of the ethical evolution of man. Sometimes it is rather an allurement; sometimes it partakes more of the nature of a torment - the allurement or the torment of the Infinite appearing within the consciousness of the finite. Always, as was clearly seen when the subject was under consideration, the moral Ideal is itself undergoing a process of development. Its very ideal character shows itself in this that, the more it is pursued, the more does it retreat; the more nearly it seems to have been reached, the more distant of realization does it become.

Now, undoubtedly, it is in the nature of man's moral and social Selfhood that one must discover the proximate account for the origin of his moral ideals. Just as man makes his own moral laws, and imparts to them the sanctions before whose holy inviolability he acknowledges his allegiance to be due, so does he frame the ideals of individual goodness and 
of the morally perfect human society which the keeping of these laws is supposed progressively to secure. How he can achieve with any measure of success so important a task the psychology of the Moral Self attempts to describe. Thus, too, does the historical and anthropological study of the influences under which the different types of the Virtuous Life lave appeared supply the proximate causes for the structure and growth of the Ultimate Moral Ideal. Yet here again the answer of psychological analysis and of historical insight does not furnish all that the philosophy of conduct demands. How can man do for himself this significant work of idealizing, unless his nature is born of an Absolute Ethical Spirit? How can he develop such an Ideal, in whose life he shares, unless his history may be understood from the side of the "Overman" as under the inspiration and guidance of this Spirit? It is in the answer to these inquiries that the metaphysics of Ethics finds itself obliged to adopt some position corresponding to that from which religion regards all the derelopment of lummanity. Of this tenet of the religious consciousness Pfleiderer ${ }^{1}$ forcefully says : "And here too Paul pointed out the right way, founding his philosophy of religion on the thought which in modern thinking must always be the principal point of view: the thought, namely, of a development of the moral spirit under the guiding education of God. Each stage of the developinent has its corresponding moral ideal ; none of them is fortuitous or arbitrary, each rests on a divine ordinance and is good and necessary for its own time, and for its own time only."

In one word, if man's moral nature and moral development are held in themselves to furnish the account for the origin and development of man's moral ideals, then a fortiori is it man himself, with this llature and undergoing this development, who demands to have an account of his origin and his history. In his efforts to introduce in the form of

1 The Philosophy of Religion, IV, p. 254. 
ethical postulates all those most precious ethico-religious conceptions and truths which had been denied to knowledge, Kant found himself compelled to draw heavily upon the resources of an invisible, non-sensuous, and ideal World. Knowledge had been proved, he thought, to be only of phenomena - albeit of "objective" phenomena, and so of phenomenal reality. But the moral law, which appears in human consciousness as a categorical imperative, demands that we should not only think the possibility of our being, but believe that we actually are, free and noumenal beings, belonging to this kingdom of persons where moral values, howerer unrealizable in the world of phenomena, are unconditional and supreme. This is Kant's uncoutl way of acknowledging that man's moral being, however its historical unfolding and psychological explanation may appear to the understanding, is, after all, dependently connected in reality with the World-Ground. For this great thinker, in order to make rational our experience with this ideal side of human selfhood and human history, God must be beliered in as the Lawgiver, the Sanctioner, and Rewarder of the moral life of humanity.

In accounting for the nature of cognition - of knowledge, faith, feeling, opinion, etc. - we are obliged to differ from the author of the Critique of Pure Reason in many and radical ways. In our treatment of the nature of moral conscionsness, too, we have tried to keep much nearer to life and to experience than did he; and so to be more truly rational than was Kant with his quite too vacillating and expansive conception of reason itself. In this way we expect to aroid the deep-cutting schism, the irreconcilable contradiction, which he sets up within the heart of reason itself. There are, in fact, no such contradictions within the realm of appearances, or between appearances and Reality, as the Kantian dialectic aims to disclose, whether this dialectic be wielded in the hands of its great master or in the far feebler grasp of some of his successors and imitators. But the final necessities which all the 
agnostic dialecticians come to acknowledge are most significant. In man's moral nature, if not elsewhere (although, as I believe, also elsewhere and everywhere), the voice of the Personal Absolute is more plainly to be heard. Faith in this voice is imperative here. Faith in this voice is the height of rationality here. The account of the origin and the ongoing of the physical universe may seem complete without the recognition of a Spirit whose self-conscious Life is the source and the inspiration of an otherwise dead and even nonexistent nature ; the account, I say, may seem complete, especially if the inquirer does not inquire too profoundly, and if he is content to deceive himself with words that either possess no real content of thought or else do service for thoughts which they do not legitimately represent. But for the origin and the historical development of man's ethical and spiritual life - with its laws that transcend all experience of consequences, its sanctions that evoke a derotion which oversteps all the bounds of a merely personal regard, its ideals that are ever arising and fading, but only to appear more bright and alluring and inspiring still - what account can possibly be found in impersonal cosmic processes, or in a World-Ground that is not itself an ethical and spiritual Life?

And, finally, with the adoption of the postulate that the ground of morality is to be found in the World-Ground conceived of as Ethical Spirit, the theoretical and practical antitheses with which the psychological and historical study of ethical phenomena left our minds embarrassed, are much softened and relieved, if they are not wholly remored. That they are not wholly remored must be frankly admitted. The virtuous life is still a problem and a conflict for the truly religious man. It is not the reward of religious faith to deliver the soul from all the puzzling conflicts of thought, or eren the manifold conflicts of a practical sort. But both reason and will, both the speculative demands and the necessities of clearsighted action, are in a measure - and in increasingly good 
measure, as acquaintance with the ethical problem increases in width and in depth — satisfied by the view which finds the ground of morality in an ethical and spiritual World-Ground.

Among the theoretical and practical antitheses in which we were left by the empirical study of the Moral Self and of the Virtuous Life was the conflict which exists between the interests of the sentient and the commands of the moral being of man. Naturally and inevitably the sentient nature demands satisfaction; but many of its most imperative and fundamental satisfactions are either quite constantly or more infrequently restricted, or even forbidden, by the moral law. Theoretically considered this conflict is often inscrutable; and from the practical point of view, it is generally annoying and difficult of a reasonable settlement. It is not my purpose at present to sing the praises of those consolations, and even reversals of the natural results of this conflict, which are afforded by religious faith. It is enough here briefly to say that, to the thinker who refers this dual and antagonistic nature of man to its source in an ideally righteous and holy Will, and who regards this Will as pledged and empowered to see the finite Moral Self through to a triumphant issue in this conflict, to such a one the confliet itself assumes a quite different aspect. Suffering in the interests of morality, if this suffering is caused by a blind, irrational, and hopeless confusion seated in the nature of an impersonal Universe, is hard indeed to justify. Suffering, in the interests of morality, with the added confidence that in the suffering we are showing our allegiance to an Ethical Spirit, whose sympathy we may claim and to whose righteous judgments we may appeal, is not nearly so hard. The most refined arguments of Naturalism in Ethics give, I think, no sort of intellectual satisfaction, and no sufficient semblance even of a support to the man who is putting down, and putting behind him, his lower sensuous cravings in the interests of the moral life - whether his own, or that of his fellow men. 
The same thing is true of the conflicts which arise among the virtues themselves. As we have already seen (p. $451 \mathrm{f}$.), the different virtues seem to display a kind of antagonistic or antitletic character. This is emphasized in the classification which, however, we refused to accept, - namely, into egoistic and altruistic virtues. What solution offers itself when my own best interests seem to conflict with the equally good and desirable interests of others? No theoretical answer to this problem must, indeed, be admitted which solves the problem by dissolving the individual personality, with its definite concrete interests, in the vague and boundless conception of an allembracing Infinite. The "oneness of man in God" has not infrequently been so taught by the metaphysics of ethics as to frame such a reason for doing away with moral conflicts that the reason itself, taken seriously, does away with all intelligible apprehension of the nature and grounds of morality itself. I am one person, - in my moral Selfhood exclusire of all other personality and individually responsible in a very real and significant way. $M y$ morality is my own; there is no reality answering to the term the "Social Self;" but the morality of the Moral Self is ever an individual and concrete affair. The moral selfhood of erery human being is peculiarly lonely. And a pantheistic metaphysics of ethics which either remores the attributes of good and bad conduct from the indiridual, or which merges them all together in the Universal, is above all forms of this branch of philosoply most to be avoided and dreaded. This way of reconciling moral antitheses cuts morality up by the roots.

None the less, however, is it necessary to emphasize the social nature of morality, and the amelioration which all moral conflicts receire from the religious doctrine of the Fatherhood of God, and the membership in the Divine family of all the "sons of men." Religion teaches that men are all born of one Ethical Spirit; the sons of men are also sons of God. From this point of view the hard and sharp antithesis 
between the so-called egoistic and the so-called altruistic duties softens and seems to melt quite away. If I, in my conduct, strive to conserve and promote the moral interests of my better Self; - this I do as one of the members of the Divine family and with their interests as truly as my own at heart. If in this interest I oppose others to the death of the body and to the destruction of all the material interests of myself and of them, provided this opposition has secured the eharacteristics of wisdom, truth, and benevolence on its side, I am still contending for their most worthy life as well as for my own. And in all this devotion to others - to consider the individual's conduct from the other and reverse point of view - I am realizing my own ideal of the morally most worthy Self. Thus this "suffusion of vague personality" which has everywhere appeared in our study of ethical phenomena is made to erystallize into a definite doctrine of a personal Ground for all these phenomena. The distinction between persons is not abrogated; the rather is it emphasized and elevated.

The attempt to construe the World-Ground in a so-called "scientific" and totally impersonal way tends always to minimize the authority and value of personal life. A bubble rising, briefly remaining, and then soon bursting upon the surface of Nature's boundless sea, seems scarcely worth the attention which the study of the Moral Self of man, and of his rising moral Ideals, urges us to bestow. But a single child of God may sanely be held to have no mean potential value. And to believe that what is done for one - whether that one be one's self or some other one - is somehow done for all, and that the Ethieal Spirit in whom all have their life and being is the Source and Guarantor of the moral interests of all, can scarcely fail to assist in both the theoretical and the practical solution of the antithesis between the egoistic and the altruistic virtues so called.

Especially, however, does the heart of man crave the as- 
sistance of some well-assured hope in its effort to bear dutifully the grave contradictions which ererywhere exist between the actual and the ethically Ideal. That things are not as they ought to be is a much more trying discovery than that things are not as they seem. The antithesis between Appearance and Reality which has been so often exploited in a showily dialectical rather than in a profoundly philosophical manner is, for the most part, a specious and not rery alarming affair. But the contradietions which exist between the moral and social ideals of humanity and what is actual in human conduct, and in the constitution of human affairs so far as it is dependently related to conduct, are very real and very disturbing. That whaterer appears, really $i s,-$ this is a proposition which may well command the attention, and finally the consent, of every thoughtful mind. But that whatever is in conduct and in character among men is right, - this is a proposition, which, however often it is made and with whaterer brilliant dialectics it may be supported, is opposed to all the most firmly seated and valuable moral convictions of mankind.

This conflict between the Real of human experience and - the Ideal constructed by human thought and imagination, and followed - however fitfully and imperfectly - by human endeavors, is the eternal conflict. According to the myths of the ancients and the theologies of modern times, it was waged in invisible, supermundane regions, before it began to be waged upon earth. The theoretical solution of the conflict, as respects its origin, its fullest significanee, and its ultimate issue, is, however, as satisfactorily treated as is compatible with the limitations of human knowledge, when it is shown how one may beliere that the ultimate Source of both the reality and of the ideals which still await realization is one and the same World-Ground. This World-Ground is a Personal Will that is pledged and able to effect the progressive realization of the ideals which, too, owe their origrin 
and historical development to Him. In a word, the same Ethical Spirit who inspires the moral ideals of man, and who reveals his own being in their historieal evolution, will secure, and is securing, the realization of the ideals in the world's actual on-going. If one may have a reasonable faith in this conclusion, then certainly, howerer severe the temporary conflict may be, and whether this conflict be raging within the soul of the individual or within the social organization, its final issue and fuller significance are secure. Wellfounded moral optimism makes large demands on religious faith. Only when one is confident that there is a Power in human history, which is over and throughout it all, and which effectively makes for righteousness, can one hopefully survey the large and long-existing disruption between the actual moral conditions of humanity and humanity's own highest moral ideals. The only power which can be coneeived of as at once interested and suitable to effect this progressive reconciliation of the actual and the ideal is God. 


\section{CHAPTER XXVI}

\section{THE ULTLMATE MORAL IDEAL}

IN proposing to ourselves the ultimate problem of a philosophy of conduct it was said (see p. 461) that "ethics cannot avoid questions of the destiny of the individual and of the racc," if it wishes satisfactorily to treat of this problem. "All explanation is teleological and has reference to an end to be realized. Especially and most obviously true is this of the phenomena with which ethics deals." What is this End, or Goal of endeavor, to which all the strivings, howerer limited in their success, of the human race look forward, so far as the philosophy of conduct can take them into its account? The question has already been answered, but only in an approximate and partial way. Perhaps no more than an approximate and partial answer can ever be expected as the result of reflective thinking. Certainly, philosophy can now furnish no complete answer to this ethical inquiry. In such a case briefly to gather together the fragments of an opinion is all which the concluding chapter of this treatment of the problem of conduct should attempt. I believe, however, that it is quite legitimate to indulge, within carefully drawn limits, in those anticipations and conjectures which, while they never admit of scientific proof and, rarely, eren of definite and defensible statement, are, nevertheless, among the most valuable of our mental possessions as measured by that standard of worth compliance with which results in the most satisfactory living.

It was stated early in the course of this investigation that, without doubt, some form of the Good is the ultimate ideal of 
man's moral life and moral development. This phrase, "the Good," however, includes all the ends whose realization brings any form of satisfaction to the sentiont and self-conscious life of man ; and among goods are to be distinguished three classes which, although they are cognate and interconnected, just as are all the different functions of the one human soul, are not by any means precisely the same. The objects which afford the three forms of a satisfaction which may be called an initself good are designated as pleasant, or as beautiful, or as morally right. But in all cases, the actual good is the living state or activity, the actual experience, of a self-conscious soul. And when inquiry is made as to what kind of states or activities are those which merit the name of being morally good, the answer of empirical ethics is given in the cnumeration of those forms of conduct which, taken together and in harmony, constitute the Virtuous Life. This Life is the moral in-itself Good. And here I most heartily agree with Mr. Bradley when he declares:1 "Against the base mechanical Bavavoía, which meets us on all sides, with its 'What is the use of goodness, or beauty, or truth,' there is but one fitting answer from the friends of science, art, or religion and virtue, "We do not know, and we do not care ;' " if by this confession of ignorance and indifference it is meant to rebuke all attempts to reduce the value of these forms of that which is good to any merely mercantile or utilitarian standard. Moral goodness, or the virtuous life - I repeat - is in-itself good; it is the supreme moral good. And to say that such a life needs no guaranty of its own worth, which lies outside of itself, so far from being a vicious circle in conception or argument, is simply to state a fundamental truth of ethics; - namely, that man's total moral consciousness, and his entire ethical experience, alike assert and confirm the independent value of the virtuous life.

The assertion of the intrinsic worth of moral goodness as furnishing its own end does not, however, amount to a depre-

1 Ethical Studies, p. 57. 
ciation or denial of the value of other forms of good; neither does it afford the mind any means of discovering how this particular form of good is to be separated from these other forms, in the actual life of the individual or of the race. In all eonerete ethical judgments we are obliged to acknowledge the relations which exist between moral goodness and the other conceptions of that kind of personal existence which has worth. Hence in discussing, or even in barely conceiving, the nature of the moral law, the nature and ground of its sanctions, and the nature and guaranty of its ideal, eudæmonistic and æsthetical factors cannot wholly be diroreed from the ethical. Nor is this fact at all strange or in any degree unaccountable. Indeed, were the contrary an established fact, it would be unaccountable and even quite unintelligible. A perfectly virtuous but utterly miserable rational being is not only not to be met with in fact; but suel a being is not conceivable in aceordance with our knowledge concerning the vital unities established between the sentient and the moral Self. A perfectly virtuous but utterly miserable society composed of such beings is not only ideally considered an unsatisfactory conception, but is even intrinsically irrational and absurd. The ethical good may not be identified with the purely eudæmonistic; nor may the virtuous life be conceived of as merely instrumental to any other form of good lying outside of its own precious self. But as long as the unity of the various functions and experiences of human nature remains what it is - and this amounts to saying, as long as man is man - virtue and happiness cannot be wholly divoreed; nor can either be conceired of as consisting of states or activities that nerer concur in reciprocal relations within the conscious life of the soul. In a somewhat less obvious but no less profound and important way are the good of conduct and the good of art - or rather moral gooduess and beauty - interrelated. To be perfectly good morally and yet to disregard all considerations of what is beautiful is impossible. Especially are the heroic and the 
kindly virtues intrinsically adapted to call forth an admiration which partakes of both the ethical and the æsthetical sides of human inature. The perfectly good man cannot be all ugly, both without and within; neither can we deny the great value of the ministrations rendered to the moral ideal of living, in the case both of the individual and of the social organization, by the satisfactions of man's craving for, and love of, the beautiful.

It has always happened, therefore, that The Ideal before the aspiring individual, and as well before the community and the race, has been some sort of a blend of all these three forms of ideal good. The ideal Self has been thought to combine and reconcile, in some good degree at least, all the sides of liuman activity and human experience which are deemed worthy of being satisfied. Such a Self has been conceived of as worthily happy in its own good disposition and good will; and thus, too, as an æsthetically admirable and praiseworthy example of what a person ought to be.

If, however, one demands a more strict and well-defined conception of the morally ideal Self, an answer to this has been furnished by all the previous investigations. These investigations have shown that the Moral Good, which is the Ideal of Ethics, appears in human consciousness as (1) virtue, the good to realize which is worthy of approbation, individual and social; as (2) duty, or the good to realize which is obligatory upon the will; and as (3) end, the good the realization of which sets the rational goal of effort and awards the title to being felicitated by all rational beings. In a word, the moral ideal which is ultimate for every individual Moral Self is this same self's life history considered as dependent upon its own conduct and character. To live this ethically ideal life, and progressively to become this morally ideal Self, is the highest ethical good for the individual moral being.

At once, however, another cognate aspect of the ultimate 
moral Ideal is opened before the expectant imagination. This aspect emphasizes the social nature of the moral Ideal. It shows that the conclusion which seems most final from the individual's point of view really contains the demand within itself for an enlargement of its own domain. The individual Moral Self cannot develop, cannot even exist, much less successfully pursue its ideal end, in independence of other selves whose interests are either accordant with, or antagonistic to, its own. 'Thus the end of morality cannot be realized for any individual in independence of society. Nor can the good of the social organization - whether it be the good of happiness, of beauty, or of morality - be conceived of, or practically treated as though it were merely instrumental to the moral good of the individual. To treat other persons as though they, especially in respect of their attainment of the ethical ideal, were merely subsidiary to one's self is to abandon the ideal of a perfect Moral Self; it is to attain a worse the rather than a better position with reference to the standard of moral goodness. In some dim way this truth has always been recognized. As Professor T. H. Green has said: 1 "In the earlier stages of human consciousness in which the idea of a true or permanent good could lead any one to call in question the good of an immediately attractive pleasure, it was already an idea of a social good - of a good not private to the man himself, but good for him as a member of community." Thus have the thoughtful always found themselves compelled to say, on the one hand: He who seeks his own highest moral good, the perfection of his moral Selfhood, must seek to promote the same good in others, must seek to serre the social ideal of moral goodness; but, on the other hand, he who seeks the highest service to the ethico-social Ideal must realize that service primarily in conforming his own life to his own moral ideal. 
In some sort, however, the social good may be said to constitute the Ultimate Ideal - as well of morality, as also of happiness, beauty, and religion. This social good is a good at all only in so far as it consists in the actual living experience of concrete personal existences. So-called "social good," like every form of good, is realizable only in the selfconscious states and activities of individual selves. It is not itself to be personified, much less made into a fetish or one of the minor gods. But there is a cortain limited legitimacy to the prevalent custom here. This custom has been to gather into the mental grasp of some one conscious life the picture of all the good, which a vast multitude of such lives might, through long stretches of time, be able to realize; and then to conceive of this picture as representing the Ultimate Ideal Good. That the laws, sanctions, and ideals of conduct which every good man is called upon to make his own suggest something of this sort is undoubtedly true. I cannot be ideally good, cannot claim any consistent approach to the moral ideal, unless I regard the relations of my own conduct to other members of the race; - and not only those in the more immediate circle to which I see that I belong, but also to many outside that circle whom I shall never see, and even to many more who belong to the ages yet to come.

As a matter of fact, men have for countless centuries conceived of the Ultimate Moral Ideal in a social way. Above and beyond, and as embracing the particular ideal of a perfect moral selfhood which the individual strives to realize, there is the fair thought of a larger and more comprehensive ideal. This social ideal, like every other conception of great loftiness and comprehensiveness, has been rariously and always more or less imperfectly conceived. The ancient Parsis and Hindus framed it, each in their own way. With a pastoral people it differs from the conception framed by those whose interests are more agricultural or commercial. Those who prize more highly the values of science, art, and philosophy 
would construct it with a comparative disregard for the factors which, for example, the North American Indians or the Ainos would most surely introduce. The Old Testament and the Apoci'yphal Hebrew Scriptures dreamed, in a way inspired by the religious faiths and hopes of their authors, of a kingdom over which presided the nation's God, and in which the particular type of prosperity with which experience had made them familiar was to reach its highest conceivable expression. The Stoical moral ideal, too, was that of a divine commurity among men. In the triumph within the World of the "Dear City of God," Marcus Aurelius believed as ardently and as faithfully as did the Church Father, Augustine. To contribute to this triumph has long been esteemed to be the task and the privilege of the good man; and only in the completion of this task, and in the enjoyment of this privilege, could the individual moral self progressively realize its own ideal. The mediæval systems of ethics indeed emphasized the idea of perfection according to a Law - divine, or human, or a coincidence of both. But eren this more impersonal way of presenting the ultimate ideal of morality was essentially of a social character. Pre-eminently in modern times, by all the different types and forms of socialistic conceptions, is the ideal after which men feel themselves morally bound to strive in respect of conduct and of character, an ideally constituted community of morally upright men.

Thus has the imagination of man constructed some form of a social order which should transcend anything hitherto realized by human experience; and the actualization of this superior social order has been held up before the mind and the will of the race as the goal of its endeavors. As with the more indiridual, so with the more social Ideal, the imagination has never been satisfied wholly to exclude from the picture any of the forms of the in-itself Good. However constructed - whether by the most altruistic of communists and socialists or by the most orthodox and old-fashioned of 
theologians - the end of social development is made somehow to combine the realization of the conditions for the highest happiness, together with the most perfect beauty, and the most exalted goodness, of the entire community.

The Ultimate Moral Ideal, however, makes prominent the conception of a social organization which is arranged on a basis of righteousness and good will; and in which all the different members are, each in his own way, realizing his own ideal and yet all contributing to the righteous, happy, and beautiful life of all the others. In a word, the goal set before the ethieal history and evolution of the race is the formation and continuance of a community of moral selres, all of whom are contributing by their conduct and their eharacter to the highest and most worthy social life conccivable, - so far as this highest conecivable social life is dependent upon the conduct and the charaeter of the members of the eommunity.

The religious form of a similar conception is embodied in sueh titles as a "Divine Community," a "City of Gud," a "Kingdom of Heaven," or a "Kingdom of God." From the point of view lield by this eonception, the nature of the right is ever more clearly defined in eonnection with the progressive "coming" of that Kingdom; the superior and all-inclusive good for man is to share in a happy, beautiful, and holy community, - an ever-blessed society, whose inspirer, ruler, and immanent life is the Absolute Ethical Spirit whom religious faith ealls God. That the Ultimate Moral Ideal has, in faet, been eonstrued in some such way as this by minds influenced not only by religious faith, but also by insight into the significance of human society and of its history, is true beyond dispute. What Paulsen says ${ }^{1}$ of one great poet and philosopher may be said of many another: "Even for a man like Goethe, who stands firmly upon the earth and joyfully appropriates it with his entire being, it has always been the deepest yearning of his heart to gaze into a boundless,

1 A System of Ethics, p. 161. 
purer realm, in which everything that the hazy atmosphere of our narrow earthly existence encompasses dissolves and vanishes."

To prove the objective validity of man's trust in such an Ultimate Moral Ideal by an appeal to the history of man's ethical development lies outside of the bounds of ethics. The philosophy of conduct could not depend on such historical evidence, even if it were discoverable to a still larger extent than it is. The highest ideal constructions of the moral Self, under the influence of its social cravings and social faiths, hopes, and aspirations, do not admit of having their possibility demonstrated in a scientific and historical way. Neither do I find that any proof can be derived from the so-called "pure reason" of man, whether regarded in its more cognitive or more practical aspect. But here again, and for the last time, it appears that the acceptance with a lively faith and a cheerful hope of the postulates of religion affords the mind of the inquirer the highest attainable satisfaction with regard to the prospect of man's realizing the construct of his own supremely noble and desirable activity of the imagination in the form of an Ultimate Moral Ideal.

Upon one point, howerer, a few words are pertinent in this connection. It is sometimes held that the rery conception which we have attached, in the name of the world's best thinking and believing, to the words, an "Ultimate Moral Ideal," is full of internal and mutually destructive contradictions. ${ }^{1}$. The realization of this fair hope, that is to say, would

1 This view is maintained in a very obtrusive and even morally offensive way by Mr. A. E. Taylor in his recent work, called The Problem of Conduct. This author seems determined to find all reality and all human life fairly undermined with autinomies, although the arowed object of his treatise is to discuss the ethical problem, abjuring all metaphysics. First, the nature of morality is shown to be "all unprincipled compromise" (p. $244 \mathrm{f}$ ). Then the claims of self-culture and those of social justice are shown to be irreconcilably opposed (p. 295 f.). Then the ideal of a perfect society, or Kingdom of God, is declared to be, however useful, an "ultimately illnsory ideal" (p.420 f.). And, finally, the religions experience of humanity is confideutly accused of being (a) "full of unresolved 
involve the extinction of all morality; for the perfect society is that in which the very conditions which are necessary to the existence and development of the truly virtuous life have come to an end. The morality which is conceived of as no longer being a clioice of good rather than evil - and this, when it is diffieult to do right because temptations abound, and the possibilities and opportunities of doing wrong are frequent - is thus declared to be not genuine morality at all. The realization of the moral ideal is confessedly progressive; in its intrinsic character it is a struggle upward on the part of the individual and of the race; therefore, we are told that to speak of it either as an "unending progress" or as a "finished process" is to leave out of our conception the most essential of its factors. In a word, morality is always and necessarily the antithesis of immorality; the right can never have its nature manifested except through the opposition of the wrong; the reign of goodness is neither eonceivable nor capable of actualization except in the form of a perpetual triumph over the hosts and forees that make for evil. The kingdom of the Devil is the necessary foil of the kingdom of God.

In reference to the conception of an Ultimate Moral Ideal I beg leave to quote at some length what I have said in another connection." "It is indeed given to man to know the world of concrete real beings and of actual erents as falling under the principle of final purpose. This world is known to be a teleological system, a construction controlled by immanent ends. But it is not given to man to 'know' what is the one ultimate end of the world; or whether the world's cause has only one such end; much less, whether this one ultimate purpose of Nature - of the world's system and course of things and of selves - is the realization of man's moral ideal, and unresolvable contradictions," and thus (b) defective, except so far as it is capable "of emptying all our purely moral conceptions of all significance" (p. 427 f.).

1 A Theory of Reality, p. 390 f. 
as Kant conceived of it. With regard to each of these three teleological problems, - although they are all essential factors in the one problem of teleology, as this all-inclusive problem is viewed in the Critique of Judgment,- - only the better hope, or the more reasonable opinion is, at best, attainable. For neither of the three can rightly claim the dignity of a postulate of moral reason; nor is either of them essentially connected with any so-called ' ethico-teleological' proof for the Being of God.

"First, - and strictly speaking, - an ' ultimate' purpose of the world's being and course, as such, may well seem something unattainable and even inconceivable. The End to be attained cannot be regarded as the complete cessation of the process of its own attainment. The ultimate purpose of Nature cannot be a statical condition. The very idea of teleology is an incitement to strice on and live on ; the idea itself perishes in its own completed realization. To be sure, indiridual men get tired and come to consider Nirrâna as the ultimate ideal ; or they get pessimistic, and regard the condition when the world shall be a burned-out coal, as something deroutly to be wished. But the World itself is not tired; and the strictly ultimate purpose is always beyond where man's hope and faith - not to say man's knowledge - can go.

"Moreover, second, the most ultimate purpose which we

- can conccive is not one purpose; it is not an ideal end that can be brought under any strict unity of conception. Some sort of a Unity the final purpose of the World's course undoubtedly must be. But the higher the sort of unity is, the more complex and inclusive is it of erery conceirable form of good; - and of yet more bejond. Who shall define to knowledge or describe to faith and hope the single, the alone idcal end which it shall seem a worthy end of all the World's Force to realize through the infinite Life of the world's time? A certain singleness of aim is necessary for the plysical and mental resources of finite mortals. Yet there is no real thing so mean, so limited in resources, so meagre in time, and so 
single-handed in service, as not to have many ends to attain. The only worthy aim which the most exalted intelligence can set for itself is to play its assigned part well everywhere in the infinitely varied and ever-changing system of selves and things. This is the true service of Self, of the World, and of God; but its unity is best expressed in an indefinite variety of actual transactions, and of diversified forms of being.

"Nor, finally, can man attain the assurance of faith that his own moral culture forms the one ultimate purpose served by the Nature of which he is, or esteems himself to be, the crowning product. No word of ours shall erer depreciate or minimize the moral ideal. Without its light to shed upon the course of physical things, down to the lowest depths and into their minutest details, this course is darker than it otherwise need be. But not even the most exalted religious faith which raises man to the rank of a child of God, and grasps, as its supreme ideal, the redemption of the race, justifies exactly the confidence which Kant assigns to this postulate of reflective teleological judgment. Indeed, the conception of 'moral culture' may be so pressed as to divide human nature against itself, separate human nature from other nature, and eren take man out of sympathy with the wellbeing of God. For man is not all ethical, in the Kantian conception of the 'ethical'; neither is the ethical so strictly set apart from the natural as that the one can dispense with the truths of the other. Nor, finally, is God an unattainable Ding-an-sich to knowledge, but a necessary postulate of moral realities; and yet altogether without a warm and vital co-conscious indwelling in his own children."

So much agnosticism as this, howerer, is a quite different affair from that dogmatic agnosticism which somehow claims to know that the realization of the Ultimate Moral Ideal is forever unattainable because it seems inherently self-contradictory. Indeed, there does not appear to be any adequate reason for inflicting upon this conception the charge of in- 
herent self-contradictions. That moral life, like all other life, has in fact thus far developed under conditions of conflict and struggle against moral evil is not an adequate proof that the continued existence of moral evil is an indispensable pre-condition of all moral life. The "evil times" which have hitherto prevailed, and which still prevail, in the ethical development of humanity do, indeed, call imperativcly for a certain class of virtues that fit men to contend successfully with, and to triumph over, a prevalent unmoral or immoral social environment. And it is quite in accordance with the nature of moral consciousness, as well as of the most fundamental principles affecting the sanctions and grounds of moral development, that those who fight well should be esteemed heroically and most worthily good. Nor will I deny that the Ethical Spirit in whose Will and Reason are found the final explanation of the principles, sanctions, and ideals of the moral life of humanity, is Himself somehow interested and engaged in this mighty and enduring conflict between the morally good and the morally evil.

But there is another side to the virtuous life ; and this side, too, has its sanctions and its own inalienable right to participate far more largely than is its wont, at the present time, in the conceptions which correspond to the ideals of morality. In the present World-Age all men must fight or they cannot claim the title to be good, or eren to be aspirants for this title. But fighting is not the only ethical good; and the good fighter is not the exclusirely good Self; nor is the ideal of virtuous living essentially a picture of one eternal and unremitting battle. The quiet kindly offices of friendship, the calin and resigned acceptance of pain and defeat in the interests of the ligher ideals of life, the willing and joyful doing of duty, and the joy in living the divine life and in membership in the Diviue Kingdom, are entitled to recognition among the chief moral goods. The Hindu seeker for Nirvana, the ascetic monk of ancient or mediæval Christianity, the mystic 
among the Buddhists, and the philosopher who regards as his ideal the contemplative blessedness of the "God-intoxicated" Spinoza,- however one-sided and ethically defeetive their theory and practice may be (and certainly they are no more defective than many an advocate of the so-called "strennous life"), - have certain truths to teach the candid student of the philosoplyy of eonduct. The picture which the highest exercises of poctical and philosophical imagination frames of the Ultimate Ideal of Morality is certainly not that of a community of inactive and dreaming selves. But because the goal is not Nirvâna or the undisturbed intuition of the Absolute, it does not follow that one may dogmatically declare a social life, which has passed beyond the necessity of conflicts with moral evil, to be inherently self-contradictory.

Moreover, it must be remembered that ethics deals primarily with the morally Ideal, and with the other elements of the ideal social life, only so far as these are dependently connected with human eonduct, its consequences, and its own peculiar goal of endeavor. This restriction of its most comprehensive and eren improbable conceptions leares abundant room in the environment of morality for the healthy stimulus of pain, disappointment, and loss - for all the eonflict and discipline of the moral life of humanity which it essentially needs. It would be foolish, because contrary to all our growing scientific knowledge of man's more permanent environing conditions, to suppose that right conduct can ever do away with all suffering and struggle from human life. On the contrary, it is man's inescapable finiteness which furnishes those more important conditions which will always be productive of these kinds of evil. The Kingdom of God on earth, at any rate, can never be free from pain, and tears, and disappointments, and struggles.

At last, however, ethical discussion must confess that it has reached its utmost limits. The philosophy of conduct can only recognize the nature of those deep-seated faiths and 
hopes which it finds in the ethico-religious consciousness of humanity. It can invoke the aid of the philosophy of religion to render more clearly well-founded, more explicit, and more reasonable these faiths and hopes. So far as they converge upon this Ideal of a morally perfect social community, in which wrong-doing shall be no more, not because all do alike, or think alike, or are shaped after the one pattern, but because all acknowledge supreme allegiance and render unflinching obedience to the manifoldly differentiated worth of a Moral Self living in all the relations, which personality compels or justifies, with other moral selves, - so far as this is true of these faiths and hopes, ethics can defend them against the charge of inherent and self-destructive inconsistency. But here it must lay down its task. For ethics has now returned to the truth which Plato saw but did not clearly state: "No single category will adequately express the nature of our highest ideals of the Good." 1 This conclusion points out the way along which the mind of the inquirer must pass, after the more legitimate confines of the philosophy of conduct hare been transcended. The moral nature of man must blend its voice in harmony with his artistic and religious nature. Ethics must clasp hands with Esthetics and with the Philosophy of Religion. And such a threefold cord, which binds humanity to the Ideal, cannot be casily or quickly serered.

Our inrestigation of the phenomena of man's moral life and moral development began with the lowly attempt to comprehend the nature of the Moral Self. It then passed on to a surrey of those kinds of conduct which by a common, if not a strictly universal consent have come to be established in the constitution of human society as having a preferred claim upon the consciousness of obligation, and as entitled to he approbated and rewarded for their conformity to the ideal of

1 See Taylor, The Problem of Conduct, p 241. 
a Virtuous Life. But when the attempt was made to give a satisfactory solution to those more ultimate problems connected with the Nature of the Right and its relations to the World of Reality, it seemed that the postulates of religion became, if not necessarily implied and authenticated, at least needed in an important way for the help which they could afford. And so the whole discussion was lifted into the invisible domain where the Ideals of the loftiest thought and imagination of man hold their potent though not undisputed sway.

It now remains only to gather into a few concluding words the results of this lengthy discussion. And, first, the impression is confirmed and justified that the moral ideals of humanity are the most important factors in the moral life and historical derelopment of man. That this estimate is true has been abundantly proved by the study of ethical phenomena. A similar estimate can be justified of man's more definitively æsthetical and religious ideals. In fact, human history - whether it be the history of the individual, or of the race, or of any particular part of the race, or particular social organization cannot be understood without admitting that it is all largely founded upon, shot through and through with, guided and inspired by, ideals and judgments of worth. Human history is the record of man's striving to realize lis own progressively unfolding ethical, artistic, and religious ideals.

This fundamental truth has its practical side. No philosophy which does not give large room, profound significance, and a mighty potency to the Ideal can account for the experience of man. Not to use the word in a narrow and technical way, Idealism is the only form of philosophy which can claim to explain the realities of human experience. In a way which gives the key to the rules of right moral practice, it may also be asserted that no one who is not an idealist can possibly be a good man, can even know what kind of a reality is meant by the very word "goodness." Virtue necessitates belief in the permanency and uncon- 
ditioned worth of ideas. For virtue is the realization by the actual and historical self of an ideal selfhood. Morality, or subjective goodness, consists in devotion to the ideal. The nature of the right and the goal of objective morality is given in the progressive realization of the universal, social Ideal. Thus it is that without the constructive, idealizing activities of thought and imagination, and without the awakening of faith, hope, and inspiration having for their object these constructions, and without the dominance and guidance of the practical life by these activities, morality is impossible for man. No other work could be less easily spared by man's moral erolution than that which is wrouglit by this constructive and idealizing activity of his imagination in the ethicoreligious life.

On the other hand, however, morality concelns that which is practicable under the actually existing conditions of man's physical and social environment. Right conduct demands the recognition, therefore, of the real environment, and of the actual consequences of all human conduct; and, as far as possible, of each particular piece of conduct. Justness, wisdom, the measuring and apprehension of opportunity and of the results of success or failure in seizing the opportunity, are essential forms of the virtuous life. What is popularly called "good, sound sense" is the precondition and the accompaniment of all good conduct. The loftiest idealism and the firmest grasp upon the unseen realities which are constituted or recognized by the idealizing actirities of man cannot dispense with the necessity for experience with the actual behavior of things and men, in their manifold shifting relations, of things with things, and of men with men. Here is the erer-present chance, yes! the certainty of mistake and conflict, of disappointment and temporary defeat, - not to be avoided even by those who most firmly and intelligently hold the highest and worthiest ideals; but often the more certain to be met with by those whose ideals are highest and worthiest. 
These two conceptions give us the picture of the Moral Self striving to realize its ideals in the midst of the real conditions furnished by its physical and social environment.

Between these two conceptions of the moral life - namely, that which regards it in its ideal aspects, and that which lays emphasis rather upon actual experience with causes and effects, means and ends, conduct and its proximate sources and nearer consequences - there is another mediating conception which ethics teaches us particularly to emphasize. This mediating conception is that of Development. All realization of the Moral Ideal, whether in the individual or in the social organization, is necessarily partial and progressive. The environment of man, and so the physical and social circumstances on which his moral evolution is dependent, is itself in a process of development. By a ceaseless interchange of actions and reactions between moral selves and this environment the moral development of the race is secured. For the individual and for the race there is no way to be moral but to become moral. The only possible realization of the moral ideals is itself a process in which the ideals, as well as the actualities corresponding more or less imperfectly to them, are changing. But it is the hope and faith of humanity - a hope and a faith that are not entirely irrational or devoid of all foundations in experience - that this process of changing is a real progress; and that the goal of this progress is the establishment of that blessed and perfect society which religion calls the "Kingdom of God."

Therefore, the exhortation of that system of ethical conclusions which acknowledges fully the ideality of moral facts, and the reality of the Moral Ideal, is somewhat as follows: "Hold to the Ideal and ever lift it up; be scnsible and wise in practical affairs, patient with yourself, and with all men, and with God, - also, courageous, and full of faith and hope." 
The Philosophy of Conduct has a special message to the social and political organizations of the present day ; - special, not because they differ from all the preceding social and. political organizations of humanity, in respect of the fundamental relations which they sustain to morality, but because they are themselves so highly specialized, and so big with portentous consequences affecting the welfare of the race. Perhaps it is not altogether fanciful to regard this message as threefold, after the analogy of the three divisions of its topics which has been adopted by the present treatise. Thus the first lesson to learn will lave regard to the kind of men that make society and the nations strong and great. It is in the character of the Moral Selfhood of the individual that the enduring and effective forces of social and political strength and greatness are to be found. Human organizations that are cemented by ethical bonds, and that exist between staunch and tried moral selves, alone have the character which can best resist all the forces of dissolution - cosmic, commercial, social, and political - that assail them under the limitations of space and of time. That it is righteousness which magnifies and greatens nations is as true to-day as it has ever been; - witness the ruins of other forms of greatness and power which are spotted over the face of the whole earth, and in spite of the current confidence in rich treasuries, strong navies, and multitudes of armed men.

And, again, if one inquires after the marks of a truly advanced civilization, and of such a genuine prosperity as shall rightly claim a high estimate in the scale of the values of human existence, it is in the conception of the Virtuous Life that one's answer must be found. For socicty and for the nation to be virtuous through and through is to enjoy the right to be felicitated for its prosperity, and assigned the highest place in the ranks of civilized living. But it must be remembered that the list of virtues which enter into this completer conception of the life of the good man is no meagre affair. Wisdom 
and trueness are also fundamental virtues; the cultivation and management of the intellectual forces is an affair of good or bad conduct; and he who remains wilfully ignorant of that which he might know, and ought to know, is so far forth prevented from realizing the demands of virtuous living. What is true of individuals is true of communitics and nations as well. While, on the one hand, then, the advancement of the arts and sciences will never of itself make men highly civilized or really prosperous, the cultivation of the arts and sciences and the distribution of the results of their cultivation throughout the entire multitude of the nation is the duty and the moral privilege of those who would lead the people in the improvement of its moral standards and in the uplifting of its scale of ethical living. For man's nature is a spiritual unity ; and if there is any one heresy which the philosoplyy of conduct desires to correct, rebuke, and exorcise, it is the heresy of schism between reason and morality, between the cognitice and the moral Self. Nor is strength of character and power to overcome difficulties an unimportant factor of the virtuous life. For the prosperity which consists in the realization of this life is, for human beings under existing circumstances, always a conquest; and advancing civilization call never hope to substitute the life of ease for the heroic struggle on which its advances constantly depend. These are more important factors in civilization than great wealth, or large armies, or strong navies.

Finally, ethics has a message to the nations which follows from its study of the more ultimate nature of the principles, the sanctions, and the ideals that cluster about the conception of the Right. Nations, like individuals, cannot afford to lose their faiths, aspirations, and hopes, as these are all directed toward and into the non-sensuous and invisible World. Nations, like individuals, cannot live by bread alone. For nations, as for individual souls, it is the things which are not seen that are eternal. And well is it for nations in their conduct to 
recognize the sacred duty and the blessed privilege of holding before themselves, and before one another, the Moral Ideal; and of helping lumanity in its longing for, and its striving after, the realization of this Ideal. For such is the deeper and truer significance of human history. As Rothe ${ }^{1}$ so grandly said: "He who does not unconditionally believe in the Might of Goodness in the world, and in its final victory, he can no longer lead in luman affairs - I do not say rightly, but even with any lasting success. For we live in the Kingdom of Redemption, and no longer in the kingdom of this world."

1 Theologische Ethik, V. p. 291 f. 


\section{INDEX}

Absolete Self, the, as Ground of Morality, 112, 536, 567 f., $600 \mathrm{f}$., $609 \mathrm{f} ., 630 \mathrm{f}$; and an Ethical Ideal, $252,536,567$ f., $58+f$., 630 f. ; Kantian view of, $567 \mathrm{f}$, 601,629 (see also World-Ground).

Activity, consciousness of, $146 \mathrm{f}$., $150 \mathrm{f}$; plyysiological basis of, 149 ; relation of, to deliberation, $150 \mathrm{f}$.

Esthetics, relation of, to Fthics, $198 \mathrm{f}$., 650.

Anthropology, relation of, to Ethics, $26 \mathrm{f}$., 473 ; on primitive man, $473 \mathrm{f}$.

Antinomies, the Ethical, nature of, 135.f, $449 \mathrm{f}$., $582 \mathrm{f}$.; influence of religion upon them, $582 \mathrm{f}$.; solution of them, by philosophy of religion, $631 \mathrm{f}$.

Approbation (and Disapprobation), the moral feeling of, $62 \mathrm{f} ., 93 \mathrm{f}$., 100 ; differences of, from feeling of obligation, $93 \mathrm{f}$. ; pleasures of, $95 \mathrm{f}$., $97 \mathrm{f}$; xsthetical character of, $97 \mathrm{f}$.; development of the feeling of, $100 \mathrm{f}$.

Aquinas, Thos., lis doctrine of the virtues, 581.

Aristotle, his ethical terminology, $8 \mathrm{f}$; on ethics as politics, 15, 548; his use of psyclological method, $21 \mathrm{f}$; ; views on exactncss of method, 33 (note); on happiness as supreme good, $36 \mathrm{f}$.; his classification of the virtues, 61,106 , 225 ; on voluntary action, $66 \mathrm{f}$., 150 ; his doctrine of "the mean," 107,122 , $233 \mathrm{f}$.; on consciousness of freedom, $150 \mathrm{f}$., $163 \mathrm{f}$, ; on courage, 234,237 , $238 \mathrm{f}$.; and temperance, 247 ; on virtue as trained faculty, 264, 393; on truth, $296 \mathrm{f}$, 306; and friendship, $311,313,318,321,329$; on permanence of moral principles, 393 ; and casuistry, 415 ; his conception of happiness, $475 \mathrm{f}$., $478 \mathrm{f}$.

Art, influence of, upon growth of kindly feeling, 326, $328 \mathrm{f}$.
BAcos, on the ideal of conduct, 494.

Bain, on happiness as only final good, 42.

Balfour, Mr., on the origin of moral principles, 400.

Bhagavad Gītā, its morality, 573 (see also Hinduism).

"Book of the Dead," the Egyptian, the morality of, 565,585 .

Bowne, l'rof., his definition of merit, 101.

Bradley, Mr., on utilitarian etlics, 637.

Browning, on the vice of indecision, 229 ; and on happiness and morality, 493.

Buddhism, its influence on hnman passion, 254; and on the growth of humane feeling, 330 ; its representation of the Divine pity, $5.56 \mathrm{f}$.

Carlyle, on pleasure as an end, 482 (note).

Carricre, on the moral World-order, 626.

Carus, on relation of duty and belief in God, 577 (note).

Caspari, on moral freedom, 138.

Casuistry (chap. XVII.), nature of, $415 \mathrm{f} ., 418 \mathrm{f}$; ; as ethical discipline, 417 f., 569 ; sources of, $418 \mathrm{f}$., $422 \mathrm{f}$. ; spliere of, $423 \mathrm{f}$.

Causation, consciousness of, in moral development, 107, $111 \mathrm{f} ., 168 \mathrm{f}$; ; law of, as related to moral freedom, $164 \mathrm{f}$., $168 \mathrm{f}$., $183 \mathrm{f}$. ; psychological origin of, $184 \mathrm{f}$.

Character, the conception of, $174 \mathrm{f}$., $231 \mathrm{f}$.; strength of, $231 \mathrm{f}$., $248 \mathrm{f}$. (see also Moral Self, development of;.

Christianity, influence of, on humane feeling, 330, $331 \mathrm{f}$., $404 \mathrm{f}$. ; its conception of perfect morality, $351 \mathrm{f}$., $443 \mathrm{f}$.; and of ideal manhood, $443 \mathrm{f}$.

Cicero, use of the word "mora!," 9. 
Commercialism, influence of, on humanitarian feeling, 332 $\mathrm{f}$.

Communism, ethics of, 260 .

Conduct, importance of, $3 \mathrm{f}$., $156 \mathrm{f}$., $342 \mathrm{f}$, $416 \mathrm{f}$; ; ethics, the science of, $7,537 \mathrm{f}$., 654 ; the Ideal of, $10,11 \mathrm{f}$., $442 \mathrm{f}$., $491 \mathrm{f}$. (see also Moral Ideal); low different from action, $10 \mathrm{f}$., $156 \mathrm{f}$., 269,342 ; inputability of, $156 \mathrm{f}$, $162 \mathrm{f}$., $176 \mathrm{f}$; judgment, a species of, $269 \mathrm{f}$; as an art, $442 \mathrm{f}$.

Confucius, on duty of blood-revenge, 158 ; and ethies of marriage, 256.

Conscience, popular meaning of, 60 , $90 \mathrm{f.,} 189 \mathrm{f}$, $417 \mathrm{f}$; ; divergent views of, $90,189 \mathrm{f}$; proper use of the term, $90 \mathrm{f} ., 189 \mathrm{f}$. ; anthority of, 191, $384 \mathrm{f}$., 417 f. ; pathological lack of, 417 (sce also Consciousuess, as moral, and Moral Self).

Consciousness, as moral, analysis of, $53 \mathrm{f} ., 69 \mathrm{f}$., 129, $189 \mathrm{f}$.; as imposing obligations, $384 \mathrm{f}$.

Crawford, on relation of happiness to virtue, 488.

Custom, as related to morality, $27 \mathrm{f}$., $292 \mathrm{f}$., $342,615 \mathrm{f}$., $618 \mathrm{f}$; ; conformity to, not virtue, $3+2 \mathrm{f}$.

Defian Isscription, on the kiuds of the Good, 36.

Determinism, a scholastic theory, 136, 145 ; its basis in fact, $139 \mathrm{f}$., 142 , $169 \mathrm{f}$.; its fallacy of hypostasizing, 145 , $154 \mathrm{f}$., 163, 169; its objections to moral freedom, $164 \mathrm{f}$., $169 \mathrm{f}$., $183 \mathrm{f}$; the "Old-Fashioned," $165 \mathrm{f}$., $168 \mathrm{f}$, ; and the "New-Fashioned," $165 \mathrm{f}$., $178 \mathrm{f}$; its conception of the Self, $169 \mathrm{f}$; ; its statistical argument, $180 \mathrm{f}$. (see also Will).

Derelopment, importance of conception of, $201 \mathrm{f}$., 203 , $443 \mathrm{f}$., $495,526 \mathrm{f}$., $534 \mathrm{f}$., 653 ; as applied to the Moral Ideal, 206 f., 443 f., 447, 461 f., 526 f., 531 f., $653 \mathrm{f}$; ; naturalistic theory of, $602 \mathrm{f}$.

Dewey, Prof., on moral action, 11 (note), 130 ; and idea of duty, $366 \mathrm{f}$; on distinction between pleasure and happiness, 478; and hedonistic theory, 486.

Döring, on the highest good, 469.

Dogmatism, immurality of, 304.
I)ress, customs regulating, $122 \mathrm{f}$.

Dumout, on hedonistic calculations, 489 (noce).

Duties, classification of, 223 ; conflict of, 415 f., 427 f., 430 f., 433 f., 514 f.; the so-called religious, $565 \mathrm{f}$.

Duty, conception of, $365 \mathrm{f}$., $370,376 \mathrm{f}$., 379,388 ; duties prior to, $367 \mathrm{f}$.; varieties of, $369 \mathrm{f}$; 䜣 always negative, $370 \mathrm{f}$; relation of, to virtue, $371 \mathrm{f}$, $373 \mathrm{f}$.; relation of inclination to, $375 \mathrm{f}$; influence of, upon ima rination, $377 \mathrm{f}$; as related to Moral Law, 379 .

Ecoxonics, relation of, to Ethics, 540 , 542 f., $545 \mathrm{f}$.

Edwards, Jonathan, on nature of tho motive, $345 \mathrm{f}$.

Eliot, George, on happiness and morality, $493 \mathrm{f}$.

Epicureans, the ancient, 488 (see Iledonism).

Ethics, sphere and problem of, $3 \mathrm{f} ., \mathrm{l} ; \mathrm{f}$., 25,31 f., 60 f., 457 f., 539 f., 636 ; a science, $7 \mathrm{f}$., $32 \mathrm{f}$; ; its problems classified, 7 f., 31 f.; distinctions implied in, $8 \mathrm{f}$; begins with facts, $8 \mathrm{f} ., 16 \mathrm{f}, 29 \mathrm{f}$.; "Data" of, 9 f., 24, 29 f.; relation to the Ideal, $8 \mathrm{f}$., $11 \mathrm{f}$., 14, 55, $462 \mathrm{f}$., $637 \mathrm{f} ., 641 \mathrm{f} ., 645 \mathrm{f}$., 649 ; as dealing with the Ought, $12 \mathrm{f}$; d definition of, 14 ; as politics, 15 ; methods and divisions of 19, $20 \mathrm{f}$., $29 \mathrm{f}$.; Kantian method of, criticised, 20 f., 502 f., 592 ; psychology of, $20 \mathrm{f}$;; its method, historical and objective, $29 \mathrm{f}$.; but also philosophical, $30 \mathrm{f}$., 457 f., $463,588 \mathrm{f}$., $636 \mathrm{f}$.; precision in study of, $32 \mathrm{f}$. (note); ultimate problem of, $457 \mathrm{f}$, 461 f., 588 f., 606 f., 636 f.; Schools of, $464 \mathrm{f}$.; relation of, to economics, $540 \mathrm{f}$., $545 \mathrm{f}$. ; and to politics, $540 \mathrm{f}$., 547,548 ; and to sociolog $y, 5+3 \mathrm{f}$; the "universals" of, 589 f.; inclusive character of the metaphysics of, $530 \mathrm{f}$., 592 f. ; Naturalism in, 602 f., 605 f., 631.

Eudæmonism, its conception of the Good, 42 f., $51 \mathrm{f}$. (note), 475 ; on the virtue of benerolence, 352 ; the, of Aristotle, $475 \mathrm{f}$. ; (see also lledonism and ('tilitarianism). 
Euripides, on principle of friendship, 329.

Erolution (see Development).

Farrer, on fear among savages, 236 ; savages' view of death, 244; and punishment of anger, 253 ; on savage character, $285 \mathrm{f}$.

Feeling, kinds of the ethical, 60, $61 \mathrm{f}$., $93 \mathrm{f} ., 310 \mathrm{f} ., 325$; relations of, to right conduct, 85 f., 88 f., 115 f., 312 f., 315,326 ; Virtues of (Chap. XIII). 310 f., 315 f., 320 f., 326 f., 333 f.

Fichte, on untruthfuluess, $436 \mathrm{f}$. ; on the World-order, $60 \%$.

Freedom, Moral, nature of, $133 \mathrm{f}$. (chap). VIII.) 139 f., 150 f., 164 f., 165 f. ; complex problem of, $133 \mathrm{f}$., $139 \mathrm{f}$., $150 \mathrm{f}$., $165 \mathrm{f}$. ; interest of ethics in, $134 \mathrm{f}$., $136 \mathrm{f}$. ; proofs of, $139 \mathrm{f}$., $142,143 \mathrm{f}$., $148 \mathrm{f}$., $156 \mathrm{f}$.; development of, $147 \mathrm{f}$; objections to, auswererl, $164 \mathrm{f} ., 172 \mathrm{f}$, $177 \mathrm{f}$., $180 \mathrm{f}$.

Friendship, Aristotle's view of, 313,318 ; mysterious nature of, $317 \mathrm{f}, 319 \mathrm{f}$;; Plato's view of, $318 \mathrm{f}$.

Gellics, on pleasure as an end, 482 (note).

Gizycki, hedonistic theory of, 469 .

God, influence of belief in, upon ethics, $569 \mathrm{f}$, $572 \mathrm{f}$., $574 \mathrm{f}$., $591 \mathrm{f}$; as the Moral Illeal, 574 f., 584 f., 591 f., $626 \mathrm{f}, 628,632 \mathrm{f}, 647 \mathrm{f}$. ; and ground of ethical laws, $608 \mathrm{f} ., 612 \mathrm{f}$.; and of ethical sanctions, $613 \mathrm{f}$., $620,623 \mathrm{f}$. (see also Absolnte Self).

"Gool," 'The, Greek conception of, 10, $34 \mathrm{f} ., 4+3$; especially the P'latonic, 34 ; difficulty of analyzing, $34 \mathrm{f}$., 37 ; psycholugy of the conception, $36 \mathrm{f}$.; always sentient life, 37 ; distinction of instrumental and final, $38 \mathrm{f}$., $198 \mathrm{f}$., $490 \mathrm{f}$. ; degrees of the, $39,41 \mathrm{f}$., $482 \mathrm{f}$.; means of estimating, $40,41 \mathrm{f}$., $46 \mathrm{f}$.; different values of, $40 \mathrm{f}$., $47 \mathrm{f}$., $479 \mathrm{f}$., $636 \mathrm{f}$. ; discipline as means of realizing, $43 \mathrm{f}$.; the Litinate and Supreme, 50 f., 55,198 f., 490 f., 636 f. ; the distiuctively ethical, $55,199,636 \mathrm{f}$., 639.

Grant, Sir A., on Aristotle 33 (note), 106 (note).
Green, Prof. T. H., on ethical derelop. ment, 55, 640; and moral law as an " exterual imponent," 383 ; on conflict of duties, 428 ; and oneuess of liumanity, 625 ; on the ultimate good, 640.

Grot, Prof. N. Ia. on " Freedom of Will," 188 (note).

Gummere, on the origin of wergild, 253.

Habit, influence of, in ethical life, $82 \mathrm{f}$., 168 f., 175 f., 266, 637 f. ; as reigning over Will, $168 \mathrm{f}$, $175 \mathrm{f}$.

Happiness, conception of, in ethics, $469 \mathrm{f}, 477$ f., 481 f.; distinction between pleasure and, $47 \mathrm{l} \mathrm{f}$, $478 \mathrm{f}$, $492 \mathrm{f}$. ; relation of, to virtue, $471 \mathrm{f}$., 481 f., 489 f., 493 f., 637 f.; and to moral developmeut, $637 \mathrm{f}$.

Helonism, the method of, 20, $482 \mathrm{f}$; its conception of the Good, 42 f., 469 , $482,484 \mathrm{f}$., $492 \mathrm{f}$.; as related to Utilitarianism, 467 f., 481 f. ; modern theory of, 469 f., 481,489 f. ; the quantitative and egoistic, $482 \mathrm{f}$; ; as altruistic, 484 f., 487 f.; and qualitative, 489 f., 492 f.; the calculıs of, $489 \mathrm{f}$., (see also Utilitarianism).

Hegel, on the value of constancy, 355 . Herbert, George, on temperance, $247 \mathrm{f}$. Hinduism, its confusion of euston and morality, 11, 257 ; ceremonial ethics of, $13,125,565$; sexual morality of, $257 \mathrm{f}$., 571 ; ethical tenets of, 263,298 f., 330 f., 5 f:5, 571 ; especially as respects truthfulness, 298; and humanitarian feeling, $330 \mathrm{f}$; on purity of heart, $572 \mathrm{f}$.

Hobbes, lis theory, $123 \mathrm{f}$.

Höffling, on Determinism, 138.

Hopkins, Prof., on the good man in the Rig Veda, 298.

Hospitality, considered as virtuous, $320 \mathrm{f}$.

Humboldt, on frivolity, 272.

Iluxley, Prof., on Etlies and Evolution, 602 f., 606, 619.

IDesL, nature of an, 10, 589 f. (see Moril Ideal).

Idealism, in Ethics, 444 (chap. XXII.); essential character of, $507 \mathrm{f}$., $509 \mathrm{f}$.. 
511, 526 f., 589 f., 651 f.; problems before it, $511 \mathrm{f}$., $529 \mathrm{f}$.; different forms of, $512 \mathrm{f}$; ; individualism of, $518 \mathrm{f}$.; yet essentially social, $524 \mathrm{f}$; and evolutionary, $526 \mathrm{f}$., 531 ., $651 \mathrm{f}$.

Intention, nature of an, 346 ; the " good," 347 ; not the whole of virtue, 346 f., 349.

Intuitionism, its method in ethics, 20, $513 \mathrm{f}$.; the "Emotional," 85, 515; as a form of Idealism, $513 \mathrm{f}$., 518, $530 \mathrm{f}$; the "perceptive," $515 \mathrm{f}$., $518 \mathrm{f}$; facts contradictory to, $519 \mathrm{f}$.

JANET, M., his classification of the virtues, 218.

Jowett, on I'lato's view of friendship, $318 \mathrm{f}$.

Judgment, Ethical, nature of, 65 f., $83 \mathrm{f}$, (chap. VII., passim), $115 \mathrm{f}$. $269 \mathrm{f}_{\text {. }}$; earliest forms of, $83 \mathrm{f}$., $106 \mathrm{f}$., 285 ; dependent on feeling, $86 \mathrm{f}$., $113 \mathrm{f}$., 115; importance of, $106 \mathrm{f}$., $113 \mathrm{f}$., $270 \mathrm{f}$. ; grounds of, $113 \mathrm{f}$., $119 \mathrm{f}$., $126 \mathrm{f}$., $397 \mathrm{f}$.; relation of, to volition, $117,129 \mathrm{f}$, 270 ; the predicate of, $117 \mathrm{f}$.; as intuitive, 119,125 ; historical origins of, $120 \mathrm{f}$., $126 \mathrm{f}$. ; development of, $125 \mathrm{f}$., $130 \mathrm{f}, 283,397 \mathrm{f}$; dependence of, on the individual, $126 \mathrm{f} ., 273,420 \mathrm{f}$; ; virtues of (ehap. XII.), 271 f., $283 \mathrm{f}$; ; as Moral tact. $420 \mathrm{f}$.

KANT, his use of the word reason, 15 ; method in ethies, $20,502 \mathrm{f}$., 592 ; conception of the Good, 37 ; and of Duty, $377 \mathrm{f}$; on untruthfulness, 4.33 ; his legalism, $502 \mathrm{f}$; ; categorieal imperative of, 503 ; his fundamental law of moral reason, $503 \mathrm{f}$., $505 \mathrm{f}$,, 592 ; view of relations between religion and morality, 567,629 ; on teleological judgment, 647 .

Karma, moral import of the doctrine, $109,368 \mathrm{f}$.

Irrafft-Ebing, on moral perversity, 417.

Latrie, Prof., on the "Good Will," 437 ; and relations of morality and religion, 579 .

Law, the Moral, conception of, 365, 379, 381 f., 388,497 f. ; not impersonal, 380 ,
$382,384 \mathrm{f}$., $387,498 \mathrm{f}$; ; but a product of moral conscionsness, $381,384 \mathrm{f}$., $505 \mathrm{f}$; ; as an "external imponent," $384 \mathrm{f}$, $387,500 \mathrm{f}$.; and related to the Moral Ideal, $386 \mathrm{f}$., $497 \mathrm{f}$., $503 \mathrm{f}$.; and to moral principles, $389 \mathrm{f}$., $501 \mathrm{f}$; ; ultimate Souree of, 609 f., 613.

Lessing, on superstition, 385 (note).

Locke, un nature of morality, 343 ; on intention, 346.

Lotze, on consisteney as virtue, 264; and resignation, 282 ; on retribution, $289 \mathrm{f}$.; and on benevolence, 353, 358 . Luys, M., on Deterninism, 138.

$M_{A N}$, as ethical, $59 \mathrm{f}, 67 \mathrm{f}$., 148, 162 , $202,325,436 \mathrm{f}$; as rational and free, $162 \mathrm{f}$; t the so-called "primitive," 202, 325 ; concept of the good (chaj). XVIII.), 442 f. (see also Moral Self). Marcus Aurelius, motto from, 456 ; on painstaking morality, 494; his differentiation of virtues, $504 \mathrm{f}$.

Marriage, eustoms regulating, $120 \mathrm{f}$., 256 ; ethics of, 255 f., 258.

Martensen, on abstract morality, 581.

Materialism, in the psychology of volition, 166, 177 f., 180; and as Naturalism in Ethics, $602 \mathrm{f} ., 605 \mathrm{f}$.

Martineau, his classification of the virtues, 217 (note).

Merit (and Demerit), feeling of, 63, $101,375 \mathrm{f}$.; complexity of the conception, 101 ; and its social implications, $102 \mathrm{f}$; ; and relation to pleasnre-pains, $104 \mathrm{f}$; ; and to inclination, $375 \mathrm{f}$.

Mill, J. S., his testimony to the Moral Ideal, 243.

Moral Ideal, the, 12, 14, 15 f., Is, 110 , 129,206 f., 363, 574 f., 589 f., 626 f., $639 \mathrm{f}$; ; as Selfhookl, $110 \mathrm{f}$, 229, 363, 432 f., 439 f., 443 f., 532 f.; development of, $206,443 \mathrm{f} ., 447 \mathrm{f} ., 519 \mathrm{f}$, $521 \mathrm{f}$; relation of, to virtue, 229 , 274 f., 344 f., 363 f., 442 f.; and to Moral Law, 386 f., $626 \mathrm{f}$; ; as inclividual, $433 \mathrm{f}$., $439 \mathrm{f}$., $452 \mathrm{f}$, $517 \mathrm{f}$; reality of, $447 \mathrm{f}$., $574 \mathrm{f}$., $584 \mathrm{f}$., $595 \mathrm{f}$.; in God, as perfect Personality, $584 \mathrm{f}$., 591 f., 626 f., 628 ; possibility of knowledge of, $595 \mathrm{f}$; ; the ultimate moral (chap. XXVI.), 637 f., 639 f., $641 \mathrm{f}, 643,645 \mathrm{f}$. 
Moral Self, the, conduct as belonging to, $11,15,17 \mathrm{f} ., 24 \mathrm{f}$., $145 \mathrm{f}$., $156 \mathrm{f}$. (chap. IX.), 195 f., 220 f., 507 f. ; always social, $15 \mathrm{f}$., $76 \mathrm{f}$., $189 \mathrm{f}$., $194 \mathrm{f}$., 286,445 ; the Ideal of a, 18, 52, $100 \mathrm{f}$., 191, 363, 386, $432 \mathrm{f}$., $516 \mathrm{f}$; ; complex nature of a, $24 \mathrm{f}$., $59 \mathrm{f}$. (Part First, passim), 67, 89, 92, $191 \mathrm{f} ., 194$ f., $27 \mathrm{l}$, $532 \mathrm{f}$; satisfaction of, 52 ; conduct imputable to, $156,158 \mathrm{f}$., $532 \mathrm{f}$.; development of the, $201 \mathrm{f}$., $361,432 \mathrm{f}$., $439 \mathrm{f}$., $\mathbf{4 4 5} \mathrm{f}$.; as furnishing the principle of unity for the virtues, $361 \mathrm{f}$., 632 ; God as the Absolute, $385 \mathrm{f} ., 536$, $630 \mathrm{f}$. ; not a mechanism, $408 \mathrm{f}$.

Moral Principles, universality of (cliap. XVI.), 389, 392 f., 394, 401 f., 404 f., 412 ; relation of to moral laws, $389 \mathrm{f}$.; nature of, $389 \mathrm{f}$., 391 ; development of, 391 f., 396 f., 401 f., 404 f., 412 ; valiulity of, 392,396 .

Morality, as different from custom, $27 \mathrm{f}$., $273 \mathrm{f}$., $342 \mathrm{f}$., 484 ; function of the total Self, 227, $229 \mathrm{f}$, 271, 342 f., $439 \mathrm{f}$., $517 \mathrm{f}$; f filelity to an Ideal, 265 f., 274,352 f., 437 f., 458 f., 485 f., $522 \mathrm{f}$., $528 \mathrm{f}, 558$; implies evaluation of ends, $273,479 \mathrm{f}$; and their realization, $274 \mathrm{f}$., $439 \mathrm{f}$; ; not ilentical with any one virtue, $352 \mathrm{f} ., 357 \mathrm{f}$; as related to Reality, $458 \mathrm{f}$., $567 \mathrm{f}$, $597 \mathrm{f}$, $601 \mathrm{f} ., 613 \mathrm{f}$; ; individuality essential to, $518 \mathrm{f}$; and yet social, $523 \mathrm{f}$, $615 \mathrm{f}$, $618 \mathrm{f}$, 624 ; relation of, to religion (chap. XXIV.), 552 f., 560, 561 f., 568 f., 571 f., 575 f., 578 f., $582 \mathrm{f}$; ; danger of "double morality," $580 \mathrm{f}$. ; as obedience to God, $584 \mathrm{f}$., 612; ultimate Ground of (chap. XXV.), $588 \mathrm{f}$., $609 \mathrm{f}$., $613 \mathrm{f}$.; source of the sanctions of, $613 \mathrm{f}$., $620,622 \mathrm{f}$, 625.

Morals, conception of, $8 \mathrm{f} ., 27,292 \mathrm{f}$; relation of, to custom, $292 \mathrm{f}$., 342 ; and to philnsophy and religion, $326 \mathrm{f}$; not identical with morality, $342 \mathrm{f} ., 375$.

Mosaic Code, etlices of, 256, 259, 280, $350 \mathrm{f}$; on love as the fulfilling of the Law, $350 \mathrm{f}$.; its view of God as Righteousness, 585.

Motive, feeling of obligation as a, $94 \mathrm{f}$; nature of a, $139 \mathrm{f}$., $151 \mathrm{f}$., $165 \mathrm{f}$., $170 \mathrm{f}$; quality of, not all of virtue, $343 \mathrm{f}$; the "good," 345.

Muirhead, on relations of philosophy to ethics, $30 \mathrm{f}$.

Nature, unethical conception of, $602 \mathrm{f}$., 615 ; its right to command, $615 \mathrm{f}$.; as Ethical Spirit, 617.

Nicomachean Ethics, referred to, 9, 15, 22,33 (note), $36,61,66,106,150 \mathrm{f}$., 163,225 f., 233 f., $238,247,264,278$, 284 f., 311, 313, 318, 329, 339, 346, $393,402,415,475$ f., 548.

Obligation, feeling of, $69 \mathrm{f}$., $89 \mathrm{f}$, $366 \mathrm{f}$., $384 \mathrm{f}$., $614 \mathrm{f}$.; its primary character, 70 f., 79,88 f., 91 f., 614 ; connection with pleasure-pains, $72 \mathrm{f}$., $77 \mathrm{f}$. ; origin of, $73 \mathrm{f}$., 617 ; development of, $83 \mathrm{f}$., $89 \mathrm{f}$., $617 \mathrm{f}$.; relation of, to duty, $366 \mathrm{f}$. ; and to moral law, $38+\mathrm{f} ., 61+\mathrm{f}$.

Old 'Testament, morality of, 123 ; moral ideal of, $6+2$.

Ouglit, the feeling of, 12 f., 62 f., $70 \mathrm{f}$, $91 \mathrm{f}$; conditions of its origin and development, $74 \mathrm{f}$., $83 \mathrm{f}$.; uniquely lunman, $80 \mathrm{f}$. (sce also Obligation, feeling of).

Partisanship, immorality of, $304 \mathrm{f}$.

Paulhan, M., on volition and psychic systems, 151.

Paulsen, on ethics as natural science, 17 ; on Will, 153; on Plato's Republic, 225; ancient Saxon view of courage, 244 ; his view of falsehood, 297,434 ; and conception of duty, $370 \mathrm{f}$.; on hedonistic theory, 469 ; and relation of morality to religion, 559; on the moral ideal, $643 \mathrm{f}$.

Person, see Self.

Personality, importance of conception of, $201 \mathrm{f}$., $361 \mathrm{f}$., $533 \mathrm{f}$., 651 ; as furnishing a principle for unifying the virtues, 361 f. (see also Moral Self).

Perty, on natural sympatlyy, 325.

Pfleiderer, on morality and religion, 552 ; and the development of moral ideals, 628 .

Philosophy, relations of, to Ethies, $30 \mathrm{f}$., $133,188,326$ f., 458 f., 463 f., 590 f., 
$593 \mathrm{f}$; ; influence of, on the development of benevolence, $326 \mathrm{f}$.

Piety, as an inclusive virtue, $\mathbf{5 6 0}$.

Plato, his psychological Ethics, $21 \mathrm{f}$., $224 \mathrm{f}$; ; conception of the Good, 34 ; classification of the virtues, $224 \mathrm{f}$., 363 ; and loctrine of wisdom, 270; and of justice, 295; on friendship, $318 \mathrm{f}$; his view of influence upon morals, of the popular religion, $573 \mathrm{f}$; on morality and immortality, $586 \mathrm{f}$.

Pleasure-pains, psychology of, $43 \mathrm{f}$., $338 \mathrm{f}$., $470 \mathrm{f}$, 475 ; influence of, in ethical discipline, $43 \mathrm{f}$, $73,470 \mathrm{f}$; relation of, to feeling of obligation, $73 \mathrm{f},, 76 \mathrm{f}$., $339 \mathrm{f}, 471$; sources of the, $472 \mathrm{f}, 475 \mathrm{f}$.

Politics, relation of, to Ethics, $540 \mathrm{f}$., $547 \mathrm{f}$; ; Aristotle's view of, 548 .

Psychology, relation of to Ethies, $20 \mathrm{f}$., $43 \mathrm{f}$., 133 f., 338 f., 470 f., 554 (note); its loctrine of pleasure-pains, 339, $470 \mathrm{f}$.

Reality, theory of, as related to Ethics, 459 f., 463 f., 511 f., 568,593 f., 597 f., $599 \mathrm{f} ., 611 \mathrm{f}$.

Religion, as a source of morals, $124 \mathrm{f}$., $329 \mathrm{f}$., $404,556 \mathrm{f}$., $563 \mathrm{f}$. ; general relation of, to Ethics, $198 \mathrm{f}$., $329 \mathrm{f}$., $404 \mathrm{f}$., 650 ; and to morality, $552 \mathrm{f}$., $559 \mathrm{f}$., $561 \mathrm{f}$., $568 \mathrm{f}$., $573 \mathrm{f}$., $578 \mathrm{f}$., $611 \mathrm{f}$., $628 \mathrm{f}$.; nuiversality of, $555 \mathrm{f}$.; ethical roots of, $559 \mathrm{f}$.; special effect on morality of the postulates of, 561 f., 566 f., 571 f., 576 f., 578 f., 582 f., 584 f., 588 .

Riehl, on moral freedom, 138.

Right, the, conception of, $65 \mathrm{f}$., $117 \mathrm{f}$., $520 \mathrm{f}$, 528; the ground of, $491 \mathrm{f}$.; suljective character of, $520 \mathrm{f}$., 528 ; objective character of, $520 \mathrm{f}$., $529 \mathrm{f}$; ; as unchanging, 52l (Nature of the, Part Third).

Rose, M., on the influence of civilization upon savage virtues, 314 .

Roskoff, on relation of morality and religion, $552 \mathrm{f}$.

Rothe, on the might of gooluess, 656 .

SAUssaye, on the relation of morality to religion, 556 .

Schopenhauer, on the conception of
"Ought," $13 \mathrm{f}$; ; and of the Good, 37 ; on appetite of sex, $256 \mathrm{f}$.

Schurman, on morality of the family, 255.

Schwarz, Hermaun, on intuitive moral feeliugr, 87.

Self, consciousness of, a condition of moral development, $107,109 \mathrm{f} ., 142 \mathrm{f}$; the Ideal of, $110 \mathrm{f}$., $191 \mathrm{f}$. (see Moral Ideal); defective conceptions of, $158 \mathrm{f}$, $160 \mathrm{f}$.; the Social, as included in the Moral, $192 \mathrm{f}$. ; (see also Moral Self).

Selfhood, importance of conception of, $201 \mathrm{f}$. (see also Personulity and Moral Self).

Seth, Prof. James, on distinction between pleasure and happiness, 478 .

Shaftesbury, Lord, on moral emotions, 85 f., 88.

Sidgwick, on ethics as ideal. 9 ; on feeling of olligation, 81 ; and "Free Will controversy," 136; his Hedonism, 487 (and note).

Simmel, on conflict of duties, 428 .

Sociology, relation of, to ethics, $548 \mathrm{f}$.

Sophists, the, their ideas on Ethics, 31.

Sophocles, on the Divinity of moral Law, 572.

Spencer, Ilerbert, on ethics as " doubly ideal," 9 ; feeling of approbation, 103.

Spinoza, on the intellectual love of God, 357,476 ; his conception of virtue, 476 . Stephen, Leslie, on voluntary action, 66 ; on feeling of obligation, $80 \mathrm{f}$; on truthfulness, 360 .

Stoics, the, their conception of the "good man," 250.

Sympathy, nature of the feeling, $75 \mathrm{f}$, 310 f., 323,325 ; relation of, to morality, 87 f., 310 f., 312, $323 \mathrm{f}$.

TACT, need of, in conduct, $419 \mathrm{f} ., 422$; psychology of, $420 \mathrm{f}$. ; factors in, $42 \mathrm{l}$, $422 \mathrm{f}$. ; cultivation of, $422 \mathrm{f}$.

Taylor, Mr. A. E., on problem of conduct, $6+4$ (note).

Thilly, on classifation of ethical theories, 468 (note).

Time, consciousness of, in moral development, $107 \mathrm{f} ., 109$.

Tourgucineff, on the conception of duty, $378 \mathrm{f}$. 
Truth, regarl for, 296, 299 f., 301 f., $359 \mathrm{f}$. ; its value for personality, $300 \mathrm{f}$., 303,307 f., $360,433 \mathrm{f}$. ; abstract conception of the, $301 \mathrm{f}$.

Tylor, on relation between ethics and Animism, $141 \mathrm{f}$.

Urilturarianism, its method, 20, $489 \mathrm{f}$; its conception of the Good, $52 \mathrm{f}$. (notc), 474, 490, 637; as related to hedonistic theories, 467 f., $479 \mathrm{f}$, 481 f., 489 f., 494 f.; development of, 480 f., 490 f.; problems before it, $481 \mathrm{f}$., $491 \mathrm{f}$., $495 \mathrm{f}$.; modern forms of, $489 \mathrm{f}$.

Virtue, conception of, 211 f., 226, 264 f , 338, 342 f., 371 f., 388 ; possilility of a theory of, $213 \mathrm{f}$, $226 \mathrm{f}$, $337 \mathrm{f}$; ; as function of the total Self, 227 f., 229 f., 343 f., 347 ; constancy essential to, $264 \mathrm{f}$., 355 ; unity of (chap. XIV.), 338, f. 346 f., 352 f., 361 ; not identical witl motive, 34.3 ; or intention, 346 f., 349 ; or any one virtne, $352 \mathrm{f}$., $357 \mathrm{f}$.

Virtues, the, Aristotelian classification of, $6 \mathrm{I}, 106 \mathrm{f}$., 225 ; proper classification of (cluap. X.), 217 f., $22+$ f., 226 f., $371 \mathrm{f}$; lists of, 217 ; self-regarding and social, $218 \mathrm{f}, 451 \mathrm{f}$; ; as related to duties, $3 i l$ f.; conflicts among the, $451 \mathrm{f}, 632 \mathrm{f}$.

Volition, facnlty of, as necessary to morality, $65 \mathrm{f}, 117 \mathrm{f}$., $150 \mathrm{f}$; as dependent on judgmeut, $117 \mathrm{f}$; ; relation of, to psychic systems, $15 \mathrm{I}$ f.; termi nation of the process of, $152 \mathrm{f}$.

WAITz, on relation of morality and religion, 552.

Watson, Prof., on the Sophists, 31 ; and on hedonistic theories, 468 (note); on relation of morality and religion, 592.

Will (see also Moral Freedom, eliap. VIII.), physical theories of, 138 , 149 f., $164 \mathrm{f}$; ; as self-determining, $137 \mathrm{f}$., $143 \mathrm{f}$., 148,150 f., $155,163 \mathrm{f}$, 248 ; virtues of the (chap. XI.), $231 \mathrm{f}$, $246 \mathrm{f}$., $260 \mathrm{f}$., $266 \mathrm{f}$. ; central in character, $232 \mathrm{f}$; so-called "good will," 232,437 ; conception of the Divine, $612,624 \mathrm{f}$.

World-Ground, the, philosophic view of, $590,597 \mathrm{f}$., $599 \mathrm{f}$, $632 \mathrm{f}$.; as also the ground of morality, $590 \mathrm{f}$., 593, $596 \mathrm{f}$., $601 \mathrm{f} ., 608 \mathrm{f}$., $612 \mathrm{f}$; ; and of its sanctions, $61.3 \mathrm{f} ., 620,622 \mathrm{f}$. ; and of moral ideals, $626 \mathrm{f}$., 647 .

Wundt, his conception of Ethies, 7,17 , 27 ; view of custom, 27 ; on ethical vocabulary, 49 ; endowment of primitive man, 202, 325, 393; on the virtue of hospitality, 321 ; on the influence of Christianity upon self-sacrifice, 330 ; on morality and religion, 552, 556. 



\section{The 佂hillosophical Mortks of GEORGE TRUMBULL LADD}

Professor of Pbilosopby in rale University

General

Descriptive

Psychology

Physiological

Psychology

Philosophy

Theology
Outlines of Descriptive Psychology $800 . \$ 1.50$ net Psychology: Descriptive and Explanatory 8vo. $\$ 4.50$

\section{$12 \mathrm{mo} . \$ 1.00$ net}

Elements of Physiological Psychol= ogy With numerous illustrations. 8vo. $\$ 4.50$ Outlines of Physiological Psychology Illustrated. 8v0. $\$ 2.00$

Introduction to Philosophy

Philosophy of Mind

8vo. $\$ 3.00$

8vo. $\$ 3.00$

Philosophy of Knowledge

A Theory of Reality

8v0. $\$ 4.00$

8vo. $\$ 4.00$

Philosophy of Conduct

8vo. $\$ 3.50$ net

What is the Bible

12mo. $\$ 2.00$

The Doctrine of Sacred Scripture 2 vols. 8vo. $\$ 7.00$

The Principles of Church Polity 8vo. $\$ 2.50$ 


\section{THE}

\section{Philosophical Works}

of

\section{GEORGE TRUMBULL LADD,}

\section{Professor of Philosophy in Yale University,}

$7 \mathrm{HE}$ philosophical writings of Dr. Ladd have now become so numerous and are so widely known in a general way, that the publishers take pleasure in giving them some special notice, with the object that the adaptation and purpose of each volume may be better understood. It is believed that this author's "Primer of Psychology," "Outlines of Descriptive Psychology," " Psychology; Descriptive and Explanatory," "Elements of Physiological Psychology," and "Philosophy of Mind" form a continuous course in the subject which surpasses any similar course that has appeared. Naturally, where several books by one author treat of the same subject, some confusion in ordering results, and it is to prevent this, as well as in the hope of leading to a wider interest in the books, that the following description has been prepared.

\section{Outlines of Descriptive Psychology}

\section{By George T. Ladd, LL.D., Professor of Philosophy in Yale University. Illustrated. 8vo. pp. 42r. \$r.50 net.}

This work is especially prepared as a text-book for all Colleges and Universities that have not time for the larger treatise, and for use in Normal Schools, and by teachers in the Public Schools who are studying the subject. As a classroom text, the book is sure to meet with a warm welcome. It is in the first place unusually rich in material, without becoming unduly prolix in its presentation. There is, moreover, a well-ordered system running through the whole. Particularly happy and judicious is the introduction of much material from experinental sources. - The Philosophical Review.

For the general reader who desires a better acquaintance with the better part of himself, Professor Ladd's book makes the task as simple as it can be made consistently with thorough treatment. . . . The book is a model of its kind on a subject whose importance for education and pedagogy, theology and philosophy, has only in our day been appreciated. - The Outlook.

In the department of psychology, Professor Ladd has been a strong influence in the dissemination of an intelligent interest in the phenomena of the mental life. A larger and a briefer compendium of physiological psychology, a primer, a larger and now a smaller volume on descriptive psychology, have all appeared within a dozen years. These volumes are stimulating as well as useful, systematic as well as discriminating, scholarly as well as readily intelligible. 


\section{Philosophical Works of George Trumbull Ladd}

\section{Psychology: Descriptive and Explanatory}

A Treatise of the Phenomena, Laws, and Developinent of Human Mental Life. By George Trumbull Ladd, LL.D., Professor of Philosophy in Yale University. 8vo. pp. 676. \$4.50.

A GENERAL treatise for those who wish to gain a thorough A knowledge of the subject. The size and scope, the amount and kind of material, and the style of its presentation unite in making it a suitable book for mature students, as those usually are who begin the subject in colleges. It is therefore a college text-book, and is recommended without qualification for such use.

I find it a most excelient and useful work. I shall take pleasure in recommending it to my classes as a most thorough and exhaustive treatment of psychology. I'rof. J. H. Hyslop, of Columbia College.

The beauty of this mighty work is that it informs us regarding all well-defined modern psychology, that it makes us think at our best, that it tends to make the reader a master in psychologic thought. It does not make the reader a slave, but it tends to emancipate him from his own vague knowledge and vicious ignorance. It is the great masterpiece in Americanized modern psychology. - Fournal of Education.

\section{Primer of Psychology}

By George Trumbull Ladd, LL.D., Professor of Philosophy in Yale University. I2mo. pp. 226. \$r.00 net.

A TEXT-BOOK for elementary students, and was written by this eminent author because no book in $\Lambda$ merica had been found satisfactory for academies and high schools, and for a large class of general readers who might find some pleasure and perhaps more profit in reading a very brief and simple treatise on psychology.

Contents : I. The Mind and its Activities - II. Consciousness and Attention - III. Sensations - IV. Feeling - V. Mental Images and Ideas - VI. Smell, Taste and Touch - VII. Hearing and Sight - VIII. Memory and Imagination - IX. Thought and Language$X$. Reasoning and Knowledge-XI. Emotions, Sentiments and Desires - XII. Will and Character-XIII. Temperament and Development.

This little book is not an abstract of a larger work. It is a compact statement in the simplest words the author could select of the purport and achievements of the new science. Even experts might find it convenient as an introduction to Professor Ladd's system. - New York Tribune.

Professor Ladd has come to be so high an authority in psychology that any who desire to begin its study may naturally be drawn to this book. Their expectations will be met. The outlines of the subject are so happily treated, in a plain, familiar style and with abundant illustraiion, as to create and deepen interest in all intelligent readers who care to know anything of the life of the mind. - The Outlook. 


\section{Philosophical Works of George Trumbull Ladd}

\section{Elements of Physiological Psychology}

A Treatise of the Activities and Nature of Mind from the Physical and Experimental Point of View. With numerous illustrations. By George Trumbull Ladd, LL.D., Professor of Philosophy in Yale University. 8vo. pp. 696. \$4.50.

$\mathrm{T}$ distinction from the introspective psychology and as a companion 1 to it, this book is devoted to physiological and experimental psychology. It was the first book in English to discuss the whole subject, and is the only one which may be regarded as an adequate treatise. It includes the latest discoveries, and the most competent critics pronounce it a credit to American scholarship and an unrivalled authority.

A calm, unprejudiced survey of this comparatively new science, and a very full and comprehensive one. - Atlantic Monthly.

D'après ce court résumé, le lecteur peut avoir une idée suffisante de la composition genérale et de l'esprit de ce livre ! mais l'analyse ne peut faire connaître l'abondance des informations, le nombre des documents, mémoires, monographies que M. Ladd a utilisés. Pour ceux qui suivent le mouvement de la psychologie contemporaine dans les divers pays, $\mathrm{il}$ est inutile de dire que ce $n$ 'est pas là une petite tâche. - M. T. R1вот.

Ich habe mit vielem Interesse mehrere Theile aus diesem Werke gelesen, und mich über die vortreffliche Weise der Darstellung sowie über die reiche Sachkenntniss gefreut, von der es Zeugniss ablegt. Ich halte es für sehr verdienstlich, dass Sie in englischer Sprache ein Werk geschaffen haben, welches so gut geeignet ist den Anfänger in diesen schwierigen Gegenstand einzufihren; nur so mehr als ihr Werk, so viel ich weiss, das Erste ist, welches nach den meinigen über denselben verfasst wurde. - PROF. W. WundT, of Leipzig.

\section{Outlines of Physiological Psychology}

\section{A Text-Book of Mental Science for Academies and Colleges. By Prof. George T. Ladd, Yale University. Crown 8vo. pp. 505. \$2.00.}

$7 \mathrm{HE}$ volume is not an abridgment or revision of the larger book, 1 "Elements of Physiological Psychology," which is still to be preferred for mature students, but, like it, surveys the entire field, though with less details and references that might embarrass beginners. The author aims to furnish a complete yet correct text-book for the brief study of mental phenomena, from the experimental and physiological point of view.

We regard it as even better than the larger work, as it is more judicious and mature, having the advantages of longer reflection upon the subject and larger experience in teaching it. For its purpose there is not a better text-book in the language. - The Nation.

We regard a knowledge of physiological psychology as absolutely necessary to an appreciation of psychology in general. The only book in the language which pretends to cover the entire field within the compass of a volume of five hundred pages is this smaller work of Professor Ladd. His larger work stands without a superior in any language. - Fournal of Pedagogy. 


\section{Philosophical Works of George Trumbull Ladd}

\section{Introduction to Philosophy}

An Inquiry after a Rational System of Scientific Principles and their Relation to their Ultimate Reality. By George Trumbull Ladd, LL.D., Professor of Philosophy in Yale University. 8vo. pp. 426. \$3.00.

An introduction to philosophy is an excessively difficult thing to write, that is, the kind of introduction which Professor Ladd undertakes. It would be easy to write an introduction to a particular philosophy, but to write what may serve as an introduction to all of them is another matter. This is the merit of Professor Ladd's book. It introduces philosophy, but not a particular philosophy. It states the sources, problems, divisions, methods, and possible solutions of philosophy better than any other work of its size in English. - Prof. J. MARK BALDwin, of Princeton University.

He is liberal, able, and full of knowledge. . . . He thus adopts, if we may judge, the safest, most penetrative, and most progressive form of thought. - The Dial.

A really admirable book. - Saturday Review, London.

\section{Philosophy of Mind}

An Essay in the Metaphysics of Psychology. By George Trumbull Ladd, LL.D., Professor of Philosophy in Yale University.

Octavo. pp. 412. \$3.00.

7 HIS is a speculative treatment of certain problems suggested, but 1 not discussed, in the study of psychology. The subjects treated are : Psychology and the Philosophy of Mind, The Concept of Mind, The Reality of Mind, The Consciousness of Identity and the so-called Double Consciousness, The Unity of Mind, Mind and Body, Materialism and Spiritualism, Monism and Dualism, Origin and Permanence of Mind, Place of Man's Mind in Nature.

It is one of the most important works in the field of philosophy published in recent years. The subject itself, and the acknowledged position and influence of the author, should strongly recommend this volume to all students and to all readers in philosophy. - Jонn E. Russels, Williams College.

\section{Philosophy of Knowledge}

By George Trumbull Ladd, LL.D., Professor of Philosophy in Yale University. 8vo. pp. 6r4. \$4.00.

$7 \mathrm{HE}$ book appeals to the general reader by reason of the relation 1 this subject bears to questions now so prominently before the philosophical and religious world, as well as through the broad sympathy of the author with different phases of thought. It will also find a place waiting for it as a text-book for advanced and postgraduate students in logic and the laws of thought.

In this analysis of truth and error, of knowledge and reality, dualism and monism, and of knowledge and the absolute, Professor Ladd's discussion and conclusions will be of great value to all students of philosophy and anthropology. One of the most interesting features is its criticism of Kant's "Critique of Pure Reason." . . The two chapters on the history of opinion, from Socrates to Kant, and from Kant to the present, form a valuable part of the book. - The Congregationalist. 


\section{Philosophical Works of George Trumbull Ladd}

\section{The Theory of Reality}

An Essay in Metaphysical System upon the Basis of Human Cognitive Experience. By George Trumbull Ladd, LL.D., Professor of Philosophy in Yale University. 8vo. pp. 556. \$4.00.

7 HIS volume brings to its close the series of books in which the author has dealt with the general problem of reality - things and minds - and the possibility and the validity of knowledge. The former volumes were "Philosophy of Knowledge and Philosophy of
Mind."

Professor Ladd has been in the eye of the philosophical public for so many years that much can be taken for granted concerning any work on metaphysics that may issue from his hand. We can be certain, before opening the book, that its know!edge is broad and accurate; that its psychology is well digested; that its method is the analysis of experience rather than speculative synthesis; that the spirit and the results of the sciences pervade its pages, and that its general standpoint is some form of theism sharply contrasting with both materialism and absolute idealism. These general virtues of his "Theory of Reality" may therefore be dismissed with a mere reference. - Philosophical Review.

Professor Ladd has made every lover of Christian philosophy his debtor as few Americans have done, and this noble volume forms a fitting climax of his work in the paired hemispheres of thought and truth. - Presbyterian and Reformed Review.

\section{Philosophy of Conduct}

A Treatise of the Facts, Principles, and Ideals of Ethics, in three parts :

I. The Moral Self.

II. The Virtuous Life.

III. The Nature of the Right. 8vo. \$3.50 net. (Postage 20 cents.)

HOLLOWS "The Theory of Reality" in sequence and development, treating, in the introduction, of the sphere and problems of Ethics, and developing the subject under the heads noted above.

In Part I. the author deals with morals from the point of view of modern psychology and antliropology, with special discussions of moral freedom and current forms of determination.

He offers in Part II. an original classification of virtuous conduct, surveying men's opinions, and considering virtue as a unit; with special discussions of Moral Tact and the Character of the Good Man.

Part III. takes up the ultimate problems of Ethics, and shows how all conceptions and ideals of human conduct are indissolubly connected with the principles and ideals of general philosophy and, in particular, the philosophy of religion.

This is Professor Ladd's most popular and most literary work, as well as his newest, and the one of all others into which he has put his heart. 


\section{Philosophical Works of George Trumbull Ladd}

\section{What is the Bible}

An Inquiry of the Origin and Nature of the Old and New Testaments in the Light of Modern Biblical Study. 12mo. \$2.00. By George Trumbull Ladd, D.D.

Summary of Contents: Jewish and Early Christian Views - The Bible and the Sciences of Nature - The Miracles of the Bible - The Histories - The Prophecies - Moral and Religious Teaching of the Bible - Authorship of the Biblical Books - The Bible as Literature - The Canon and the Text-- Revelation and Inspiration, etc.

A work of inestimable value to pastors, to laymen, and to teachers. - New Englander.

This will prove a very interesting and instructive book for the steadily increasing army of Bible students who want to learn more of the genesis and development of the sacred Scriptures. The author has adopted his former work without any loss of power. We see the same qualities of patient research, of wide information, of candid and courageous facing of difficulties. - The Interior.

For those who take interest in the question which forms the title of this book, Professor Ladd's volume will prove both interesting and valuable. . . . His view of the subject of inspiration, as popularly set forth in most confessions of Protestant churches, is well worth consulting. . . . Other noteworthy chapters are those which treat of "The Bible and the Sciences of Nature," "The Miracles of the Bible," "The Prophecies of the Bible," and "The Canon and the Text." Professor Ladd faces the difficulties in a manly way, and in substance upholds the ordinary Christian view of these topics. - New York Times.

\section{The Doctrine of Sacred Scripture}

A Critical, Historical, and Dogmatic Inquiry into the Origin and Nature of the Old and New Testaments. 2 vols. 8vo. \$7.00. By George Trumbull Ladd, D.D.

It is the most elaborate, erudite, judicious discussion of the doctrine of the Scripture, in its various aspects, with which I am acquainted. I have no hesitation in saying that, for enabling a young minister to present views alike wise and reverent respecting the nature and use of Sacred Scripture, the faithful study of this thorough, candid, scholarly work will be worth to him as much as half the studies of his seminary course. - J. HENRY THAYER, D.D.

In truth there lies imbedded in the book, as incidental to the discussion, a vast critical commentary, from an accomplished scholar, on all parts of the Bible. The exegetical student, who may care comparatively little for doctrinal or philosophical discussion, will resort to these volumes as an extremely valuable contribution to his own special department. - Prof. George P. Fisher, of Yale University, in New York Tribune.

The present volumes are evidently the result of much labor and research. They are also of special interest to Biblical students at this time, as being an earnest as well as vigorous effort to deal satisfactorily with a subject of the highest importance to mankind. - New York Times.

What is the Bible? . . The answer which has been supplied to this question is so clear and striking, is built up with so much solid learning, and delivered in a manner so perspicuous and pleasing, that we believe it calculated to play an important part in the theological revolution now in progress throughout Christendom. - London Christian World. 


\section{Philosophical Works of George Trumbull Ladd}

\section{The Principles of Church Polity}

Crown 8vo. \$2.50.

Contents. Introduction. Lecture I. The Principles of Congregationalism - II. The Principles of Congregationalism applied to man as a rational soul - III. The Principles of Congregationalism applied to man as a social being - IV. The Principles of Congregationalism applied to man as a citizen - V. The formal Principle of Congregationalism - VI. The Principle of a Regenerate Menbership - VII. The Principles of Congregationalism applied to the purity of the ministry - VIII. The Principle of the Communion of ChurchesIX. The Principle of the Communion of Churches $-X$. The SelfPropagation of Congregationalism-XI. Congregationalism and Foreign Missions - XII. Present and Prospective Tendencies of Congregationalism.

7 HIS volume gives a philosophical analysis of the principles which 1 should enter into any scheme of church polity, and then endeavors to show how far these principles have been acknowledged and illustrated in modern Congregationalism.

A richness of practical suggestion runs all through this logical development of the principles and facts, which is very refreshing and stimulating to the reader. In this respect the book is peerless among many essays upon the same general subject. - Hartford Religious Herald.

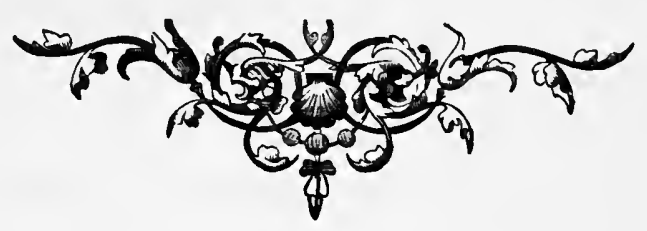

\section{CHARLES SCRIBNER'S SONS,}

\section{Publishers, 153-157 Fifth Ave., New York.}




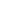




.




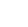






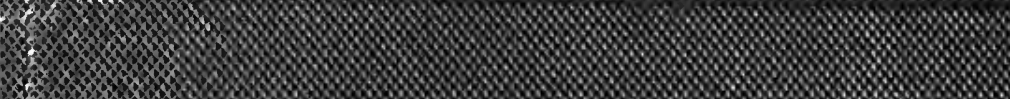

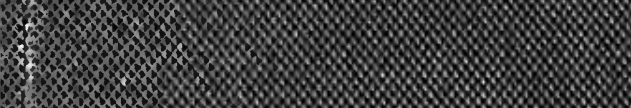

$\ldots$ $\ldots$

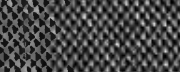

m.

con

\%

$\%$

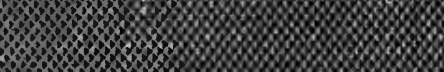

${ }^{3}, \mathrm{~m}$.

.

7700020002

Pow

603070002002



P,

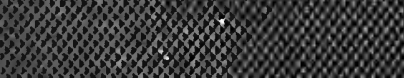

30

$3 \%$

 